\title{
Instrumentação para o Ensino de Física IV
}

Prof. Dr. Luiz Adolfo de Mello 


\section{Instrumentação para o Ensino de Física IV \\ Elaboração de Conteúdo}

Prof. Dr. Luiz Adolfo de Mello

Copyright $\odot$ 2011, Universidade Federal de Sergipe / CESAD.

Nenhuma parte deste material poderá ser reproduzida, transmitida e gravada por qualquer meio eletrônico, mecânico, por fotocópia e outros, sem a prévia autorização por escrito da UFS.

Ficha catalográfica produzida pela Biblioteca Central Universidade Federal de Sergipe

UNIVERSIDADE FEDERAL DE SERGIPE

Cidade Universitária Prof. "José Aloísio de Campos"

Av. Marechal Rondon, $s / n$ - Jardim Rosa Elze

CEP 49100-000 - São Cristóvão - SE

Fone(79) 2105 - 6600 - Fax(79) 2105- 6474 


\section{Conteúdo Instrumentação IV}

Cap.01 - Movimento Harmônico Simples. MHS

Movimento Circular Uniforme - M.C.U.

Cap.02 - Pêndulo Simples

O Pêndulo De Torção

O Pêndulo Físico

Cap03 - Óptica Geométrica ou Óptica de Raios

Luz

Reflexão e a Refração da Luz

Espelhos Planos

Cap04 - Lentes e Espelhos Esféricos

Cap.05 - Ondas E Suas Aplicações

Ondas Harmônicas

Ondas Planas

Ondas Eletromagnéticas

Cap.06 - Ótica \& Luz

O Princípio De Huygens

Dualidade Onda Partícula

Fótons

Cap.07 - Explicando As Cores

A Percepção Das Cores

Teoria Das Cores

Cap. 08 - Som

Produção do Som

Transmissão do Som

Fenômenos Sonoros

Efeito Doppler

Cap.09 - Instrumentos Ópticos

Cap10 - Física Moderna

Efeito fotoelétrico

Efeito Compton

Raio X 


\section{AULA 1 - MOVIMENTO HARMÔNICO SIMPLES. MHS}

Metas:

- Fazer que o estudante comece a pensar no ensino de ciências como algo "orgânico" que está em profunda transformação.

- Fazer com que os alunos percebam, através de uma atividade lúdica, que podemos ensinar física através de experimentos muito simples.

- Fazer com que os alunos aprendam a usar os recursos de multimídias.

- Fazer com que os alunos percebam as aplicações da física no cotidiano.

Objetivos:

- Ao final da aula, os alunos devem estar cientes das novas possibilidades e dos desafios que envolvem o ensino de ciências em geral.

- Estes, também devem perceber que para se ensinar física não precisamos ficar presos ao livro didático.

- Que ensinar física não é ensinar a resolver problemas e que a física é uma mera aplicação da matemática.

- Que existe muito material na forma de multimídia para ser usado em sala de aula e como complemento da aula.

Pré-requisitos: Os alunos deveram ter cursado as disciplinas de Psicologia da Educação, Física A, B e C.

\section{INTRODUĈ̣̃O}

Essa é a primeira aula de uma série de 10 aulas sobre instrumentação para o ensino de física voltada para Oscilações e Física Moderna. Se você fizer uma breve pesquisa sobre o que foi publicado na área, verá que há várias propostas e muitos experimentos de baixo custo para uma aula de ondulatória e de física moderna. Mas, há vários artigos discutindo a problemática de se 
ensinar física moderna no ensino médio e pouco sobre ondulatória. Como esse é o ultimo curso de instrumentação, esperamos que você esteja mais maduro e independente nos seus estudos. Assim, nessa série de aulas vamos delegar mais atividades extra-aula para você.

Como no presente momento só temos duas ou no máximo três horas aulas dedicadas à disciplina de física nas escolas estaduais, temos que vários tópicos do curso de física não são abordados no ensino médio. A física ondulatória está entre elas, principalmente por esta fazer grande emprego das funções trigonométricas. Apesar disto, este tema é muito rico em aplicações (ondas eletromagnéticas, luz, raios- $X$, som, etc.) e cai recorrentemente no vestibular. Assim, vamos dar mais ênfase aqui à física ondulatória do que a moderna.

Como o objetivo central da disciplina de instrumentação é o de estudar e aplicar técnicas de ensino de um determinado conteúdo de física e não o de introduzi-lo, dividimos o conteúdo de MHS em duas partes. Nesta primeira aula vamos definir o MHS e usaremos como exemplo o MCU e o do corpo preso a uma mola sujeito somente a força elástica. Deixamos o estudo dos pêndulos simples, de torção e o físico para a próxima aula. Assim, poderemos trabalhar melhor este conteúdo.

$\mathrm{Na}$ primeira parte da aula usaremos como referência os textos produzidos para os sites de ensino brasilescola [1] e física.net [2]. Na segunda parte usaremos o material didático usado para o site de ensino e-física [3].

Se olharmos a maioria das matrizes curriculares do 3 grau veremos que o curso de ondulatória inicia com o estudo do MHS. Pois, todos usam o MHS como exemplo concreto para ilustrar porque as funções senoidais são as funções naturais para representar matematicamente o movimento ondulatório. Todos os cursos começam analisando um movimento sujeito a uma força restauradora que resulta em uma equação do $2^{\circ}$ grau do tipo

$$
\frac{d^{2} x}{d t^{2}}=-\frac{k}{m} x
$$

cuja solução é uma função senoidal ou cossenoidal. Como não podemos usar uma equação diferencial no ensino médio temos que fazer uma transposição didática como a que segue abaixo.

\section{O MOVIMENTO HARMÔNICO SIMPLES}

Uma das coisas mais simples e que regula a nossa vida é o tempo (no sentido de horas, minutos, etc.). Mas, nem sempre foi assim. Até hoje se faz 
pesquisa de como se determinar esta grandeza física de forma mais exata e precisa. Um dos movimentos usados é o movimento harmônico simples.

Todo movimento que se repete em intervalos de tempo iguais é chamado de periódico. Mais precisamente, podemos dizer que no movimento periódico o móvel deve ocupar a mesma posição na trajetória, sempre com a mesma velocidade e a mesma aceleração. O intervalo de tempo para que ele se encontre duas vezes nessa posição é sempre o mesmo e é denominado de período do movimento. Símbolo T. Exemplos deste tipo de movimento são:

a) o movimento circular uniforme;

b) o movimento da Terra em torno do Sol;

c) o movimento de um pêndulo;

d) o movimento de uma lâmina vibrante;

e) o movimento uma massa presa à extremidade de uma mola, etc.

Quando um corpo oscila periodicamente em torno de uma posição de equilíbrio descrevendo uma trajetória retilínea, pode-se dizer que este corpo efetua um movimento harmônico simples linear. Como veremos, este ocorre em razão da ação de uma força restauradora.

\section{SISTEMA MASSA-MOLA}

No estudo que faremos do MHS utilizaremos como exemplo um sistema massa-mola, que pode ser visualizado na figura a seguir.

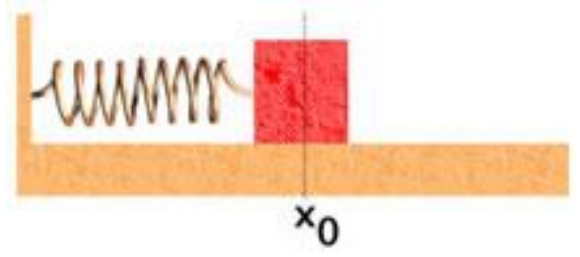

Figura 1 - $O$ bloco em vermelho ligado a uma mola tendo como posição de equilíbrio do sistema a posição Xo.

Nesse sistema desprezaremos as forças dissipativas (atrito e resistência do ar). O bloco, quando colocado em oscilação, se movimentará sob a ação da força restauradora elástica, que pode ser calculada pela seguinte expressão:

$$
F_{e l}=-K \cdot x
$$


A força elástica é diretamente proporcional à deformação da mola $[X(m)]$, sendo $K(N / m)$ a constante elástica da mola.

\section{PERÍODO}

O período de um corpo em MHS é o intervalo de tempo referente a uma oscilação completa e pode ser calculado através da seguinte expressão:

$$
\mathrm{T}=2 \pi \cdot \sqrt{\frac{m}{K}}
$$

O período $[\mathrm{T}(\mathrm{s})]$ depende da massa do corpo colocado em oscilação $[\mathrm{m}(\mathrm{kg})]$ e da constante elástica da mola $[\mathrm{k}(\mathrm{N} / \mathrm{m})]$.

\section{FREQUÊNCIA}

A frequência de um corpo em MHS corresponde ao número de oscilações que esse corpo executa por unidade de tempo e essa grandeza pode ser determinada pela seguinte expressão:

$$
\mathrm{F}=\frac{n^{0} \text { de oscilações }}{t}
$$

A unidade associada à grandeza frequência no s.i é dada em hertz $(\mathrm{Hz})$. Frequência é inversamente proporcional ao período e pode ser expressa matematicamente pela seguinte relação:

$$
\mathrm{F}=\frac{1}{T}
$$

\section{ANÁLISE QUALITATIVA DE UMA OSCILAÇÃO}

Façamos, agora, um estudo qualitativo de uma oscilação completa realizada por um móvel, analisando velocidade, aceleração e força atuante, em distintos pontos da trajetória. Para tanto consideremos (fig. 2) um corpo, apoiado em um plano horizontal, preso à extremidade de uma mola; desprezemos qualquer forma de atrito. Precisamos, entretanto, primeiramente caracterizar dois novos termos que utilizaremos daqui por diante no estudo das oscilações, quais sejam elongação e amplitude.

- Elongação de uma oscilação em um dado instante é a distância a que o móvel se encontra da posição de equilíbrio no instante considerado. 
- Amplitude de um movimento oscilatório é a máxima elongação, isto é, a maior distância que o móvel alcança da posição de equilíbrio em sua oscilação.

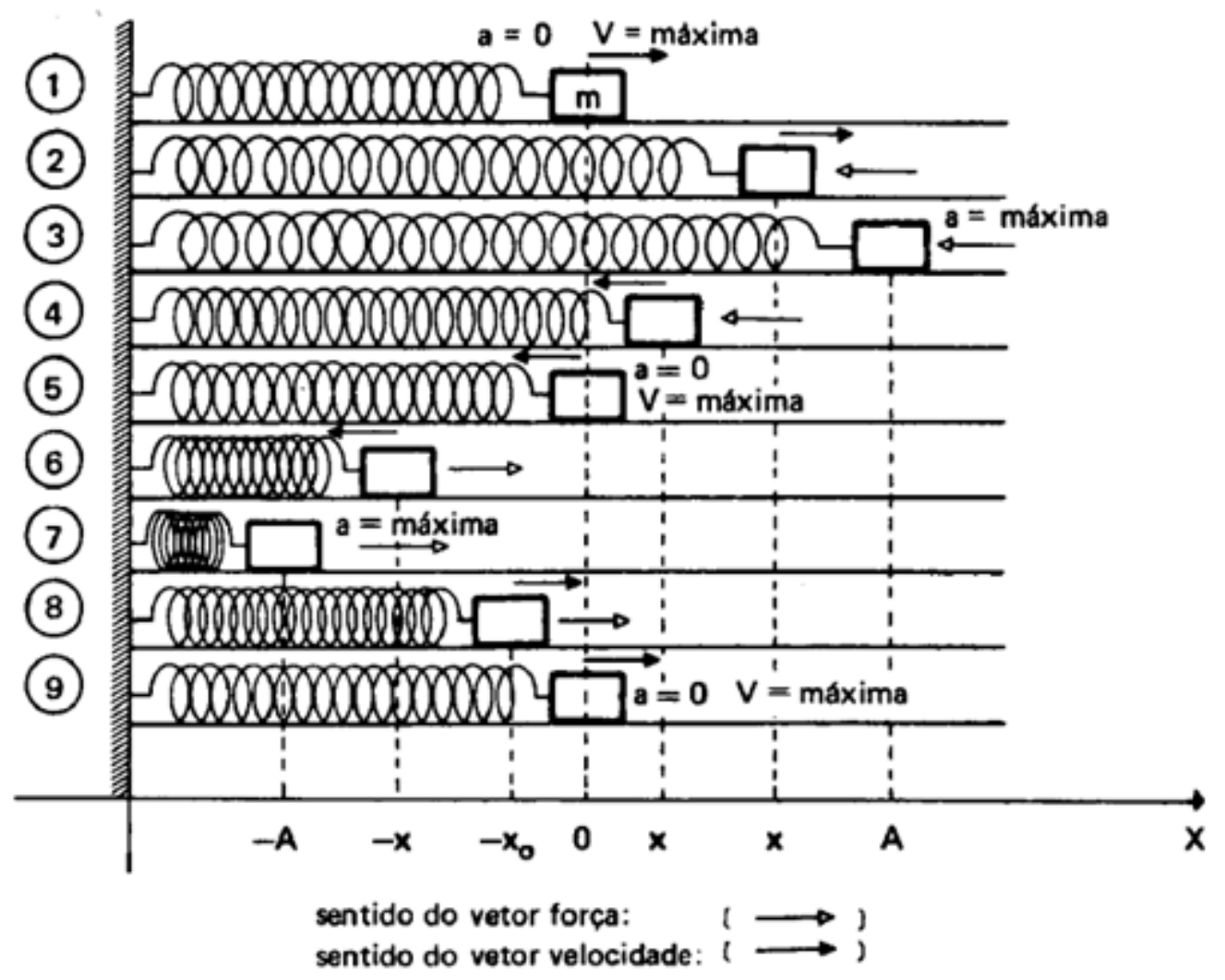

Figura 2

Tomemos um eixo horizontal $\mathrm{X}$ onde 0 é origem e representa a posição de equilíbrio. Suponhamos o movimento já em desenvolvimento e comecemos a analisá-lo a partir do momento em que o móvel passa pela posição de equilíbrio. Após esse instante a mola passará a exercer sobre o corpo uma força, a já referida força restauradora (de caráter elástico, no caso), que procura fazê-lo retornar a 0 . Na medida em que $\mathrm{m}$ se afasta do equilíbrio, aumentando as elongações, a força restauradora cresce, mas nota-se que tem orientação contrária à do eixo. Portanto, da mesma forma a aceleração cresce a medida que a massa se afasta de $A$.

Por outro lado, a velocidade do móvel decresce até atingir valor zero quando o móvel chega à posição $\mathrm{A}$, onde a força restauradora será máxima. Partindo de A o móvel começa o retorno com velocidade crescente, porém, conforme diminuam as elongações, a força atuante sobre ele diminui em intensidade bem como a aceleração.

Observamos que de A para 0 , os vetores força, aceleração e velocidade têm todos a mesma orientação, contrária à do eixo. Ao atingir o ponto $0 \mathrm{a}$ 
velocidade do corpo será máxima e, como aí a força é nula, em função da inércia o corpo passa dessa posição indo em direção à -A. De 0 para -A a força restauradora cresce, assim como a aceleração, sendo máximas em -A. A velocidade, nesse trajeto, decresce até atingir valor nulo no extremo da trajetória. De -A para 0 os vetores velocidade, aceleração e força têm o mesmo sentido do eixo.

Porém, enquanto a força e a aceleração decrescem, o valor da velocidade cresce, na medida em que o corpo aproxima-se de 0 . Se o móvel oscila em torno de sua posição de equilíbrio por ação de uma força que seja proporcional às elongações, então o movimento oscilatório é dito harmônico simples. Assim, sendo o corpo deslocado "x", do equilíbrio, por ação de uma força restauradora F, essa será dada por

$$
F=-K \cdot x
$$

onde o sinal (-1) indica que o sentido da força será contrário ao deslocamento, quando $\mathrm{x}$ for positivo, e que terá o mesmo sentido quando $\mathrm{x}$ for negativo. Observamos que a força restauradora é tal que é sempre dirigida para a posição de equilíbrio, sendo por isso, algumas vezes, chamada força central.

\section{QUESTÕES}

1 - O texto apresentado acima é uma típica aula ministrada em um curso de escola tradicional. Você acha que poderíamos aplicá-lo em uma escola estadual?

2 - A figura 2 é um exemplo de como motivar o aparecimento das funções senoidais na ondulatória. Você acha que os alunos teriam paciência para ver você fazendo toda essa demonstração no quadro?

3 - Como o seu livro didático expõe esse tema? Compare como nosso.

4 - Abra a simulação "Oscilações Vertical" no link: www.fisica.ufs.b/ladmello e analise se a simulação ajuda no entendimento da explicação acima. 


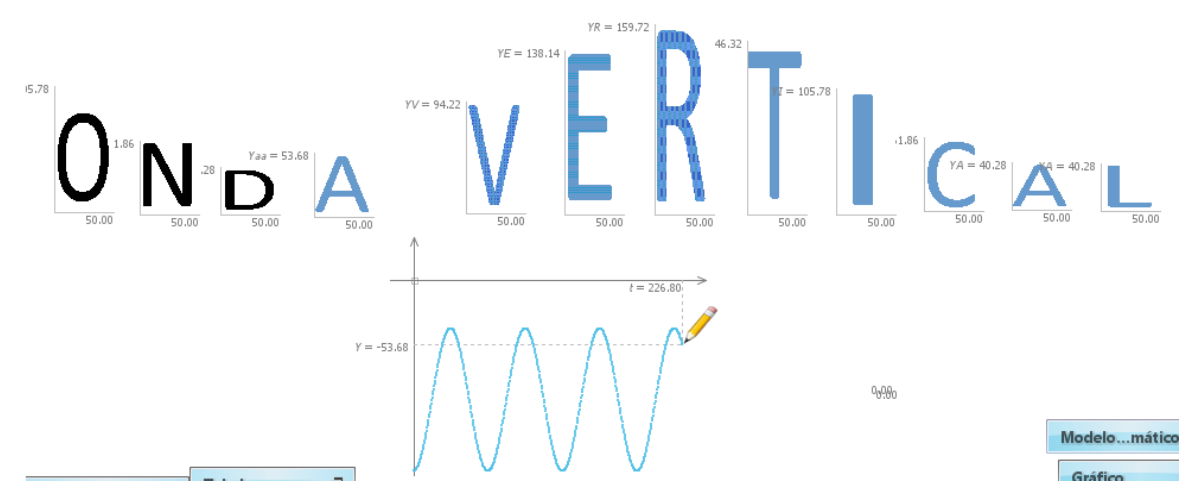

Figura 3 - Animação de uma onda transversal feita usando o Modellus.

MOVIMENTO CIRCULAR UNIFORME - M.C.U.

Antes de definirmos as funções horárias da posição, velocidade e aceleração do MHS façamos uma breve revisão do MCU.

Definição de radiano: É a razão entre o comprimento do arco $L$ e o raio $\mathrm{R}$ da circunferência.

\begin{tabular}{|l|l|}
\hline & $\alpha=\frac{L}{R}$ \\
\hline & \\
\hline
\end{tabular}

\section{ESPAÇO ANGULAR $(x)$}

O espaço angular é dado pela função horária:

$$
\phi=\phi_{0}+\omega . \mathrm{t}
$$

em que:

$\phi:$ espaço angular 
$\phi_{0 \text { : }}$ espaço angular inicial

$\omega$ : velocidade angular

Lembre-se que:

$$
\begin{gathered}
\phi=\frac{S}{R} ; \quad \phi_{0}=\frac{S_{0}}{R} \quad \text { e } \quad \omega=\frac{V}{R} \\
\omega=\frac{\Delta \phi \boxminus}{\Delta t}(\text { definição) }
\end{gathered}
$$

A aceleração centrípeta do M.C.U. pode ser dada por duas relações:

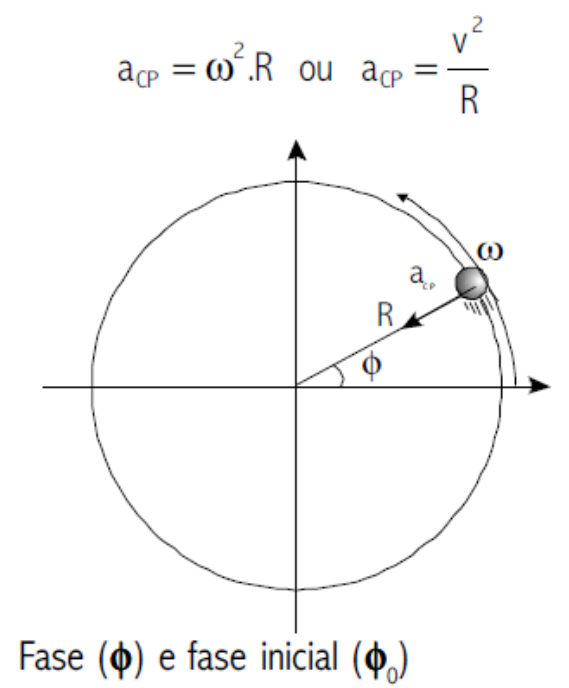

Figura 5

A fase inicial tem por referência a posição inicial de um M.C.U. auxiliar (imaginário). Por exemplo:

$\phi_{0}=0 \mathrm{rad}$ 


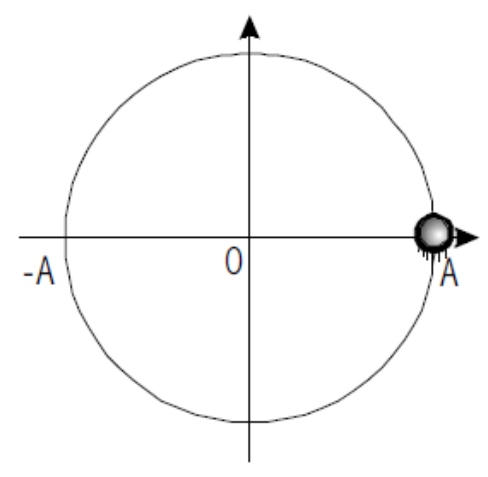

Figura 6

Neste caso imagina-se um M.C.U., cuja posição angular inicial é $\phi_{0}=0$ radianos. Como a posição do objeto que realiza o M.H.S. é a projeção sobre o eixo $x$, então tem-se que o móvel encontra-se na posição $x=A$, movendo-se no sentido contrário da orientação do eixo $x$.

$$
\phi_{0}=\pi / 2 \mathrm{rad}
$$

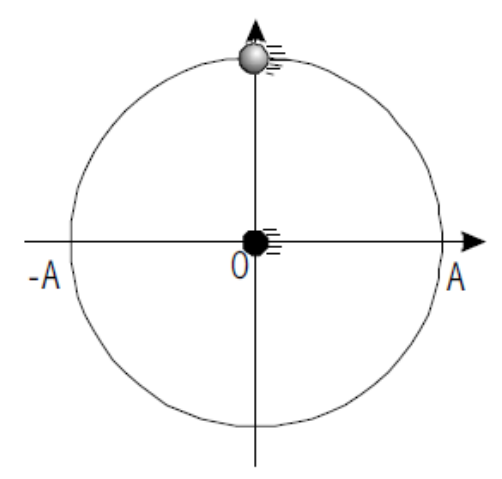

Figura 7

A velocidade linear do M.C.U. se relaciona com a velocidade angular através da relação $V=\omega . R$. Assim, a relação passa a ser:

$$
\mathrm{V}_{\mathrm{MHS}}=\omega \cdot \operatorname{Rsen} \phi
$$


Mais uma vez, lembrando que a amplitude do MHS é igual ao raio do M.C.U., temos:

$$
\begin{aligned}
& R=A \text { e } \phi=\phi_{0+} \omega \cdot t \\
& V_{M H S}=\omega \cdot A \cdot R \operatorname{sen}\left(\phi_{0+} \omega \cdot T\right)
\end{aligned}
$$

Note que não tem sentido mais a denominação velocidade angular para um M.H.S., portanto $\omega$ será denominado de frequência angular. $O$ sentido do M.C.U. auxiliar é anti-horário. Fazendo a correção necessária devido a orientação do eixo $x$, temos:

Atividade usando o software Modellus

1 - Abra o exemplo "MCU" e faça uma análise do modelo matemático. Verifique o significado das equações do modelo.

2 - Faça uma análise comparativa dos gráficos das coordenadas $x$ e y em função de te de $v_{x} e v_{y}$ em função de $t$.

3 - Abra a tabela e verifique os valores de $x, y, v_{x}, e v_{y}$.

Obs: Se você não se lembra mais como usar o software Modellus há um tutorial no site da física da UFS. URL: http://www.fisica.ufs.br/ladmello/ 


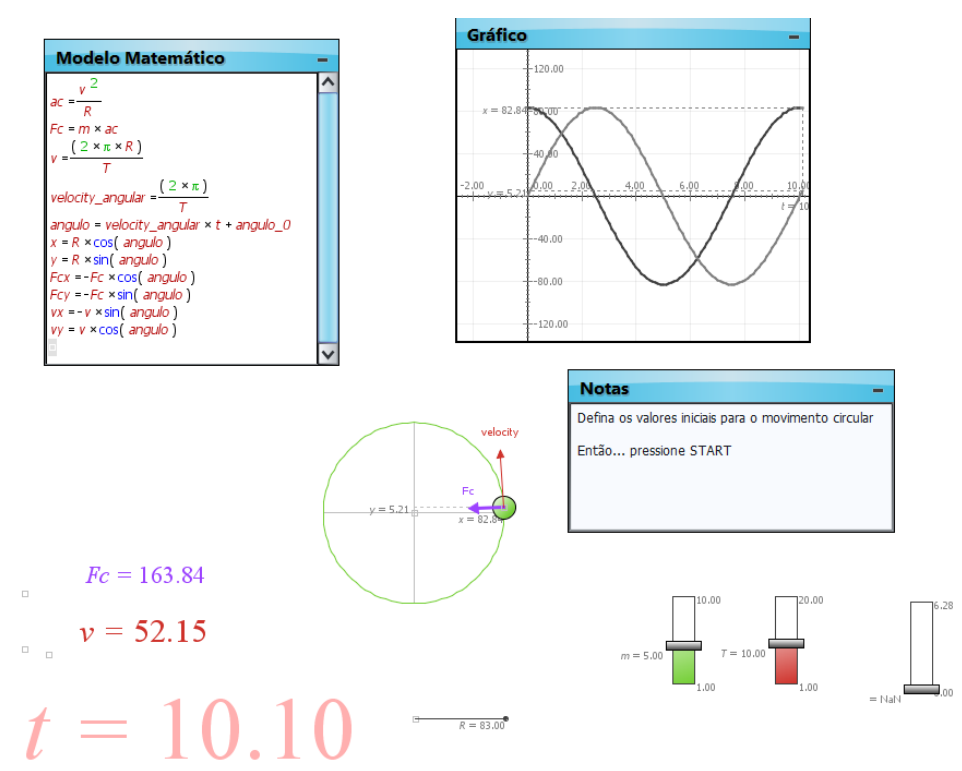

Figura 8

\section{FUNÇÃO HORÁRIA DA ACELERAÇÃO DO M.H.S.}

A aceleração do M.H.S. será a componente no eixo $x$ da aceleração centrípeta do M.C.U. A relação entre as acelerações será dada pela função coseno.

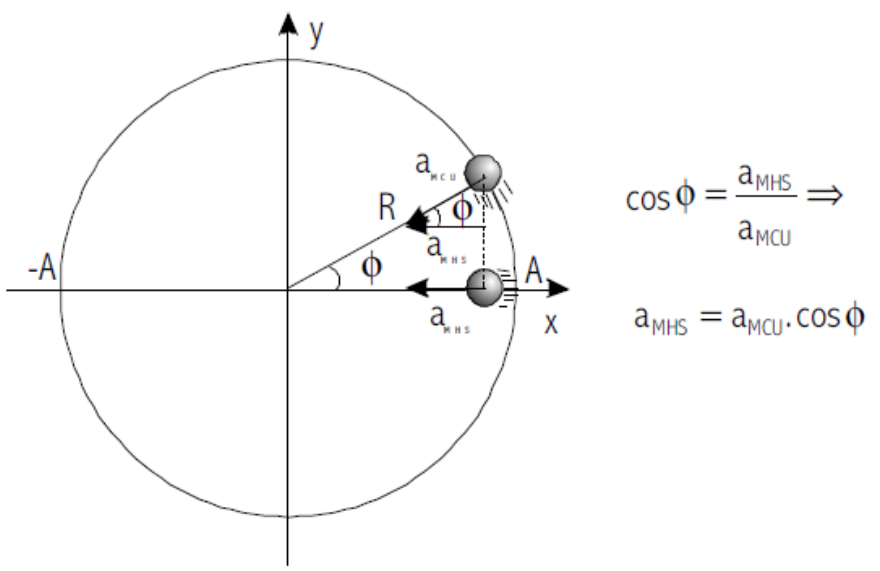

Figura 9 
Como a aceleração centrípeta é $a_{c p}=\omega^{2} \cdot R$, temos $a_{M H S}=\omega^{2} \cdot R \cos \phi$.

Corrigindo o sinal da aceleração devido a orientação do eixo $x$ e substituindo $\mathrm{R}=\mathrm{A}$ e $\phi=\phi 0+\omega . \mathrm{t}$, temos a função:

$$
\mathrm{a}_{\mathrm{MHS}}=-\omega^{2} \cdot A \cdot \cos (\phi 0+\omega \cdot \mathrm{t})
$$

Equação Fundamental do M.H.S.

Como a definição do M.H.S. é de um movimento no qual a aceleração é proporcional a posição, temos:

$$
a=k \cdot x
$$

comparando a função horária do espaço:

$$
x=A \cdot \cos \left(\phi_{0}+\omega \cdot t\right)
$$

com a função horária da aceleração:

$$
a_{M H S}=-\omega^{2} \cdot A \cdot \cos \left(\phi_{0}+\omega \cdot t\right)
$$

chegamos a função fundamental do M.H.S.:

$$
a_{M H S}=-\omega^{2} \cdot x
$$

em que: $\mathrm{k}=-\omega^{2}$

Assim, pela segunda lei de Newton temos

$$
\mathbf{F}=\mathbf{m a}=\mathbf{m} \cdot \mathbf{a}_{\mathrm{MHS}}=-m \omega^{2} \cdot A \cdot \cos \left(\phi_{0}+\omega \cdot t\right)
$$

\section{Posição do Móvel em MHS}

A equação que representa a posição de um móvel em MHS será dada a seguir em função do tempo. 


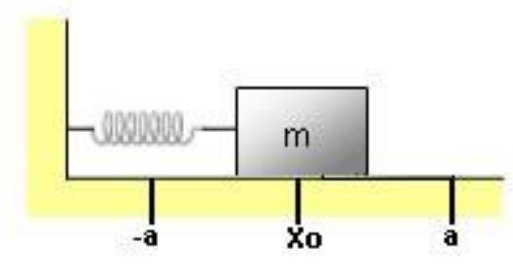

Figura 10 - As posições a e -a são deformações máximas que a mola terá quando o bloco de massa $m$ for colocado em oscilação.

$$
X=A \cdot \cos (\omega \cdot t+\varphi)
$$

A posição X é dada em função do tempo.

$\mathrm{a}$ = elongação máxima $(\mathrm{m})$

$\omega=$ frequência angular (rad/s)

$\varphi=$ espaço angular que um ponto projetado pelo bloco sobre uma circunferência realiza (rad).

$\mathrm{t}=$ intervalo de tempo

\section{FORÇAS QUE PRODUZEM O MHS (CEPA)}

O movimento harmônico simples ocorre como consequência de um tipo muito especial de forças. Para entendermos as características dessas forças lembramo-nos de que no MHS temos a relação:

$$
A=-\omega^{2} \cdot x(t)
$$

Multiplicando a equação acima por m obtemos

$$
m \cdot a=-\left(\omega^{2} m\right) x=-k \cdot x .
$$

onde $k=\omega^{2} \cdot m$

Lembrando agora a segunda Lei de Newton,

$$
\mathrm{F}=\mathrm{m} \cdot \mathrm{a},
$$

vemos que o MHS ocorre sempre que atuar sobre uma partícula uma força da forma 


$$
\mathrm{F}=-\mathrm{kx}
$$

Como sabemos, são as forças elásticas que têm esta característica. A seguir veremos alguns exemplos.

\section{ENERGIA DO MOVIMENTO HARMÔNICO SIMPLES (CEPA)}

Já vimos no curso de Mecânica que a energia potencial associada a uma força elástica é dada por

$$
\mathrm{E}_{\mathrm{p}}=\frac{1}{2} \mathrm{k} \cdot \mathrm{x}^{2}
$$

Utilizando a expressão $x(t)=A \cos \left(\omega t+\varphi_{0}\right)$ vemos que a energia potencial varia com o tempo de acordo com a expressão

$$
\mathrm{E}_{\mathrm{p}}=\frac{k \cdot A^{2}}{2} \cos ^{2}\left(\omega \cdot \mathrm{t}+\varphi_{0}\right)
$$

A energia cinética, dada por

$$
\mathrm{E}_{\mathrm{c}}=\frac{1}{2} \mathrm{~m} \cdot \mathrm{v}^{2}
$$

Também, varia com o tempo. Utilizando $v(t)=-A \omega s e n\left(\omega . t+\varphi_{0}\right)$ vemos que a dependência da energia cinética com o tempo é dada por

$$
E_{c}=\frac{m \cdot A^{2} \cdot \omega^{2}}{2} \operatorname{sen}^{2}\left(w \cdot t+\varphi_{0}\right)=\frac{k \cdot A^{2}}{2} \operatorname{sen}^{2}\left(w \cdot t+\varphi_{0}\right)
$$

onde, na expressão acima utilizamos a relação $\omega^{2}=\mathrm{k} / \mathrm{m}$.

A soma da energia cinética com a energia potencial nos dá a energia mecânica (E). Nesse caso escrevemos

$$
E=E_{c}+E_{p}=\frac{1}{2} m \cdot v^{2}+\frac{1}{2} k \cdot x^{2}
$$

Sabemos que a energia mecânica se conserva no movimento. Podemos verificar isso explicitamente somando as expressões 7 e 9 obtemos:

$$
E=E_{c}+E_{p}=\frac{k \cdot A^{2}}{2}\left[\operatorname{sen}^{2}\left(w \cdot t+\varphi_{0}\right)+\cos ^{2}\left(w \cdot t+\varphi_{0}\right)\right]
$$


Sabemos que $\operatorname{sen}^{2} \varphi+\cos ^{2} \varphi=1$. Portanto, segue de

$$
E=E_{c}+E_{p}=\frac{k \cdot A^{2}}{2}
$$

A figura abaixo ilustra o que acontece com as várias formas de energia, à medida que o tempo passa.

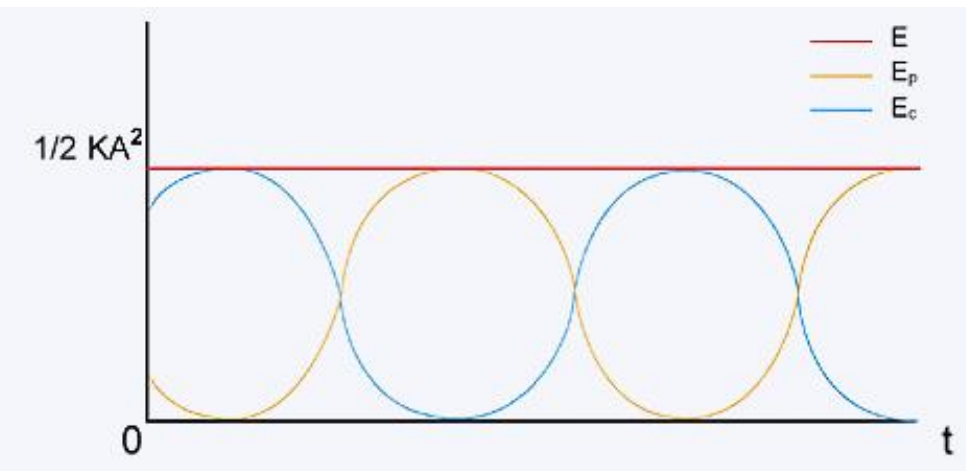

Figura 11

Atividade usando o software Modellus

1 - Abra o exemplo "Energia-MCU" e faça uma análise do modelo matemático. Verifique o significado das equações do modelo.

2 - Faça uma análise comparativa dos gráficos das coordenadas $x$ e y em função de te de $E_{c}$ e $E_{p}$ em função de t.

3 - Abra a tabela e verifique os valores de $x, y, E_{c}$ e $E_{p}$.

4 - Abra o exemplo "Oscillator and Energy" na pasta "Modellus.files" e discuta se essa animação é um bom exemplo de sistema que conserva a energia. 


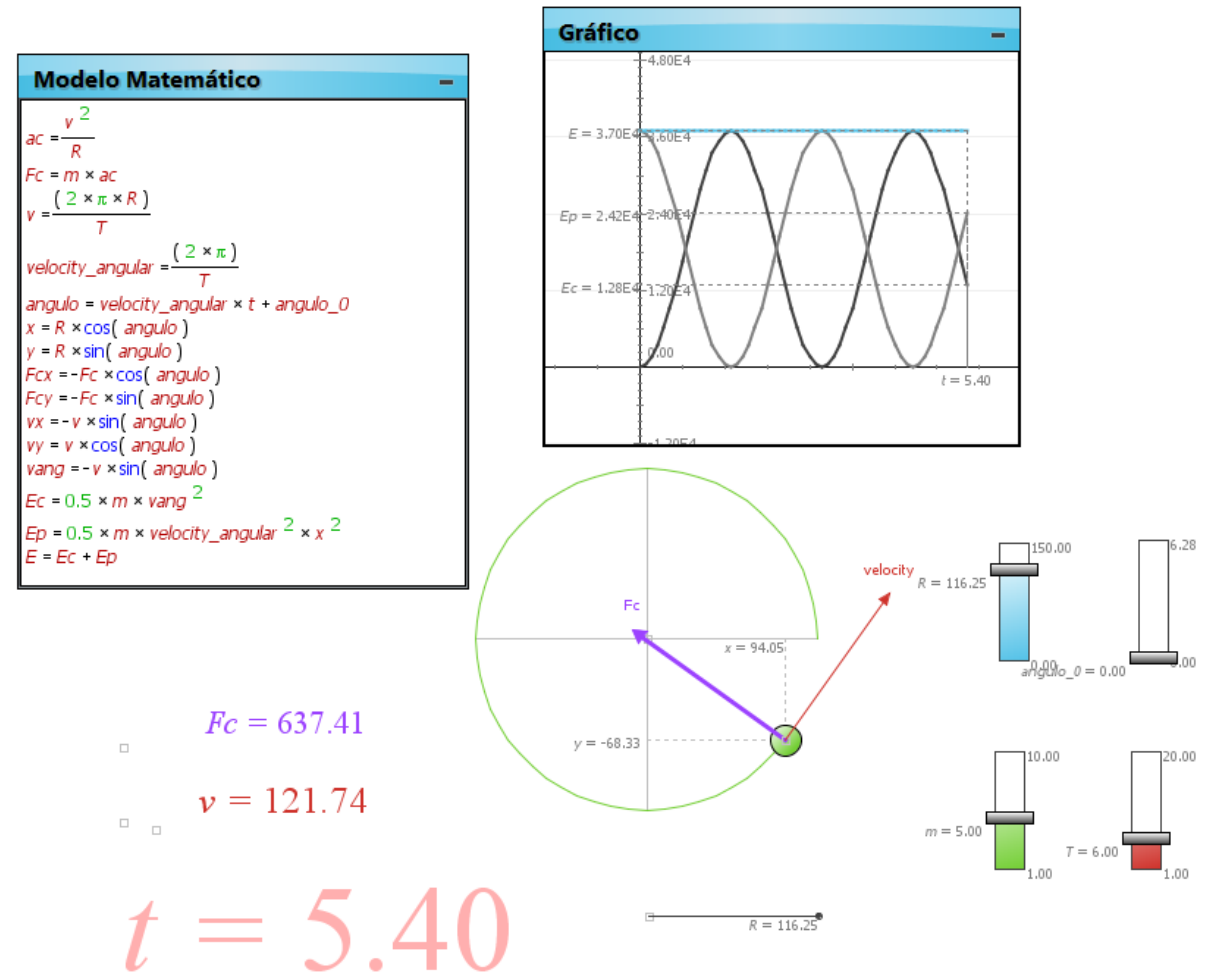

Figura 12 - Exemplo de Animação da Energia no MCU

Fig. - Exemplo de Animação da Energia no MCU

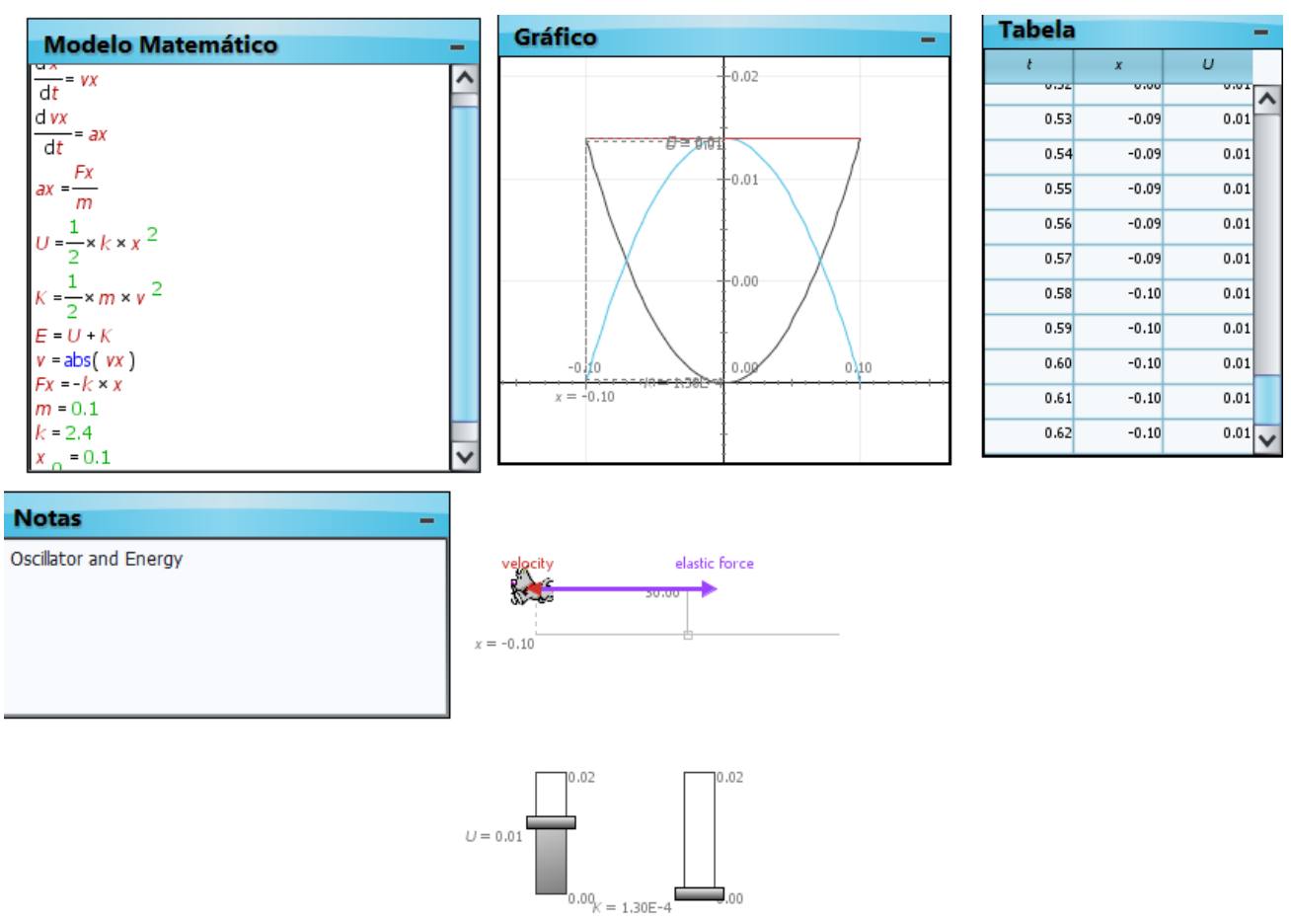




\section{ATIVIDADES}

\section{1 - LUDOTECAS}

Segue abaixo duas formas de se fazer o experimento do pêndulo de mola. A primeira muito simples feito por alunos do curso de Licenciatura em Física IFUSP. Outro um pouco mais elaborado feito por alunos da licenciatura em física da UFS e do projeto PIBID.

1 - Produção de Material Didático

Frequência e Período do Movimento Harmônico Simples

Introdução

Determinar o tempo de forma precisa é de fundamental importância para a humanidade, pois há diversos fenômenos naturais periódicos no dia-a-dia, por exemplo, as estações do ano, a duração do dia, o período da Lua e a passagem de um cometa. Historicamente, Robert Hooke estudou o sistema de molas e constatou que tal sistema oscilava de maneira uniforme e era possível utilizá-lo para se medir o tempo de forma precisa. Então, propomos essa atividade para alunos do segundo ano do Ensino Médio para que possam verificar a utilização da mola para medição do tempo.

Materiais - Uma mola espiral de um caderno de 200 folhas; · Cronômetro; · Um massor (bolinha que tenha diâmetro maior que o da mola, ou seja, mais ou menos $3 \mathrm{~cm}$ de diâmetro); · Fita adesiva.

Montagem Fixar uma extremidade da mola com fita adesiva de modo que a outra extremidade possa se movimentar livremente na direção vertical. Feito isto, colocar o massor na extremidade livre.

Procedimento Obs.: Pendurar a mola em algum suporte, de modo que a mesma possa oscilar livremente, caso não seja possível, segurar firmemente a mola com mão, tomando o máximo de cuidado para que a mão não oscile junto, pois se acontecer haverá erros nos dados. Colocar o massor na extremidade livre e esperar o sistema atingir o equilíbrio; . Esticar a mola verticalmente o suficiente para uma pequena oscilação; 


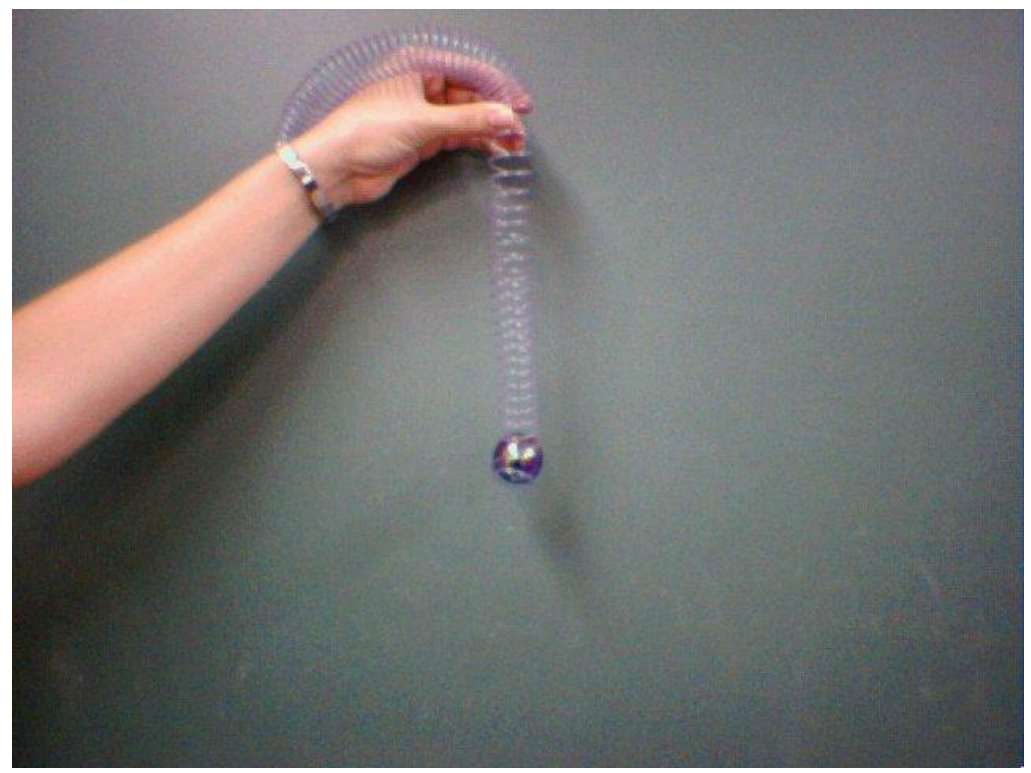

Figura 14

Com um cronômetro, um aluno mede o tempo "t" de dez oscilações completas. Fazer pelo menos cinco vezes e tirar a média para melhor precisão; · Calcular a frequência da seguinte forma: $f(\mathrm{~Hz})=10 / \mathrm{t}$. Calcular o período da seguinte forma: $\mathrm{T}(\mathrm{s})=1 / \mathrm{f}$. Realizar o mesmo procedimento alterando a massa suspensa e verificar o que altera.

Roteiro 1. A frequência e o período dependem da massa colocada e da mola utilizada? 2. Por que a mola estica ao colocar a bola? 3. Na posição de equilíbrio pode-se dizer que a força exercida pela mola nesse instante é igual ao peso da massa pendurada? 4. Esse sistema massa-mola teria alguma utilidade prática? 5 . Se cortarmos a mola ao meio o que acontecerá com 0 período e com a frequência?

Conclusões: O estudo do Movimento Harmônico Simples (MHS) é importante, pois possibilita mostrar aos alunos as grandezas físicas envolvidas, a manipulação e fazer analogias com outros movimentos periódicos, pêndulo com pequeno ângulo de abertura e a marcha de um atleta. Ao manipularem as grandezas envolvidas, os alunos irão notar as relações de dependências entre tais, o que é muito importante na ciência de maneira geral, além de desenvolverem a observação, análise, senso crítico e treinamento.

1.2 - Oscilações Simples - Sistema Massa-Mola [ ]

I - INTRODUÇÃO 
Nesta experiência estudaremos um tipo de movimento oscilatório bastante simples: o sistema massa-mola. Quando um corpo de massa m é suspenso por uma mola de constante elástica $\mathrm{k}$ como mostrado na figura 1 , as forças que atuam sobre o corpo serão a força peso $\mathrm{P}$ e a força de restituição elástica da mola $\mathrm{F}$, dadas por:

$$
F=-k x \quad \text { e } \quad P=m g
$$

Se deslocarmos a massa $\mathrm{m}$ da sua posição de equilíbrio o soltarmos, o corpo passará a oscilar com uma certa frequência característica, em cada instante do movimento sempre poderemos escrever que a força resultante $R$ é dada por (desprezando o efeito do atrito):

$$
\vec{R}=\vec{P}+\vec{F}=(m g-k x) \vec{i}
$$

Aplicando a $2^{2}$ Lei de Newton, temos:

$$
\vec{R}=m \vec{a}=m \vec{x} \vec{i}=(m g-k x) \vec{i}
$$

O movimento resultante é uma oscilação:

$$
x(t)=A \cos \left(\omega_{0} t+\phi\right)+\frac{m g}{k}
$$

onde A é a amplitude do movimento oscilatório e $\square_{0}$ é a frequência angular do movimento que é dada por:

$$
\omega_{0}=\sqrt{\frac{k}{m}}
$$

Como o período o movimento $T_{0}$ pode ser associado à frequência angular $\square_{0}$ por:

$$
T_{0}=\frac{2 \pi}{\omega_{0}} \Rightarrow T_{0}=2 \pi \sqrt{\frac{m}{k}}
$$

II - OBJETIVOS:

Determinar a dependência do período de oscilação de um sistema massamola com a massa e com a constante elástica da mola.

III - MATERIAL UTILIZADO:

Molas diversas, porta pesos e pesos aferidos, haste, grampo de sustentação, régua e cronômetro. 


\section{IV - PROCEDIMENTO:}

$1^{a}$ parte: Dependência de $T$ com a massa $m$

1) Escolha uma das molas. Pendure-a ao suporte e pendure um porta massor a ela.

2) Calcule o valor da constante elástica da mola segundo o procedimento 1. Anote o valor de $\mathrm{k}$ da mola escolhida.

3) Pendure uma determinada quantidade de massa a esta mola e ponha 0 sistema para oscilar distendendo a mola de certa distância e depois abandonando o corpo. Verifique o que ocorre com a frequência quando você distende a mola por diferentes comprimentos.

4) Com o auxílio do cronômetro meça, ao menos 3 vezes, o tempo t para o corpo completar 10 oscilações completas. Monte uma tabela anotando também a massa do corpo.

5) Repita a operação do item 3 para outros 4 valores de massa.

2aㅡ parte: Dependência de T com $k$

6) Na parte anterior, você estudou a dependência do período T com a massa $\mathrm{m}$, mantendo $\mathrm{k}$ fixo. Nesta parte, $\mathrm{m}$ deverá ser fixo para que se possa estudar a dependência de T com K. Escolha, então, um certo valor de $\mathrm{m}$ e anote-o.

7) Pendure esta massa $m$ a uma das molas e meça, ao menos 3 vezes, o tempo t para que o sistema complete 10 oscilações. Monte uma nova tabela. Não esqueça das incertezas.

8) Repita o procedimento do item 6 para outra duas molas completando a tabela. Lembre que o primeiro valor pode ser aproveitada da tabela anterior !!!

\section{V - DISCUSSÃO:}

1a parte : Dependência de T com $m$

9) Com base na 1a tabela, calcule o valor médio do tempo de dez oscilações $t$ e, a partir deste, obtenha o período T para cada valor de massa escolhido.

10) Faça, em papel di-log, um gráfico de $T \times m$. Qual deve ser o formato da curva? Por que ? Calcule, a partir do seu gráfico este dois coeficientes, com suas respectivas incertezas, e compare com os valores esperados. Discuta a exatidão dos resultados.

$2^{\underline{a}}$ parte : Dependência do com $k$ 
11) com base na $2 a$ tabela, calcule o valor médio do tempo de dez oscilações $t$ e , a partir deste, obtenha o período T para cada valor de $\mathrm{k}$ escolhido.

12) Faça, em papel di-log, um gráfico de $T \times k$. Qual deve ser o formato da curva? Por que?

13) Quais são os valores esperados para o coeficiente angular e coeficiente linear para a curva do item anterior? Por que ?

Calcule, a partir do seu gráfico estes dois coeficientes, com suas respectivas incertezas, e compare com os valores esperados. Discuta a exatidão dos resultados.

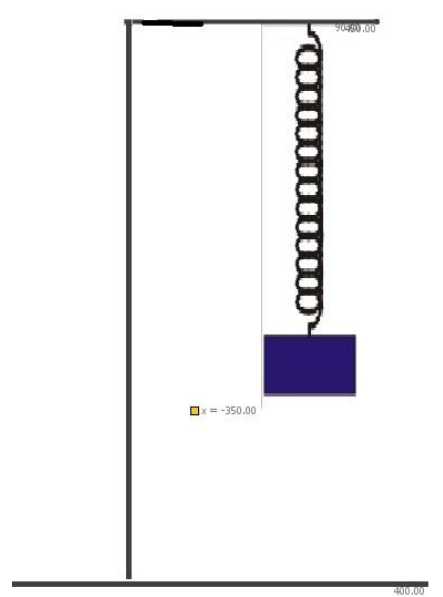

Figura 15

1.3 - Sistema Carro x Duas Molas

- Abra o modelo "MHS-Carro" e verifique se animação gráfica corresponde ao experimento. Você saberia resolver este sistema de forma diferencial? Como você colocaria o amortecimento? 


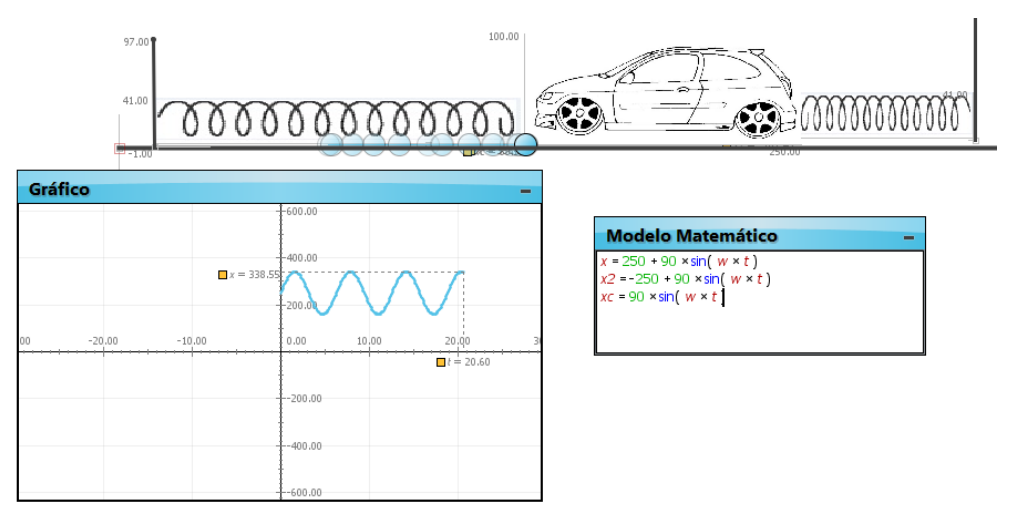

Figura 16

Ver definição e animações na página da Wikipédia.

http://pt.wikipedia.org/wiki/Movimento harm\%C3\%B4nico simples

Ver texto de Estudo Dirigido de Física On-Line sobre Movimento Harmônico Simples (M.H.S.)

http://www.fisica.ufpb.br/ mkyotoku/texto/texto.htm

Ver texto do site Feira de ciências.

http://www.feiradeciencias.com.br/sala04/04 RE 09.asp

Física_Net.

http://www.fisica.net/mecanicaclassica/mhs movimento harmonico simples.pd f

CEPA -

http://www.cepa.if.usp.br/e-fisica/mecanica/universitario/cap13/cap13 03.php

Cienciamão.

http://www.cienciamao.if.usp.br/tudo/busca.php?key=pendulo\%20de\%20mola

Applets de ensino 
1 - CREF. Centro de Referencia para o Ensino de Física. Site adaptado do site do professor Walter-Fendt. Título: Carrossel (Resultante Centrípeta das Força).

URL: http://www.if.ufrgs.br/cref/maikida/appletforcacentripeta.htm

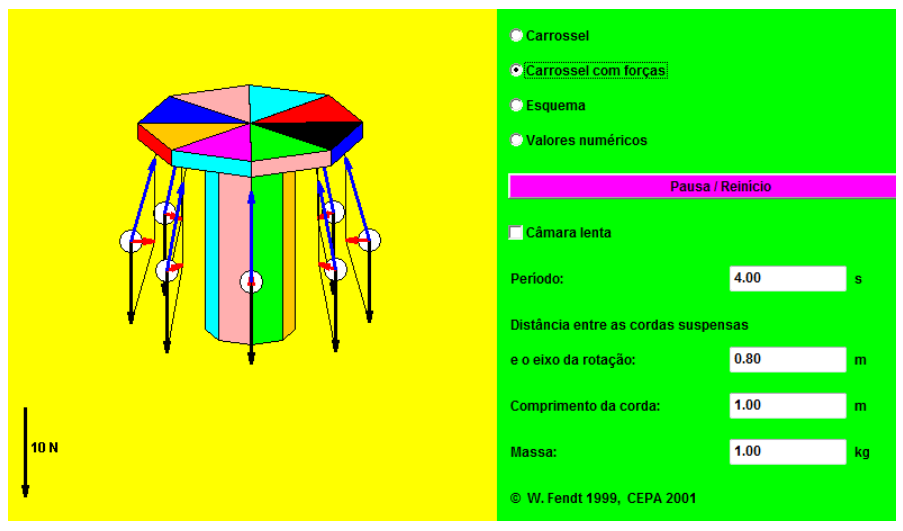

Figura 17 - Disponível em: http://www.if.ufrgs.br/cref/maikida/appletforcacentripeta.htm

2 - MHS - Energia no MHS - http://www.myphysicslab.com/spring1.html

Esse applet simula o movimento de um oscilador amortecido. Mas você pode mudar e até zerar o coeficiente de atrito (damping). Opcional.

Texto: Esta simulação mostra uma massa única de uma mola, que está ligada a uma parede. Este é um exemplo de um oscilador linear simples. Você pode alterar os parâmetros na simulação, tais como massa, rigidez da mola e do atrito (amortecimento). Você pode arrastar a massa com o mouse para mudar a posição de partida.

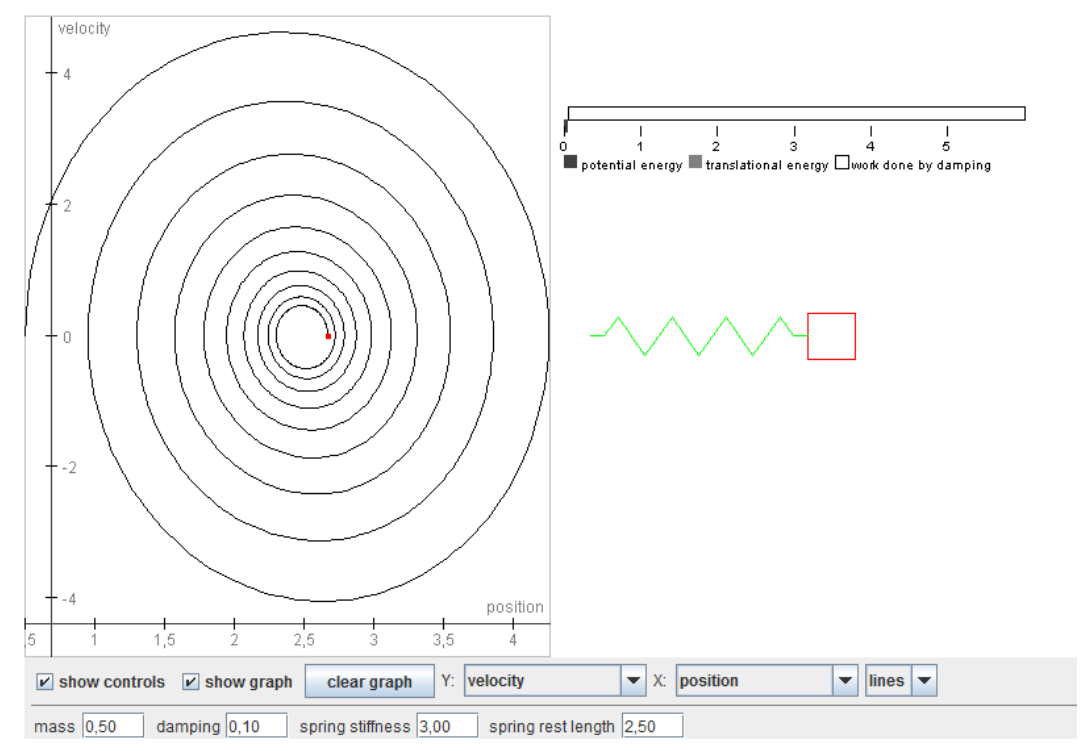

Figura 18 - MHS - Energia no MHS. Disponível em: http://www.myphysicslab.com/spring1.html 
3 - Site do Professor Wu Kwang. www.phy.ntnu.edu.tw/java/shm/shm.html

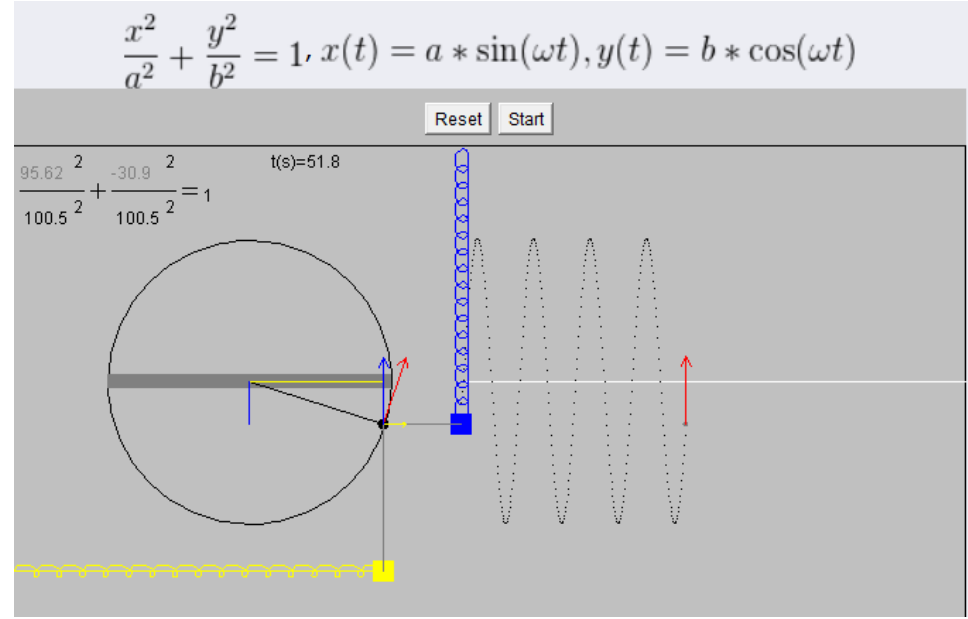

Figura 19 - Site do Professor Wu Kwang. Disponível em:

www.phy.ntnu.edu.tw/java/shm/shm.html

4 - Walter-Fendt. http://www.walter-fendt.de/ph14pt/circmotion pt.htm

Nesta aplicação simula-se um movimento circular uniforme, podendo 0 utilizador observar num sitema de eixos a evolução com o tempo de Força, Aceleração, Velocidade e Posição. O raio da trajectória, a massa do objecto e o período do movimento são ainda passíveis de definição pelo utilizador dentro de certos limites, nas respectivas caixas de texto (não esquecer de validar cada dado).

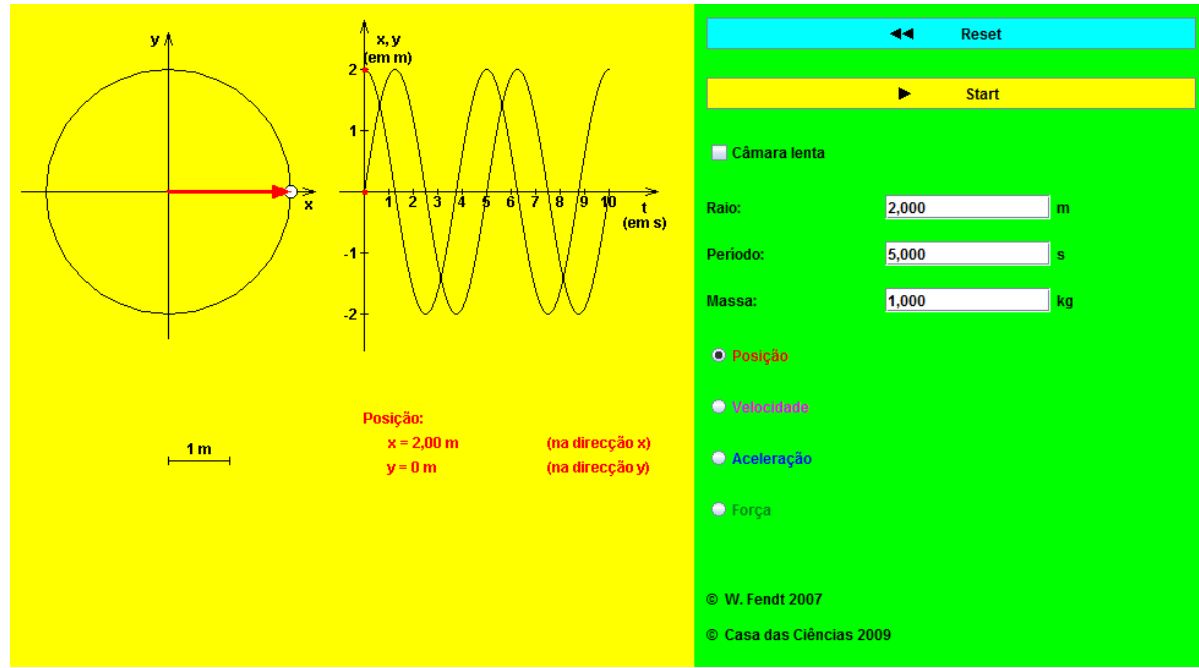

Figura 20 - Physclips. Disponível em: http://www.animations.physics.unsw.edu.au/mechanics/

Physclips. http://www.animations.physics.unsw.edu.au/mechanics/

5 - Ciência a Mão. Movimento Harmônico simples. Ludoteca.if.usp.br 
URL: $\quad$ http://www.cienciamao.usp.br/tudo/exibir.php?midia=tex\&cod= movimentoharmonicosimples.

Descrição - Neste programa vamos mostrar um ponto que realiza um movimento harmônico simples e os gráficos correspondentes à esse movimento: sua posição, velocidade e aceleração em relação ao tempo.

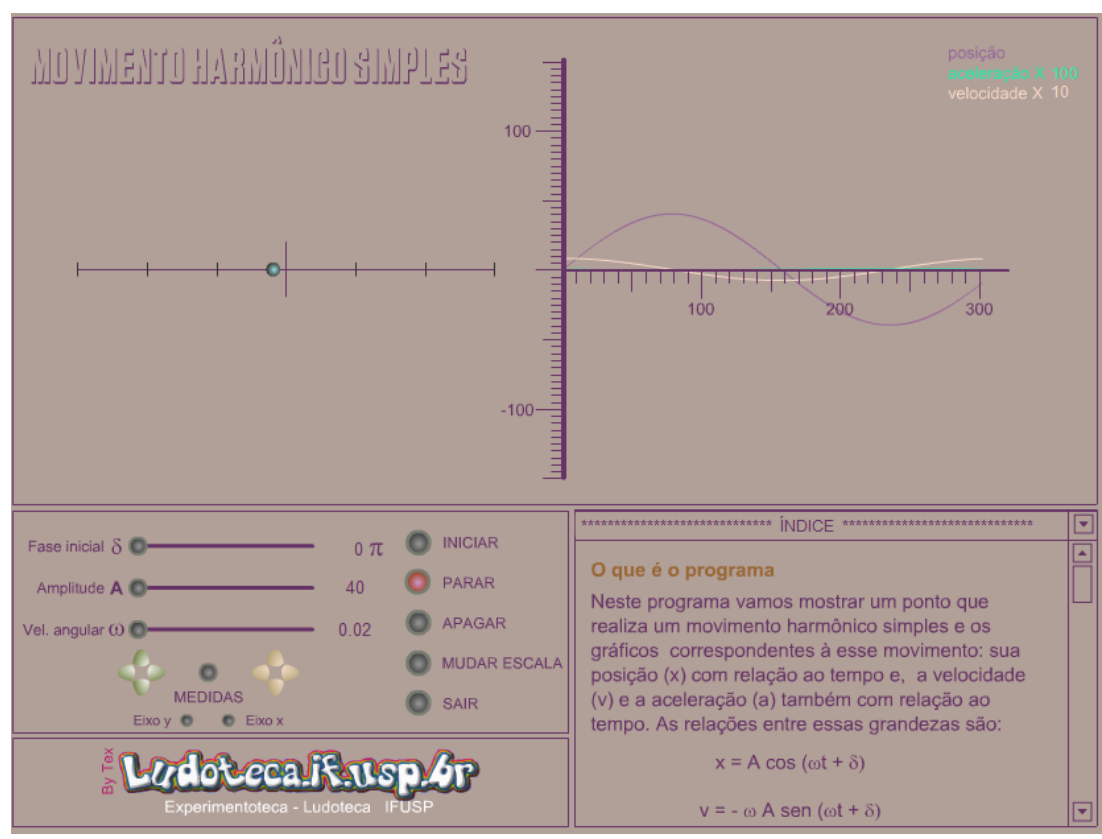

Figura 21 - Disponível em: http://www.cienciamao.usp.br/tudo/exibir.php?midia=tex\&cod= movimentoharmonicosimples.

6 - Site de ensino dedicado à física Moderna. Se você acessar pelo internet Explorer ele tem a opção de traduzir para o português.

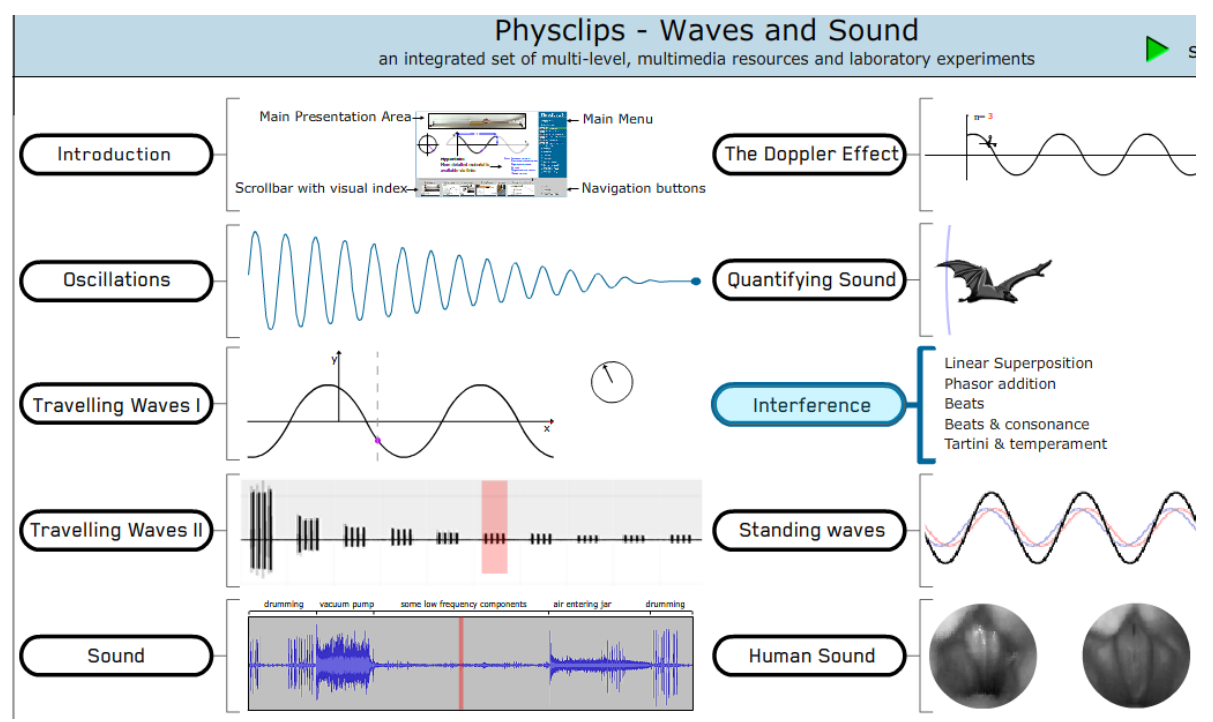


Figura 22 - Disponível em: http://www.phys.unsw.edu.au/jw/chladni.html\#name

Vídeos Aulas

1 - Vídeo Aula Física - Movimento Circular - Parte 1 até 5. URL: http://www.youtube.com/results?search query=movimento+circular+video+aula \&oq=movimento+circular $+\& a q=5 \& a q i=g 10 \& a q \mid=\& g s \quad l=y o u t u b e .1 .5 .0110 .1121 .6$ 978.0.14915.19.11.0.3.3.0.844.4129.1j0j3j1j3j0j2.10.0...0.0.wl16kVTzRpU.

2 - Movimento Circular - Física - Vestibulando Digital.

URL: http://www.youtube.com/watch?v=8IMO5dn1mCc\&feature=related

\section{CONCLUSÃO}

COMENTÁRIOS

RESUMO

RESPOSTA ÀS QUESTÕES

\section{REFERÊNCIAS BIBLIOGRÁFICAS}

1 - Frederico Borges de Almeida. Equipe Brasil Escola: http://www.brasilescola.com/fisica/movimento-harmonico-simples.htm

2 - A. R. Präss. Física.net. URL: http://www.fisica.net/mecanicaclassica/ mhs_movimento_harmonico_simples.pdf

3 - Gil da Costa Marques. e-Física

4 - Elaborado Wilian Faias da Silva, Bruna Schwarz, Viviane da S. Olivares, Willians Nascimento Marcolongo, Ivan de Abreu Magalhães

5 - Referência Alunos da disciplina Produção de Material Didático (FEP 458) Licenciatura em Física - IFUSP -- Turma: Noturno/2005

6 - L. A. de Mello, Diego, Projeto PIBID. 


\section{Cap.02 - Pêndulo Simples}

Meta: Fazer que o estudante comece a pensar no ensino de ciências como algo "orgânico" que está em profunda transformação. Fazer com que os alunos percebam, através de uma atividade lúdica, que podemos ensinar física através de experimentos muito simples. Fazer com que o aluno percebam as aplicações da física no cotidiano.

Objetivos: Ao final da aula, os alunos devem estar cientes das novas possibilidades e dos desafios que envolvem o ensino de ciências em geral. Que para se ensinar física não precisamos ficar presos ao livro didático. Que ensinar física não é ensinar a resolver problemas e que a física é uma mera aplicação da matemática.

Pré-requisitos: Os alunos deveram ter cursado psicologia da educação física A, B e C.

\section{Introdução:}

Como o objetivo central da disciplina de instrumentação é o de estudar e aplicar técnicas de ensino de um determinado conteúdo de física, e não o de introduzir, dividimos o conteúdo de MHS em duas partes. Na aula anterior definimos o MHS e usamos como exemplo o MCU e o do corpo preso a uma mola sujeito somente a força elástica. Deixamos estudo dos pêndulos simples, de torção e o físico para essa aula. Assim, poderemos trabalhar melhor este conteúdo.

Como dissemos na aula passada, a maior aplicação do MHS é o estudo das formas de se medir o tempo. Outra grande aplicação está no estudo dos movimentos circulares e ondulatórios. Em geral os textos didáticos começam definindo o objeto ou tema a ser estudado, em seguida apresentam um pouco de sua história ou de seu descobridor ou inventor. Em seguida expõe a teoria e encerram com exercícios de aplicação.

No caso de um exemplo tão simples de ser confeccionado, como de um pêndulo, não poderíamos começar apresentando um pêndulo e estuda-lo experimentalmente. Somente depois defini-lo e seguir o roteiro de aula tradicional.

Vamos aqui the propor que em vez de começar a ler a aula que se segue, que você confeccione um pêndulo e o estude com cuidado. Para ajuda veja nossas atividades no final do capítulo (página ). 


\section{PÊNDULO SIMPLES [1]}

Um pêndulo é um sistema composto por uma massa acoplada a um pivô que permite sua movimentação livremente. A massa fica sujeita à força restauradora causada pela gravidade.

Existem inúmeros pêndulos estudados por físicos, já que estes o descrevem como um objeto de fácil previsão de movimentos e que possibilitou inúmeros avanços tecnológicos, alguns deles são os pêndulos físicos, de torção, cônicos, de Foucalt, duplos, espirais, de Karter e invertidos. Mas o modelo mais simples, e que tem maior utilização é o Pêndulo Simples.

Este pêndulo consiste em uma massa presa a um fio flexível e inextensível por uma de suas extremidades e livre por outra, representado da seguinte forma:

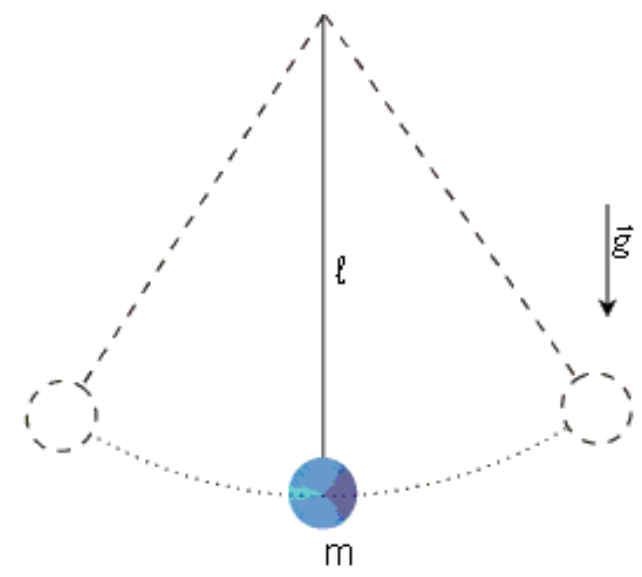

Quando afastamos a massa da posição de repouso e a soltamos, o pêndulo realiza oscilações. Ao desconsiderarmos a resistência do ar, as únicas forças que atuam sobre o pêndulo são a tensão com o fio e o peso da massa $m$. Desta forma:

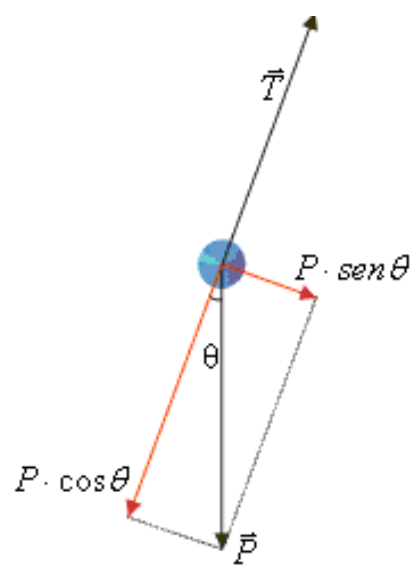

A componente da força Peso que é dada por P. $\cos \theta$ se anulará com a força de Tensão do fio, sendo assim, a única causa do movimento oscilatório é a P.sen $\theta$. Então:

$$
F=P \cdot \operatorname{sen} \theta
$$


No entanto, o ângulo $\theta$, expresso em radianos que por definição é dado pelo quociente do arco descrito pelo ângulo, que no movimento oscilatório de um pêndulo é $x$ e o raio de aplicação do mesmo, no caso, dado por $\ell$, assim:

$$
\theta=\mathrm{x} / \ell
$$

Onde ao substituirmos em F:

$$
F=P \cdot \operatorname{sen}(x / \ell)
$$

Assim é possível concluir que o movimento de um pêndulo simples não descreve um MHS, já que a força não é proporcional à elongação e sim ao seno dela. No entanto, para ângulos pequenos, $\theta \leq(\pi / 8) \mathrm{rad}$, o valor do seno do ângulo é aproximadamente igual a este ângulo.

Então, ao considerarmos o caso de pequenos ângulos de oscilação:

$$
\begin{gathered}
F=P \cdot \operatorname{sen}(x / \ell)=P \cdot x / \ell \\
F=P \cdot x / \ell
\end{gathered}
$$

Como $\mathrm{P}=\mathrm{mg}, \mathrm{e} m, g$ e $\ell$ são constantes neste sistema, podemos considerar que:

$$
\mathrm{K}=\mathrm{P} / \mathrm{l}=\mathrm{m} \cdot \mathrm{g} / \mathrm{l}
$$

Então, reescrevemos a força restauradora do sistema como:

$$
\mathrm{F}=\mathrm{K} \cdot \mathrm{x}
$$

Sendo assim, a análise de um pêndulo simples nos mostra que, para pequenas oscilações, um pêndulo simples descreve um MHS.

Como para qualquer MHS, o período é dado por:

$$
T=2 \pi \sqrt{\frac{m}{K}}
$$

e como

$$
\mathrm{K}=\mathrm{m} \cdot \mathrm{g} / \mathrm{l}
$$

Então o período de um pêndulo simples pode ser expresso por: 


$$
\begin{aligned}
& T=2 \pi \sqrt{\frac{m}{\frac{m \cdot g}{\ell}}} \\
& T=2 \pi \sqrt{\frac{\ell}{g}}
\end{aligned}
$$

\section{QUESTÕES}

1 - Na 6 a edição do volume dois do livro do Ramalho, Nicolau e Toledo, eles definem e expõe a teoria do pêndulo simples sem usar a definição de força de restituição.

Como seu livro texto descreve a teoria do pêndulo simples?

2 - Por que Galileu estudou o pêndulo simples?

3 - Como você começaria uma aula sobre esse tema? Através de um exemplo prático ou através da teoria? Comente.

4 - Abra o modelo "Pendulo simples" e discuta se ele ilustra o funcionamento das projeções da força peso. Deveríamos esconder o modelo matemático? Ele é muito complexo?

5 - Aplicações da Teoria do pêndulo simples. Como funcionam os relógios de pêndulo. http://ciencia.hsw.uol.com.br/relogios-de-pendulo.htm

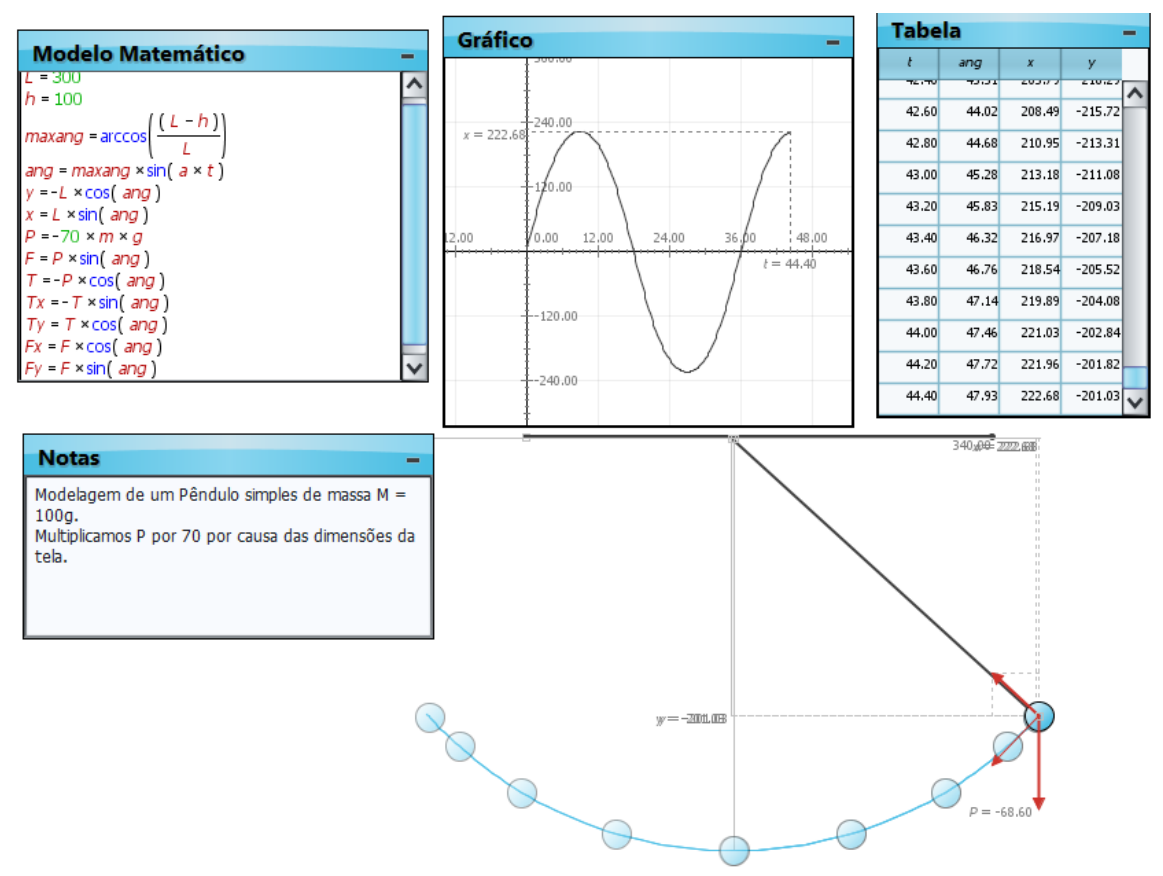

Obs: Se você precisar recordar como se usa o software Modellus há um tutorial do na página da física. URL: http://www.fisica.ufs.br/ladmello/aula modellus/ 


\section{O PÊNDULO DE TORÇÃO [3]}

O pêndulo de torção consiste em um disco suspenso por um fio inextensível e de massa desprezível e preso ao centro de massa do disco (Figura42- 2). Se o disco é girado de um ângulo $\theta_{\mathrm{m}}$ a partir de sua posição de equilíbrio (indicada pela linha OP da figura), o fio é torcionado dando origem a um torque restaurador que tende a fazer o fio voltar à sua forma original.

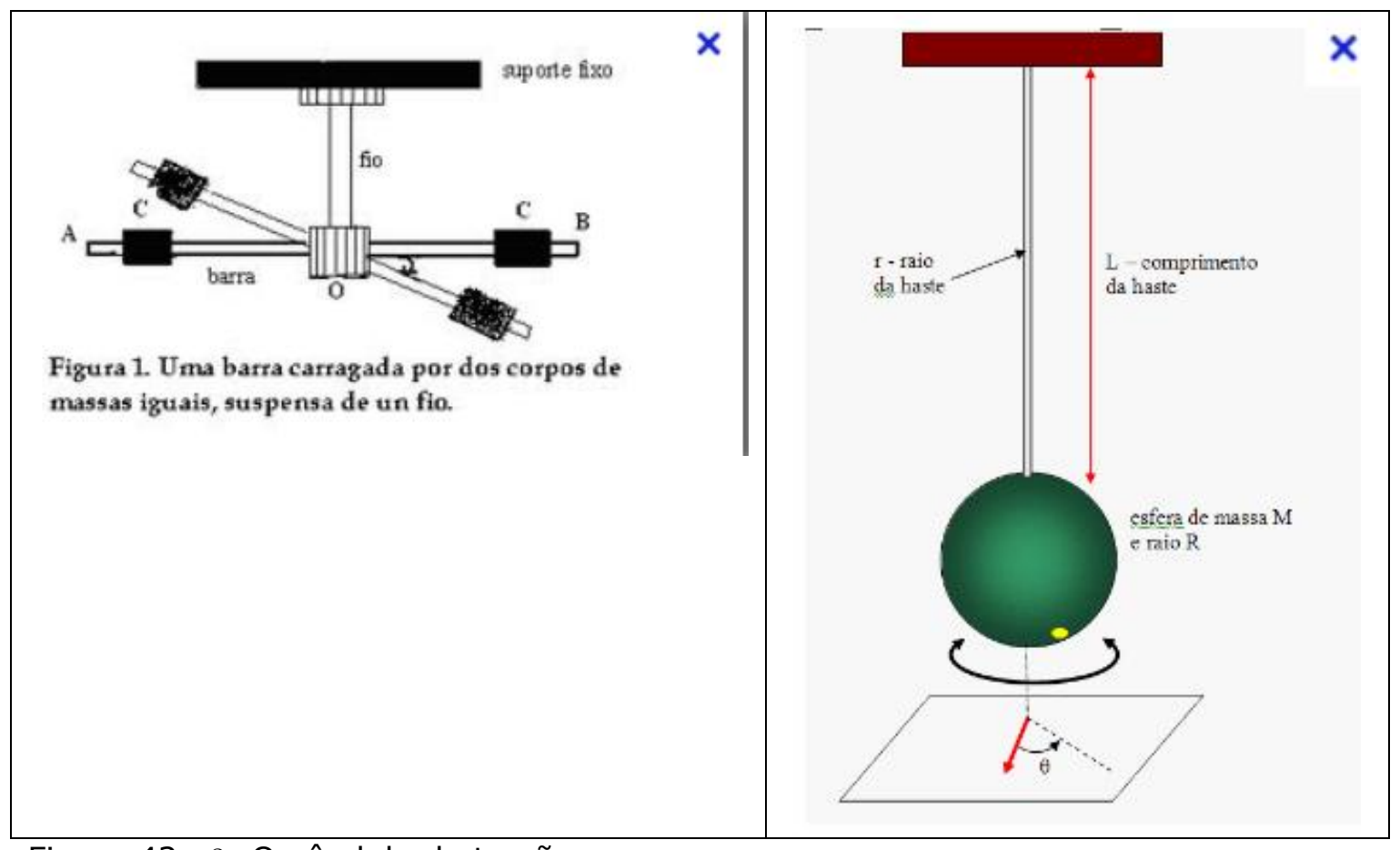

Figura 42 - 2: O pêndulo de torção

Para pequenas torções, o torque restaurador é proporcional ao deslocamento angular $\theta$ do disco e podemos escrever:

$$
\tau=\text { k. } \theta
$$

em que $\mathrm{K}$ é a constante de torção do fio, que depende das propriedades dele. Como:

$$
\tau=\alpha . I
$$

em que l é o momento de inércia do disco relativo ao centro de massa, a segunda lei de Newton para a rotação nos dá:

$$
\tau=\mathrm{k} . \theta=\alpha . \mathrm{I}
$$

Ou $\quad \alpha=k / I$

que mostra que, para pequenas deformações do fio, o movimento do pêndulo é harmônico simples. A solução da equação acima é:

$$
\theta=\theta_{m} \cos \left(\omega_{0} t+\varphi\right)
$$

sendo $\theta_{\mathrm{m}}$ a ampitude do movimento e $\omega_{0}$ dado por:

O período do pêndulo é:

$$
\omega_{0}=\mathrm{I} / \mathrm{k}
$$




$$
\mathrm{T}=2 \pi \sqrt{\frac{I}{\kappa}}
$$

Em geral, o pêndulo pode ser qualquer corpo laminar, isto é, cuja espessura seja muito menor que as suas outras dimensões.

\section{O PÊNDULO FÍSICO}

O pêndulo físico consiste em um corpo posto para oscilar preso por de seus pontos, o qual chamamos de pivô, podendo se mover no plano vertical.

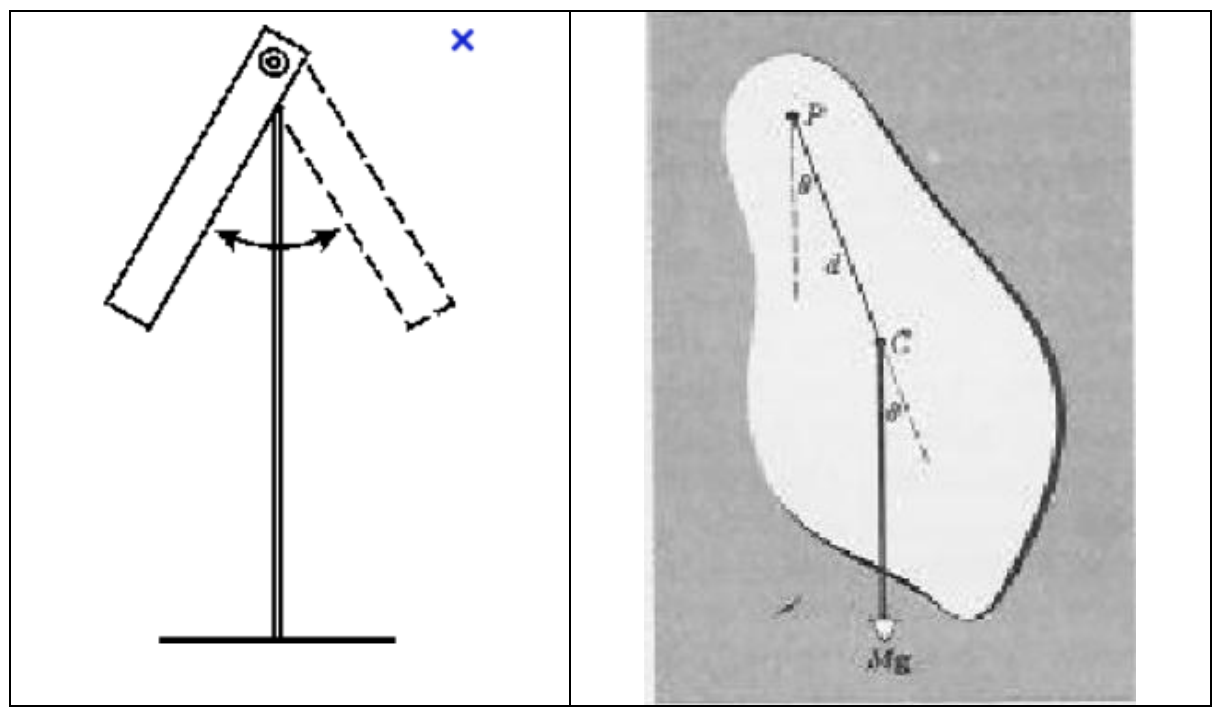

A Figura 42- 3 mostra um corpo rígido preso pelo ponto $\mathrm{P}$, podendo girar sem atrito em torno de um eixo horizontal passando por $\mathrm{P}$. Em equilíbrio, a linha OP que liga $\mathrm{P}$ ao centro de massa $\mathrm{C}$ do corpo é vertical. Quando o corpo é tirado dessa posição, PC faz com a vertical um ângulo $\theta$ e a força peso do corpo exerce sobre ele um torque $\vec{t}$ relativo a $\mathrm{P}$, que tende a tornar $\mathrm{PC}$ vertical. $\mathrm{O}$ torque é dado por:

$$
\vec{\tau}=-d \times m \cdot \vec{g}=-d m g \cdot \operatorname{sen} \theta
$$

em que d é o módulo do vetor $\overrightarrow{P C}$. O sinal negativo indica que o torque se opõe ao deslocamento do corpo. O torque é proporcional a $\operatorname{sen} \theta$, mas para pequenos valores de $\theta$, podemos escrever:

$$
\tau=-\mathrm{mgd} \cdot \operatorname{sen} \theta
$$

Então, tal como no pêndulo de torção, a equação de movimento de rotação para o corpo é:

$$
\alpha=\frac{-m g d}{I} \theta
$$

$\mathrm{Ou}:$

$$
\omega_{0}^{2}=\frac{-m g d}{I} \theta
$$


O período de oscilação do pêndulo físico é:

$$
T=\frac{2 \pi}{\omega_{0}}=2 \pi \sqrt{\frac{I}{m g d}}
$$

Para amplitudes grandes, o pêndulo físico continua a ter movimento harmônico, mas ele não é harmônico simples.

A equação acima pode ser resolvida para o momento de inércia, dando:

$$
I=\frac{m g d T^{2}}{4 \pi^{2}}
$$

Notemos que o pêndulo simples é um caso particular do físico. Com efeito, como toda a massa do pêndulo simples está concentrada na extremidade livre dele, o seu momento de inércia relativo ao ponto de suspensão é $I=m L^{2}$; o centro de massa do pêndulo simples coincide com a massa $m$. Então, $d=L$. Assim, o período do pêndulo é:

$$
T=\frac{2 \pi}{\omega_{0}}=2 \pi \sqrt{\frac{I}{m g d}}=2 \pi \sqrt{\frac{m L^{2}}{m g d}}=2 \pi \sqrt{\frac{L}{g}}
$$

\section{Atividades}

1 - Experimentos de Baixo custo

\section{1 - Experimento: Pêndulo Simples}

Objetivos:

- Obter experimentalmente a equação geral para o período de oscilação de um pêndulo simples;

- Determinar a aceleração da gravidade local;

- Verificar a independência do período com a massa. Para isso iremos:

- Estudar o movimento de um pêndulo, verificando a relação entre o período e o comprimento do fio;

- Observar a independência do período de oscilação de um pêndulo simples, em função do ângulo $\theta$ (ângulo inicial de lançamento);

- Observar a relação entre o período e a massa pendular;

- Construção de gráficos a partir dos dados experimentais; 


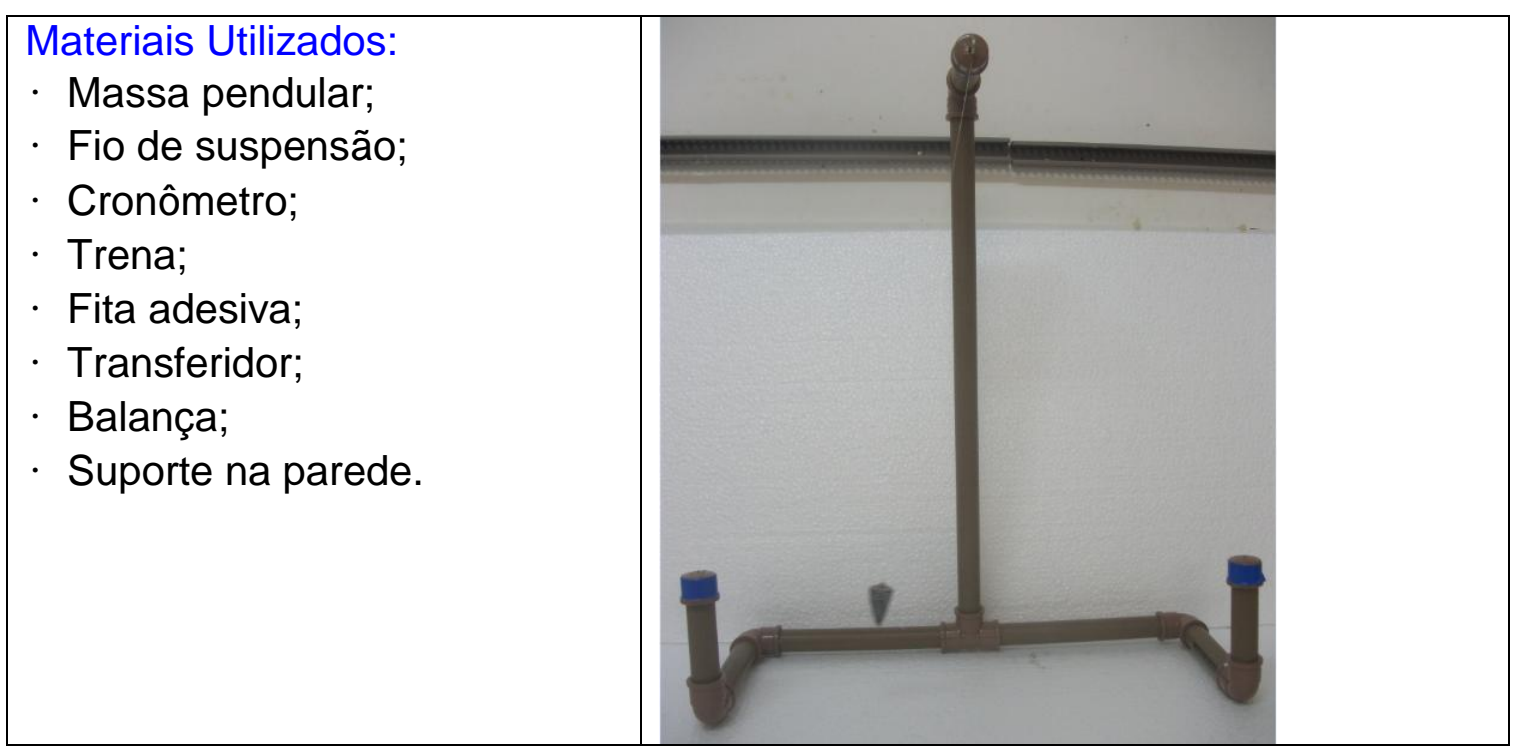

Resumo da Teoria

Um pêndulo simples se define como uma massa $m$ suspensa por um fio inextensível, de comprimento $L$ com massa desprezível em relação ao valor de $m$. O período de oscilação que vamos chamar de T é o tempo necessário para a massa passar duas vezes consecutivas pelo mesmo ponto, movendo-se na mesma direção, isto é, o tempo que a massa leva para sair de um ponto e voltar ao mesmo ponto percorrendo o mesmo arco.

\begin{tabular}{|l|l|} 
Na ilustração (Fig. 6.1), as \\
componentes da força peso segundo \\
as direções radial e tangencial valem: \\
Direção radial : $P_{y}=m g \cos \theta$ \\
Direção tangencial : $P_{x}=m g \operatorname{sen} \theta$
\end{tabular}

\section{Período do pêndulo simples}

Quando o ângulo a for muito pequeno ( aproximadamente $3^{\circ}$ ) $\Rightarrow \operatorname{sen}(\theta)$ é aproximadamente igual a $\theta$. Neste caso o período pode ser calculado pela expressão:

$$
\mathrm{T}=2 \pi(\mathrm{L} / \mathrm{g})^{1 / 2}
$$


Procedimento:

1. Ajuste o comprimento do fio do pêndulo de modo que tenha uma medida pré-determinada da ponta do fio ao centro de massa da massa pendular; 2. Para a realização do experimento, desloca-se a massa pendular da posição de equilíbrio, até um ângulo $\theta$, obedecendo a relação de que este ângulo não deve ser maior do que $15^{\circ}$.

3. Após ter deslocado a massa e determinado uma posição inicial de lançamento, solta-se a massa e marca-se o tempo de 10 oscilações completas, repetindo esta operação 3 vezes para cada comprimento $L$ do fio; Utilize 5 diferentes comprimentos para L;

4. Marque na tabela 1 os valores de $L$ e o respectivo período médio, $T$ para três valores de massa pendular.

\begin{tabular}{|c|c|c|c|c|c|}
\hline \multicolumn{2}{|c|}{$\mathrm{M}_{1}=$} & $\mathrm{g}$ & \multicolumn{2}{c|}{$\mathrm{M}_{2}=$} & \multicolumn{2}{c|}{$\mathrm{M}_{3}=$} & $\mathrm{g}$ \\
\hline $\mathrm{L}(\mathrm{cm})$ & $\mathrm{T}(\mathrm{s})$ & $\mathrm{L}(\mathrm{cm})$ & $\mathrm{T}(\mathrm{s})$ & $\mathrm{L}(\mathrm{cm})$ & $\mathrm{T}(\mathrm{s})$ \\
\hline & & & & & \\
\hline & & & & & \\
\hline $\mathbf{1 0 0}$ & & $\mathbf{1 0 0}$ & & $\mathbf{1 0 0}$ & \\
\hline & & & & & \\
\hline & & & & & \\
\hline
\end{tabular}

Tabela 1 - Tabela de dados experimentais - Sugestão: cada equipe executa o experimento com uma massa diferente e preenche-se a tabela.

5 - Compare a medida da aceleração gravitacional obtida experimentalmente em sala de aula (aceleração determinada pela equação do período utilizando os dados experimentais) com o valor existente na literatura científica (dada por: $\left.\mathrm{g}=9,8 \mathrm{~m} / \mathrm{s}^{2}\right)$ e determine o desvio percentual;

6 . Discuta os desvios encontrados entre os valores de g (valor obtido em sala de aula com o da literatura);

\section{2 - Experimento: Pêndulo Físico}

Objetivos:

- Obter experimentalmente a equação geral para o período de oscilação de um pêndulo físico;

- Determinar a aceleração da gravidade local;

- Observar a independência do período de oscilação de um pêndulo físico, em função do ângulo $\theta$ (ângulo inicial de lançamento);

- Observar a relação entre o período e momento de inércia do pêndulo; 


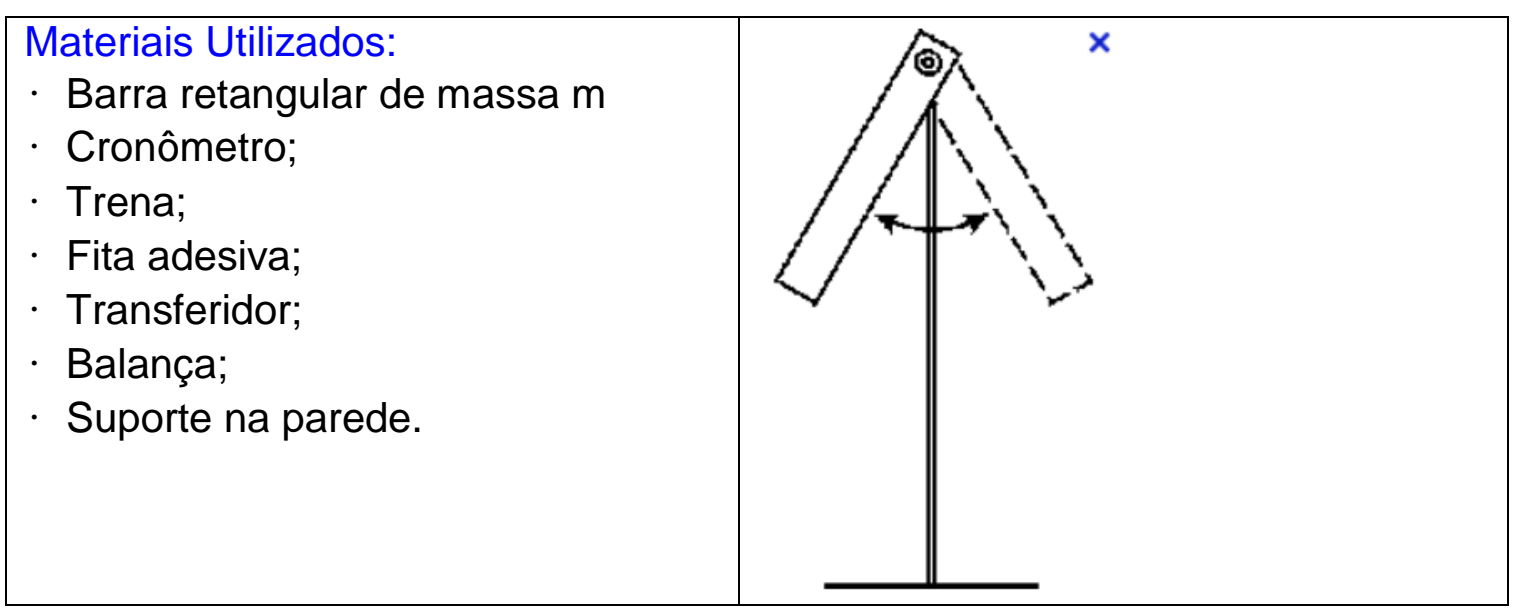

Resumo da Teoria

O pêndulo físico consiste em um corpo posto para oscilar preso por de seus pontos, o qual chamamos de pivô, podendo se mover no plano vertical. A Figura abaixo mostra um corpo rígido preso pelo ponto $\mathrm{P}$, podendo girar sem atrito em torno de um eixo horizontal passando por $P$. Em equilíbrio, a linha OP que liga $P$ ao centro de massa $C$ do corpo é vertical. Quando o corpo é tirado dessa posição, PC faz com a vertical um ângulo $\theta$ e a força peso do corpo exerce sobre ele um torque $\vec{t}$ relativo a $\mathrm{P}$, que tende a tornar $\mathrm{PC}$ vertical. $\mathrm{O}$ torque é dado por:

$$
\vec{\tau}=-d \times m \cdot \vec{g}=-d m g \cdot \operatorname{sen} \theta
$$

em que dé o módulo do vetor $\overrightarrow{P C}$. $\mathrm{O}$ sinal negativo indica que o torque se opõe ao deslocamento do corpo.

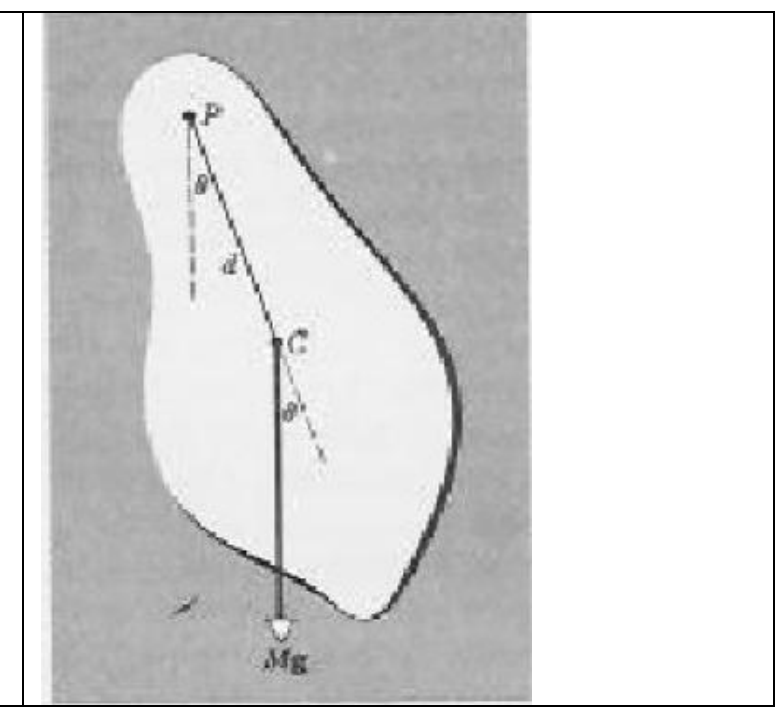

O período de oscilação que vamos chamar de T é o tempo necessário para a barra de madeira passar duas vezes consecutivas pelo mesmo ponto, movendo-se na mesma direção, isto é, o tempo que a barra leva para sair de um ponto e voltar ao mesmo ponto percorrendo o mesmo arco.

\section{Período do pêndulo físico}

O período de oscilação do pêndulo físico é: 


$$
T=\frac{2 \pi}{\omega_{0}}=2 \pi \sqrt{\frac{I}{m g d}}
$$

Para amplitudes grandes, o pêndulo físico continua a ter movimento harmônico, mas ele não é harmônico simples.

Procedimento:

1. Ajuste o comprimento do fio do pêndulo de modo que tenha uma medida pré-determinada da ponta do fio ao centro de massa da massa pendular;

2. Para a realização do experimento, desloca-se a barra da posição de equilíbrio até um ângulo $\theta$, obedecendo a relação de que este ângulo não deve ser maior do que $15^{\circ}$.

3. Após ter deslocado a barra e determinado uma posição inicial de lançamento, solta-se a massa e marca-se o tempo de 10 oscilações completas, repetindo esta operação 3 vezes.

4. Marque na tabela 1 os valores de I, de $\Theta$ e o respectivo período médio, $T$.

5. Repita o procedimento acima para outra barra.

\begin{tabular}{|ll|ll|ll|ll|}
\hline $\mathrm{I}=$ & $\left(\mathrm{kg} \cdot \mathrm{m}^{2}\right)$ & $\mathrm{D}=$ & $(\mathrm{cm})$ & $\mathrm{I}=$ & $\left(\mathrm{kg} \cdot \mathrm{m}^{2}\right)$ & $\mathrm{D}=$ & $(\mathrm{cm})$ \\
\hline$\Theta=$ & & $\mathrm{T}=$ & $(\mathrm{seg})$ & $\Theta=$ & & $\mathrm{T}=$ & $(\mathrm{seg})$ \\
\hline$\Theta=$ & $\mathrm{T}=$ & $(\mathrm{seg})$ & $\Theta=$ & & $\mathrm{T}=$ & $(\mathrm{seg})$ \\
\hline$\Theta=$ & $\mathrm{T}=$ & $(\mathrm{seg})$ & $\Theta=$ & & $\mathrm{T}=$ & $(\mathrm{seg})$ \\
\hline$\Theta=$ & $\mathrm{T}=$ & $(\mathrm{seg})$ & $\Theta=$ & & $\mathrm{T}=$ & $(\mathrm{seg})$ \\
\hline$\Theta=$ & $\mathrm{T}=$ & $(\mathrm{seg})$ & $\Theta=$ & & $\mathrm{T}=$ & $(\mathrm{seg})$ \\
\hline
\end{tabular}

Tabela 1 - Tabela de dados experimentais - Sugestão: cada equipe executa o experimento com uma massa diferente e preenche-se a tabela.

5 - Compare a medida da aceleração gravitacional obtida experimentalmente em sala de aula (aceleração determinada pela equação do período utilizando os dados experimentais) com o valor existente na literatura científica (dada por: $\mathrm{g}=9,8 \mathrm{~m} / \mathrm{s}^{2}$ ) e determine o desvio percentual;

6 . Discuta os desvios encontrados entre os valores de $\mathrm{g}$ (valor obtido em sala de aula com o da literatura);

\section{2 - APPLETS DE ENSINO}

2.1 - Física com Ordenador.

http://www.fisica.ufs.br/egsantana/dinamica/trabajo/pendulo/pendulo.htm

\section{http://www.fisica.ufs.br/egsantana/solido/torsion/torsion.htm}

2.2 - Phet. Universidade do Colorado 


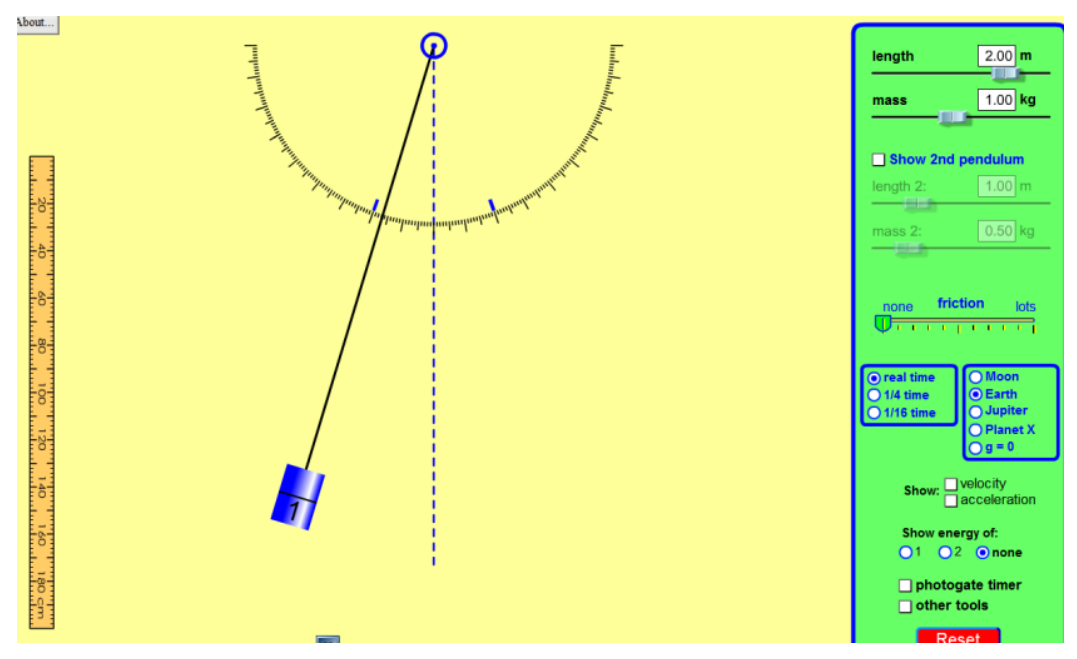

2.4 - Applet do site do prof. Falter-fendt. http://www.walter-fendt.de/ph14pt/ springpendulum pt.htm. Ele simula um Pêndulo em Mola.

Descritivo: Esta pequena aplicação em Java (applet) mostra a variação das grandezas associadas à oscilação de uma massa suspensa de uma mola elongação, velocidade, aceleração, força e energia - durante a oscilação (assumindo a não existência de atrito).

O botão "Reset" coloca corpo na posição inicial. O outro botão permite controlar a animação. Ao escolher a opção "Câmara lenta", o movimento surgirá dez vezes mais lento. A constante da mola, a massa do corpo, a aceleração da gravidade e a amplitude da oscilação podem ser definidas pelo utilizador dentro de certos limites. A escolha da grandeza a observar no gráfico, faz-se selecionando um dos cinco botões de rádio existentes na zona verde.

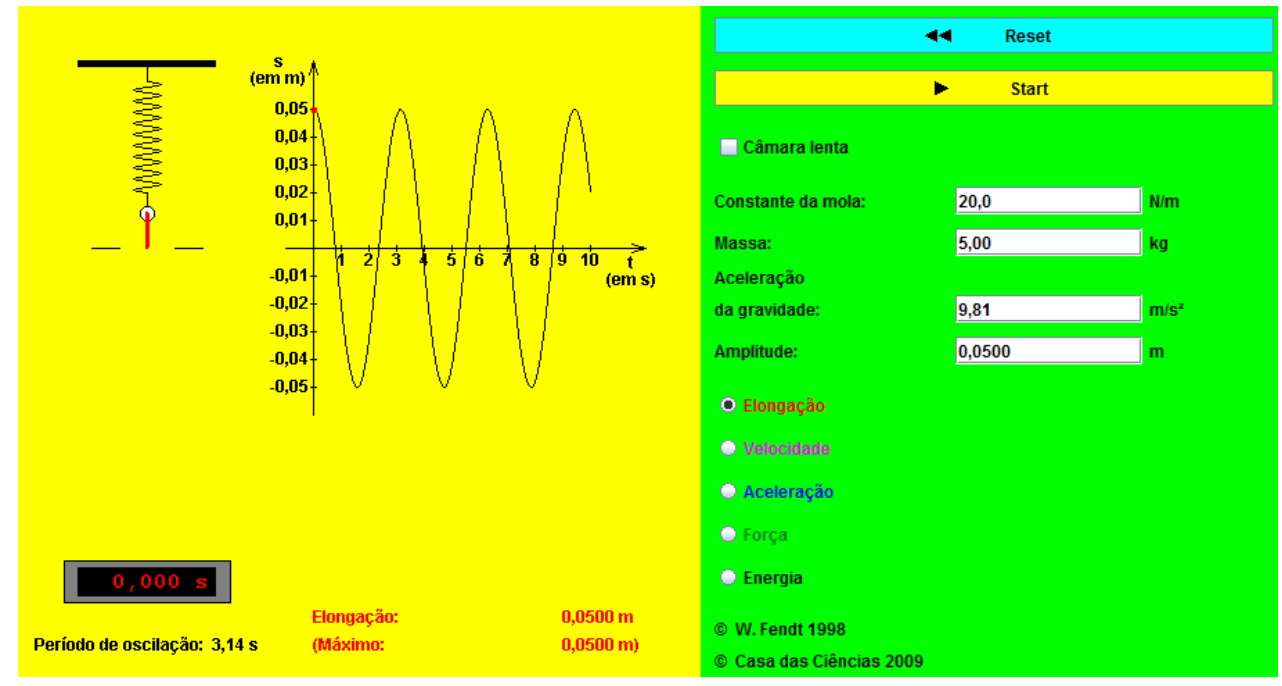

3 - Vídeos Aulas

3.1 - Pêndulo simples. http://www.youtube.com/watch?v=poSxzQ 4O3U

3.2 - Pêndulo simples. http://www.youtube.com/watch?v=ebF8K5E-ths 
3.3 - Pêndulo Físico. http://www.youtube.com/watch?v=FoSe72vpHVU

3.4 - Pêndulo Físico Amortecido. http://www.youtube.com/watch?v=26HI5Efs4sI

3.5 - http://www.youtube.com/watch?v=nM-d5D4NTsw\&feature=related

3.6 - Pêndulo de torção.

http://www.youtube.com/watch?v=fUGllioQJyl\&feature=related

\section{COMENTÁRIOS:}

Os estudantes devem ter achado muito legal esta aula.

Eles devem recordar como se usa o software de ensino Modellus para o acompanhamento desta aula como das demais.

\section{CONCLUSÃO:}

Mostramos aqui como uma aula sobre pêndulo pode ser muito interessante e divertida. Mostramos que existe na literatura muito material de apoio didático a este tema. Que podemos usar experimento de baixo custo junto com animações gráficas como apoio didático a aula normal.

\section{RESUMO:}

Apresentamos aqui uma opção de aula sobre pêndulo simples, de torção e físico. Complementamos com alguns experimentos de baixo custo, vários applets de ensino e vídeos aula.

Referências

[1] - Pêndulo Simples. http://www.sofisica.com.br/conteudos/Ondulatoria/MHS/ pendulo.php

[2] - GEF - http://www.ufsm.br/gef/MHS/mhs05.pdf

[3] - http://www13.fisica.ufmg.br/ wag/TRANSF/FMECDIST/U15 A42 Oscilacoes Aplicacoes MHS.pdf

[4] - L.A. de Mello. Tutorial do software Modellus. URL:

http://www.fisica.ufs.br/ladmello/aula_modellus/ 


\section{Cap03 - Óptica Geométrica ou Óptica de Raios}

Meta: Fazer que o estudante comece a pensar no ensino de ciências como algo "orgânico" que está em profunda transformação. Fazer com que os alunos percebam, através de uma atividade lúdica, que podemos ensinar física através de experimentos muito simples, e que física é uma ciência aplicada e que pode ser aprendida através da observação de vários dispositivos do nosso cotidiano. Fazer com que 0 aluno percebam as aplicações da física no cotidiano. Mostrar que existem muitas animações virtuais sobre o tema, e que ensinar e aprender física pode ser uma atividade divertida e interessante.

Objetivos: Ao final da aula, os alunos devem estar cientes das novas possibilidades e dos desafios que envolvem o ensino de ciências em geral. Que para se ensinar física não precisamos ficar presos ao livro didático. Que ensinar física não é ensinar a resolver problemas e que a física é uma mera aplicação da matemática. Devem ter compreendido que a óptica geométrica é um ramo fundamental da física com aplicações tecnológicas e de ciência básica (Astronomia por exemplo). Que se ensinar através de exemplos reais (experimentais) pode ser muito mais interessante e divertido. Estes devem estar cientes que é possível explorar vários recursos de multimídias e de experimentos de baixo custo em sala de aula.

Pré-requisitos: Os alunos deveram ter cursado psicologia da educação física A, B e C. 


\section{Introdução:}

O tópico óptica geométrica não é abordado no nosso curso de física da UFS, mas é parte integrante do currículo do ensino médio e matéria preferida nos vestibulares. Assim, se faz necessário que o abordemos em detalhes no nosso curso de Instrumentação IV. Além do mais, esse tópico é muito rico em exemplos de fácil execução e muitos sites de ensino abordam esse tema. Devido a óptica geométrica ser toda baseada em geometria, temos uma gama muito grande de simulações envolvendo este tema.

Como o objetivo central das disciplinas de instrumentação é o de desenvolver todo tipo de material didático e paradidático para o ensino de física, vamos aproveitar o máximo os recursos disponíveis para o ensino do tema "óptica geométrica" dividindo este tema em duas partes. Neste vamos abordar as questões básicas começando com ótica de raios, indo até espelhos planos. Deixaremos o tema "espelhos curvos e lentes" para a próxima aula.

O texto que se segue foi inteiramente baseado no material preparado por mim sobre notas do Professor Gil da Costa Marques para o e-física nível universitário [1].

\section{Luz (Baseado no e-física)}

Os fenômenos associados com a luz estão entre aqueles com os quais o ser humano tem uma relação mais íntima e constante ao longo da sua existência. A luz está presente em todas as atividades do dia a dia do homem. Muitos são os fenômenos associados ás propriedades da luz. Alguns, como a formação de sombras e de penumbras é corriqueira. Comuns são também os fenômenos da reflexão e da refração da luz. Por exemplo, a nossa imagem em um espelho é o produto da reflexão da luz. Abaixo vemos os raios da lua refletidos nas águas do mar. Como veremos, a Lua é uma fonte secundária de luz. Ela reflete a luz proveniente do Sol. Também vemos como a imagem de uma caneta é distorcida pela água de um copo (refração da luz).

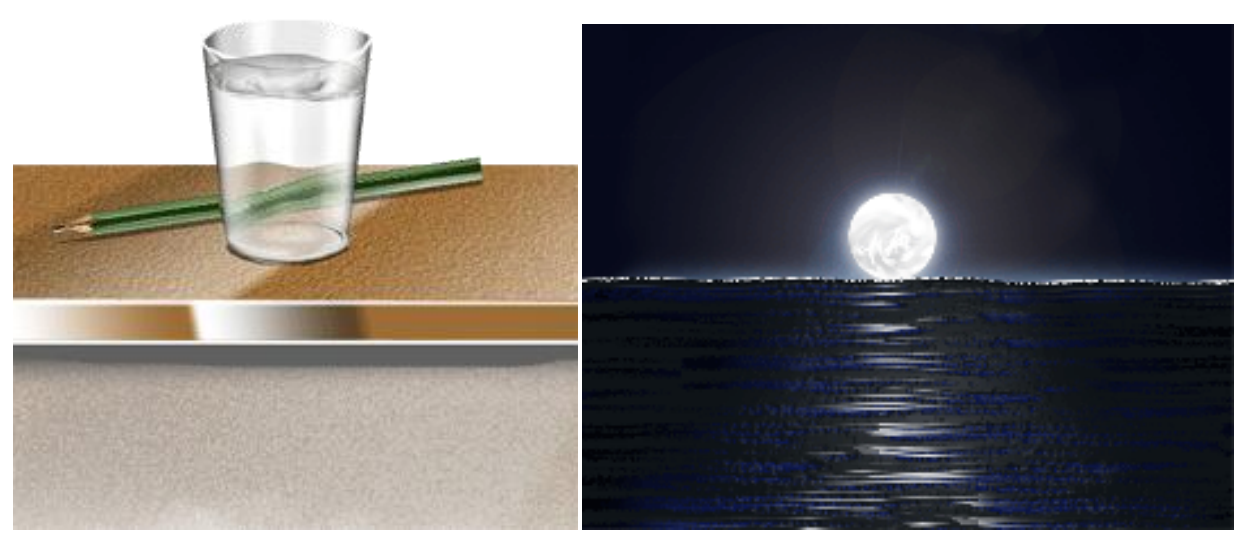


Fenômenos envolvendo a luz podem ser menos comuns e, ás vezes, requer aparatos especiais para serem observados. Dentre esses podemos citar a interferência e a difração da luz. Outros fenômenos são bem mais sutis de serem observados e interpretados, como o efeito fotoelétrico ou o espalhamento Raman.

A área da óptica é um campo de estudos fascinante. De maneira simplificada, podemos dizer que ela é o ramo da Física que estuda a propagação da luz e sua interação com a matéria.

Em muitas áreas da ciência e tecnologia, o entendimento de determinados conceitos pode ser difícil porque seus efeitos não são facilmente visualizados. Na óptica, entretanto, o simples uso de um laser permite a visualização de um dado efeito como função de vários parâmetros, facilitando o aprendizado. Isto se deve principalmente à coerência (mesma fase de onda), monocromaticidade (mesma freqüência) e colimação da luz proveniente deste instrumento, que permitem a observação de fenômenos tais como interferência e difração, nos quais a natureza ondulatória da luz se manifesta claramente. Entretanto, para se chegar ao desenvolvimento deste dispositivo, e de vários outros que são importantes no nosso cotidiano, um longo caminho foi percorrido e este percurso gerou um histórico bastante rico. Alguns aspectos que merecem destaque estão ligados às idéias sobre a natureza da luz e aos caminhos paralelos que a óptica e o eletromagnetismo trilharam durante séculos. Para se entender um pouco estes fatos, está feito no e-livro óptica básico [1], uma breve revisão histórica do desenvolvimento dos conceitos principais ligados à óptica.

A óptica é a área da Física que estuda a Luz: sua natureza, suas propriedades e suas aplicações. A óptica se propõe também a estudar a interação da luz com a matéria.

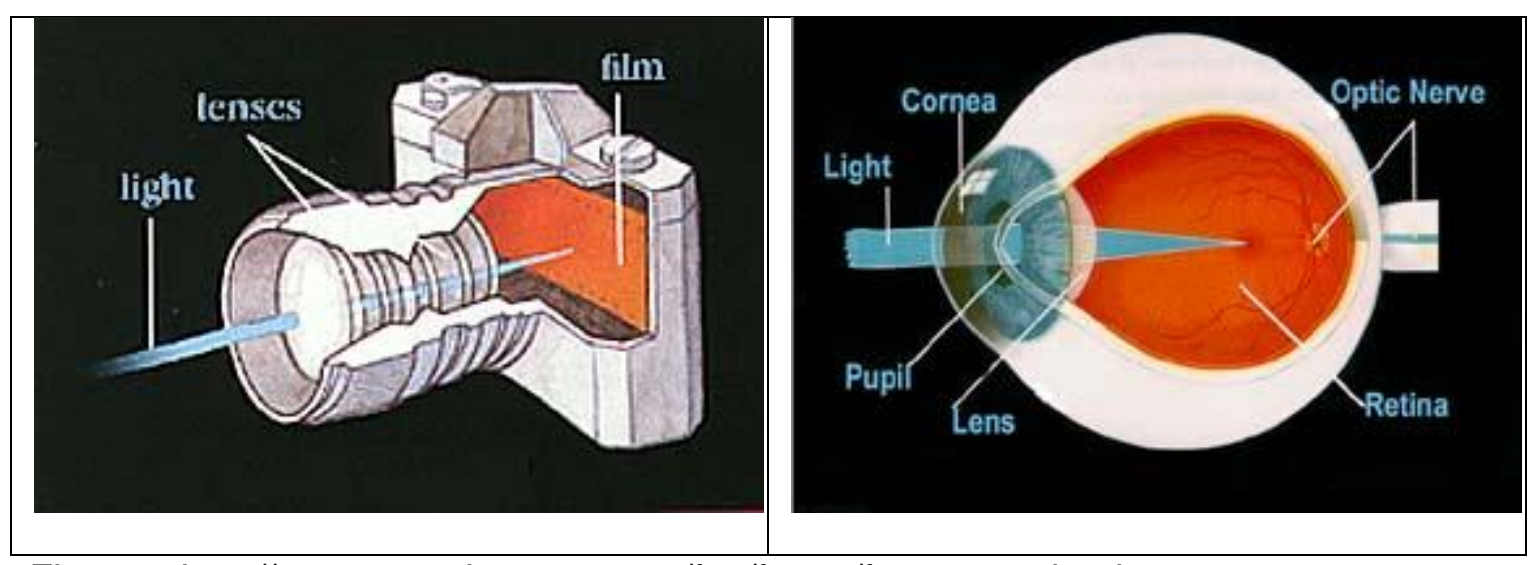

Fig.1.1 - http://www.pasadenaeye.com/faq/faq15/faq15_text.html 


\section{Exercícios:}

1 - Cite três instrumentos ópticos.

2-O que é uma lente anti-reflexo.

3-O que são as artes visuais.

\section{Óptica Geométrica ou Óptica de Raios}

Ao tratarmos o tópico óptica de raios, também conhecida como óptica geométrica, não levamos em consideração o caráter ondulatório da luz, nem sua polarização. Nestas condições, efeitos tais como difração e interferência não se evidenciam.

Do ponto de vista da ótica entende-se como meio homogêneo aquele no qual o índice de refração não depende da posição, sendo, portanto constante. Note que o meio pode ser simultaneamente homogêneo e anisotrópico, caso comum em cristais, para os quais o índice de refração tem valores diferenciados para distintas direções de propagação da luz. Já no meio não homogêneo, o índice de refração é dependente da posição, em geral devido às flutuações de densidade, temperatura, ou composição química do material.

\section{1: Propagação da luz em meios homogêneos}

Os trabalhos realizados até a primeira metade do século XVII estabeleceram que quando um raio de luz se propaga, obedece aos seguintes princípios:

a) nos meios homogêneos a propagação é retilínea, como na figura abaixo, e

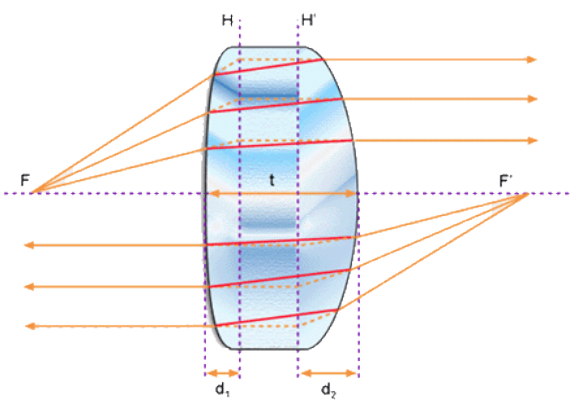

Fig.1.2 - Propagação Retilínea da Luz

b) quando um raio (raio 1) atinge a interface que separa dois meios distintos temos uma fração refletida (raio 2) e outra refratada (raio 3), conforme mostra a Fig. 2.2.

Como discutido por Huygens, cada meio é caracterizado por um parâmetro chamado índice de refração, $\mathrm{n}$, que determina a velocidade com que o raio se 
propaga naquele meio. A direção seguida pelos raios 2 e 3 não é arbitrária, eles obedecem as seguintes regras:

(i) os raios 1, 2 e 3 estão todos num mesmo plano, o qual é chamado de plano de incidência,

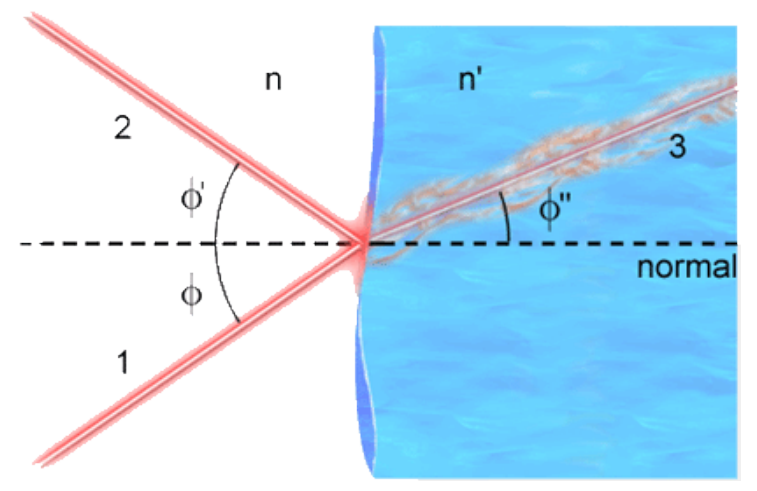

Fig. 1.3 - Reflexão e refração de um raio luminoso numa interface dielétrica.

(ii) O ângulo de incidência é igual ao da reflexão: $\quad \phi=\phi^{\prime} \quad$ e

(iii) n sen $\phi=$ n'sen $\phi^{\prime \prime}$ (lei de Snell).

Estas leis são muito importantes para o traçado dos raios ópticos na presença de interfaces dielétricas. Note que pela expressão,

(iii) quando um raio penetra num meio de índice de refração maior ( n' $>$ n) ele se aproxima da normal.

$$
\varnothing=\operatorname{arcsen}\left(\frac{n^{\prime}}{n} \operatorname{sen} \emptyset^{\prime}\right)
$$

\section{Exercícios}

1 - Tome uma caneta laser, um espelho e um transferidor e verifique as regras i e ii acima.

2 - Pegue um copo com água, um transferidor e um palito de churrasco e verifique a lei de Snell.

\section{Princípio da independência dos raios}

Admitimos que os fótons não interajam entre si. Isto é, os fótons, ao se aproximarem ou ao se cruzarem não são influenciados por outros fótons. Os fótons são, portanto, independentes entre si. Segue daí que os raios luminosos são independentes. 


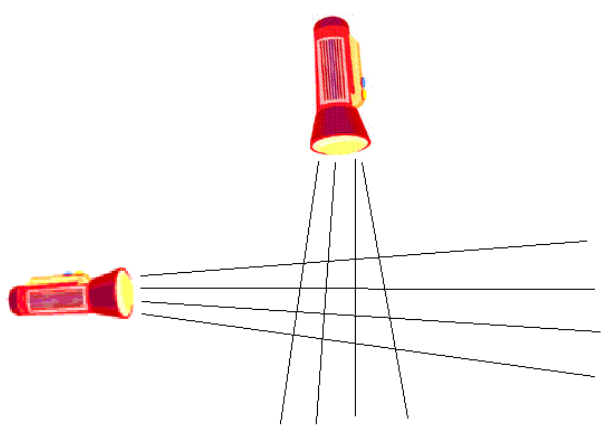

Fig.1.4 - Cruzamento de Raios de Luz

\section{Princípio da reversibilidade da luz}

Finalmente, salientamos que se a trajetória dos fótons (e, portanto, da luz) for percorrida num certo sentido, o sentido oposto é também possível. Por exemplo, se a luz seguir uma série de segmentos de reta ao longo dos segmentos $A B, B C, C D$ da figura (1.5), então o percurso ao longo dos segmentos $D C, C B$ e BA é igualmente possível.

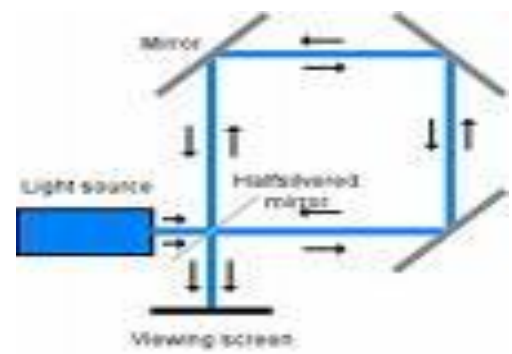

Fig.1.5 - Princípio da Reversibilidade

Isso quer dizer que se um raio de luz seguir uma trajetória num certo sentido e se esse raio for refletido passando por uma parte da trajetória, ele fará a trajetória inteira. Essa é base do princípio da reversibilidade da luz. Qualquer sentido de trajetória de um raio luminoso é possível.

\section{Exercícios:}

3 - Pegue duas lanternas e um espelho e confirme as leis 2 e 3 acima.

4 - Porque uma colher parece estar quebrada quando a olhamos através de um copo cheio de água?

5 - Pegue um conjunto de espelhos planos e verifique o principio da reversibilidade da luz. 


\section{A Reflexão e a Refração da Luz}

A reflexão da luz é um dos fenômenos mais comuns envolvendo a propagação da luz. A reflexão ocorre quando a luz incide sobre a superfície de separação entre dois meios com propriedades distintas. A reflexibilidade é a tendência dos raios de voltarem para o mesmo meio de onde vieram.

Quando a luz incide sobre uma superfície separando dois meios, podem ocorrer dois fenômenos distintos: reflexão da luz e refração da luz. Parte da luz volta e se propaga no mesmo meio no qual a luz incide (a reflexão da luz). A outra parte da luz passa de um meio para o outro propagando-se nesse segundo. A esse último fenômeno (no qual a luz passa de um meio para o outro) dá-se o nome de refração da luz.

Os dois fenômenos ocorrem concomitantemente. Pode haver predominância de um fenômeno sobre o outro. Que fenômeno predominará vai depender das condições da incidência e da natureza dos dois meios.

Se a superfície de separação entre os dois meios for plana (por exemplo, superfície de um metal) e polida (uma superfície regular) então a um feixe incidente de raios luminosos paralelos corresponderá um feixe refletido de raios luminosos igualmente paralelos. A reflexão nesse caso será denominada de regular.

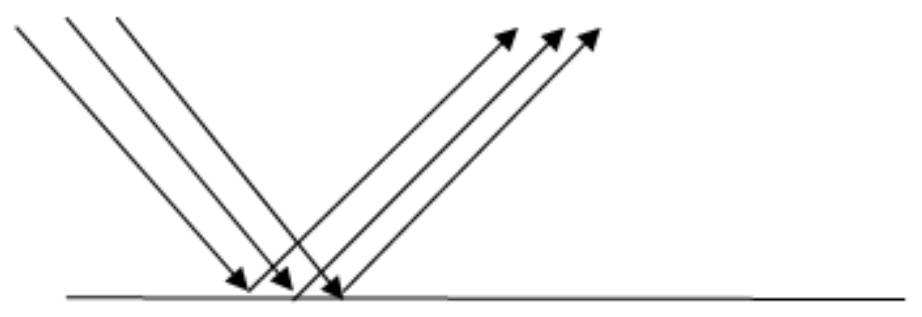

Fig.1.6 - Reflexão Regular

Se a superfície de separação apresentar rugosidades a reflexão será difusa. A luz será espalhada em todas as direções. Se considerarmos um feixe de raios luminosos incidentes paralelos, os raios refletidos irão tomar as mais diversas direções. A grande maioria dos objetos reflete a luz de uma maneira difusa. Isso nos permite vê-lo de qualquer posição que nos situarmos em relação a ele. 


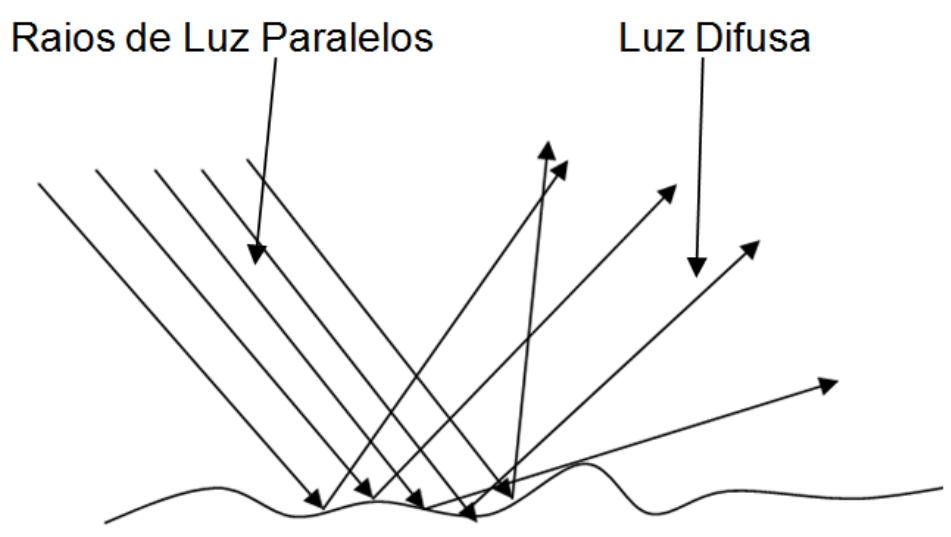

Fig.1.7 - Reflexão de luz por superfície irregular

Parte da luz é absorvida pelo objeto. Diferentes materiais absorvem luz de forma diferente e por isso vemos objetos das mais variadas cores.

\section{As leis da reflexão}

Para entendermos as leis que regem o fenômeno da reflexão precisamos introduzir as definições de planos de incidência da reflexão e ângulos de incidência. Quando o raio de luz incidir sobre a superfície de separação entre dois meios, ela o fará num ponto $\mathrm{P}$ sobre a superfície. Por um ponto qualquer de uma superfície podemos fazer passar uma reta perpendicular a ele e que 0 atravessa. Essa é a reta N, normal à superfície.

O ângulo formado pelo raio (i) incidente e a reta normal $(\mathrm{N})$ é o ângulo de incidência (representado por î ).

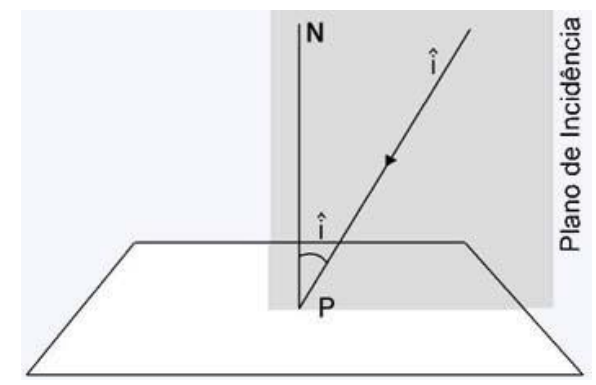

Fig.1.8 - Plano de Incidência

O ângulo de reflexão ( $r$ ) é o ângulo formado pelo raio refletido e a reta normal $\mathrm{N}$.

O plano formado pelo raio incidente (ou a reta que o contém) e a reta normal, é o plano de incidência. Analogamente, o plano de reflexão é o plano que contém o raio refletido $r$ e a reta normal $\mathrm{N}$. 


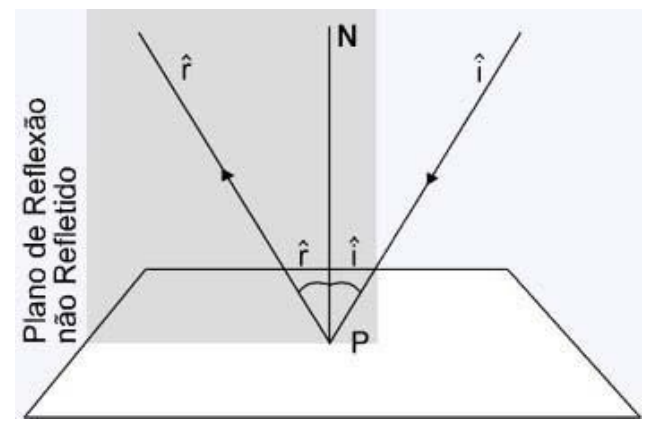

Fig.1.9 - Plano de Reflexão

O fenômeno da reflexão é descrito por duas leis - as leis da reflexão. Tais leis tem uma base empírica. Isto é, elas seguem de inúmeras observações do fenômeno.

\section{Primeira lei}

\section{O plano de incidência coincide com o plano de reflexão.}

Dito de outra forma essa lei estabelece que "O raio de incidência a reta normal e o raio refletido estão contidos no mesmo plano."

\section{Segunda lei}

\section{O ângulo de incidência é igual ao ângulo de reflexão.}

$\mathrm{Na}$ verdade essas duas leis, essencialmente empíricas, podem ser entendidas a partir da natureza corpuscular da luz. De fato, podemos pensar na reflexão como resultado de colisão dos fótons com a superfície de separação entre dois meios.
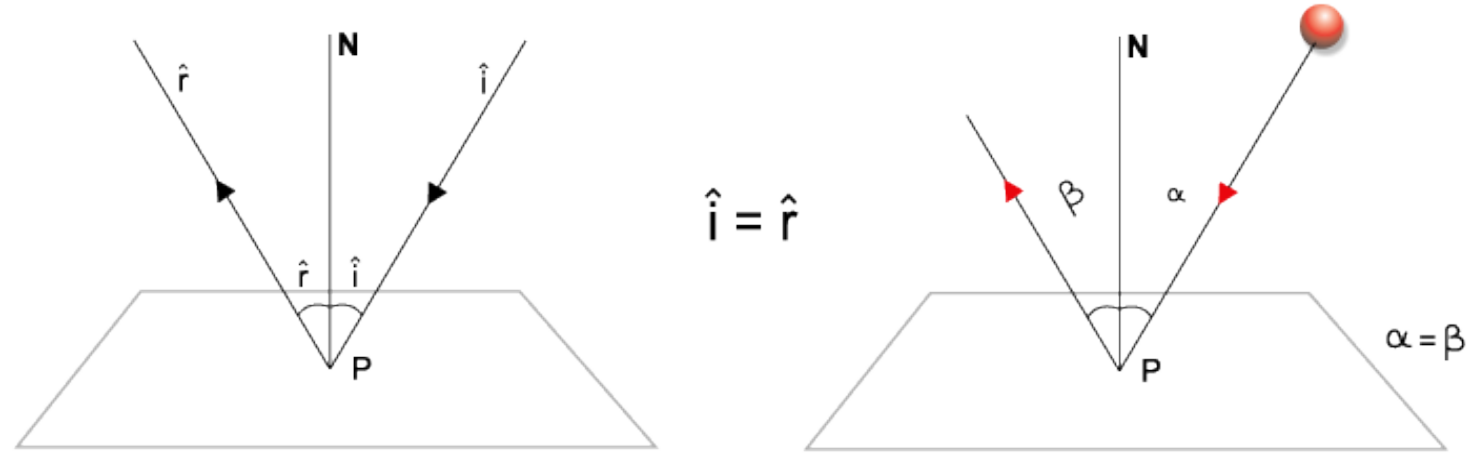

Fig.1.10 - Ângulo de Incidência e Reflexão 
Exercício:

6 - Pegue uma luz laser e um espelho e confirme estas leis.

\section{Espelhos}

Quando a superfície de separação entre dois meios permitir que a maior parte da luz seja refletida e essa reflexão for regular, dizemos que a superfície entre os dois meios se constitui num espelho.

Se essa superfície for plana (se ela se constituir num plano) então o espelho é dito plano. Se a superfície for esférica, o espelho é dito esférico.

\section{Formação de Imagens}

Uma das utilidades dos espelhos é facilitar a observação de objetos que não estejam diante de nossos olhos. Permitem-nos, por exemplo, ver o que está atrás de nós. Esse é um dos usos dos espelhos retrovisores colocados nos veículos automotores.

O uso do espelho é possível como conseqüência da formação de uma imagem, por exemplo, através do espelho. O processo de formação da imagem tem a ver com a reflexão. Para entendermos o processo de formação das imagens em espelhos começaremos pela análise da imagem de um ponto. Isto é, começaremos a discussão de formação da imagem de um objeto muito pequeno. Tão pequeno que sua dimensão é desprezível.

\section{Imagem de um objeto puntiforme}

Um objeto muito pequeno de dimensões desprezíveis pode ser representado como uma fonte de luz puntiforme. Consideremos esse ponto (ponto $\mathrm{P}$ ) a uma distância d do espelho. Tal fonte emite luz em todas as direções. Analisemos agora o que acontece quando um desses raios incide sobre um espelho plano. 

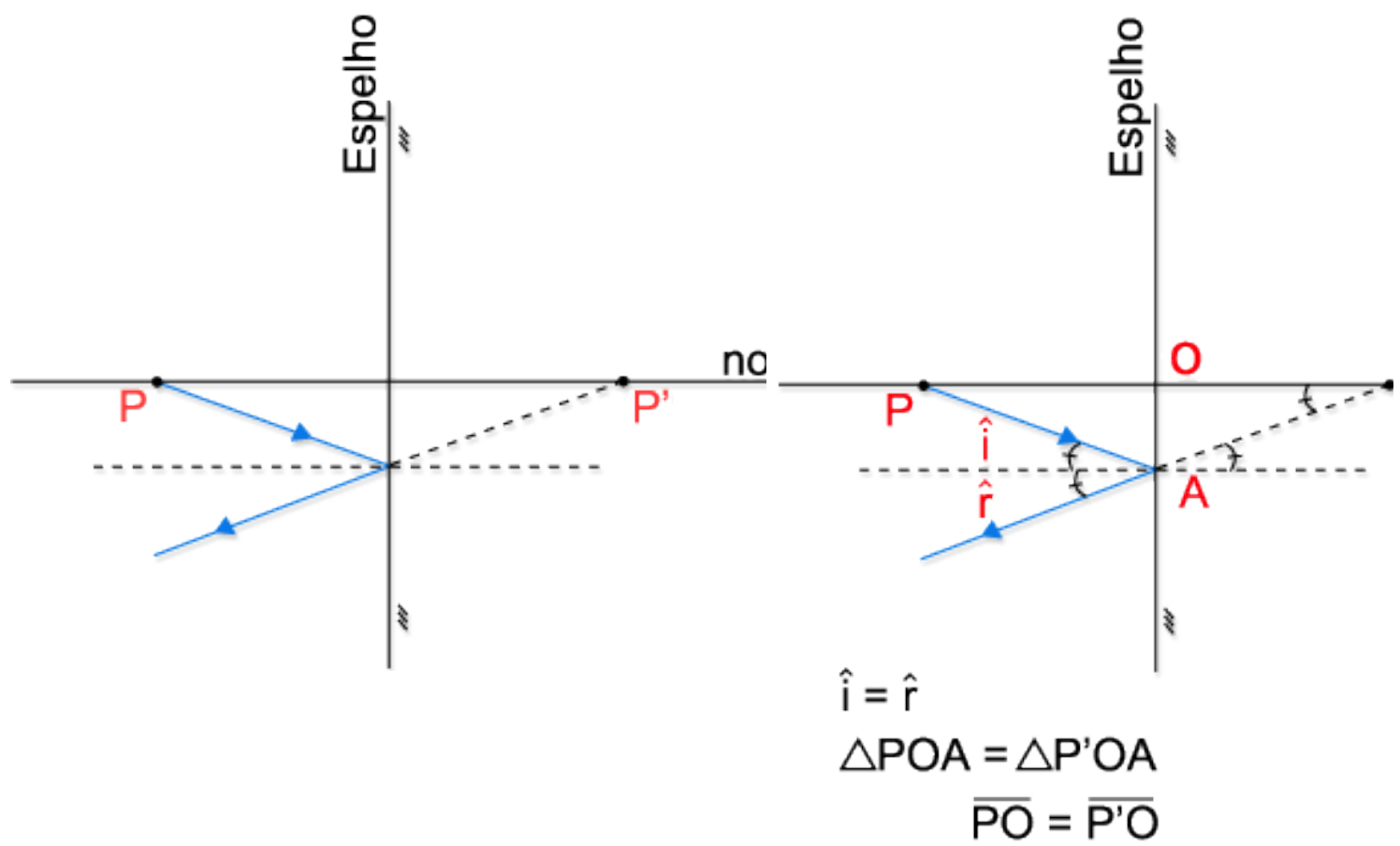

Fig.1.11 - Raio incidente sobre um espelho plano

Ele vai refletir de tal modo que os ângulos î e $\hat{r}$ sejam iguais. Desse modo se projetarmos o raio $\vec{r}$ esse atingira o ponto $\mathrm{P}^{\prime}$ igualmente distanciado do espelho como P.

Consideremos agora o que acontece com outros raios luminosos provenientes de P. Consideremos agora o prolongamento de todos os raios luminosos refletidos. Eles se encontram num ponto $\mathrm{P}^{\prime}$. Tal ponto está à mesma distância d do espelho. Os pontos $\mathrm{P}$ e $\mathrm{P}^{\prime}$ são simétricos em relação ao espelho.

$O$ ponto $\mathrm{P}^{\prime}$ é o ponto imagem do ponto $\mathrm{P}$.

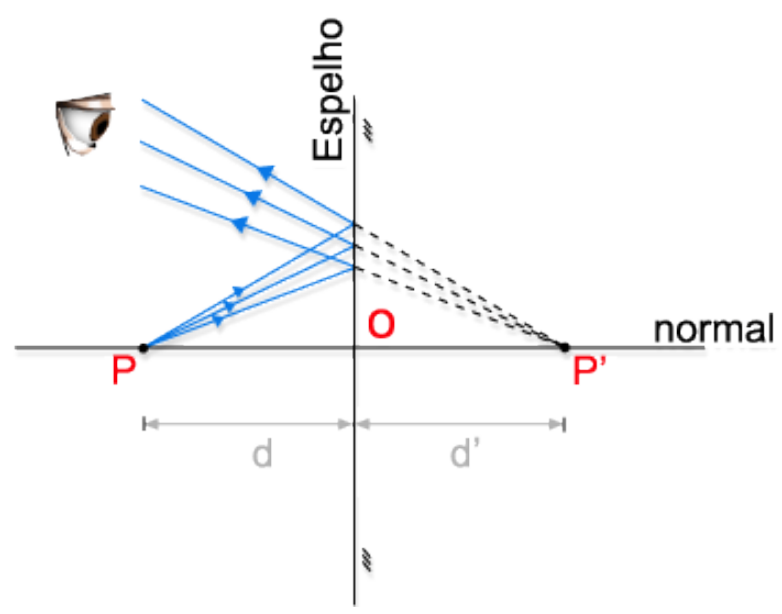

Fig.1.12 - Ponto objeto e ponto imagem. 
Um observador em frente a um espelho verá a imagem do objeto localizado no ponto $\mathrm{P}^{\prime}$. Por que isso acontece? O olho humano opera de tal forma que o que ele "vê" é aquilo que está na direção dos raios luminosos que atingem o olho.

\section{Imagem de um objeto extenso}

Consideremos a imagem de um objeto extenso na frente de um espelho plano. Usemos a construção mental de que um objeto extenso é constituído de um grande número de pontos. Tudo que devemos fazer agora é analisar a imagem de cada um desses pontos. O conjunto das imagens dos pontos dá a imagem do objeto.

Em primeiro lugar é bom saber que a imagem de cada ponto é simétrica em relação ao plano do espelho. O objeto e a imagem serão, portanto, simétricos em relação ao plano do espelho. Como conseqüência, o tamanho da imagem será igual ao tamanho do objeto. A distância de cada ponto do espelho ao objeto é igual à distância da imagem ao espelho. Daí resulta a simetria em relação ao espelho.

Outra coisa interessante a respeito dos espelhos é que a imagem de um objeto nem sempre é igual ao do objeto. Em geral a imagem não se superpõe ao objeto. $O$ espelho troca a direita pela esquerda e vice-versa. Diz-se em linguagem científica que o objeto e sua imagem são figuras enantiomorfas (formas opostas).

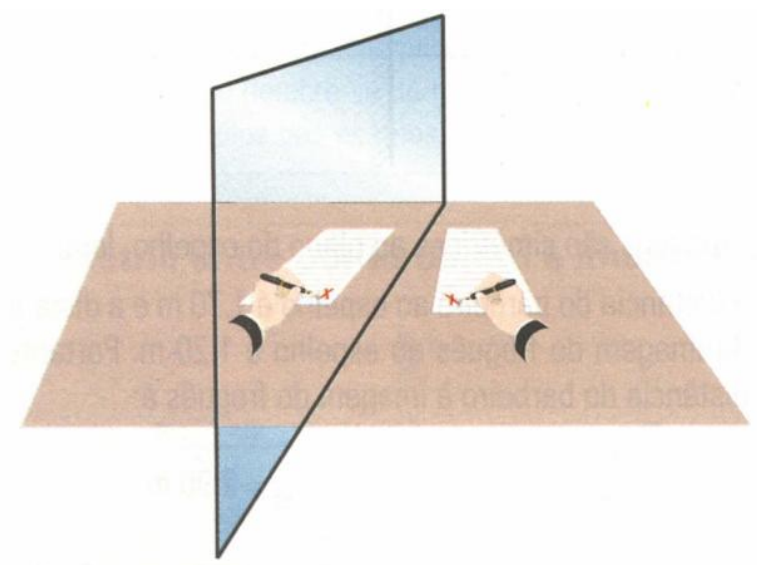

Se você escreve com a mão direita, sua imagem escreve com a esquerda.

Fig.1.13 - Imagem Refletida

\section{Imagens reais e virtuais}

Quando se forma uma imagem no processo de reflexão, essa imagem pode ser real ou virtual. Denominamos a imagem obtida no processo de reflexão de real quando esta imagem é obtida mediante o encontro dos próprios raios luminosos refletidos.

Uma imagem é virtual quando ela é formada pelo processo de prolongamento dos raios luminosos refletidos (e não dos próprios raios). 


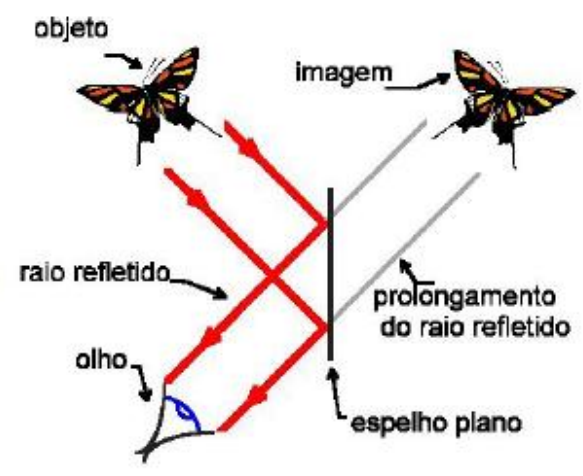

Fig.1.14 - Imagem Virtual gerada por um espelho plano.

A imagem de um objeto diante de um espelho plano é uma imagem virtual. Imagens reais podem ser obtidas quando se usa espelho côncavo ou convexo.

\section{Campo visual de um espelho plano}

Um espelho tem um campo visual restrito para um dado observador. O campo visual é a região do espaço dentro do qual todos os objetos nela situados serão vistos. Objetos fora dessa região não são observados. O campo visual depende do tamanho do espelho, da distância do observador ao espelho e da localização do espelho em relação ao observador.

A razão da existência do campo visual é que os raios luminosos provenientes dos objetos devem ser refletidos pelo espelho e devem chegar até o olho humano. Consideremos um ponto próximo de um espelho. Ele será acessível ao observador (na figura representada pelo olho do mesmo) se os raios luminosos refletidos atingirem o olho.

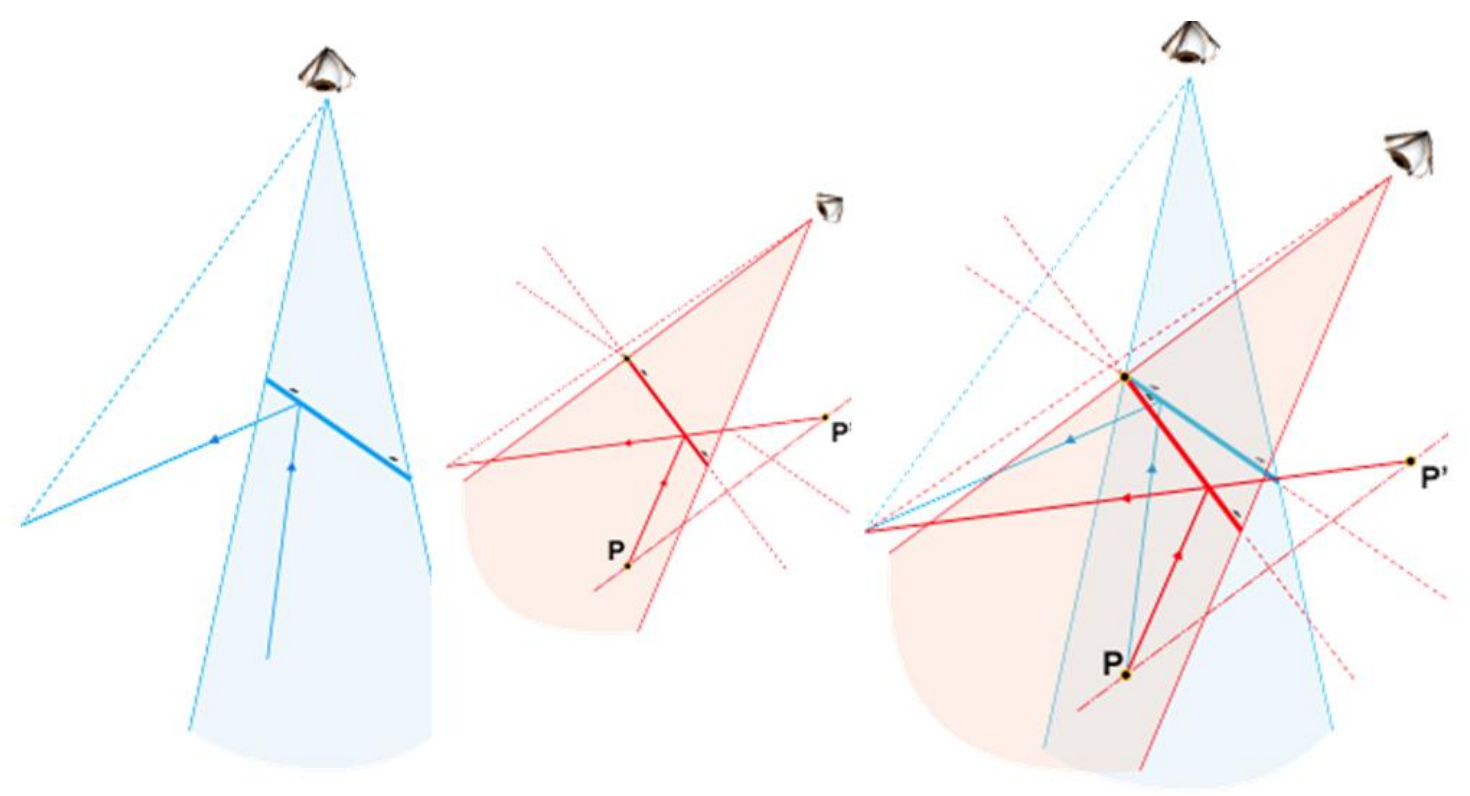


Fig.1.15 - Campo visual de um espelho plano

Para determinarmos o campo visual consideremos a imagem do olho no espelho. A partir da imagem do olho tracemos duas retas as quais interceptarão o espelho pelas duas extremidades. A região do espaço compreendida entre as duas retas e o espelho é o campo visual do mesmo. Note-se que o campo visual depende da posição do observador em relação ao espelho e das dimensões do mesmo.

\section{Translações e rotações de um espelho plano}

Quando fazemos uma translação de um espelho plano (isto é, o afastamos ou o aproximamos mantendo-o paralelo ao original) verificamos que a forma da imagem é preservada. No entanto, a distância da imagem do espelho se altera no mesmo valor da distância de aproximação ou afastamento do espelho. Assim, se um espelho se deslocar de um valor d (uma distância d) a imagem se deslocará em relação ao espelho, pelo mesmo valor $\mathrm{d}$. O deslocamento da imagem em relação ao observador será de $2 \mathrm{~d}$.

Se um objeto se aproximar (ou afastar) correndo em direção a um espelho com velocidade $v$ sua imagem também se aproximará (ou afastará) do espelho com velocidade $v$ (mas com sentido contrário). Portanto, a velocidade da imagem em relação ao objeto será $2 \mathrm{v}$.

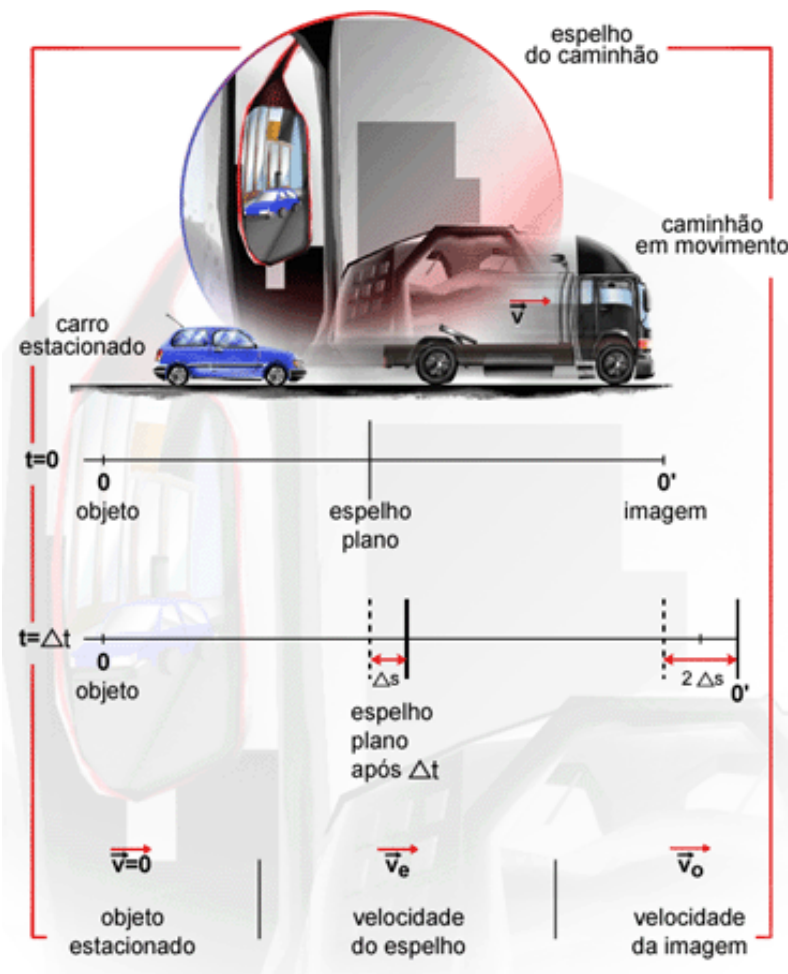




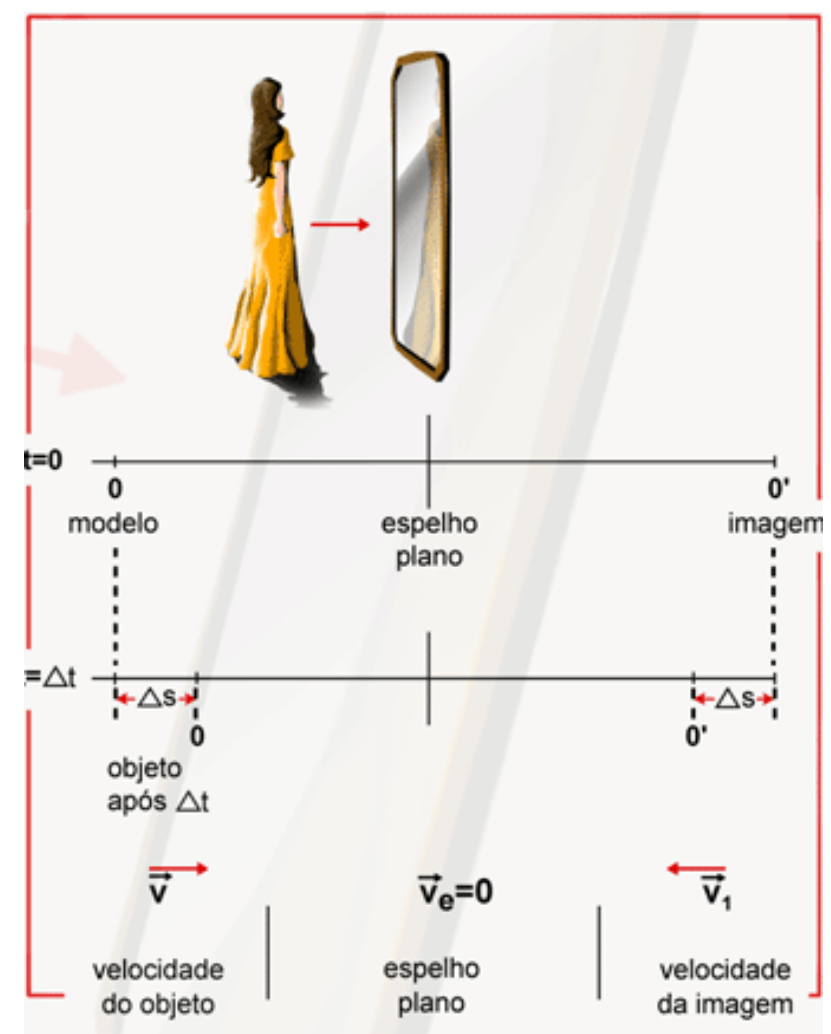

Fig.1.16 - Translação e Rotação de Espelhos

\section{Sistemas de espelhos planos}

Às vezes empregamos um sistema de espelhos. Alguns arranjos produzem efeitos deveras interessantes. Com eles podemos obter muitas imagens de um objeto, simulando situações deveras impressionantes. Outras vezes estamos apenas interessados em construir sistemas ópticos simples.

Consideremos dois espelhos colocados perpendicularmente um em relação ao outro. É fácil verificar que nesse caso são formadas três imagens. À medida em que o ângulo aumenta, o número de imagens diminui. Vale o contrário também. À medida em que o ângulo diminui o número de imagens aumenta. Uma situação curiosa é aquela na qual os espelhos são dispostos paralelamente um ao outro. Formam-se infinitas imagens.

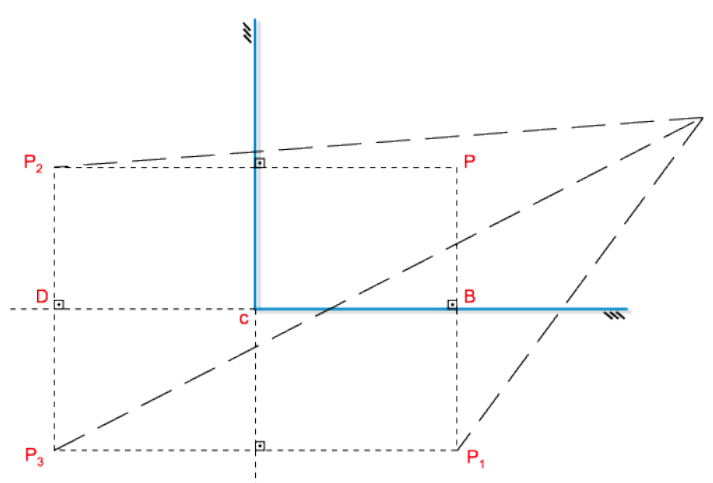


Por que as imagens se multiplicam? Isso ocorre porque as imagens na frente de um espelho se comportam como objetos na frente dos mesmos produzindo uma nova imagem. Em quando a imagem de um espelho se colocar na frente do outro espelho o processo se repete.

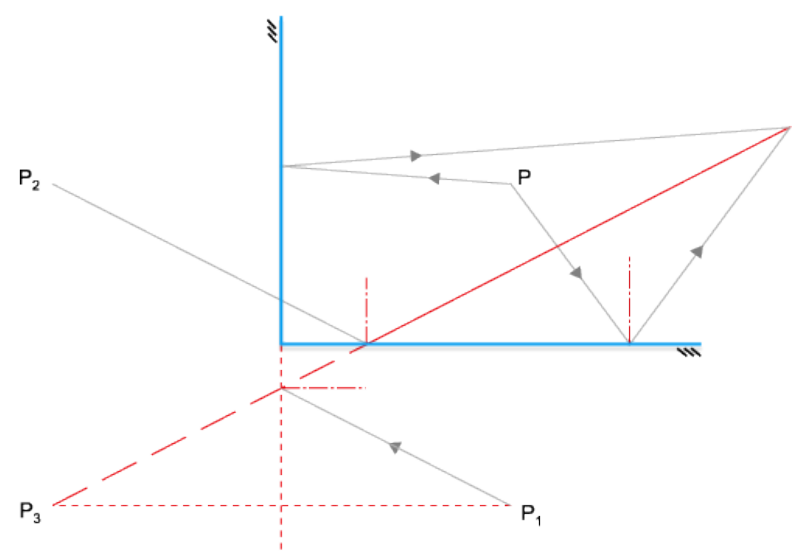

Quantas imagens se formarão?

Sendo ${ }^{\theta}$ o ângulo (medido em graus) entre os espelhos, então, se $360 /{ }^{\theta}$ for um número inteiro par, o número de imagens será dado por

$$
M=\frac{360}{\theta}-1 .
$$

Se $360^{\circ}{ }^{\theta}$ for um número ímpar a expressão acima só valeria para objetos localizados no plano bissetor de ${ }^{\theta}$.

No caso anterior, em que $360 /{ }^{\theta}=4$ obtemos o número correto de imagens, isto é

$$
M=\frac{360}{\theta}-1=4-1=3
$$

Se o ângulo for $60^{\circ}$ o número de imagens será 5. 


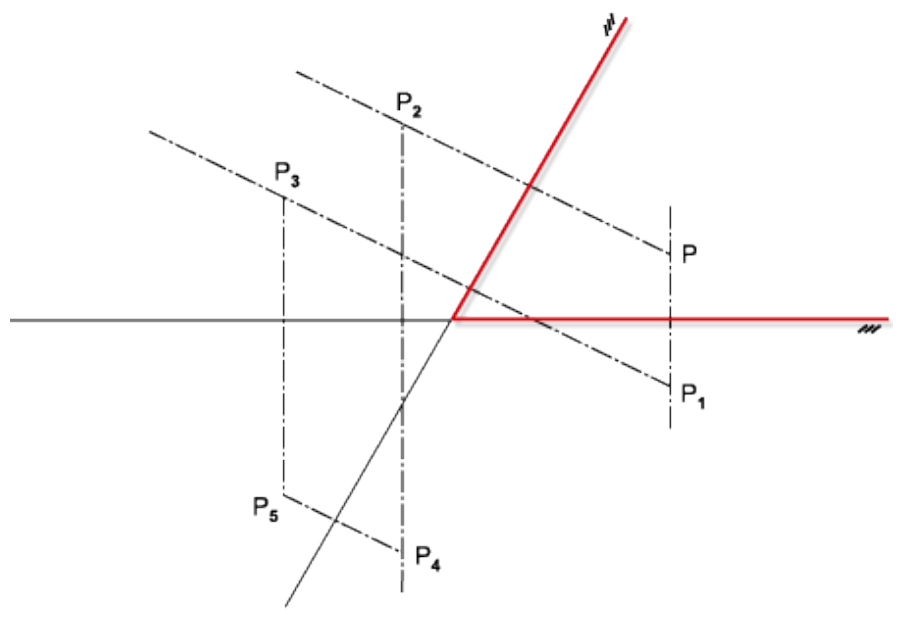

Em seguida trataremos o caso da propagação da luz em meios não homogêneos, para o qual obviamente um meio homogêneo é um caso particular. Através do princípio do tempo mínimo, ou princípio de Fermat, vamos deduzir a lei dos senos. Apresentaremos ainda quatro abordagens teóricas diferentes, que serão aplicadas a algumas situações específicas, em particular ao caso em que o índice de refração depende de apenas uma coordenada.

\section{Questões}

1 - Abra a modelagem "dois_espelho" e verifique as leis acima.

2 - Faça a experiência com uma moeda e dois espelhos.

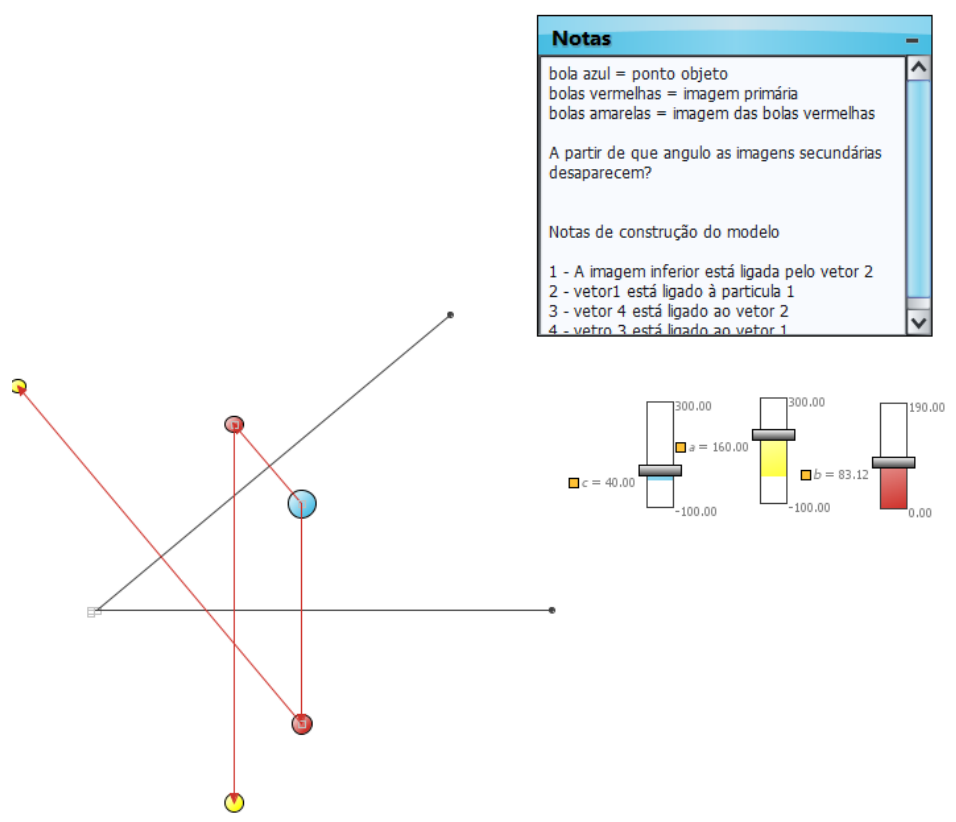




\section{3: Propagação da luz em meios não homogêneos}

A motivação para o estudo da propagação de raios em meios não homogêneos encontra-se nas diversas aplicações práticas e situações que ocorrem no nosso cotidiano, e só será vista no óptica nível avançado. Dentre os vários exemplos que podem ser citados, destacamos os seguintes:

\section{1 - Turbulência Atmosférica}

Ao olharmos para as estrelas numa noite de céu claro, notamos que elas tremem ou piscam. Isto se deve às turbulências atmosféricas, tais como flutuações de pressão e densidade, que levam à formação de correntes de vento e variações do índice de refração do ar. Como conseqüência, o caminho percorrido pelo raio de luz não é estável, levando a dificuldades para as observações astronômicas de corpos celestes distantes, o que obriga o uso de satélites, como por exemplo, o Hubble, ou o emprego de óptica adaptativa. $\mathrm{Na}$ óptica adaptativa emprega-se um laser de corante para excitar átomos de sódio existentes na camada superior da atmosfera. Isto gera uma mancha circular brilhante devido à luminescência do sódio, que devido as flutuações atmosféricas é visto de uma forma distorcida pelo telescópio. Um sistema servo-mecânico corrige então a curvatura de um dos espelhos do telescópio, de maneira a eliminar estas distorções. $O$ tempo de resposta deste sistema de correção é da ordem de $0.1 \mathrm{~s}$.

\section{2 - Efeito miragem}

O aquecimento do ar próximo à superfície da Terra modifica seu índice de refração e isto faz com que a luz execute uma trajetória não retilínea. Este efeito é claramente observado nas transmissões de corridas de carros pela TV. $\mathrm{O}$ ar, aquecido pelo contato com o asfalto, realiza um movimento convectivo ascendente fazendo tremer as imagens dos carros, como se houvesse uma tênue fumaça diante deles. O efeito do desvio da luz é ainda mais evidente para os raios rasantes, como quando viajamos de carro e observamos a imagem do céu e nuvens refletidas no asfalto, dando a impressão de poças d'água. Nesta situação, os raios rasantes são desviados pelo ar aquecido localizado próximo ao asfalto e atingem o olho do observador. Este efeito, conhecido como miragem, é comum em desertos, mas também pode ocorrer no mar, só que neste caso, a água resfria o ar e a imagem é invertida. 


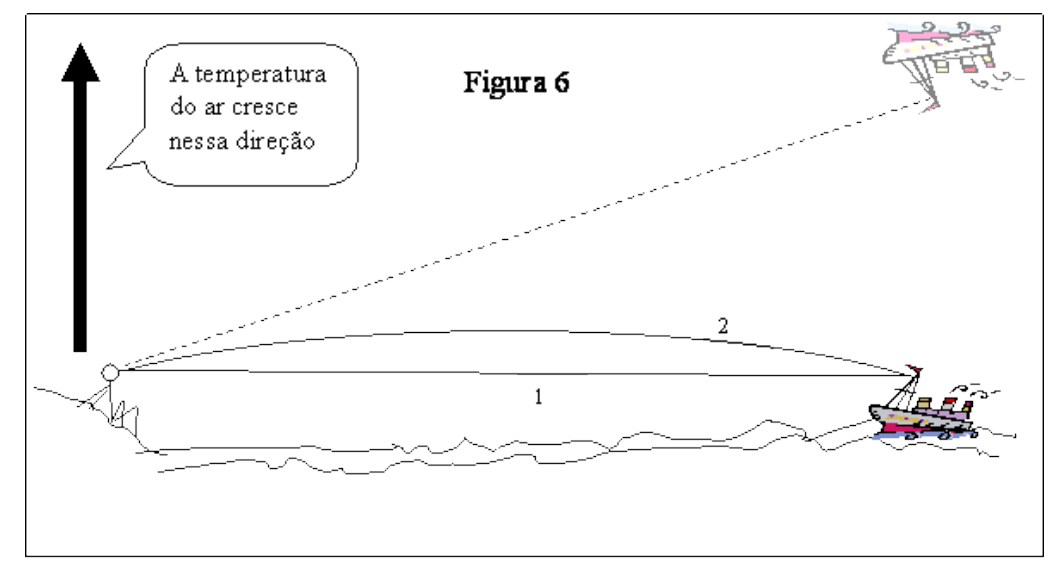

Fig.1.17 - Efeito Miragem. http://axpfep1.if.usp.br/ otaviano/miragens.html

\section{3 - Comunicações ópticas}

$\mathrm{Na}$ transmissão de informações com luz, o meio no qual o raio se propaga desempenha um papel importante. Na transmissão de microondas por visada direta, onde o sinal gerado por uma antena parabólica é captado por outra, flutuações na atmosfera produzem ruído no sinal transmitido, devido à instabilidade na trajetória dos raios, que por vezes não atingem perfeitamente a antena receptora. Nas comunicações via fibra óptica, a luz gerada por um laser semicondutor fica confinada principalmente no núcleo, que possui índice de refração maior que a casca. Assim, a variação do índice de refração novamente modifica a propagação dos raios. A própria focalização de luz em fibras ópticas é muitas vezes realizada por uma lente do tipo GRIN (gradient index), cujo índice de refração diminui radialmente, de forma contínua. A propagação de luz nestes meios do tipo lente será discutida após introduzirmos as ferramentas matemáticas necessárias.

\section{ATIVIDADES}

1 - Analise os sites com applets abaixo:

1.1 - Lab/Metro. Site da Universidade Federal de Santa Catarina. http://www.labmetro.ufsc.br/Disciplinas/EMC6422/APPLETS/EspelhoPlano/EspelhoPlano.html 


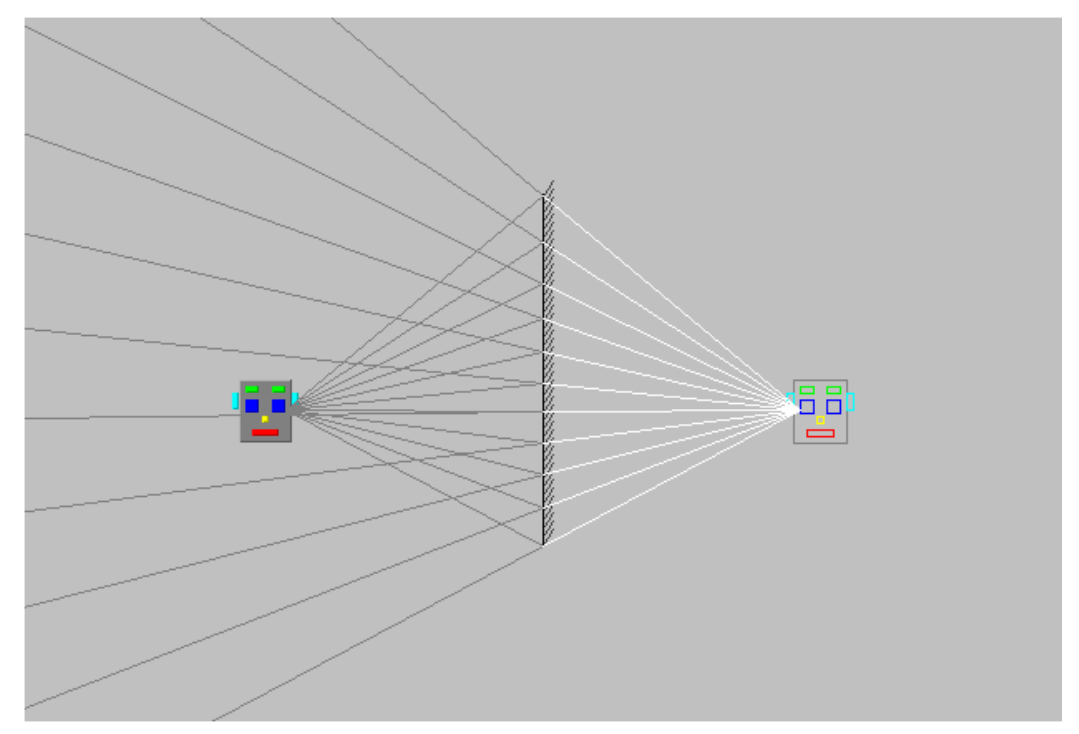

1.2-Refração da Luz. Autor Walter-Fendt. http://www.walterfendt.de/ph14br/refraction br.htm

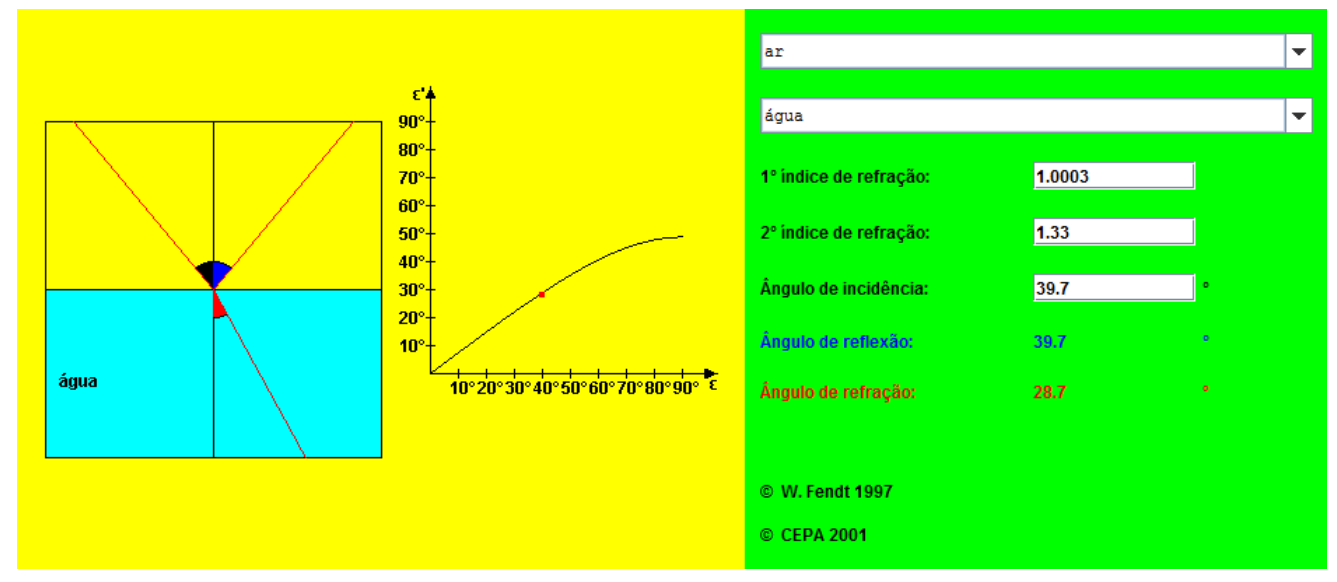

1.3 - EducaPlus.org. URL: http://www.educaplus.org/luz/reflexion.html

Site com texto em Espanhol, mas muito ilustrativo.

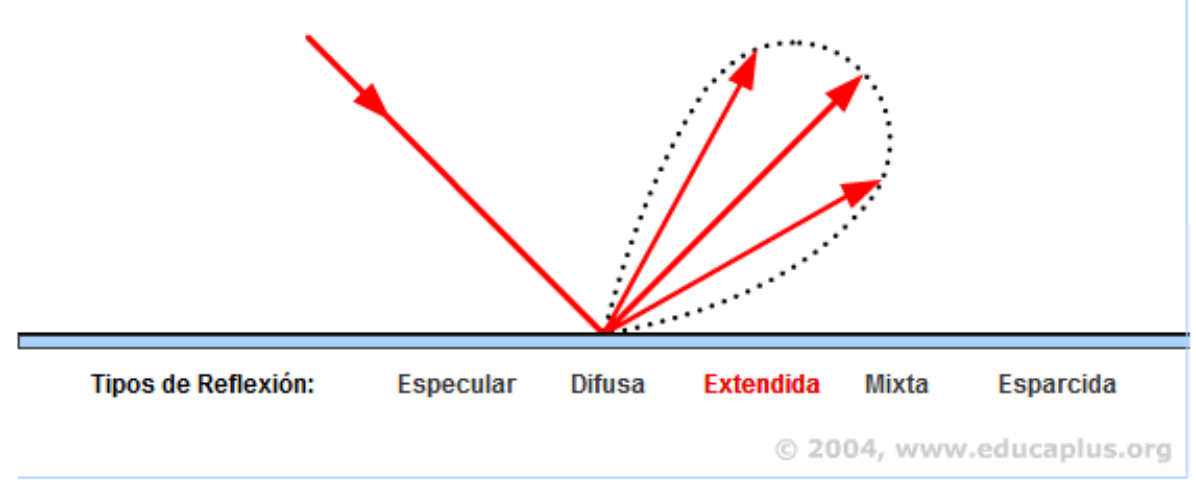

2-Analise o site educacional: 


\section{1 - Programa Educar; http://educar.sc.usp.br/otica/}

3 - Applet que ensina como se desenha uma imagem em frente de um espelho plano. (Em Italiano). Se você for no link direto: URL - http://zitogiuseppe.com/museo/esp71/

Specchio.html - você pode brincar diretamente. É só arrastar o ponto no lado direito da tela.

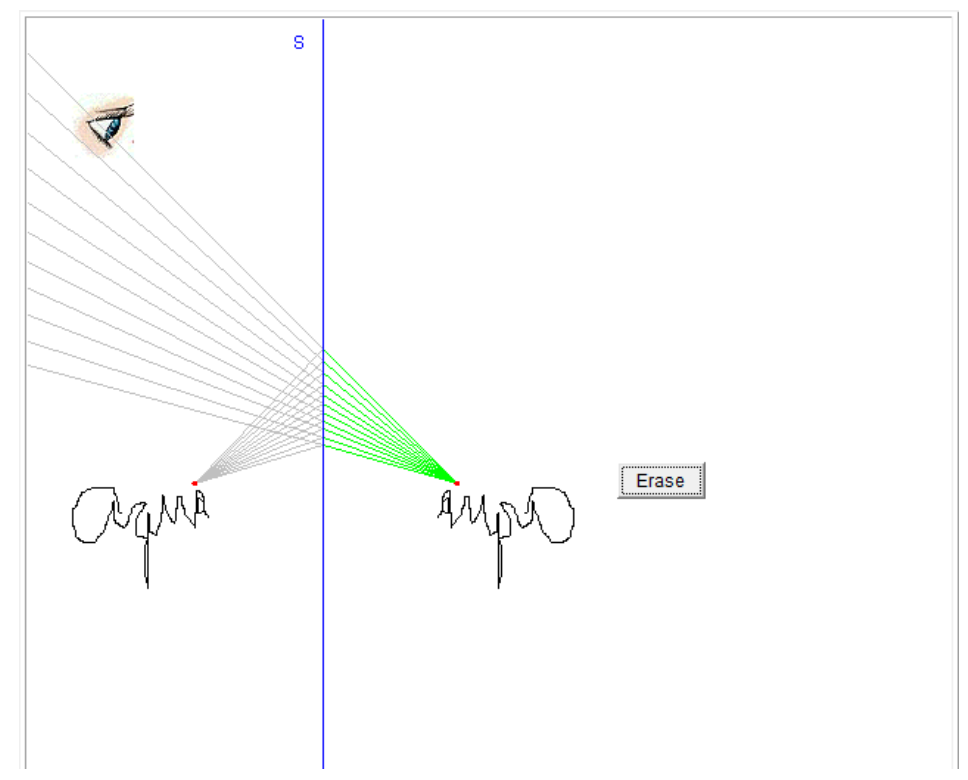

4 - Projeto Phet. Óptica Geométrica. URL: http://phet.colorado.edu/sims/geometricoptics/geometric-optics_en.html

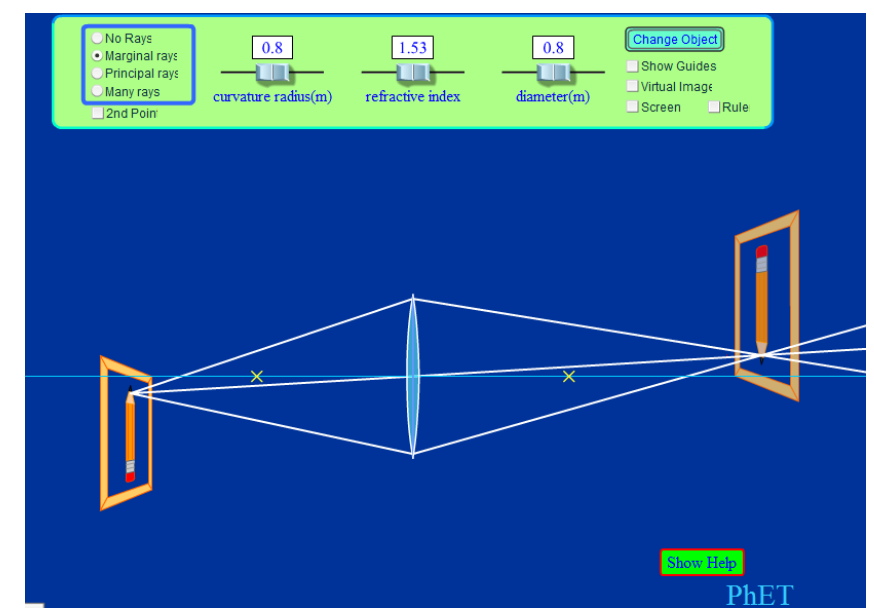

\section{2 - VIDEOS EDUCACIONAIS}

Assista o vídeo "Experiência com Espelhos Planos" e repita o experimento.

2.1 - URL: http://dicasdeciencias.com/2008/09/15/experiencia-com-espelhos-planos/ Obs: No final da apresentação há um outro vídeo muito legal. Ver figura abaixo.

2.2 - URL: http://www.youtube.com/watch?v=0 y2UFchplw\&feature=endscreen\&NR=1

2.3 - Sei mais Física. Lei da Reflexão. http://www.youtube.com/watch?v=GvLMaVleaA0 
2.4 - Lei da Reflexão e Refração da Luz. http://www.youtube.com/watch?v=lwVyy5vix6Y

2.5 - Telecurso 2000. Óptica Geométrica.

http://www.youtube.com/watch?v=1IC6TatGcNg\&feature=related

2.6 - Telecurso 2000. Reflexão. http://www.youtube.com/watch?v=4WRNfvpvmXc

2.7 - Telecurso 2000. Refração. http://www.youtube.com/watch?v=kgy2T-16eXw

2.8 - Mago da Física - A Curva da Luz (Efeito Miragem)

URL: http://www.youtube.com/watch?v=UmHa-RbofVM\&feature=related

\section{3 - LUDOTECAS}

\section{1 - Formação e posição da imagem nos espelhos planos Experiência 4.Il do projeto portal do professor do MEC [ ]}

Posição da imagem no espelho plano

1. Disponha, verticalmente, um espelho plano sobre a folha de papel (que deve estar sobre a placa de isopor) com auxílio de 2 alfinetes, presos ao espelho com fita adesiva (Fig. 25).

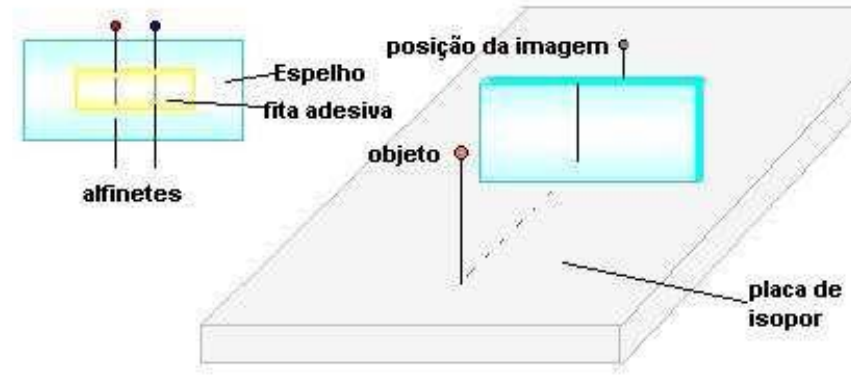

Figura 25: Montagem para a determinação da posição da imagem

2.Coloque um alfinete, de ponta colorida, de pé, em frente ao espelho, a uma distância de $4 \mathrm{~cm}$ do mesmo.

3. Com auxílio de outro alfinete, este de ponta comum, atrás do espelho, procure obter a posição coincidente com a posição da imagem do alfinete de ponta colorida. Esta posição é obtida quando não se observar mais paralaxe entre o alfinete de ponta comum (atrás do espelho) e a imagem do alfinete de ponta colorida. Marque então a posição encontrada.

a) Usando a régua, meça a distância entre as posições do espelho e da imagem do objeto.

O que se observa?

b) Repetindo algumas vezes os três últimos procedimentos para diferentes distâncias espelho objeto,

\section{o que se pode concluir quando a relação entre as distâncias espelho-objeto e} espelho-imagem ?

Formação da imagem no espelho plano

4. Repita o procedimento do item 1.

5. Espete um alfinete de ponta colorida a $4 \mathrm{~cm}$ do espelho (este alfinete será nosso objeto). Procure alinhar os alfinetes (de ponta comum) com a imagem do alfinete de ponta colorida que você vê visando-a de uma posição um pouco a esquerda do espelho (Fig. 26). 


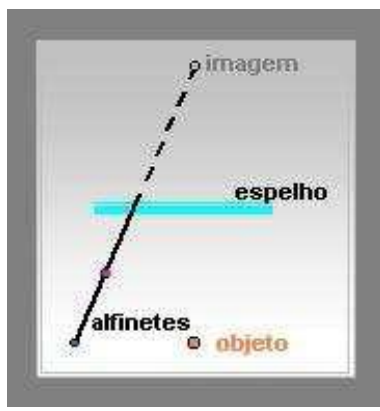

Figura 26: Alinhando os alfinetes com a imagem observada.

6. Agora, alinhe dois alfinetes com a imagem do alfinete de ponta colorida que você vê visando-a de uma posição um pouco à direita do espelho (Fig. 27).

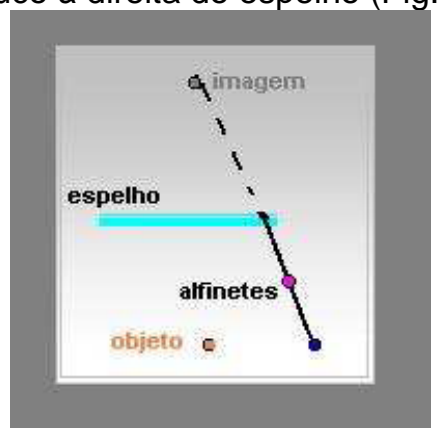

Figura 27: Alinhando os alfinetes com a imagem em outra posição

7. Retire o espelho, marque sua posição e trace as retas que contém os alfinetes do lado esquerdo com a imagem e os alfinetes do lado direito com a imagem.

8. As duas retas obtidas no procedimento anterior seccionam a posição marcada do espelho em pontos que se denominam de "pontos de incidência". Trace agora duas retas que unam o objeto (alfinete de ponta colorida) aos pontos de incidência.

As retas que ligam o objeto ao espelho, ou melhor, ao ponto de incidência do espelho, representam os raios luminosos que chegam ao espelho saindo do objeto - são denominados "raios incidentes" (Fig. 28). As retas que ligam os alfinetes alinhados com a imagem ao espelho (no ponto de incidência) representam os "raios refletidos".

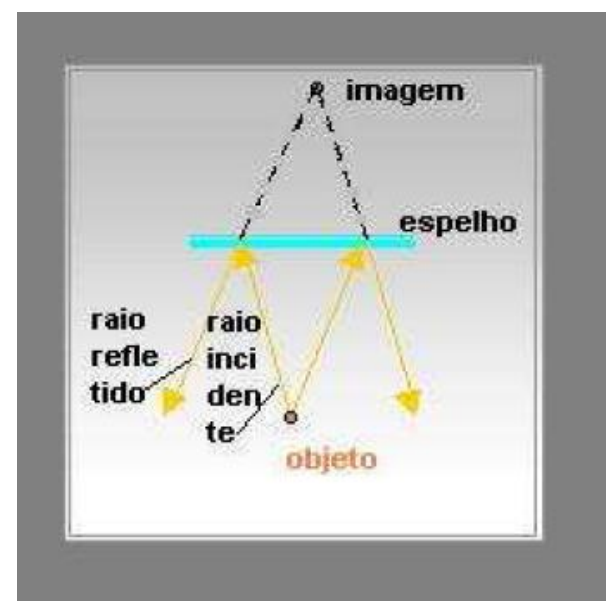

Figura 28: Representação geométrica dos raios incidentes e refletidos em um espelho plano

Os raios incidentes e refletidos78 formam com a "normal" (reta perpendicular ao espelho no ponto de incidência), ângulos denominados de incidência (i) e de reflexão (r) (Fig. 29). 


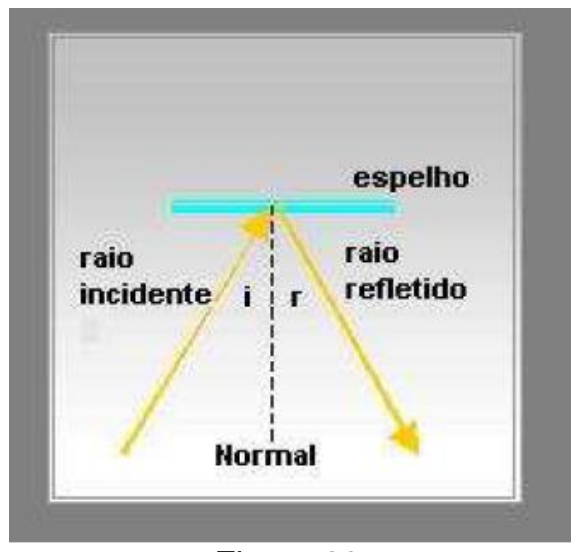

Figura 29

9. Mudando a posição do objeto (alfinete de ponta colorida), meça três vezes os ângulos de incidência e seus correspondentes ângulos de reflexão (use o transferidor).

A partir dos resultados obtidos nas medidas dos ângulos de incidência e reflexão, pode-se dizer que existe alguma relação entre eles? Qual?

\section{Respostas:}

\section{Experiência 4.II}

3.a Observa-se que a distância entre espelho-objeto e espelho-imagem são iguais. 3.b Pode-se concluir que o objeto e sua imagem estão à mesma distância do espelho plano. 9. Variando os valores dos ângulos de raios de incidência e observando o que acontece com o ângulo dos raios refletidos, pode-se observar que o ângulo de incidência é sempre igual ao ângulo de reflexão.

\section{2 - Projeto Ripe Material Simples Para o Estudo da óptica Geométrica INTRODUÇÃO}

Este texto mostra como construir o material de ótica geométrica que será utilizado em alguns experimentos descritos em textos posteriores.

O material está dividido em dois grupos aquele destinado à reflexão, e umoutro, que estuda a refração.

Procedimento

I ) Material para reflexão.

\section{I.1 Espelhos planos metálicos}

Os espelhos comuns são construídos com uma película de material refletor que está apoiada sobre um pedaço de vidro. Dessa maneira, ao efetuarmos experimentos usando um espelho comum, o vidro pode acarretar erros de medida que prejudicam a obtenção dos dados.

A idéia é usar superfícies metálicas polidas em lugar dos espelhos comuns. Assim, lâminas de cobre, alumínio ou latão servem bem para tal fim. Basta polirmos as mesmas com polidor de metal como Kaol, por exemplo. 
A foto ao lado mostra uma lâmina de microscópio forrada com uma lâmina de alumínio.

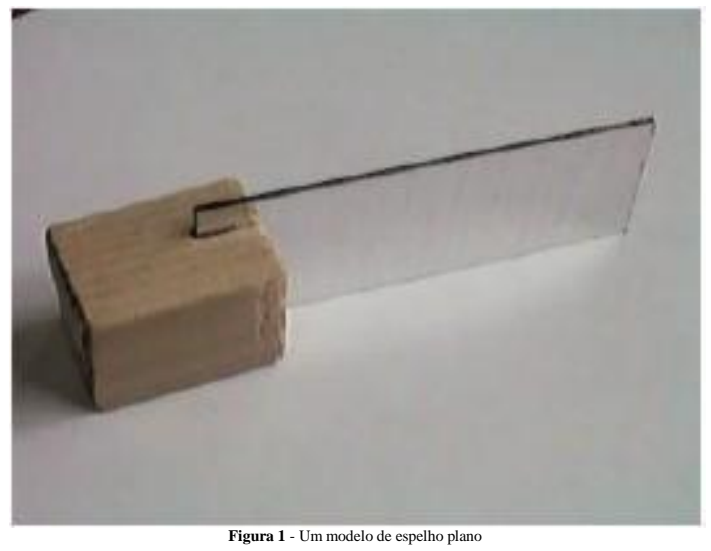

Existem, no comércio, lâminas de alumínio auto adesivas. Assim, uma outra maneira seria colar um pedaço dessa fita sobre uma superfície plana. Outra possibilidade é usar um pedaço de perfil de alumínio usado em arremates para cantos de móveis ou paredes. Também neste caso, é necessário polir o alumínio.

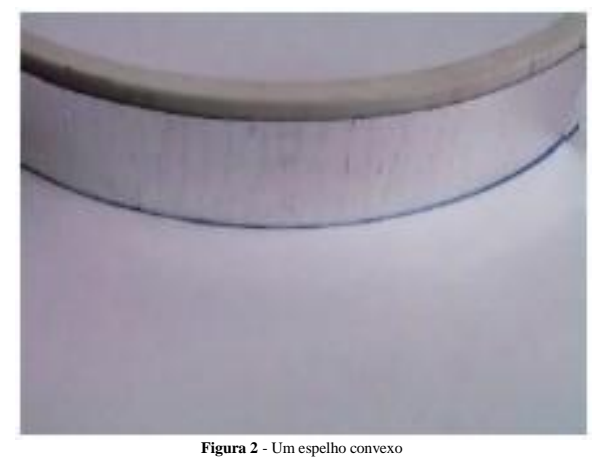

Os espelhos côncavos e convexos também podem ser construídos com alumínio auto adesivo colado em tubo de PVC de diâmetro grande $15 \mathrm{~cm}$ por exemplo. Colando-se o alumínio na parte interna teremos um espelho côncavo e quando colado na parte externa produziremos um espelho convexo. Vale a pena lembrar que o alumínio deve ser sempre polido.

II ) Material para refração.

O material para refração: cubas, prismas, lentes etc... pode ser construído com PVC plano e transparente (com espessura da ordem de $0,5 \mathrm{~mm}$ ). Esse material é facilmente colado com cola de PVC ("Tigre", por exemplo). Constrói-se uma caixa que, depois, é preenchida com água.

II.1 A lâmina de faces paralelas.

Trata-se de um prisma com dimensões aproximadas de 3 x 6 x12cm. Para sua construção coloca-se um pedaço de PVC transparente sobre uma folha de papel milimetrado e recorta-se com um estilete uma figura como a que está abaixo. 


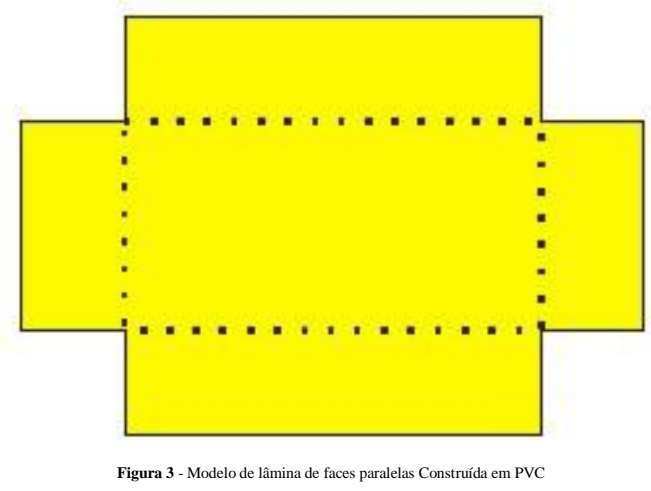

Nas linhas pontilhadas passa-se um objeto pontiagudo para riscar o PVC para poder dobrá-lo facilmente. Depois de dobrada as faces, o PVC fica com uma forma de caixa aberta nas laterais. Nesses pontos veda-se cola. Depois de seca faz-se um teste para verificar se não existem vazamentos. Caso ocorram coloca-se mais cola para vedar.

Para o caso da lâmina, existem caixas de plástico transparentes (algumas caixas de bombons) que são excelentes e nada precisa ser feito.

II.2 Outras formas usadas na refração - o prisma.

O prisma é construído da mesma maneira que a lâmina de faces paralelas. Corta-se um pedaço de PVC transparente como está mostrado na figura ao lado, risca se com um objeto pontiagudo e dobra-se. Em seguida, colam-se as partes abertas com cola Tigre para PVC.

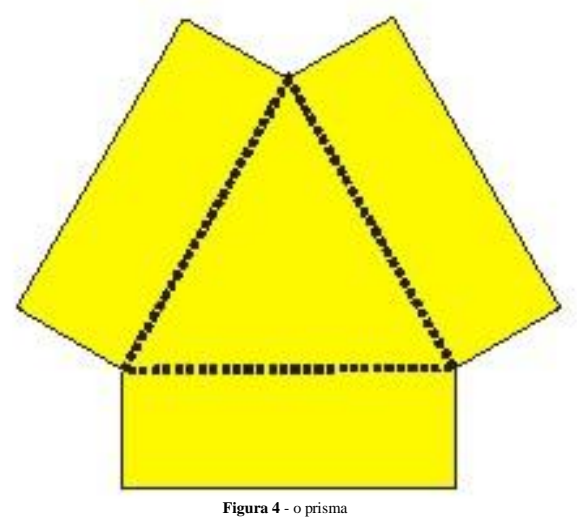

II.3 Outras formas usadas na refração - a cuba semicircular.

Para construirmos a cuba semicircular, devemos, antes, dobrar uma lâmina de PVC transparente - com uma forma cilíndrica.

Para isso, cortamos inicialmente a lâmina e prendemos a mesma, com fita adesiva, numa lata vazia cilíndrica como mostra a Figura 5. 


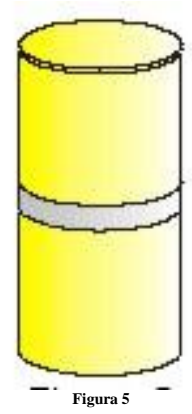

Em seguida a lata a lata é preenchida com água fervendo. Aguarda-se algum tempo e solta-se a lâmina.

O plástico fica, dessa maneira, com uma forma parecida com a da lata. Depois recortase um pedaço desse plástico para construir a cuba. Todo o conjunto é depois colado numa base de PVC (ver Figura 6).

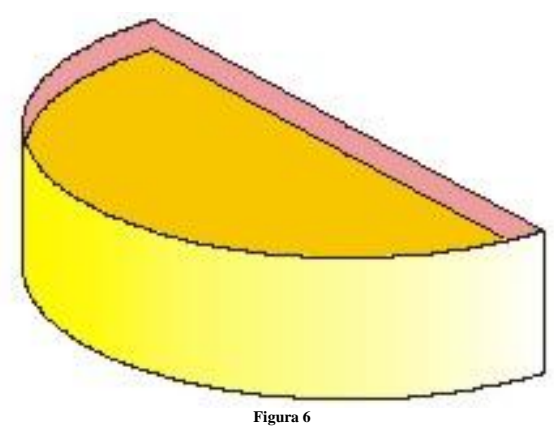

Dessa maneira também são construídas lentes convergentes e divergentes.

3.3 - Inversão ... sim ou não?

Outro procedimento com "mutreta" (truque, enganação, engodo), e ainda realmente científico é o da lente cilíndrica para evidenciar a dispersão e inversão. A montagem é super simples:

-uma base de madeira, -um tubo de ensaio cheio de água (uma rolha de borracha) e -suporte de lâmina fina de lata para o tubo.

Abaixo ilustramos a montagem. Deixe uma bolha de ar no tubo! 


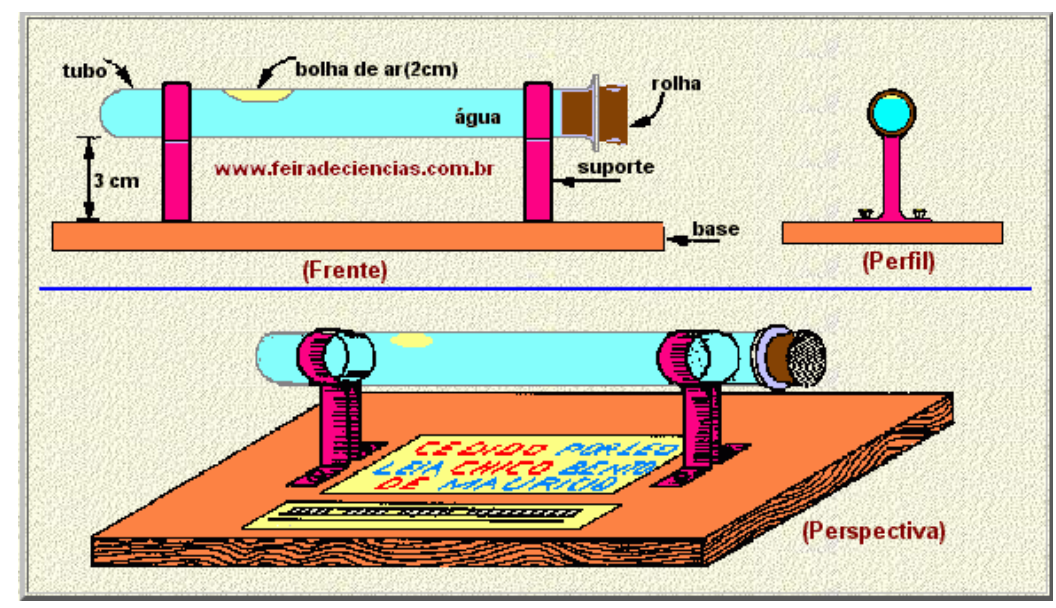

$\mathrm{Na}$ folha de papel colada na base, sob a região central do tubo escreva o ilustrado abaixo, exatamente como indicado.

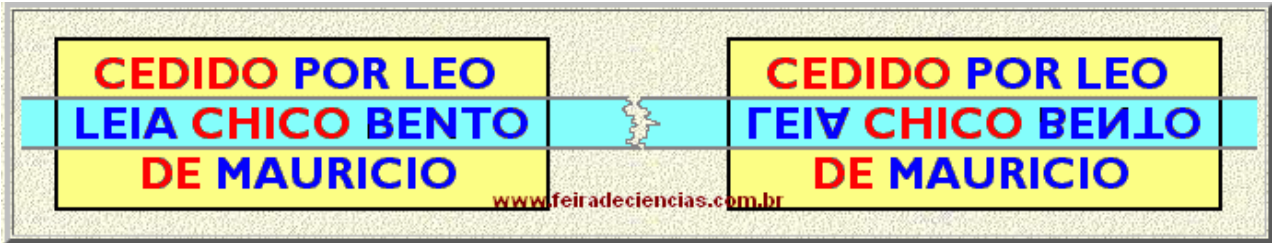

Atenção, no texto proposto, as palavras CEDIDO, CHICO e DE são escritas em vermelho e as palavras POR LÉO, LEIA, BENTO e MAURÍCIO são escritas em azul (canetas esferográficas ou de ponta porosa, é indiferente).

Olhando essas palavras através da lente cilíndrica (tubo de ensaio com água), aquelas escritas em vermelha serão vistas normalmente (CEDIDO, CHICO e DE) e as escritas em azul serão vistas invertidas (veja na direita da ilustração acima a linha central ). Porquê?

Essa é a pergunta que vem na tirinha de papel, também, colada na base: "Por quê as palavras em azul invertem e as em vermelho não?"

Prepare-se para as respostas do mais profundo teor científico - dispersão, índice de refração diferente para tais cores, desvios diferentes na lente cilíndrica, teoria dos dióptros centrados e outras elucubrações.

Nada disso tem a ver com a proeza, todas invertem, porém, as palavras escritas em vermelho têm simetria horizontal (simetria segundo uma linha horizontal que passa pelo meio da letra); $\mathrm{C}$ invertido é $\mathrm{C}, \mathrm{H}$ invertido é $\mathrm{H}$, I invertido é I etc.

Desse modo, você pode inventar as próprias frases, basta escolher palavras que têm simetria horizontal e outras que não a tenham.

Outra observação curiosa é que quando a bolha de ar passeia lentamente pelo tubo, e você olha as letras através da bolha, todas as palavras são vistas menor e direita ou seja todas são lidas normalmente (sem inversão) e são reduzidas. 
Esse 'brinquedinho' eu apresentei, também, ao amigo T. N. O. FolmerJohnson. Após observações (e boas risadas), levantou-se o problema teórico de uma simples, dupla ou tripla inversões. Imediatamente o mestre Johnson propôs:---"Deixa comigo o brinquedinho, vou mostrar aos netos e aproveito para examinar a questão teórica".

Passado vários dias (não havia pressa, nada de urgência) recebo um envelope. Vou reproduzi-lo na íntegra para que sirva de modelo a alunos e professores.

"Caro Léo:

Ai vai a solução do problema de óptica.

Poder-se-ia aplicar a equação do dióptro cilíndrico, para solução quantitativa. No caso da lente de ar, seria preciso fazer hipótese sobre a curvatura do menisco.

Considero excesso de zelo.

Contento-me com o esquema.

Se você tiver proposta diversa, queira participar-me.

\section{Abraço.}

Johnson"

\section{Lente cilíndrica com bolha de ar}

a) O azul inverte, o vermelho também.

b) O objeto é $A B$ real. $O$ cilindro gera imagem $A^{\prime} B$ ' invertida, logo real (atualmente, é $A^{\prime} B^{\prime}<A B$ ). O processo da paralaxe confirma a posição da imagem.

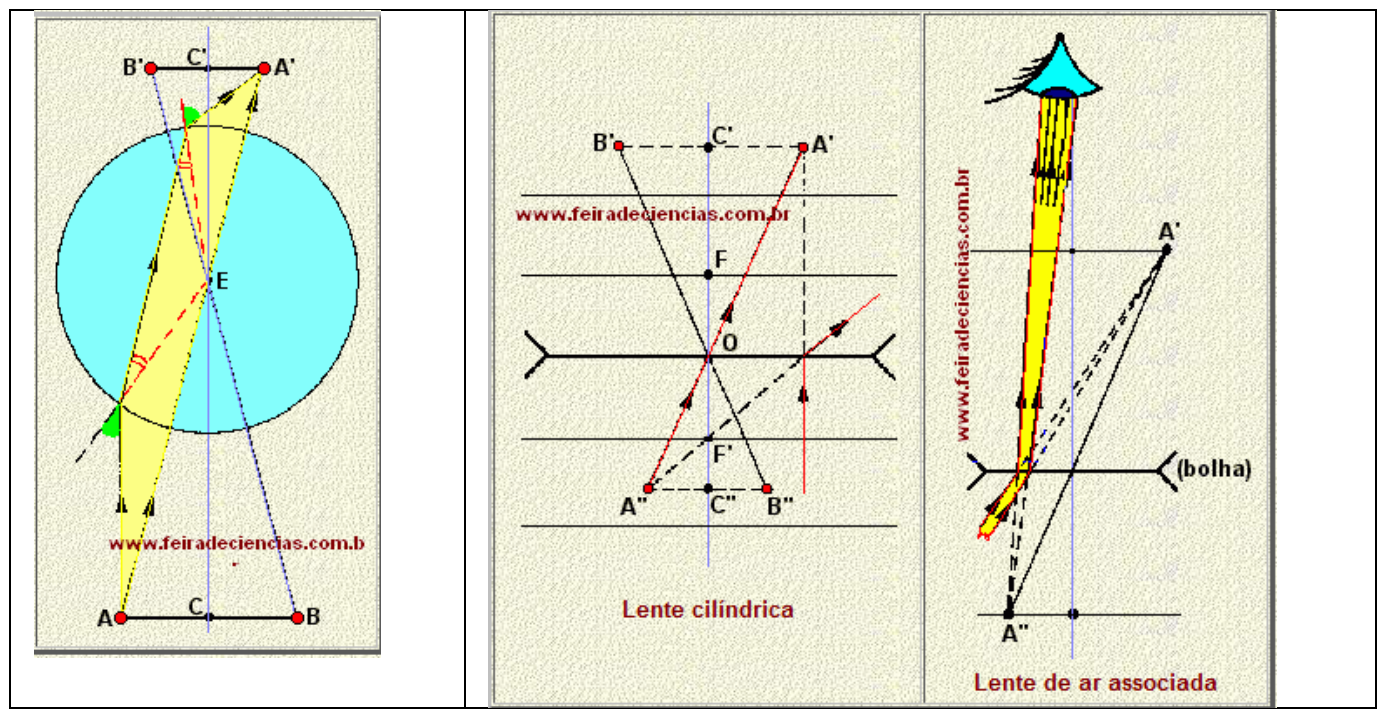


Embora a distância do olho a C' seja menor que a do olho a C", acredito ser $A^{\prime \prime} B^{\prime \prime}<A^{\prime} B^{\prime}$, para o que é preciso ser OC' $>2$. $|f|$.

Nota: Com A"B" > A'B', seria $|f|<O C^{\prime}<2$. $|f|$.

\section{4 - ECLIPSES [9]}

Material utilizado: lanterna, uma bola de isopor e um anteparo de papelão.

Posiciona-se a bola em cima de algum objeto e, com a lanterna, projeta-se a sombra da bola sobre o anteparo de papelão (vide figura abaixo).

A lanterna representa o Sol e a bola de isopor, a Lua. A sombra e a penumbra formadas no anteparo ilustram o que ocorre nos eclipses totais e parciais do Sol. $\mathrm{Na}$ região mais escura ocorre o eclipse total e onde há penumbra, o eclipse parcial.

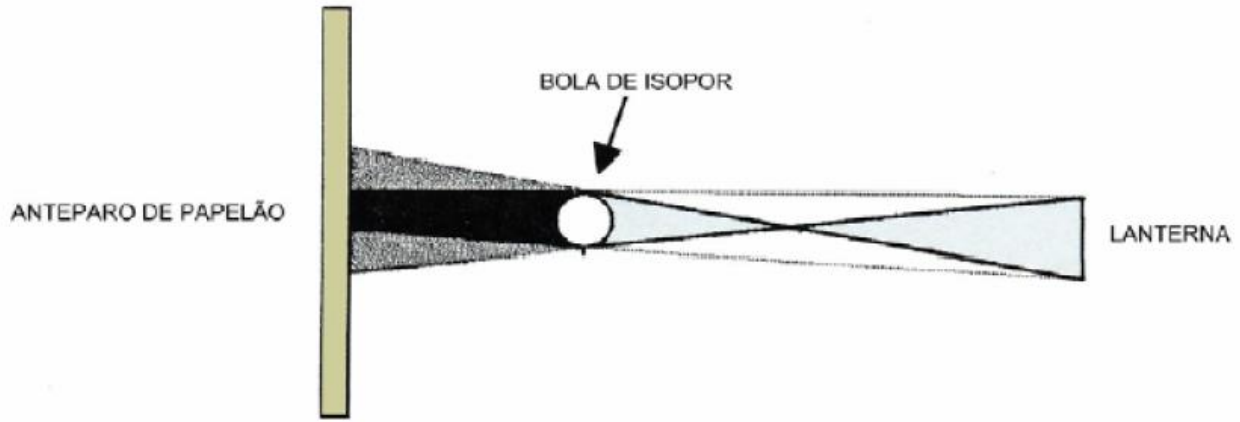

\subsection{MOEDA MÁGICA (REFRAÇÃO) [9]}

Material utilizado: um recipiente de plástico, uma moeda, uma garrafa com água e um espeto de churrasco para cada grupo.

Coloca-se a moeda no fundo do recipiente vazio. Os alunos ficam de pé e afastamse até não conseguirem mais visualizar a moeda. Nesse momento, um aluno joga água no recipiente até os demais conseguirem enxergar a moeda (vide figura abaixo). Depois disso, um dos alunos tenta acertar a moeda com o espeto.

Experimento da moeda mágica. No desenho da esquerda, a posição do observador e a propagação retilínea da luz impedem a visualização da moeda.

Quando se adiciona água (direita), a luz sofre refração, sendo desviada e permitindo que a moeda seja vista.
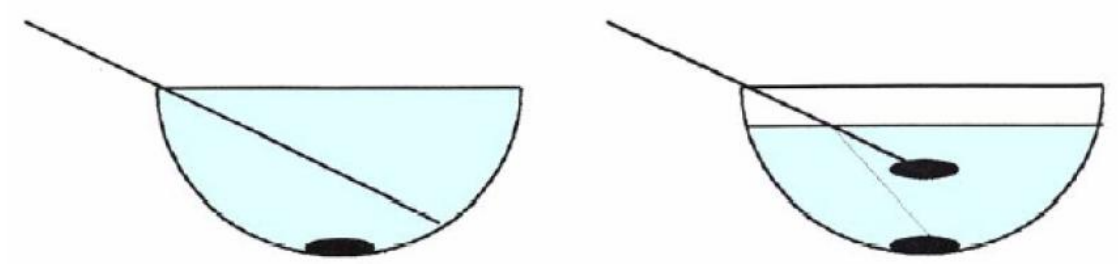

\section{COMENTÁRIOS:}

Os experimentos de demonstração propostos aqui são muito simples e os estudantes devem ter sido capazes de realiza-los.

As atividades experimentais são um pouco mais elaboradas, mas na sua maioria de fácil realização. 
As vídeos aulas e os applets de ensino são muito bons e ilustram o conteúdo desta aula.

Experimento 3.4 - A luz é refletida.O ângulo de incidência é o ângulo da luz que incide no espelho e o ângulo de reflexão é da luz que é refletida.

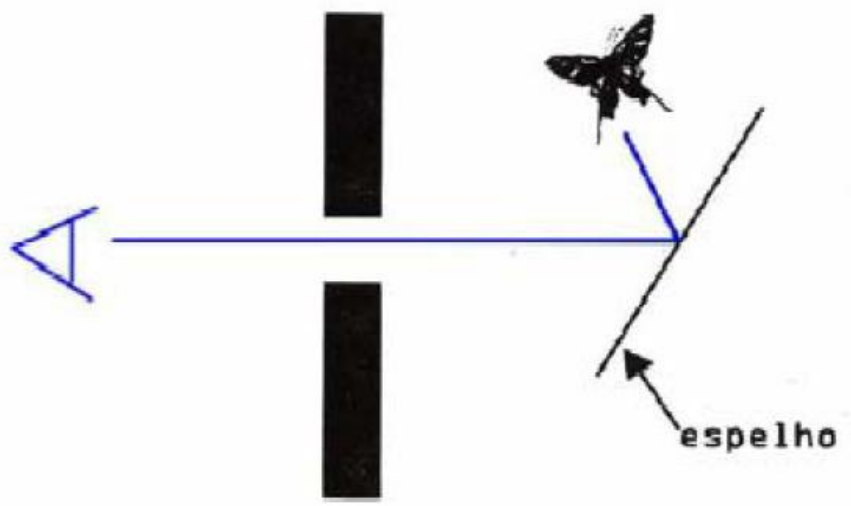

A luz sofre um desvio na sua trajetória e se aproxima da normal. Sofre refração.

A lanterna representa o Sol e a bola de isopor, a Lua. A sombra e a penumbra formadas no anteparo ilustram o que ocorre nos eclipses totais e parciais do Sol. Na região mais escura ocorre o eclipse total e onde há penumbra, o eclipse parcial.

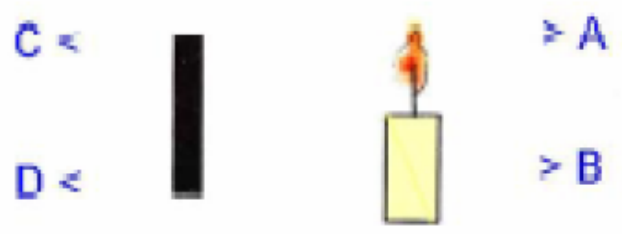

Não. O observador D não consegue ver a vela acesa, pois o meio é opaco e a luz não passa por ele.
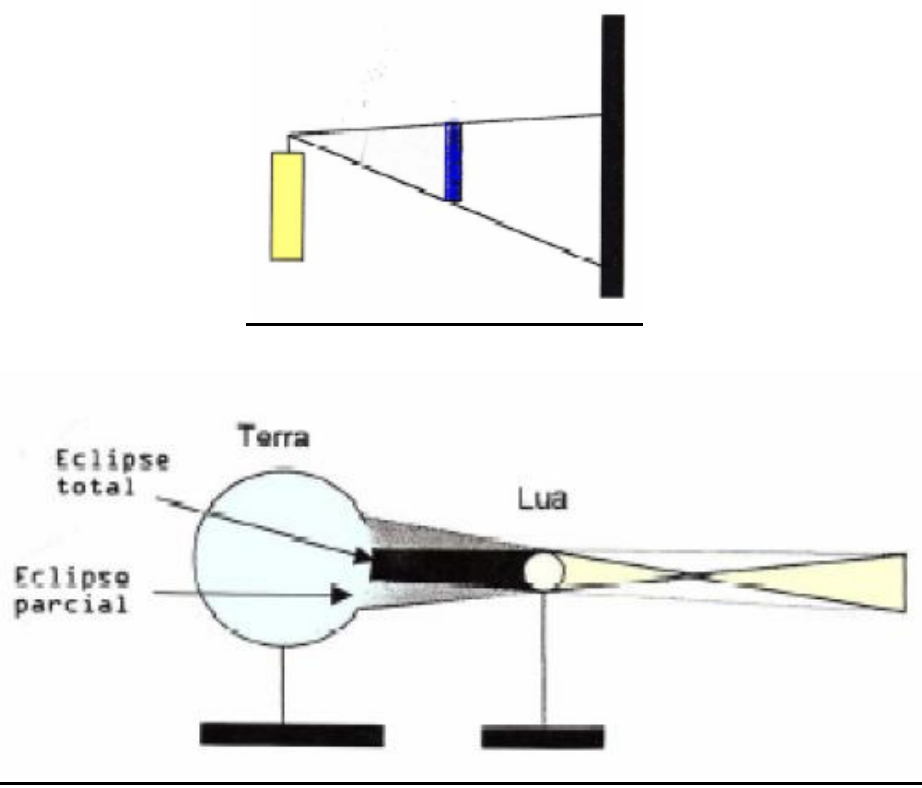
Experimento 3.5 - Experimento da moeda mágica. No desenho da esquerda, a posição do observador e a propagação retilínea da luz impedem a visualização da moeda. Quando se adiciona água (direita), a luz sofre refração, sendo desviada e permitindo que a moeda seja vista.

1 O aluno não conseguirá acertar a moeda, a não ser que mude a direção do espeto. Neste momento cabe levantar a questão de como o índio é capaz de pescar utilizando um arpão. Obviamente ele não conhece os conceitos envolvidos no fenômeno de refração, mas sabe que não pode atirar o arpão exatamente no que ele está vendo.

\section{CONCLUSÃO:}

O estudante deve ter concordado que uma aula sobre óptica geométrica é muito interessante e leva os estudantes do segundo grau a gostarem um pouco mais da física. Que esse tópico da física possui muitos recursos didáticos e deve ser abordado no ensino médio. Que sempre podemos ilustrar a aula com experiências de demonstração.

\section{RESUMO:}

Apresentamos aqui uma aula sobre óptica geométrica, sem abordarmos os temas espelhos esféricos e lentes, que deixamos para a próxima aula. Apresentamos várias sugestões de exemplos práticos e experimentos de demonstração. No final da aula apresentamos alguns exemplos de experimentos de baixo custo, applets de ensino e vídeo aulas. Fizemos algumas animações com o software Modellus.

(http://educar.sc.usp.br/otica/reflexao.htm\#teoria2, WWW.unb.br/iq/kleber/cursosvirtuais/qq, http://www.phy.ntnu.edu.tw/oldjava/portuguese/luz optica/fermat arquivos/fermat.htm)

http://www.cnet.com.au/downloads/soa/TelescopeSimulator/0,239030382,10205556s,00.htm

http://astro.unl.edu/classaction/animations/telescopes/telescope10.html http://www.cfn.ist.utl.pt/ varandas/aulas/aula 11.pdf http://www.ufjf.br/ioaoxxiii/files/2008/12/otica-1-introducao-e-reflexao-da-luz.pdf 9 - http://www.ib.usp.br/iec/arquivos/anexo1_33.pdf 


\section{Cap04 - Lentes e Espelhos Esféricos}

Meta: Fazer que o estudante comece a pensar no ensino de ciências como algo "orgânico" que está em profunda transformação. Fazer com que os alunos percebam, através de uma atividade lúdica, que podemos ensinar física através de experimentos muito simples, e que física é uma ciência aplicada e que pode ser aprendida através da observação de vários dispositivos do nosso cotidiano. Fazer com que o aluno percebam as aplicações da física no cotidiano.

Objetivos: Ao final da aula, os alunos devem estar cientes das novas possibilidades e dos desafios que envolvem o ensino de ciências em geral. Que para se ensinar física não precisamos ficar presos ao livro didático. Que ensinar física não é ensinar a resolver problemas e que a física é uma mera aplicação da matemática. Devem ter compreendido que a óptica geométrica é um ramo fundamental da física com aplicações tecnológicas e de ciência básica (Astronomia por exemplo). Que se ensinar através de exemplos reais (experimentais) pode ser muito mais interessante e divertido. Estes devem estar cientes que é possível explorar vários recursos de multimídias e de experimentos de baixo custo em sala de aula.

Pré-requisitos: Os alunos deveram ter cursado psicologia da educação física $A, B$ e C.

\section{Introdução:}

Como dissemos na aula anterior, deixamos o tema "Espelhos Curvos e Lentes" para ser tratado nesta aula. Como sempre, tomamos um texto escolhido arbitrariamente

O texto que se segue foi inteiramente baseado no material

Ao se cortar uma esfera por um plano se obtém duas calotas esféricas. Espelhos esféricos é uma calota esférica (fig.1) na qual uma de suas faces é espelhada produzindo reflexão regular (especular). Assim, surgem dois tipos de espelhos, os côncavos cuja superfície refletora é a parte interna da calota e os convexos, onde a superfície refletora é a externa. Esses espelhos obedecem às mesmas leis de reflexão da luz dos espelhos planos da Óptica geométrica, ver cap.01. [1] 


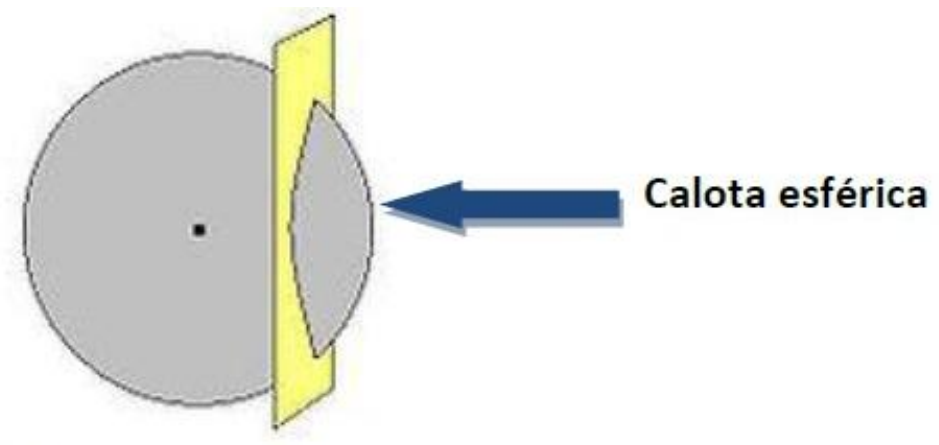

Esfera seccionada

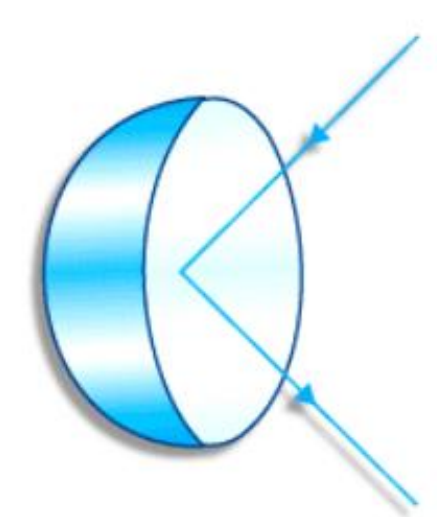

Espelho esférico côncavo

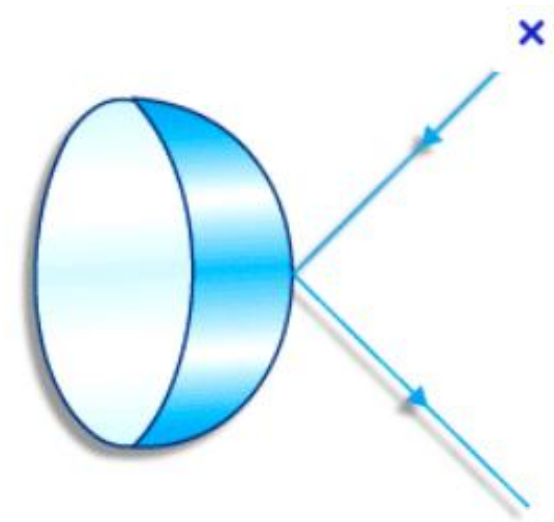

Espelho esferico convexo

Fig. Tipos de Espelhos

\section{Reflexão da luz em espelhos esféricos}

Como nos espelhos planos os espelhos esféricos obedecem as leis da reflexão, ou seja, os ângulos de incidência e reflexão são iguais, os raios incidentes e refletidos e a reta normal ao ponto de incidência são coplanares, ver figura abaixo.

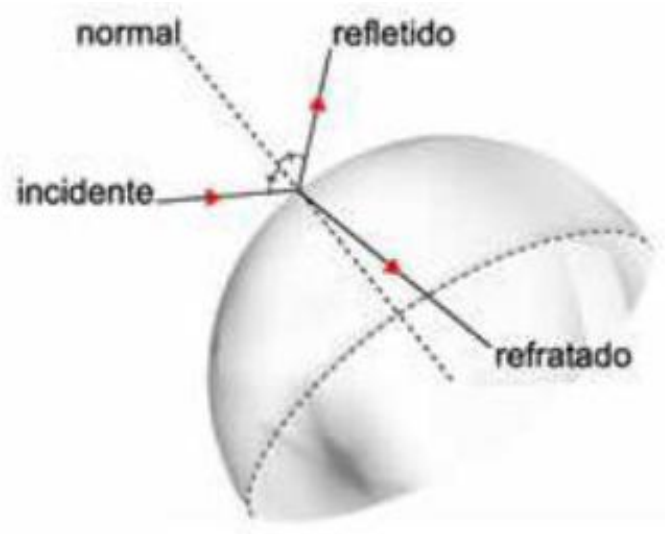


Para facilitar o estudo da formação da imagem definisse os elementos geométricos dos espelhos esféricos como:

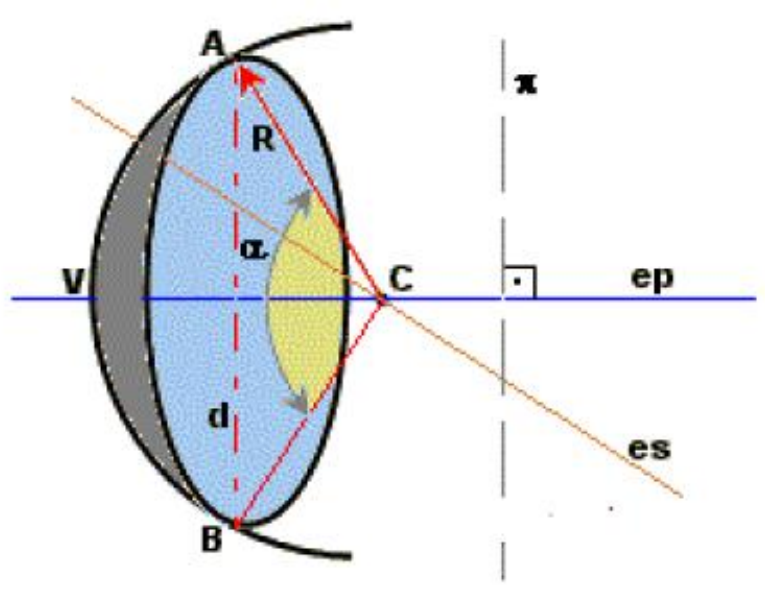

- C é o centro da esfera;

- V é o vértice da calota;

- O eixo que passa pelo centro e pelo vértice da calota é chamado eixo principal.

- As demais retas que cruzam o centro da esfera são chamadas eixos secundários.

- O ângulo a, que mede a distância angular entre os dois eixos secundários que cruzam os dois pontos mais externos da calota, é a abertura do espelho.

A abertura ( $\alpha$ ) de um espelho, como mostra a figura varia diretamente com o diâmetro d ( $\mathbf{R}$ é mantido constante) e inversamente com o raio de curvatura $\mathbf{R}$ (d é mantido constante).

O raio da esfera $\mathbf{R}$ que origina a calota é chamado raio de curvatura do espelho.

Um sistema óptico que consegue conjugar a um ponto objeto, um único ponto como imagem é dito estigmático. Os espelhos esféricos só são estigmáticos para os raios que incidem próximos do seu vértice $V$ e com uma pequena inclinação em relação ao eixo principal. Um espelho com essas propriedades é conhecido como espelho de Gauss. Um espelho que não satisfaz as condições de Gauss (incidência próxima do vértice e pequena inclinação em relação ao eixo principal) é dito astigmático. Um espelho astigmático conjuga a um ponto uma imagem parecendo uma mancha.

Assim, para se ter nitidez na imagem, o ângulo de abertura do espelho tem que ser inferior a 10 graus. Se essas condições forem obedecidas, esses espelhos são chamados de espelhos esféricos de Gauss.

\section{Focos dos Espelhos Esféricos}

Define-se como foco de um espelho convexo como o ponto entre o centro de curvatura e o vértice no qual os raios refletidos pelo espelho convergem (côncavo) ou divergem (convexo). Observe as imagens abaixo: 

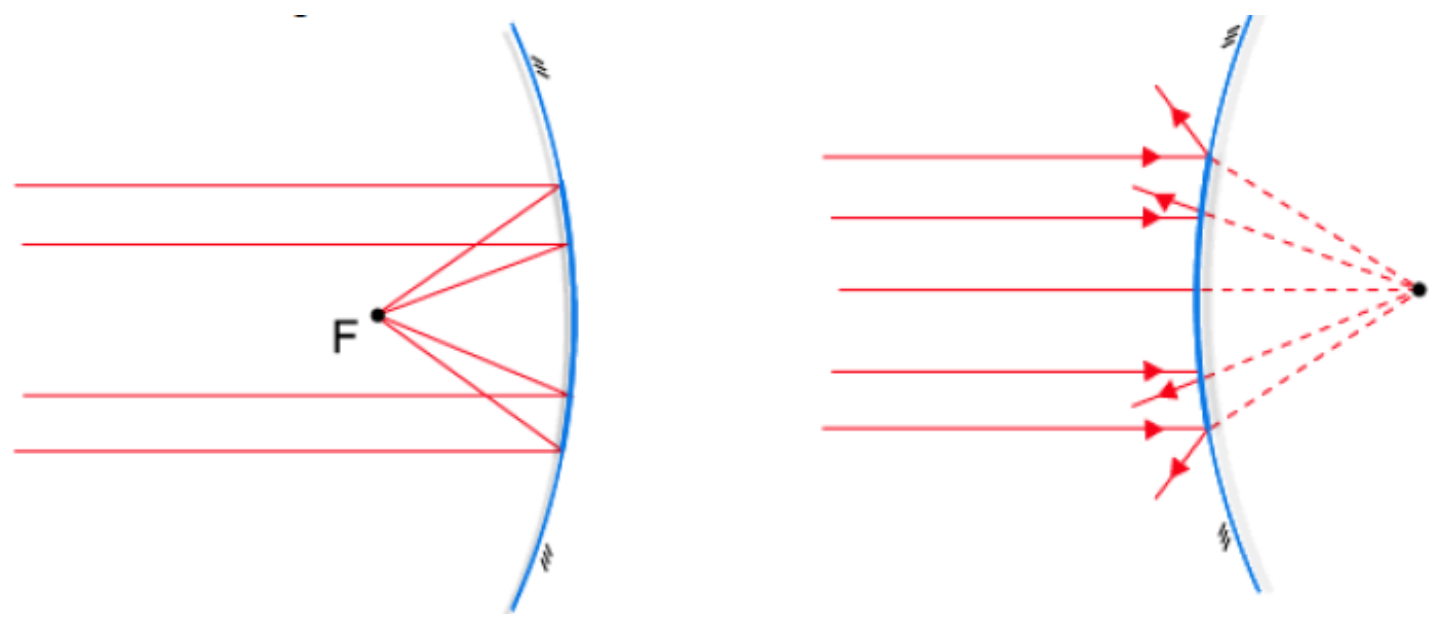

Fig. 2.3 - Focos de um espelho côncavo e um convexo.

Vemos que no caso dos espelhos côncavos (convergentes) o foco é real, pois é formado pelo cruzamento direto dos raios refletidos, e para os espelhos convexos (divergentes) o foco é virtual, pois é formado pelo cruzamento dos prolongamentos dos raios refletidos.

A distância entre o foco e o vértice do espelho é chamada distância focal $\left(f_{0}\right)$. Nos espelhos de Gauss podemos considerar $f_{0}=R / 2$, onde $R$ é o raio de curvatura (o raio da esfera seccionada).

\section{Determinação das Imagens}

Considere um objeto diante de um espelho esférico e em posição perpendicular ao eixo principal do espelho. Sabemos da experiência que:

- Uma imagem pode ser real ou virtual. No caso dos espelhos, dizemos que a imagem é virtual se ela se encontra "atrás" do espelho e real se ela se encontra em frente ao espelho (podendo ser projetada em um anteparo).

- A imagem ainda pode ser classificada de acordo com o seu tamanho em maior, menor ou igual ao tamanho do objeto.

- A imagem pode ser invertida em relação ao objeto. Se não houver sua inversão dizemos que ela é direita.

Para que possamos determinar o tipo de imagem e sua posição em relação ao vértice do espelho nos espelhos esféricos, devemos conhecer alguns raios chamados raios notáveis, que obedecem às chamadas propriedades fundamentais dos espelhos esféricos.

1-Todo raio de luz que incide paralelamente a um eixo (principal ou secundário), se reflete na direção do foco (principal ou secundário) 


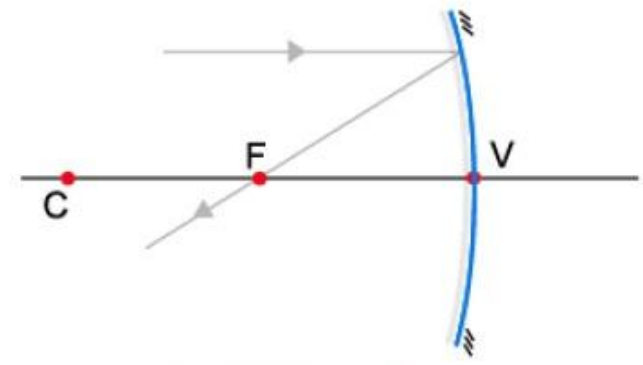

ESPELHO CONCAVO

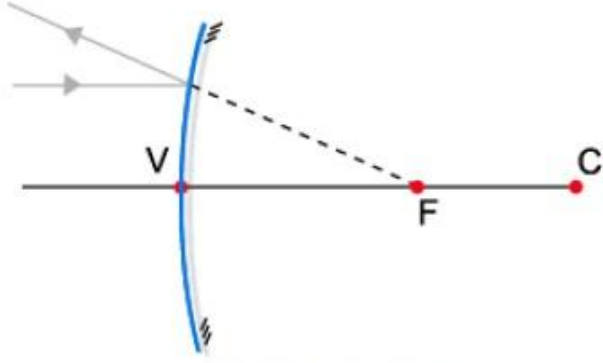

ESPELHO CONVEXO

2- Todo raio de luz que incide na direção do foco, é refletido paralelamente ao eixo

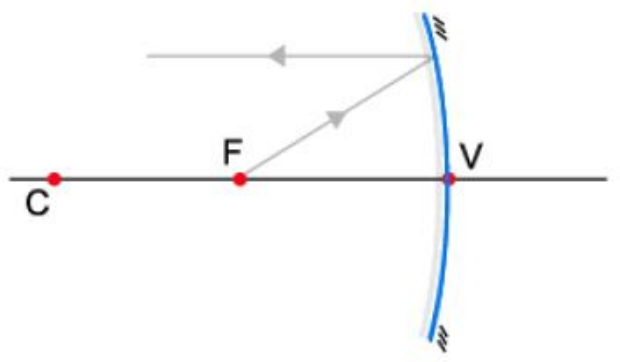

ESPELHO CONCAVO

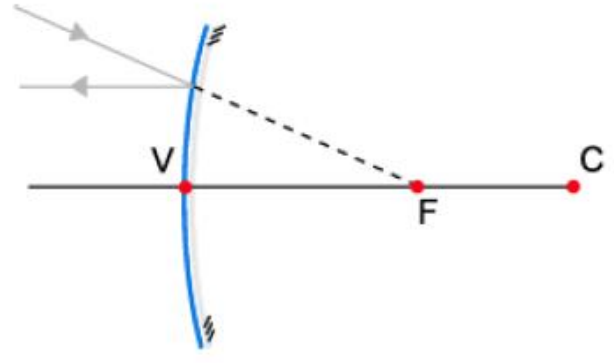

ESPELHO CONVEXO

3- Todo raio de luz que incide na direção do centro de curvatura, é refletido sobre si mesmo

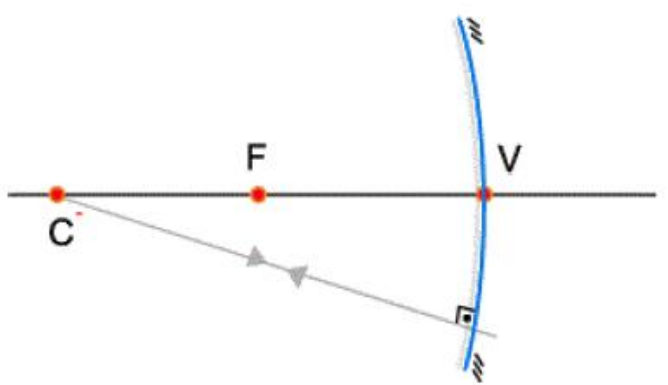

ESPELHO CONCAVO

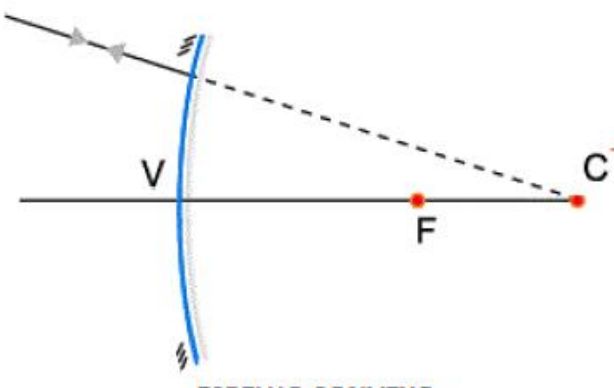

ESPELHO CONVEXO

4-Todo raio de luz que incide sobre o vértice, é refletido simetricamente em relação ao eixo principal. 

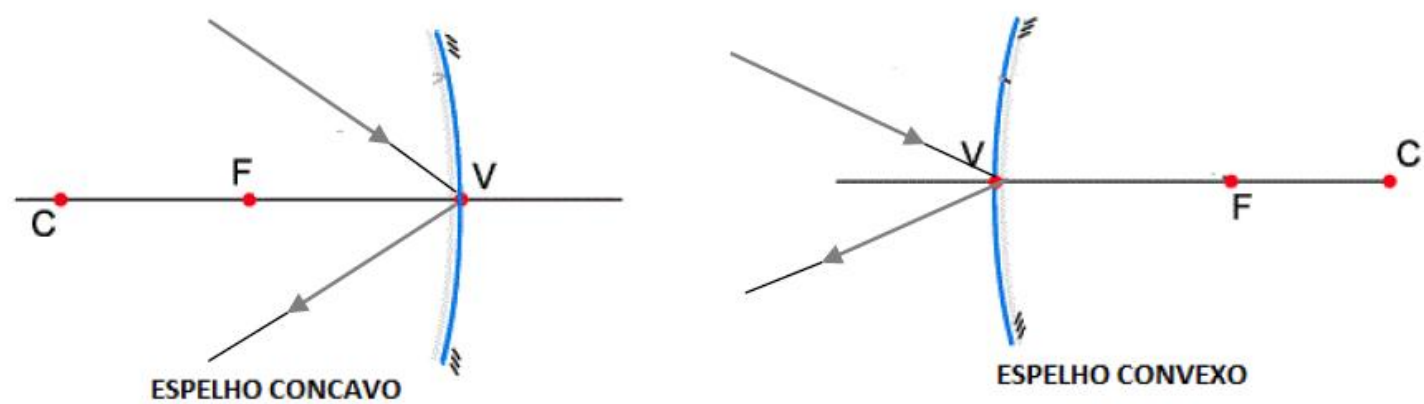

Veremos que nos espelhos côncavos, a característica da imagem formada depende da posição do objeto em relação a ele e nos convexos, a imagem formada tem sempre a mesma característica qualquer que seja a posição do objeto

\section{Espelhos côncavos}

1-Objeto além do centro de curvatura

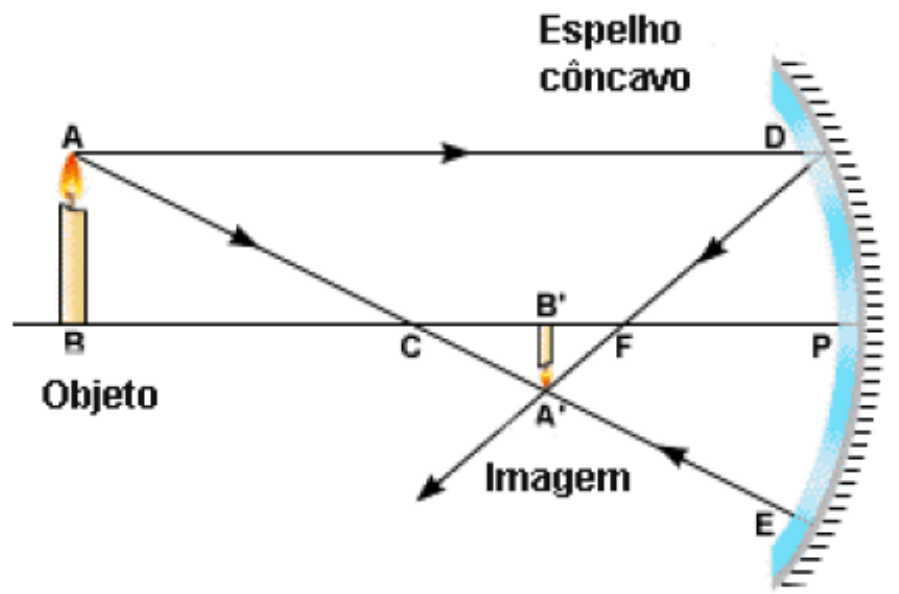

Imagem real, invertida e menor

2-Objeto no centro de curvatura 


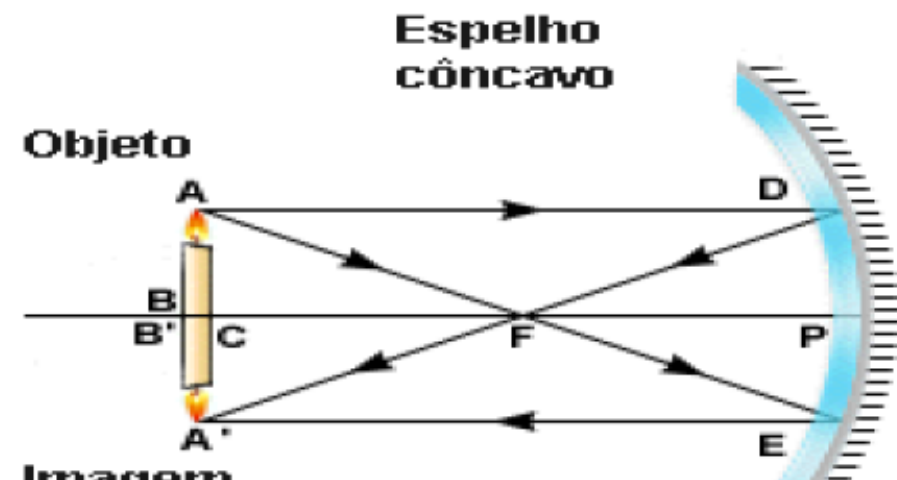

Imagem

Imagem real, invertida e igual

3-Objeto entre o foco $(F)$ e o centro de curvatura (C)

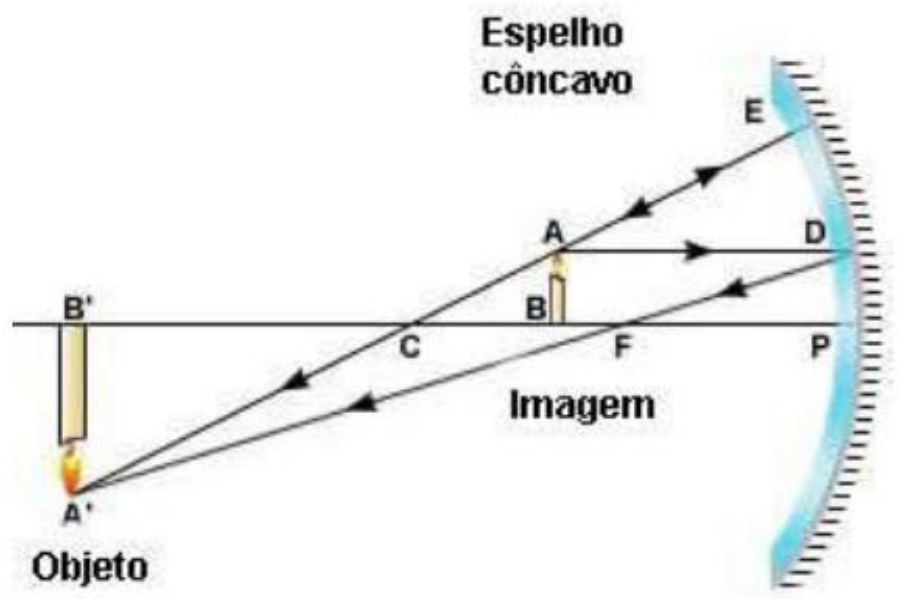

Imagem real, invertida e maior

4 - Objeto no foco 


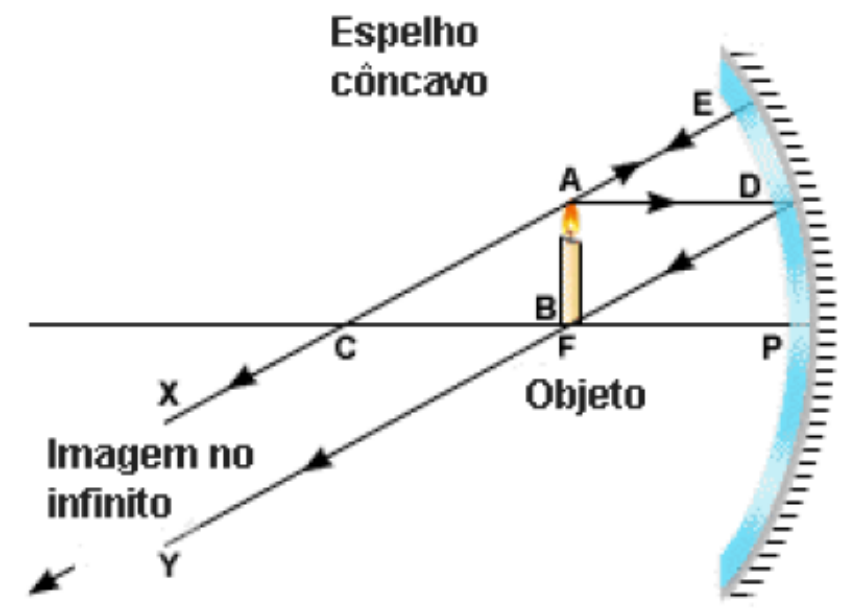

Imagem imprópria

5- Objeto entre o foco $(F)$ e o vértice $(P)$

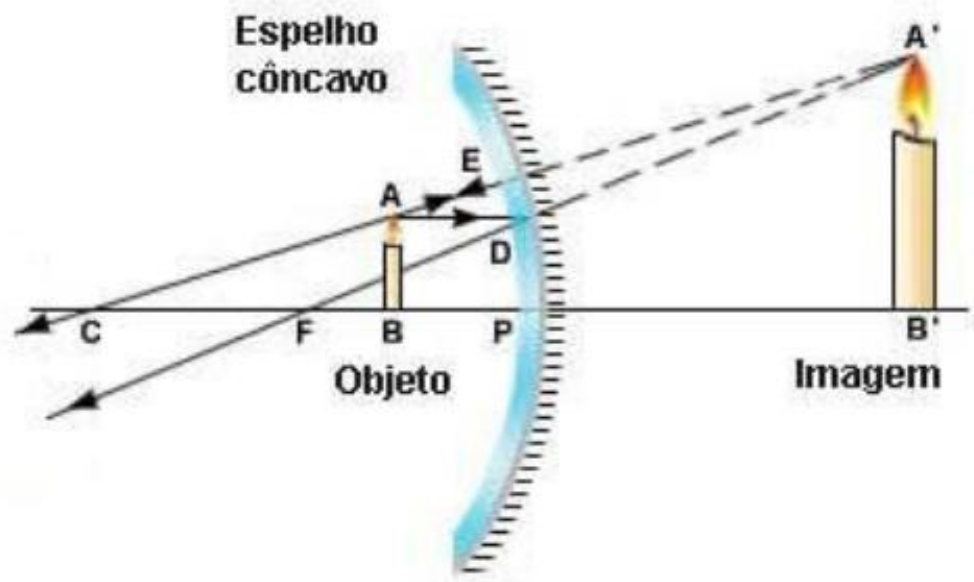

Imagem virtual, direita e maior

Espelhos convexos

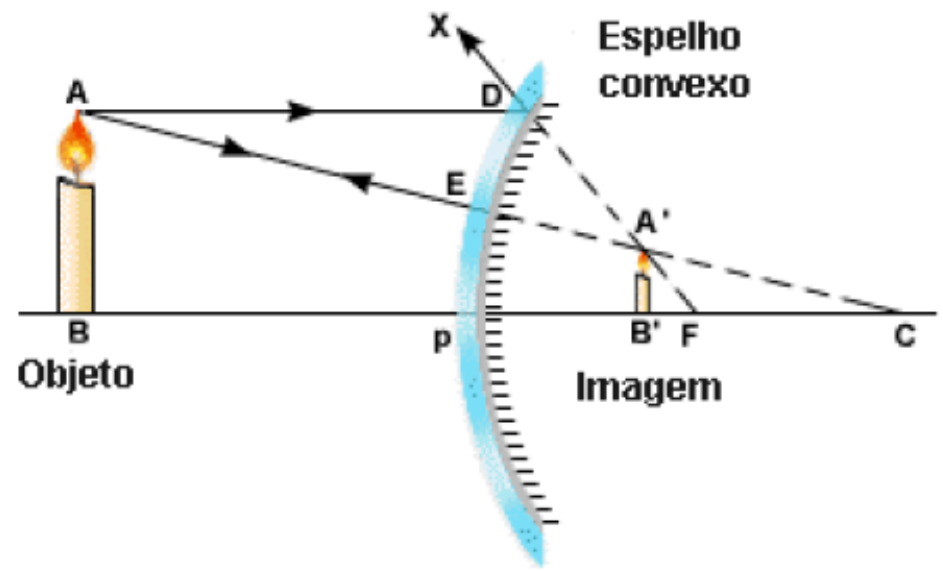

Imagem virtual, direita e menor 
Estudo analítico dos espelhos

Referencial de Gauss

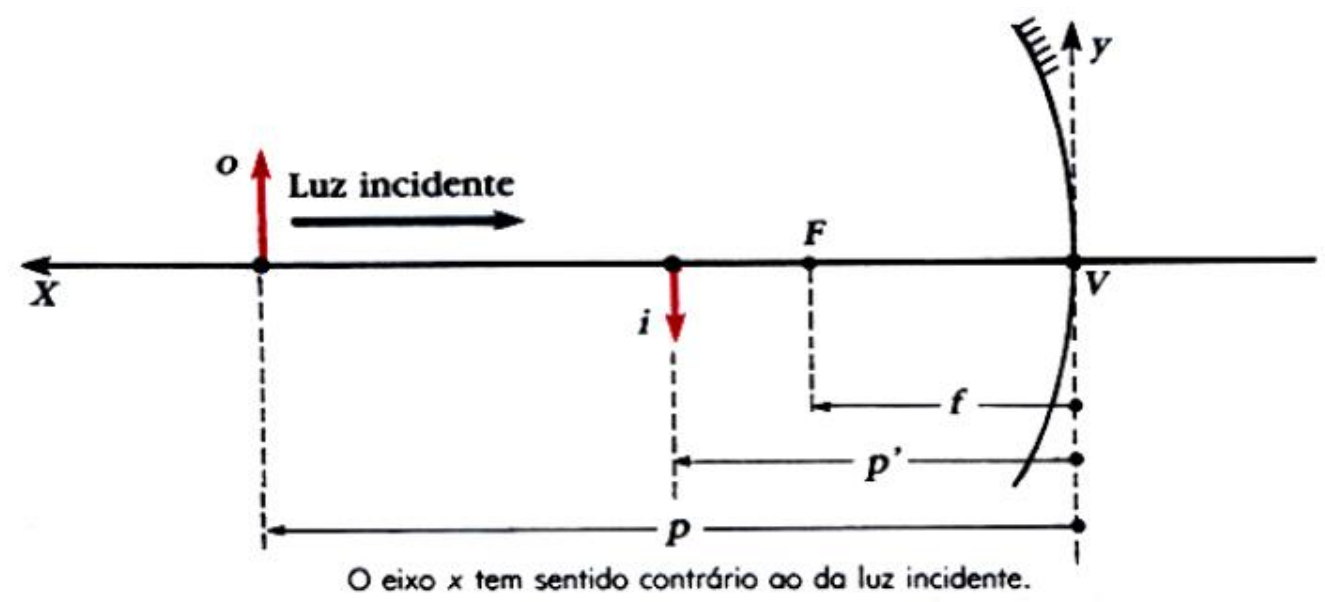

Fig. Referencial de Gauss

Esse estudo basicamente é uma forma determinar matematicamente a posição da imagem. Considerando o espelho da figura acima onde:

$0=$ Tamanho do objeto

$\mathrm{i}=$ Tamanho da imagem

$f=$ Distância focal

$p=$ Distância do objeto ao espelho

$p^{\prime}$ = Distância da imagem ao espelho

\section{Estudo de sinais}

Considerando o objeto sempre real $(p>0)$, temos então:

Espelho côncavo: $f>0$; Espelho convexo: $f<0$

Imagem real: $p^{\prime}>0$. Ou seja, se p' for um número positivo a imagem estará sendo formada antes do espelho;

Imagem virtual: $p^{\prime}<0$. Ou seja, se $p^{\prime}$ for um número negativo a imagem estará sendo formada dentro do espelho;

Imagem direita: $\mathrm{i}>0$. Ou seja, se i for um número positivo a imagem estará sendo formada acima do eixo principal;

Imagem invertida: $\mathrm{i}<0$. Ou seja, se i for um número negativo a imagem estará sendo formada abaixo do eixo principal

Quanto à ampliação:

Se $A<0$ a imagem é invertida;

Se $A>0$ a imagem é direita;

Se $A>1$ a imagem é maior que o objeto;

Se $A<1$ a imagem é menor que o objeto; 
Por semelhança de triângulos poderíamos deduzir a equação de Gauss e a lei da ampliação da imagem, que simplesmente forneceremos aqui:
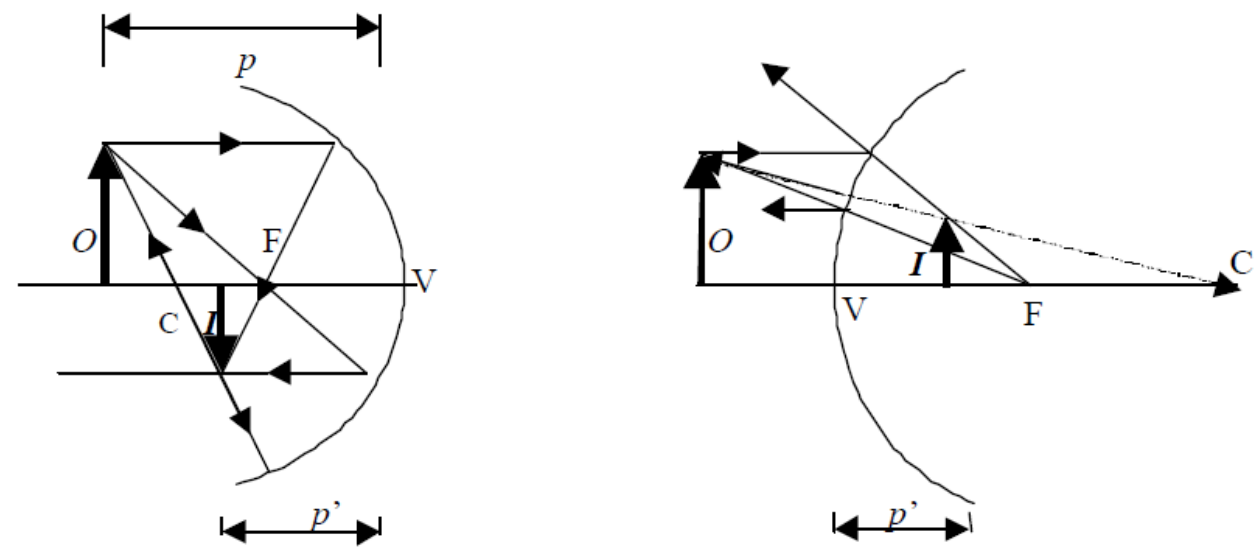

Figura 2 - Formação de imagens em espelhos esféricos
a) côncavo
b) convexo

Lei de Gauss

$\frac{1}{F}=\frac{1}{P}+\frac{1}{P I}$
Lei da Ampliação da Imagem

$$
A=\frac{i}{o}=-\frac{P^{\prime}}{P}=\frac{F}{F-P}
$$

Questões

Q1 - Abra o modelo "imagem_esp_côncavo" e verifique as leis acima.

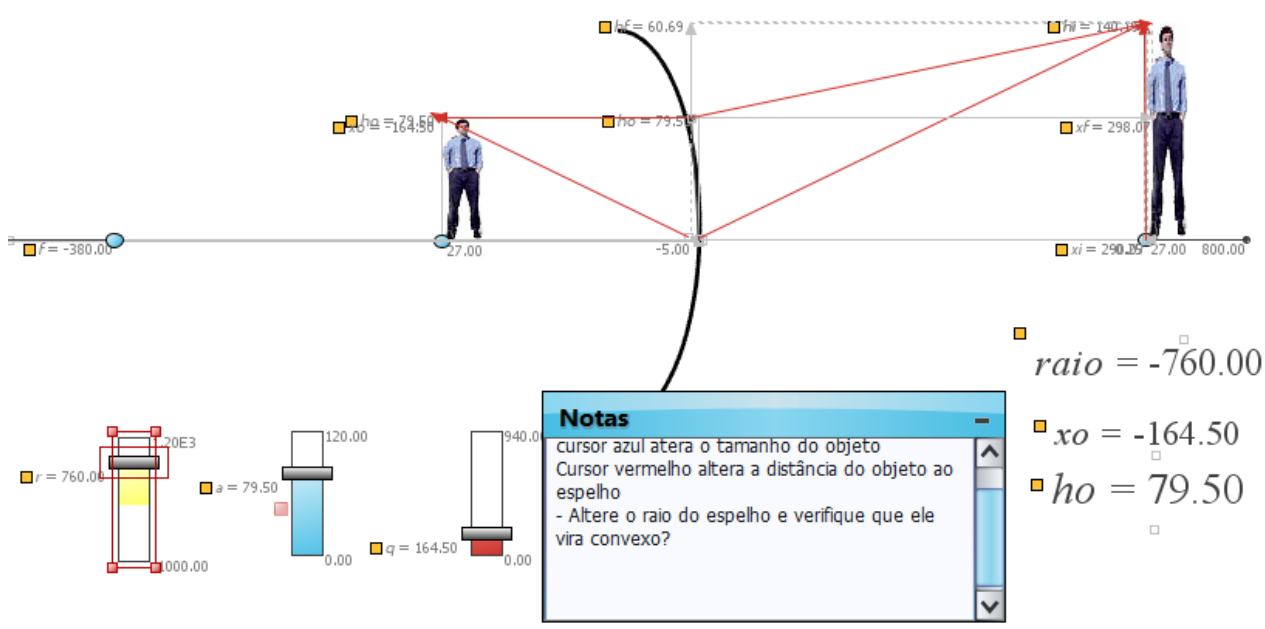




\section{LENTES [7]}

Lente é um meio transparente limitado por duas superfícies curvas. A forma mais comum de lentes são aquelas de faces esféricas, ou uma face plana e outra esférica.

Para efeito de classificação, pode-se dividir as lentes em dois grupos: as lentes convergentes e as divergentes.

As lentes convergentes são mais espessas na parte central, ao passo que as divergentes o são nas bordas. O centro de curvatura $\mathrm{C} 1$ é o centro da esfera de raio $R 1$ que origina uma face da lente; o centro C2 é o centro da esfera de raio $R 2$ que origina a outra face da lente. A linha que une os dois centros de curvatura denomina-se eixo principal.

Uma importante simplificação no tratamento matemático das lentes é abstrair sua espessura. Com este propósito, cria-se a figura da lente delgada, isto é, uma lente cuja espessura pode ser desprezada para todas as finalidades de formação de imagem.

Um feixe de raios paralelos ao eixo principal, incidindo numa lente convergente, refrata-se, convergindo para um ponto denominado foco $F$. A distância do centro geométrico da lente ao foco é a distância focal $f$ da lente. Se o feixe incidir numa lente divergente, o feixe se refrata, divergindo de um ponto localizado no mesmo lado do feixe incidente, formando o foco virtual, como está esquematizado na figura 3.

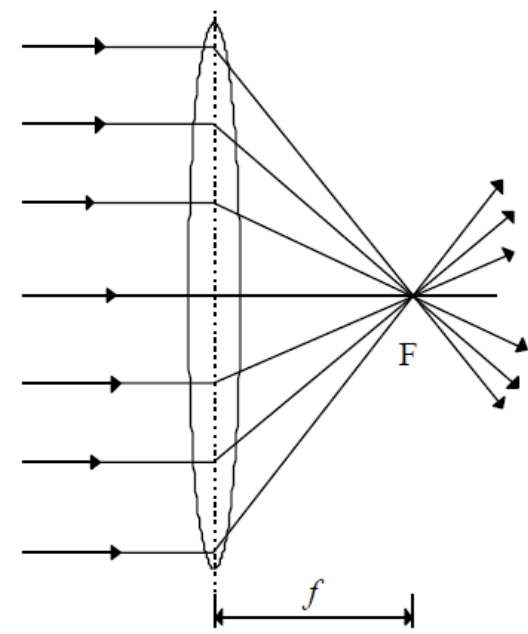

Figura 3 - Lentes delgadas

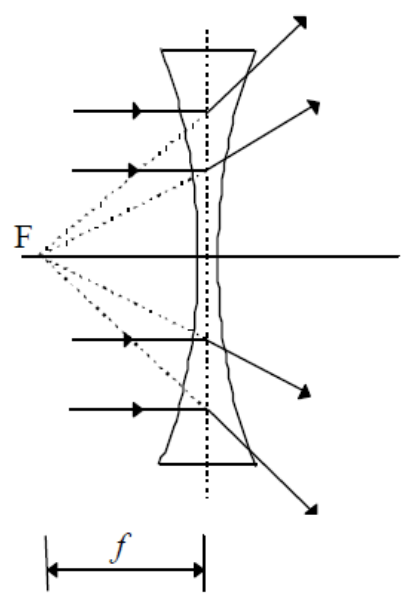

b) divergente

Conhecendo-se o tamanho $(O)$ e a distância $(p)$ de um objeto em relação a uma lente, e a direção de incidência de dois dos três raios principais, pode-se determinar graficamente o tamanho $(I)$ e a distância $\left(p^{\prime}\right)$ da imagem, tal como foi feito para os espelhos.

Os três raios principais de uma lente convergente são (figura 4):

1. Um raio paralelo ao eixo principal refrata-se na lente passando pelo foco;

2. Um raio que passe pelo centro geométrico não sofre desvio (porque a lente é delgada e o centro geométrico coincide com o centro ótico);

3. Um raio que passe pelo foco refrata-se na lente e sai paralelamente ao eixo principal. 

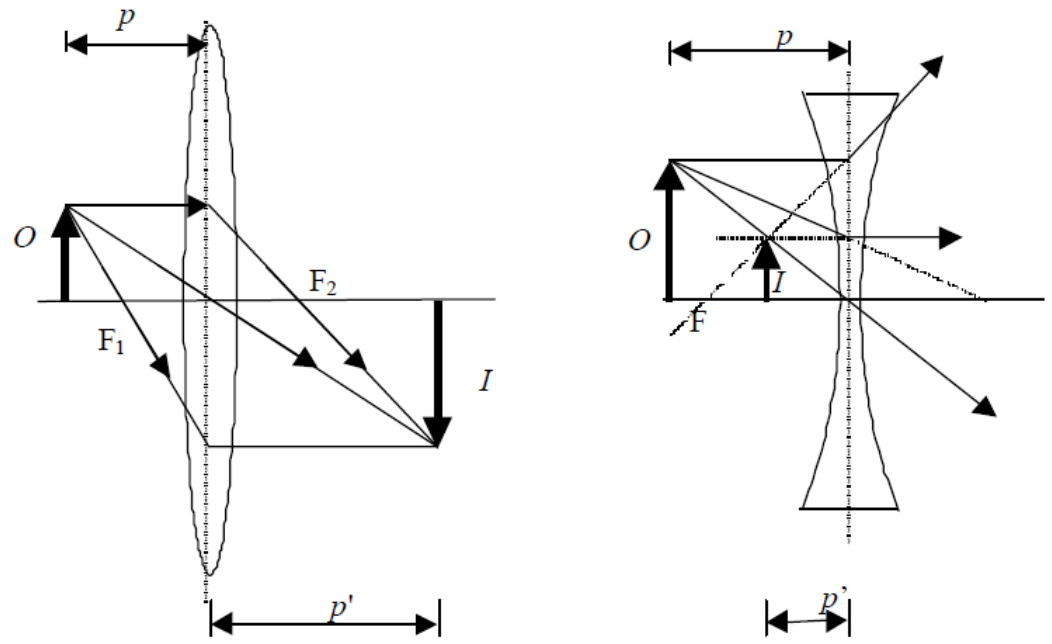

Figura 4 - Raios principais

a) lente convergente

b) lente divergente

A seguir apresenta-se um conjunto de equações que se aplicam a espelhos de pequena abertura e lentes delgadas, e que permite determinar algebricamente:

a. distâncias focais $(f)$;

b. distâncias do objeto $(p)$ e imagem $(p)$ ao espelho ou lente;

c. ampliação ou aumento linear $(M)$;

d. tamanhos de objeto $(O)$ e imagem (I).

Equação dos pontos conjugados: $\quad \frac{1}{f}=\frac{1}{p}+\frac{\prime}{p^{\prime}}$

Ampliação:

$$
M=\frac{I}{O}=\frac{-p \prime}{p}
$$

Para espelhos, a equação que relaciona distância focal e raio de curvatura é:

$$
f=\frac{R}{2}
$$

Para lentes, a "equação dos fabricantes de lentes" relaciona $f$ com os raios de curvatura e o índice de refração da lente com o meio que a envolve, sendo $n=$ $n_{2} / n_{1}$, onde $n_{2}$ é o índice de refração do material da lente e $n_{1}$ o índice de refração do meio que a envolve.

$$
\frac{1}{f}=(n-1)\left(\frac{1}{R_{1}}+\frac{1}{R_{2}}\right)
$$

A utilização das equações acima segue a seguinte convenção de sinais:

a) Todas as medidas são feitas a partir do vértice de um espelho, ou centro ótico de uma lente.

b) As medidas para determinar a posição de um objeto ou imagem, reais, são positivas.

c) As medidas que determinam a posição de um objeto ou imagem, virtuais, são negativas.

d) Um cálculo que fornece um resultado negativo implica em objeto ou imagem, virtuais, e resultado positivo, objeto ou imagem reais. 
e) A distância focal de um espelho côncavo e de uma lente convergente é sempre positiva; para um espelho convexo e uma lente divergente, negativa. f) $O$ tamanho $O$ de um objeto é sempre um número positivo; o tamanho da imagem será positivo se esta for direita (virtual) e negativa se for invertida (real).

g) Os raios de curvatura das lentes serão positivos, se dentro da concavidade houver material da lente; caso contrário, negativos.

A Tabela 1 resume o exposto.

\begin{tabular}{|c|c|c|c|c|c|c|}
\hline Espelh & ôncavo & & Lente & nvergente & & \\
\hline$f>0$ & & & $f>0$ & & & \\
\hline$p>0$ & $O>$ & & $p>0$ & $O>0$ & & \\
\hline$p^{\prime}>0$ & $I<0$ & $\mathrm{M}<0$ real & $p^{\prime}>0$ & $I<0$ & $M<0$ & real \\
\hline$p^{\prime}<0$ & $I>0$ & $M>0$ virtual & $p^{\prime}<0$ & $I>0$ & $M>0$ & virtual \\
\hline$R>0$ & & & $R_{1}>0$ & $R_{2}>0$ & bicon & vexa \\
\hline Espelh & onvexo & & Lente & vergente & & \\
\hline$f<0$ & & & $f<0$ & & & \\
\hline$p>0$ & $O>0$ & & $p>0$ & $O>0$ & & \\
\hline$p^{\prime}<0$ & $I>0$ & $M>0$ virtual & $p^{\prime}<0$ & $I>0$ & $M>0$ & virtual \\
\hline$R<0$ & & & $R_{1}<0$ & $R_{2}<0$ & & bicôncava \\
\hline
\end{tabular}

\section{ATIVIDADES}

1 - Analise os sites com applets abaixo:

1.1 - Lab/Metro. Site da Universidade Federal de Santa Catarina.

http://www.labmetro.ufsc.br/Disciplinas/EMC6422/APPLETS/EspelhoEsferico/EspelhoEsferico $\underline{. h t m l}$

1.2 - Lentes. http://www.walter-fendt.de/ph14e/imageconvlens.htm 


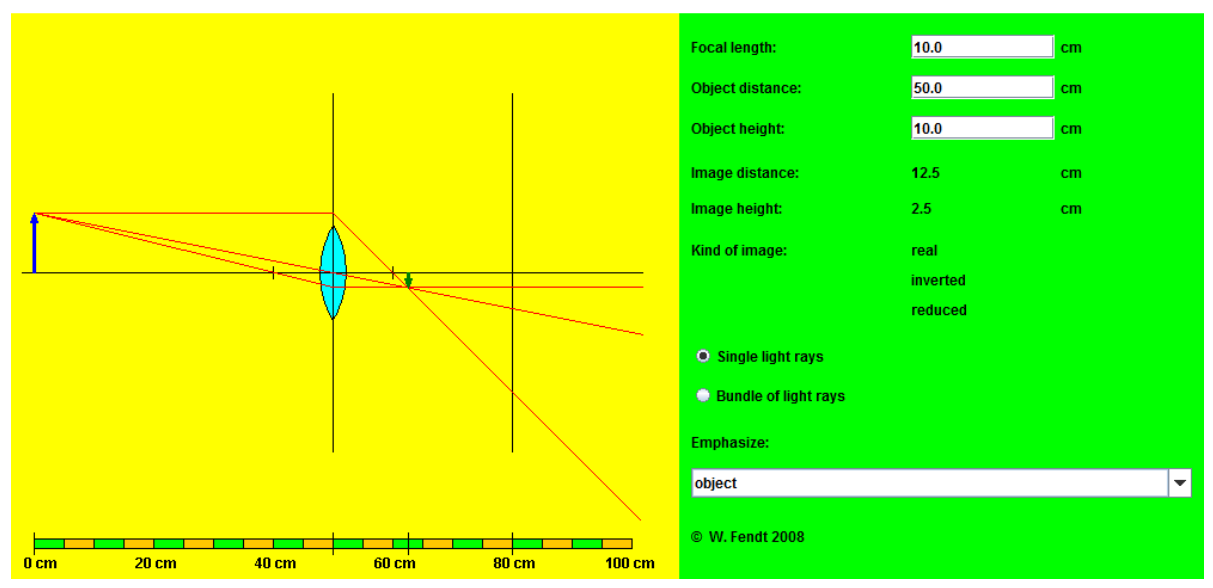

1.3 - Lentes Fu-Kwun Hwang: URL -

http://www.phys.hawaii.edu/ teb/java/ntnujava/Lens/lens_e.html

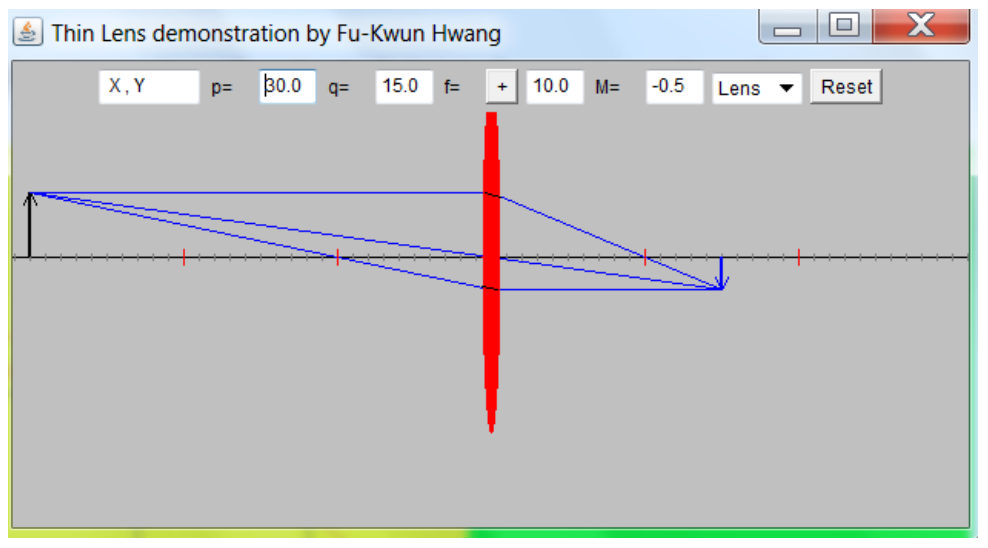

1.4 - Site do EducaPlus.org. URL: http://www.educaplus.org/luz/espejo2.html

Clicando no botão "mais" inverte o sinal do foco.

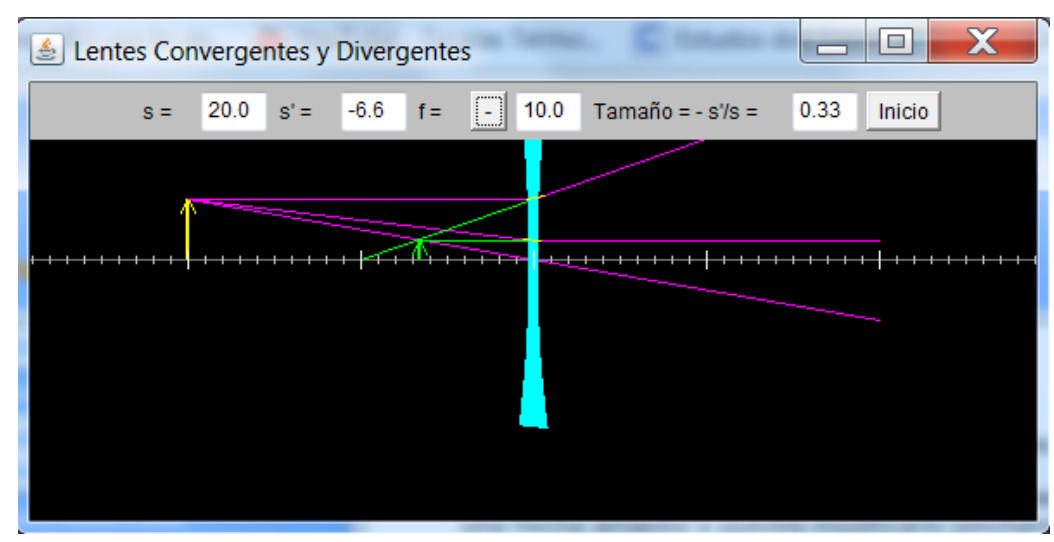

1.6 - Espelhos 


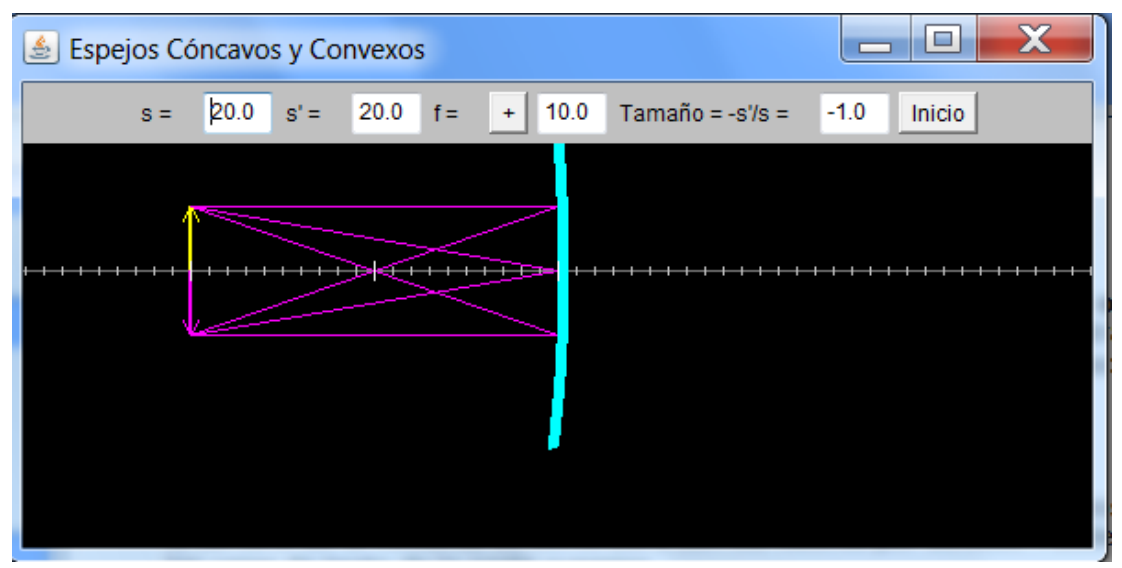

1.7 - General Physics Java Applets. URL: http://www.schulphysik.de/suren/Applets.html

Tem que clicar e arrastar o ponto objeto.

\begin{tabular}{|l|l|}
\hline Cabeçalho & Rodapé \\
\hline Focal lenght = Distância focal & Image distance = distância da imagem \\
Object Distance = Distância do Objeto & Image height = Altura da imagem \\
Object Height = altura do objeto & Magnification = Ampliação \\
\hline
\end{tabular}

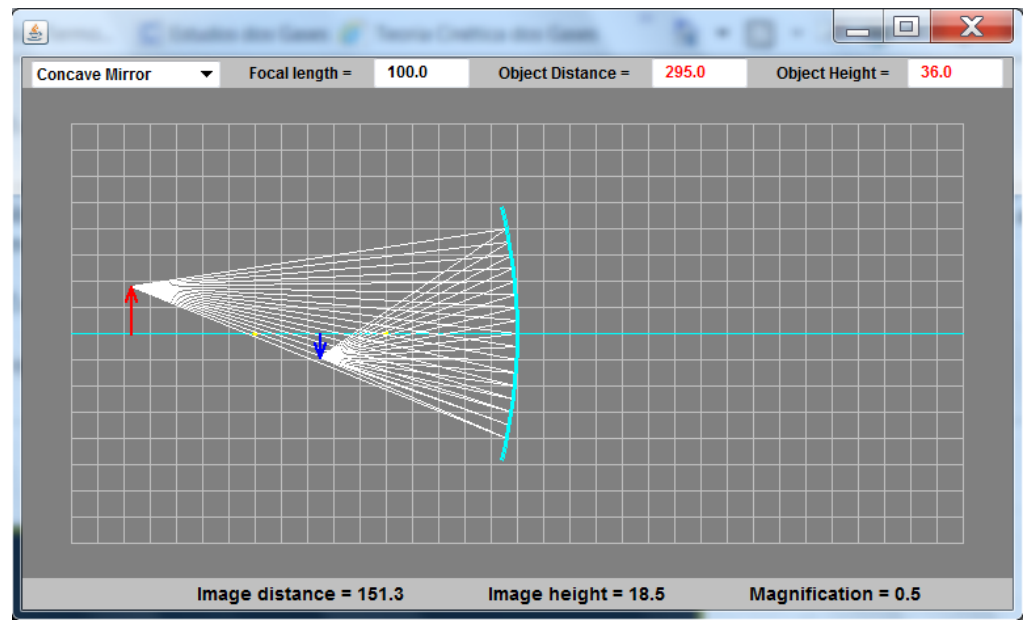

\section{COMENTÁRIOS:}

As vídeos aulas e os applets de ensino são muito bons e ilustram o conteúdo desta aula.

RESUMO: 
Apresentamos aqui uma aula 'padrão' sobre o tópico da óptica geométrica "lentes e espelhos". Complementamos com uma animação gráfica feita com o software Modellus, com experimentos de baixo custo, applets de ensino e vídeo aula.

\section{CONCLUSÃO:}

O estudante deve ter concordado que uma aula sobre espelhos esféricos e lentes é muito interessante e leva os estudantes do segundo grau a gostarem um pouco mais da física. Que esse tópico da física possui muitos recursos didáticos e deve ser abordado no ensino médio. Que sempre podemos ilustrar a aula com experiências de demonstração.

Referências

1 - Wikipedia.

1 - http://fisicacomabud.com.br/01.04.11/Espelhos\%20esf\%C3\%A9ricos.pdf

2 - http://caldeiradigital.files.wordpress.com/2010/05/espelhos-esfericos.pdf

$3-$

http://www.cdcc.usp.br/exper/medio/fisica/kit5_otica_lente_espelho/exp1_lente_ espelho.pdf

4 - http://objetoseducacionais2.mec.gov.br/bitstream/handle/mec/9008/ projecaodeimagensemespelhosesfericos. pdf?sequence $=1$

5 - http://www.singularsaobernardo.com.br/portal/emn/ar/professores/suzana/ terceiro_ano/espelhos_esfericos/espelhos_esfericos.pdf

6 -

http://fisicacomabud.com.br/18.05.2011/LENTES\%20ESFERICAS\%20docx.pdf

7 - http://www.fisica.ufsc.br/ lab2/pdfs/exp09.pdf 


\section{Cap.05 - ONDAS E SUAS APLICAÇÕES}

Meta: Fazer que o estudante comece a pensar no ensino de ciências como algo "orgânico" que está em profunda transformação. Fazer com que os alunos percebam, através de uma atividade lúdica, que podemos ensinar física através de experimentos muito simples. Fazer com que os estudantes percebam que podemos usar os softwares de ensino de matemática no ensino de física. Fazer com que o aluno percebam as aplicações da física no cotidiano.

Objetivos: Ao final da aula, os alunos devem estar cientes das novas possibilidades e dos desafios que envolvem o ensino de ciências em geral. Que para se ensinar física não precisamos ficar presos ao livro didático. Os estudantes devem ficar cientes que podemos usar os softwares de matemática para facilitar o ensino de física. Que ensinar física não é ensinar a resolver problemas e que a física é uma mera aplicação da matemática.

Pré-requisitos: Os alunos deveram ter cursado psicologia da educação física A, $\mathrm{B}$ e C.

\section{Introdução:}

Apesar de haver vários applets de ensino de física sobre o tema "Ondas", vamos aproveitar o fato das propriedades de superposição, e da representação da função de onda pela função $f(x, t)=A \cdot \operatorname{sen}(k \cdot x-w . t)$ para introduzir uma poderosa ferramenta (software) de ensino denominado de "winplot". Utilizamos esse software matemático para fazer várias de nossas ilustrações, mas achamos que ele pode ser muito mais útil do que simplesmente para realizar ilustrações. Assim, se você não conhece essa ferramenta antes de começar a estudar esta aula você deve ler o manual desse software que fizemos para vocês. Este se encontra no final desta aula. Lá você encontrará o link para baixar este programa.

Define-se uma onda como qualquer perturbação que atravesse um determinado meio sem transportar partículas desse meio. Por exemplo, as ondas do mar andam sobre a sua superfície sem entanto carregar as águas deste junto com ela. $\mathrm{Na}$ corda abaixo o pulso de onda viaja sobre esta e, no entanto a corda continua presa 
entre a parede e a mão da pessoa que a segura. $O$ que vemos se deslocar sobre o meio é o perfil da onda, ou seja, a perturbação sobre este.

Do ponto de vista do meio em que as ondas se propagam, temos as ondas mecânicas que exigem um meio material (um metal, por exemplo) para se propagarem, e as ondas eletromagnéticas que não requerem a existência de um tal meio para se propagarem. Ou seja, elas se propagam no vácuo.

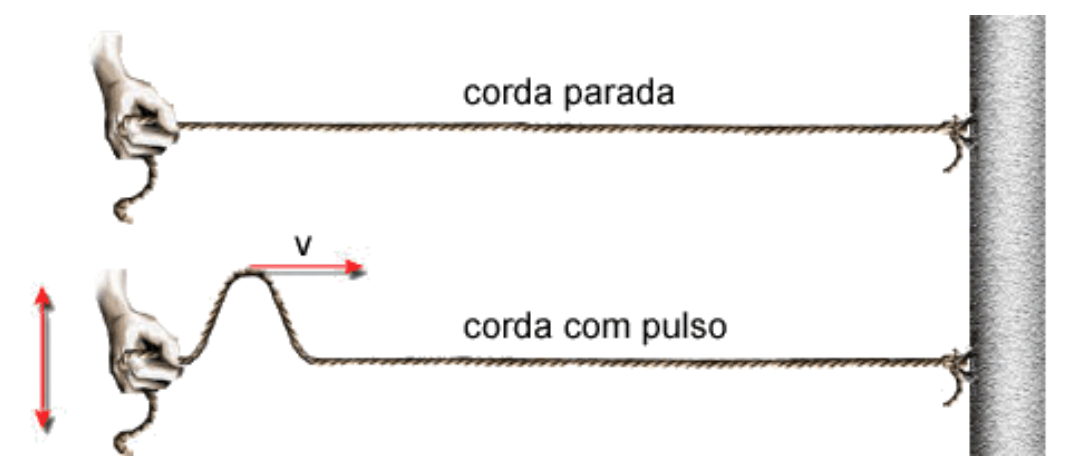

Fig. 3.1 - llustração de um pulso propagando-se numa corda.

Outro modo de se classificar as ondas é quanto à direção do deslocamento das partículas do meio em relação à direção de propagação da onda. Se as partículas se deslocam na direção perpendicular à direção de propagação da onda, ver figura acima, temos uma onda transversal. Se o deslocamento for na mesma direção da onda temos uma onda longitudinal.

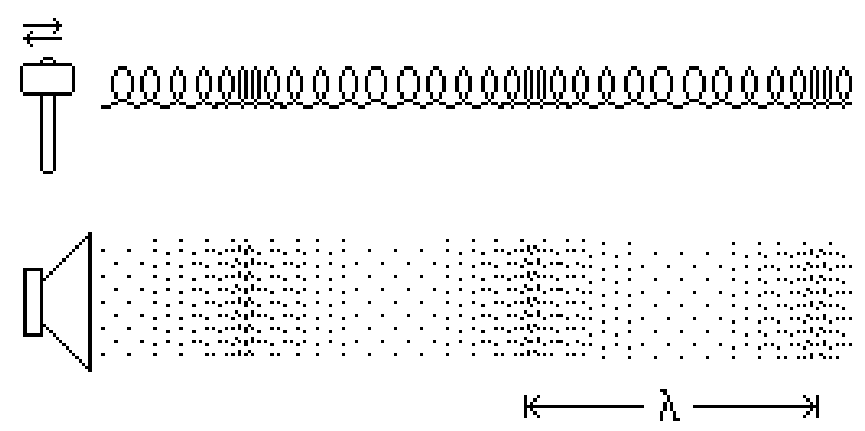

Fig.3.2 - Ondas Longitudinais.

Um pulso, ou uma perturbação, que se propague na direção do eixo x, e no sentido positivo do eixo (coordenadas crescentes com o tempo), pode ser representado por uma função $f$ de $x$ e $t$ (o perfil da onda), que depende da coordenada $x$ e do tempo, da seguinte forma: 


$$
f(x, t)=f(x-v t)
$$

Onde $v$ é uma constante que corresponde à velocidade de propagação da onda. A dependência funcional de f com o tempo t é a de uma equação horária do movimento $(\mathrm{S}=\mathrm{So}+\mathrm{V}$. t $)$, que descreve a posição de um ponto do pulso, deslocamento vertical, no decorrer do tempo.

(http://www.if.ufrj.br/teaching/fis2/ondas1/ondulatorio.html)

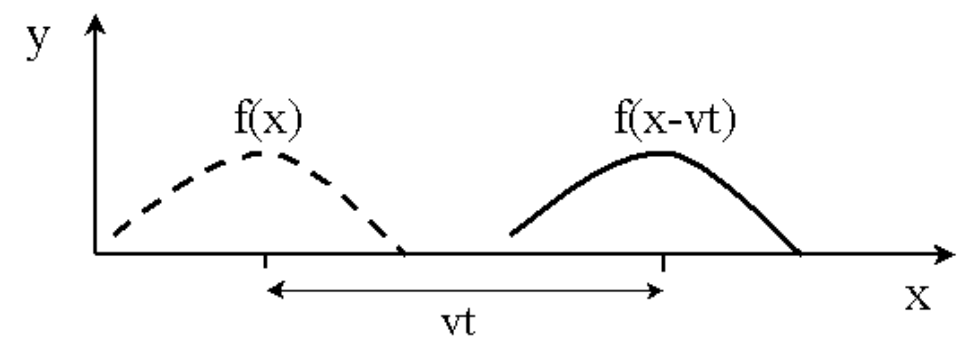

Fig.3.3 - FUNÇÃO PERFIL

A velocidade de propagação depende das propriedades do meio no qual este se propaga. Por exemplo, consideremos uma corda com densidade linear de massa igual a $\mu$ e sujeita a uma tensão T. Neste caso uma onda sobre a corda tem uma velocidade que é dada por:

$$
v=\sqrt{\frac{T}{\mu}}
$$

Ou seja, como mais tracionada a corda mais rápido a onda viaja e quanto mais pesada a corda (inércia) menor a sua velocidade.

Um pulso, ou uma perturbação, que se propague na direção do eixo $x$, mas no sentido negativo do eixo (coordenadas decrescentes), com um perfil descrito pela função $g$, é descrito pela função de $x$ e $t$

$$
g(x, t)=g(x+v t)
$$


As funções f e g são aquelas adequadas para descrever o perfil da onda considerada. Um exemplo simples de uma onda é aquela que podemos produzir acionando a extremidade de uma corda presa por uma das extremidades a uma parede, figura acima.

Questões:

1 - Algum professor seu já levou uma corda para sala de aula? Você levaria uma corda para sala de aula?

2 - Você levaria uma mola helicoidal para sala de aula.

3-Abra as simulações "ondas longitudinais" e "ondas transversais" do modellus e discuta se elas ajudam no entendimento do assunto.

ONL 4 - Abra o software winplot e abra o arquivo "função perfil", e discuta se ele esclarece o significado da representação do perfil de onda pela função

1.3

as car

senoidal. Elas são produzidas, por exemplo, esticando-se uma corda, e depois puxando-a para cima e para baixo de uma mesma distância e com mesma velocidade até que se produza uma figura estacionária, como a abaixo. Uma onda harmônica não precisa ser estacionária, ela pode propagar indefinidamente.

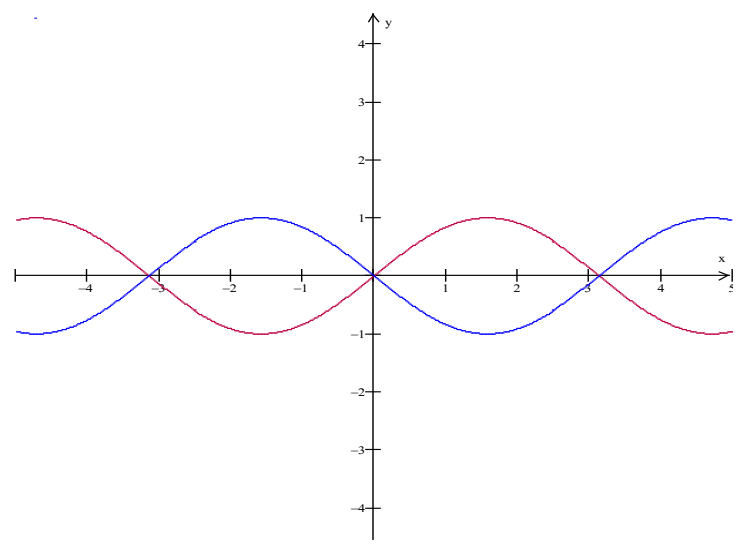

Fig.3.4 - Ondas Harmônicas

Elas são caracterizadas por uma função que descreve o perfil da onda na forma seno ou cosseno. Ou seja, para uma onda harmônica escrevemos:

$$
f(x-v t)=A \cos (k(x-v t)) \quad[A \sin (k(x-v t))]
$$


Onde A na equação acima é a amplitude da onda, pois é o máximo da função f, e k é uma constante que caracteriza a onda harmônica e que é conhecida pelo estranho nome de vetor de onda. Logo, o fator A está relacionado com a intensidade do impulso que fornecemos à corda e k com o seu deslocamento na horizontal. Uma outra forma de escrever a expressão acima, e que é bastante comum, é:

$$
f(x-v t)=A \cos (k x-\omega t) \quad[A \sin (k x-\omega t)]
$$

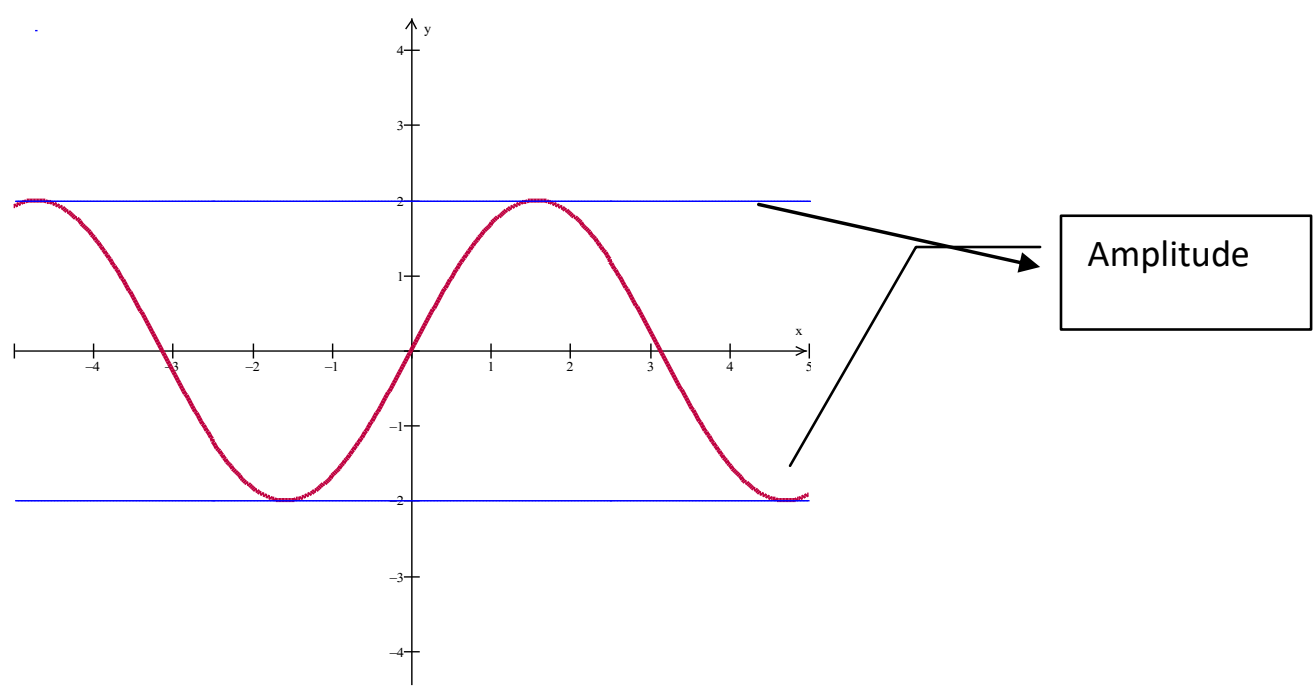

Fig.3.5 - Amplitude da Onda

A expressão acima parece introduzir uma nova constante para descrever a onda (a constante $\omega$ ). Esse, no entanto, não é o caso uma vez que comparando $\omega$ e $v$ concluímos que essa constante é dada por:

$$
k v=\omega
$$

Veremos mais tarde que $\omega$ é a freqüência angular da onda. Numa onda harmônica é usual representar o seu perfil através da função exponencial com argumento puramente imaginário. Ou seja, representamos a onda pela função

$$
f(x-v t)=A e^{i(k x-\omega t)}
$$

A função exponencial ( $e^{x}$ ) é apenas uma forma econômica de representar tanto a função seno quanto a função cosseno. Isso porque a seguinte identidade é válida para números complexos:

$$
e^{i \theta}=\cos \theta+i \sin \theta
$$

Tomando-se a parte real ou a parte imaginária de (1.7) teremos as ondas harmônicas da expressão (1.4). 
O que é notável, observando-se (1.5) é que uma onda harmônica tem um perfil que se repete no espaço e no tempo. Isso decorre do fato de que, depois de um intervalo de tempo T conhecido como o período da onda harmônica, dado por

$$
\omega T=2 \pi
$$

a onda se torna indistinguível da onda inicial. Portanto, de (1.6) segue que o período é dado, em função de k e $v$ por:

$$
T=\frac{2 \pi}{\omega}=\frac{2 \pi}{k v}
$$

Define-se a freqüência $(v)$ da onda como o inverso do período:

$$
v \equiv \frac{1}{T}=\frac{k v}{2 \pi}
$$

A unidade de freqüência mais utilizada para ondas em geral, é o Hertz, definido como o inverso do segundo.

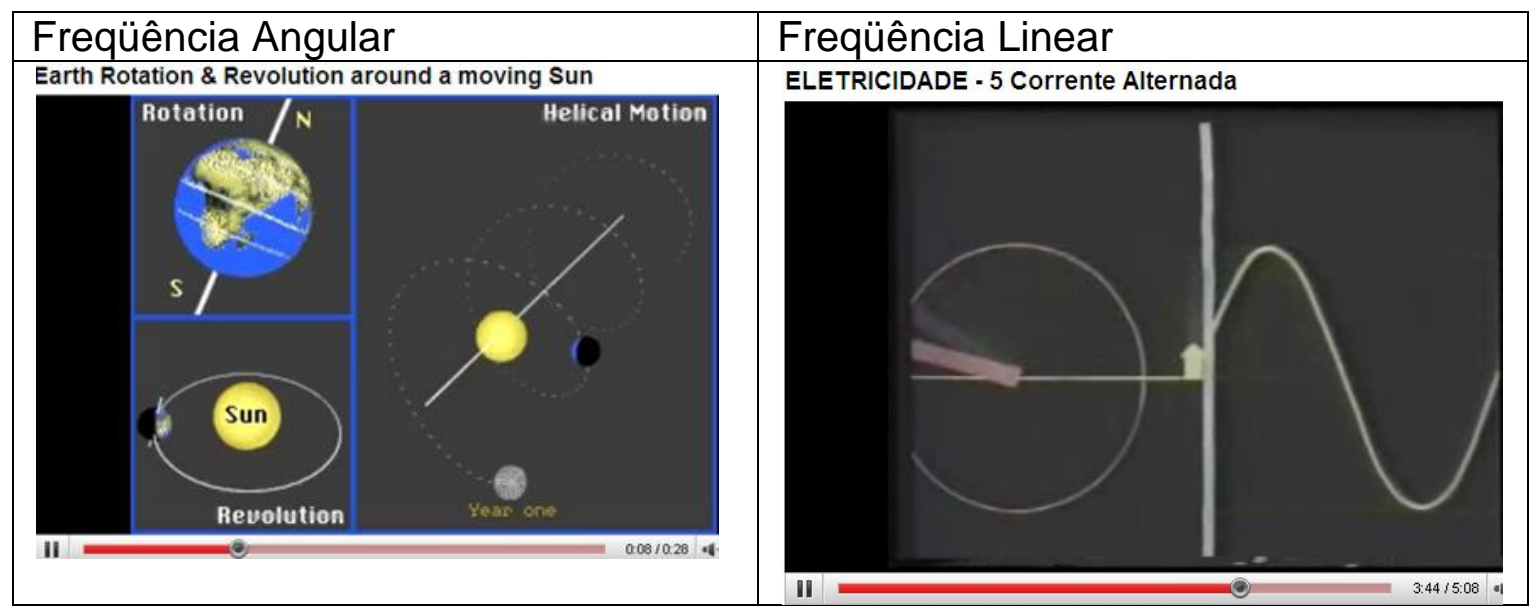

Fig.3.6 - Freqüência Angular x Linear

Depois de percorrido um intervalo de distancia, no espaço, denominado de um comprimento de onda ( aqui representado pela letra $\lambda$ ) a onda se torna indistinguível daquela de quando se iniciou o percurso. Isso ocorre para valores de $\lambda$ tais que:

$$
k \lambda=2 \pi
$$

Assim, o comprimento da onda nada mais é do que a distancia entre, por exemplo, dois máximos da onda (vide figura abaixo). 
De (1.11) e (1.12), nota-se que existe uma relação bem simples entre a velocidade da onda, a freqüência e o comprimento de onda:

$$
v=\lambda v
$$

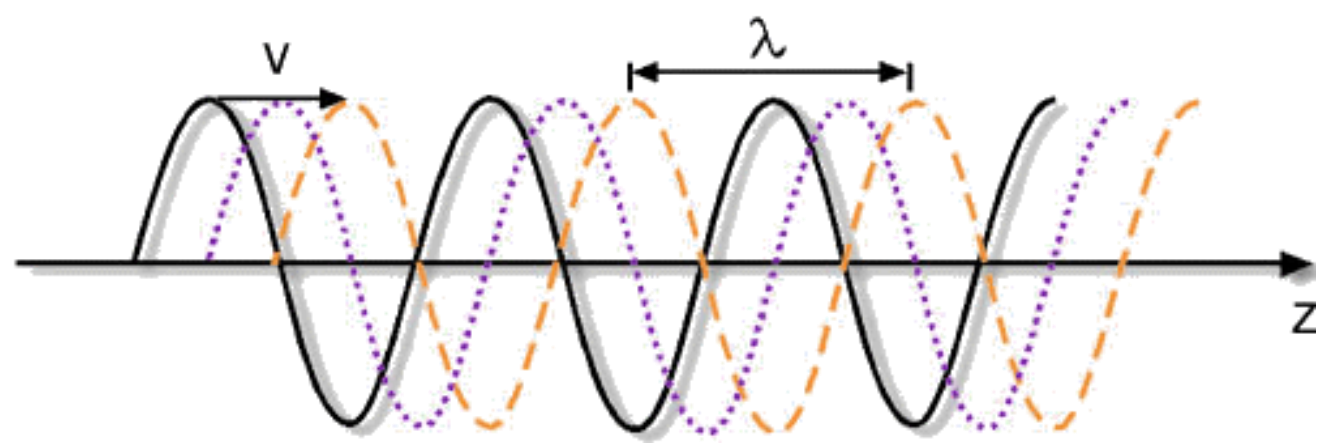

Fig.3.7 - Propagação de Onda

Questões:

5 - Abra o software winplot e faça o gráfico da função $y=a$ sen(a.x $x+b)$.

Abra a janela "anim" e click em "Parametros A-W". Vai abrir a janela "valor inicial de $A$ " (veja abaixo). Varie o valor de $A, B$ e $C$ até 1 . Agora fique variando o valor de B, o que ocorreu? Fique variando o valor de $C$, o que ocorreu? Para que valores de $\Delta C$ (ou $\mathrm{C}$ ) o pico (crista da onda) passa pela origem.

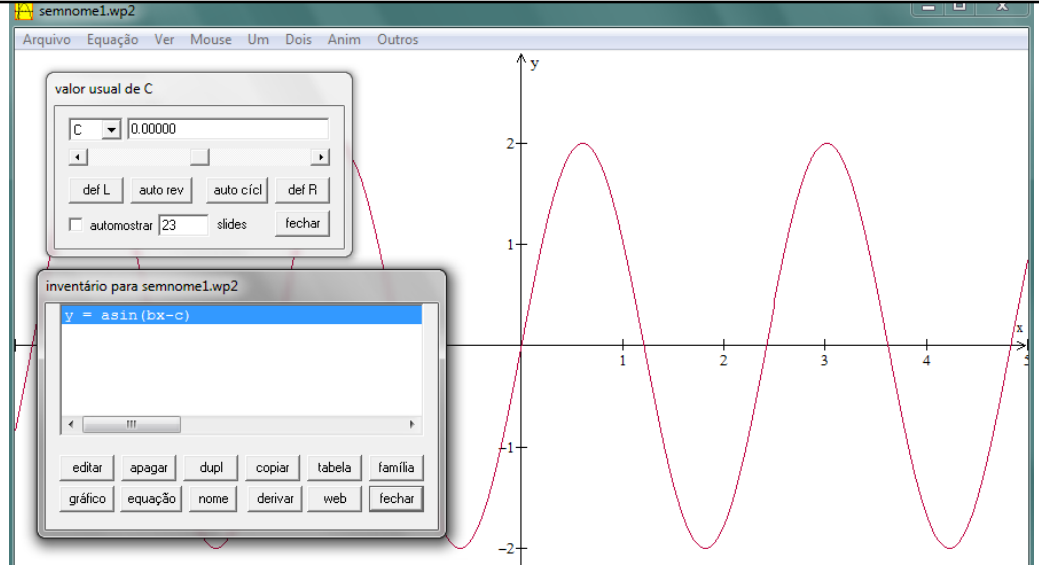

\section{Princípio de Superposição}

Outra propriedade muito importante das ondas é que, ao contrário das partículas materiais, estas podem se cruzar, se chocar, sem que se altere as suas propriedades. Ou seja, duas ondas viajando sobre uma corda, ao se cruzarem vão produzir momentaneamente uma terceira onda, e quando estas deixarem de ocupar a mesma região da corda voltarão a ser as mesmas ondas. Ver fig.3.9. 


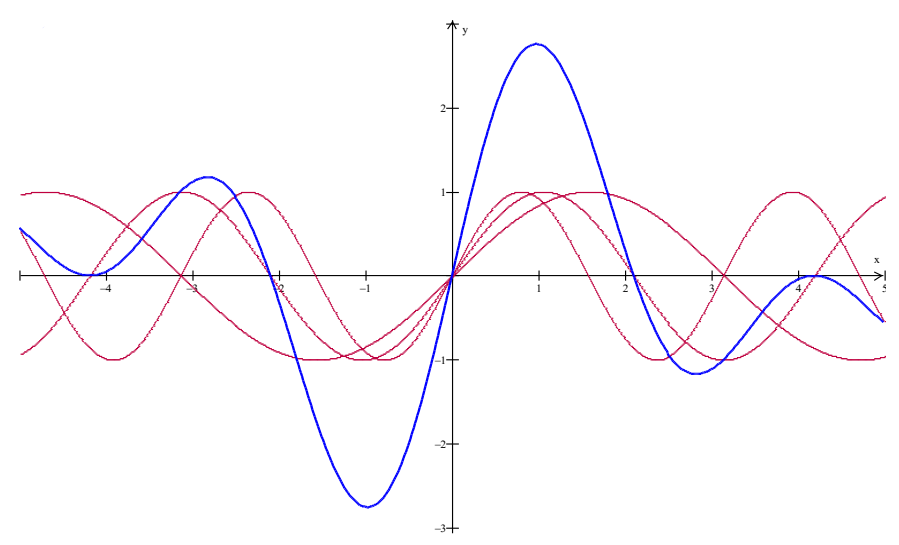

Fig.3.8 - A onda azul é a soma das ondas vermelhas.

Dizendo de outro modo, duas ou mais ondas podem se cruzar na mesma região do espaço, movendo-se independentemente uma da outra. $O$ deslocamento de qualquer partícula do meio em um dado instante é a soma dos deslocamentos que seriam produzidos pelas ondas individualmente.

Esse constitui o princípio de superposição e vale para ondas em meios elásticos se as forças de restauração são proporcionais às deformações.

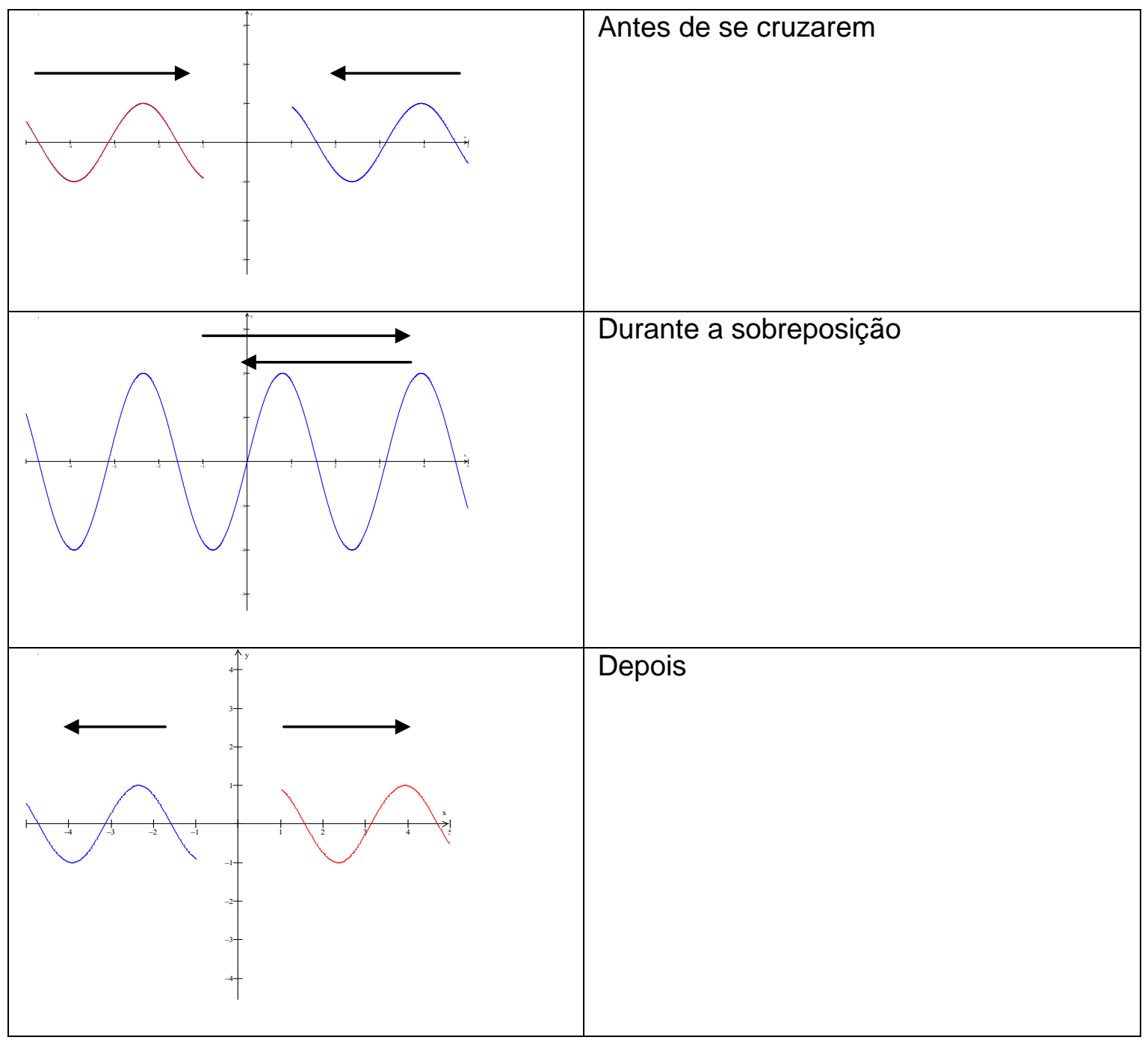


Se tivermos $n\left(=2,3,4\right.$..) ondas com amplitudes $A_{i}$ e defasadas de $d_{i}$ entre si se sobrepondo, teremos que a onda resultante será a soma algébrica de todas elas. Usando a notação abreviada para indicar a função de onda $u_{n}$ resultante temos:

$$
\mathrm{U}_{\mathrm{n}}=\sum_{i=1}^{n} u_{i}=\sum_{i=1}^{n} A_{i} \cos \left(x-w_{i} \cdot t+d_{i}\right)
$$

Inversamente, qualquer movimento ondulatório pode ser analisado como combinação de movimentos ondulatórios simples (harmônicos, por exemplo). Aplicação disto são os filtros de ondas e os seletores de freqüência.

Os efeitos físicos associados à superposição de duas ou mais ondas são chamados de interferência.

Como exemplo clássico considere duas ondas de mesma direção e sentido, mas uma atrasada em relação à outra de uma fase $d$. Se elas possuem freqüências, amplitudes e velocidades iguais têm-se:

$$
\begin{aligned}
& u_{1}(x, t)=A \operatorname{sen}(k x-w t-d) \\
& u_{2}(x, t)=A \operatorname{sen}(k x-w t)
\end{aligned}
$$

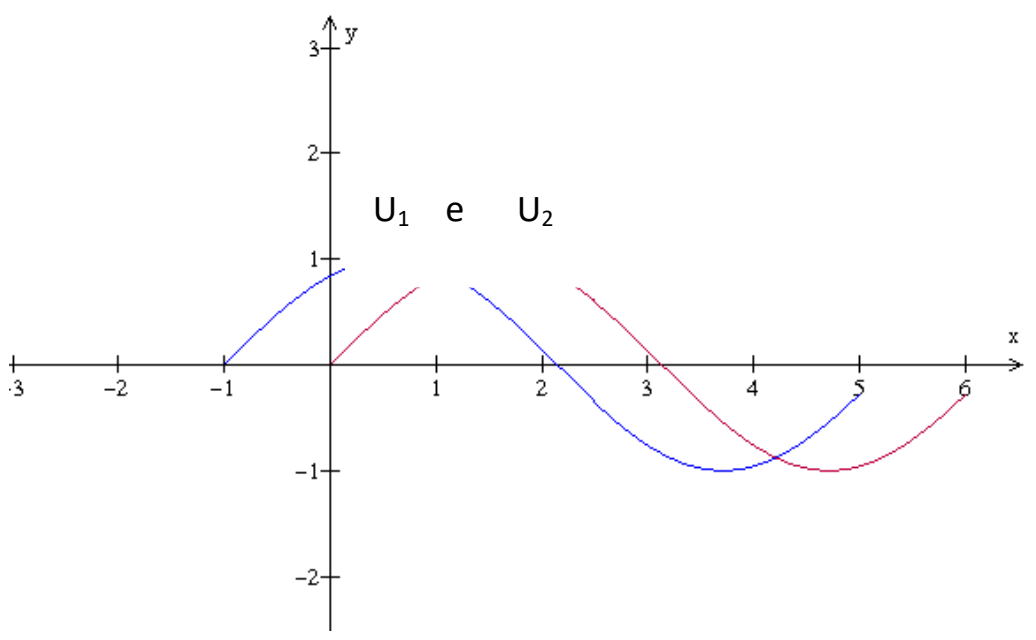

Numa dada posição ( $x$ fixo), $u_{1}$ e $u_{2}$ representam dois movimentos harmônicos simples defasados por um intervalo de tempo $d / \mathrm{w}$. A onda resultante da superposição de $u_{1}$ e $u_{2}$ é dada por:

$$
u_{1}(x, t)+u_{2}(x, t)=A[\operatorname{sen}(k x-w t-d)+\operatorname{sen}(k x-w t)]
$$

Da relação trigonométrica:

$$
\operatorname{sen} A+\operatorname{sen} B=2 \operatorname{sen}[(A+B) / 2] \cos [(A-B) / 2]
$$

a expressão acima fica:

$$
u_{1}(x, t)+u_{2}(x, t)=[2 A \cos (d / 2)] \operatorname{sen}(k x-w t-d / 2)
$$


Portanto, a onda resultante é uma onda com mesma freqüência angular w que as ondas descritas por $u_{1}$ e $u_{2}$ e com fase $d / 2$. Mas a sua amplitude é dada pelo fator $2 \mathrm{~A}$ $\cos (\mathrm{d} / 2)$.

Para $d=2 \pi n$ (n inteiro), ou seja, para $y 1=y 2$, a amplitude da onda resultante vale 2A e diz-se que existe interferência construtiva entre y1 e y2 (condição de máximo). É muito comum dizer-se que as ondas estão em fase quando esta difere de $d=2 \pi n$ (n inteiro).

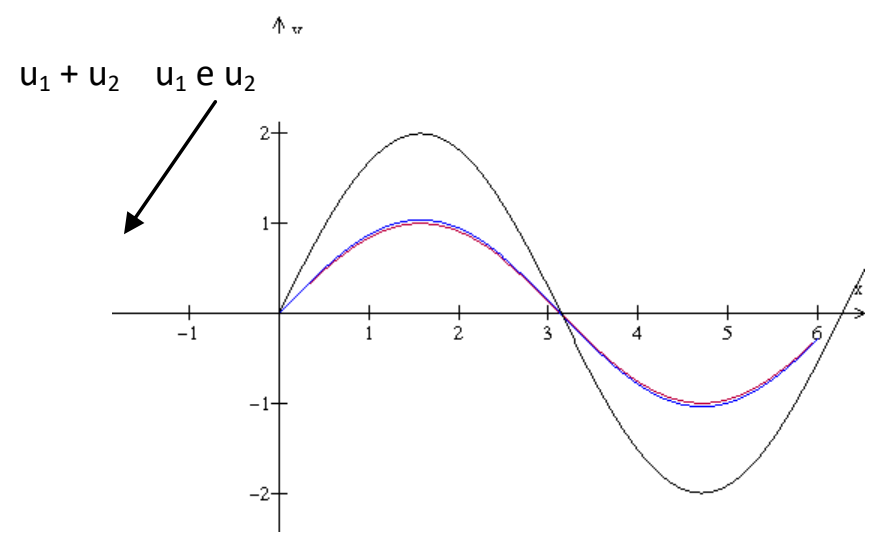

Para $d=(n+1 / 2) \pi$, ou seja, para $u_{1}=-u_{2}$, a amplitude da onda resultante vale zero e diz-se que existe interferência destrutiva entre $u_{1}$ e $u_{2}$ (condição de mínimo). Diz-se que as ondas estão fora de fase quando esta difere de $d=\pi(n+1 / 2)$ ( $n$ inteiro).

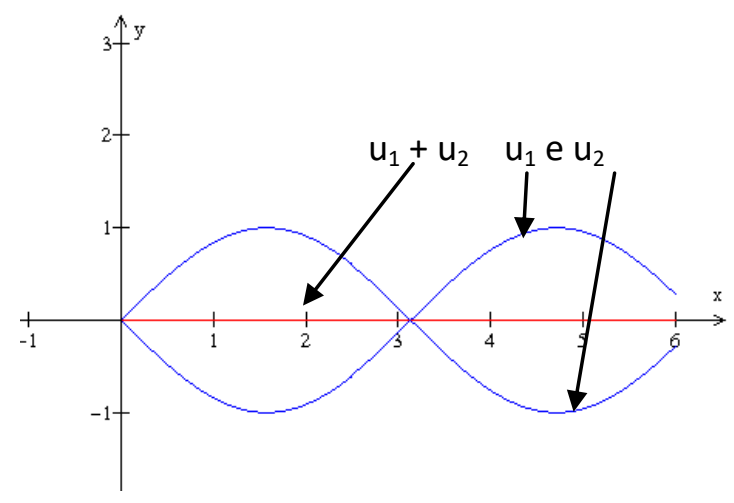

De modo geral, pode haver interferência entre ondas com quaisquer freqüências e/ou amplitudes e com qualquer diferença de fase. Nesse caso não há uma expressão tão simples como a 1.16b e a onda resultante em geral não é harmônica. Veja o caso simples da função $y=$ $\operatorname{sen}(x+1)+1.5 \operatorname{sen}(2 x)+1.2 \operatorname{sen}(1.5 x)$ 


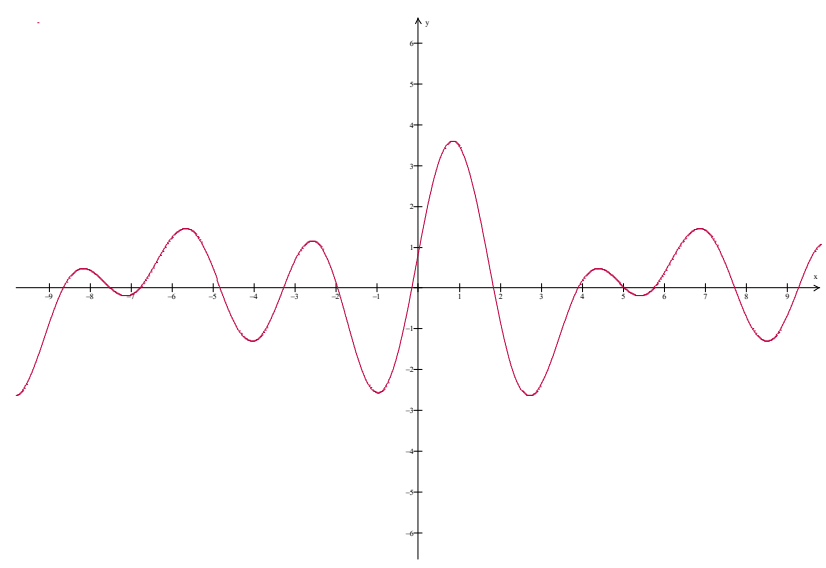

\section{ONDAS PLANAS}

O análogo, em três dimensões, de uma onda harmônica que se propaga ao longo do eixo x ( vide equação (1.5)), è:

$$
f(\vec{r}, t)=A e^{i(\vec{k} \cdot \vec{r}-\omega t)}
$$

Onde $\vec{k}$ é o vetor de onda, e A é a amplitude da onda.

A expressão (1.21) descreve uma onda que se propaga na direção dada pelo vetor $\vec{k}$. Uma onda que se propague no sentido oposto será escrita como:

$$
f(\vec{r}, t)=A e^{i(\vec{k} \cdot \vec{r}+\omega t)}
$$

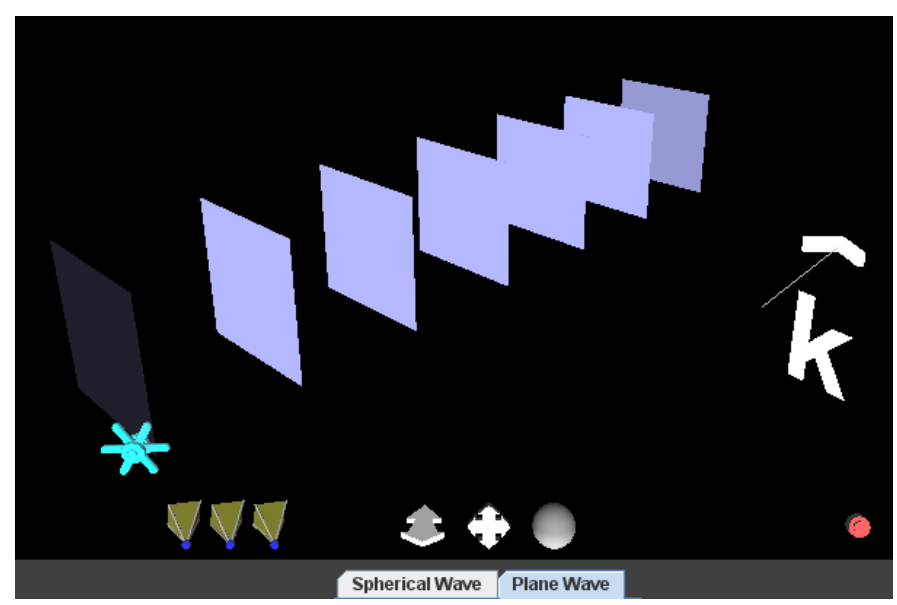

Fig. 3.10 - Trem de ondas planas (optics Project)

Tendo em vista que o lugar geométrico dos pontos para os quais

$$
\vec{k} \cdot \vec{r}=\text { constante }
$$


é um plano, denomina-se uma onda da forma

, como uma onda plana.

A característica mais notável de uma onda plana é que sua fase é a mesma para cada superfície plana, dada pela expressão (1.22). Vide figura abaixo.

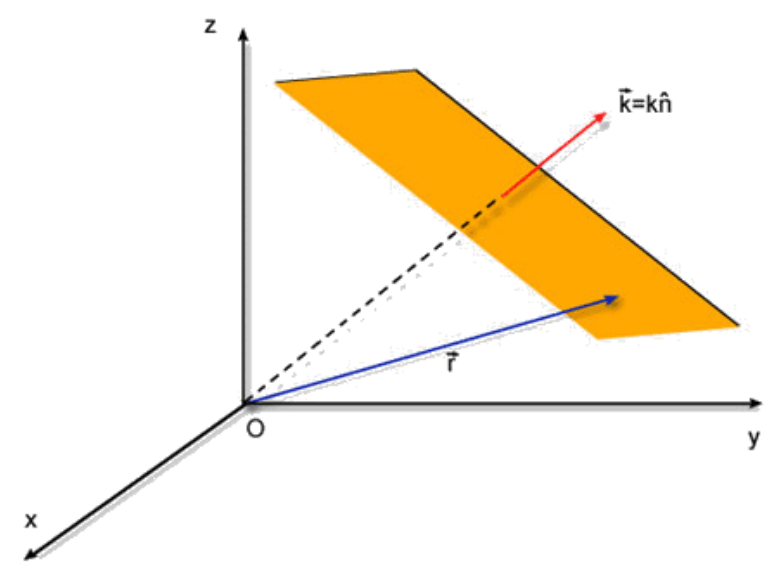

Para uma onda plana vale, substituindo-se a solução (1.21a) em (1.20), a seguinte relação:

$$
\vec{k}^{2}=\frac{\omega^{2}}{v^{2}}
$$

que é uma relação análoga a (1.18b), mas para 3 dimensões.

\section{ONDAS ELETROMAGNÉTICAS}

James Clerk Maxwell deu a mais significativa contribuição à ciência do eletromagnetismo. Em 1864 Maxwell sugeriu que se pode encontrar a descrição de todos os fenômenos eletromagnéticos a partir das soluções de um conjunto de 4 equações a derivadas parciais de primeira ordem no tempo e no espaço. Essas equações são hoje conhecidas como as Equações de Maxwell. Elas são equações para os campos elétricos e magnéticos uma vez conhecidas as distribuições das cargas elétricas e das correntes.

Animação $\rightarrow$ http://www.walter-fendt.de/ph14br/emwave br.htm

http://www.phy.ntnu.edu.tw/oldjava/emWave/emWave-port.html

Maxwell foi um pouco mais além da fenomenologia do eletromagnetismo conhecido aquela época e acrescentou um novo termo a uma das equações, termo esse conhecido como a corrente de deslocamento tornando a lei de Ampère mais geral. Esse novo termo, a corrente de deslocamento é tal que prevê o surgimento de um campo magnético pelo mero fato do campo elétrico variar com o tempo. Ou seja, um 
campo elétrico variável tem o mesmo papel que uma corrente elétrica. Estas equações, conhecidas atualmente como equações de Maxwell, estão discutidas em detalhes nos textos básicos de eletromagnetismo (ver referência 4.1). Elas são:

$$
\begin{array}{r}
\vec{\nabla} \cdot \overrightarrow{\mathrm{D}}=\rho \\
\vec{\nabla} \cdot \overrightarrow{\mathrm{B}}=0 \\
\vec{\nabla} \times \overrightarrow{\mathrm{E}}=-\partial \overrightarrow{\mathrm{B}} / \partial \mathrm{t} \\
\vec{\nabla} \times \overrightarrow{\mathrm{H}}=\overrightarrow{\mathrm{J}}+\frac{\partial \overrightarrow{\mathrm{D}}}{\partial \mathrm{t}}
\end{array}
$$

onde o sistema internacional (MKS) foi adotado. O último termo da eq. (1.24d) representa a corrente de deslocamento introduzida por Maxwell.

Cada uma destas equações corresponde a uma lei física descoberta empiricamente. De acordo com a ordem usada acima temos:

1. lei de Gauss, diz que o fluxo de campo elétrico através de uma superfície fechada é igual a quantidade de carga contida dentro dela.

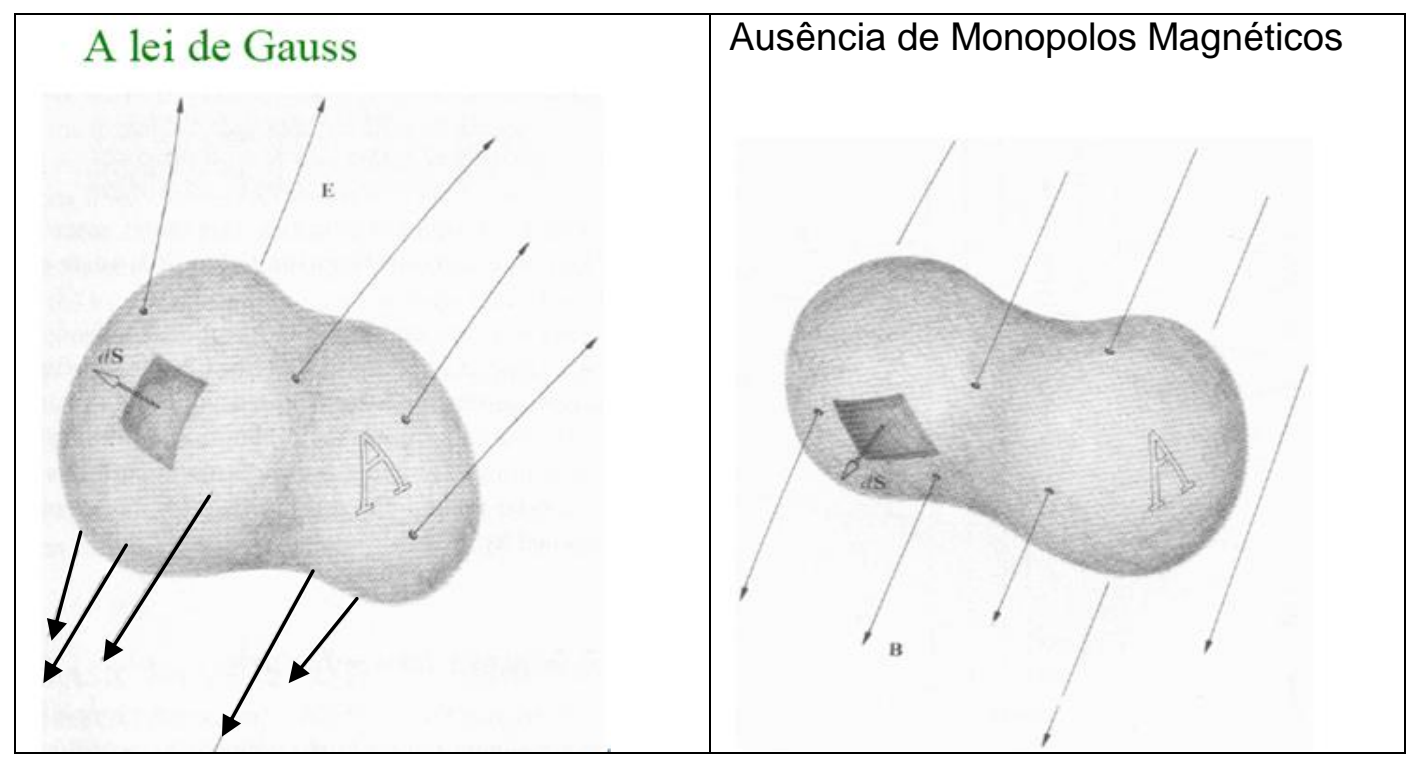

2. A equação $1.24 \mathrm{~b}$ diz que não existe monopolo magnético.

3. A equação $1.24 c$ é a lei da indução de Faraday que afirma que a variação temporal do campo magnético $\overrightarrow{\mathrm{B}}$ gera uma circulação do campo elétrico $\vec{E}$. 


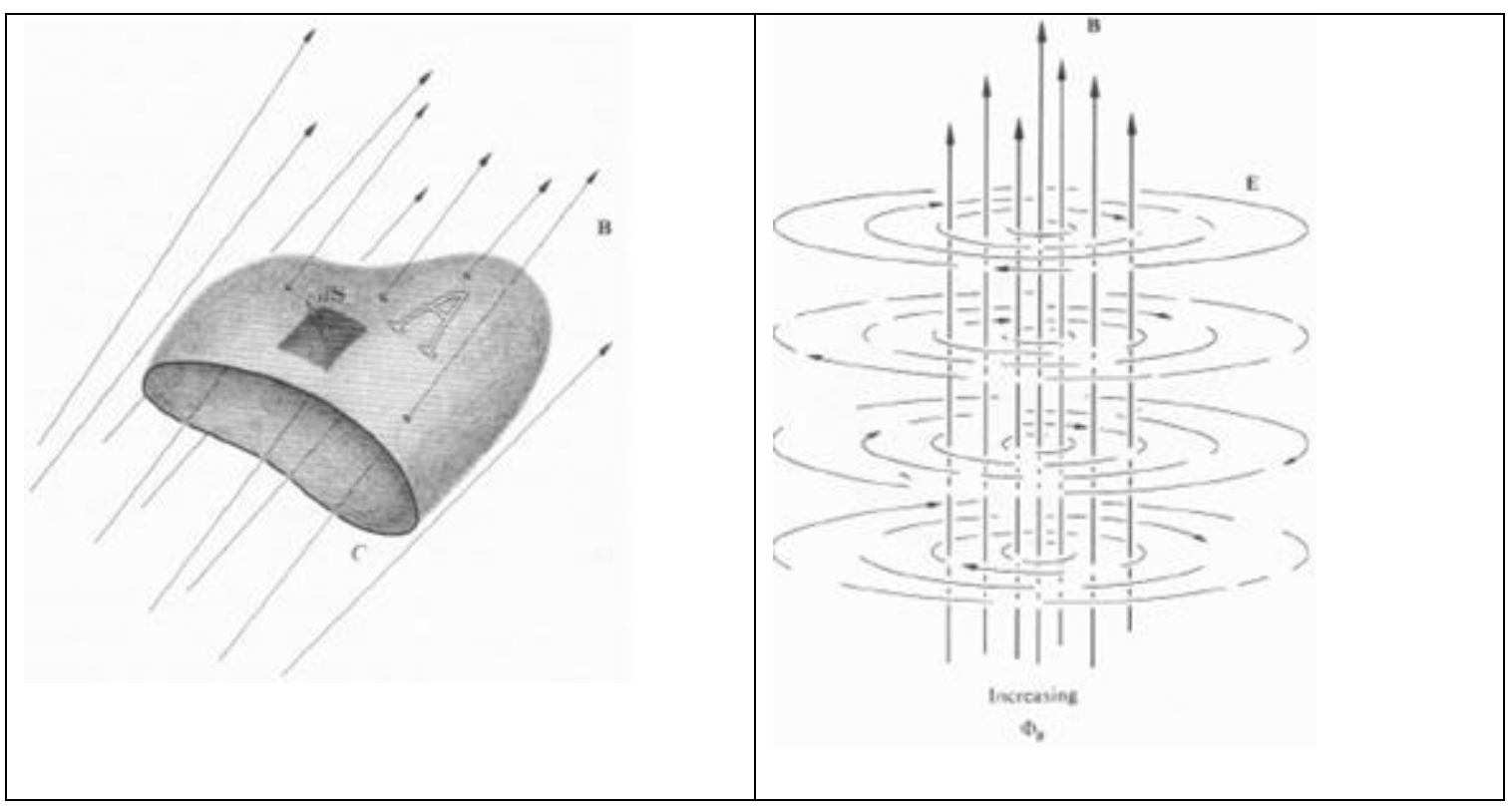

4. A equação $1.24 d$ é a lei de Ampère-Maxwell diz que a variação temporal do campo elétrico $\vec{E}$ gera uma circulação do campo magnético $\overrightarrow{\mathrm{B}}$.

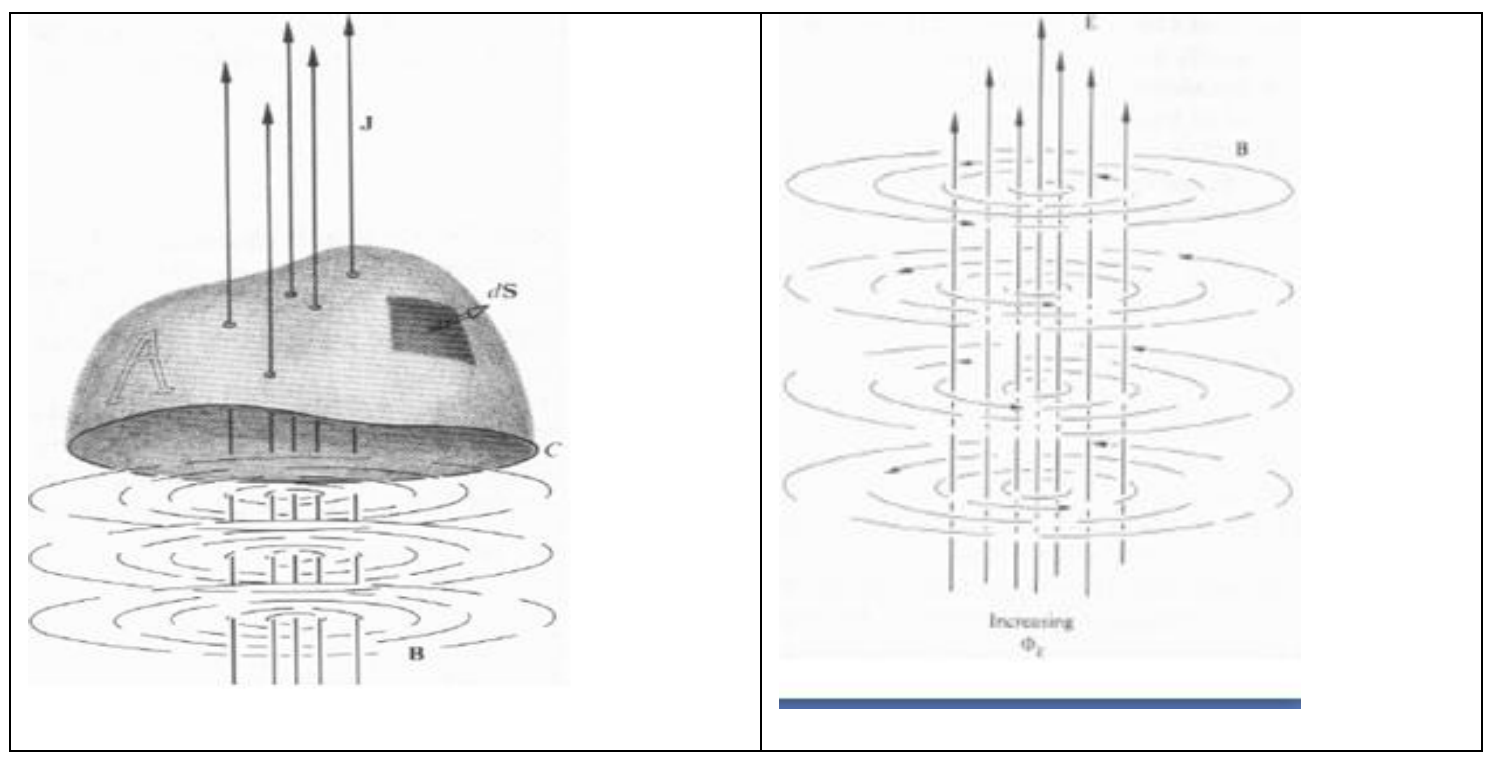

O significado das grandezas que aparecem neste conjunto de equações é o usual: $\vec{E}$ é o campo elétrico, $\vec{B}$ é a indução magnética, $\rho$ é a densidade de portadores livres, $\vec{J}$ é a densidade de corrente devida aos portadores livres, $\vec{D}=\varepsilon_{0} \vec{E}+\vec{P}$ é 0 deslocamento elétrico e $\overrightarrow{\mathrm{H}}=\overrightarrow{\mathrm{B}} / \mu_{0}-\overrightarrow{\mathrm{M}}$ é o campo magnético. Introduzimos assim, a polarização elétrica $\mathrm{P}$ e a magnetização $\mathrm{M}$, que correspondem à resposta do meio devido à presença dos campos elétrico e magnético, respectivamente. As constantes $\varepsilon_{0}=8.854 \times 10^{-12} \mathrm{~F} / \mathrm{m}$ e $\mu_{0}=4 \times 10^{-7} \mathrm{H} / \mathrm{m}$, determinadas empiricamente, são 
denominadas respectivamente de permissividade e permeabilidade do vácuo.

Analisando com um pouco de mais detalhes temos que:

\section{$\underline{\text { Simetria das Equações }}$}

Olhando as quatro equações duas a duas - a $1^{\underline{a}} \operatorname{com}$ a $3^{\underline{a}}$ e a $2^{\underline{a}} \operatorname{com}$ a $4^{\underline{a}}$ temos que elas diferem pelo fato de que nas primeiras as cargas estão em repouso e na segunda estas estão em movimento. Logo, se tomarmos uma carga em movimento e observá-la em um RI que se move com esta (mesma velocidade) temos que o campo magnético terá que se tornar em elétrico. Ou seja, estes devem ser duas faces de uma mesma grandeza, denominada de campo eletromagnético.

Como dissemos acima, as equações de Maxwell podem ser combinadas de forma a gerar uma nova equação que descreve a onda eletromagnética.

Equação de ondas:

$$
\nabla^{2} \overrightarrow{\mathrm{E}}=\mu \frac{\partial^{2}}{\partial \mathrm{t}^{2}} \overrightarrow{\mathrm{D}}=\mu \varepsilon \frac{\partial^{2} \overrightarrow{\mathrm{E}}}{\partial^{2}}
$$

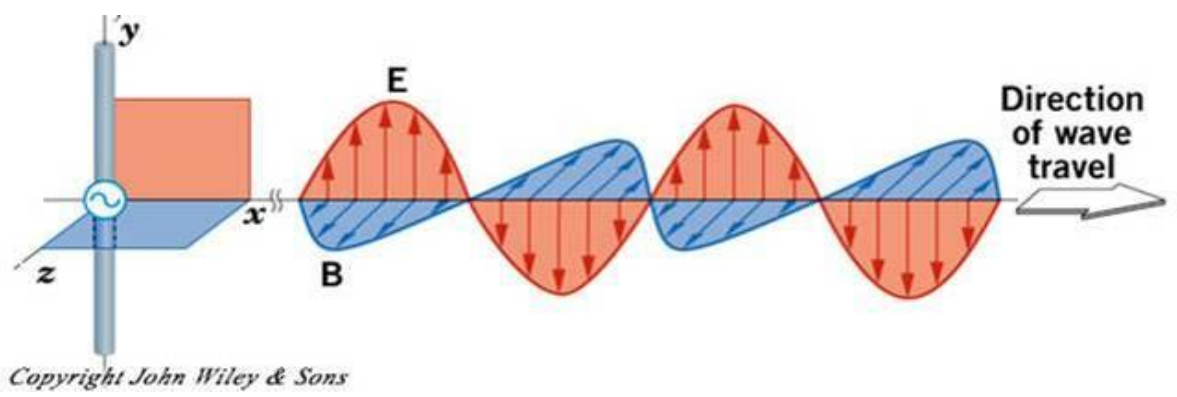

Este tipo de equação já era conhecido na época, de forma que Maxwell pode concluir que se tratava de uma onda com velocidade de propagação $v=1 / \sqrt{\mu \varepsilon}$.

Q1. Abra o applet "antena" e discuta se ele ajuda no entendimento do processo de geração de uma onda EM. 

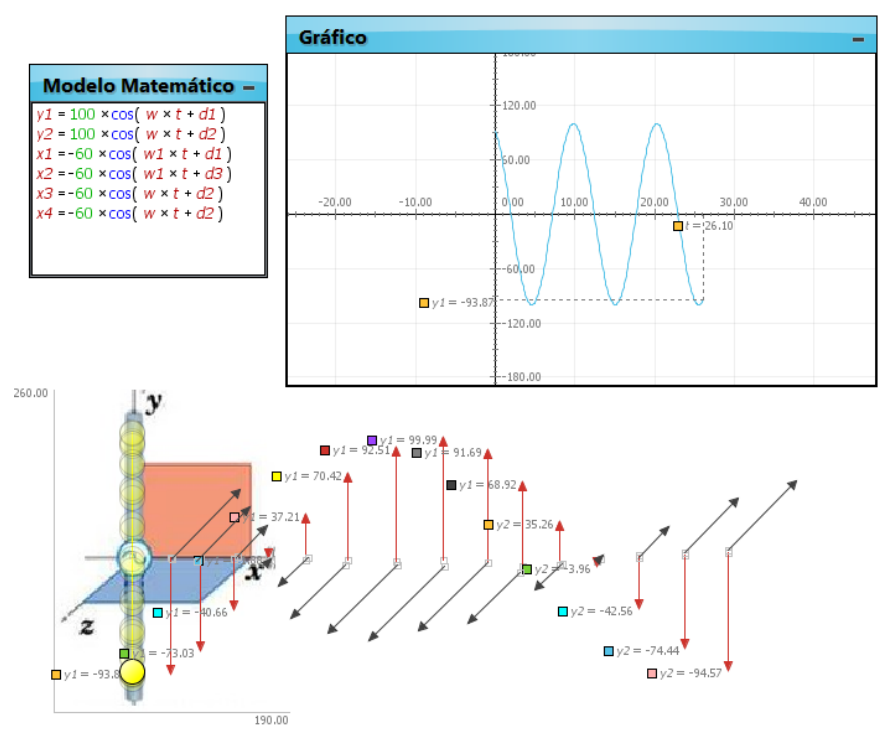

\section{Num ponto $\mathrm{P}$ distante (onda plana):}
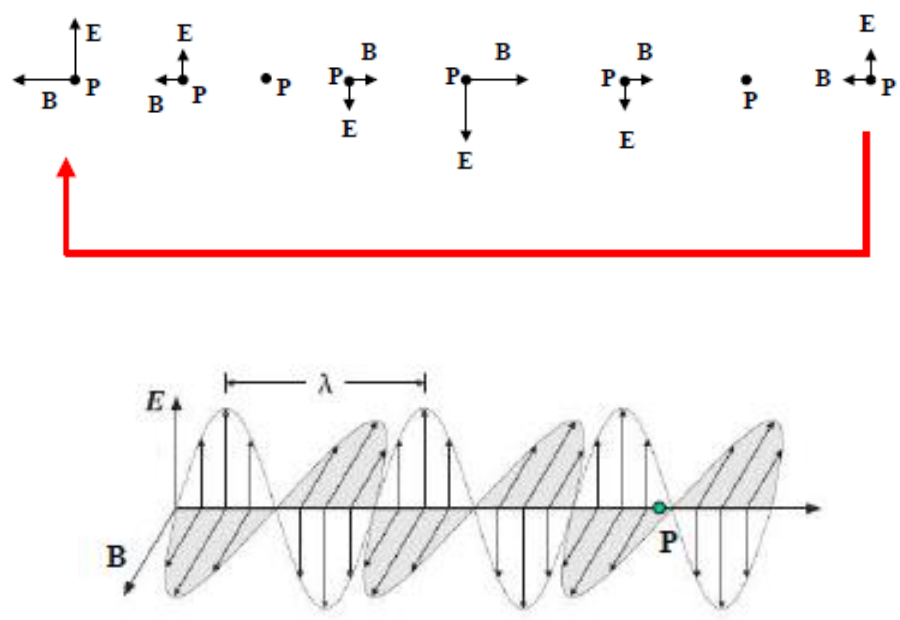

(ver animação: http://www.walter-fendt.de/ph14br/emwave br.htm)

Tais ondas recebem o nome de ondas eletromagnéticas. Sua velocidade de propagação é dada por:

$$
v=\sqrt{\mu \varepsilon}
$$

Onde $\mu$ e $\varepsilon$ estão associadas a propriedades magnéticas $(\mu)$ e elétricas $(\varepsilon)$ do meio. São as constantes denominadas de permeabilidade magnética e permitividade elétrica do meio. As ondas eletromagnéticas têm, portanto, uma velocidade de propagação que depende das propriedades eletromagnéticas do meio.

Portanto, os campos elétrico e magnético podem se propagar como ondas no espaço. Os campos são os componentes da onda. A razão para a sua propagação mesmo no 
vácuo tem a haver com o fenômeno da indução no eletromagnetismo. Um campo elétrico variando com o tempo induz um campo magnético variando com o tempo e esse último ao variar induz um campo elétrico variando com o tempo e assim sucessivamente.

É interessante enfatizar que quando estas equações foram obtidas pouco se conhecia sobre a natureza da luz. Apenas quando Maxwell substituiu os valores de $\mu$ e $\varepsilon$, conhecidos empiricamente através de medidas de capacitância e indutância, obtevese que a onda eletromagnética tinha uma velocidade de propagação igual à da luz, e assim pode ser feito o relacionamento entre a óptica e o eletromagnetismo.

$$
C=V=1 / \sqrt{\mu \varepsilon}
$$

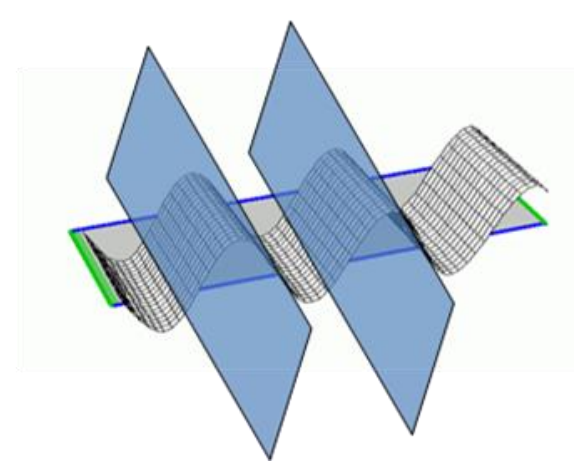

Existe ainda um conjunto de equações similares para o campo magnético. Todas são equações diferenciais lineares, de segunda ordem, que podem ter uma infinidade de soluções, dependendo das condições de contorno impostas pela geometria de cada situação particular.

A análise de Máxwell lhe permitiu concluir que:

The agreement of the results seems to show that light and magnetism are affections of the same substance, and that light is an electromagnetic disturbance propagated through the field according to electromagnetic laws.

Dessa forma Maxwell percebeu que a descrição dos fenômenos associados à luz podem ser entendidos a partir do eletromagnetismo. Deu-se assim o que denominamos hoje de unificação do eletromagnetismo com a óptica.

\section{ONDAS TRANSVERSAIS}

Pode-se classificar as ondas em duas grandes categorias quanto á direção de propagação em relação á direção na qual a onda oscila. Quanto a esse aspecto temos dois tipos de ondas: Ondas Longitudinais e Ondas Transversais. Nas ondas longitudinais, as ondas oscilam na mesma direção de propagação da onda. As ondas Transversais são aquelas para as quais as oscilações ocorrem numa direção que é ortogonal á direção de propagação da onda. 
Pode se provar que as ondas eletromagnéticas são ondas transversais. Isto é enquanto as onda se propagam, por exemplo, ao longo do eixo $x$ os campos elétricos e magnéticos oscilam ao longo do plano y-z que é um plano perpendicular a essa direção . Vide figura abaixo.

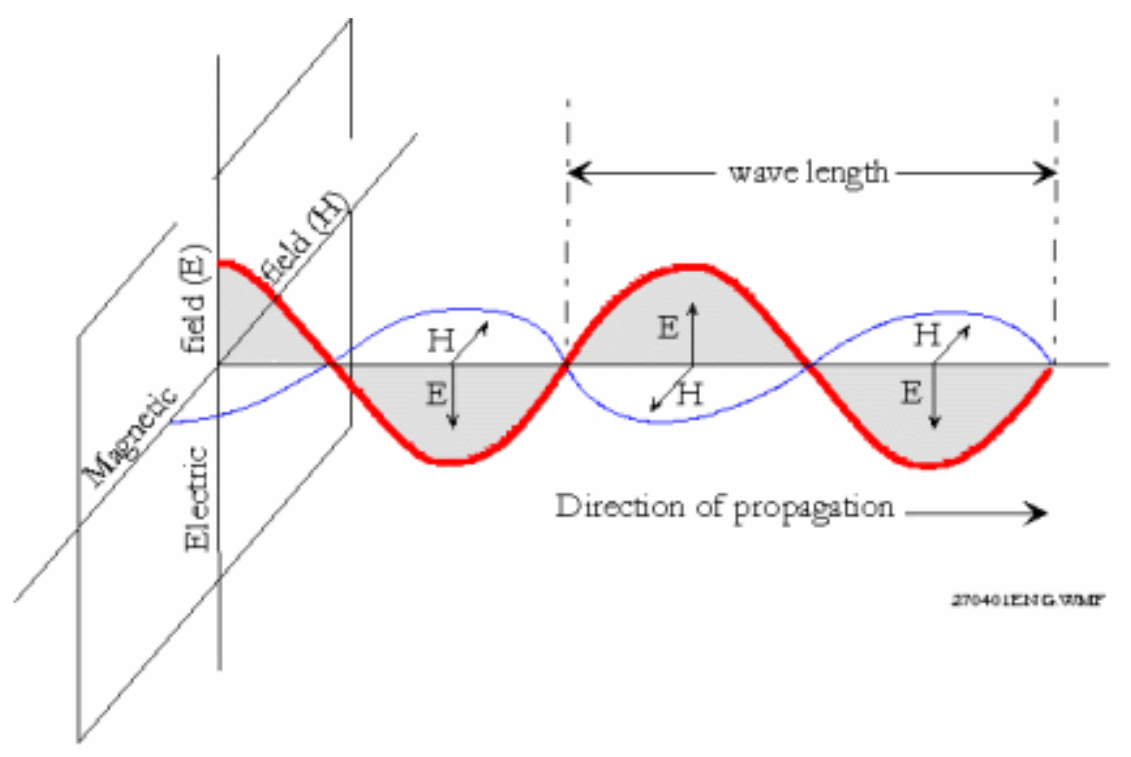

\section{POLARIZAÇÃO}

Polarização de uma onda eletromagnética diz respeito ao comportamento da direção dos campos elétricos e magnéticos quando analisado num plano perpendicular ao sentido de propagação da onda. As ondas eletromagnéticas podem ser polarizadas de duas formas distintas.

No caso de uma onda plano polarizada, o campo elétrico oscila sempre num plano. O mesmo ocorrerá, naturalmente, com o campo magnético. Ele oscilará nesse caso num outro plano perpendicular ao plano de oscilações do campo elétrico. Esses dois planos contém as possíveis direções do campo elétrico (e do campo magnético) e da direção de propagação da onda.

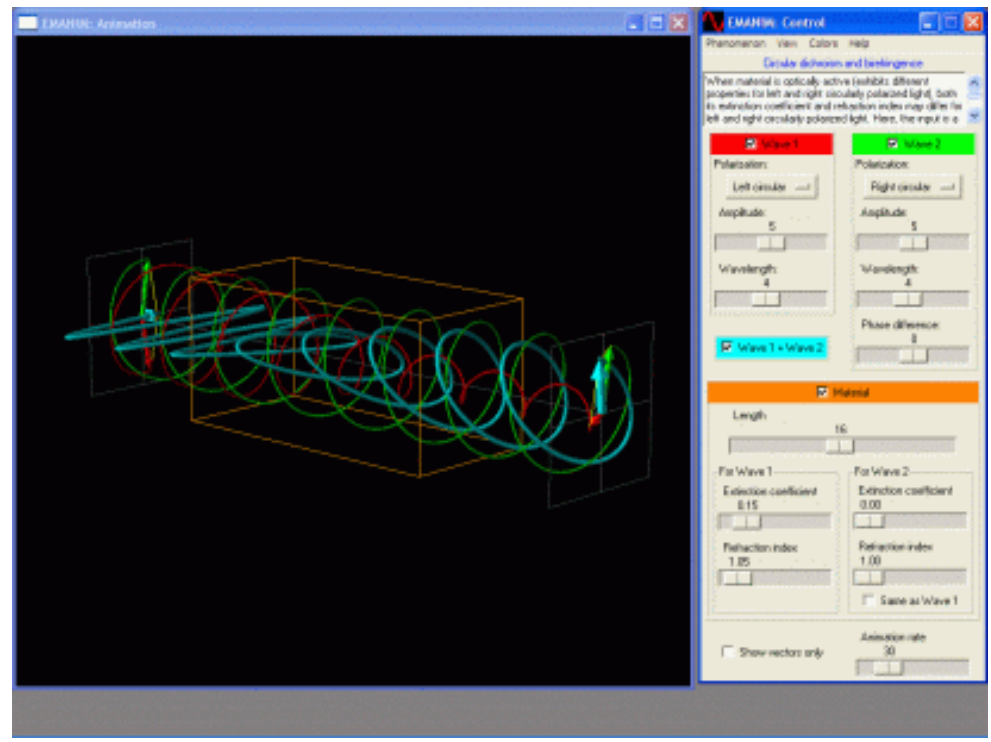


Uma onda circularmente polarizada é tal que á medida em que a onda se propaga, o campo elétrico executará um movimento tal que, observando-se o seu comportamento a partir do plano perpendicular ao movimento, seu movimento será semelhante aquele do movimento circular uniforme.

\section{SUPERPOSIÇÃO DE ONDAS ELETROMAGNÉTICAS}

A superposição de duas ondas gera uma nova onda. A superposição de duas ondas monocromáticas não é uma onda monocromática. Para a superposição de ondas monocromáticas escrevemos:

$$
\begin{aligned}
& \vec{E}(r, t)=\sum_{i} \vec{E}_{i 0} e^{i\left(\vec{k}_{i} \vec{r}-\omega_{i} t\right)} \\
& \vec{B}(r, t)=\sum_{i} \vec{B}_{i 0} e^{i\left(\vec{k}_{i} \cdot \vec{r}-\omega_{i} t\right)}
\end{aligned}
$$

Para a superposição de um número muito grande de ondas, que se aproxime de um contínuo, substituímos a soma por uma integral sobre as freqüências, isto é:

$$
\begin{aligned}
& \vec{E}(r, t)=\int \vec{E}_{0}(\omega) e^{i(\vec{k}(\omega) \cdot \vec{r}-\omega t)} d \omega \\
& \vec{B}(r, t)=\int \vec{B}_{0}(\omega) e^{i(\vec{k}(\omega) \cdot \vec{r}-\omega t)} d \omega
\end{aligned}
$$

A partir das equações de Maxwell, e das soluções propostas acima, pode-se verificar que os vetores $\vec{E}_{0}$ e $\vec{B}_{0}$ e $\vec{k}$ são perpendiculares entre si. Isto é:

$$
\vec{E}_{0} \cdot \vec{B}_{0}=0, \quad \vec{E}_{0} \cdot \vec{k}=0, \quad \vec{B}_{0} \cdot \vec{k}=0
$$


Assim, um aspecto importante a respeito das ondas eletromagnéticas harmônicas, é que o campo elétrico oscila numa direção que é ortogonal á direção na qual oscila o campo magnético.

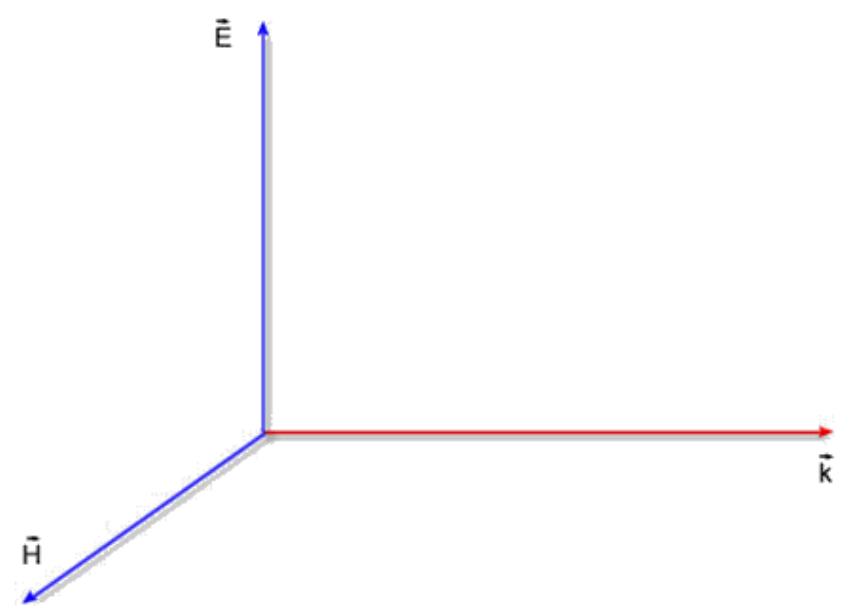

As ondas eletromagnéticas foram previstas pela primeira vez por Maxwell e observadas por Heinrich Hertz. Como as demais ondas, as ondas eletromagnéticas podem ser caracterizadas pela freqüência ou, equivalentemente, pelo seu comprimento de onda. $O$ conjunto de freqüências define o espectro da radiação.

\section{O ESPECTRO ELETROMAGNETICO}

Denominamos de luz a uma parte do espectro eletromagnético. São as ondas eletromagnéticas cujos comprimentos de onda estão compreendidos no intervalo entre 400 e 700 nm (nanômetros). A luz visível é, assim, apenas uma onda eletromagnética. Outros tipos, são igualmente importantes.

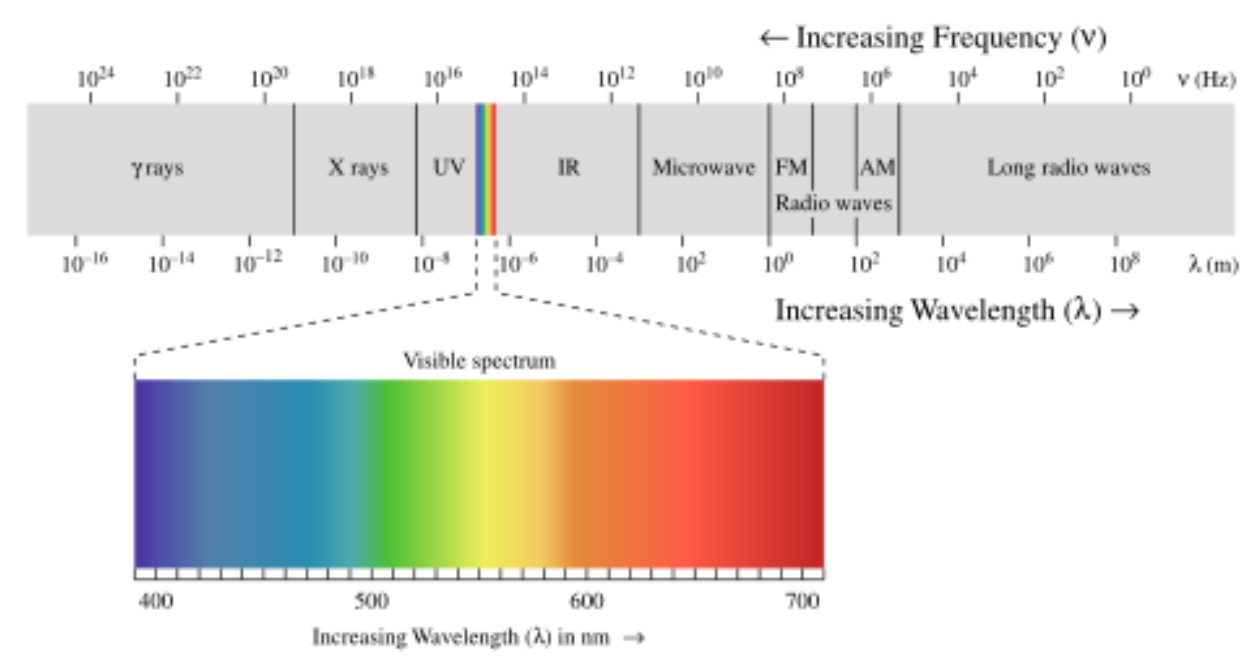

Ondas de Rádio São as de menor freqüência dentro do espectro eletromagnético. Parte desse espectro é utilizado para comunicações em geral 
(via rádio e celulares). As estações de radio FM operam num domínio de freqüências próximo de $10^{8} \mathrm{~Hz}$. As estações de rádio $\mathrm{AM}$ operam em freqüências próximas de $10^{6} \mathrm{~Hz}$. Ondas de rádio têm freqüência de até 300 $\mathrm{MHZ}$ (megahertz).

Microondas É um subconjunto das ondas de radio. Têm freqüências compreendidas no intervalo entre $300 \mathrm{MHZ}$ e $300 \mathrm{GHZ}$. As microondas têm três características importantes que definem a sua utilidade na fabricação de fornos de microondas: elas são absorvidas pelos alimentos em geral, elas são refletidas por metais e conseguem atravessar uma gama bem grande de materiais que usamos como embalagens de alimentos (vidro, papel, plástico, etc)

As microondas têm utilizações industriais. São utilizadas em radares da policia rodoviária e em comunicações,

Radiação infravermelha São as ondas com freqüências próximas do espectro visível. Possui freqüências abaixo da luz visível de tom avermelhado. $O$ comprimento de onda estaria no domínio entre $700 \mathrm{~nm}$ e $1 \mathrm{~mm}$.

Existem muitas aplicações para a radiação infravermelha. Mais recentemente ela tem sido utilizada em equipamentos para visão noturna, quando não há luz suficiente. Um corpo (como o corpo humano) a $37^{\circ} \mathrm{C}$ emite radiação eletromagnética na região infravermelha. Assim basta detectar a radiação emitida e traduzi-la em termos de imagens numa tela. Objetos mais quentes aparecendo com tons diferentes de objetos mais frios

Radiação infravermelha é também utilizada em redes sem fio e aquecimento de objetos (como retirar gelo das asas de um avião antes da decolagem).

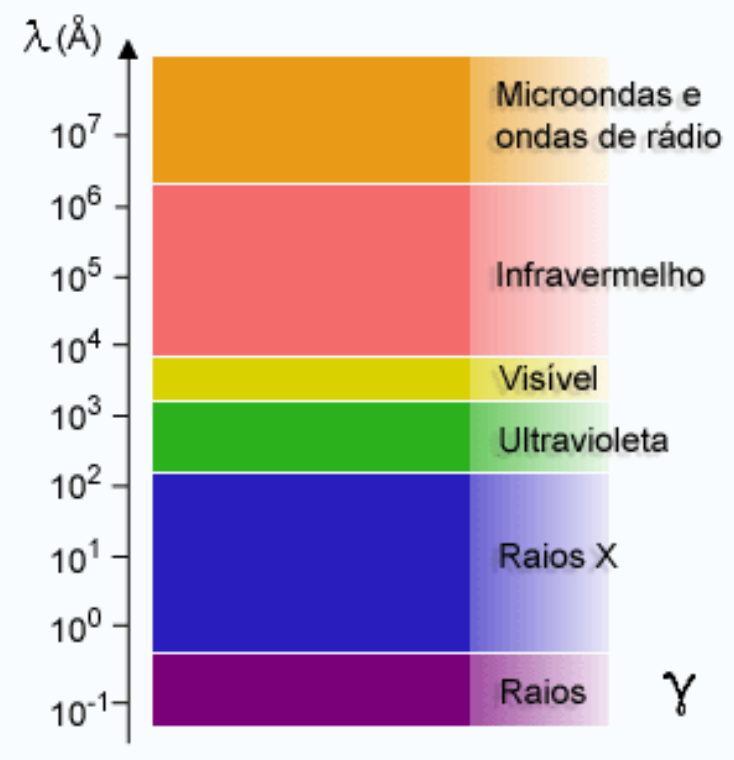

Radiação ultravioleta Também são ondas com freqüências próximas do espectro visível, mas na outra extremidade do espectro em relação ao 
vermelho. A freqüência dessa radiação está acima daquela associada á luz visível de tom violeta.

A utilidade dos raios ultravioletas se faz sentir quando vamos á praia. O corpo fica bronzeado como uma reação natural, fisiológica, á exposição da pele á radiação ultravioleta proveniente do Sol. Como resposta contra a radiação ultravioleta, o corpo produz a melanina. Essa substancia dá a tão apreciada coloração ao corpo humano. Desnecessário dizer que exposição excessiva á radiação UV podem acarretar conseqüências desastrosas do ponto de vista da saúde humana. A pele, os olhos e o sistema imune podem ter problemas agudos e ás vezes crônicos.

Lâmpadas ultravioletas podem ser utilizadas para esterilizar ferramentas em hospitais e laboratórios. Radiação UV pode ser útil no processo de pasteurização de sucos de fruta.

Raios-x è a radiação cujos fótons que a compõem têm a energia das mais altas. Estão abaixo apenas dos raios_ $\gamma$. O comprimento de onda dessa radiação está dentro do domínio de valores entre 10 e 0,01 nm.

Os raios-z são parte do conjunto de radiações ditas ionizantes. Representam, portanto risco á saúde. Radiação ionizante é todo tipo de partícula (o onda) a capaz de ionizar átomos e moléculas. Radiação alfa, beta ou gama são exemplos de radiação ionizante.

Raios-x são empregados na área médica (diagnósticos), na área cientifica (cristalografia), e na construção civil..

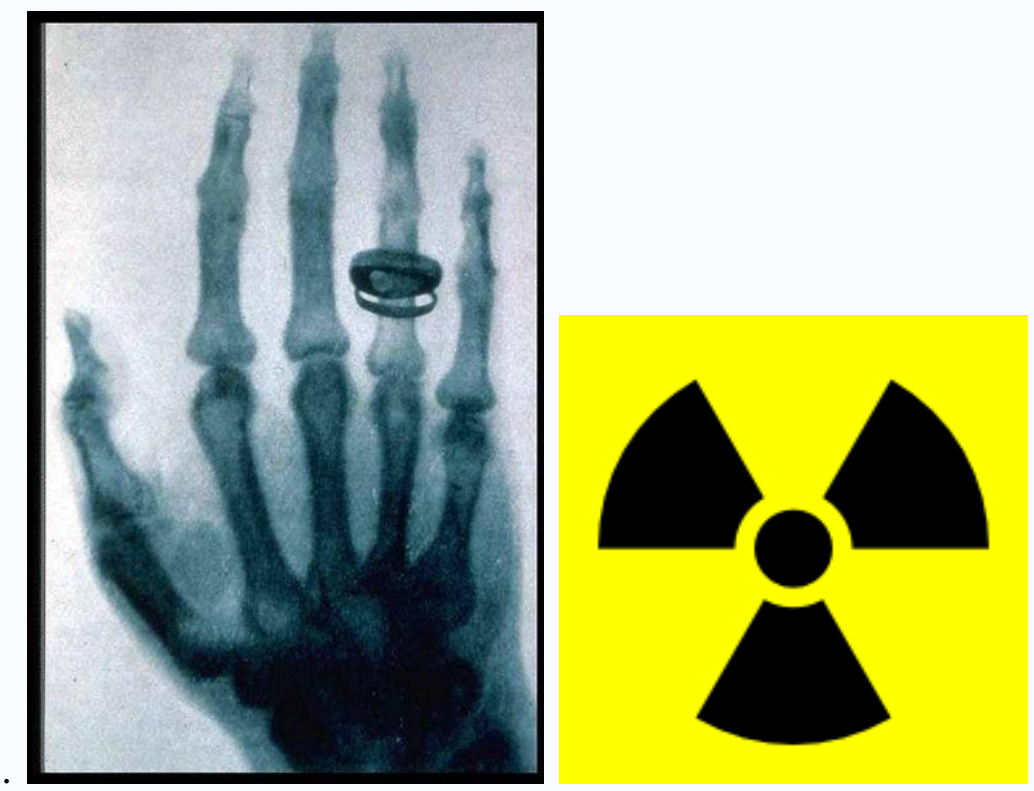


Raios- $\gamma$ São as ondas de maior freqüência do espectro eletromagnético. Elas são compostas por fótons de maior energia. Assim, ela é capaz de ionizar quase todos os átomo e moléculas. Representam altíssimo risco para a saúde.

\section{ATIVIDADES}

1 - Compare o texto acima com um texto de um livro didático e com o seu curso de Física C, e discuta se a transposição didática feita por mim e a feita pelo seu livro estão boas ou deixam a desejar.

2 - Lei os textos abaixo que se dispõe a explicar o funcionamento de um forno de micro-ondas e comente sobre a qualidade deles e que se é necessário conhecer as equações de Maxwell para poder entender estes textos.

http://pt.wikipedia.org/wiki/Forno de micro-ondas

http://www.efeitojoule.com/2008/09/como-funciona-forno-microondas.html

comotudofunciona - http://casa.hsw.uol.com.br/culinaria-de-microondas.htm

3 - O que são raios infravermelhos e quais as suas aplicações.

4 - Analise os applets abaixo.

4.1 -

4.2- Explicação da Lei de Snell usando frente de Ondas. Principio de Huygens.

Link $\rightarrow$ http://www.walter-fendt.de/ph14br/huygenspr br.htm 


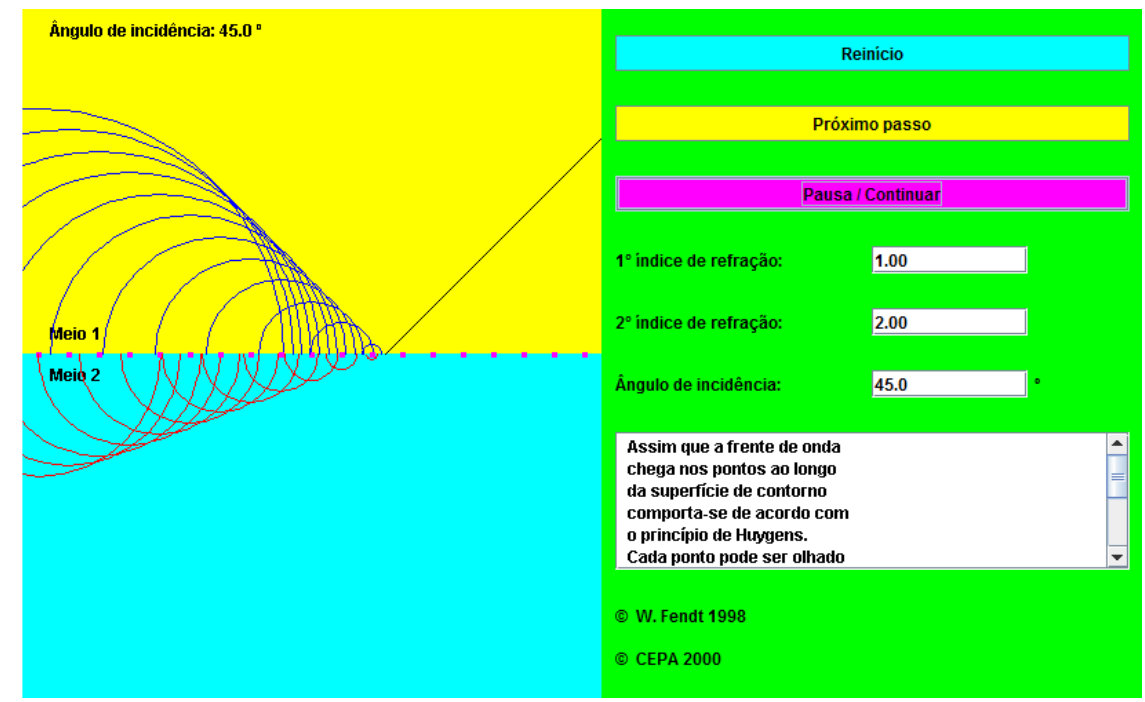

4.6 - Explicação da Lei de Snell usando frente de Ondas. Principio de Huygens. Link $\rightarrow$ http://www.fisica.ufpb.br/prolicen/

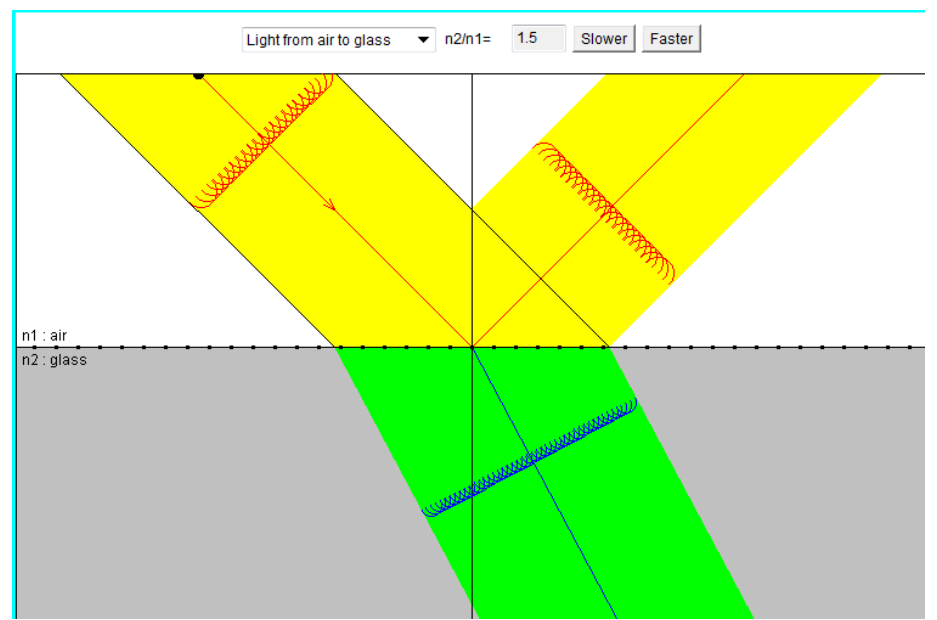

4.7 - superposição de Ondas. Fu-Kwun Hwang 


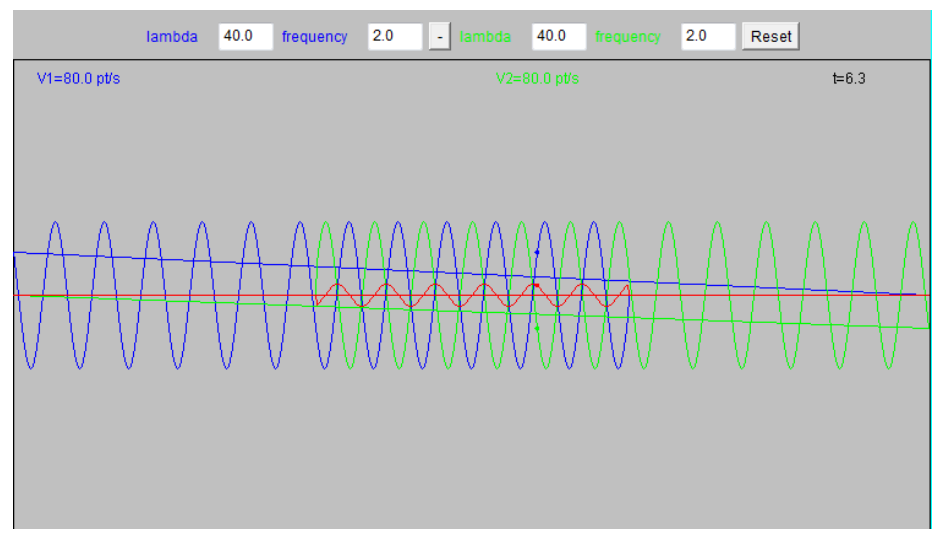

4.8 - Site de Ensino $\rightarrow$ EducaPlus.org.

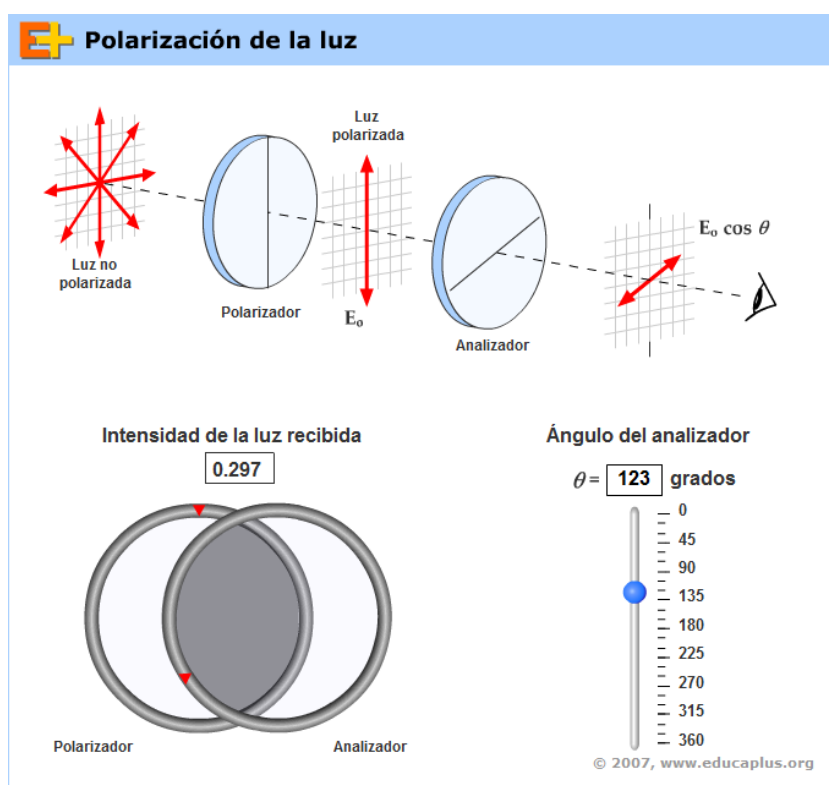

4.7 - Interferência de ondas. Fu-Kwun Hwang

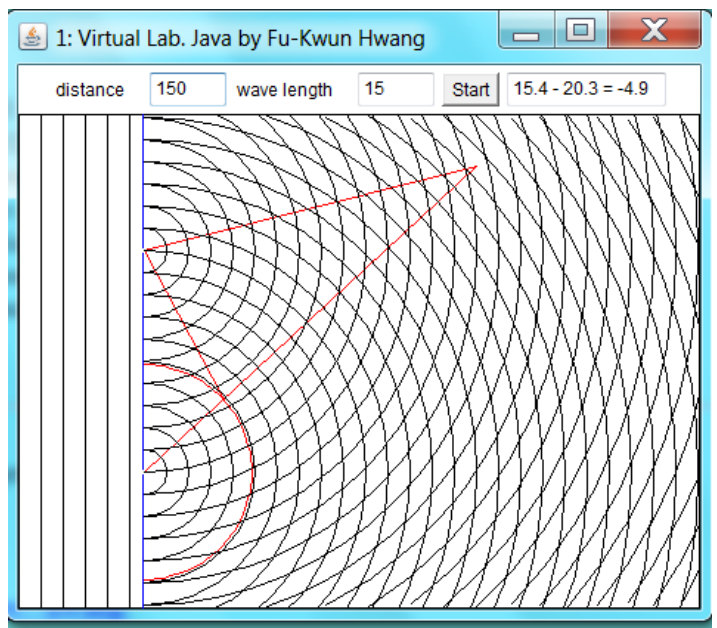


4.8 - Esta animação mostra uma onda eletromagnétia, denominada onda plana polarizada, que se propaga na direção x positivamente. Os vetores do campo elétrico (vermelho) são paralelos ao eixo y, os vetores do campo magnético (azul) são paralelos ao eixo z. URL: http://www.walterfendt.de/ph14br/emwave br.htm

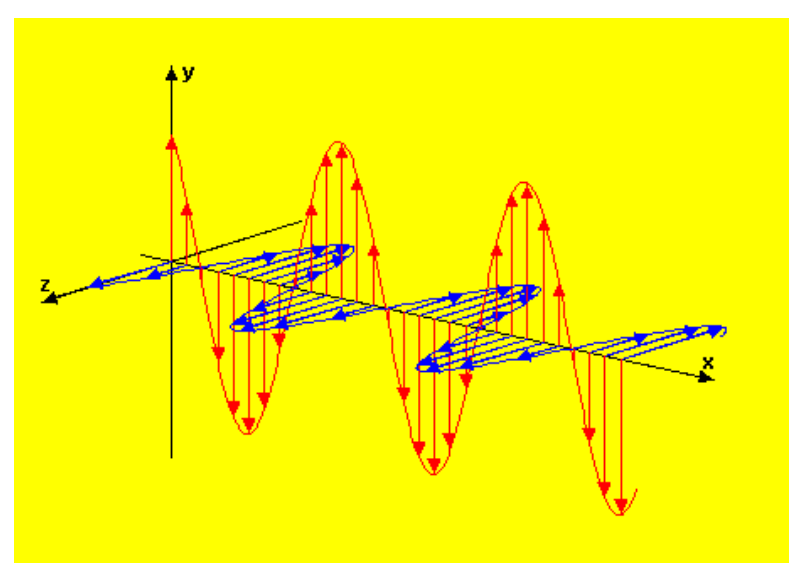

5 - Analise as vídeos aulas abaixo.

5.1 - Mago da física. Ondas Estacionárias. http://www.youtube.com/watch?v=pDkd$\underline{\mathrm{vO} 1 \times 9 \mathrm{k}}$

5.2 - Ondas Estacionárias.

http://www.youtube.com/watch?v=wBt6J69zwVk\&feature=related

5.3 - Ondas Estacionárias. Um exemplo muito simples.

http://www.youtube.com/watch?v=BnEKwOpDJf0\&feature=relmfu

5.4 - Ondas Estacionárias em duas dimensões.

http://www.youtube.com/watch?v=w9ByYTOzZEU\&feature=related

5.5 - Novo Telecurso. Ondas, Aula 29 parte 1.

http://www.youtube.com/watch?v=i9hanB1iuU8

5.6 - Novo Telecurso. Ondas, Aula 29 parte 2.

http://www.youtube.com/watch?v=eXcPIm4_S8

COMENTÁRIOS: 
Esta aula ficou um pouco extensa, mas muito ilustrada. Ela serviu como base para a introdução do uso do software de ensino de matemática "winplot". Ela serviu para que os estudantes fizessem uma revisão deste tópico recheada com animações e experimentos de demonstração.

Apesar de deste tópico da física ter pouco experimentos de baixo custo, muitos dos experimentos de demonstração são de fácil realização. Este tópico possui muito applets de ensino, simulações matemáticas e vídeo aula, que compensam a falta do primeiro.

\section{CONCLUSÃO:}

Devido a grande aplicabilidade na vida prática moderna, não podemos deixar de ministrar pelo menos uma aula sobre ondas em um curso de física. Apesar da dificuldade matemática deste tema, e possível ministrar uma aula mais conceitual sobre este tema usando simulação matemática, applets de ensino e vídeo aula.

\section{RESUMO:}

Apresentamos aqui uma aula sobre ondas. Apresentamos várias sugestões de exemplos práticos e experimentos de demonstração. Introduzimos o uso do software de ensino de matemática "winplot" nesta aula. No final da aula apresentamos alguns exemplos de experimentos de baixo custo, applets de ensino e vídeo aulas. Fizemos algumas animações com o software Modellus.

\section{REFERÊNCIAS}

1 -G.C. Marques. e-Física: URL: efisica.if.usp.br

2 - Rick Parris. Peanut Software Homepage. URL: http://math.exeter.edu/rparris/ winplot.html 


\section{APÊNDICE}

\section{Manual Winplot (Curso de Instrumentação)}

Esse é um breve manual ou tutorial do software de ensino Winplot. O objeto dele é fornecer os conhecimentos básicos do uso deste software de modo que qualquer pessoa possa acompanhar as atividades do curso de Instrumentação.

Como instalar no seu computador: Vá até o cite:

http://math.exeter.edu/rparris/winplot.html e baixe a versão em português brasil. Click com o botão direito do mouse sobre ele e crie um atalho dele. Arraste para a sua área de trabalho (tela).

Abra o programa. Deve aparecer esta tela.

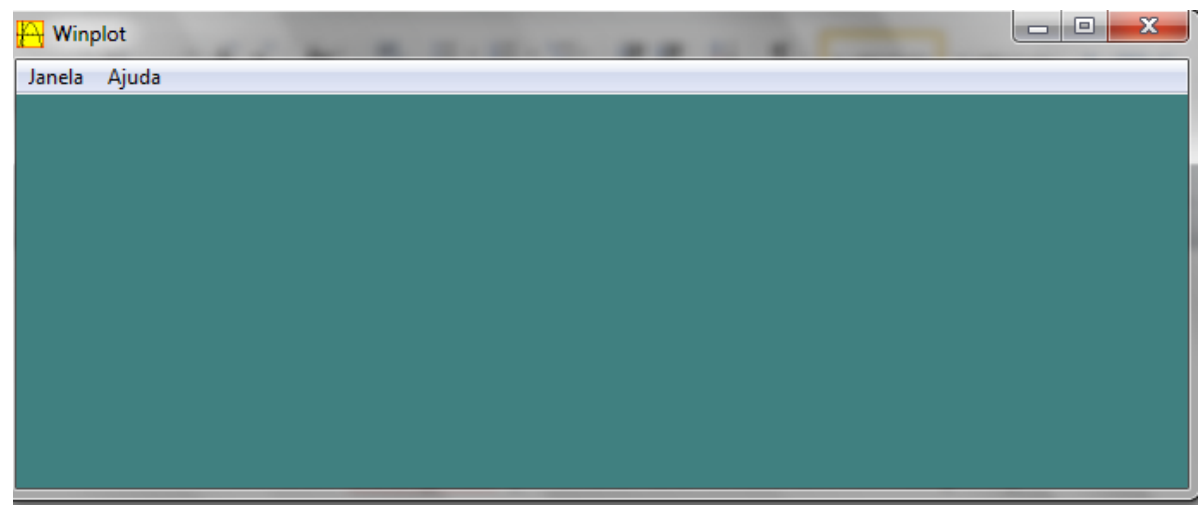

Click em janela e escolha 2-dim (F2). Primeira opção. Deve aparecer esta tela.

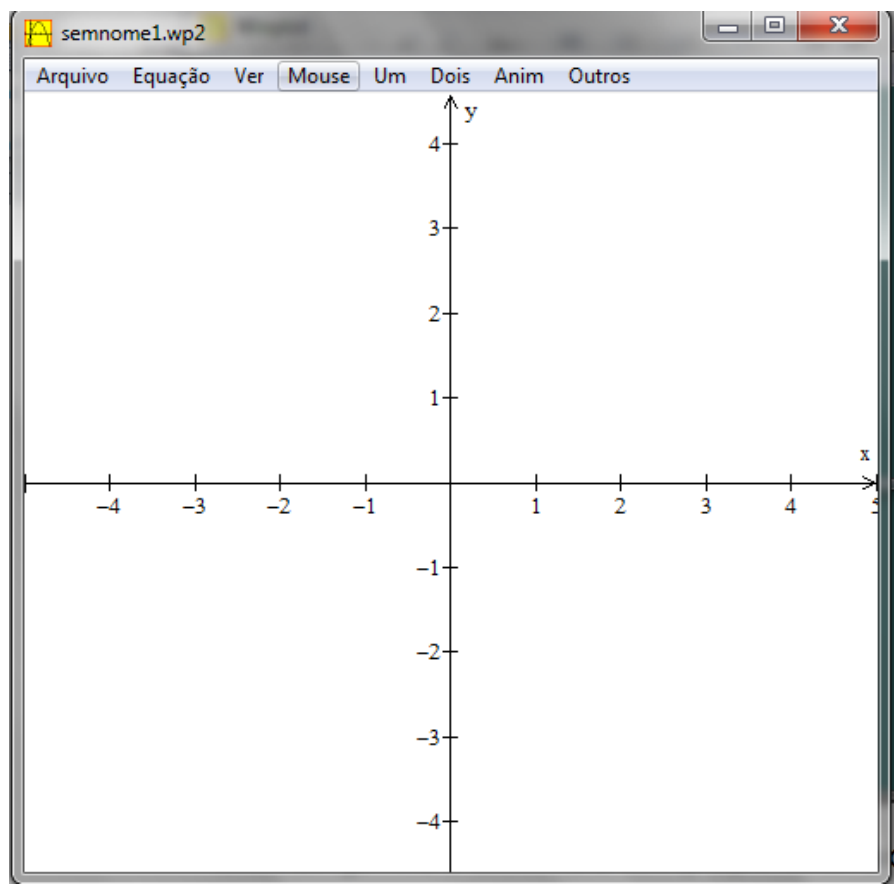


Click em equação e escolha explícita. Deve aparecer a janela da esquerda. Digite $2 \sin (x)$ no campo " $f(x)=$ " e click ok". Deve aparecer o gráfico em vermelho da função seno $(\sin (x)$ em inglês).

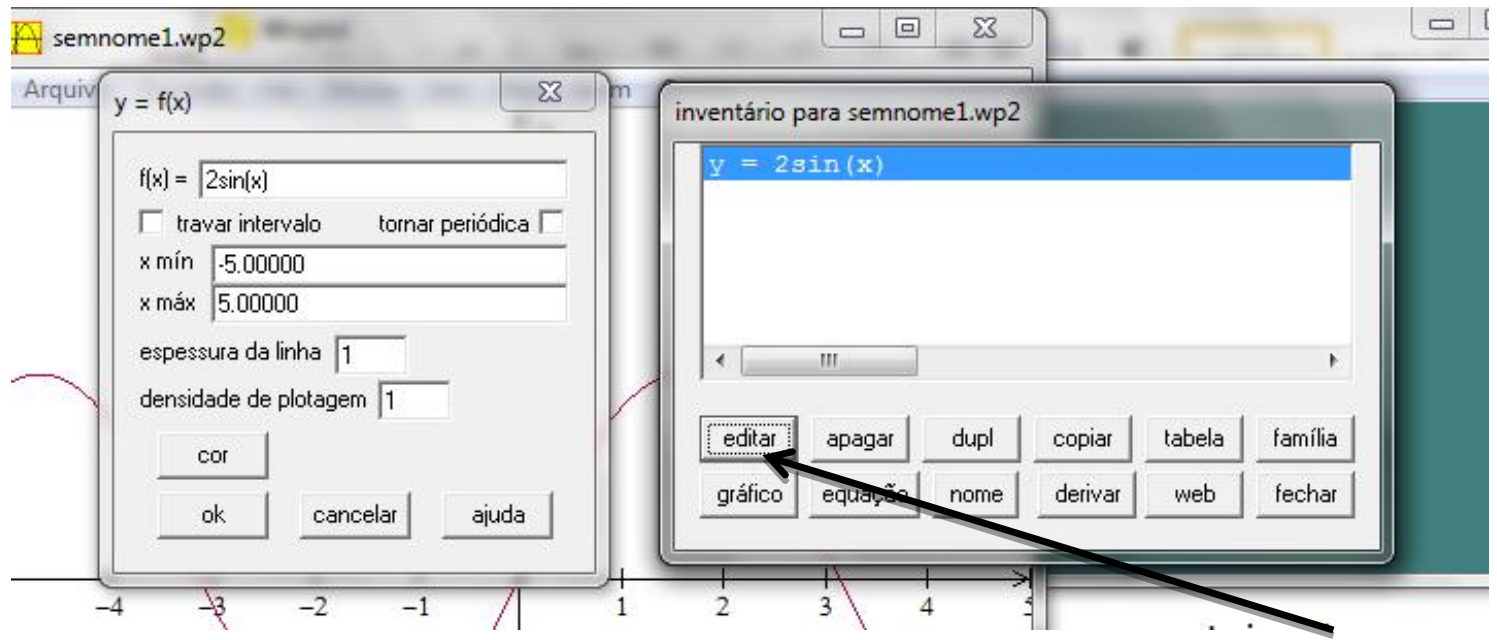

Agora na sua tela temos janela semnome1.wp1 e a inventário para... Se você quiser que a janela $y=f(x)$ apareça novamente você tem que clicar em editar na janela inventário.

Click em duplicar na janela inventário e digite $2 \sin (2 x)$ na janela $y=f(x)$ e click em ok. Deve aparecer o gráfico abaixo.

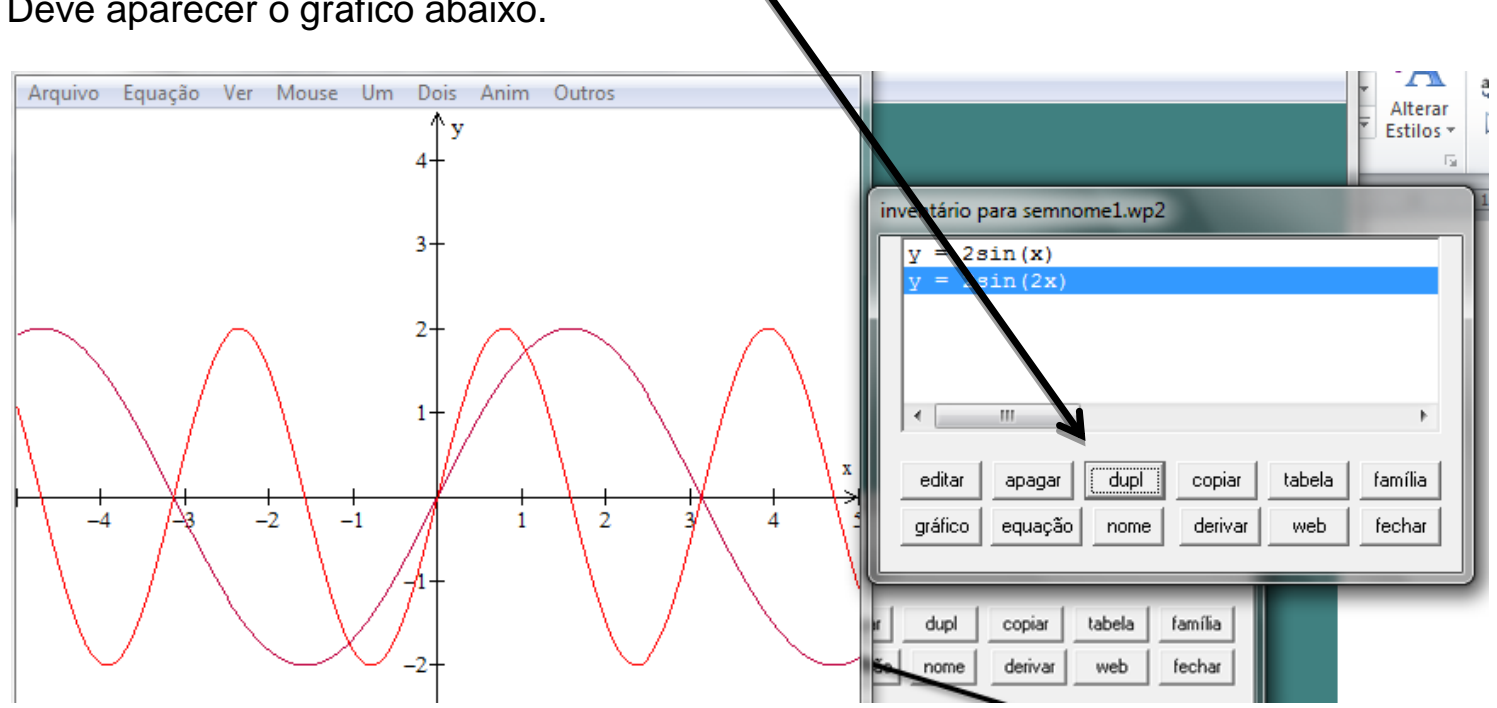

Click em duplicar na janela inventário e digite $2 \sin (x)+2 \sin (2 x)$ na janela $y=f(x)$ e click em ok. Não esqueça de mudar a cor e espessura da linha. Deve aparecer o gráfico abaixo. 


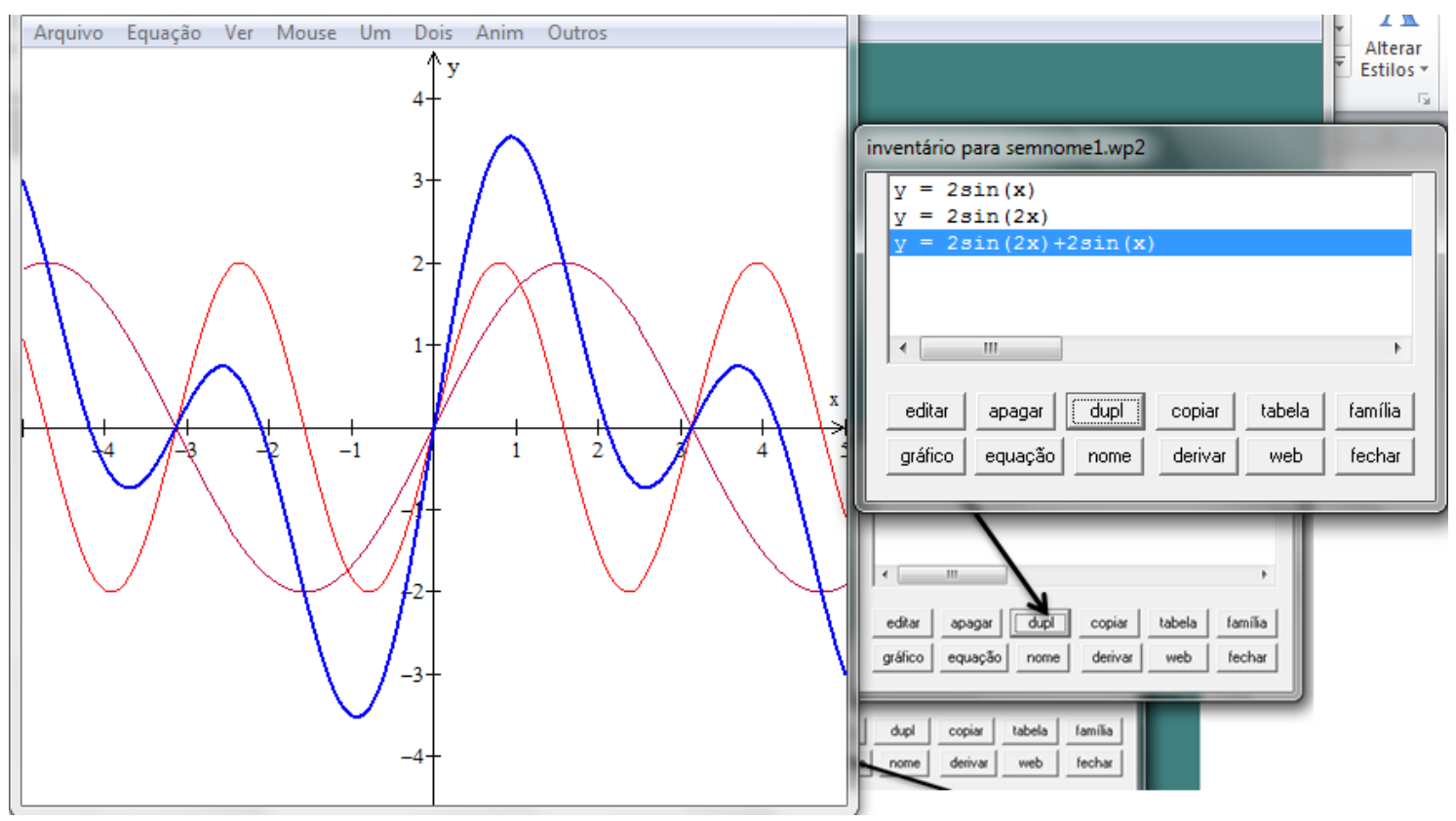

Click em editar na janela inventário e digite $2 \sin (x)+a \sin (b x)$ na janela $y=f(x)$ e click em ok. Não esqueça de mudar a cor e espessura da linha. O gráfico de $2 \sin (2 x)$ deve desaparecer. Click em Anim na janela abaixo e escolha "Parâmetros A-W". Mude os valores de $A$ e de $B$ e veja o que acontece.

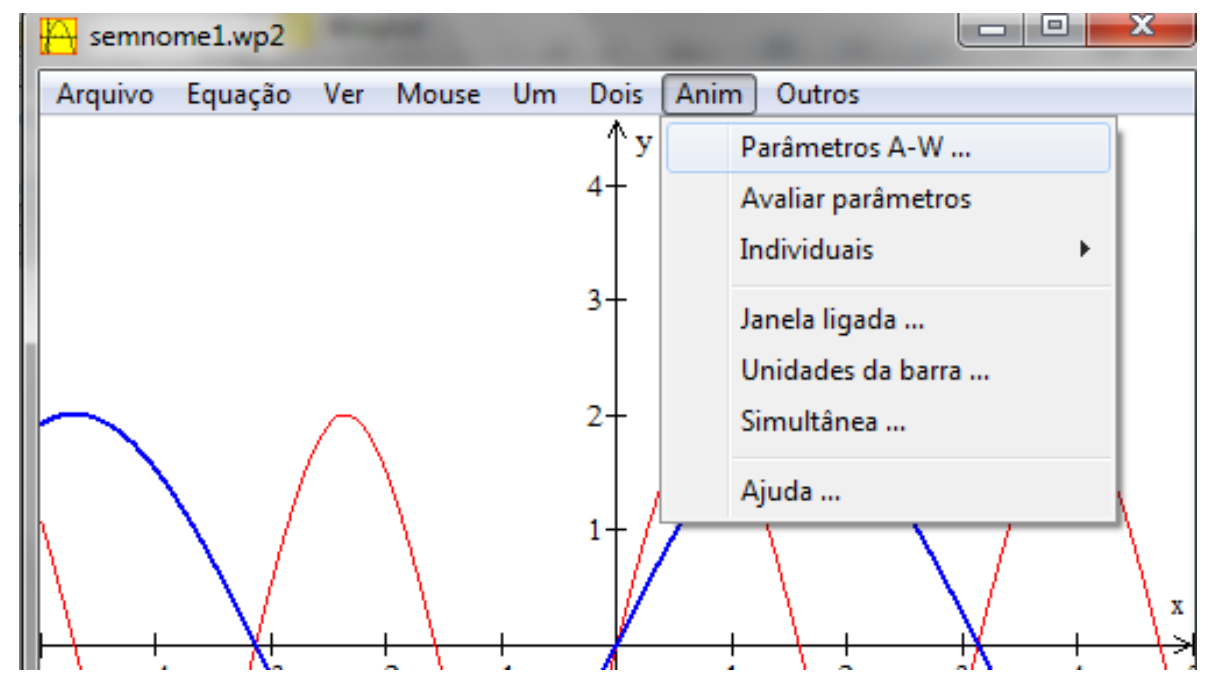

Deve aparecer o gráfico abaixo. Salve seu gráfico como superposição de ondas-1. E feche sua janela superposição de ondas- 1 .

Passos: Click em "arquivo" e depois em "salvar como". 


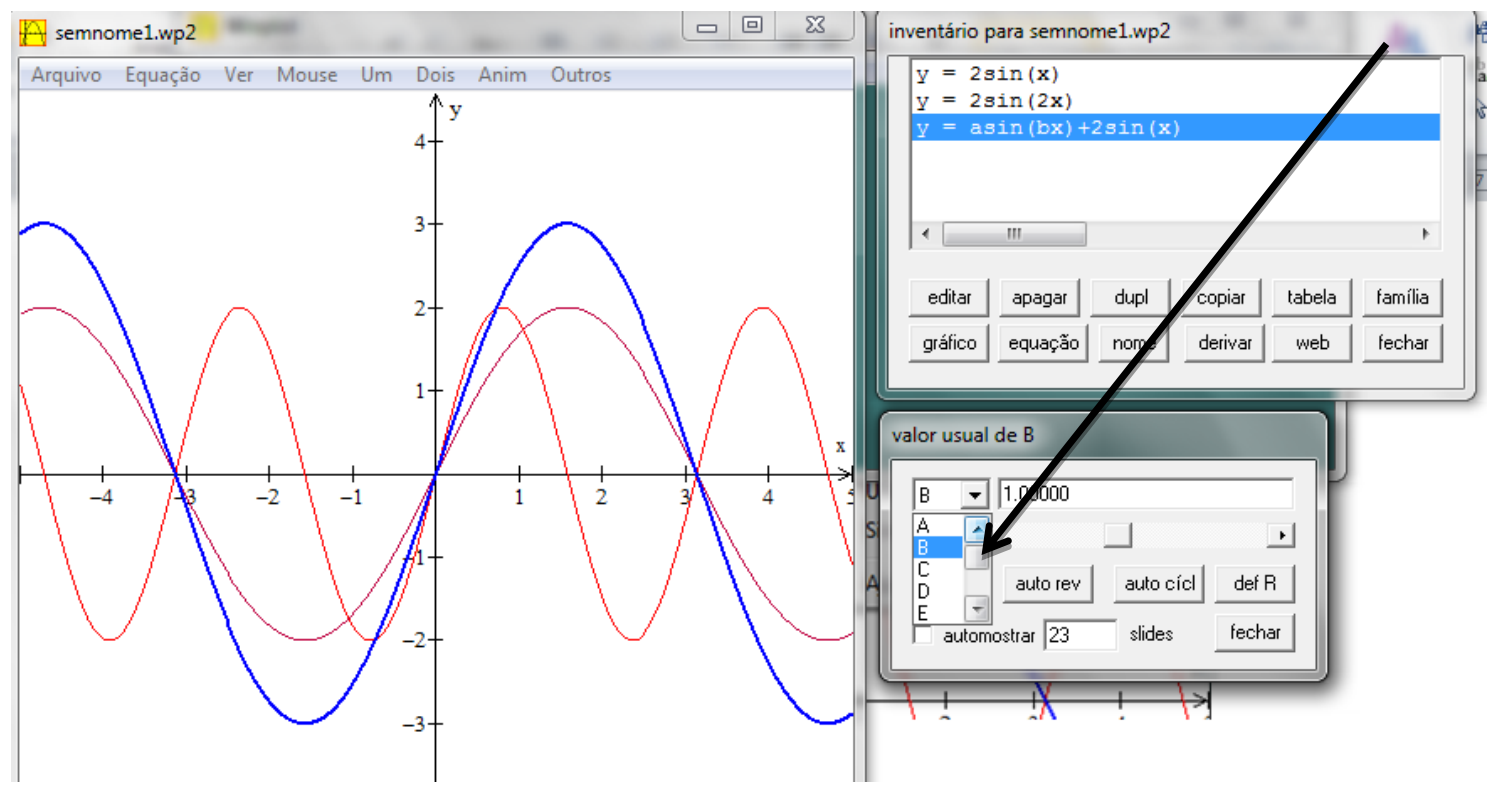

Fazendo Gráficos 3-D

Agora você deve estar somente com a janela winplot (tela verde).

Click em "janela" e depois em 3-dim 


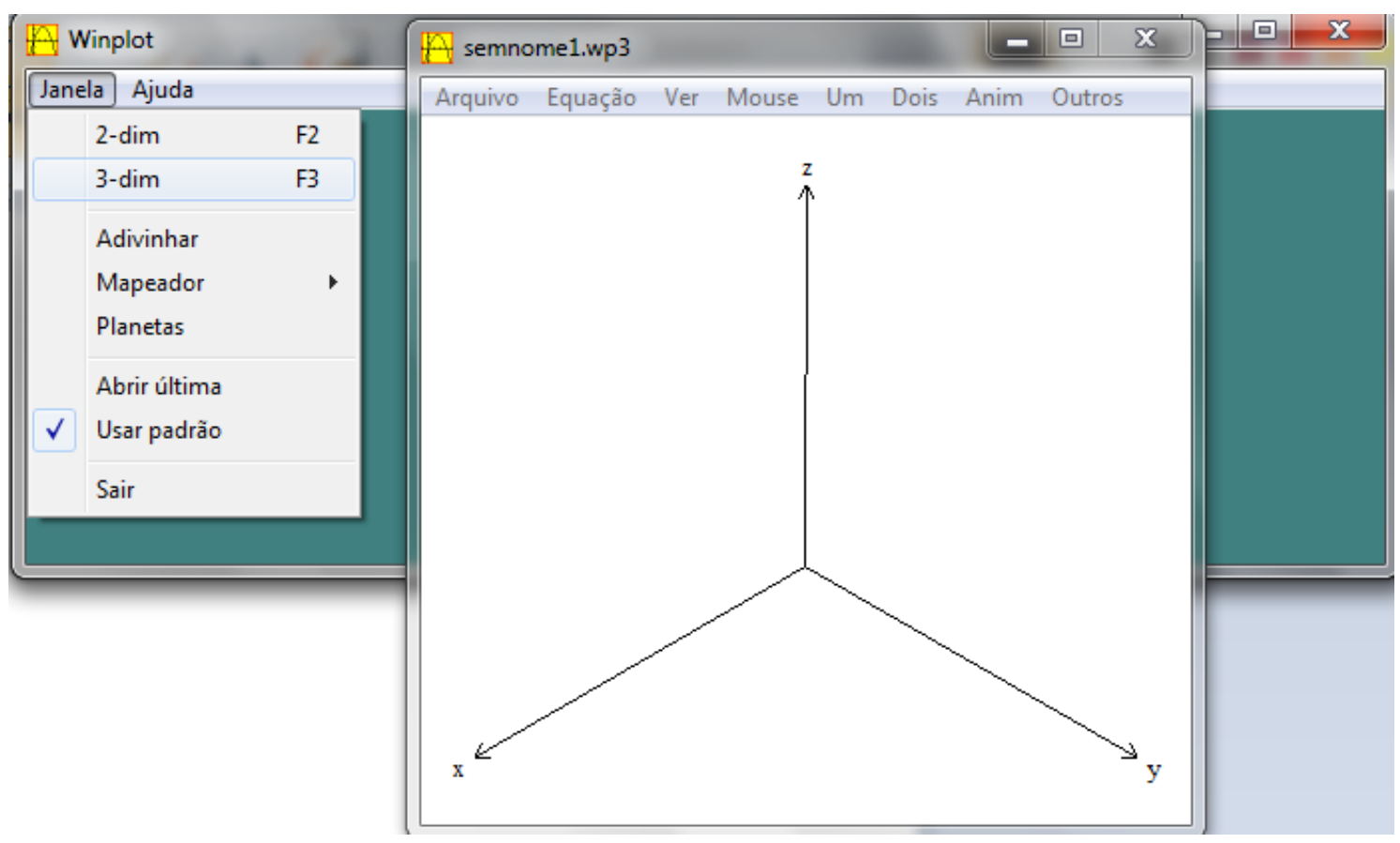

Deve aparecer a janela acima. Click em "equação" e depois em "explicita". Digite na janela " $z=" \sin (x+y)$.

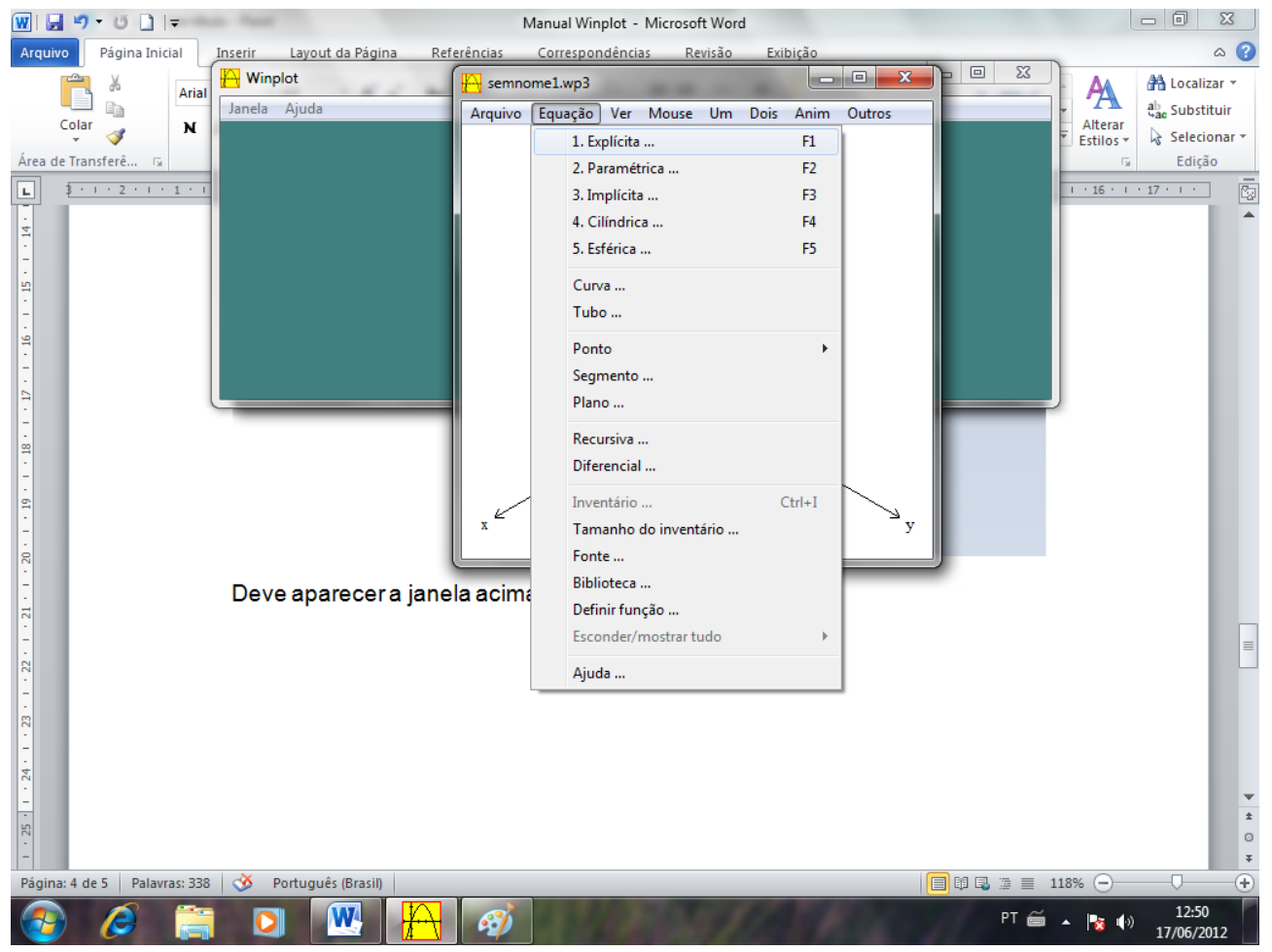

Deve aparecer o gráfico abaixo. 


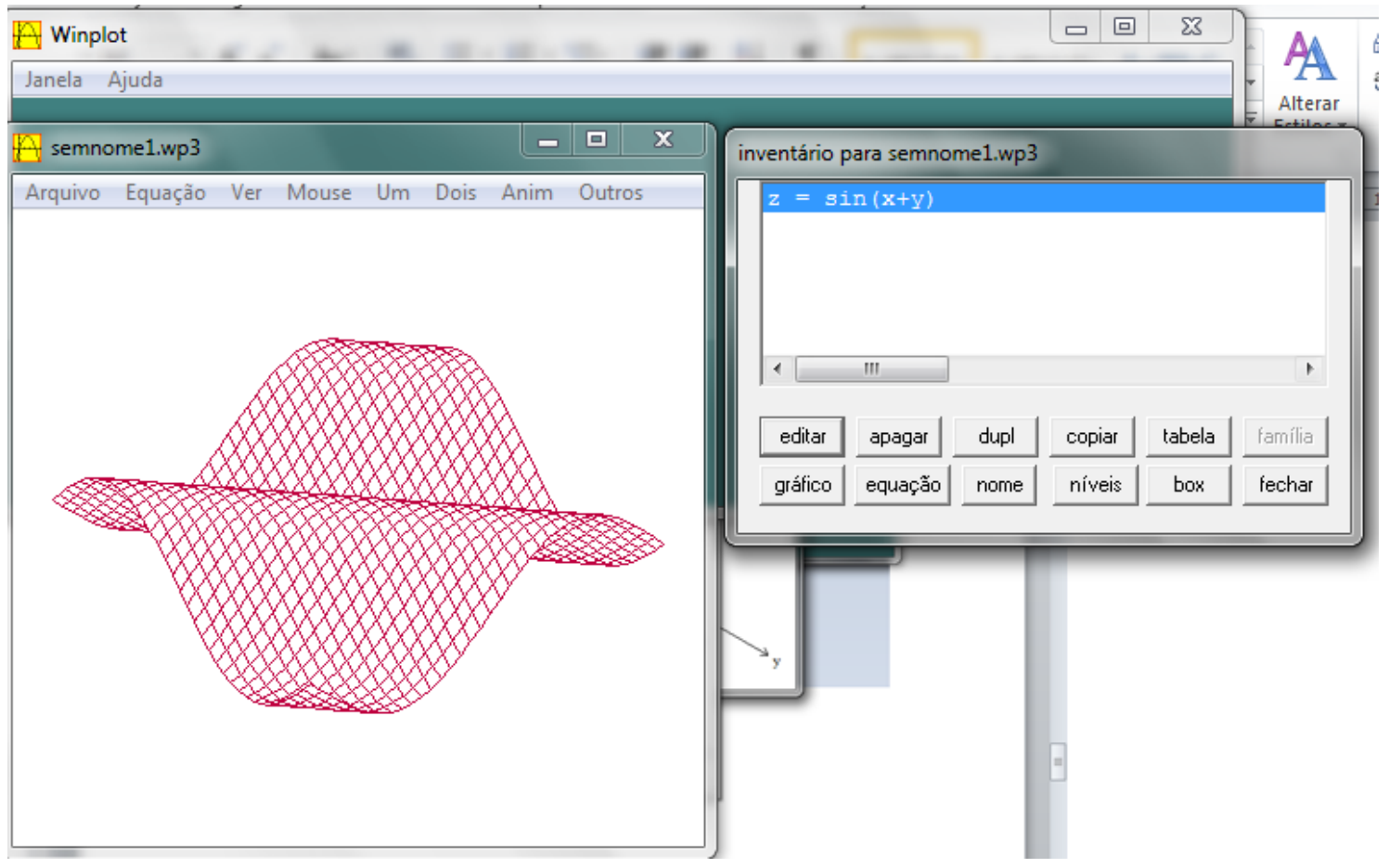




\section{Cap.06 - Ótica \& Luz}

Meta: Fazer que o estudante comece a pensar no ensino de ciências como algo "orgânico" que está em profunda transformação. Fazer com que os alunos percebam, através de uma atividade lúdica, que podemos ensinar física através de experimentos muito simples. Fazer com que o aluno percebam as aplicações da física no cotidiano.

Objetivos: Ao final da aula, os alunos devem estar cientes das novas possibilidades e dos desafios que envolvem o ensino de ciências em geral. Que para se ensinar física não precisamos ficar presos ao livro didático. Que ensinar física não é ensinar a resolver problemas e que a física é uma mera aplicação da matemática.

Pré-requisitos: Os alunos deveram ter cursado psicologia da educação física $A, B$ e C.

\section{Introdução:}

Neste capítulo do nosso curso vamos tratar de um assunto tão corriqueiro e ao mesmo tempo muito complexo, que é o de tratar da natureza da luz. Antes da introdução da física moderna na grade do ensino médio esse assunto era raramente abordado nos livros didáticos. Hoje em dia, a grande maioria dedica um capitulo para este tema. Por outro lado, este tema está por trás da maioria das aplicações da física moderna, Ex: fibra ótica, laser, leitoras de DVD e cd, etc.

Devido a sua grande aplicabilidade surgiu na literatura e na web vários materiais didáticos, de difusão científica sobre o tema. Neste capítulo vamos apresentar um resumo feito por mim, baseado no material do CEPA [1], e vamos ao longo do texto convidá-lo a fazer uma reflexão e comparação com outros textos e materiais de apoio. 
No final deste capítulo colocamos um texto muito interessante sobre pressão da radiação para o estudante poder entender melhor os efeitos da radiação solar sobre a nossa ionosfera.

\section{Texto Teórico}

Os fenômenos associados com a luz estão entre aqueles com os quais 0 ser humano tem uma relação mais íntima e constante ao longo da sua existência. A luz está presente em todas as atividades do dia a dia do homem. Muitos são os fenômenos associados ás propriedades da luz. Alguns, como a formação de sombras e de penumbras é corriqueira. Comuns são também os fenômenos da reflexão e da refração da luz. Por exemplo, a nossa imagem em um espelho é o produto da reflexão da luz. Abaixo vemos os raios da lua refletidos nas águas do mar. Como veremos, a Lua é uma fonte secundária de luz. Ela reflete a luz proveniente do Sol. Também vemos como a imagem de uma caneta é distorcida pela água de um copo (refração da luz).

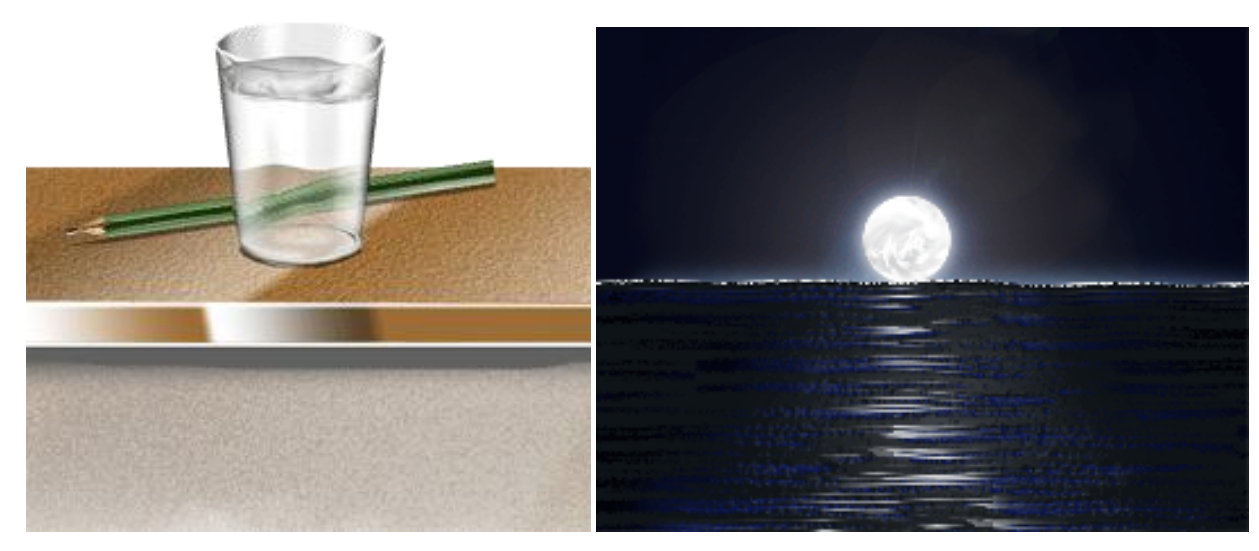

Fenômenos envolvendo a luz podem ser menos comuns e, ás vezes, requerem aparatos especiais para serem observados. Dentre esses podemos citar a interferência e a difração da luz. Outros fenômenos são bem mais sutis de serem observados e interpretados, como o efeito fotoelétrico ou o espalhamento Raman.

A área da óptica é um campo de estudos fascinante. De maneira simplificada, podemos dizer que ela é o ramo da Física que estuda a propagação da luz e sua interação com a matéria.

Em muitas áreas da ciência e tecnologia, o entendimento de determinados conceitos pode ser difícil porque seus efeitos não são facilmente visualizados. Na óptica, entretanto, o simples uso de um laser permite a visualização de um dado efeito como função de vários parâmetros, facilitando o 
aprendizado. Isto se deve principalmente à coerência (mesma fase de onda), monocromaticidade (mesma frequência) e colimação da luz proveniente deste instrumento, que permitem a observação de fenômenos tais como interferência e difração, nos quais a natureza ondulatória da luz se manifesta claramente. Entretanto, para se chegar ao desenvolvimento deste dispositivo, e de vários outros que são importantes no nosso cotidiano, um longo caminho foi percorrido e este percurso gerou um histórico bastante rico. Alguns aspectos que merecem destaque estão ligados às idéias sobre a natureza da luz e aos caminhos paralelos que a óptica e o eletromagnetismo trilharam durante séculos. Para se entender um pouco estes fatos, fizemos no e-livro óptica básico, uma breve revisão histórica do desenvolvimento dos conceitos principais ligados à óptica.

\section{A óptica é a área da Física que estuda a Luz: sua natureza, suas} propriedades e suas aplicações. A óptica se propõe também a estudar a

\section{interação da luz com a matéria.}

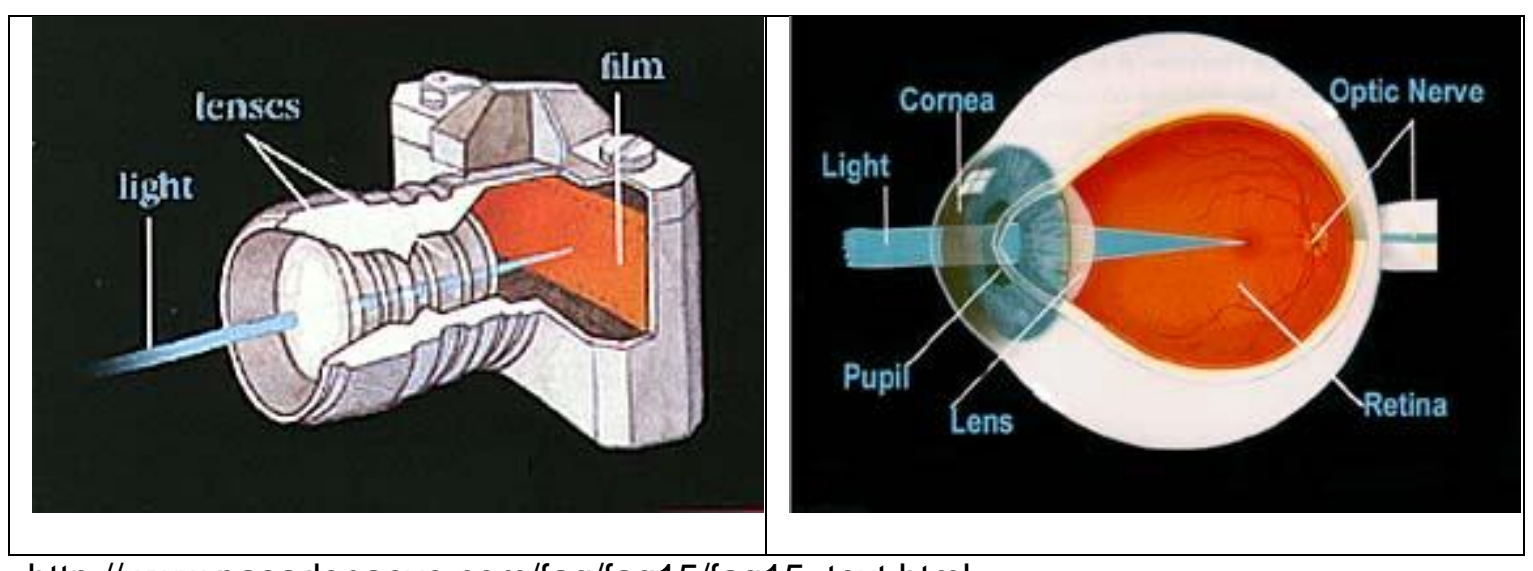

http://www.pasadenaeye.com/faq/faq15/faq15_text.html

\section{A NATUREZA DA LUZ}

Desde a antiguidade os filósofos e os cientistas (estes depois do renascimento) se dedicaram a explicar os fenômenos envolvendo a luz. Desde a época de Newton uma das questões centrais foi o debate sobre a natureza da luz. Este debate envolveu grandes filósofos e cientistas. A questão central poderia ser resumida da seguinte forma:

Teria a luz uma natureza ondulatória ou uma natureza corpuscular?

\begin{tabular}{|l|l|}
\hline Luz como ondas se propagando & Fótons se propagando = Raios de Luz \\
\hline & \\
\hline
\end{tabular}




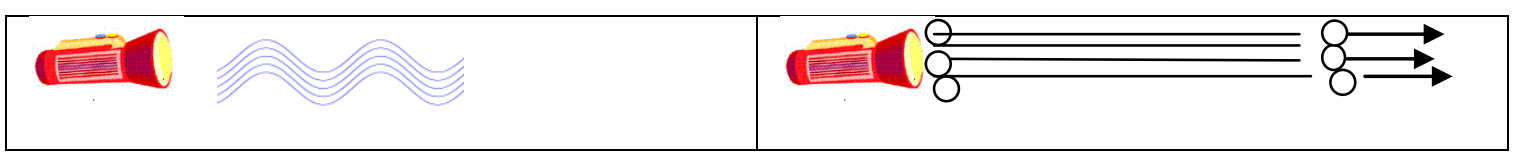

\section{A evolução do conceito de fóton}

Hoje sabemos que a luz é composta de partículas denominadas de fótons. Sendo a luz constituída dessas partículas diminutas, podemos nos perguntar por que só neste século nos demos conta disso?

O homem conhece a luz e seus efeitos desde eras remotas. É claro que ela despertava a curiosidade dos antigos. A formação de sombras e penumbras ocorre no dia-a-dia de todos os seres humanos. Os eclipses já eram utilizados alguns séculos antes de Cristo como um meio de determinar a distância da Terra até a Lua. Tales de Mileto, seis séculos antes de Cristo, já aprendera o método de triangulação para medir distâncias, inferindo a altura da Pirâmide de Gizé a partir da sombra projetada no solo pela pirâmide. Erastótenes utilizou a sombra de uma haste fincada no solo (um gnomo) para determinar o raio da Terra.

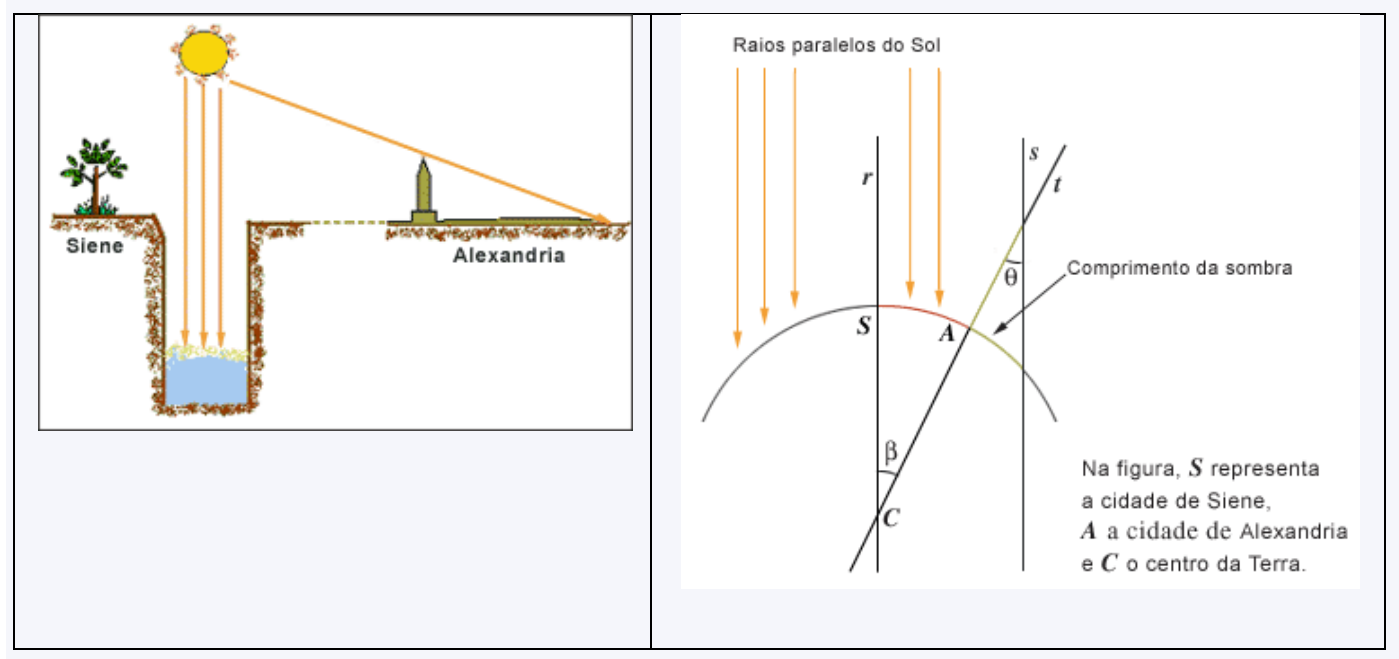

Fig.1. - Método de Erastótenes para se medir o raio da Terra

As sombras e penumbras podem ser explicadas pelo Princípio da Propagação Retilínea da Luz. Princípio esse já enunciado pelos gregos e aparece na obra de Euclides (300 a.C.)

Outros fenômenos associados à luz, como a reflexão e a refração, já eram conhecidos na Antigüidade. Fala-se muito em instrumentos utilizados com muita engenhosidade por Arquimedes na defesa de Siracusa. Dentre eles estavam alguns espelhos para provocar confusão nas hostes inimigas (os romanos).

A suspeita de que a luz tinha velocidade finita começou provavelmente com Galileu. Na época de Newton, ele já tinha conhecimento da determinação da sua velocidade feita por Roemer. De acordo com ele, a luz levaria sete minutos para passar do Sol à Terra. Esses fatos, bem como outros, 
poderiam ser explicados se a luz fosse composta por partículas. Por isso, Newton elaborou uma teoria para a luz, cujo ponto básico é a sua constituição por corpúsculos de luz. O livro de Newton começa definindo:

Por raios de luz entendo as partes mínimas da luz e as que tanto são sucessivas nas mesmas linhas como simultâneas em várias linhas.

Newton se interessou pela óptica antes que pela mecânica. Publicou seu primeiro trabalho em óptica aos 29 anos. Preocupou-se com um fenômeno que naquela época era célebre: o fenômeno das cores. Esse fenômeno, objeto do trabalho de decomposição da luz em diversas cores ao passar por um prisma, já fora detalhadamente descrito por ele aos 23 anos, em 1666. No seu livro "Óptica" Newton afirma que "é evidente que a luz consiste em partes" e se utiliza de termos como "corpos minúsculos" e "partículas de luz".

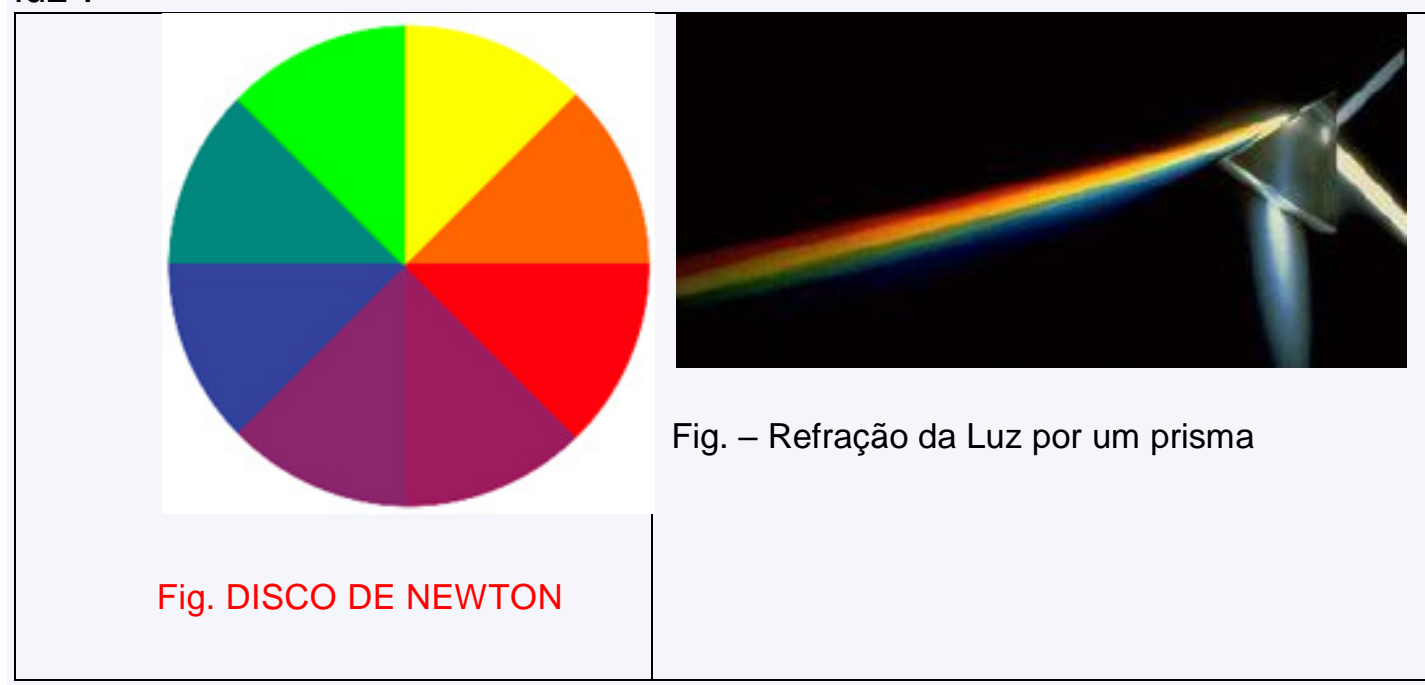

Muitos físicos, de valor excepcional, se opuseram à teoria de Newton. Dentre eles, Robert Hooke e Christiaan Huyghens. A idéia dominante era a de que a luz era a pressão ou o movimento de alguma perturbação que atravessa um determinado meio. Muito próximo, portanto, do que hoje denominamos de ondas.

A idéia da teoria corpuscular da luz prevaleceu (a despeito da oposição) durante o século XVII. Em parte graças ao prestígio de Newton e em parte por falta de evidências contrárias à teoria de Newton.

A teoria de Newton sofreu, no entanto, um grande abalo com os trabalhos de Young e Fresnel a respeito do fenômeno da interferência da luz. A teoria de Newton não é compatível com esse fenômeno.

Podemos ilustrar essa questão imaginando um dispositivo que contém duas fendas (elas estão a uma certa distância uma da outra) com um anteparo a uma certa distância delas. Podemos fazer três experiências. Em cada uma delas enviamos um feixe de partículas.

a) Manter a fenda inferior fechada.

b) Manter a fenda superior fechada.

c) Manter as duas fendas abertas.

O resultado de Young e Fresnel mostrava que a luz exibia interferências. As ondas, ao se superporem (com as duas fendas abertas), podem produzir 
máximos (quando ocorre interferência construtiva) ou mínimos (interferência dita destrutiva). As experiências de Young e Fresnel levaram à Teoria Ondulatória da Luz. A luz seria constituída por vibrações (oscilações de campos elétricos e magnéticos, como se viu depois) transversais à direção de propagação.

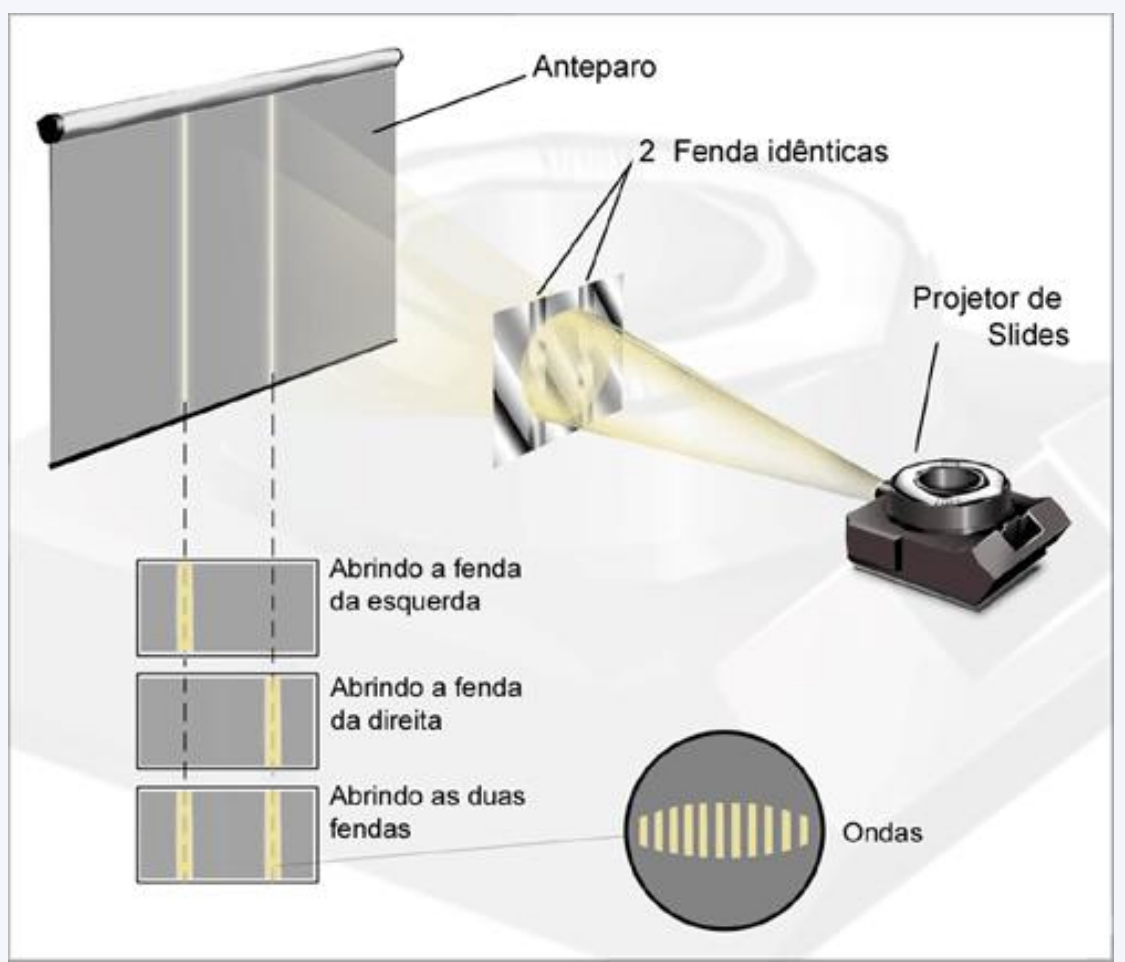

\section{O PRINCÍPIO DE HUYGENS}

A teoria ondulatória de Huygens (de 1678), voltada para explicar a propagação de uma perturbação como um fenômeno ondulatório é baseado num só princípio:

"Cada ponto numa frente de onda se comporta como fonte de ondas secundárias: a frente de ondas num instante posterior é a envoltória dessas ondas secundárias."

Consideremos primeiramente a propagação de ondas esféricas já que todo ponto atingido pela onda se torna a origem de fontes secundárias esféricas.

Se em algum instante de tempo temos uma onda esférica como aquela da figura ( ), então depois de um tempo t, e considerando-se cada ponto como a origem de fontes secundárias, teremos depois desse intervalo de tempo várias ondas secundárias, pois cada ponto sobre a superfície se convertem em fontes de ondas secundárias. Vê-se que a envoltória dessas ondas secundárias é também uma onda esférica. 


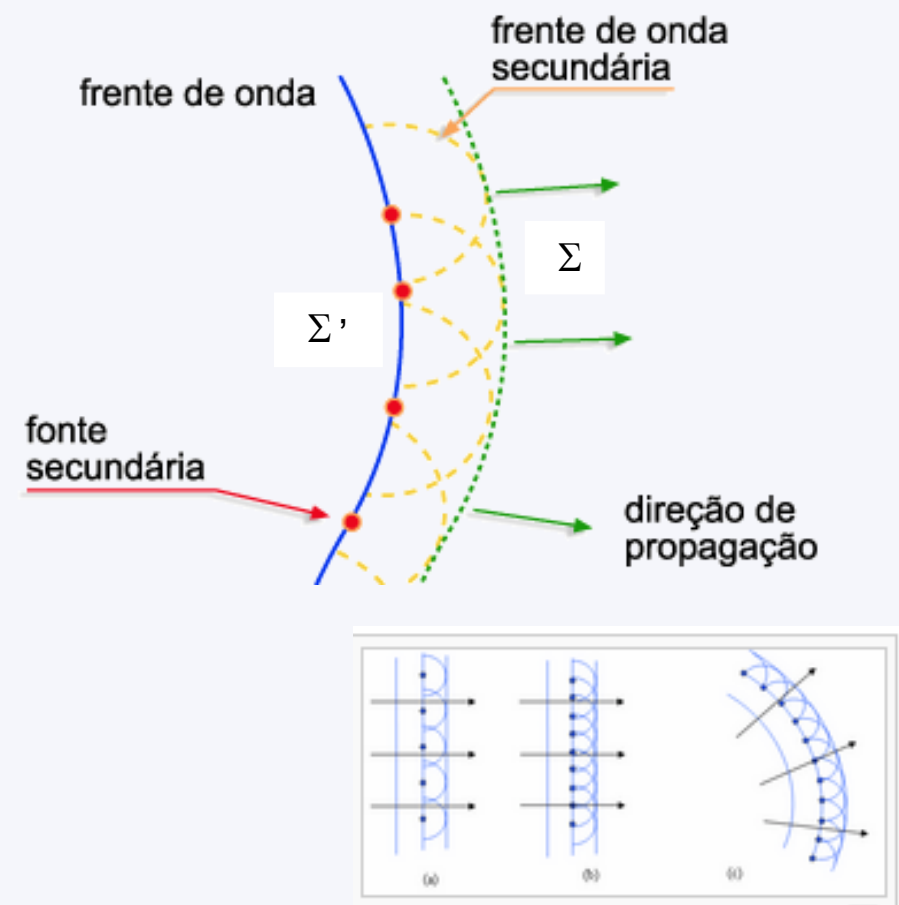

Fig.1 Princípio de Huygens

FIG. Princípio de Huygens

Na realidade temos a formação de duas envoltórias esféricas. Temos como resultado, no entanto, um grande número de ondas secundárias. O que acontence com essas ondas secundárias? Huygens foi capaz de demonstrar que no volume entre as superfícies $\Sigma$ e $\Sigma^{\prime}$ as ondas secundárias se cancelam. $O$ resultado é que depois de um tempo $t$ temos outra perturbação esférica, pois só na região da envoltória $\Sigma$ o resultado é não nulo.

Mais geralmente, isto é, para qualquer tipo de onda, vale o principio de que os vários pontos de uma superfície arbitrária (S) se tornam centros de ondas secundárias. A envoltória geométrica dessas ondas em qualquer tempo posterior representa a posição da frente de ondas. Essa é a base da construção de Huygens.

O lugar geométrico varrido pelas frentes de onda é a região iluminada. 


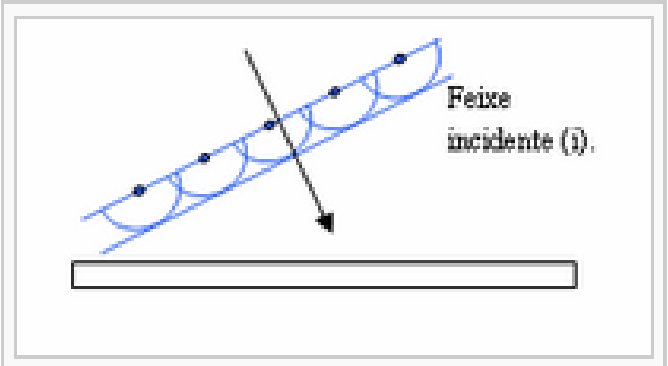

Fig. 2 (a)Frente de ondas Incidentes $\square$

A construção de Huygens nos leva á idéia de raios luminosos. Isso acontece porque podemos pensar a luz como se propagando ao longo de raios os quais, por definição, são perpendicular ás frentes de onda.

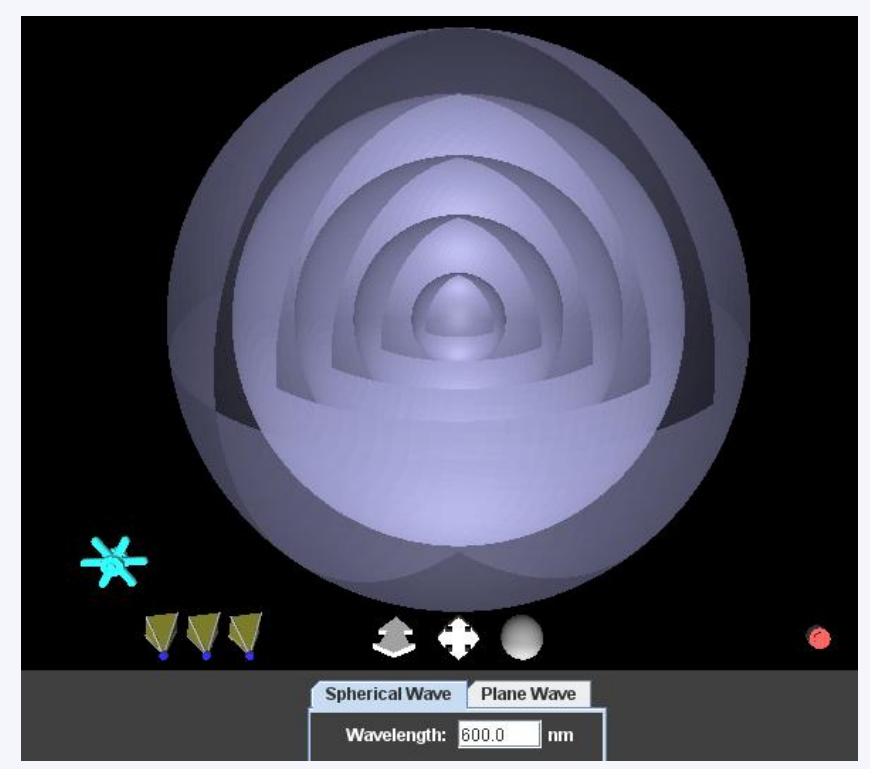

Fig. - Frente de Onda Esférica - Optics Project

Nos meios homogêneos a luz tem a mesma velocidade em qualquer direção. Pela construção de Huygens, podemos facilmente verificar que a luz se propaga em linha reta. Isso pode ser verificado facilmente para ondas esféricas ou planas.

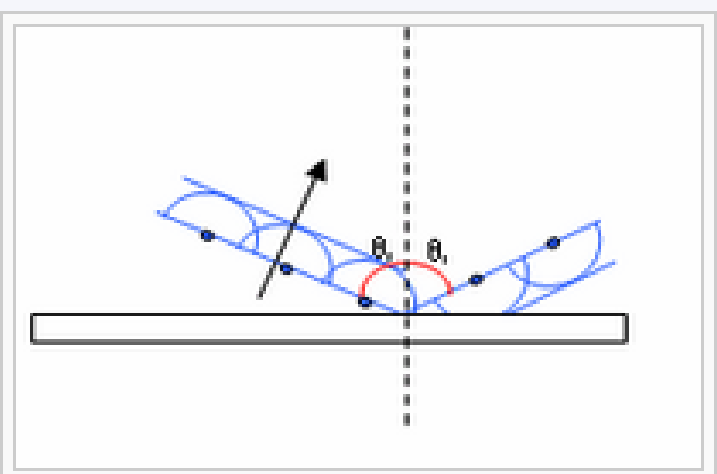

Fig. 2 (c)Frente de ondas refletidas $\square$ 
Tomemos uma frente de onda que esteja se deslocando com velocidade $v$ em um meio com índice de refração $n$. Ao percorrer uma distância d ele gasta um tempo t, tal que

$$
t=\frac{d}{v}=\frac{n d}{c}
$$

O produto do índice de refração pela distância percorrida no meio, nd, denominamos de caminho ótico associado ao percurso no meio ótico.

Questões

1 - Abra o modelo Huygens e verifique essa lei.

\section{DUALIDADE ONDA PARTÍCULA}

A partir dos trabalhos de Young e Fresnel, a teoria de Newton caiu no esquecimento. Foi de outra forma retomada depois do trabalho pioneiro de Einstein em 1905 sobre o efeito fotoelétrico.

Esse efeito pode ser resumido assim. Podemos arrancar elétrons de uma placa se fizermos incidir luz sobre ela. Essa é a origem do nome "fotoelétrico". Sabemos que, para arrancar um elétron, devemos despender uma certa quantidade de energia, pois os elétrons estão presos (ligados) à placa.

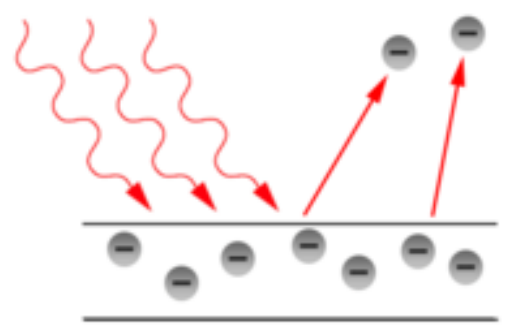

Se a luz não fosse constituída por corpúsculos, haveria a necessidade de um intervalo de tempo entre a luz incidir e o elétron sair. Isso porque se acreditava na necessidade de o elétron acumular energia vinda da radiação luminosa. Ademais, qualquer onda eletromagnética serviria (dizemos de qualquer comprimento de onda). Algumas seriam apenas mais eficientes do que outras. Isto é, arrancariam em menor tempo do que outras.

Duas surpresas ocorreram. A primeira é a de que só radiação com uma freqüência acima de certo valor podia arrancar elétrons. $E$ a segunda é a de que, para essa radiação, não havia a necessidade de se esperar nada.

Einstein então, em 1905, interpretou, corretamente, que o efeito fotoelétrico com essas características só poderia ser explicado se a luz fosse composta por partículas denominada por ele de quanta de luz. Hoje estas são denominadas de fótons. Os fótons observados deram razão a Einstein. Desde então as evidências têm-se acumulado em favor da teoria 
corpuscular da luz, que é a teoria vigente.

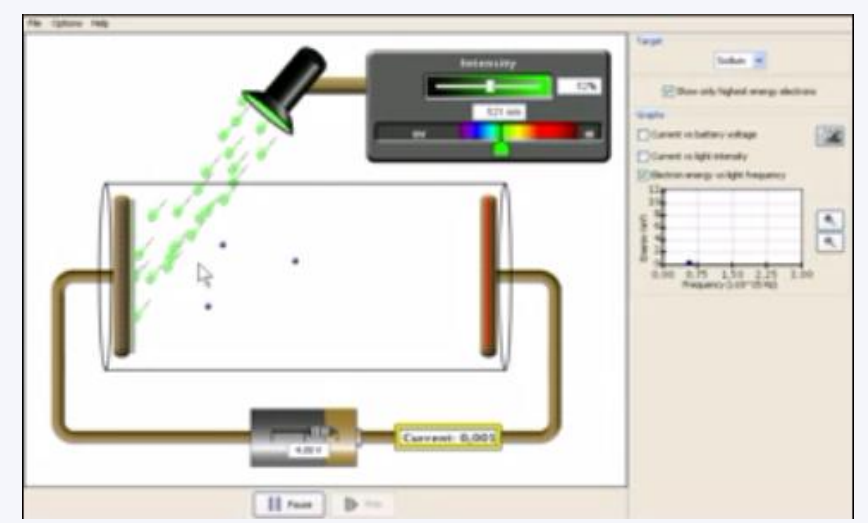

Fig. - Efeito Fotoelétrico (tirado de http://www.youtube.com/watch?v=bnR1syXU5dU )

Como todas as partículas, os fótons exibem uma natureza dualística: onda e partícula. Os fótons em alguns fenômenos exibem mais claramente a natureza ondulatória (como na interferência de Young) e em outros se torna mais evidente a natureza de partículas (como no efeito fotoelétrico). Hoje, com o dualismo onda-matéria podemos conciliar a idéia de Newton com os resultados de Young e de Fresnel.

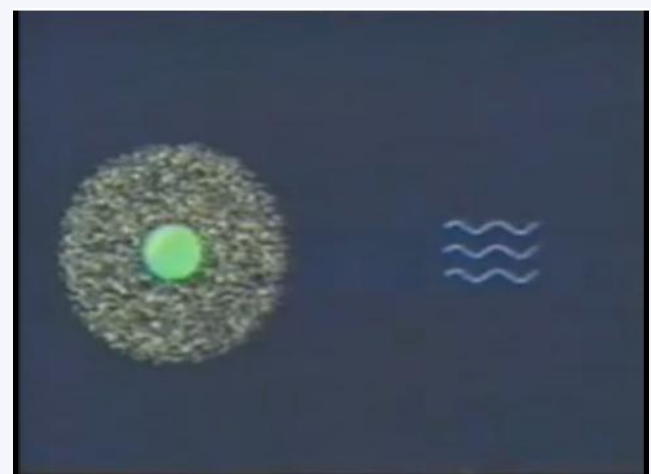

Fig. Quantum de Energia - http://www.youtube.com/watch?v=CEuMmMxD-vl

A confirmação inequívoca de que a luz exibe a natureza corpuscular veio com a descoberta, em 1923, do efeito Compton (em homenagem ao seu descobridor, Arthur Compton). Nesse efeito, o fóton exibe um comportamento típico de bola de bilhar. Isto é, a colisão entre o fóton e um elétron obedece às regras de colisão entre partículas. 
X-ray Physics: Compton Effect
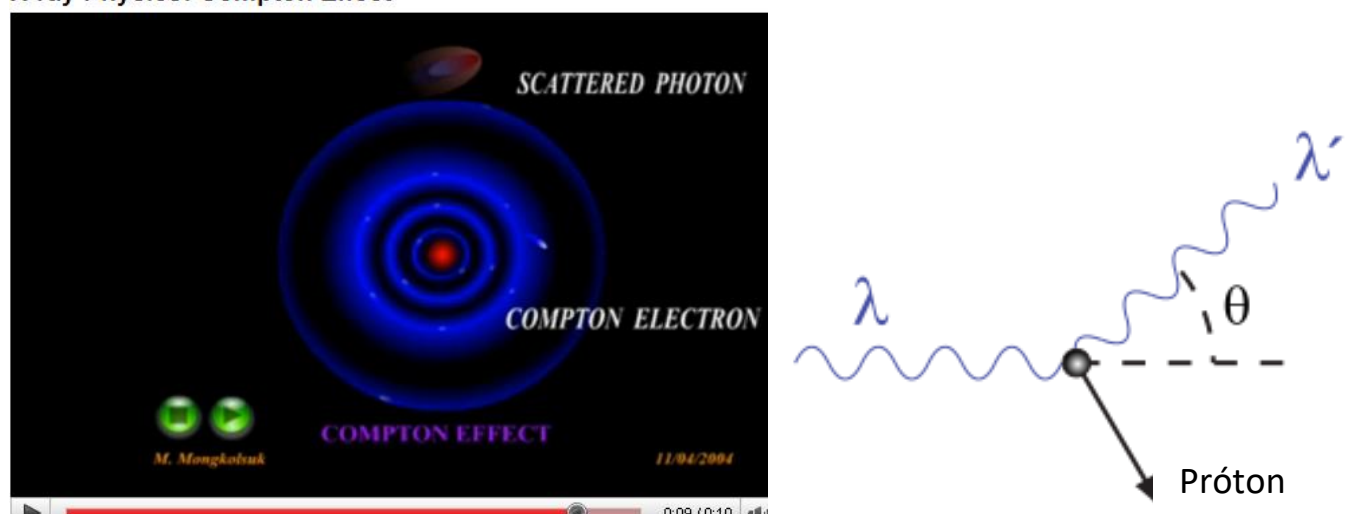

Fig. - Efeito Compton - http://www.youtube.com/watch?v=zYZNTzviBxs\&feature=related

Os fótons são afinal, como todas as partículas. Os elétrons, por exemplo, exibem a mesma natureza dualística: onda e partícula. Hoje, com o dualismo onda-matéria podemos conciliar a idéia de Newton com os resultados de Young e de Fresnel. Apesar dessas características serem excludentes, elas são de fato complementares.

Vídeo - http://www.youtube.com/watch?v=CEuMmMxD-vl

\section{A VELOCIDADE DA LUZ}

A luz ao incidir sobre um determinado meio tende a se propagar através dele. A velocidade com que a luz se propaga depende do meio material.

A velocidade máxima de propagação da luz denominada de c ocorre num meio do qual extraímos toda a matéria. Tal meio é o que denominamos de vácuo. Por exemplo, podemos considerar o meio entre a Terra e o Sol, ou entre a Terra e as estrelas como sendo o vácuo. A partir da formulação da Teoria da Relatividade Restrita e das experiências de Michelson e Morley ficou constatado que a velocidade da luz é uma constante universal, ou física. Medidas experimentais modernas determinam que essa velocidade é de aproximadamente

$$
c=299.792 .458 \frac{m}{s}
$$




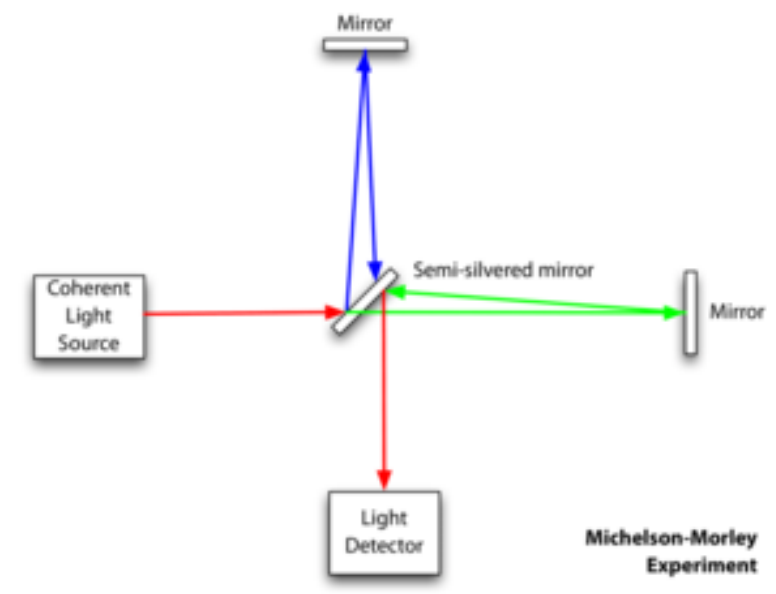

Fig - Experimento de Michelson e Morley - http://pt.wikipedia.org/wiki

A relação entre a velocidade da luz num determinado meio e a velocidade da luz no vácuo é dada por:

$$
\mathrm{C}=\mathrm{nV}
$$

Onde n é o índice de refração do meio. Assim, como a luz se propaga na água a uma velocidade maior do que no ar, temos que $n$ para a água é maior que 1. O índice de refração entre dois meios quaisquer é dado pela razão inversa entre os seus índices de refração:

$$
\mathrm{N}_{12}=\mathrm{n}_{2} / \mathrm{n}_{1}=\mathrm{v}_{1} / \mathrm{v}_{2}
$$

Após a teoria de Maxwell, podemos relacionar $\mathrm{n}$ com as propriedades eletromagnéticas do meio.

\section{PRESSÃO DA RADIAÇÃO}

\section{Modelo Clássico}

A pressão de radiação é a pressão exercida sobre certa superfície devido a incidência de uma onda eletromagnética. Apesar de não possuir massa, isto ocorre porque uma onda eletromagnética possui momento linear. Logo, o princípio da conservação do momento linear exige que a interação da radiação eletromagnética sobre a superfície deve transmitir momento linear. Isto é, Maxwell mostrou que a magnitude do momento transferido $\Delta$ p pela radiação em uma absorção total por um corpo é proporcional à variação da energia deste:[Hallidey]

$$
\Delta p=\frac{\Delta U}{c}
$$

Onde c é a velocidade da luz. A direção do momento adquirido pelo corpo é o da onda incidente. 


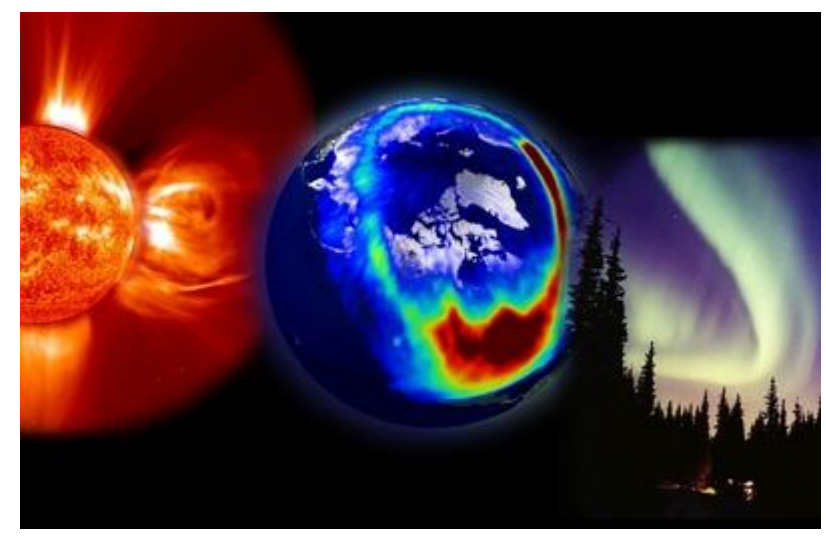

Fig. Vento Solar. Aurora Boreal. (http://www.tecnoclasta.com/)

No caso de um onda refletida, a lei da conservação do momento impõe que a variação do momento deve ser o dobro do caso da absorção total:

$$
\Delta p=\frac{2 * \Delta U}{c}
$$

Suponha que a radiação esteja sendo refletida ou absorvida por uma superfície de área A que esta tem intensidade I. Logo, a variação de energia em uma reflexão total é

$$
\Delta \mathrm{U}=2 \mathrm{IA} \Delta \mathrm{t}
$$

e a variação no momento linear é

$$
\Delta p=\frac{2 * I * A \Delta t}{c}
$$

Usando a segunda lei de Newton temos

$$
F=\frac{\Delta p}{\Delta t}=\frac{2 * I * A}{c}
$$

Calculando-se a razão entre a força atuante sobre a superfície e a área total de atuação encontra-se a pressão de radiação.

$$
P=\frac{f}{A}=\frac{2 * I}{c}
$$

A pressão da radiação é um efeito muito importante em astrofísica. Ela é um dos efeitos que mantém uma estrela estável. Ou seja, que a atração gravitacional não colapse em um ponto todo o gás desta.

\section{Modelo Quântico}

A pressão de radiação é devida ao fato da radiação denotar energia. Max Planck, ao conceber a física quântica e apresentar seu artigo sobre a distribuição de energia no espectro normal, a 2 de fevereiro de 1900, estabeleceu experimentalmente que para cada unidade da escala de freqüência $(\mathrm{Hz})$, a energia mecânica, em J-s $=\mathrm{N}-\mathrm{M}^{2} / \mathrm{s}^{2}$, é de $\mathrm{h}=$ 6,602.10-34 J-s. Se formos analisar por este parâmetro, em vista de que newtons 
equivalem a hectogramas-força, podemos converter a constante de Planck h para gramas-força $\mathrm{gF}$, e dividirmos $1 \mathrm{~g}$ por ela, o resultado é um valor que, em escala de freqüência, equivale a frequiência de energia mecânica de um grama.

Do ponto de vista do modelo fotoelétrico da radiação temos que cada fóton de freqüência $\mathrm{v}$ ao se chocar sobre uma superfície qualquer qualquer irá transmitir um momento $\mathrm{p}=\mathrm{h} / \lambda$ a esta. Como força é dada por:

$$
F=\frac{d p}{d T}
$$

e pressão é definido como força por unidade de área ( $\mathrm{P}=\mathrm{F} / \mathrm{A})$, temos que $\mathrm{n}$ fótons exerceram uma pressão igual a:

$\mathrm{P}=\frac{n}{A} * \frac{d p}{d T}$

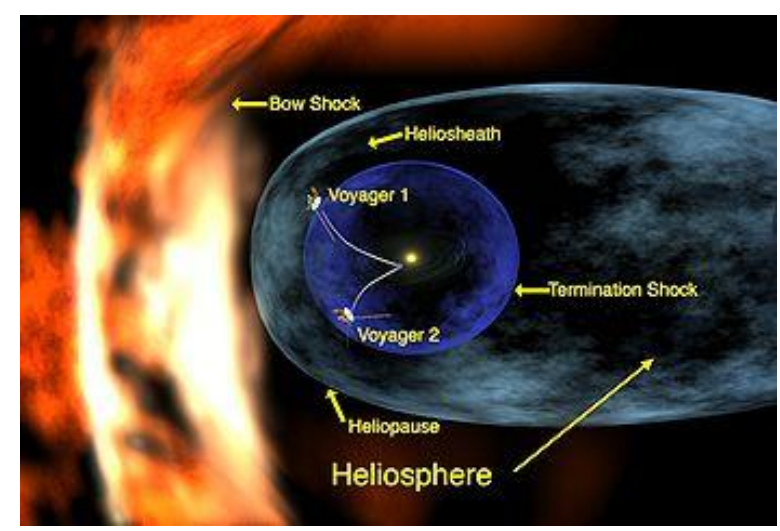

Fig. - Formação da Heliosfera em torno da Terra. (http://pt.wikipedia.org/wiki/)

\section{ATIVIDADES}

1 - Analise os applets sobre difração da luz por uma fenda simples e dupla.

Link: Simples. http://www.walter-fendt.de/ph14e/singleslit.htm

Dupla. $\rightarrow$ http://www.walter-fendt.de/ph14e/doubleslit.htm 


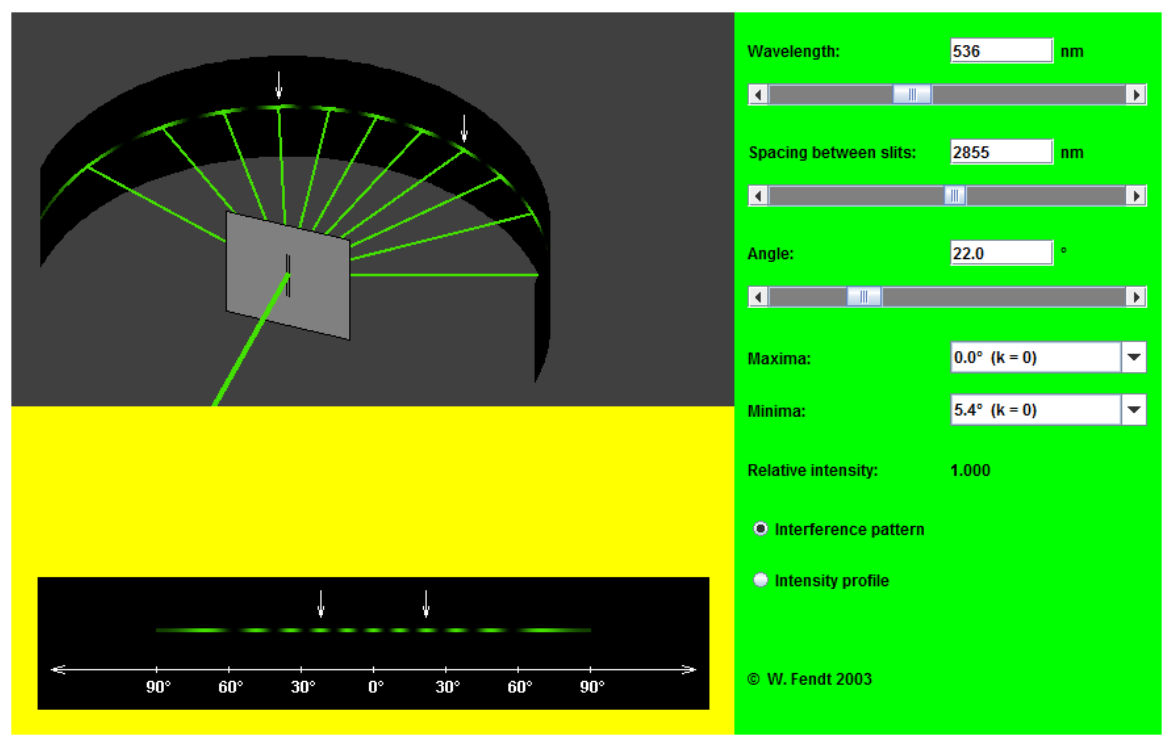

4.5 - Projeto Prolicen. Applets do professor Fu-Kwun Hwang Analise os applets sobre difração da luz por uma fenda dupla.

Link $\rightarrow$ http://www.fisica.ufpb.br/prolicen/

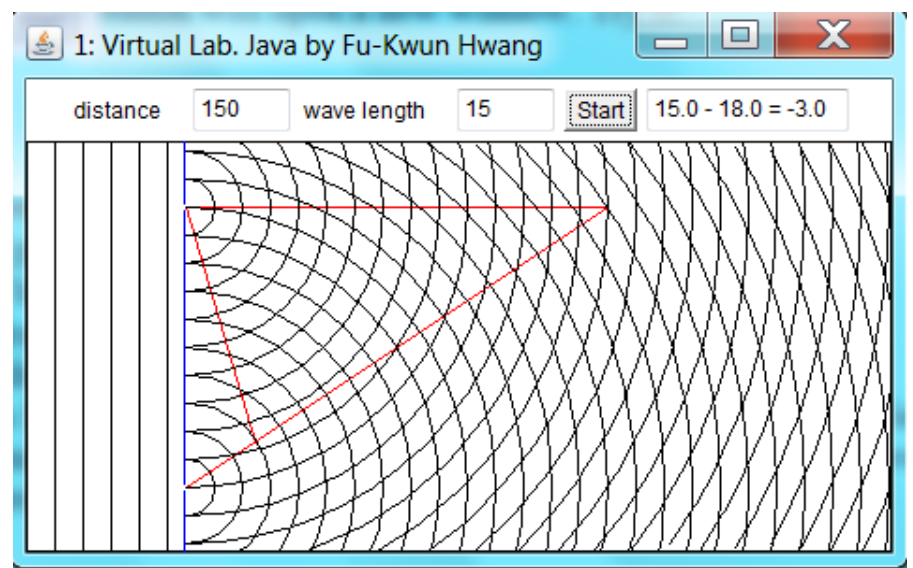

4.6 - Analise os applets do site da universidade do Colorado.

http://phet.colorado.edu/en/simulation/photoelectric 


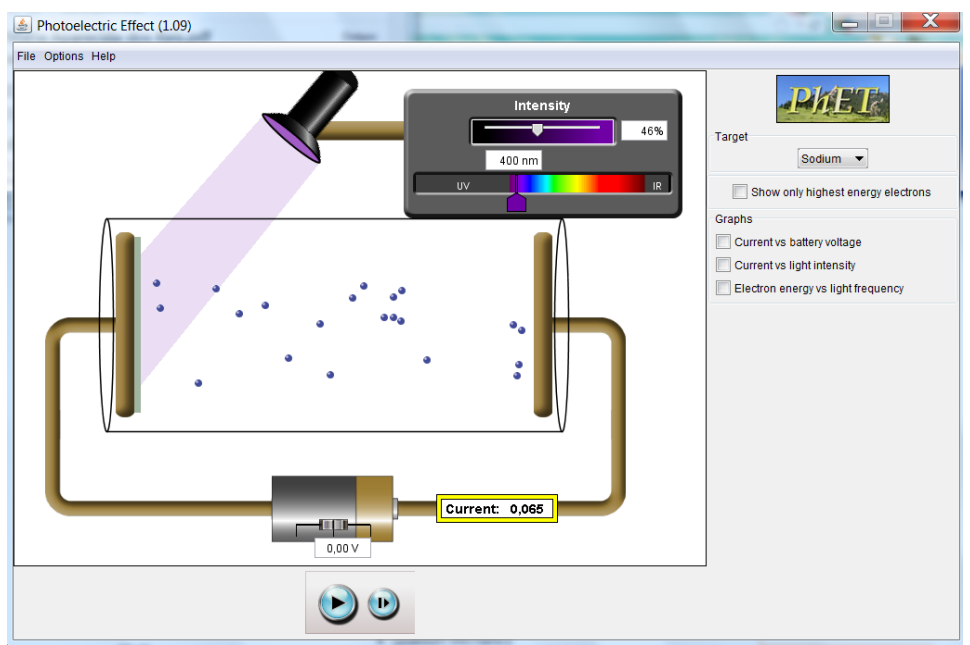

Analise os applets do site da King's Centre of Visualitation in Science;

1 - Efeito Compton: HTTP://www.kcvs.ca/site/projects/physics.html

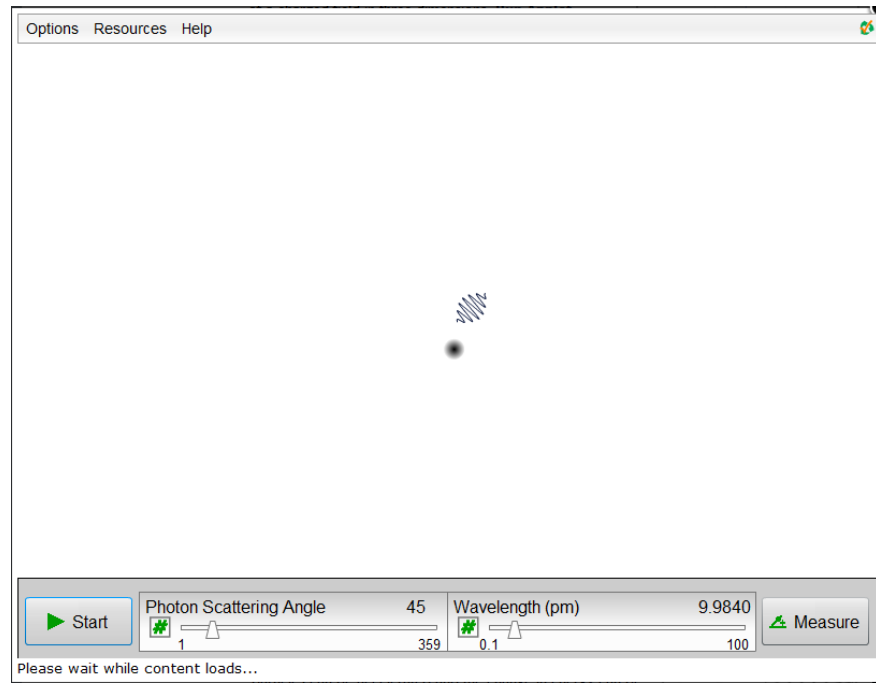

\section{2 - Efeito Fotoelétrico}

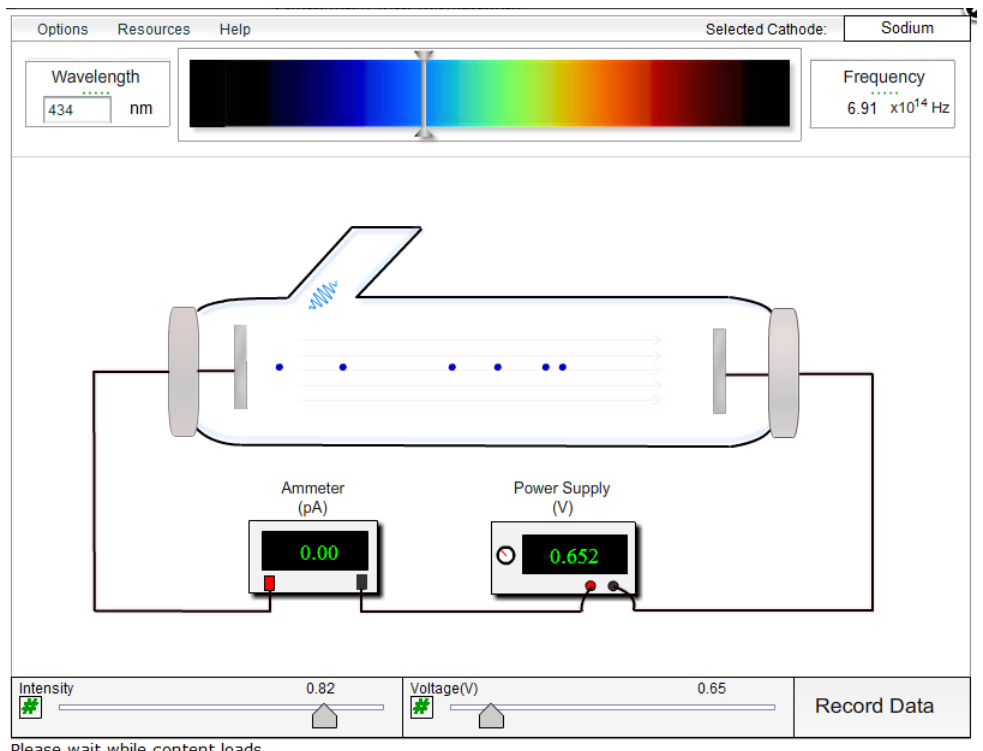




\section{2 - Vídeo aula}

2.1 - Novo Telecurso. Natureza da Luz. http://www.youtube.com/watch?v= EKew0LTzgKU\&feature $=$ results_main\&playnext=1\&list=PLAEFD3124BDBA530A

2.2 - Novo Telecurso. Natureza da Luz. Parte 2. http://www.youtube.com/watch?v=DBtE2xxSm5s.

2.3 - Dualidade Onda Partícula. http://www.youtube.com/watch?v=rqwKPJ3wlul\&feature=related

2.4 - Dualidade Onda Partícula. Dr. Quantum. http://www.youtube.com/watch?v=2NuLa29WKnl\&feature=related

2.5 - Principio de Huygens. http://www.youtube.com/watch?v=QDrnFDAyEjE 2.6 - Cuba de Ondas. http://www.youtube.com/watch?feature=endscreen\&v=ORgFE$\underline{Q Q M 2 w \& N R=1}$

2.7 - Efeito Fotoelétrico. http://www.youtube.com/watch?v=5BcdTs2CSTg

\section{3 - Experimentos de Baixo custo}

3.1 - Projeto Experimentos de Física com Materiais do Dia-a-Dia - UNESP/Bauru

\section{PULVERIZADOR}

Objetivo

O objetivo deste experimento é visualizar um feixe de luz, observando sua existência e comportamento.

Contexto

A luz, para a maior parte dos fenômenos cotidianos, propaga-se em forma de raios. Estes, são compostos de partículas (fótons), e se propagam sempre retilinearmente a partir da fonte. Feixe de luz é um conjunto de raios luminosos.

Idéia do Experimento

Um lanterna é colocada em uma posição fixa iluminando um obstáculo (parede). Nesta situação, só é possível observar a luz que é gerada pela lanterna e o efeito que ela causa no obstáculo. É aparentemente possível que a luz descreva qualquer trajetória até atingir a parede (como por exemplo, uma trajetória curva ou em "zig-zag"). Pulveriza-se água colorida com leite ao longo do feixe de luz que vai da lanterna até a parede. Assim, é possível observar que o feixe luminoso criado pela lanterna, propaga-se em linha reta e não de qualquer outro modo até o obstáculo. 
Tabela do Material

\begin{tabular}{|l|l|}
\hline Item & Observações \\
\hline Pulverizador & Desses usados para regar plantas \\
\hline Lanterna & \\
\hline Leite & Duas ou três colheres das de sopa \\
\hline Água & \\
\hline
\end{tabular}

Montagem

- Coloque água dentro do pulverizador e adicione leite até que a água fique esbranquiçada.

- Posicione a lanterna de modo que ilumine o obstáculo.

Comentários

- O local no qual o experimento for realizado deve permanecer escurecido ou na penumbra.

- Se o experimento for realizado em sala de aula, o pulverizador pode ser substituído por dois apagadores. Batendo um apagador no outro, em uma posição, de preferência, acima do feixe, produz-se uma nuvem de pó na região deste. Este procedimento resulta no mesmo efeito do pulverizador.

Esquema Geral de Montagem

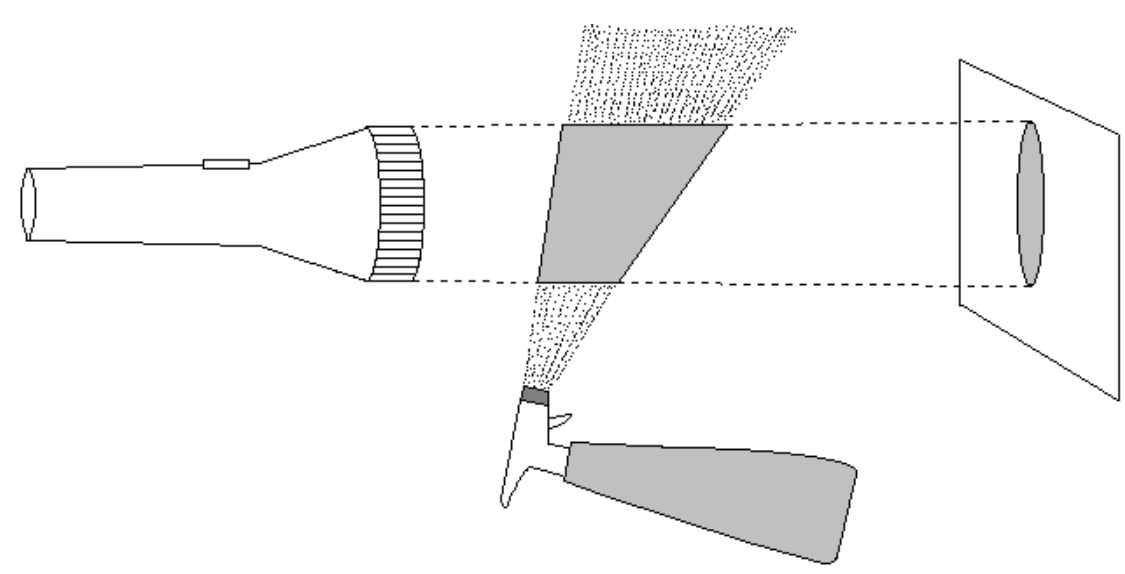

3.2 - CARTÕES FURADOS (Projeto Experimentos de Física com Materiais do Dia-a-Dia - UNESP/Bauru)

Objetivo

Este experimento tem por objetivo demonstrar que os raios de luz se propagam em linha reta. 
A luz, para a maior parte dos fenômenos cotidianos, propaga-se em forma de raios. Estes, são compostos de partículas (fótons), e se propagam sempre retilinearmente a partir da fonte. Em algumas situações, a luz também pode comportar-se como onda. Isto é perfeitamente explicado pela Física.

Idéia do experimento

Três cartões iguais com um pequeno orifício no meio são dispostos em fila de forma que fiquem exatamente alinhados. Em um extremo é colocada uma vela acesa cuja chama fica alinhada com os furos do cartões. No outro extremo fica o observador. Há duas situações de observação. Na primeira, os furos dos cartões ficam alinhados e é possível ver a chama da vela do outro lado porque a luz se propaga em linha reta através dos furos. No segundo caso, retira-se qualquer um dos três cartões do alinhamento e não mais é possível ver a luz porque ela esbarra em um dos cartões. Para que se pudesse enxergar a luz, ela teria que ter uma trajetória curva. Com os resultados de ambas disposições, se conclui que a luz se propaga em linha reta.

Tabela do Material

\begin{tabular}{|l|l|}
\hline Item & Observações \\
\hline Cartolina & Pode ser substituída por qualquer tipo de papelão não muito grosso. \\
\hline Vela & Pode ser substituída por uma lanterna. \\
\hline
\end{tabular}

Montagem

- Corte três retângulos $(10 \mathrm{~cm} \times 15 \mathrm{~cm})$ iguais de cartolina (veja figura abaixo).

- Faça um corte reto $(5 \mathrm{~cm})$ no meio do lado menor de cada cartão.

- No lado cortado, dobre cada parte para um lado de modo que se crie um apoio para que o cartão fique na vertical.

- Coloque os cartões em fila de modo que fiquem exatamente alinhados.

- Em um extremo da fila, coloque uma vela acesa cuja chama fique alinhada com os furos dos cartões. 


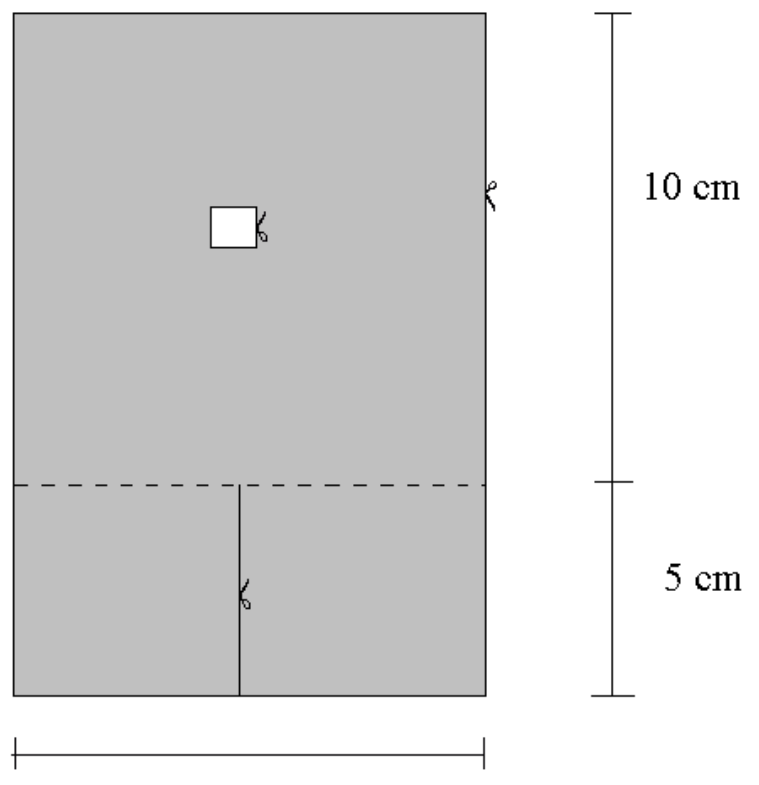

\section{Comentários}

- Para o bom andamento do experimento é importante que os cartões sejam exatamente iguais.

- A altura da chama da vela deve ser igual à dos furos dos cartões.

Esquema Geral de Montagem

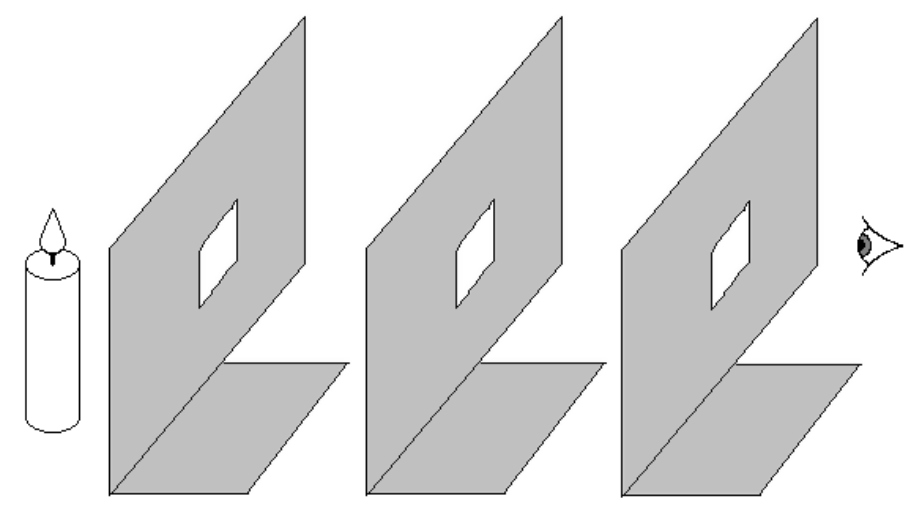

3.3 - PENTE REFLEXIVO (Projeto Experimentos de Física com Materiais do Diaa-Dia - UNESP/Bauru)

Objetivo

O objetivo deste experimento é observar a reflexão e comprovar a lei que rege este fenômeno. 
Reflexão é o fenômeno pelo qual a luz ao encontrar um obstáculo é rebatida. Para melhor compreender este fenômeno é preciso antes definir as duas etapas da reflexão. Na primeira etapa (incidência) o raio de luz chega até o espelho. Ao ângulo que este raio forma com o espelho damos o nome de ângulo de incidência. Já na segunda etapa, o raio de luz sai do espelho (reflexão). Ao ângulo que este raio forma com o espelho damos o nome de ângulo de reflexão. Para a reflexão existe uma lei: o ângulo de incidência é igual ao ângulo de reflexão.

\section{Idéia do Experimento}

Um espelho é colocado na posição vertical em contato com a superfície de uma mesa. Em sua frente, coloca-se um pente com os dentes encostados na mesma superfície. Posiciona-se uma lanterna de modo que a sombra produzida pelos dentes do pente atinjam o espelho fazendo sombra na superfície, tanto quando incide no espelho, como quando refletem. Para conferir a lei da reflexão coloque um papel na superfície da mesa, em baixo do espelho e do pente. Risque o papel com um lápis na base do espelho. Risque a trajetória de um dos raios que saem do pente e são refletidos pelo espelho. Observe que no papel aparecerá a trajetória de um dos feixes de luz. É possível medir com um transferidor os ângulos de incidência e reflexão e constatar que eles são iguais.

Tabela do Material

\begin{tabular}{|l|l|}
\hline Item & Observações \\
\hline Pente & $\begin{array}{l}\text { Desses pequenos com as bordas alaranjadas. São encontrados em } \\
\text { qualquer supermercado ou bazar. }\end{array}$ \\
\hline Espelho & \\
\hline Lanterna & $\begin{array}{l}\text { Este instrumento só será utilizado para medir os ângulos de incidência e } \\
\text { reflexão. Por isso, sua ausência não comprometerá o funcionamento do } \\
\text { experimento, uma vez que é possível observar a olho nú a semelhança dos } \\
\text { ângulos. }\end{array}$ \\
\hline Lápis ou \\
\hline Traneta
\end{tabular}

Esquema Geral de Montagem 


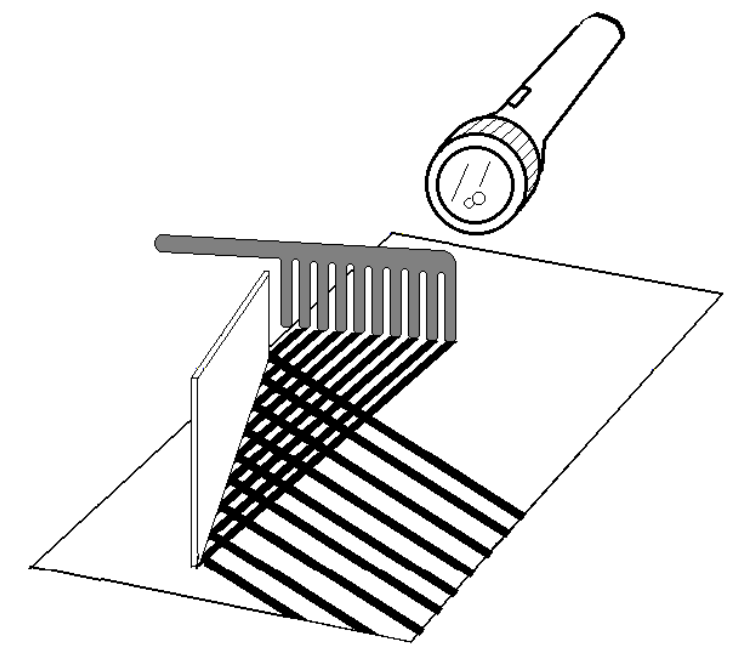

\section{4 - BURAQUINHO}

\section{Objetivo}

Este experimento tem como objetivo compreender qual o efeito visual resultante de uma difração.

Contexto

Existem dois estudos feitos acerca da natureza de propagação da luz. Um deles prevê que a luz é composta de minúsculas partículas (fótons) que se propagam sempre em linha reta formando raios. A este estudo dá-se o nome de óptica geométrica. A outra linha de raciocínio diz que a luz é uma onda e se comporta como tal. Esta teoria é chamada óptica ondulatória. Por ser descrita por essas duas teorias, diz-se que a luz apresenta dualidade partícula-onda. Neste experimento só nos ateremos ao comportamento ondulatório da luz.

Quando a fonte luminosa se encontra razoavelmente afastada, a luz praticamente se propaga na forma de ondas planas. Se estas frentes de ondas se chocarem contra um aparato que contém um orifício com diâmetro comparável ao comprimento de onda da luz, ocorrerá um espalhamento destas frentes. Este fenômeno recebe o nome de difração. Só a teoria ondulatória explica tal fenômeno. Porém, se pensarmos que os raios de luz são perpendiculares às frentes de onda, o que ocorreria seria um espalhamento dos raios, como mostra a figura abaixo.

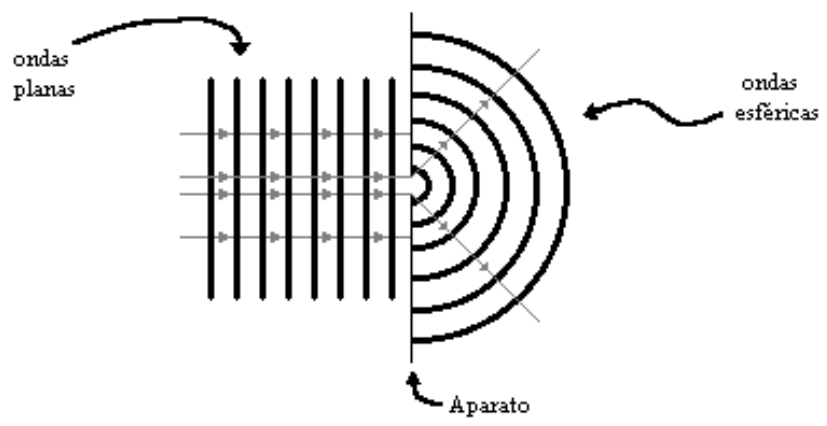


A teoria ondulatória de Huygens pode explicar bem este fenômeno. Cada frente de onda é formada pela soma de infinitas ondas esféricas, como ilustra a figura abaixo. Quando esta frente de onda, ao se propagar, encontra uma barreira com um pequeno orifício, é como se apenas uma das ondas esféricas passa pelo furo, permitindo que só esta se propague a partir daí, o que resultaria em uma onda esférica que se propaga radialmente do orifício.

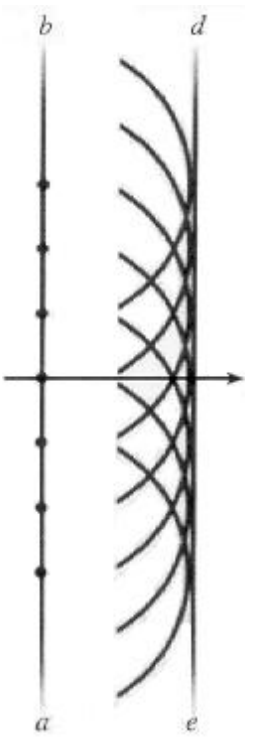

\section{Ideia do Experimento}

Um pequeno orifício feito num papel funciona como uma lente de aumento, permitindo que se veja uma imagem ampliada de um objedo que se encontra muito próximo do olho do observador. Isso se deve ao fenômeno de difração que neste caso, faz com que os raios que saem do objeto sejam espalhados, tornando a imagem maior que o objeto (figura abaixo). Também é possível corrigir miopia com difração pois, este fenômeno, faz com que a luz se comporte da mesma maneira que quando é submetida a uma lente divergente, que é a lente utilizada na correção desta patologia.

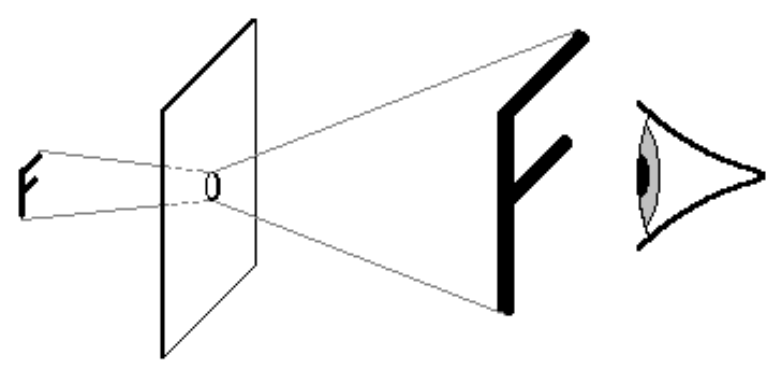

Tabela do Material

\section{Item Comentários}

Cartolina De preferência escura porém, pode ser utilizado qualquer papel. 
Montagem

- Faça, com o alfinete, um furo no papel.

- Aproxime, do olho, algo que quer ser lido a aproximadamente $10 \mathrm{~cm}$.

- Coloque o papel com o furo e olhe através dele.

- Pode-se então notar que além da imagem ficar mais nítida, houve um aumento dela.

Comentários

- Se a pessoa que realizar o experimento for portador de um grau não tão alto de miopia, pode utilizar este pequeno orifício para conseguir enxergar algo que esteja longe, sem os óculos.

Esquema Geral de Montagem

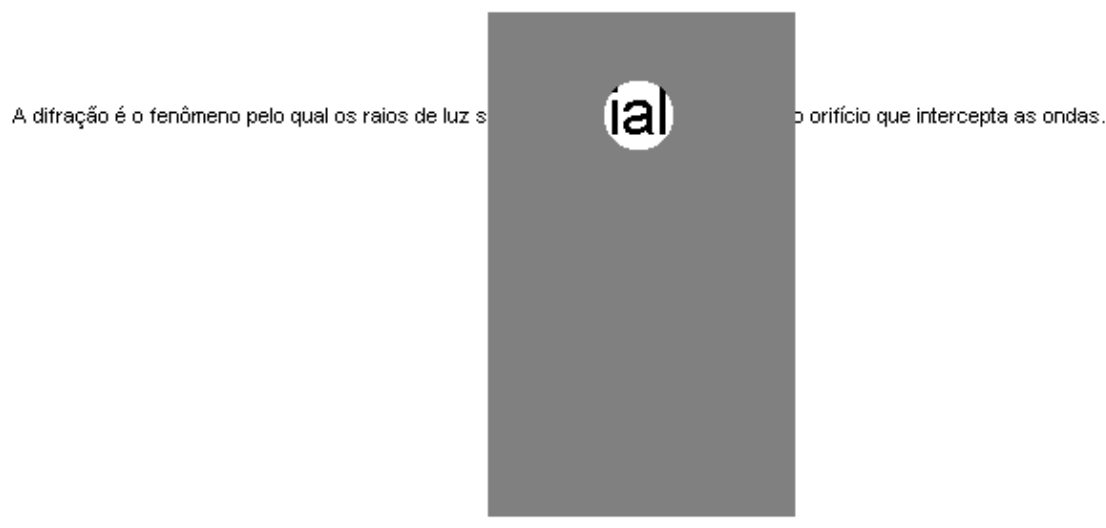

O orifício que aparece na figura acima, apesar de parecer grande, tem o diâmetro de uma seção transversal em um alfinete.

\section{5 - ÁGUA ÓPTICA}

Objetivo

O objetivo deste experimento é construir um sistema em que uma coluna de água conduza luz de forma curva, o que mostra o fenômeno da reflexão total.

Contexto

Quando um raio de luz se propaga em um meio com um determinado índice de refração e tenta atravessar para outro meio com índice de refração menor do que este em que ela vêm se propagando, parte da luz será refratada e a outra parte será refletida. Se aumentarmos o ângulo de incidência do raio de luz neste novo meio, chegará a um ângulo em que toda luz será refletida. À este ângulo damos o nome de Ângulo Limite e à este fenômeno Reflexão Total.

Idéia do Experimento 
Um sistema é arranjado de modo tal que a água que escoa de um furo feito em uma garrafa e iluminado por uma lanterna, conduza alguns raios desta luz emitida pela lanterna durante sua trajetória. Colocando um aparato (como a mão por exemplo) no final do feixe de água que sai da garrafa, observa-se uma luminosidade de espessura do feixe d'água. Pode-se concluir então que o feixe d'água conduz a luz até o aparato. É interessante salientar que este é o mesmo princípio utilizado pela condução de luz dentro da fibra óptica.

Tabela do Material

\begin{tabular}{|l|l|}
\hline Item & Comentários \\
\hline $\begin{array}{l}\text { Garrafa de óleo } \\
\text { de cozinha }\end{array}$ & Plástica e transparente. \\
\hline Tinta acrílica & $\begin{array}{l}\text { Pode-se também usar qualquer tipo de tinta ou fita isolante para } \\
\text { impedir que a luz atravesse uma das faces da garrafa de óleo. }\end{array}$ \\
\hline $\begin{array}{l}\text { Pincel para } \\
\text { aplicar a tinta }\end{array}$ & \\
\hline Lanterna & \begin{tabular}{l} 
Pode ser utilizado uma bacia ou um recipiente grande qualquer. O \\
experimento também pode ser realizado em uma pia, sendo que, a água \\
que escoa da garrafa pode vir direto da torneira e ser recolhida pela pia \\
\hline Água
\end{tabular} \\
\hline Recipiente parando sai da garrafa. \\
\hline colher a água
\end{tabular}

Montagem

- Corte a parte superior da garrafa, retirando a boca. Limpe o interior dela com detergente.

- Faça um furo, com aproximadamente meio centímetro de diâmetro, em uma das faces da garrafa de óleo, o mais baixo possível.

- Pinte com tinta a face da garrafa em que foi feito o furo. Nós usamos tinta acrílica e deixamos secar por aproximadamente um dia.

- Tape o furo, coloque água na garrafa e ilumine, com a lanterna, a face oposta à face que está pintada.

- Solte o furo e coloque a mão no feixe da água que escorre da garrafa.

Comentários

- Para que o experimento seja realizado com sucesso o ambiente deve permanecer o mais escuro possível.

Esquema Geral de Montagem 


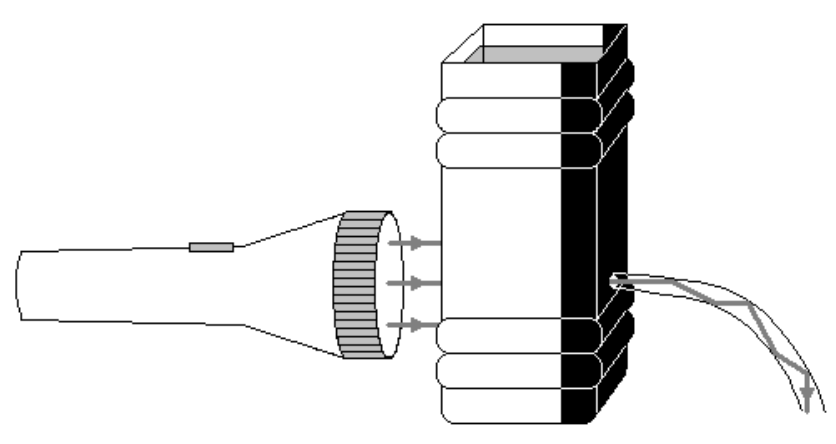

COMENTÁRIOS:

CONCLUSÃO: 


\section{Cap.07 - EXPLICANDO AS CORES}

Meta: Fazer que o estudante comece a pensar no ensino de ciências como algo "orgânico" que está em profunda transformação. Fazer com que os alunos percebam, através de uma atividade lúdica, que podemos ensinar física através de experimentos muito simples. Fazer com que o aluno percebam as aplicações da física no cotidiano.

Objetivos: Ao final da aula, os alunos devem estar cientes das novas possibilidades e dos desafios que envolvem o ensino de ciências em geral. Que para se ensinar física não precisamos ficar presos ao livro didático. Que ensinar física não é ensinar a resolver problemas e que a física é uma mera aplicação da matemática.

Pré-requisitos: Os alunos deveram ter cursado psicologia da educação física $A$, $\mathrm{B}$ e C.

\section{Introdução:}

As cores sempre exerceram um grande fascínio sobre os seres humanos. Por isso, o entendimento do fenômeno sempre foi objeto de investigações e especulações ao longo de muitos séculos. As investigações sobre o fenômeno estão longe de ter chegado ao fim. 
Uma análise cientifica e mais completa do fenômeno das cores vai além da Física, pois envolve aspectos biológicos. Podemos dividir o estudo das cores em três aspectos.

- Percepção das cores

- Propriedades da luz

- Propriedades físicas dos Objetos

Primeiramente, analisaremos a questão de como os seres humanos percebem as cores. É o problema da percepção das cores. Essa questão foge á competência e interesse dos físicos. Faremos, no entanto uma rápida discussão sobre o tema.

O segundo aspecto diz respeito á relação das cores com as propriedades da luz e, mais geralmente, com as propriedades do espectro eletromagnético. É nesse contexto que se encaixa o trabalho pioneiro de Newton, o qual relacionou o fenômeno das cores ás propriedades da luz.

Finalmente é importante frisar que as cores exibidas pelos objetos podem ser entendidas a partir de determinadas propriedades físicas dos mesmos.

\section{A PERCEPÇÃO DAS CORES}

A visão a cores é uma capacidade inerente a alguns seres vivos de distinguir os objetos com base em uma propriedade da luz que provem dos mesmos. Alguns animais são destituídos dessa capacidade. Estes animais são sensíveis á luz mas são insensíveis a essa propriedade da luz.

Essa propriedade que nos permite distinguir objetos com base na cor, é a freqüência (ou o comprimento de onda) da onda eletromagnética. Levando-se em conta a natureza corpuscular da luz podemos dizer que os nossos olhos são sensíveis á energia dos fótons que compõem a radiação eletromagnética..

Para entendermos como funciona a percepção da visão a cores, isto é como adquirimos a capacidade de distinguir as cores dos objetos, apresentamos na figura abaixo, a seção transversal do olho humano.

http://www.webciencia.com/11 32visao.htm

http://www.pasadenaeye.com/faq/faq15/faq15 text.html

http://br.youtube.com/watch?v=Fznl7|xO96o

http://br.youtube.com/watch?v=F2wrPm0zFbA\&feature=related 

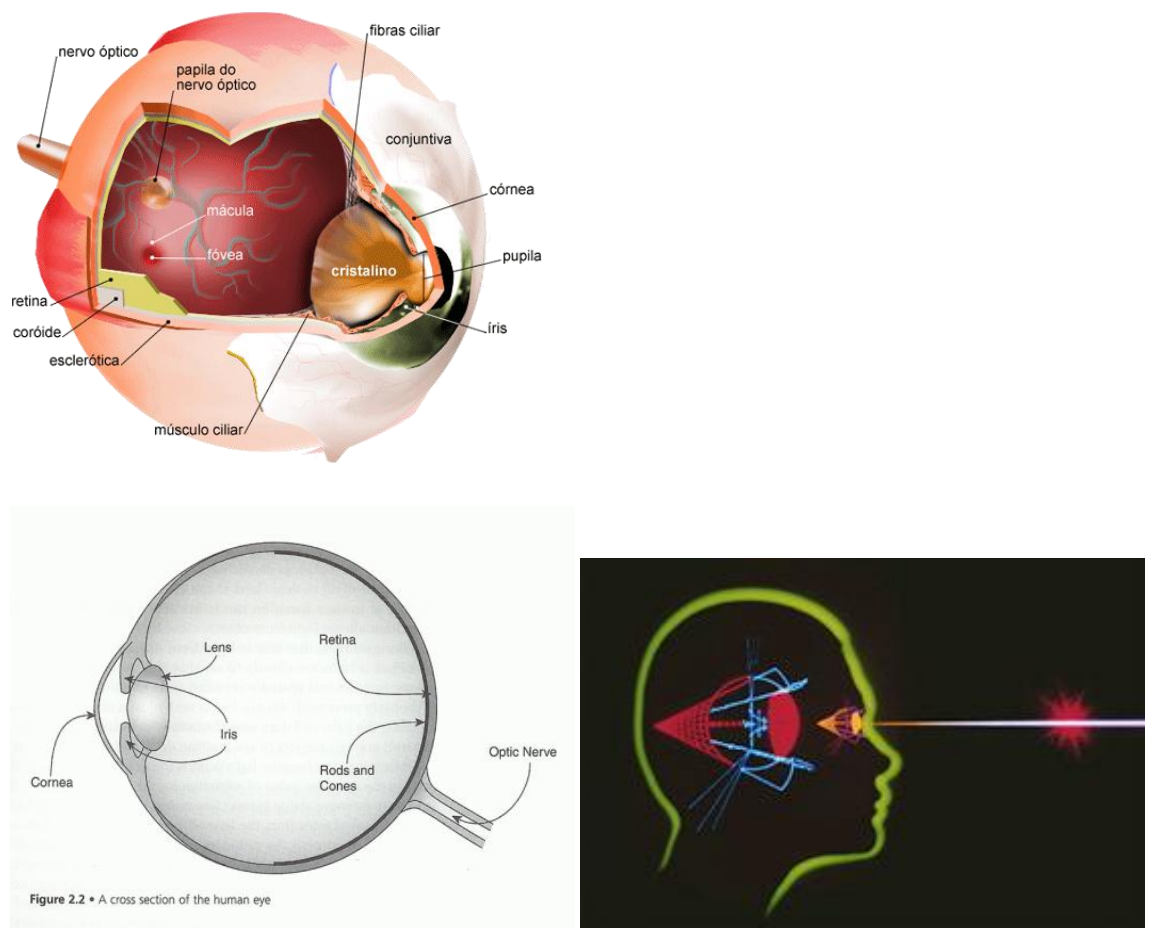

Fig. Como o olho percebe as cores.

Do ponto de vista do mecanismo da percepção das cores, é essencial entender como a cor é registrada no nosso cérebro, a partir do momento em que ela incide numa pequena parte do nosso globo ocular.

Primeiramente lembramos que os raios luminosos provenientes de um objeto incidem primeiramente numa parte do globo ocular conhecida como Córnea. Em seguida os raios passam pela Íris. A íris tem um diâmetro variável cuja função é controlar a quantidade de luz que entra no olho. No centro da íris está a pupila do olho. Em seguida a luz atinge uma lente conhecida como cristalino. O cristalino é a lente (biconvexa) do olho. A finalidade dessa lente ajustável é focalizar a luz numa parte do olho conhecida como Retina e localizada na parte detrás do globo ocular. A retina é uma camada fina composta de células neurais e que cobre uma fração dessa parte do olho. Grosso modo poderíamos dizer que os vários componentes ópticos do globo ocular (como a íris e o cristalino) têm a função de fazer chegar a luz até a retina e na medida da necessidade. A retina desempenha um papel central no que diz respeito á visão. Ela pode ser comparada ao filme de uma máquina fotográfica. 


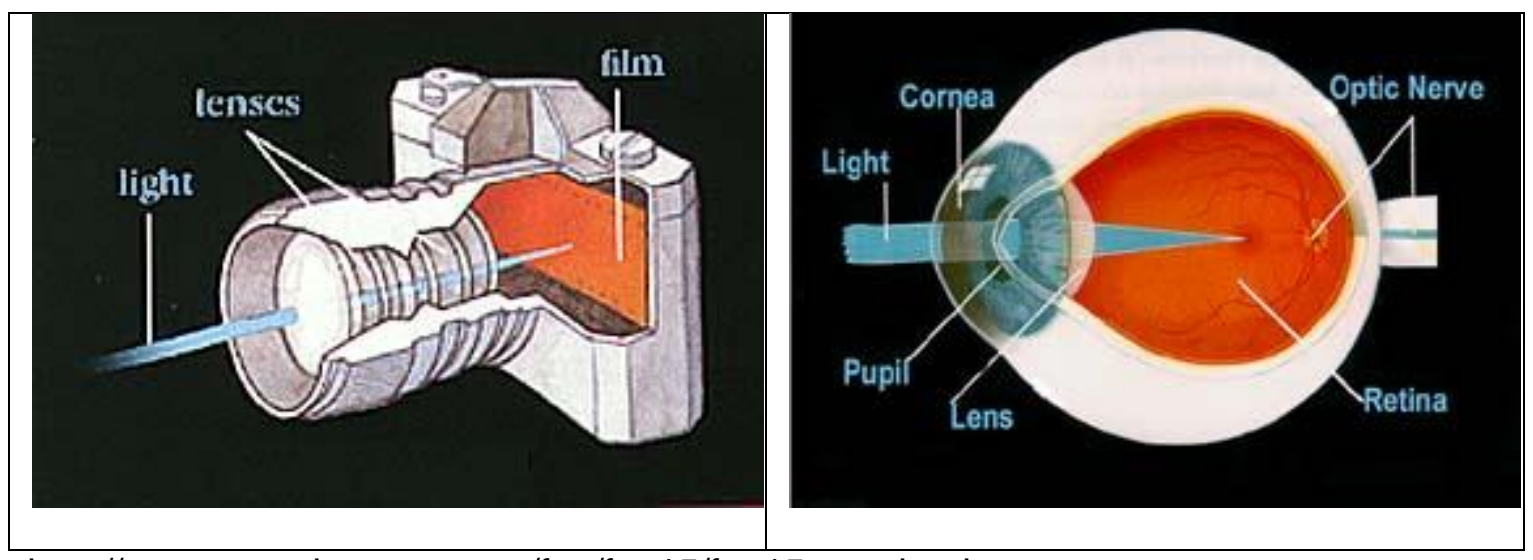

http://www.pasadenaeye.com/faq/faq15/faq15_text.html

A retina faz parte do sistema nervoso central, e é composta de dois tipos de células: Cones e Bastonetes. Essas células são fotos sensíveis. Os nomes têm a ver com sua forma geométrica. A retina contém cerca de 90 milhões de bastonetes e um número menor de cones (cerca de 5 milhões). Tanto os cones quanto os bastonetes são sensíveis á luz e nos auxiliam no processo da visão. Os dois tipos de células têm, no entanto, funções distintas no mecanismo da visão.

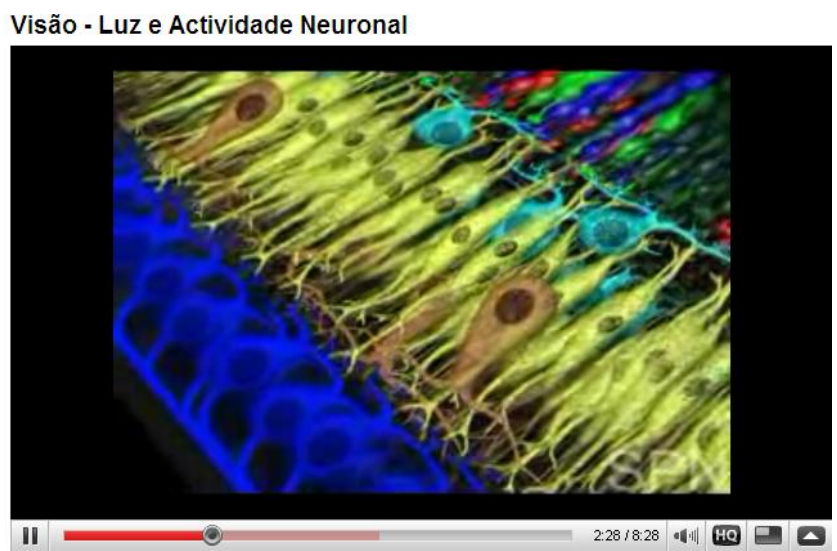

Figura - Video 3D neurociência

(http://www.youtube.com/watch?v=ikNJuVXfux4\&feature=related)

Quando a luz atinge a retina, ela produz reações químicas tanto nos cones como nos bastonetes. Os níveis dessas reações são dependentes da intensidade da luz que atinge as células. No caso dos cones a luz é capaz de converter moléculas de um tipo( cis-retinal) em outra moléculas de outro tipo (trans-retinal).

Os bastonetes são cerca de 100 vezes mais sensíveis á luz do que os cones. Para sensibilizar os bastonetes basta uns poucos fótons. Devido a essa extrema sensibilidade, eles são responsáveis pela visão noturna.O sentido da visão provida pelos bastonetes no entanto, é uma visão a duas cores: branco e preto. Com pouca luz é possível observar formas e movimentos, mas não cores. 
- Bastonetes $\rightarrow$ Visão noturna

- Cones $\rightarrow$ Visão a cores

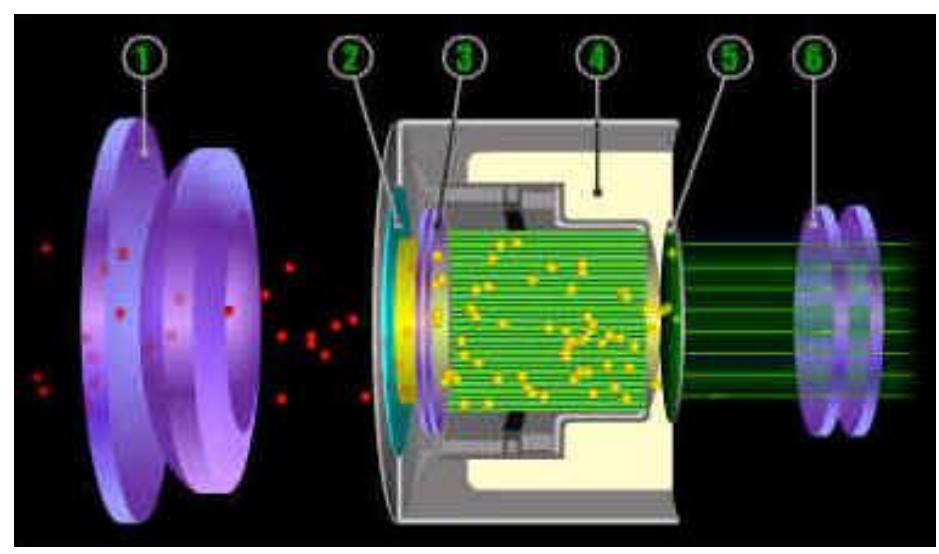

- 1. Lentes Frontais 4. Fonte de Alta Voltagem 2. Catodo 5. Tela de fósforo 3. Prato com Microcanal 6. Eyepiece

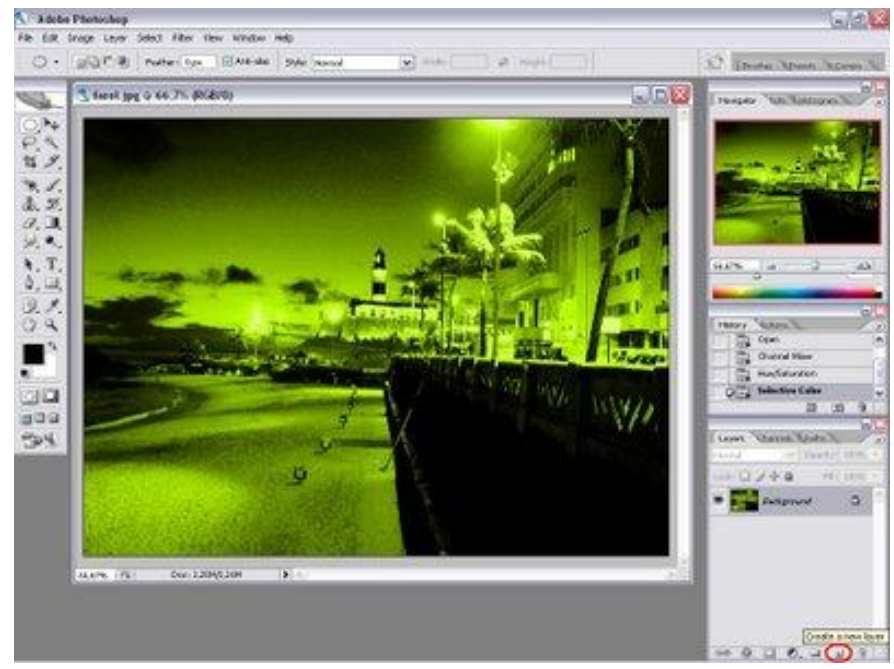

Os Cones são responsáveis pela visão a cores. Isto é, os cones são capazes de diferenciar as ondas eletromagnéticas com base na sua freqüência. Na verdade estamos falando de três tipos de cones. Longos (cerca de $20 \%$ do total) Médios (cerca de $78 \%$ do total de cones) e Curtos (2\% do total). Os cones longos são mais sensíveis á luz de menor freqüência (na região do vermelho), e, por isso são ás vezes denominados de cones vermelhos. Os demais cones (verde e azul) são mais sensíveis á luz composta por ondas de freqüências maiores.

Os cones ocupam a região central da retina conhecida como Fóvea. Os bastonetes se encontram na região mais periférica da retina.

As reações químicas aludidas acima serão processadas no globo ocular e informações sobre as mesmas são enviadas, através do nervo óptico, para o cérebro. Este último é o responsável pelas sensações que experimentamos e que associamos ás cores. 
Curtos, Médios e Longos
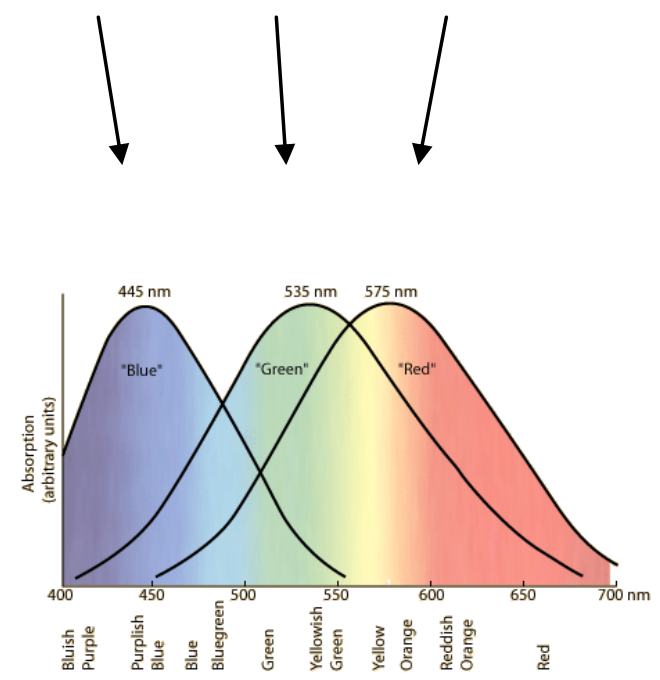

Ocorre que só sensibilizamos os nossos sentidos, para efeito de enxergar os objetos, se as ondas eletromagnéticas estiverem dentro de determinados valores. A parte do espectro eletromagnético visível está no intervalo entre $400 \mathrm{~nm}$ até $700 \mathrm{~nm}$. Outros animais podem ser sensíveis a outro domínio do espectro eletromagnético.

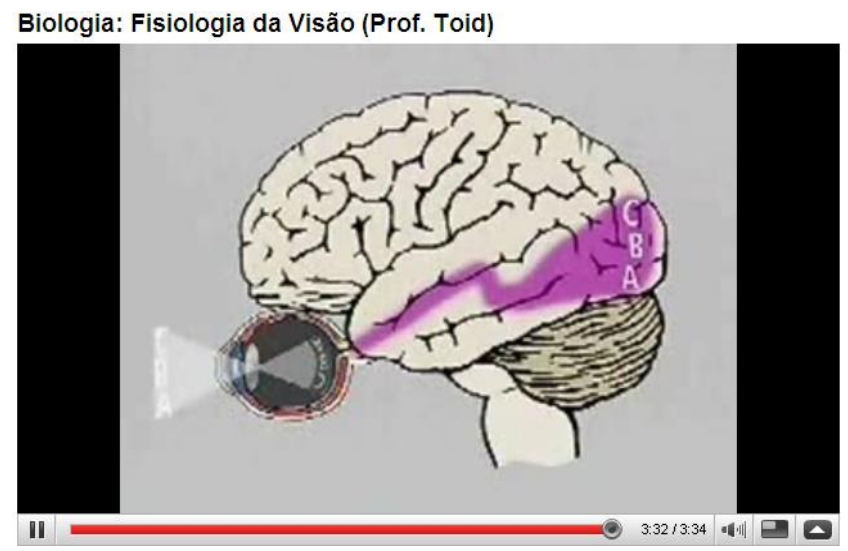

Figura - Vídeo sobre o funcionamento do olho Humano (http://www.youtube.com/watch?v=hf26vde1TXE )

http://www.geocities.com/seriecorpohumano/oolhoeavisao.htm 
Credita-se a Aristóteles os primeiros trabalhos escritos sobre a natureza da luz bem como sobre visão a cores. Coube a Newton, cerca de dois séculos depois, esclarecer que a visão a cores tem alguma coisa a ver com a luz.

"No começo do ano de 1666 (época em que me dedicava ao polimento de vidros ópticos de outras formas além da esférica), obtive um prisma de vidro triangular para tentar observar com ele o célebre fenômeno das cores."

"Tendo escurecido meu quarto e feito um pequeno orifício na folha da janela a fim de deixar entrar uma quantidade conveniente da luz solar, coloquei o meu prisma no orifício de modo que a luz pudesse ser refratada, por esse processo, para a parede oposta. No começo foi uma diversão muita agradável ver as cores vivas e intensas produzidas por aquele processo, mas depois de me aplicar por um momento a considerá-las com mais cuidado, fiquei surpreso ao ver que tinham forma oblonga, que, de acordo com as leis recebidas da refração, eu esperava fosse circular".

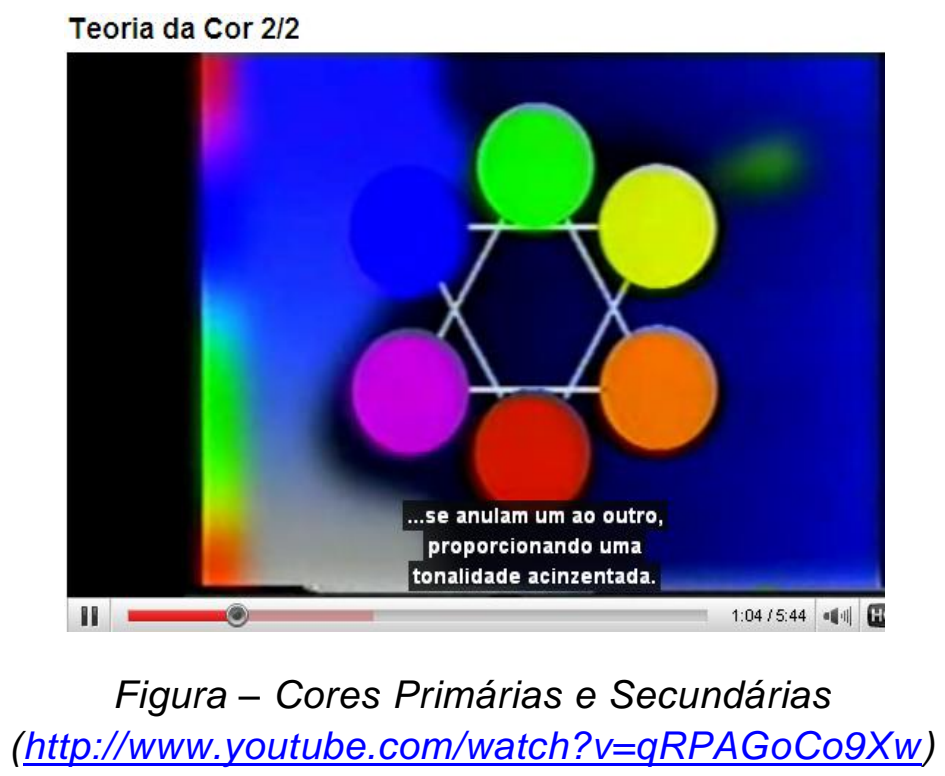

"As cores não são qualificações da luz, derivadas das refrações ou reflexões dos corpos naturais (como se acredita geralmente); são propriedades originais $e$ inatas que diferem em raios diferentes. Alguns raios tendem a apresentar uma cor vermelha e nenhuma outra, outros uma cor amarela e nenhuma outra, outros uma cor verde e nenhuma outra, e assim por diante. Não há apenas raios próprios e particulares às cores mais dominantes, e sim a todas as suas gradações intermediárias."

Essas palavras de Isaac Newton (1642-1727) foram escritas em seu primeiro trabalho publicado', dois meses depois que ele completou 29 anos 
Newton fez duas importantes descobertas em relação ás cores. A primeira que é possivel decompor a luz branca e, como consequencia disso, propos que a a luz seria uma mistura das várias cores. Abaixo apresentamos um dispositivo (o disco de Newton) para comprovar sua teoria de uma forma bem simples.

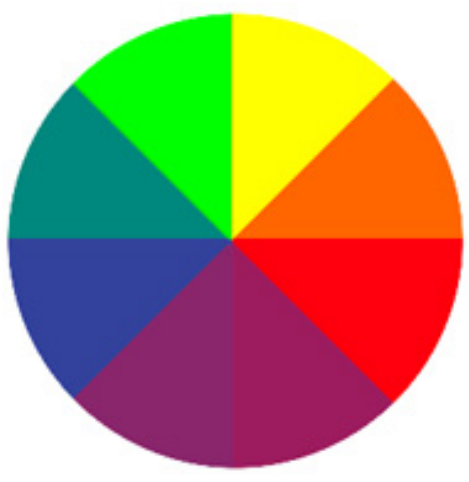

Fig. DISCO DE NEWTON

http://br.youtube.com/watch?v=kh-zvLB27XA

\section{TEORIA DAS CORES}

Goethe foi um dos grandes pensadores do século XIX . Era escritor, filósofo e cientista. Ele publicou em 1810 um livro com o sugestivo titulo de "Teoria das Cores". Sua teoria seria mais geral do que a Newton, a qual combatia. A obra de Goethe continha elementos sobre a natureza das cores que posteriormente se revelaram corretas. Isso vale especialmente em relação ao aspecto da percepção emocional das cores. Concentrou-se nos aspectos do brilho e do contraste como fatores determinantes da percepção das cores.

O aspecto mais relevante na obra de Goethe seria o de chamar a atenção para a distinção entre uma característica da luz, associada ao espectro eletromagnético, e o fenômeno associado á percepção humana das cores. Esse último item tem a ver com a questão de como o cérebro processa os sinais emitidos pelos cones e interpreta esses sinais associando-os ás cores.

Thomas Young fez uma importante contribuição á teoria das cores ao propor a sua teoria Tricromática. Nela, Young observa, corretamente, que qualquer cor pode ser reproduzida a partir da combinação de três cores.

Uma das contribuições mais significativas para entender o fenômeno das cores foi dada por Maxwell. Em 1861 ele propôs pela primeira vez que a luz estivesse relacionada com os fenômenos eletromagnéticos. Sua teoria, que veio a público em 1864 demonstrava isso em detalhes. Como a velocidade da luz está, na sua teoria relacionada a propriedades eletromagnéticas do meio, ele estimou que a velocidade da luz deveria ser de $310,740,000 \mathrm{~m} / \mathrm{s}$. Esse resultado o levou a concluir que: 


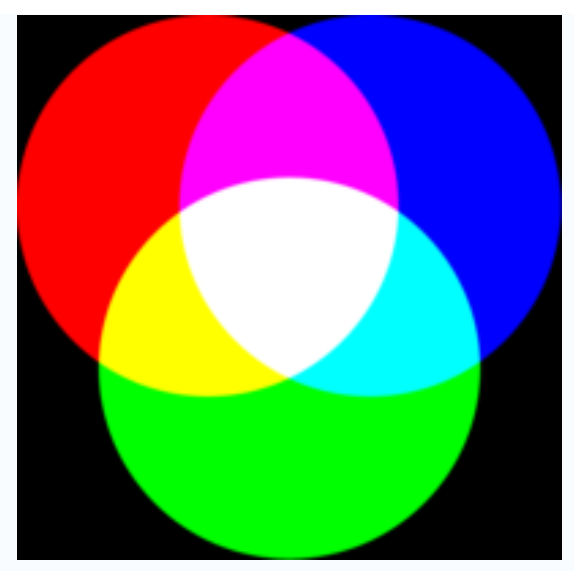

Fig. As três cores primárias.

"A concordância entre os resultados parece mostrar que a luz e o magnetismo são propriedades (facetas) de uma mesma substância, e a luz é uma pertubação eletromagnética que se propaga pelo campo de acordo com as leis do eletromagnetismo."
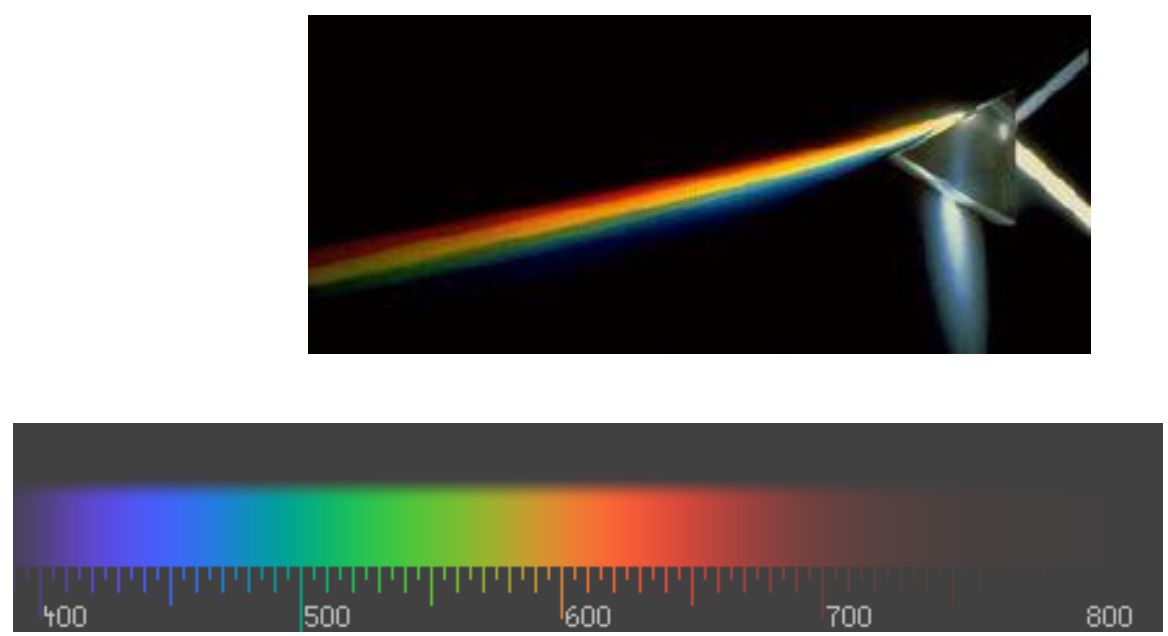

Do ponto de vista da teoria corpuscular isso pode ser entendido de outra forma, mas inteiramente equivalente á teoria ondulatória. Existem fótons com as mais variadas energias. No entanto, ao incidir sobre as nossos olhos só alguns fótons são capazes de produzir sensações visuais no ser humano. Essas sensações se traduzem na percepção das cores. O nosso olho só é capaz de traduzir em sensações visuais os fótons incidentes na retina e cujas freqüências não são demasiadamente altas, nem demasiadamente baixas. O olho não consegue processar os fótons de baixas energias nem aqueles de altas energias. 


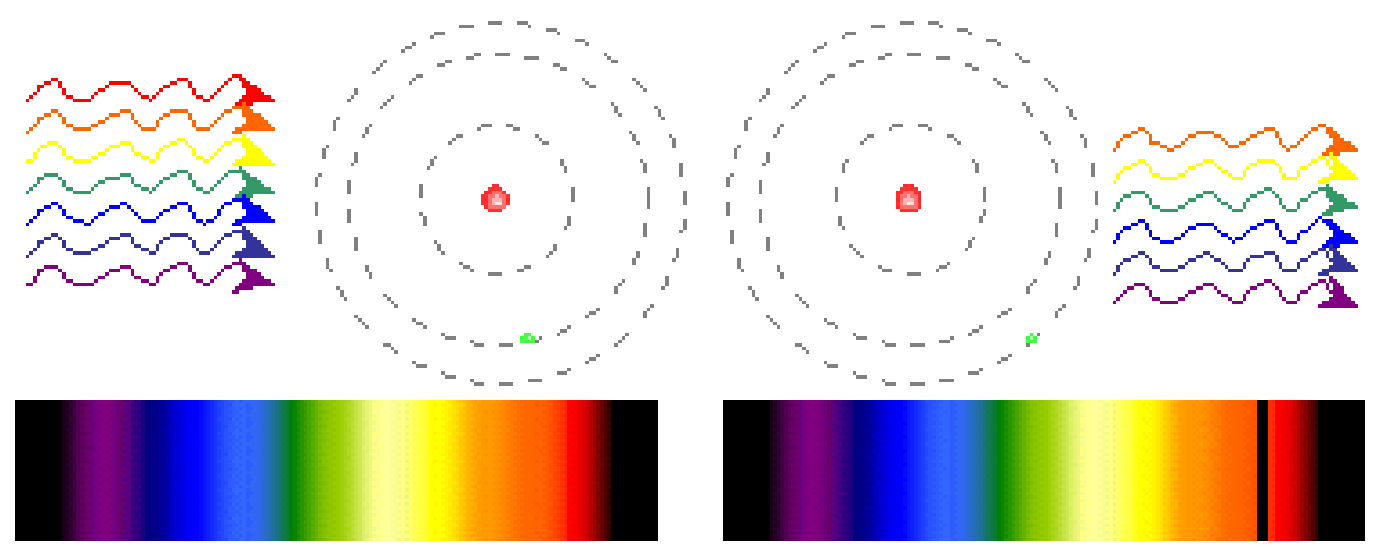

Fig. - Luz, Fótons e Cores

Cada valor da energia (ou freqüência) dos fótons que compõem a luz incidente no nosso olho é capaz de produzir uma sensação visual a qual identificamos como uma cor bem definida. A tabela abaixo ilustra isso

\begin{tabular}{|c|c|c|c|c|c|}
\hline \multicolumn{6}{|c|}{$\begin{array}{l}\text { Cor, comprimento de onda, freqüência e } \\
\text { energia da luz }\end{array}$} \\
\hline Color & $\underset{/ \mathrm{nm}}{\lambda}$ & $\begin{array}{c}V \\
/ 10^{14} \\
\mathrm{~Hz}\end{array}$ & $\begin{array}{c}\nu_{b} \\
/ 10^{4} \\
\mathrm{~cm}^{-1}\end{array}$ & $\underset{/ \mathrm{eV}}{E}$ & $\begin{array}{l}E / \mathbf{k J} \\
\mathbf{m o l}^{-1}\end{array}$ \\
\hline Infrared & $>1000$ & $<3.00$ & $<1.00$ & $<1.24$ & $<120$ \\
\hline Red & 700 & 4.28 & 1.43 & 1.77 & 171 \\
\hline Orange & 620 & 4.84 & 1.61 & 2.00 & 193 \\
\hline Yellow & 580 & 5.17 & 1.72 & 2.14 & 206 \\
\hline Green & 530 & 5.66 & 1.89 & 2.34 & 226 \\
\hline Blue & 470 & 6.38 & 2.13 & 2.64 & 254 \\
\hline Violet & 420 & 7.14 & 2.38 & 2.95 & 285 \\
\hline Near & 300 & 10.0 & 3.33 & 4.15 & 400 \\
\hline
\end{tabular}




\begin{tabular}{|l|l|l|l|l|l|}
\hline ultraviolet & & & & & \\
\hline $\begin{array}{l}\text { Far } \\
\text { ultraviolet }\end{array}$ & $<200$ & $>15.0$ & $>5.00$ & $>6.20$ & $>598$ \\
\hline & & & & & \\
\hline
\end{tabular}

Assim, a luz vermelha está associada a freqüências no entorno de $440 \mathrm{THz}$., a luz verde corresponde a freqüências proximas de $670 \mathrm{THz}$ e assim por As cores do espectro visível

\begin{tabular}{|c|c|c|}
\hline color & $\begin{array}{c}\text { wavelength } \\
\text { interval }\end{array}$ & $\begin{array}{c}\text { frequency } \\
\text { interval }\end{array}$ \\
\hline red & $\begin{array}{l}\sim 625- \\
740 \mathrm{~nm}\end{array}$ & $\begin{array}{c}\sim 480- \\
405 \mathrm{THz}\end{array}$ \\
\hline orange & $\begin{array}{l}\sim 590- \\
625 \mathrm{~nm}\end{array}$ & $\begin{array}{c}\sim 510- \\
480 \mathrm{THz}\end{array}$ \\
\hline yellow & $\begin{array}{l}\sim 565- \\
590 \mathrm{~nm}\end{array}$ & $\begin{array}{c}\sim 530- \\
510 \mathrm{THz}\end{array}$ \\
\hline green & $\begin{array}{l}\sim 500- \\
565 \mathrm{~nm}\end{array}$ & $\begin{array}{c}\sim 600- \\
530 \mathrm{THz}\end{array}$ \\
\hline cyan & $\begin{array}{l}\sim 485- \\
500 \mathrm{~nm}\end{array}$ & $\begin{array}{c}\sim 620- \\
600 \mathrm{THz}\end{array}$ \\
\hline blue & $\begin{array}{l}\sim 440- \\
485 \mathrm{~nm}\end{array}$ & $\begin{array}{c}\sim 680- \\
620 \mathrm{THz}\end{array}$ \\
\hline violet & $\begin{array}{l}\sim 380- \\
440 \mathrm{~nm}\end{array}$ & $\begin{array}{c}\sim 790- \\
680 \mathrm{THz}\end{array}$ \\
\hline
\end{tabular}
diante.

\begin{tabular}{|c|c|}
\hline & \\
\hline violet & $380-450 \mathrm{~nm}$ \\
\hline$\underline{\text { blue }}$ & $450-495 \mathrm{~nm}$ \\
\hline green & $495-570 \mathrm{~nm}$ \\
\hline yellow & $570-590 \mathrm{~nm}$ \\
\hline
\end{tabular}




\begin{tabular}{|c|c|}
\hline orange & $590-620 \mathrm{~nm}$ \\
\hline red & $620-750 \mathrm{~nm}$ \\
\hline
\end{tabular}

Note-se que a luz violeta é aquela associada aos fótons de maior freqüência que podemos "observar" (isto é, traduzir em sensações visuais). Ondas eletromagnéticas com frequencias um acima de $790 \mathrm{THz}$ são conhecidas como radiação ultravioleta.

Freqüências abaixo da freqüência do vermelho são denominadas de infravermelhas. Acima do violeta são denominadas de ultravioletas.

Se o olho humano não recebe luz, isso é traduzido pelos nossos sentidos como a cor preta. O preto representa, portanto, ausência de cor.

Se, numa região na qual incide fotons, nós aumentarmos o número de fótons incidentes, aumentaremos a intensidade da luz. Dizemos que aumentamos o brilho da luz.

\section{CORES DOS OBJETOS}

É importante ressaltar que as cores dos objetos refletem propriedades físicas inerentes a eles. Quanto ao destino da luz depois de incidir sobre um corpo qualquer, podemos classificá-los em três categorias: objetos opacos, transparentes e translúcidos.

\section{Objetos Transparentes}

Os objetos transparentes permitem a luz passar através deles. Os translúcidos permitem a passagem de apenas uma parte da luz. Como veremos depois, a transmissão da luz através de um objeto tem a ver com o fenômeno da refração da luz.

\section{http://www.ufpa.br/ccen/quimica/absorcao\%20molecular.htm}

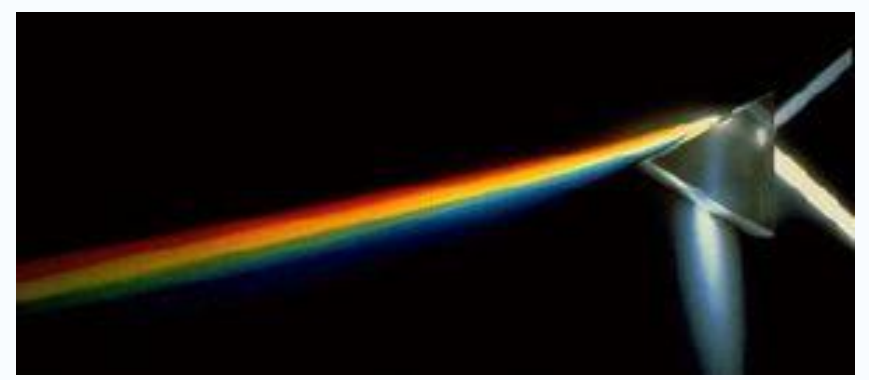

\section{Objetos opacos}


A opacidade se refere á propriedade do corpo ser impenetrável á luz. Objetos opacos podem espalhar, refletir ou absorver a luz. Eles transmitem muito pouca luz. Portanto, quando a luz incide na superfície de um objeto opaco, ela pode sofrer reflexão especular (como um espelho), pode ser espalhada (ser refletida em várias direções) ou ela pode ser absorvida. Em geral ocorre uma combinação dos três fenômenos (vide figura).

A cor dos objetos está relacionada á opacidade dos mesmos. E isso porque a opacidade de um objeto depende da freqüência da luz incidente.

http://www.ufpa.br/ccen/quimica/absorcao\%20molecular.htm

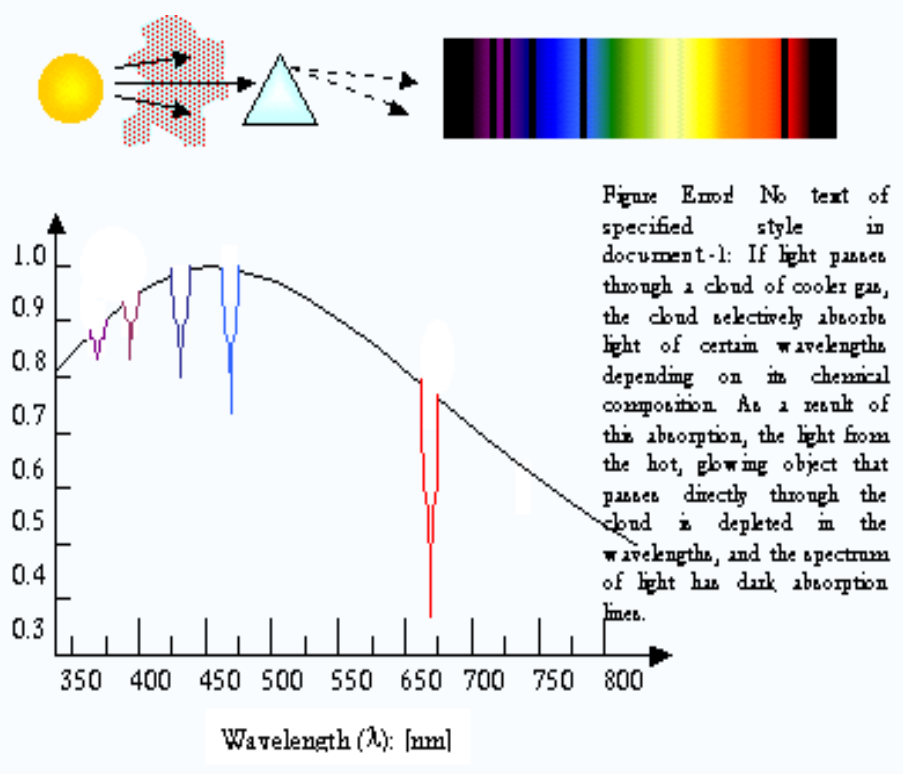

Fig. - Espectro de Absorção da Cor

Como resultado da dependência da opacidade com a frequêencia, a luz branca (constituída de uma soma de todas as cores) ao incidir sobre a maçã, terá alguns componentes da luz incidente sendo absorvidos, outros refletidos e outros serão dispersos de uma forma diferente para cada comprimento de onda. $O$ resultado é que a composição da luz que chega aos nossos olhos não é igual aquela que incidiu sobre o objeto. Cada objeto altera a luz incidente (absorvendo, por exemplo, algumas freqüências da luz incidente) de uma forma diferente. $E$ isso estabelece um mecanismo para diferenciar os objetos com base na cor. Um objeto se nos apresenta como vermelho porque ele pode ter subtraído da luz todas as demais freqüências.

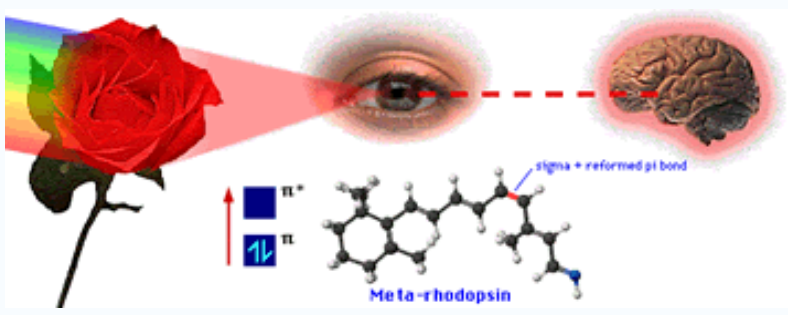


Fig. - Modelo da Visão Colorida

Objetos opacos que não exibem reflexão especular têm a sua cor determinada pelo balanço entre os comprimentos de onda que são mais espalhados e aqueles que são menos espalhados e pelos comprimentos de onda que são absorvidos. Se todos os comprimentos de onda são espalhados (e não absorvidos) o objeto vai aparecer como sendo branco. Se o objeto absorver todos os comprimentos de onda ele parecerá negro

A absorção de alguns comprimentos de onda tem a ver com o espectro de absorção dos átomos ou moléculas de uma determinada substancia. O espectro de absorção de átomos e moléculas pode ser medido experimentalmente. O resultado é aquele da figura ao lado. Por exemplo, no caso de um gás iluminado por uma fonte de luz o espectro de absorção corresponde a uma série de linhas escuras no espectro.

A existência de linhas de absorção tem a ver com a absorção de fótons pelos elétrons nos átomos $\mathrm{A}$ energia transferida pelos fótons aos elétrons são utilizadas por eles para fazerem uma transição para um nível de energia mais alto. Os fotos subtraídos deixarão de compor a luz e por isso os comprimentos de onda correspondentes estarão ausentes no espectro de absorção.
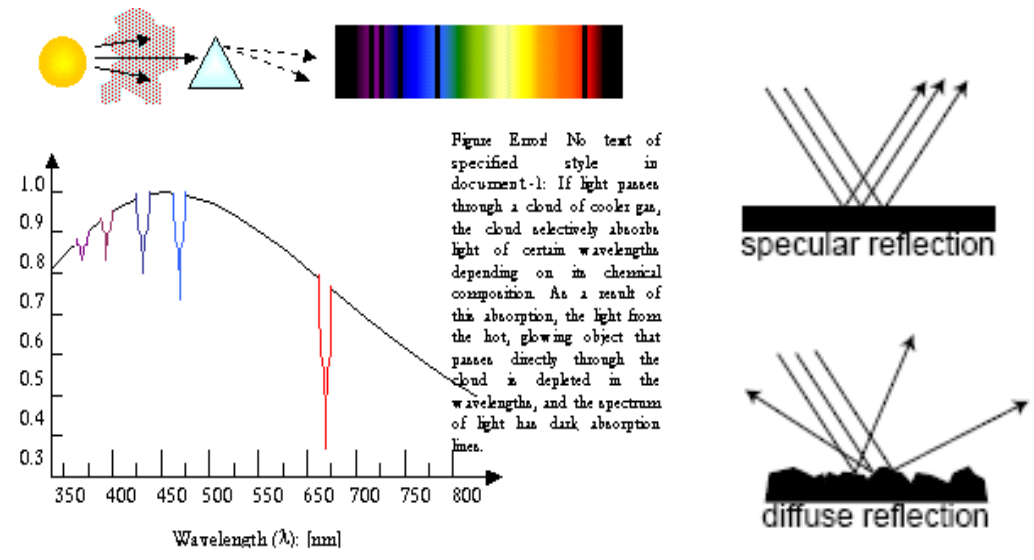

(b) Diffuse and specular reflection.

A diferença entre branco, preto, e os vários graus de cinza é matéria de qual porcentagem da luz ele absorve e qual porcentagem ele reflete. 


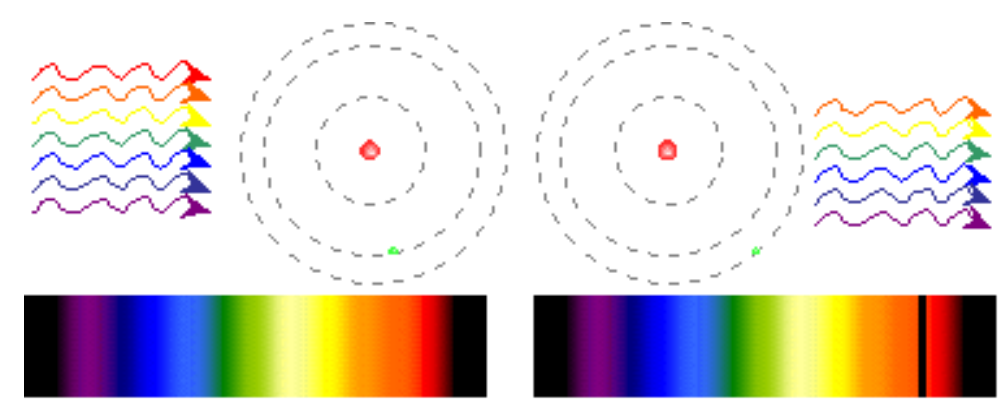

Figura : O elétron em um estado de menor energia se move para um estado de maior energia e absorve a luz com energia que corresponde exactamente à diferença de energia específica entre os dois níveis. Os espectros da luz incidente, antes e após a sua interacção com o átomo de transição e o seu nível de energia. Observe que a cor corresponde a um uma única transição específica dentro do átomo. Note-se que o átomo removeu esta energia a partir de todas as energias possíveis e o electrão foi movido para um nível de energia mais elevado.

Também percebemos que outras transições de absorção para cima vai envolver outros comprimentos de onda originais.

A conclusão é que a cor de um objeto é o resultado das propriedades físicas do mesmo. De quão rugosa, ou polida é sua superfície, das propriedades do corpo em relação á refração da luz e das suas propriedades em relação á absorção da luz incidente. Uma combinação desses efeitos irá determinar que comprimentos de onda emergirão da superfície do objeto. Essa nova combinação de comprimentos de onda define a cor dos objetos.

\section{ESPECIFICANDO AS CORES}

Existem muitas formas de se especificar as cores de um objeto. Isso porque podemos reproduzir cores lançando mão de vários modelos de cores. Cerca de 6 modelos são relativamente conhecidos.

Um modelo de cor envolve um certo número de parametros (entre tres e quatro, nos mais difundidos). Esses parametros são os componentes das cores. Esses parametros varrem um espaço tridimensional conhecido como o espaço da cor. Sob esse aspecto, um modelo de cor pode ser entendido como um modelo matemático. Queremos lembrar que esses modelos se constituem apenas em técnicas para representar um fenomeno da natureza, que é a cor.

.A seguir apresentaremos os modos de especificação de cores, conhecidos como modelos RGB, YMK e HSV.

Do ponto de vista da percepção das cores sabemos, desde os trabalhos pioneiros de Young no ininico do seculo XIX, que todas as cores podem ser obtidas a partir da superposição de apenas três cores. Essas são as cores primárias. A superposição de duas cores primárias quaisquer reproduz uma das três cores ditas secundárias (amarelo, magenta e ciano). Para entendermos porque essa tres cores, 
devemos recorrer á questão da percepção das cores. Os três tipos de cones já aludidos, são denominados de cones vermelho, verde e azul. Isso porque as curvas de resposta associadas aos tres diferentes cones processadores da cor são otimizadas para frequencias associadas a essas cores.

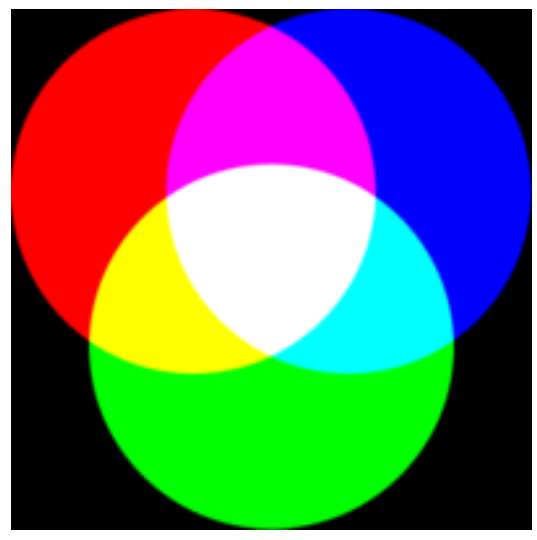

As cores são produzidas pela adição de cores primárias (como no caso da TV a cores ou o monitor do computador) ou pela subtração de cores. Se, por exemplo, adicionarmos o azul e o amarelo, obteremos o verde.

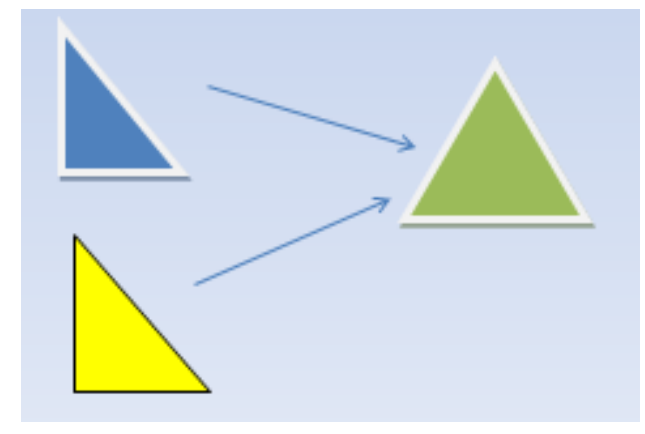

\section{MODO RGB (RED, GREEN, BLUE)}

É baseado na idéia de que podemos obter qualquer cor a partir de tres cores que denominamos primárias. O modo RGB é baseado nas aditivas primárias: vermelho, verde e azul.

As midias que proporcionam a sensação de cor superpondo luz com diferentes comprimento de onda, a partr da luz emitida pelos objetos fazem uso do sistema de cor aditivo. Ou seja, pela superposiçao das cores primárias, esse é o caso dos televisores e dos monitores de video, por exemplo.

A adição do azul ao verde leva ao amarelo. 
A mistura em proporções iguais das primárias aditivas produz os diversos matizes de cinza. Quando as três cores estão saturadas, o resultado dessa adição é o branco.

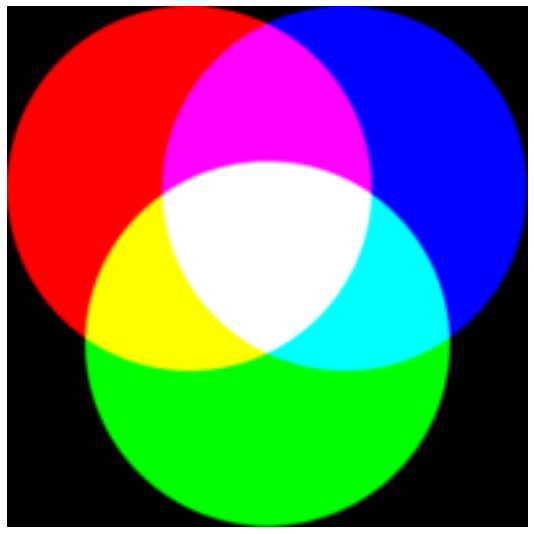

\section{MODOS CMY e CMYK}

A outra forma de obtermos as cores dos objetos é através da subtração de cores. Assim, esse modelo é subtrativo. Por exemplo, se do amarelo subtrairmos o azul, ficaremos com a cor verde. As midias que usam a luz refletida para proporcionarem a sensação de cor fazem uso das cores primárias subtrativas. Esse é o caso da mídia impressa (jornais, revistas, etc.).

As primárias subtrativas são a magenta, o amarelo e o azul cyan, definindo assim o modelo CMY. Tendo em vista algumas dificuldades em reproduzir algumas cores escuras, acrescenta-se a esse modelo a cor negra (modelo CMYK)

\section{Primárias Subtrativas}

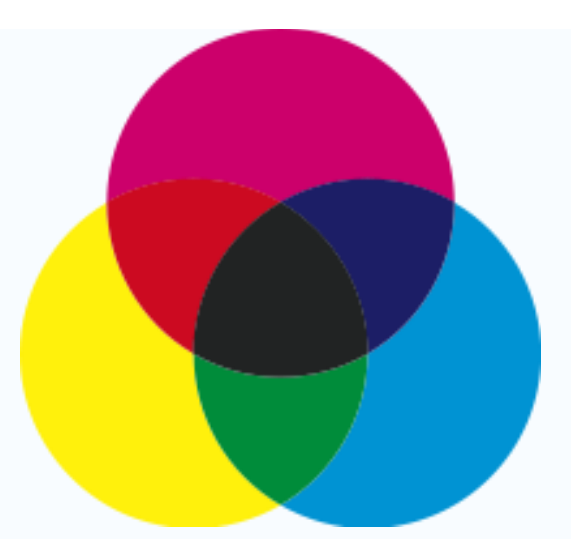


Considera-se o modelo HSV o mais apropriado para reproduzir a nossa forma de perceber as cores, como seres humanos. É o espaço de cor mais utilizado na computação gráfica. Nesse modelo a cor é especificada através das suas coordenadas: HUE, saturação e do valor. Hue é a própria cor, $\mathrm{O}$ valor é um parametro associado ao brilho (ou o quanto de preto é adicionado á cor). E a saturação determina quanto de branco é adicionado á cor.
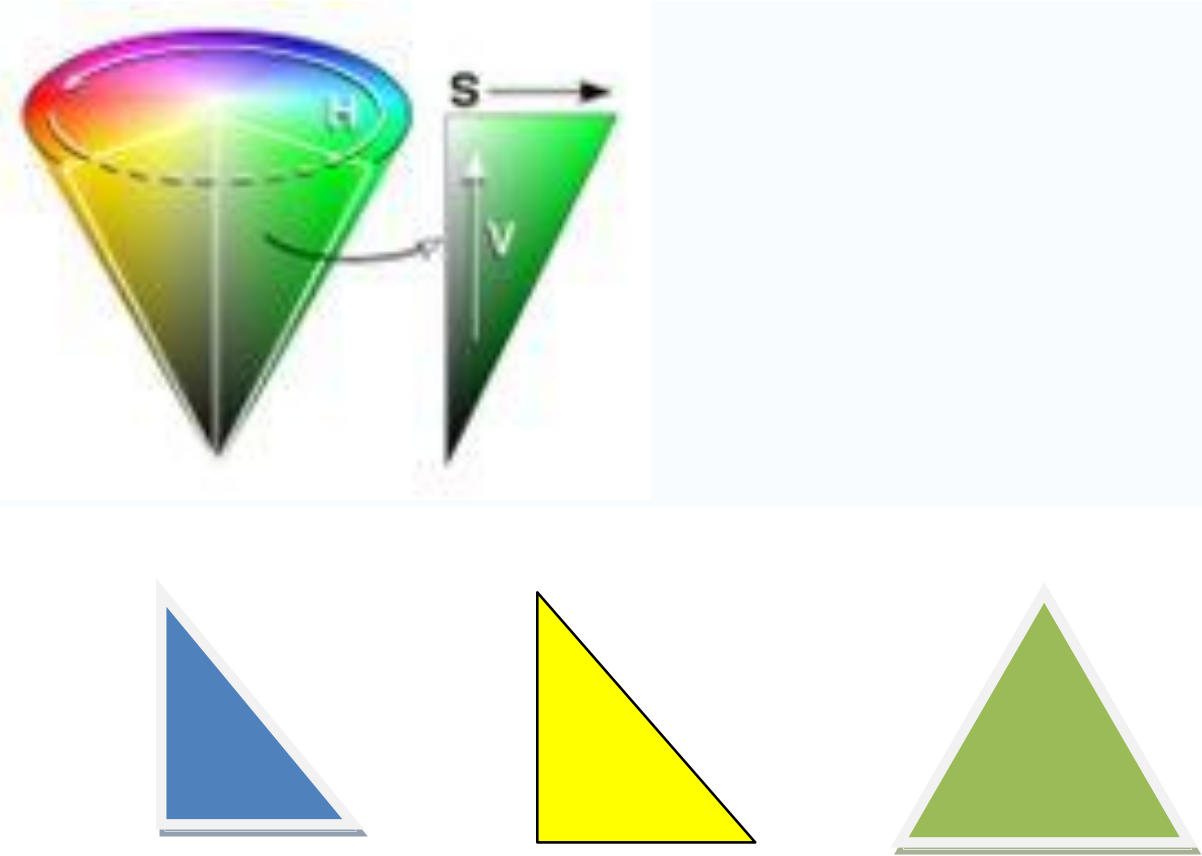

\section{ATIVIDADES}

\section{1 - Experimentos de Baixo custo}

\section{1 - AQUARELA}

Objetivo 
O objetivo deste experimento é mostrar que a luz pode ser formada de componentes coloridas. Em outras palavras, é mostrar que todas as cores podem ser obtidas pela composição das cores primárias.

Contexto

Existem instrumentos ópticos, como por exemplo o prisma, que são capazes de dividir a luz em todas as suas componentes. O contrário também acontece, ou seja, é possível, a partir de suas componentes, gerar uma cor. Na natureza existem três cores básicas, as quais podemos chamar de cores primárias, são elas: vermelho, amarelo e azul. A partir destas cores podemos gerar qualquer outra cor, inclusive o branco. Fazendo com que cada pigmento destas cores ocupem um o lugar do outro muito rapidamente, pela nossa capacidade visual, a cor que enxergaríamos seria uma mistura das duas cores. Por exemplo, se fizermos com que dois objetos de cores azul e amarelo alternem suas posições com uma frequência maior do que a frequência com que nossa visão poderia distinguir a alternância das posições, não conseguiríamos distinguir em determinado momento qual seria o objeto colorido que estaria ocupando aquele lugar. Então, o que conseguiriamos ver seria uma soma das ondas emitidas por cada pigmento desses dois objetos; neste caso, a soma das ondas luminosas entre azul e amarelo, é a onda que corresponde à cor verde.

Para se gerar a cor branca o processo é um pouco mais complicado, segundo Isaac Newton a cor branca é uma soma de todas as cores. Só que dependendo do conjunto de cores usado, cada uma tem uma proporção de participação diferente e não muito fácil de calcular.

Idéia do Experimento

Para alternar a posição das cores utilizamos um disco pintado cada parte de uma cor e o giramos utilizando uma brincadeira de criança muito comum que consiste em passar um barbante duas vezes pelos disco, enrolá-lo e depois desenrolá-lo.

Tabela do Material

\begin{tabular}{|l|l|}
\hline Item & Comentários \\
\hline $\begin{array}{l}\text { Tampa } \\
\text { plástica }\end{array}$ & $\begin{array}{l}\text { Nós utilizamos a tampa de plástico translúcido do achocolatado NESCAU devido } \\
\text { à sua leveza e a facilidade que se tem para furá-la, porém, pode-se utilizar } \\
\text { qualquer tampa plástica com tamanho aproximado. }\end{array}$ \\
\hline \begin{tabular}{l|l} 
Barbante de \\
algodão
\end{tabular} & \begin{tabular}{l} 
Aproximadamente $120 \mathrm{~cm}$. \\
\hline Papel branco
\end{tabular} \\
\hline
\end{tabular}




\begin{tabular}{|l|l|}
\hline $\begin{array}{l}\text { Canetinha } \\
\text { hidrocor }\end{array}$ & $\begin{array}{l}\text { Pode ser substituída por lápis de cor, giz de cera, tinta ou até mesmo recortes } \\
\text { de papel colorido. }\end{array}$ \\
\hline Cola & \\
\hline
\end{tabular}

Montagem

- Retire as bordas da tampa que será utilizada de maneira a formar um disco.

- Recorte um círculo de papel do tamanho do disco e divida-o em seis partes.

- Pinte cada parte utilizando as cores azul e vermelho alternadamente.

- Faça dois furos na mesma linha, não muito próximos e equidistantes do centro do disco.

- Passe o barbante pelos dois furos e ate as duas pontas.

- Coloque o disco aproximadamente no centro do barbante.

- Enrole o barbante fazendo movimentos circulares com o disco.

- Estique o barbante e o disco começará a rodar, afrouxe o barbante para que, com o movimento do disco, ele enrole novamente.

- Começe, então, um movimento de vai e vem com o barbante.

- Notar-se-á que o movimento das cores vermelha e azul resultará na cor roxa.

Comentários

- Este experimento pode ser realizado utilizando a várias combinações de cores, como azul e amarelo, que resulta na cor verde; vermelho e amarelo, que resulta em alaranjado etc.

- Sugerimos, até, que coloque-se uma combinação de cores de um lado do disco e outra do outro.

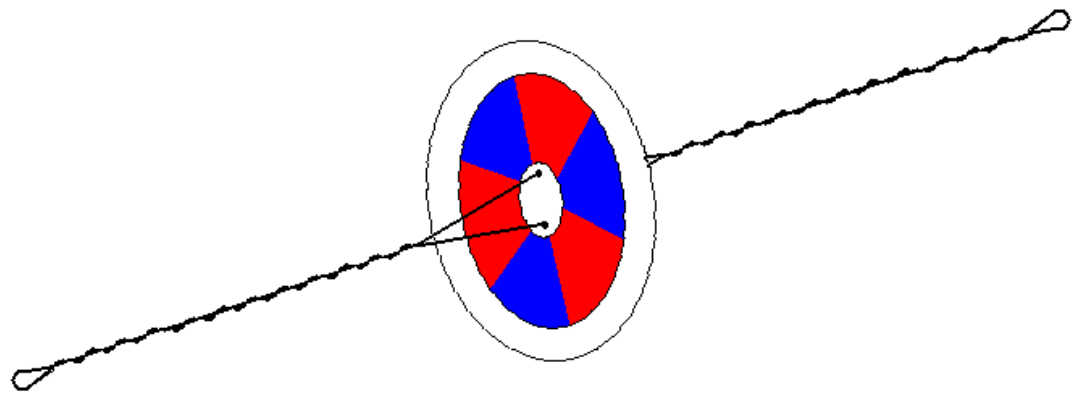

\section{2 - FÁBRICA DE ARCO-ÍRIS}

Objetivo 
O objetivo deste experimento é decompor a luz, mostrando que ela é formada por componentes coloridas.

\section{Contexto}

A luz normal, também chamada de luz branca, assim como a cor branca, é a formada por componentes de luz de todas as cores. Só podemos perceber que cada objeto tem sua cor porque quando luz branca incide sobre ele, este reflete a cor que o pigmento consegue emitir. Um objeto de cor vermelha, por exemplo, apesar de estar recebendo todas as cores, só reflete a componente vermelha; um objeto branco reflete todas as componentes e não absorve nenhuma; um objeto preto absorve todas as cores e não reflete nenhuma. Por isso é que quando estamos expostos ao sol, vestindo uma roupa branca, sentimos estar esquentando menos que com uma roupa escura: a roupa branca reflete todas as componentes coloridas da luz branca, enquanto a preta absorve todas.

Quando a luz branca sofre refração, cada cor que a compõe é refratada com um ângulo diferente. Isto se deve a cada cor ter um índice de refração diferente, $o$ que justifica cada cor ser refratada com um ângulo.

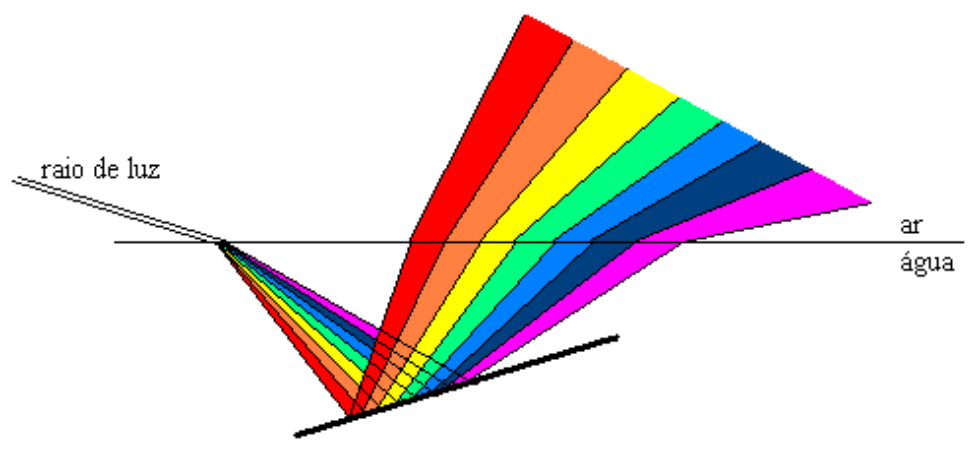

\section{Idéia do Experimento}

Um raio de luz penetra na água e sofre refração. Cada cor refrata com um ângulo diferente e então as componentes seguem caminhos separados; após, cada raio é refletido por um espelho imerso na água e volta para a superfície; quando o raio sai da água, sofre novamente refração e cada cor já decomposta se decompõe em outras cores da mesma "família", como por exemplo, a componente vermelha da luz dá origem a vários tons de vermelho. Quando os raios saem da água, atingem um aparato onde é possível ver que a luz branca que incidiu na água é decomposta em todas as cores que a constitui. Esta decomposição é chamada de espectro, que é o mesmo visto em um arco-íris.

\section{Tabela do Material}

\begin{tabular}{|l|l|}
\hline Item & Comentários \\
\hline Espelho & $\begin{array}{l}\text { Desses pequenos com moldura alaranjada. São encontrados em qualquer } \\
\text { supermercado ou bazar. }\end{array}$ \\
\hline
\end{tabular}


Assadeira Pode ser substituída por uma bandeja funda, bacia ou tuperware.

Água

Cartolina Para ser usada como aparato de observação do espectro.

Montagem

- Encha a assadeira com água.

- Coloque o espelho inclinado dentro dela.

- Faça com que a luz do Sol reflita no espelho no interior da assadeira e atinja um aparato de preferência de cor clara.

- Observe que a luz refletida é um espectro composto pelas cores do arco-íris.

Comentário

- O melhor resultado é obtido refletindo a luz do Sol em um local menos iluminado, como por exemplo uma parede clara à sombra ou uma cartolina não iluminada diretamente pela luz solar.

- Pode-se realizar também este experimento refletindo a luz emitida por uma lâmpada fuorescente (luz fria) em uma folha branca.

Esquema Geral de Montagem

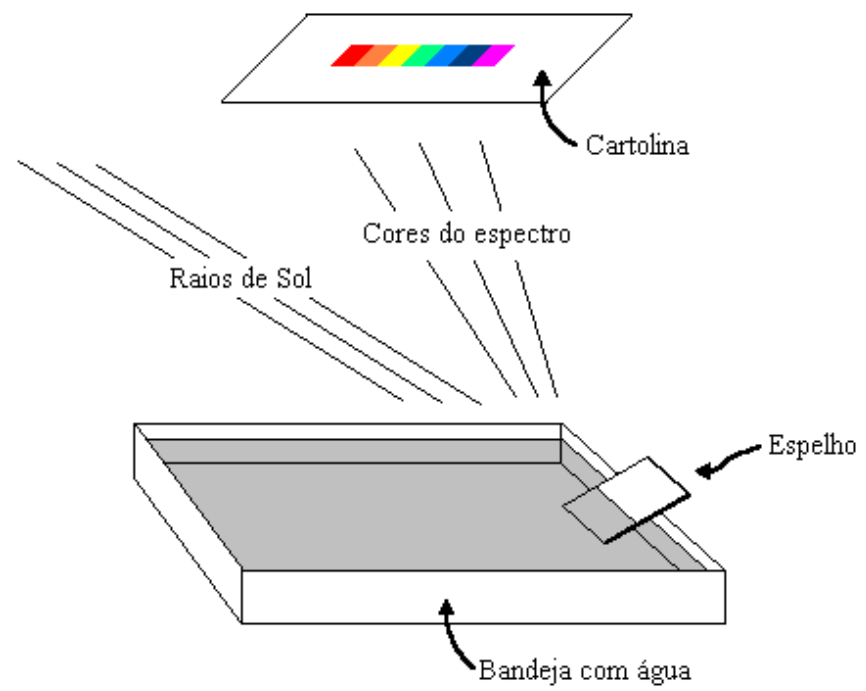

\section{3 - Experimento - Luz e Cores}

Objetivo: Observar alguns fenômenos luminosos que envolvem cores.

Material: disco de papelão, pião ou lápis, filtros de luz (vermelho, laranja, amarelo, verde, azul, anil e violeta), lápis coloridos 


\section{Procedimentos:}

\section{Parte 1 - Disco de Newton}

- Divida o disco de papelão em sete setores; depois, pinte cada setor com uma das cores do arco-íris (vermelho, laranja, amarelo, verde, azul, anil e violeta).

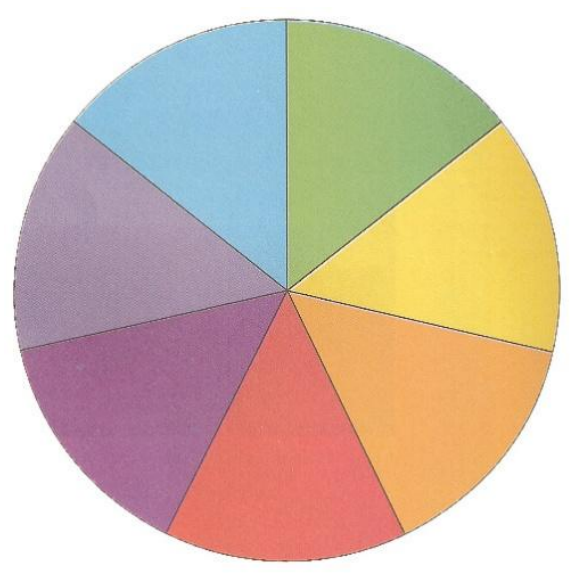

- Encaixe o disco no pião e faça-o girar; ou, faça um pequeno furo no centro do disco e passe por ele um lápis. Apóie uma extremidade do lápis próximo à borda da mesa, conforme a figura e gire o disco rapidamente. Explique o que observa.

\section{Parte 2 - Filtros de luz}

- Observe objetos que estão ao seu redor, através do filtro vermelho.

- Repita esse procedimento, utilizando, um a um, todos os filtros.

- Observe o disco de Newton, enquanto gira, utilizando todos os filtros, um a um.

Explique o que observa.

Comentário: Teoricamente, girando o disco no pião, deveríamos enxergá-lo branco. O branco é a reflexão de todas as cores simultaneamente. Mas, às vezes, os pigmentos coloridos, os setores do disco não são puros, como no caso da luz de um arco-íris, e essas impurezas provocam distorções.

Através do filtro vermelho, enxergamos vermelho ou preto, em tons mais claros e mais escuros. A cor emitida por um corpo iluminado com luz branca é a parcela refletida. Um filtro seleciona a luz que o atravessa; um filtro vermelho, por exemplo, permite somente a passagem da luz vermelha, absorvendo as demais. Por isso no disco aparecem regiões pretas, 
que são a ausência da luz. Por exemplo: se um corpo, sob luz branca, é azul, significa que reflete o azul. Visto através do filtro vermelho, parece ser preto, pois o filtro vermelho só não absorve o vermelho, absorvendo, portanto, a luz azul. A luz azul não chega até os olhos de quem está olhando com filtro azul.

\section{2 - Applets de Ensino}

2.1 - Visão Colorida. Projeto Phet. URL: http://www.fisicanimada.net.br/? $\mathrm{q}=$ otica/color-vision.

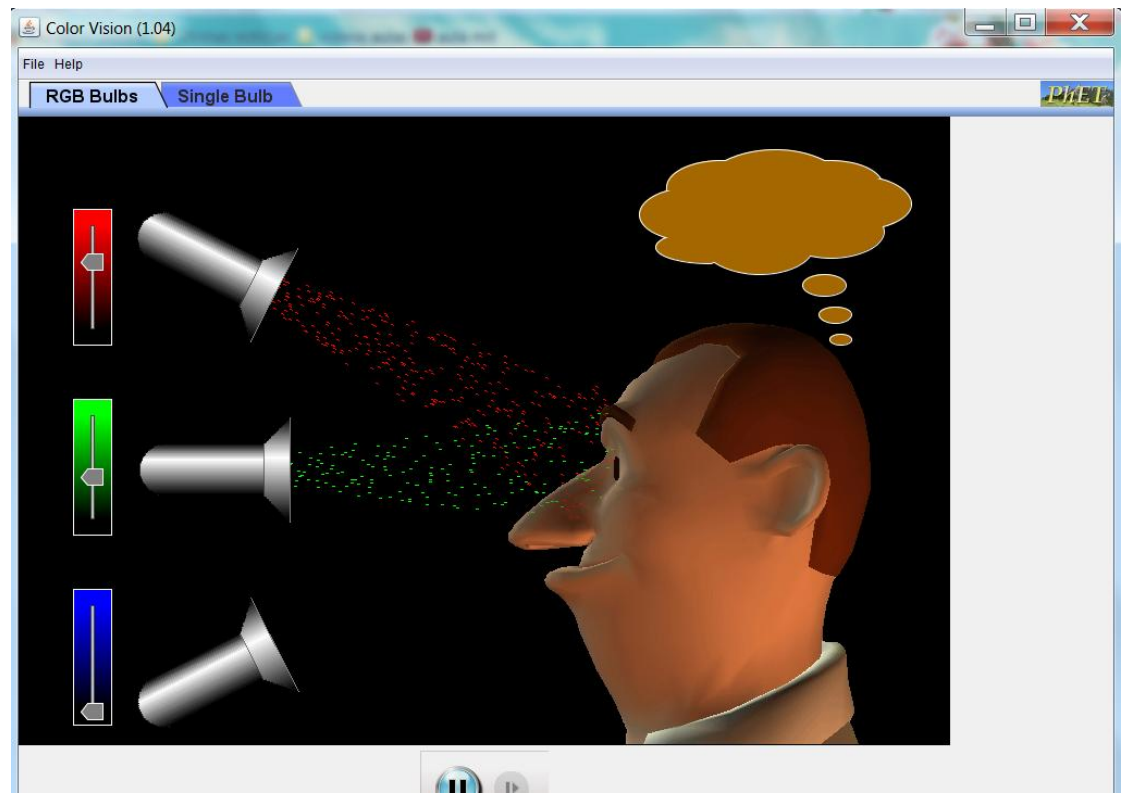

2.2 - JOptics Curso de Óptica. URL: http://www.ub.edu/javaoptics/

Apesar de estar em espanhol vá um pouco para baixo da página até achar as figuras dos applets.

Veja o olho humano (Modelo Del ojo). Se você clicar nele abrirá duas novas páginas. Ver figura abaixo. 


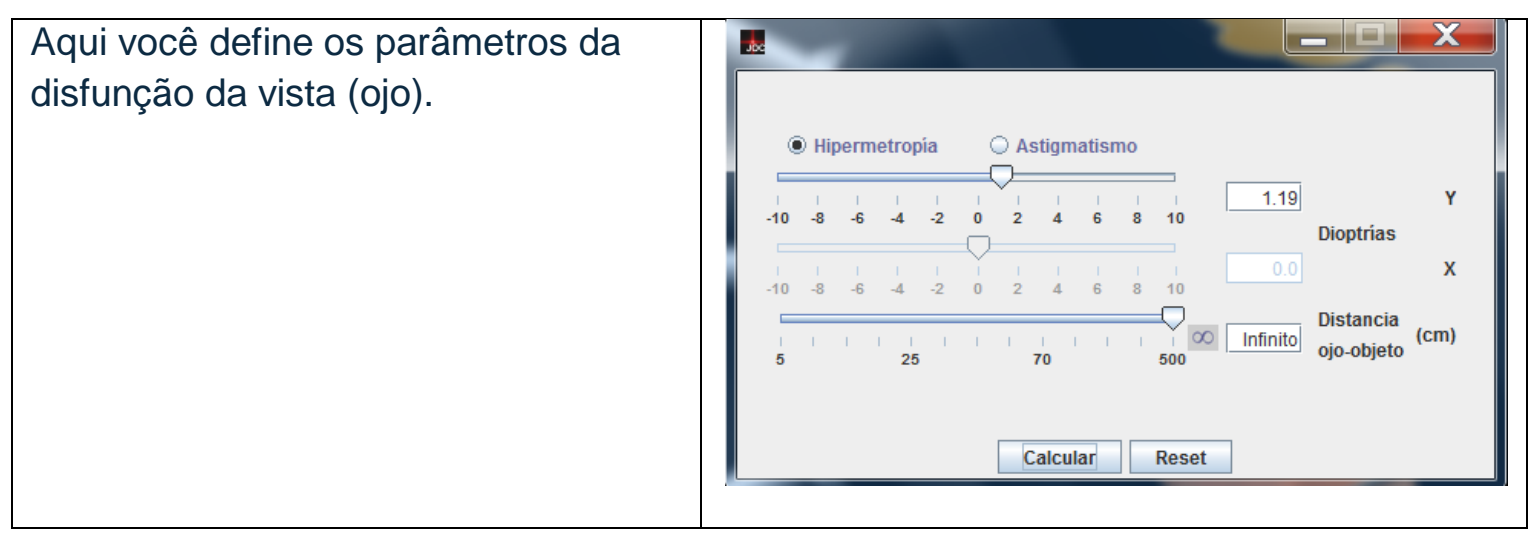

Na figura abaixo temos a imagem da paisagem e o que é visto pelo olho.

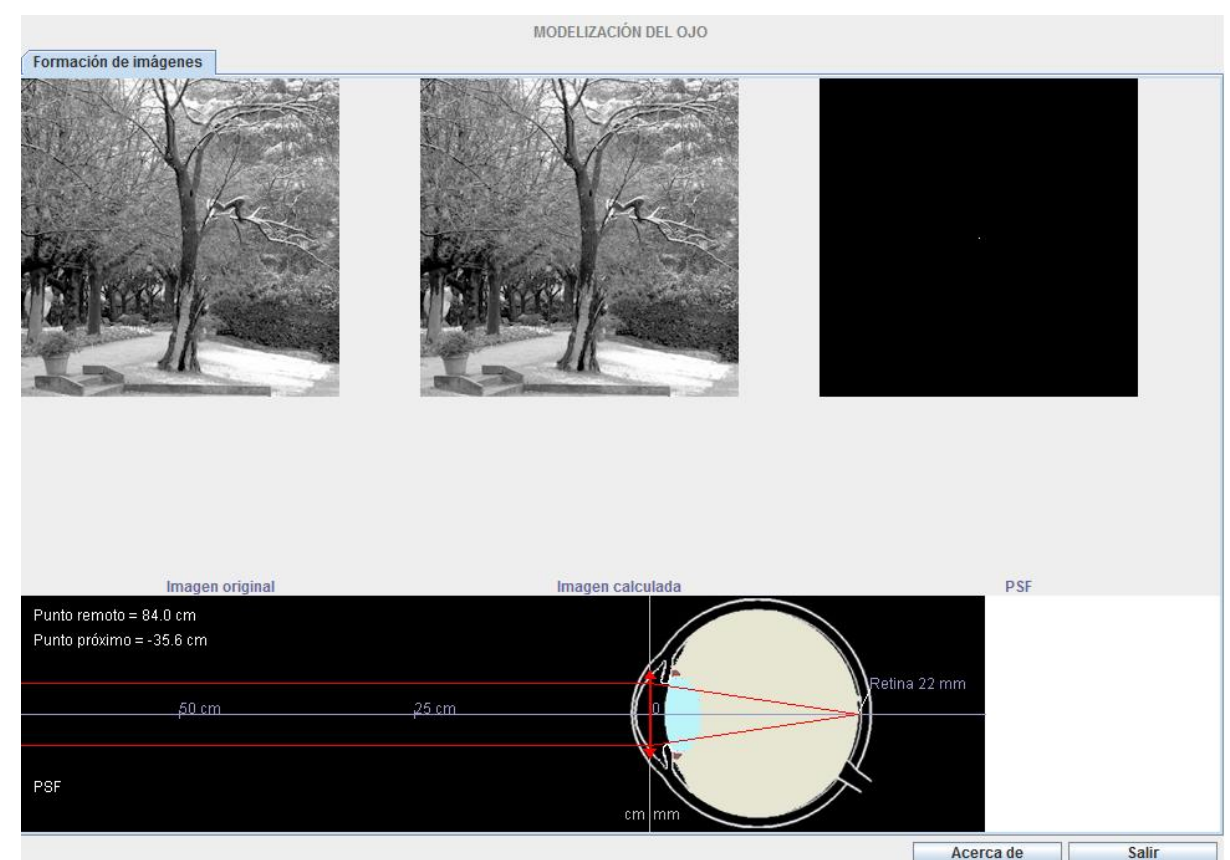

Dispersão da Luz. 


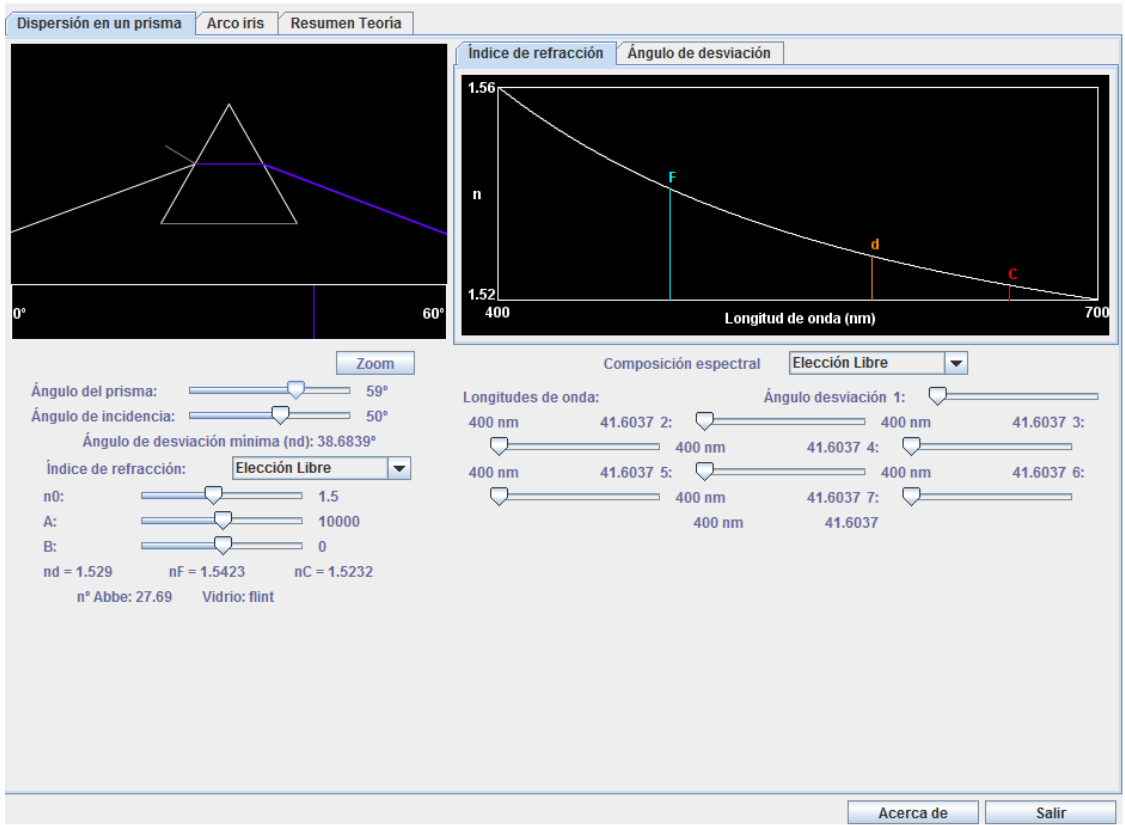

2.3 - ChemConnections. Exemplo de applet RGB. URL:

http://chemconnections.org/Java/RGB/example1.html

Tradução do texto.

Este applet permite que você misture três cores de luz (vermelho, verde e azul) e ver a cor resultante. Este é um exemplo de cor aditiva e é representativo da emissão da luz. Não é o mesmo que a mistura de tintas coloridas (um processo de absorção, ou subtractivo). Para alterar a mistura de três cores basta arrastar o controle deslizante para uma nova posição. 0 número na parte inferior representa a quantidade de vermelho, verde, azul ou presente na mistura de - 1 significa 100\% de uma cor específica, 0 significa $0 \%$ de uma cor específica.

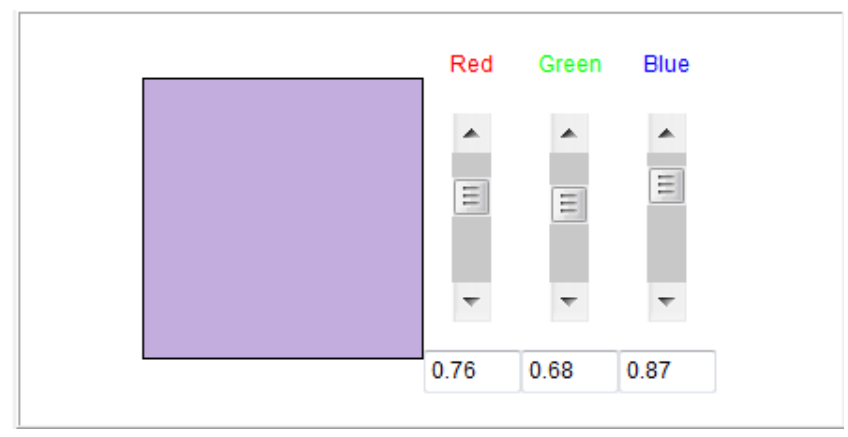

\section{3 - Vídeo aulas}

3.1 - Mago da física. Luz e Cores (Primárias e Secundárias). http://www.youtube.com/watch?v=0DaXxKzQHPO 
3.2 - Doki Descobre - Misturando as Cores.

http://www.youtube.com/watch?v=NKWV1skKY9s

3.3 - Seimaisfisica. Espectro eletromagnético.

http://www.youtube.com/watch?v=cZM6OzXfMSU

3.4 - Projeto sol Amigo. Espectro eletromagnético.

http://www.youtube.com/watch?v= v19we9TuFo

3.5 - Infravermelho (seminário). Muito legal.

http://www.youtube.com/watch?v=85oj_jAAMtw\&feature=related

COMENTÁRIOS:

CONCLUSÃO:

REFERÊNCIAS

MARCONDES, Ayrton Cesar; SARIEGO, José Carlos. Ciências: química e física - 10 Grau. São Paulo : Scipione, 1996.

PENTEADO, Paulo Cesar M; TORRES, Carlos Magno A.. Física - ciência e tecnologia. São Paulo : Moderna, 2005. Vol. 2. 


\section{Cap. $08-$ SOM}

Meta: Fazer que o estudante comece a pensar no ensino de ciências como algo "orgânico" que está em profunda transformação. Fazer com que os alunos percebam, através de uma atividade lúdica, que podemos ensinar física através de experimentos muito simples, e que física é uma ciência aplicada e que pode ser aprendida através da observação de vários dispositivos do nosso cotidiano. Fazer com que o aluno percebam as aplicações da física no cotidiano. Mostrar que existem muitas animações virtuais sobre o tema, e que ensinar e aprender física pode ser uma atividade divertida e interessante.

Objetivos: Ao final da aula, os alunos devem estar cientes das novas possibilidades e dos desafios que envolvem o ensino de ciências em geral. Que para se ensinar física não precisamos ficar presos ao livro didático. Que ensinar física não é ensinar a resolver problemas e que a física é uma mera aplicação da matemática. Que se ensinar através de exemplos reais (experimentais) pode ser muito mais interessante e divertido. Estes devem estar cientes que é possível explorar vários recursos de multimídias e de experimentos de baixo custo em sala de aula. Que a acústica é um ramo da ciência que possui muitas aplicações tecnológicas.

Pré-requisitos: Os alunos deveram ter cursado psicologia da educação física $A, B$ e C.

\section{Introdução:}

Vamos nesta aula tratar do tema sons ou ondas sonoras. Para compreendermos toda a amplitude de aplicações deste tema da física temos que lembrar que nas engenharias e na arquitetura se estuda o som dentro do tema mais amplo denominado de acústica. A Acústica é o ramo da física que 
estuda o som. O som é um fenômeno ondulatório causado pelos mais diversos objetos e se propaga através dos diferentes estados físicos da matéria [1].

Em acústica geralmente podemos dividir entre geradores de som, meios de transmissão, propagação e receptores. A acústica mensura estes meios, cria instrumentos, tabelas, etc, de forma a fornecer dados necessários aos mais diversos ramos da ciência para a utilização dos sons, de seus meios de propagação e efeitos.

Na cadeia geração e recepção acústica inclui-se o indivíduo que recebe o efeito sonoro e o evento que dá origem ao fenômeno.

A acústica é considerada uma ciência que abrange diversas disciplinas e por elas é abrangida. Os ramos científicos que estudam as propriedades acústicas, a propagação do som e efeitos são os mais diversos. Entre estes destacam-se:

\section{Engenharia Acústica}

A engenharia acústica é o ramo da engenharia que estuda formas de controle e de reprodução de fenômenos acústicos. Isto se aplica a diversas situações práticas como controle de ruído industrial, controle de ruído ambiental, acústica arquitetônica, controle de vibrações em máquinas e equipamentos, reprodução, auralização e síntese de fontes sonoras, e assim por diante. Há hoje no Brasil um único curso oferecido pela Universidade Federal de Santa Maria, no Rio Grande do Sul. No entanto, a pesquisa em engenharia acústica vem sendo conduzida em muitas universidades brasileiras, notadamente nos departamentos de Engenharia Mecânica, Engenharia Elétrica e Física.

\section{Física acústica}

A física acústica investiga a forma como a energia sonora se transmite através dos meios materiais de propagação, seus efeitos e interações com os meios sólido, líquido, gasoso e plasma.

No espaço livre, a intensidade de energia da onda diminui na medida em que ela se afasta da fonte sonora. Quando é dobrada a distância entre a fonte e o receptor, a intensidade do som cai $6 \mathrm{~dB}$ em campo livre e considerando uma fonte pontual e $3 \mathrm{~dB}$ considerando uma fonte de linha sobre um plano refletor. Uma fonte sonora produz variações de pressão no ar, diminuindo sua densidade, comprimindo-o numa onda progressiva, cujo formato esférico se move à velocidade de $340 \mathrm{~m} / \mathrm{s}$.

Numa sala fechada, a onda sonora é refletida várias vezes pelas paredes, teto, soalho e a intensidade fica mais ou menos invariável (exceto, junto da fonte sonora, onde é maior).

Os fenômenos físicos relacionados à acústica são a ressonância e o Efeito Doppler.

\section{Psicoacústica}

A psicoacústica se preocupa com as sensações auditivas produzidas pelo som audível.

\section{Fenômenos psicoacústicos}


Os fenômenos psicofísicos (psicoacústicos) relacionados à acústica são o eco, a reverberação, o batimento, o volume sonoro, a intensidade de flutuação, a agudeza, a tonalidade e a roughness.

\section{Acústica arquitetônica}

Os especialitsas de acústica arquitetônica estudam o comportamento do som em recintos fechados ou semi-abertos e a transmissão sonora entre recintos fechados. A absorção do som é importante no caso de se estudar o comportamento do som em recintos fechados ou semi-abertos, a fim de garantir boa intelligibilidade da fala ou da música. $\mathrm{O}$ isolamento sonoro nas edificações em geral, assim como nos projetos urbanísticos, é importante para minimizar a propagação de sons indesejados e assim minimizar os efeitos negativos dos mesmos. Exemplos da acústica arquitetônica são as conchas acústicas de teatro ao ar livre ou a acústica em igrejas.

\section{Acústica ambiental}

Os especialistas em acústica ambiental estão preocupados com a proteção do ruído aéreo, rodoviário, ferroviário e ruído gerado pelos equipamentos para os receptores sensíveis ao ruído, tais como habitações, escolas, hospitais, áreas verdes protegidas, etc. Em muitos países (e em muitos municípios) as leis preveem limites de exposição ao ruído destes receptores. Estes limites podem ser absolutos ou relativos ao ruído medido acima da introdução da nova fonte de ruído. O manejo do ruído ambiental é feito através da monitorização do ruído, a modelagem do ruído gerado pela introdução de novas fontes, e determinação das medidas de mitigação em conformidade com os limites da lei (ou pelo menos chegar perto desses limites por todos os meios práticos possíveis). As medidas de mitigação mais eficazes são as fontes, mas nem sempre a mitigação é possível. A segunda alternativa é introduzir barreiras acústicas entre as fontes e os receptores. Se esta alternativa não é praticável, a mitigação deve acontecer no receptor, por exemplo com a introdução de janelas de painel duplo.

\section{Música}

A observação de que a altura do som produzido por uma corda vibratória varia com o seu comprimento é atribuída a Pitágoras (século VI a.C.) descoberta que o levou à da escala musical, em que ainda se baseia a música ocidental.

Na música, a acústica é importantíssima, pois sem o estudo desta não é possível o desenvolvimento e o processo de criação artística. Sem o estudo do som, suas combinações, harmonia, interações entre as notas musicais não existe.

\section{Medicina e fonoaudiologia}

A medicina e a fonoaudiologia são as áreas que mais estudam os efeitos benéficos e maléficos da acústica na fisiologia humana. $\mathrm{O}$ interesse é focado nas pregas vocais e no sistema auditivo humano. 
Além disso, usam-se diferentes métodos acústicos para alívio de dores, destruição de cálculos, tratamentos dos mais diversos e para o diagnóstico, por exemplo no caso do estetoscópio ou do ultra-som.

\section{Produção do Som}

Fixemos uma lâmina de aço muito fina para que ela possa oscilar conforme indica a figura ao lado.

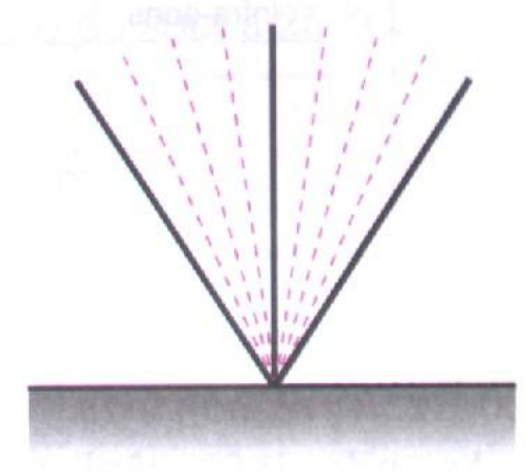

Quando deslocamos a lâmina, sua extremidade livre começa a oscilar para a direita e para a esquerda.

Se a lâmina vibrar com rapidez, produzirá um som sibilante, mostrando que os sons são produzidos pela matéria em vibração.

À medida que a lâmina oscila para a direita, ela realiza trabalho nas moléculas do ar, comprimindo-as, transferindo a elas energia na direção da compressão. Ao mesmo tempo, as moléculas do ar, situadas à esquerda, se expandem e se tornam rarefeitas, o que retira energia delas.

Quando a lâmina se move no sentido inverso, ela transfere energia para as moléculas do ar situadas à esquerda, enquanto as da direita perdem energia.

O efeito combinado de compressão e rarefação simultâneo transfere energia das moléculas do ar da esquerda para a direita, ou da direita para a esquerda na direção do movimento da lâmina, produzindo ondas longitudinais, nas quais as moléculas do ar se movimentam para frente e para trás, recebendo energia das moléculas mais próximas da fonte e transmitindo-a para as moléculas mais afastadas dela, até chegarem ao ouvido.

No ouvido, as ondas atingem uma membrana chamada tímpano. O tímpano passa a vibrar com a mesma freqüência das ondas, transmitindo ao cérebro, por impulsos elétricos, a sensação denominada som. 


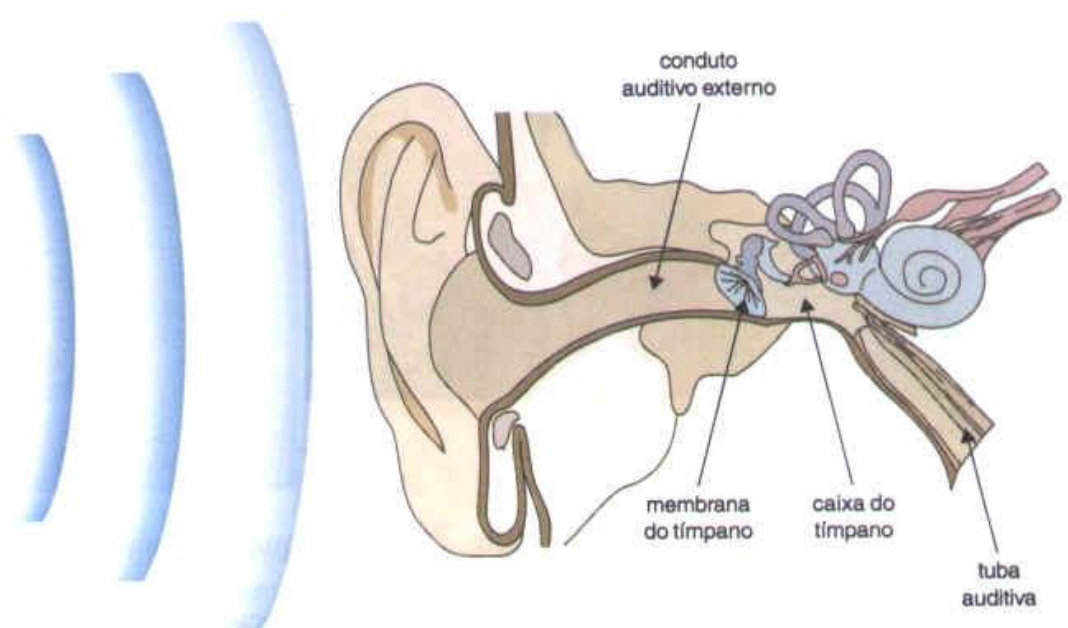

As ondas sonoras são ondas longitudinais, isto é, são produzidas por uma seqüência de pulsos longitudinais.

As ondas sonoras podem se propagar com diversas freqüências, porém o ouvido humano é sensibilizado somente quando elas chegam a ele com freqüência entre $20 \mathrm{~Hz}$ e $20000 \mathrm{~Hz}$, aproximadamente.

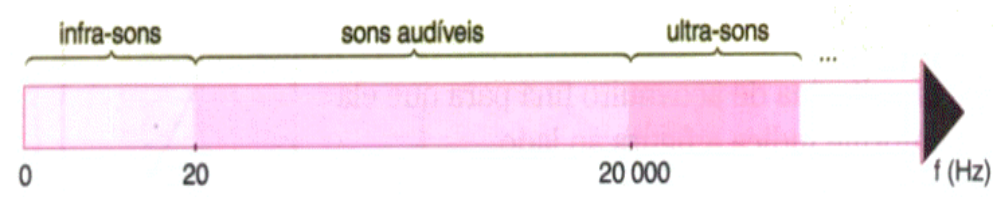

Quando a freqüência é maior que $20000 \mathrm{~Hz}$, as ondas são ditas ultrasônicas, e menor que $20 \mathrm{~Hz}$, infra-sônicas.

As ondas infra-sônicas e ultra-sônicas não são audíveis pelo ouvido humano. As ondas infra-sônicas são produzidas, por exemplo, por um abalo sísmico. Os ultra-sons podem ser ouvidos por certos animais como morcego e o cão.

As ondas sonoras audíveis são produzidas por:

- $\quad$ vibração de cordas

- vibração de colunas de ar

- vibração de discos e membranas 
O som musical, que provoca sensações agradáveis, é produzido por vibrações periódicas. O ruído, que provoca sensações desagradáveis, é produzido por vibrações aperiódicas.
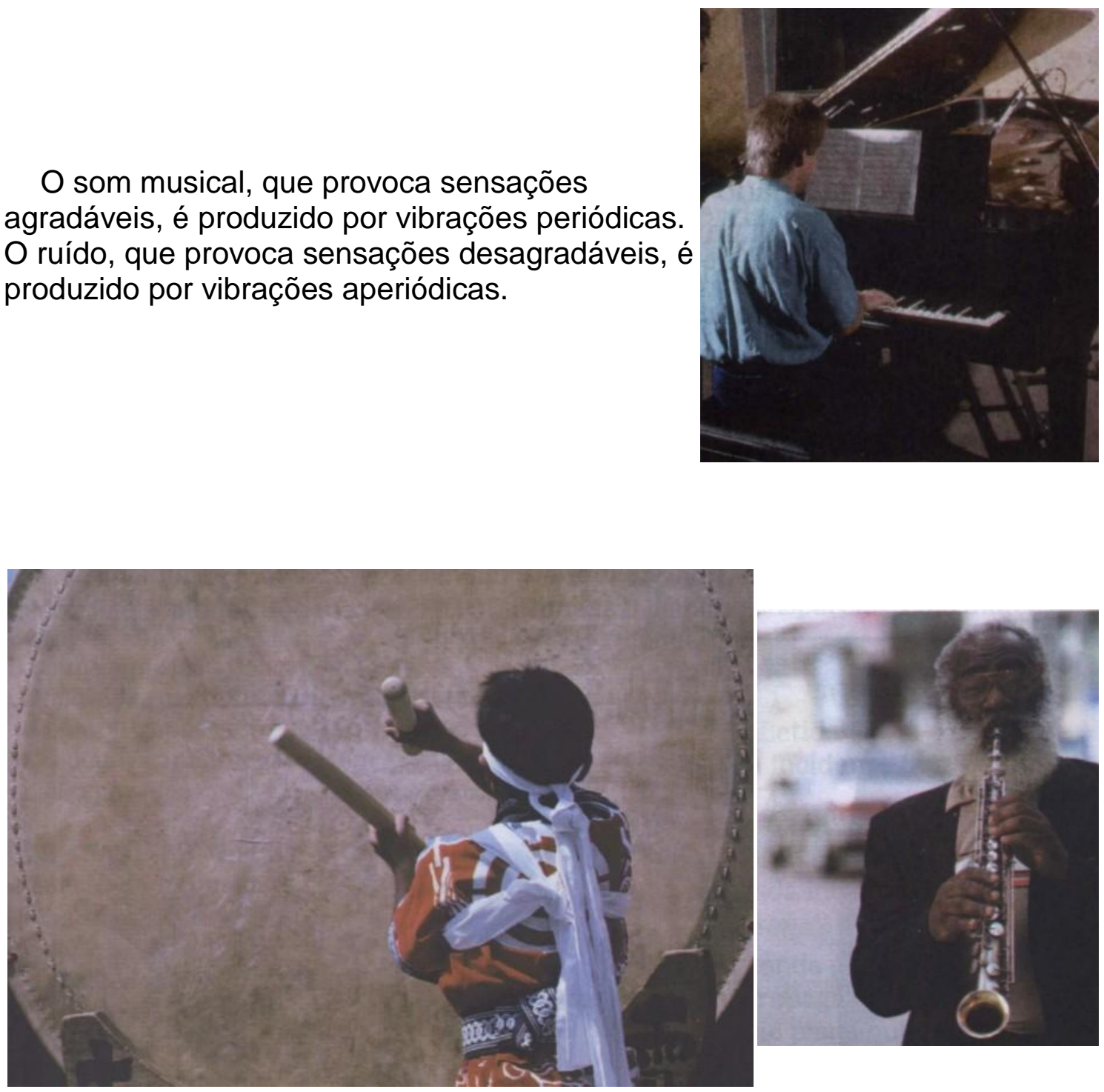

Podemos caracterizar os sons a partir de sua intensidade, altura ou timbre.

A intensidade está ligada à quantidade de energia transportada pelo som. Desta forma, conforme a intensidade do som dizemos que ele é mais forte (a onda possui maior amplitude) ou mais fraca (a onda possui menor amplitude).

A altura está relacionada com a freqüência do som. Assim distinguimos os sons mais altos como os de maior frequência (mais agudos) e os mais baixos como os de menor frequência (mais graves). As notas musicais buscam agrupar diferentes freqüências sonoras produzidas por um instrumento.

O timbre corresponde ao conjunto de ondas sonoras que formam um som. $\mathrm{O}$ timbre permite diferenciar diferentes fontes sonoras, por exemplo é fácil perceber que o som de uma guitarra e de uma flauta são completamente diferentes. 


\section{Transmissão do Som}

A maioria dos sons chega ao ouvido transmitida pelo ar, que age como meio de transmissão. Nas pequenas altitudes, os sons são bem audíveis, o que não ocorre em altitudes maiores, onde o ar é menos denso. O ar denso é melhor transmissor do som que o ar rarefeito, pois as moléculas gasosas estão mais próximas e transmitem a energia cinética da onda de umas para outras com maior facilidade.

Os sons não se transmitem no vácuo, porque exigem um meio material para sua propagação. De uma maneira geral, os sólidos transmitem o som melhor que os líquidos, e estes, melhor do que os gases.

Observe a tabela que apresenta a velocidade de propagação do som a $25^{\circ} \mathrm{C}$.

\begin{tabular}{|c|c|}
\hline Meio & Velocidade $(\mathrm{m} / \mathrm{s})$ \\
\hline Ar & 346 \\
\hline Água & 1498 \\
\hline Ferro & 5200 \\
\hline Vidro & 4540 \\
\hline
\end{tabular}

\section{Qualidades do Som}

Se a energia emitida pela fonte é grande, isto é, se o som é muito forte, temos uma sensação desagradável no ouvido, pois a quantidade de energia transmitida exerce sobre o tímpano uma pressão muito forte.

Quanto maior a vibração da fonte, maior a energia sonora, logo:

\section{Quanto maior a amplitude da onda, maior a intensidade do som.}

Em homenagem ao cientista norte-americano Graham Bell (1847-1922), que estudou o som e inventou o telefone, a intensidade sonora é medida em bel (B) ou decibéis $(\mathrm{dB})$. 

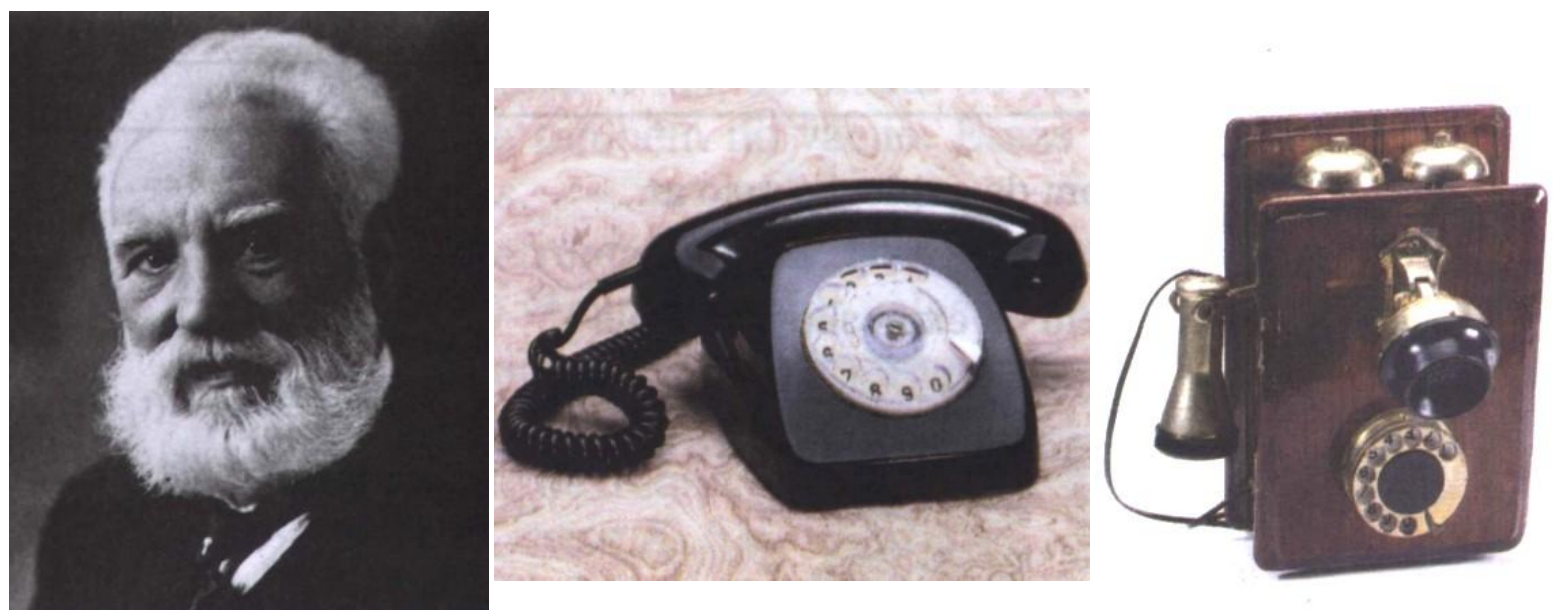

\section{Graham Bell}

Os sons muito intensos são desagradáveis ao ouvido humano. Sons com intensidades acima de $130 \mathrm{~dB}$ provocam uma sensação dolorosa e sons acima de $160 \mathrm{~dB}$ podem romper o tímpano e causar surdez.

De acordo com a freqüência, um som pode ser classificado em agudo ou grave. Essa qualidade é chamada altura do som.

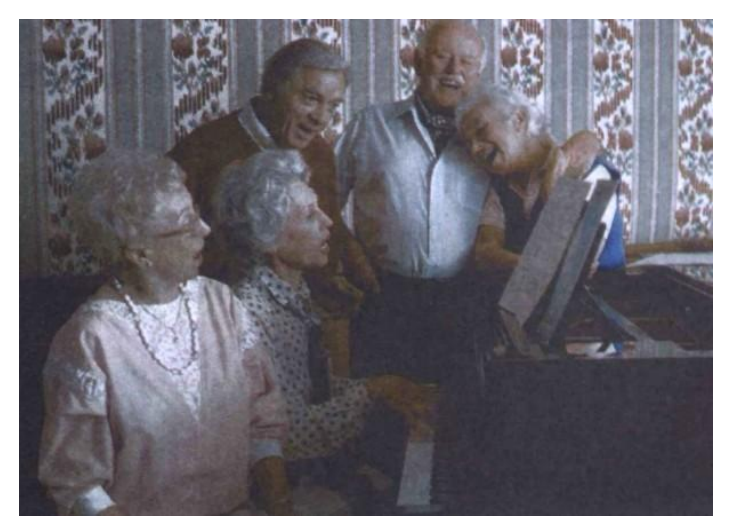

\section{Sons graves ou baixos têm frequiência menor.}

Sons agudos ou altos têm frequiência maior.

A voz do homem tem freqüência que varia entre $100 \mathrm{~Hz}$ e $200 \mathrm{~Hz}$ e a da mulher, entre $200 \mathrm{~Hz}$ e $400 \mathrm{~Hz}$. Portanto, a voz do homem costuma ser grave, ou grossa, enquanto a da mulher ser aguda, ou fina.

\section{Você Sabia?}


O som não pode se propagar no vácuo. Por essa razão, a onda sonora é chamada onda material ou onda mecânica. São também ondas mecânicas as ondas numa corda, na água e numa mola.

Essas ondas precisam de um meio material (sólido, líquido ou gás) para se propagar. Por outro lado, a luz, as ondas de rádio etc., podem se propagar em meios materiais e também no vácuo. Essas ondas são denominadas ondas eletromagnéticas.

As ondas eletromagnéticas são geradas por oscilações de cargas elétricas e se propagam no vácuo com uma velocidade aproximada de $300000 \mathrm{~km} / \mathrm{s}$. Os tipos principais de ondas eletromagnéticas são, em ordem decrescente de freqüência: raios gama, raios X, luz ultravioleta, luz visível, raios infravermelhos, ondas curtas de rádio e ondas largas de rádio.

O conjunto dessas ondas forma o espectro eletromagnético.

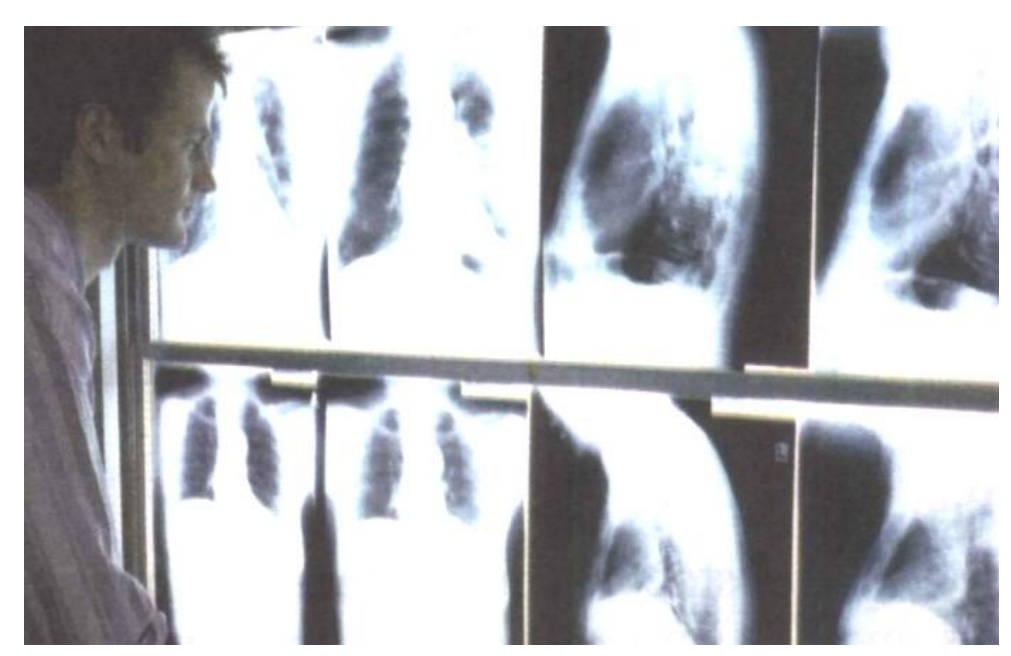

Veja algumas aplicações destes raios:

Raios gama: são emitidos por materiais radioativos e usados no tratamento de câncer e de muitas doenças de pele.

Raios $X$ : ajudam os médicos a tratar e a diagnosticar doenças.

Raios ultraviolenta: são usados como desinfetantes.

Raios infravermelhos: são emitidos por corpos aquecidos e usados para secar pinturas.

Ondas de rádio: são usadas pelas emissoras de rádio e televisão.

\section{Fenômenos Sonoros}


Sendo o som uma onda, ele apresenta as seguintes propriedades características: reflexão, refração, difração, interferência e ressonância.

\section{$1^{a}$. Propriedade: Reflexão}

Quando ondas sonoras AB, A'B', A"B" provenientes de um ponto P encontram um obstáculo plano, rígido, MN, produz-se reflexão das ondas sobre o obstáculo.

Na volta, produz-se uma série de ondas refletidas CD, C'D', que se propagam em sentido inverso ao das ondas incidentes e se comportam como se emanassem de uma fonte $\mathrm{P}^{\prime}$, simétrica da fonte $\mathrm{P}$ em relação ao ponto refletor. A reflexão do som pode ocasionar os fenômenos eco e reverberação.

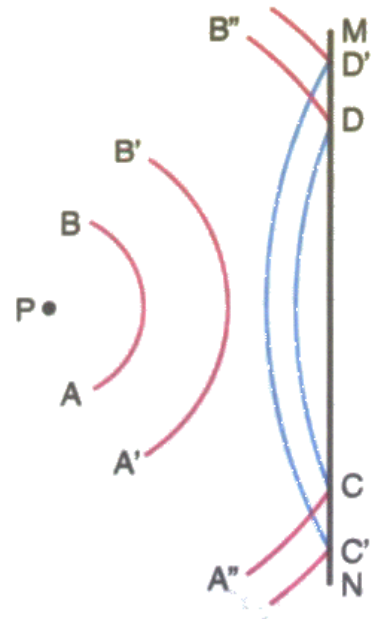

Eco

Os obstáculos que refletem o som podem apresentar superfícies muito ásperas. Assim, o som pode ser refletido por um muro, uma montanha etc. O som refletido chama-se eco, quando se distingue do som direto.

Para uma pessoa ouvir o eco de um som por ela produzido, deve ficar situada a, no mínimo, $17 \mathrm{~m}$ do obstáculo refletor, pois o ouvido humano só pode distinguir dois sons com intervalo de $0,1 \mathrm{~s}$. $\mathrm{O}$ som, que tem velocidade de $340 \mathrm{~m} / \mathrm{s}$, percorre $34 \mathrm{~m}$ nesse tempo. 


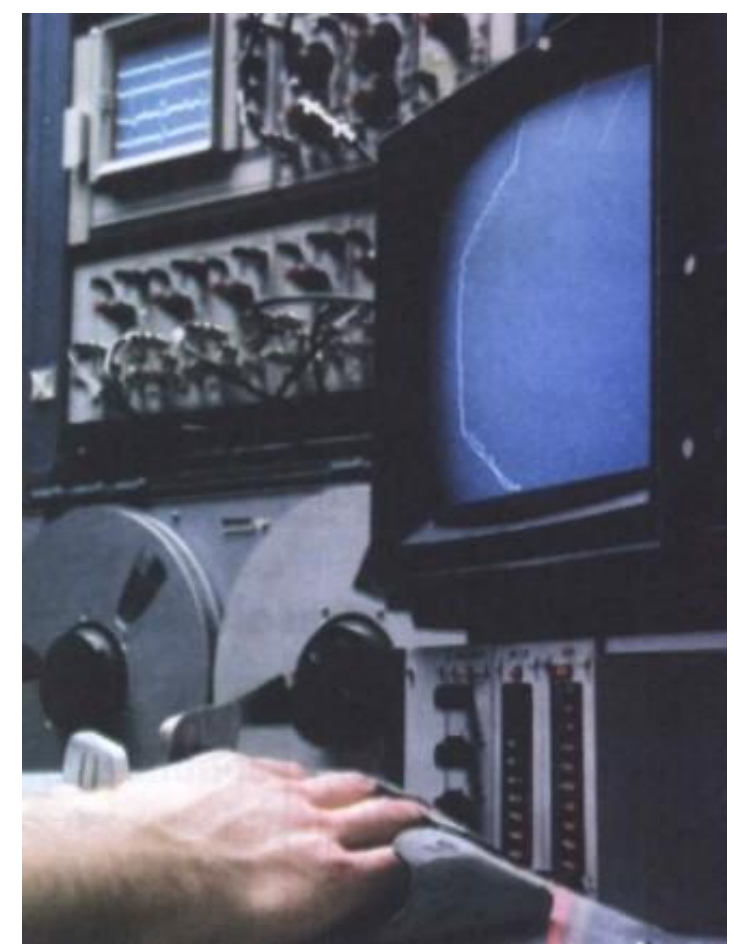

O sonar é um aparelho capaz de emitir ondas sonoras na água e captar seus ecos, permitindo, assim, a localização de objetos sob a água.

\section{Reverberação}

Em grandes salas fechadas ocorre o encontro do som com as paredes. Esse encontro produz reflexões múltiplas que, além de reforçar o som, prolongam-no durante algum tempo depois de cessada a emissão.

É esse prolongamento que constitui a reverberação. A reverberação ocorre quando o som refletido atinge o observador no instante em que o som direito está se extinguindo, ocasionando o prolongamento da sensação auditiva.

\section{- $\quad 2^{\mathrm{a}}$. Propriedade: Refração}

Consiste em a onda sonora passar de um meio para o outro, mudando sua velocidade de propagação e comprimento de onda, mas mantendo constante a freqüência. 
Fenômeno em que uma onda sonora pode transpor obstáculos.

Quando se coloca um obstáculo entre uma fonte sonora e o ouvido, por exemplo, o som é enfraquecido, porém não extinto. Logo, as ondas sonoras não se propagam somente em linha reta, mas sofrem desvios nas extremidades dos obstáculos que encontram.

\section{- $\quad 4^{\mathrm{a}}$. Propriedade: Interferência}

Consiste em um recebimento de dois ou mais sons de fontes diferentes. Neste caso, teremos uma região do espaço na qual, em certos pontos, ouviremos um som forte, e em outros, um som fraco ou ausência de som.

\section{Som forte $\rightarrow$ interferência construtiva}

\section{Som fraco $\rightarrow$ interferência destrutiva}

\section{- $\quad 5^{a}$. Propriedade: Ressonância}

Quando um corpo começa a vibrar por influência de outro, na mesma freqüência deste, ocorre um fenômeno chamado ressonância.

Como exemplo, podemos citar o vidro de uma janela que se quebra ao entrar em ressonância com as ondas sonoras produzidas por um avião a jato.

\section{Efeito Doppler}

Quando uma pessoa se aproxima de uma fonte sonora fixa, a freqüência do som do ouvido é maior do que aquela de quando a pessoa se afasta da fonte. O mesmo resultado seria obtido se a fonte se aproximasse ou se afastasse de uma pessoa parada.

Você pode observar esse fenômeno ouvido o apito de uma locomotiva em movimento. O apito é mais grave (freqüência menor) quando está se afastando, após ter passado por você.

Observe que, quando há aproximação entre o observador e a fonte, o observador recebe maior número de ondas por unidade de tempo e, quando há afastamento, recebe um menor número de ondas: 


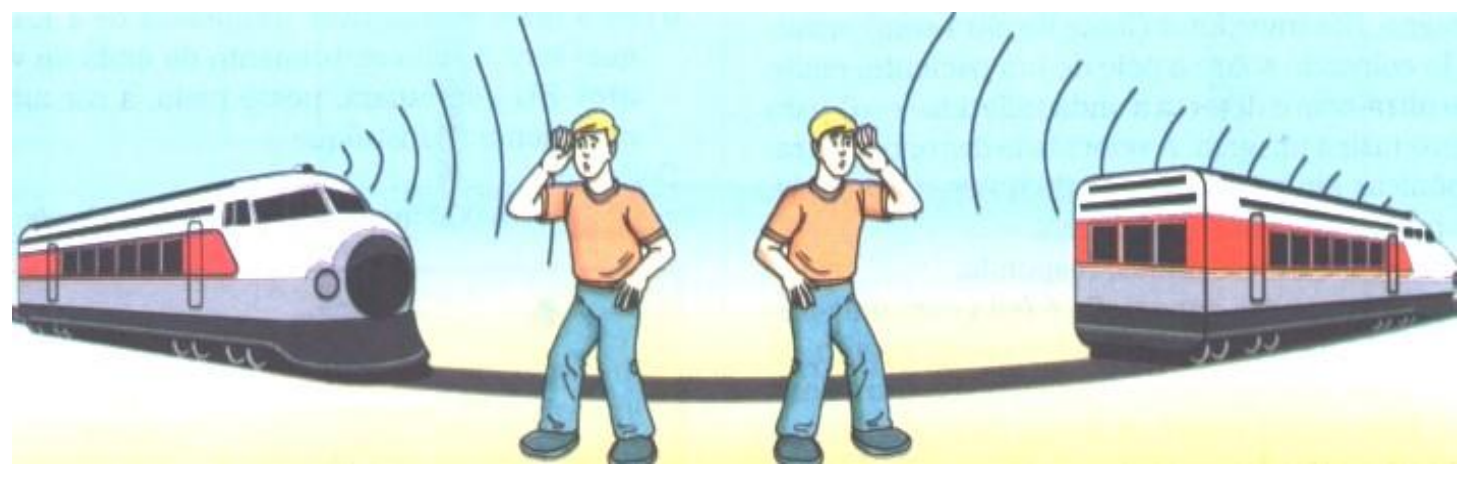

Essa variação aparente da freqüência de onda é chamada efeito Doppler, em homenagem ao físico e matemático austríaco Christian Johann Doppler (18031853), que ficou célebre por esse principio.

Denominando f' a freqüência recebida pelo observador e $f$ a freqüência emitida pela fonte, temos:

\section{Aproximação: f' $>$ f}

Afastamento: $f^{\prime}<f$

Essas grandezas são relacionadas pela expressão:

$$
f^{\prime}=f\left(\frac{v \pm v_{0}}{v \pm v_{F}}\right)
$$

Onde:

$\mathrm{v}=$ velocidade da onda

$\mathrm{v}_{\mathrm{F}}=$ velocidade da fonte

$\mathrm{v}_{\mathrm{o}}=$ velocidade do observador

$f=$ freqüência real emitida pela fonte

f' = freqüência aparente recebida pelo observador.

Os sinais mais (+) ou menos (-) que precedem o $v_{0}$ ou $v_{F}$ são utilizados de acordo com a convenção: 


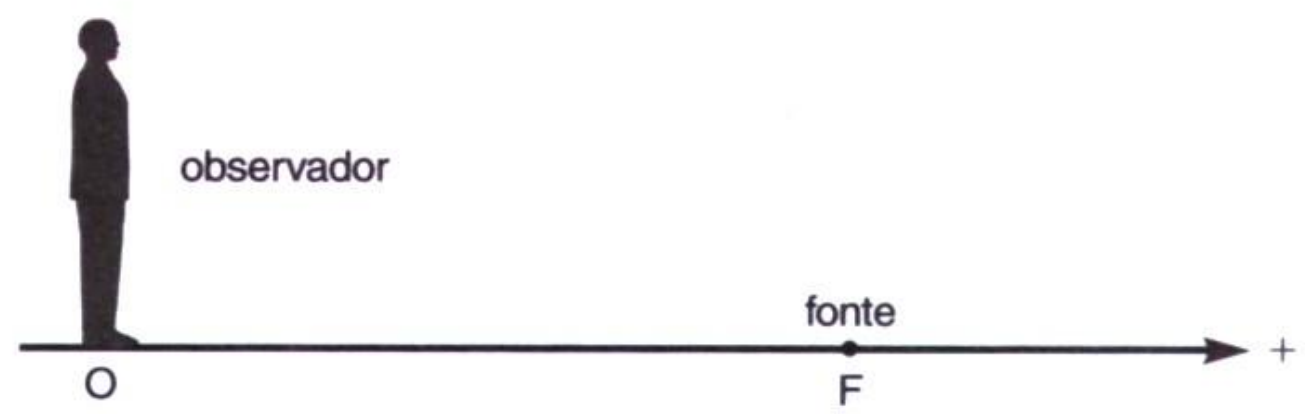

A trajetória será positiva de $\mathrm{O}$ para $\mathrm{F}$. Portanto:

$$
\begin{aligned}
& v_{0}\left\{\begin{array}{l}
\rightarrow+\text { observador se aproxima da fonte } \\
\leftarrow \quad-\text { observador se afasta da fonte }
\end{array}\right. \\
& v_{F}\left\{\begin{array}{l}
\rightarrow \quad+\text { fonte se afasta do observador } \\
\leftarrow \quad-\text { fonte se aproxima do observador }
\end{array}\right. \\
& v_{0}=0, \text { o observador está parado } \\
& v_{F}=0, \text { a fonte está parada }
\end{aligned}
$$

\section{ATIVIDADES}

1 - Experimentos de Baixo Custo

1.1 - Experimentos com o Som. Projeto prof2000. URL:

http://www.prof2000.pt/users/gracsantos/netmag/exper som.htm

\section{Experiências com o Som}

1) VER AS VIBRAÇÕES 
Material:

1 lata de bolachas grande e redonda

Folha de plástico fina

Elástico muito forte

Tabuleiro de ir ao forno, de metal

Colher de pau

Açúcar

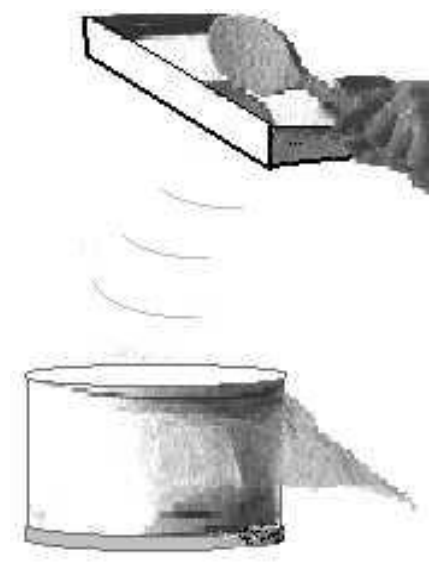

\section{Procedimento:}

1 - Faz um tambor esticando a folha de plástico de forma a cobrir uma lata redonda e grande.

2 - Prende o elástico à volta do bordo da lata, mantendo o elástico esticado.

3 - Polvilha a pele do teu tambor com uma colher de chá de açúcar.

4 - Segura no tabuleiro perto do tambor e bate-lhe com força com a colher de pau.

O que observas:

Vais ver o açúcar dançar para cima e para baixo na pele do tambor

\section{Como funciona:}

Quando bates no tabuleiro, o metal fica a vibrar, por uma fração de segundo, fazendo vibrar igualmente o ar junto dele. Estas pequenas vibrações do ar (ondas sonoras) rapidamente se espalham pelo ar em todas as direções. Quando atingem a pele do tambor, fazem-na também vibrar, e desta forma o açúcar começa a dançar para cima e para baixo. As ondas sonoras que chegam ao teu ouvido fazem-te ouvir o barulho.

\section{2) O SOM É UMA ONDA}

\section{2-A)}

Material:

Diapasão ( de preferência de baixa frequência)

Tina com uma pequena camada de água no fundo

2 colheres de chá

\section{Procedimento:}

1- Percutir o diapasão e observar as respetiva vibração, atendendo ao som que produz.

2-Experimentar tocar no diapasão em vibração. Observar e registrar.

3-Percutir o diapasão e tocar com uma 


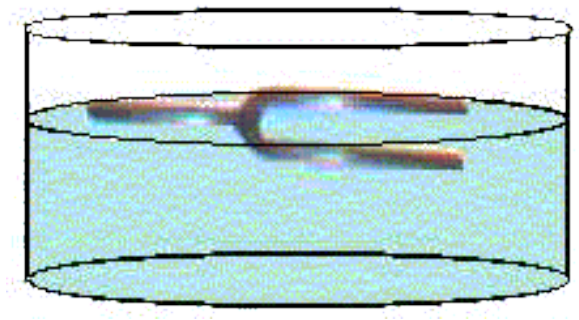

2-B)

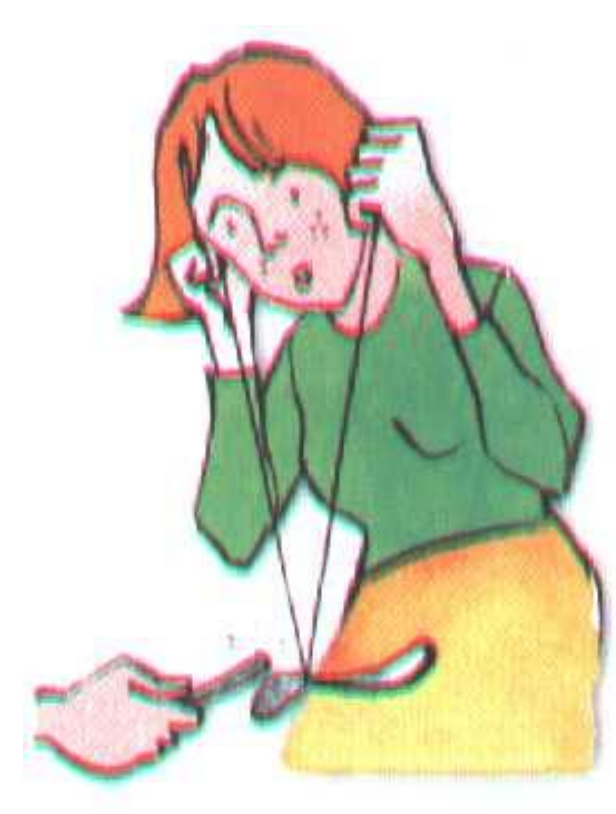

das suas hastes na superfície da água da tina.

4-Registrar o efeito provocado na superfície da água.

\section{Procedimento:}

1-Atar uma das colheres a meio do fio.

2-Passar as extremidades do cordão por trás das orelhas, segurando-as e tapando os ouvidos com as pontas dos dedos. Deve, em seguida, inclinar-se para a frente para que a colher suspensa possa oscilar livremente.

3-Pedir a outro colega para dar uma pequena pancada na colher suspensa com a outra colher.

4-Escutar com atenção o som produzido pelo choque das colheres e que foi ouvido através do fio. Registrar as observações.

\section{Reflectindo...}

Ouve-se o som quando o diapasão não vibra? Que meio atravessa o som do diapasão até chegar aos nossos ouvidos?

Os índios norte-americanos detectavam a chegada da cavalaria dos "caras pálidas" encostando o ouvido ao chão. Serás capaz de explicar porquê? 


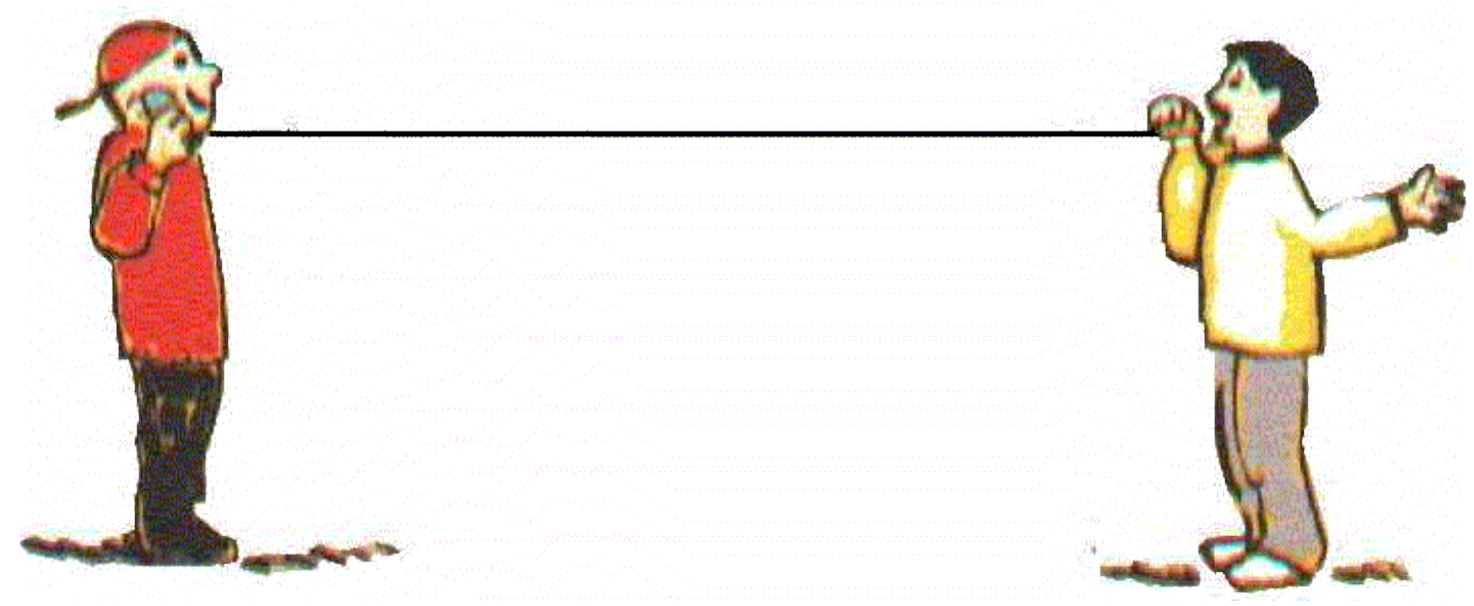

Com este pequeno brinquedo podemos comprovar o fenômeno de transmissão do som através de corpos sólidos.

Constrói um telefone de cordel para sentires como o som se propaga através dos sólidos (cordel).

\section{Material:}

1 cordel e 2 copos de plástico

\section{Procedimento:}

1- Faz um furo no fundo de dois copos de plástico

2-Faz passar pelos furos um cordel engordurado ( a gordura dá-lhe consistência) com aproximadamente $4 \mathrm{~m}$

3- Dá um nó nas extremidades do cordel de modo a não se soltar dos copos e estica o cordel.

4 - Pede ao teu amigo para falar para dentro do copo e encosta o teu copo junto ao ouvido.

4 ) A velocidade do som depende do meio em que o som se propaga

O som pode propagar-se noutros meios além do ar.

Por exemplo, um nadador consegue ouvir dentro de água alguns dos sons à superfície, ou mesmo o som de uma sineta tocada dentro de água.

A velocidade do som na água é maior do que no ar: á aproximadamente $1500 \mathrm{~m} / \mathrm{s}$. Num meio sólido, como o cimento, o som ainda se propaga mais depressa: cerca de $5000 \mathrm{~m} / \mathrm{s}$. Isto acontece porque tanto o ar como a água e o cimento são constituídos por partículas, e estas, no cimento e

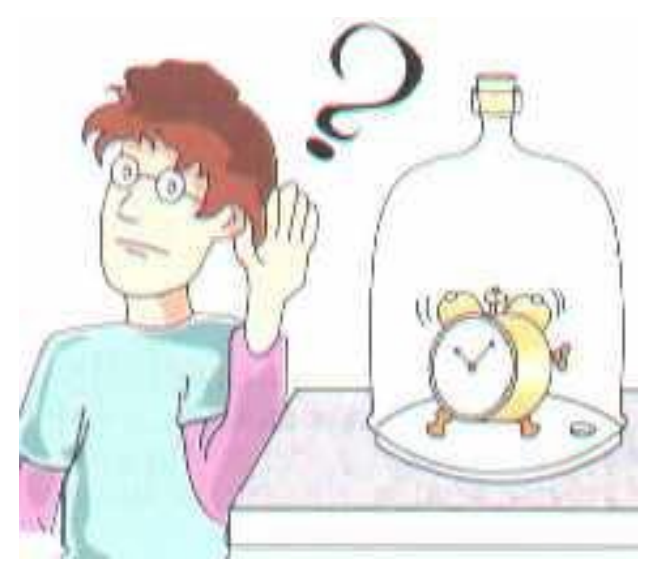


na água, encontram-se mais próximas do que no ar. As partículas vão transmitindo "sinais" (vibrações) às seguintes e é do movimento de todas elas que resulta o som. Quanto mais próximas estiverem entre si as partículas vibrantes, mais rapidamente se propagam as vibrações.

Uma sineta a tocar numa campânula onde se fez o vácuo não se ouve, pois o som precisa de um suporte material para se propagar.

\section{5) REFLECTIR O SOM}

\section{Material necessário:}

Tubos ocos, cilíndricos, de cartão ou de cana, com cerca de $0,5 \mathrm{~m}$ de comprimento 1 relógio com tique-taque audível ( ou cronometro)

1 placa lisa para reflexão do som.

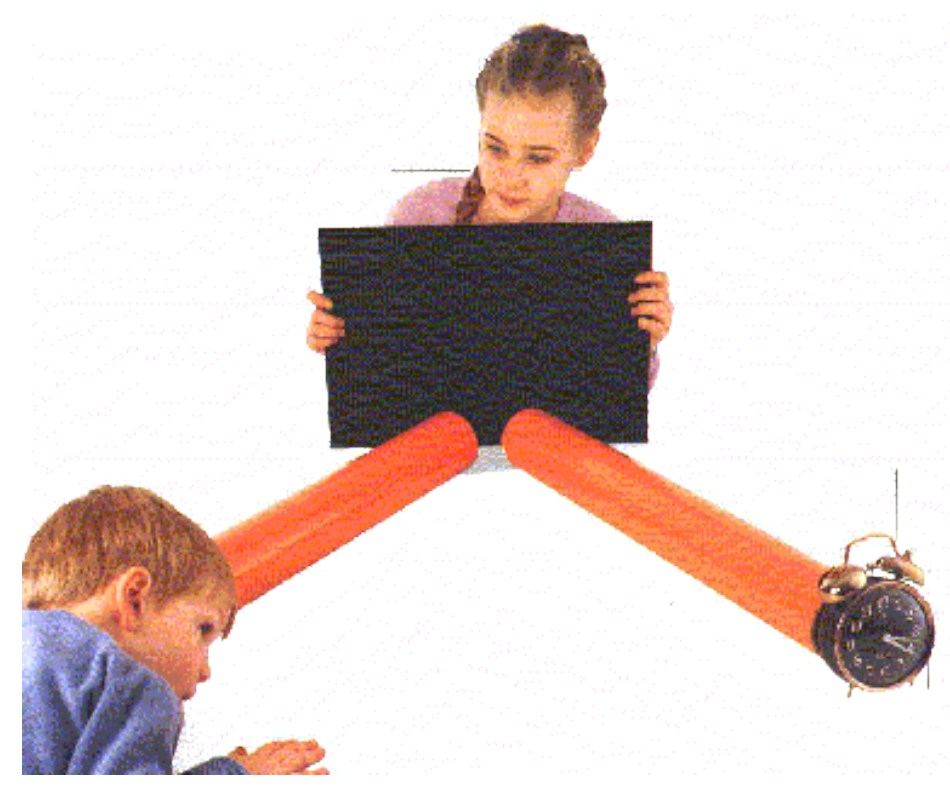

\section{Procedimento:}

1-Dispor na mesa o cronometro, a placa refletora e os tubos de acordo com o esquema indicado. Deixar um espaço de cerca de $6 \mathrm{~cm}$ entre o cartão e as extremidades dos tubos.

2- Colocar o cronometro na extremidade livre de um tubo e na extremidade do outro o ouvido, em posição tal que ouça nitidamente o tique-taque.

\section{O que se registra:}

O som propaga-se ao longo de um tubo e é refletido pelo cartão para dentro do outro tubo.

\section{O que se pode aprofundar:}


A direção do $1^{\circ}$ tubo é a direção da onda sonora incidente e a do $2^{\circ}$ tubo é a direção da onda sonora refletida. Comparar os ângulos que estas direções formam com a perpendicular à parede refletora.

Induzir uma lei da reflexão das ondas sonoras.

Substituir a placa refletora por um feltro ou uma camisola. A reflexão é boa ou má ?

\section{6) CONSTRUIR UM ESTETOSCÓPIO}

\section{Material:}

2 funis pequenos

Tubo flexível que fique bem ajustado aos funis

Balão tesoura

Elástico

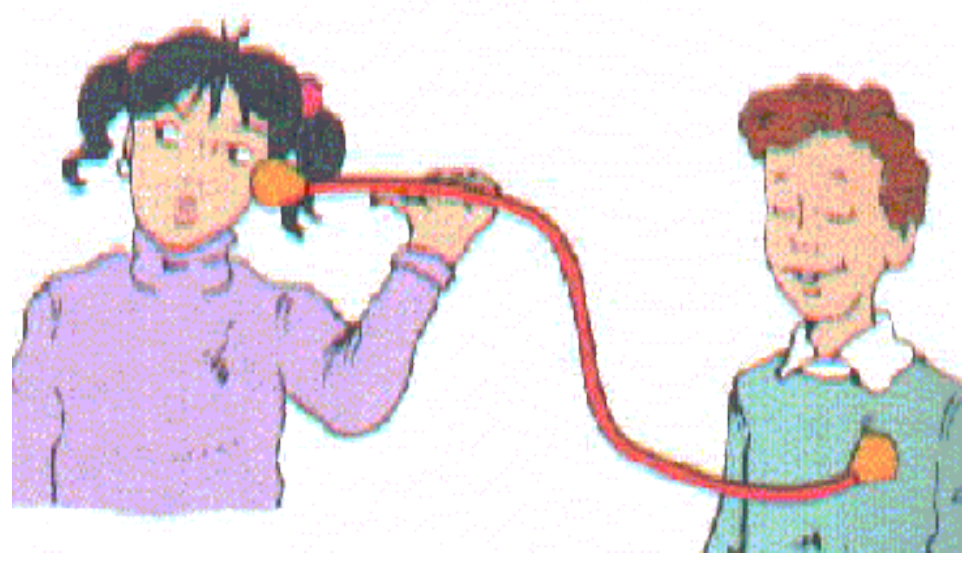

\section{Procedimento:}

1- Coloca cada uma das extremidades do tubo nos funis

2-Enche o balão com ar e deixa-o cheio durante alguns minutos para que ele dilate. 3 - esvazia o balão e corta a parte superior para ficares com uma pequena "tampa". 4-Põe o pedaço de balão sobre a parte aberta do funil, o mais esticada possível, e fixao em redor com um elástico.

\section{O sonar e o radar}

Alguns barcos utilizam o fenômeno do eco para determinar a profundidade da água por baixo deles ou a presença de cardumes.

O aparelho que faz esta determinação chama-se sonar.

O sonar possui um emissor de som especial, que faz

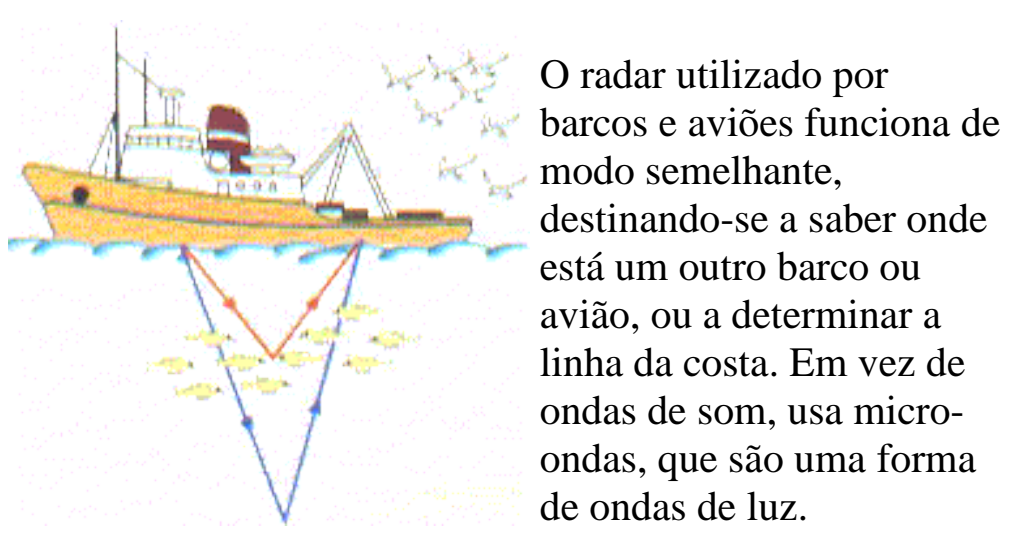
propagar o som na água, e tem associado um 
microfone, que recolhe o som refletido.

\section{7) CONSTRUIR UMA GUITARRA}

Faz um buraco circular numa caixa, por exemplo uma caixa de sapatos. Dobra um bocado de cartão para fazer um "pente" e fixa-o como na figura. Coloca seis tachas em cada extremo da caixa e estica seis elásticos ao longo da caixa e pente, enrolando-os as tachas. Toca as cordas para produzirem sons. Estica-as e verifica que produzem sons mais agudos.

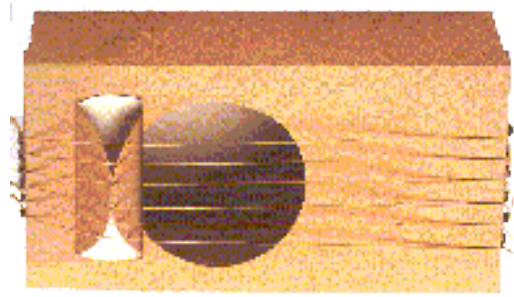

\section{8) CONSTRUIR UM XILOFONE}

1- Põe 8 garrafas em fila e deita-lhes água a alturas diferentes, de modo a que a altura do ar dentro das garrafas tenha os valores representados na figura.

2- Podes misturar um pouco de corante em cada garrafa para que o xilofone fique mais colorido.

3- Agora é só tocar.

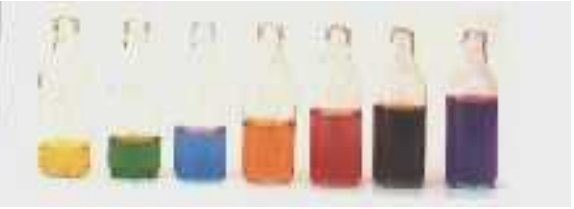

1.2 - Projeto Seara da Ciência. Neste projeto você encontra alguns experimentos um pouco mais sofisticado.

Medir a velocidade da luz.

Medindo a velocidade da luz com um televisor.

Medir a velocidade do som.

Medindo a velocidade do som com um kit multimídia.

Medir a velocidade da luz com um forno de micro-ondas.

Faça a experiência e saboreie o resultado. 
Uma harmônica de taças.

Produzindo música com taças ou copos.

Outro instrumento insólito.

Uma marimba de garrafas.

\section{2 - Applets de Ensino}

2.1 - Ver http://www.sc.ehu.es/sbweb/fisica/Introduccion/indiceApplets/indice/indice ondas.htm

2.2 - Se você conhecer um pouco de inglês vale a pena ver o site: Animações de Acústica e Vibrações. URL: http://www.acs.psu.edu/drussell/demos.html

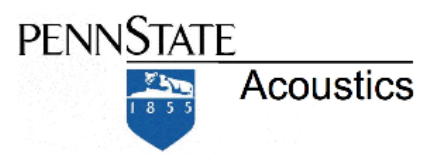

Acoustics and Vibration Animations

Dan Russell, Ph.D., Professor of Acoustics \& Director of Distance Education Graduate Program in Acoustics, The Pennsylvania State University

2.3 - Projeto Physlets. Applet tirado do livro de física de Wolfgang Christian's Physlet.

URL: http://www.cabrillo.edu/ jmccullough/physlets/sound/sound 1.html

Problema1.

Descrição:

A animação é uma representação em câmara lenta de uma seção crizada de iuma onda sonora se propagando em acrílico. Um detector, quadrado laranja, é colocado no material para medir a pressão (posição em m e tempo em s).

\section{Pergunta:}

Qual é a velocidade da onda sonora? Nota: a animação roda durante $0,1 \mathrm{~s}$; pressione "reset" para reiniciar a animação.

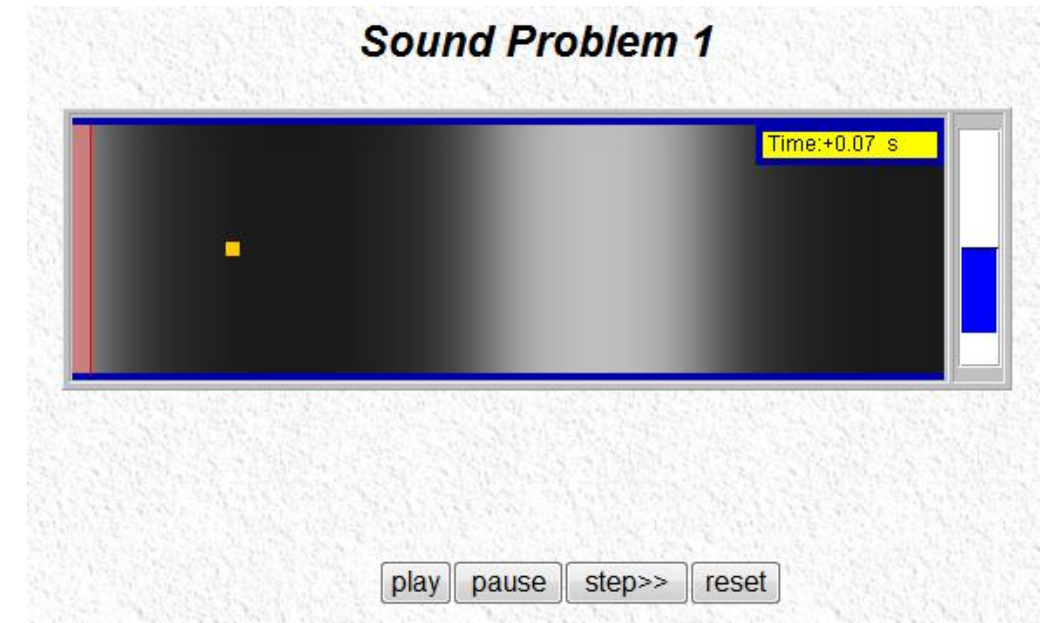

Problema2.

Descrição:

A animação representa uma secção transversal de uma onda de som de propagação em um tubo. Um detector, o quadrado de laranja é colocada no tubo e mede a pressão (posição dada em centímetros e de tempo determinado em milissegundos). 


\section{Pergunta}

Qual dos gráficos adequadamente representa o deslocamento das moléculas de ar no tubo?

\section{Sound Problem 2}
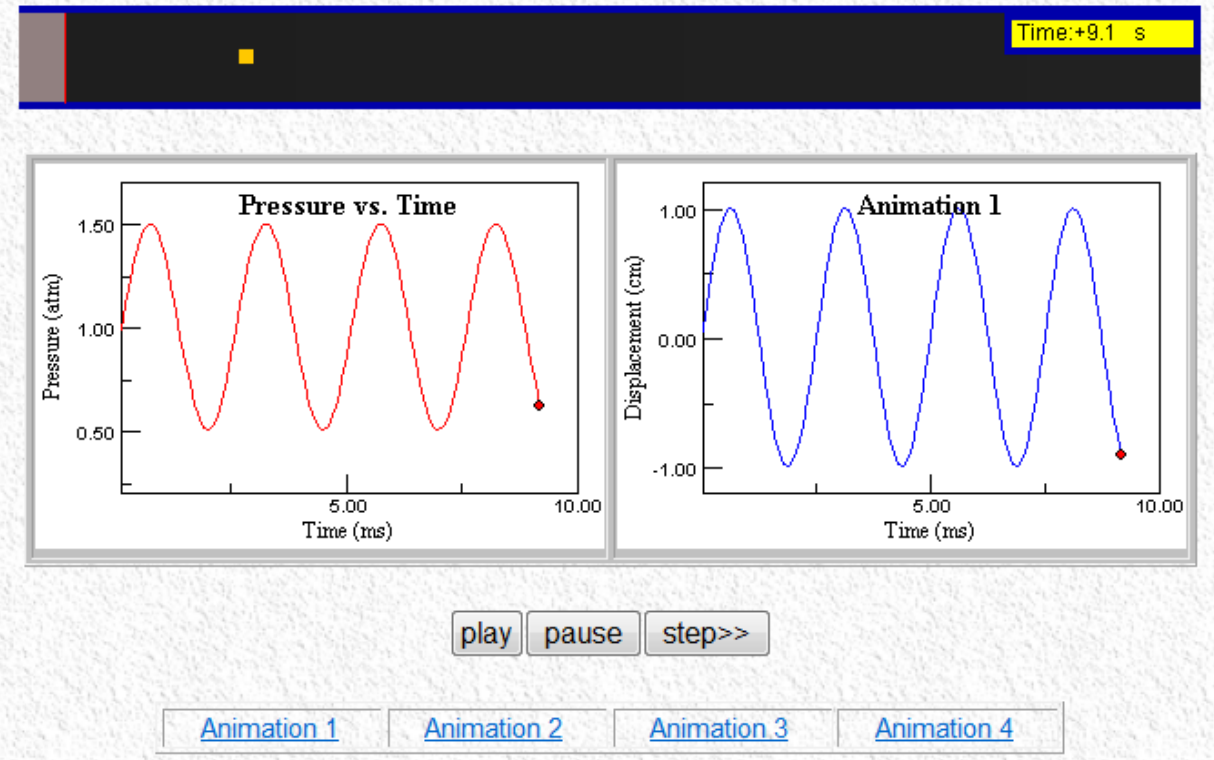

\section{Problema3.}

\section{Descrição}

A animação representa uma secção transversal de uma onda de som tridimensional de propagação de distância de uma fonte em movimento.

Pergunta

Em qual a animação (s) é que a fonte de viajar mais lenta do que a velocidade do som?

Sound Problem 3

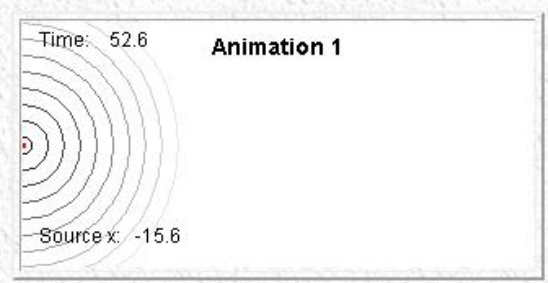

play pause

Problema4.

\section{Descrição}

A animação acima mostra o padrão de onda resultante som de duas fontes, cada uma das quais podem ser ligados e desligados. 
Por que não há pontos mortos na distribuição do som quando a esquerda ou a direita da fonte está transmitindo, mas existem vários pontos mortos quando ambas as fontes estão transmitindo?

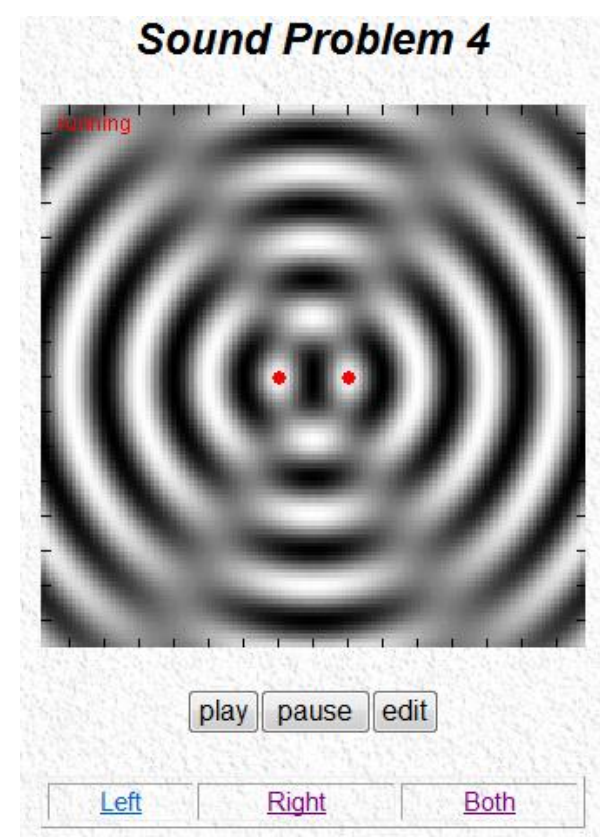

\section{4 - Projeto Phet. Universidade do Colorado. URL:}

Este applet permite estudar as ondas, o som e a luz. Podemos produzir ondas pelo pingar de uma torneira, por um alto falante (ou dois), ou por intermédio de um laser (ou dois) e observar como estão relacionadas. Todas podem ser representadas por uma sinusoidal. Para estudar o som, é muito interessante poder ver o movimento das partículas do ar durante a propagação da onda de compressão, confirmando que não ocorre transporte de matéria.

Podemos modificar a frequência e a amplitude e, no caso do som, permite ouvir o sinal produzido. Podemos adicionar obstáculos (paredes e espelhos) para estudar a reflexão. Para estudar fenômenos de interferência e difração, podemos adicionar uma ou duas fendas. Podemos encontrar pontos de interferência destrutiva e construtiva a olho, ou usando detectores. 


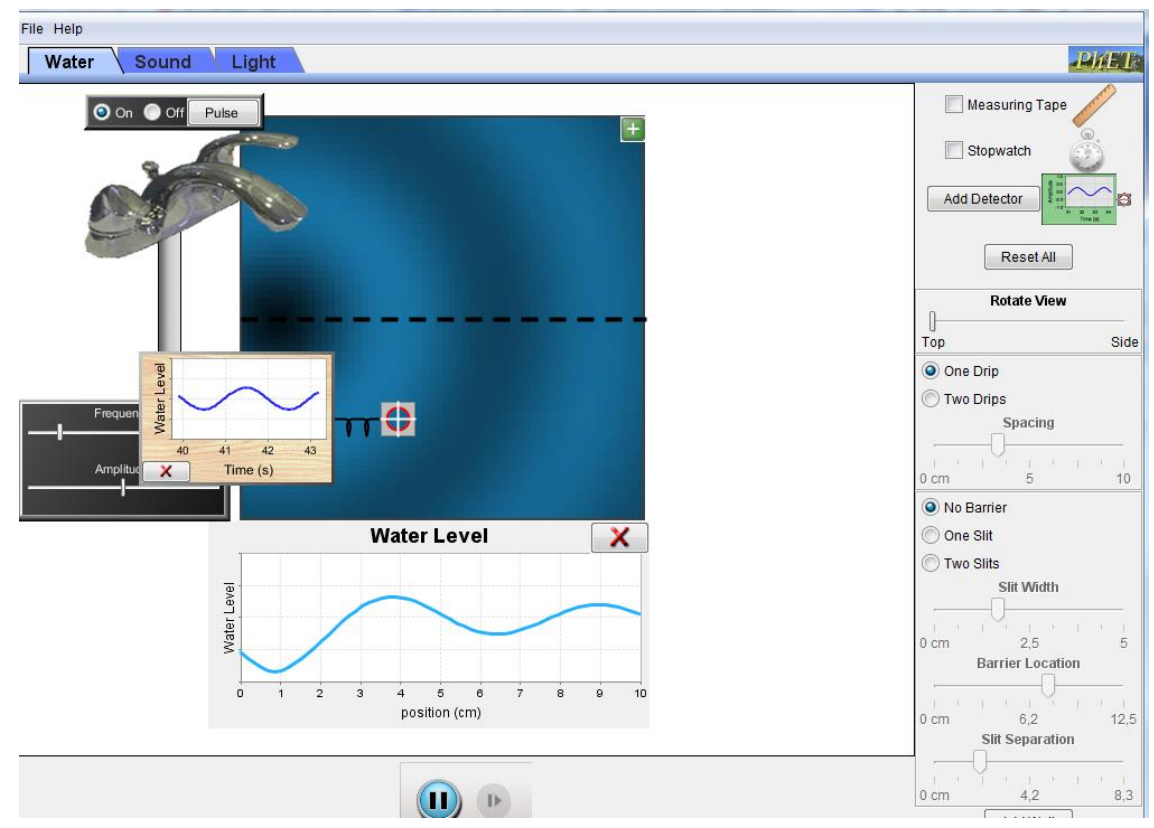

2.5 - Applets sobre o tema: Efeito dopler.

2.5.1 - Projeto Walter-fendt. URL: http://www.walterfendt.de/ph14br/dopplereff_br.htm

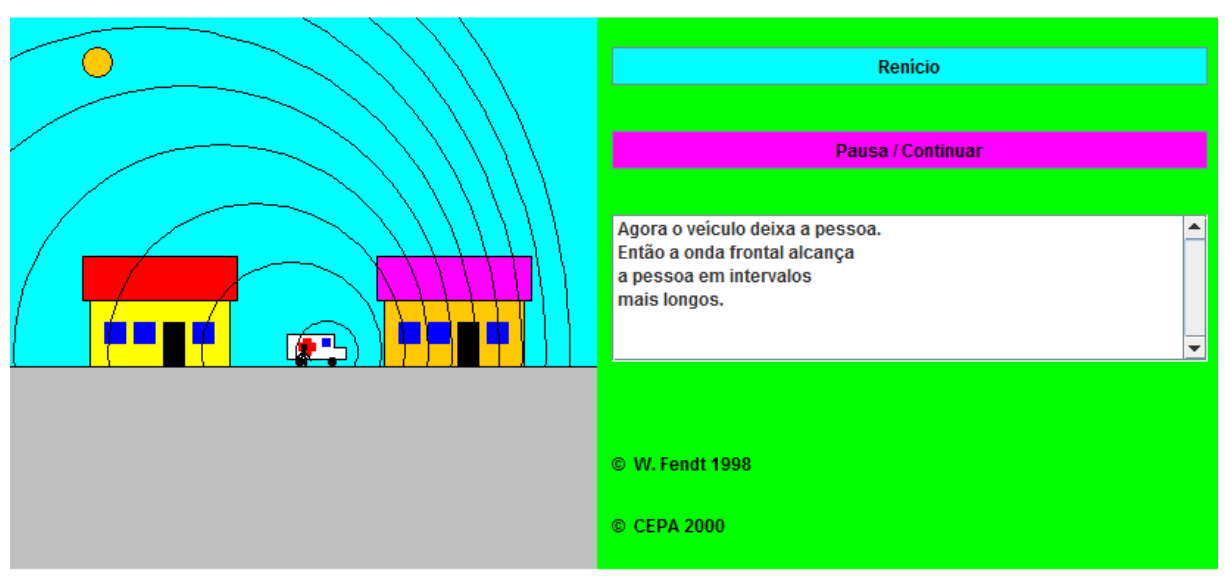

2.5.2 - Física Animada. $\rightarrow$ http://www.fisicanimada.net.br/?q=ondas/doppler_nav 


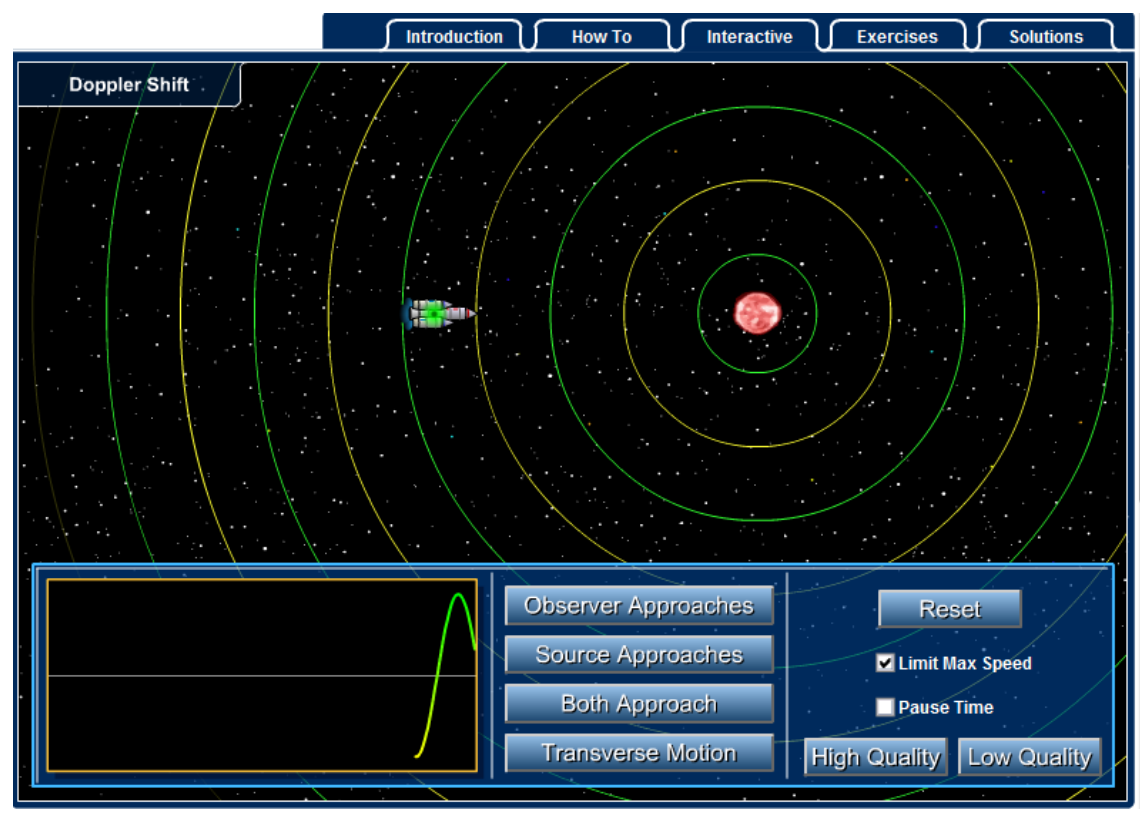

\section{3 - Vídeos Aulas.}

3.1 - Ciências: fenômenos acústicos. URL:

http://www.youtube.com/watch?v=XTgA_B2lgfo

3.2 - Filme mostrando estudantes fazendo experimentos. URL:

http://www.youtube.com/watch?v=fXRknpOkq4o\&feature=related

3.3 - Novo Telecurso. Aula 30 parte 1 e 2. URL:

http://www.youtube.com/watch?feature =endscreen\&v=tTvl3jviMKw\&NR=1 http://www.youtube.com/watch?v=peZ08VsAOVM\&feature=relmfu

3.4 - Ressonância Acústica. Ver, pois é muito interessante. Sem texto.

URL: http://www.youtube.com/watch?v=qy1c5 vYTVo\&feature=related

\section{5 - Sua voz é capaz de quebrar uma taça? Muito Legal}

http://www.youtube.com/watch?v=jNeDHUmITtl\&feature=related

3.6 - Teatro de Epidauro.

http://www.youtube.com/watch?v=H7Td1Jk4zlo\&feature=related

COMENTÁRIOS:

CONCLUSÃO: 
http://ww2.unime.it/weblab/awardarchivio/ondulatoria/acustica.htm

http://ww2.unime.it/weblab/awardarchivio/ondulatoria/experimentacoes.htm 


\section{Cap.09 - Instrumentos Ópticos}

Meta: Fazer que o estudante comece a pensar no ensino de ciências como algo "orgânico" que está em profunda transformação. Fazer com que os alunos percebam, através de uma atividade lúdica, que podemos ensinar física através de experimentos muito simples, e que física é uma ciência aplicada e que pode ser aprendida através da observação de vários dispositivos do nosso cotidiano. Fazer com que 0 aluno percebam as aplicações da física no cotidiano. Mostrar que existem muitas animações virtuais sobre o tema, e que ensinar e aprender física pode ser uma atividade divertida e interessante.

Objetivos: Ao final da aula, os alunos devem estar cientes das novas possibilidades e dos desafios que envolvem o ensino de ciências em geral. Que para se ensinar física não precisamos ficar presos ao livro didático. Que ensinar física não é ensinar a resolver problemas e que a física é uma mera aplicação da matemática. Que podemos ensinar a física das coisas e não as coisas da física. Estes devem estar cientes que é possível explorar vários recursos de multimídias e de experimentos de baixo custo em sala de aula.

Pré-requisitos: Os alunos deveram ter cursado psicologia da educação física A, B e C.

\section{Introdução:}

Esse é mais um capítulo que é um subtópico do curso de Física C. Mas, ele é central na abordagem de se ensinar a física das coisas e não se ensinar física a partir de teorias desconexas da realidade destes (alunos). Esse capítulo é um pouco longo, mas é possui um caráter mais informativo do que 
formativo do futuro professor. Existe muito exemplos de applets de ensino e experimentos de baixo custo, o que faz o tema deste capítulo muito interessante de ser trabalhado em sala de aula.

\section{Introdução}

Instrumentos ópticos desempenham um papel importante no nosso modo de viver. Uma lupa, um microscópio ou um telescópio são exemplos de instrumentos ópticos. Alguns instrumentos envolvem apenas um componente (uma lente - como a lupa) ou podem envolver vários componentes (prismas, espelhos e lentes). Vamos estudar aqui, e em linha gerais, o princípio de funcionamento dos instrumentos ópticos.

\section{A - LUPA (wiki)}

A lupa é um instrumento óptico munido de uma lente com capacidade de criar imagens virtuais ampliadas. É utilizada para observar com mais detalhe pequenos objectos ou superfícies.Também denominada microscópio simples - é constituída de uma única lente esférica convergente. Quanto maior for o aumento desejado, menor deve ser sua distância focal. A lente só se comportará como lupa quando o objeto estiver colocado numa distância inferior à sua distância focal.

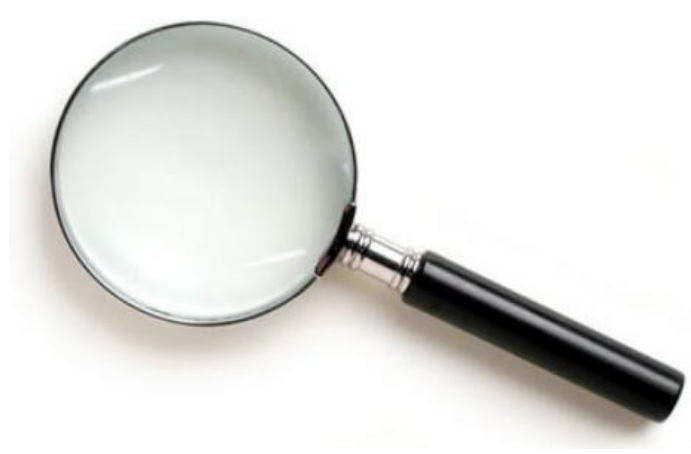

Para compreender como a utilizamos, precisamos analisar tanto como a lupa conjuga imagens, como estas imagens (objetos virtuais para o nosso olho) acabam sendo projetadas na nossa retina. (Só vemos imagens reais projetadas na nossa retina) A lupa é composta (normalmente) por uma lente biconvexa - portanto convergente - de pequena distância focal. O sistema óptico do nosso olho é similar a de uma lente convergente (córnea + cristalino + humor aquoso + humor vítreo) e um anteparo (retina). Foi criada por Roger Bacon em 1250, por meio de sua primeira invenção: os óculos. As Lupas existem de varios tipos tem as que as imagens aumentam mas ficam de ponta-cabeça. Com certa posição, as lupas podem queimar e na pele humana, provocar queimaduras de $3^{\circ}$ grau. 
Apesar dessa ampliação, a lupa não serve para a observação de objetos muito pequenos como células e bactérias, pois nesses casos se faz necessário um aumento muito grande.A solução é associarmos duas ou mais lentes convergentes, como no microscópio composto.

\section{Periscópio (educar.sc)}

Para quê serve um periscópio?

Serve para observar objetos que não estão no mesmo nível do olhos. Vocês já devem ter visto, pelo menos em filmes, que um submarinho tem um periscópio acoplado, para observar objetos fora da água.

Um periscópio é constituído, basicamente, de dois espelhos colocados inclinados de $45^{\circ}$ como mostra a fig. 7.15 , ou de dois prismas de reflexão total.

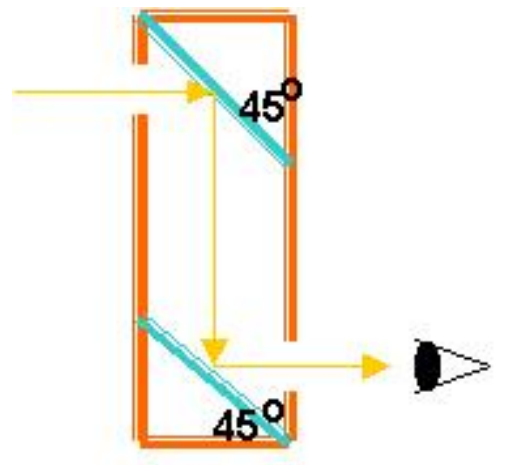

Figura 7.15 - Periscópio

O raio de luz ao incidir no primeiro espelho reflete, incidindo no segundo espelho. Após incidir no segundo espelho, o raio de luz reflete novamente, atingindo o olho do observador.

\section{Lunetas e Luneta Astronômica}

A luneta ou telescópio de refração é utilizada para observar objetos distantes. A luneta astronômica tem, como o microscópio, duas lentes convergentes: a objetiva que ao contrário do microscópio apresenta grande distância focal e a ocular.

O esquema da fig. 7.11 mostra como é obtida a imagem de um objeto distante. 


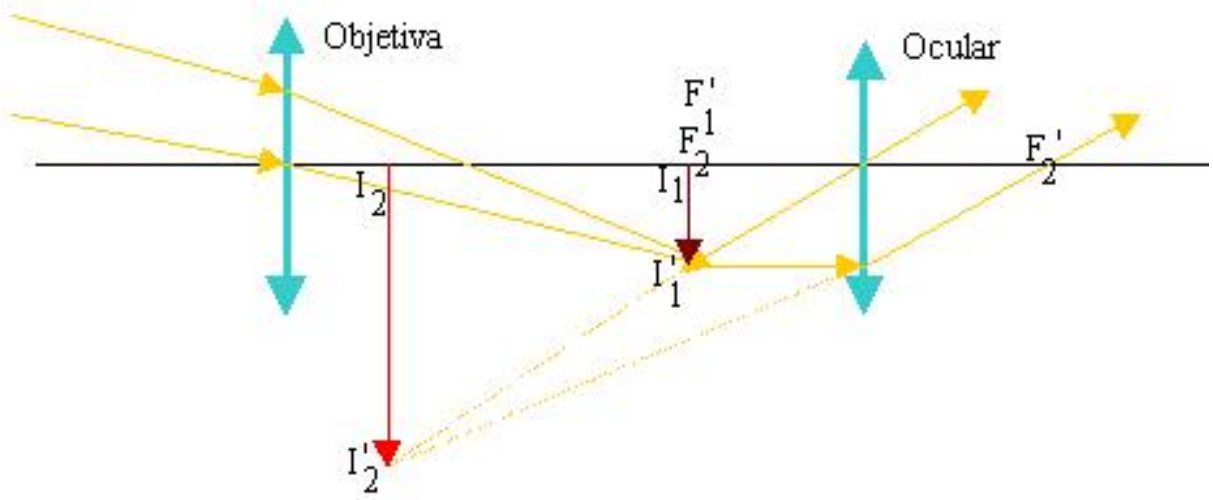

Figura 7.11 - Esquema simplificado de formação da imagem em uma luneta astronômica.

A objetiva forma a imagem $I_{1} I_{1}$ sobre seu foco e esta imagem vai servir como objeto para a ocular que fornece a imagem final do sistema $\left.\mathrm{I}_{2}\right|_{2}$ que é virtual e invertida.

Observe que os focos da ocular e da objetiva praticamente coincidem.

O aumento visual de uma luneta é expresso pela relação entre as distâncias focais da objetiva $\left(\mathrm{f}_{1}\right)$ e da ocular $\left(\mathrm{f}_{2}\right)$ :

$A=f_{1} / f_{2} \quad 7.4$

A desvantagem da luneta astronômica para observar objetos terrestres é que ela fornece uma imagem invertida.

\section{Luneta terrestre}

A luneta terrestre é semelhante à astronômica só que a imagem final obtida é direita. A fig. 7.12 mostra a luneta terrestre construída por Galileu em 1609.

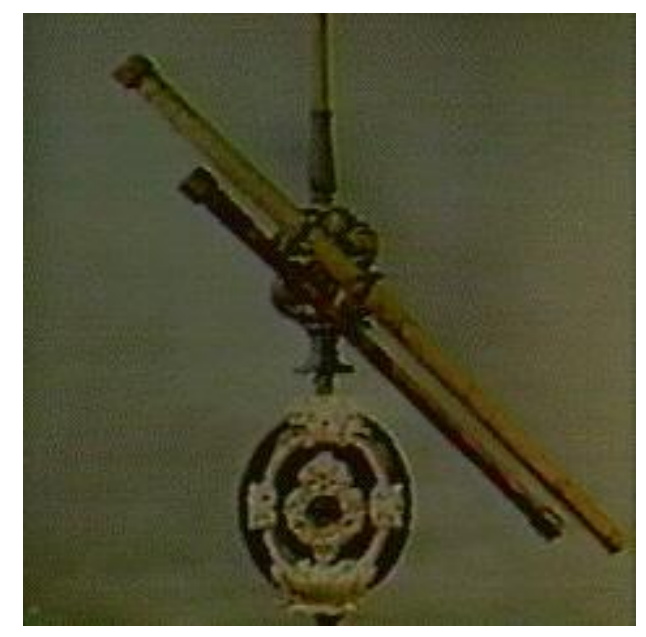

Figura 7.12 - Luneta construída por Galileu 
Esta luneta tem como elemento característico uma ocular divergente. A objetiva é uma lente convergente.

A distância entre as duas lentes é aproximadamente igual a diferença entre as duas distâncias focais (na construção do telescópio coloca-se esta distância igual). A primeira imagem $\mathrm{I}_{1} \mathrm{l}_{1}$, fornecida pela objetiva, se forma sobre o foco imagem da objetiva $\left(\mathrm{F}^{\prime}{ }_{1}\right)$. Esta imagem vai servir como objeto virtual para a ocular. A imagem final $\mathrm{I}_{2} \mathrm{l}_{2}$ é direita, virtual e maior (fig. 7.13).

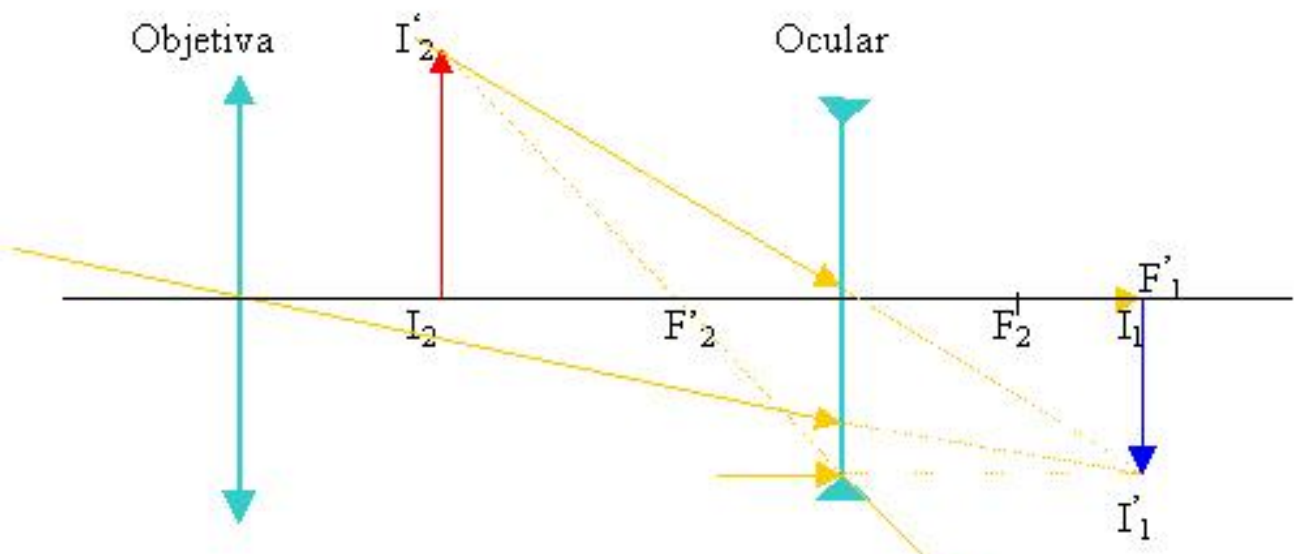

Figura 7.13 - Formação da imagem em um luneta terrestre.

O aumento angular de uma luneta $(A)$ é dado pela expressão:

$$
A=-f_{1} / f_{2}
$$

onde $\mathrm{f}_{1}$ é a distância focal da objetiva e $\mathrm{f}_{2}$ é a distância focal da ocular.

Obs: Os telescópios de reflexão (fig.7.14) utilizam um espelho parabólico côncavo no lugar da lente objetiva. A vantagem é que se tem menos aberrações e por causa disto os telescópios de reflexão são mais utilizados nos observatórios. Outra vantagem é o baixo custo

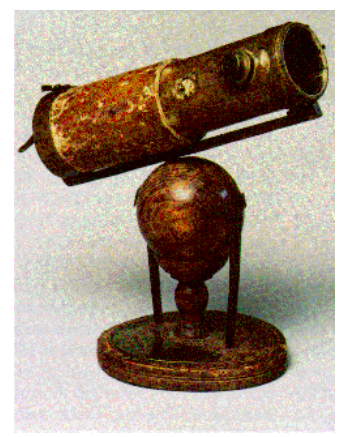

Figura 7.14 - Telescópio de reflexão de Newton

Para quem gosta de astronomia, no site do CDCC: http://www.cdcc.sc.usp.br/cda/index.html 


\section{Instrumentos de Projeção}

\section{Máquina Fotográfica}

Instrumento óptico muito utilizado no cotidiano, seu funcionamento é bem semelhante ao olho humano. As máquinas fotográficas evoluíram muito. Antigamente a objetiva da máquina fotográfica era constituída de uma única lente (fig. 7.5a) e atualmente é constituída de várias lentes (fig.7.5b). Esse instrumento é constituído por um sistema de lentes, denominado objetiva, que se comporta como uma lente convergente que forma uma imagem invertida e real do objeto fotografado. Na máquina fotográfica existe também uma série de dispositivos que permitem afastar ou aproximar a lente para melhor focalizar a imagem. Se essa focalização não é bem feita a imagem não se forma corretamente sobre o filme e assim a fotografia não fica nítida. A imagem ao ser captada fica gravada no filme por meio de reações químicas, as quais ocorrem quando a luz que vem do objeto incide sobre o filme.

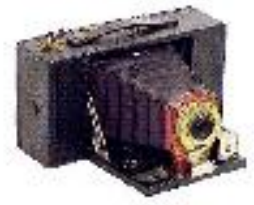

(a)

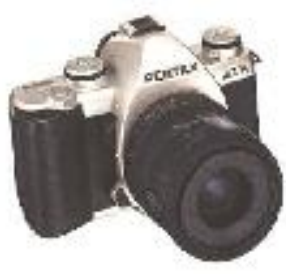

(b)

Fig. 7.5 a) Máquina fotográfica do início do século.

b) Máquina fotográfica moderna.

Se você quiser conhecer as partes de uma máquina fotográfica moderna e seu funcionamento clique aqui:

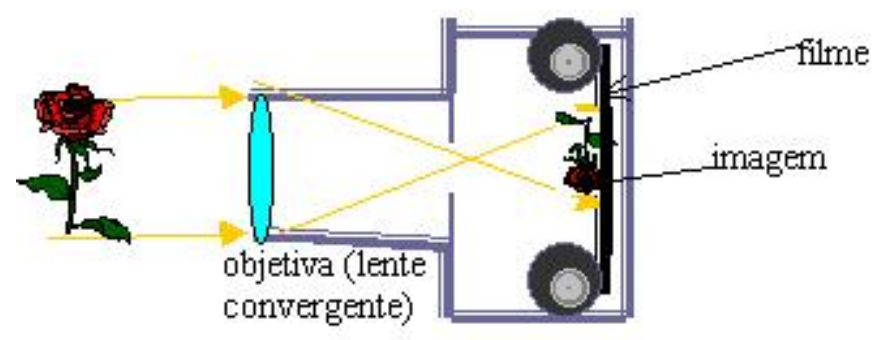

Figura 7.6 Formação da imagem em uma máquina fotográfica

Na fig. 7.6 está representada a câmara fotográfica simplificada, sem os refinamentos óticos ou mecânicos. A objetiva está representada por uma única lente convergente que forma uma imagem real e invertida do objeto fotografado, sobre o filme situado na parte posterior da máquina. 
A luz, ao incidir sobre o filme, provoca reações químicas, fazendo com que a imagem fique gravada. O filme vai apresentar a imagem em negativo, ou seja, as partes do filme que recebem mais luz tornam-se escuras e vice-versa.

Para que seja fornecida sobre o filme uma imagem real e menor do objeto, o objeto deve estar situado antes da dupla distância focal como já vimos quando estudamos lentes (fig.6.8).

\section{Projetor de Slides}

Um projetor de slides (diapositivos) serve para projetar em uma tela uma imagem real e aumentada do objeto que está no slide.

Basicamente, ele é constituído de uma lente convergente, como objetiva, e uma lâmpada cujo filamento está situado no centro de curvatura do espelho côncavo que juntos servem para iluminar com bastante intensidade o slide. A fig. 7.7 mostra um esquema bem simplificado de um projetor de slides.

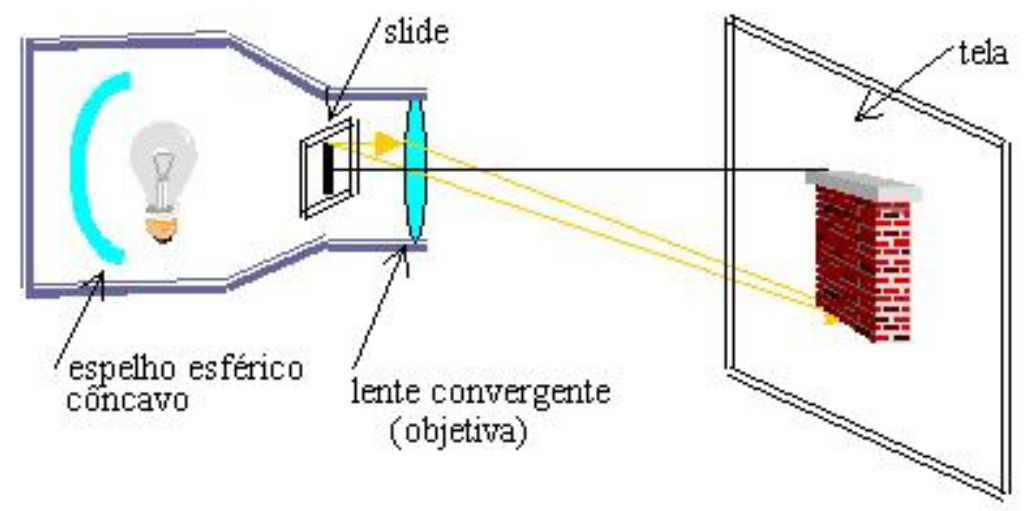

Figura 7.7 - Esquema simplificado do projetor de slides

Para obter uma imagem real, maior e aumentada, o slide precisa estar situado a uma distância menor que a dupla distância focal (antes do foco), como já foi visto quando estudamos lentes (fig. 6.5a).

\section{Associação de Lentes (CEPA)}

No estudo de sistemas ópticos existe o interesse em se determinar a imagem quando dispomos lentes delgadas de tal forma que seus eixos ópticos coincidam. Veremos a seguir que para entendermos o microscópio composto mais simples ou para entendermos um telescópio simples basta analisarmos a associação de duas lentes. 
Consideremos o caso em que dispomos de duas lentes $\mathrm{L}_{1} \mathrm{e}^{\mathrm{L}_{2}}$. Nesse caso, basta considerarmos que a lente ${ }^{L_{1}}$ conjuga ao objeto $O$ uma imagem ${ }^{i_{1}}$. Esta imagem se torna o objeto para a segunda lente.

Um caso relativamente simples de associação de lentes é aquele em que as lentes são justapostas. Quando justapostas elas estarão encostadas uma na outra. Nessa situação elas funcionam como uma única lente equivalente ao conjunto. Pode-se mostrar que para um conjunto de lentes justapostas, a lente equivalente ao conjunto tem uma vergência que é a soma das vergências das lentes que compõem o conjunto. Isto é, se ${ }^{C_{1}}$ for a vergência da primeira lente, $\mathrm{C}_{2}$ a vergência da segunda lente e assim por diante, então a vergência da lente equivalente será

$$
\mathrm{c}_{\mathrm{eq}}=\mathrm{C}_{1}+\mathrm{C}_{2}+\cdots \text {. }
$$

Pode-se facilmente demonstrar a propriedade acima para duas lentes justapostas. De fato, admitimos p como a abcissa para o objeto. Para a primeira lente escrevemos

$$
\frac{1}{p_{0}}+\frac{1}{p_{1}^{\prime}}=\frac{1}{f_{1}}
$$

A imagem de ${ }^{L_{1}}$ é o objeto para a segunda lente. Portanto $p_{2}=-p_{1}$.

A imagem estando no ponto cuja abscissa é ${ }^{p^{\prime}}$, esta será dada, para a segunda lente, por

$$
\frac{1}{-p_{1}}+\frac{1}{p^{\prime}}=\frac{1}{f_{2}}
$$

Somando as equações anteriores, teremos

$$
\frac{1}{p}+\frac{1}{p^{\prime}}=\frac{1}{f_{2}}+\frac{1}{f_{1}}=c_{1}+c_{2}
$$

Portanto, a vergência equivalente será

$$
\mathrm{C}_{\mathrm{eq}}=\mathrm{C}_{1}+\mathrm{C}_{2} \text {. }
$$

\section{PRINCÍPIOS BÁSICOS DE UM TELESCÓPIO NEWTONIANO}




\section{Introdução}

Nesse capítulo pretendemos abordar os aspectos fundamentais relativos ao projeto do tipo de telescópio mais utilizado pelo astrônomo amador, o Newtoniano[Roberto Frangetto]. Aqui poderemos ver na prática como os conceitos de ótica geométrica, interferência e difração da luz se aplicam na construção e utilização de instrumentos óticos.

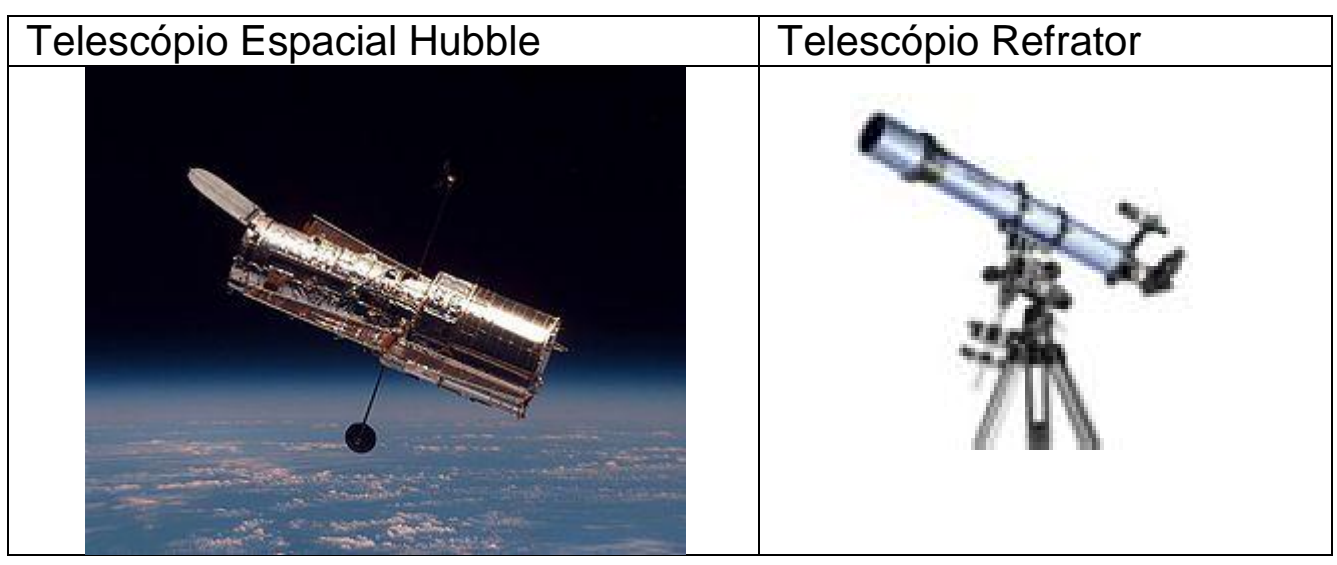

\section{Relações Geométricas Relevantes}

\section{- Diâmetro interno do tubo}

Como se pode verificar na figura, para que os raios luminosos 1 e 2 atinjam o espelho principal, se faz necessário que o diâmetro interno do tubo seja maior que o diâmetro do espelho principal.

Por simples considerações geométricas, chega-se à seguinte relação que fornece o diâmetro interno mínimo do tubo em função do diâmetro do espelho principal e da abertura máxima da ocular;

$$
D_{\text {min }}=d+a
$$

O que acontecerá se usarmos um tubo que tenha um diâmetro interno menor do que o mínimo? 
Pode-se ver na figura 6.1, que os raios luminosos 1 e 2 não penetrarão no tubo, o que fará com que o campo visual, com a ocular considerada, se apresente desigualmente iluminado. Brilhante no centro e se apagando na periferia.

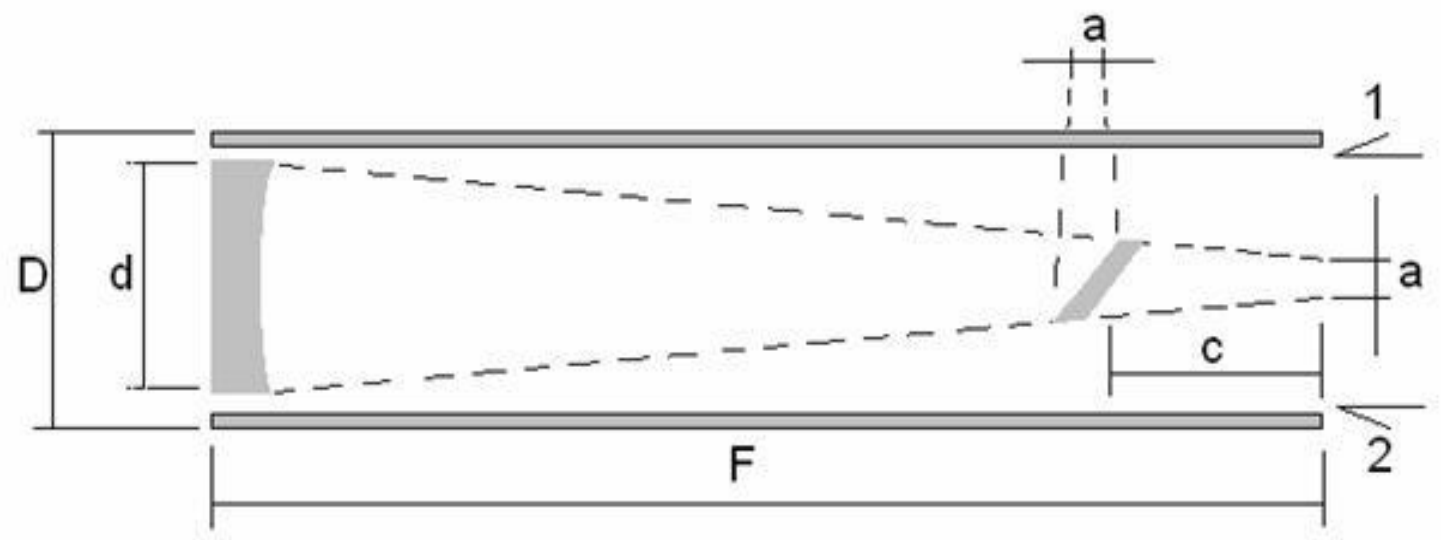

Fig.6.1 - Esquema de um telescópio refletor

- $\quad A=$ diâmetro do circulo focal [mm]

- $\quad \mathrm{C}=$ projeção do plano focal [mm]

- $\mathrm{D}=$ diâmetro do espelho principal $[\mathrm{mm}]$

- $\mathrm{D}=$ diâmetro interno do tubo $[\mathrm{mm}]$

- $F=$ distancia focal do espelho [mm]

- 1 = eixo maior do espelho diagonal [mm]

- 2 = eixo menor do espelho diagonal $[\mathrm{mm}]$
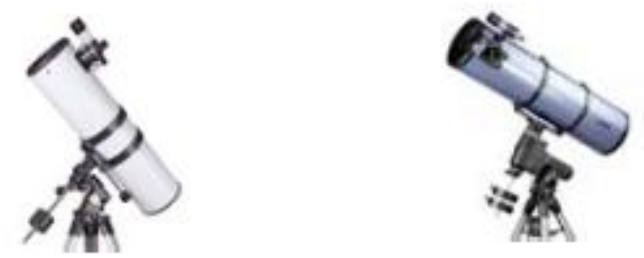

Fig. - Exemplos de Telescópio Refletor Newtoniano Comerciais.

\section{Dimensão do espelho diagonal}

Para que se obtenha a melhor qualidade possível da imagem, é essencial que o espelho diagonal tenha um contorno elíptico. Suas dimensões podem ser calculadas pelas expressões que se seguem, as quais podem ser deduzidas a partir da figura. 


$$
l_{2}=a+\frac{c \cdot(d-a)}{F} \text { e } l_{1}=\sqrt{2} \cdot l_{2}=1,414 \cdot l_{2}
$$

Se o valor de $\mathrm{I}_{2}$ for menor que $\frac{c \times d}{F}$, o resultado é simplesmente desastroso, pois somente uma parte do campo visual é preenchido pelo espelho diagonal, o que torna impraticável o uso do telescópio.

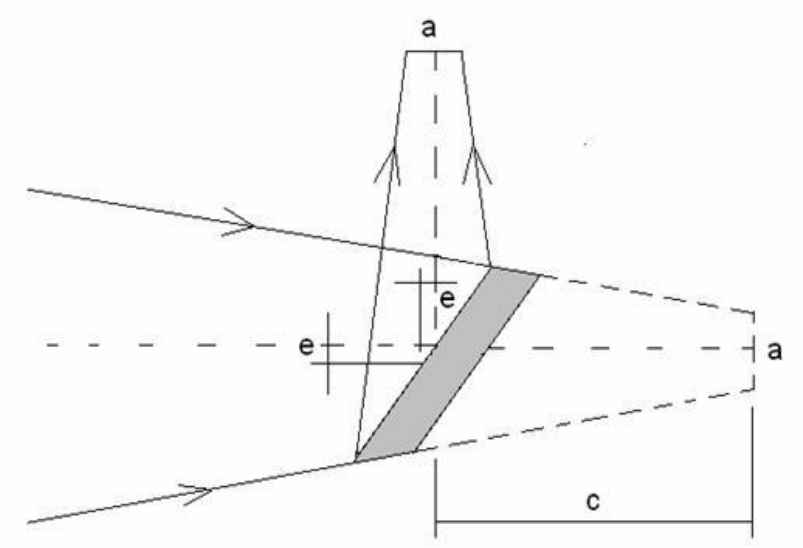

Fig.6.2 - $e=$ deslocamento do centro do espelho diagonal em $\mathrm{mm}$

\section{Campo Angular Máximo}

A partir da figura 6.2, obtém-se a expressão que fornece o campo angular visual do telescópio em função da abertura da lente de campo da ocular e da distância focal do espelho principal.

$$
\alpha=\frac{a}{F} \times 3438
$$

No caso do Instrumento ser projetado para uso geral, geralmente impõe-se para $\alpha$ um valor ao redor de 60 minutos de arco, o que permite a observação de uma grande variedade de objetos.

Já para observação específica do sol ou da lua, o projeto requer $\alpha=35^{\prime}$ e para observação de alta resolução de planetas e de estrelas binárias, basta projetar o instrumento para $\alpha$ situando-se entre 5 e 10 minutos de arco, com oculares de grandes aumentos. 


\section{Excentricidade da Montagem do espelho diagonal}

Como se pode verificar na figura 6.2, o centro do espelho diagonal deve ser posicionado com um deslocamento e em relação ao eixo do tubo. Esse deslocamento faz com que o centro do espelho diagonal fique afastado da porta ocular e "empurrado" para perto do espelho principal. A expressão que fornece esse deslocamento é:

$$
e=l_{2} \cdot \frac{d-a}{4 F}
$$

\section{Pupila de saída}

Quando, num telescópio, colocamos uma ocular com distancia focal equivalente igual a f e, em seguida, focalizamos um objeto distante, a configuração dos raios luminosos 1 e 2 se verifica conforme esquematizados na figura 6.3 abaixo:

O disco (E) formado pela convergência desses raios incidentes na periferia do espelho parabólico é chamada "pupila de saída", E NADA MAIS É DO QUE A IMAGEM DO ESPELHO PRINCIPAL FORMADA PELA OCULAR EM USO.

É possível medir o diâmetro da pupila de saída, bastando dispor-se de um dispositivo de medição de grande precisão.

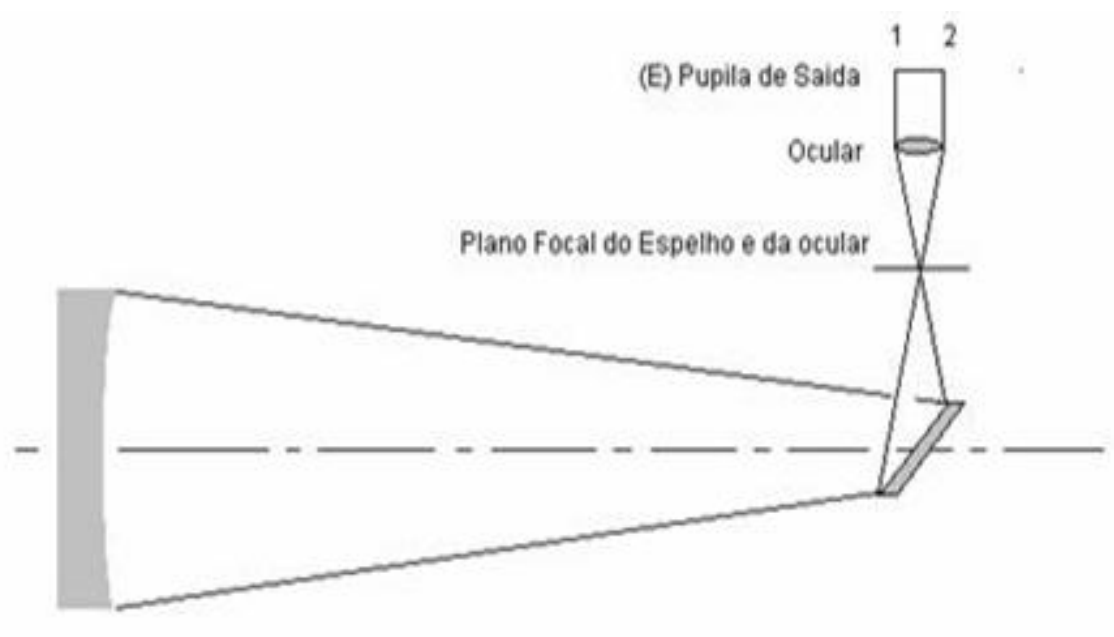

Fig.6.3 - Esquema do caminho ótico da luz desde a entrada até a pupila de saída.

Essa medição apresenta um certo interesse para o Amador, pois, através dela é possível determinar experimentalmente a distancia focal equivalente de uma ocular ou de um sistema Barlow-ocular cujas características sejam duvidosas. 
Para isso, depois de se medir o diâmetro (p) da pupila de saída, aplica-se a seguinte expressão:

$$
f=\frac{F \cdot p}{d}
$$

- onde:

- $\mathrm{F}=$ distância focal do espelho parabólico $(\mathrm{mm})$

- $f=$ distância focal do ocular ( $\mathrm{mm})$

- $\mathrm{p}=$ diâmetro da pupila de saída $(\mathrm{mm})$

- $\mathrm{d}=$ diâmetro do espelho parabólico $(\mathrm{mm})$

Além dessa importante utilidade, o conhecimento da pupila de saída nos permite avaliar se a ocular em questão é adequada para o nosso telescópio, pois, para observação visual, o diâmetro da pupila de saída não deve nunca ultrapassar o diâmetro da pupila do observador.

\section{Conceito de Magnitude}

A noção de magnitude ou grandeza foi originada na antiga Grécia, quando Hipparco, no segundo século antes de Cristo, agrupou os astros visíveis a olho nu em seis classes conforme o seu brilho decrescente.

Modernamente verificou-se que a escala de Hipparco correspondia razoavelmente bem a uma progressão geométrica com razão de 2,5 aproximadamente.

Adotando-se como unitário o valor do brilho das estrelas de sexta grandeza, obtém-se a seguinte expressão, que relaciona o brilho B de uma estrela qualquer, a sua grandeza $\mathrm{m}$

$$
B=2,512^{a-m}
$$

Na forma logarítmica,

$$
\log B=0,4(\sigma-m)
$$

\section{Magnitude Limite de um Microscópio Newtoniano}

Considerando-se que, à vista desarmada pode-se perceber uma estrela de grandeza 6.2, deduz-se, por simples considerações sobe as áreas relativas de um telescópio e a do olho humano com a pupila toda dilatada e quando a 
pupila de saída tiver diâmetro ao redor de $7 \mathrm{~mm}$, que a grandeza limite de um telescópio é dada pela expressão:

$$
M=0,8+5 \cdot \log d
$$

\section{Poder de Resolução}

O olho normal é capaz de distinguir dois pontos luminosos ou duas linhas paralelas, desde que estejam separadas o suficiente para que o ângulo de observação seja, no mínimo, um minuto de arco.

Para que haja uma certa comodidade de observação, adota-se, para efeito de projeto de sistemas ópticos, como quatro minutos de arco o valor do poder de resolução da vista desarmada.

\section{A Imagem de Difração de uma Estrela}

A distância das estrelas é tão grande que, mesmo as gigantes como Betelgeuse, são observadas sob ângulos tão pequenos, que, para todos os fins práticos, podem ser considerados como meros pontos luminosos.

No entanto, ao observarmos as estrelas com oculares de grandes aumentos, percebe-se que as mesmas produzem uma imagem constituída por um disco central luminoso acompanhado por um ou mais anéis concêntricos.

Fig.6.4- Figura de Difração

\section{Disco de Airy}

O disco central dessa figura, que, num sistema óptico perfeito, concentra cerca de $84 \%$ de toda a luz que penetra no telescópio é denominada Disco de Airy, 
em homenagem a Sir George Airy, sétimo Astrônomo Real da Inglaterra, o qual estudou detalhadamente o fenômeno da formação de imagens em telescópios.

O diâmetro angular do Disco de Airy é quem determina o poder de resolução de telescópios de pequeno e médio porte. Já para os grandes Telescópios, é a turbulência atmosférica que limita o seu desempenho, como teremos oportunidades de discutir mais adiante. O diâmetro angular do Disco de Airy, expresso em segundos de arco, é dado pela expressão a seguir:

$$
g=\frac{203}{d}
$$

\section{Poder de Resolução de um Telescópio}

Suponhamos que estamos observando um par de estrelas de sexta-grandeza sob grande aumento, e que as mesmas estão tão próximas uma da outra, que os seus Discos de Airy se apresentem interpenetrantes como na figura abaixo.

O valor de separação angular mínima, expressa em segundos de arco, que ainda nos permite perceber as duas Estrelas separadas denomina-se "Poder de Resolução".

Fig.6.5 - Figura do poder de separação de um TN

Sua expressão em função da abertura do Telescópio, foi estabelecida experimentalmente por W. R. Dawes no século dezenove, sendo por isso, também conhecido como "Limite de Dawes". Esse Limite vale:

$$
P . R=\frac{115,8}{d}
$$




\section{Videos}

http://www.youtube.com/watch?v=UoD2tRAqee0\&feature=related

http://www.youtube.com/watch?v=92FYjEJLCsl\&feature=related

http://www.youtube.com/watch?v=SpkrVw E6Nw\&feature=PlayList\&p=8DCB3F

2E1AF98B48\&index $=0$ \&playnext $=1$

http://www.youtube.com/watch?v=gvptWeFPWlg\&feature=related

http://www.youtube.com/watch?v=D0F2TK Tj6Y\&feature=PlayList\&p=3D58A2

EAB6D10187\&playnext=1\&playnext from=PL\&index $=9$

\section{MICROSCÓPIO ÓPTICO}

\section{Introdução}

O olho humano tem poder de resolução de aproximadamente $0,1 \mathrm{~mm}$ ou $100 \mu \mathrm{m}$. Isto significa que se você olhar dois pontos separados por uma distância menor que $100 \mu \mathrm{m}$, esses pontos aparecerão como um ponto único. Para distinguir estruturas separadas uma das outras por menos de $100 \mu \mathrm{m}$, há necessidade de instrumentos ópticos que tenham poder de resolução aumentada. É importante salientar a diferença entre poder de resolução e poder de aumento. Se você ampliar várias vezes uma mesma fotografia comum, a imagem aumenta, mas os pontos separados por menos de $100 \mu \mathrm{m}$ continuarão a aparecer como um ponto só,borrado. É possível,

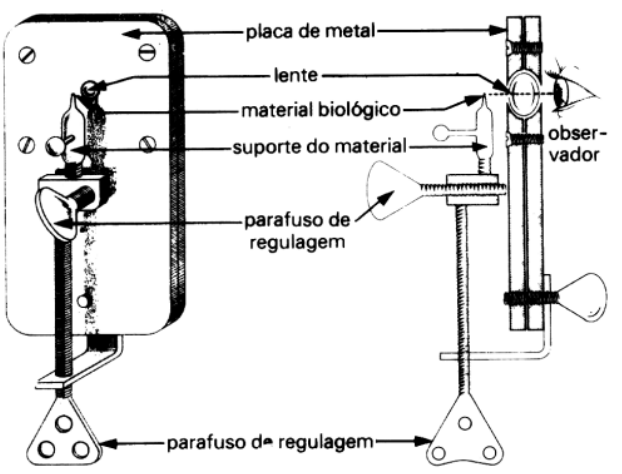
portanto, aumentar a ampliação, sem contudo melhorar a resolução.Os microscópios permitiram ao homem observar estruturas com ampliação maior e maior resolução.

O limite de resolução dos microscópios ópticos, que são aqueles que utilizam a luz para iluminar o objeto que está sendo analisado, é de cerca de $0,2 \mu \mathrm{m}$ (ou $200 \mathrm{~nm}$ ou 2000 Ao ); é melhor que o olho humano cerca de 500 vezes. Não se consegue construir microscópios ópticos com desempenho melhor que este, pois o fator limitante é o comprimento de onda da luz.

\section{O APARECIMENTO DO MICROSCÓPIO}


No final do século XVI, depois de quatro séculos a aperfeiçoar e dar novas utilizações às lentes, foi criada a lupa por Galileu e, usando-a, efetuou as primeiras observações de objetos e seres. Com ele os cientistas da época foram capazes de encontrar nos seres que já conheciam novos pormenores e características.

No século XVI, a construção de aperfeiçoamento do microscópio, particularmente do sistema de lentes, expandiu-se. Antonie Van Leeuwenhoek e Zacharias Jansen, fabricantes de óculos, desenvolveram os primeiros microscópios simples e compostos, respectivamente. Estes aparelhos utilizavam a luz refletida pelo objeto fortemente iluminado. Vários modelos foram a seguir construídos, entre os quais alguns de valor histórico, como por exemplo, o de Robert Hooke. Mas teria de decorrer quase um século até que o microscópio óptico composto, sucessivamente aperfeiçoado, fosse capaz de permitir imagens de grande qualidade.

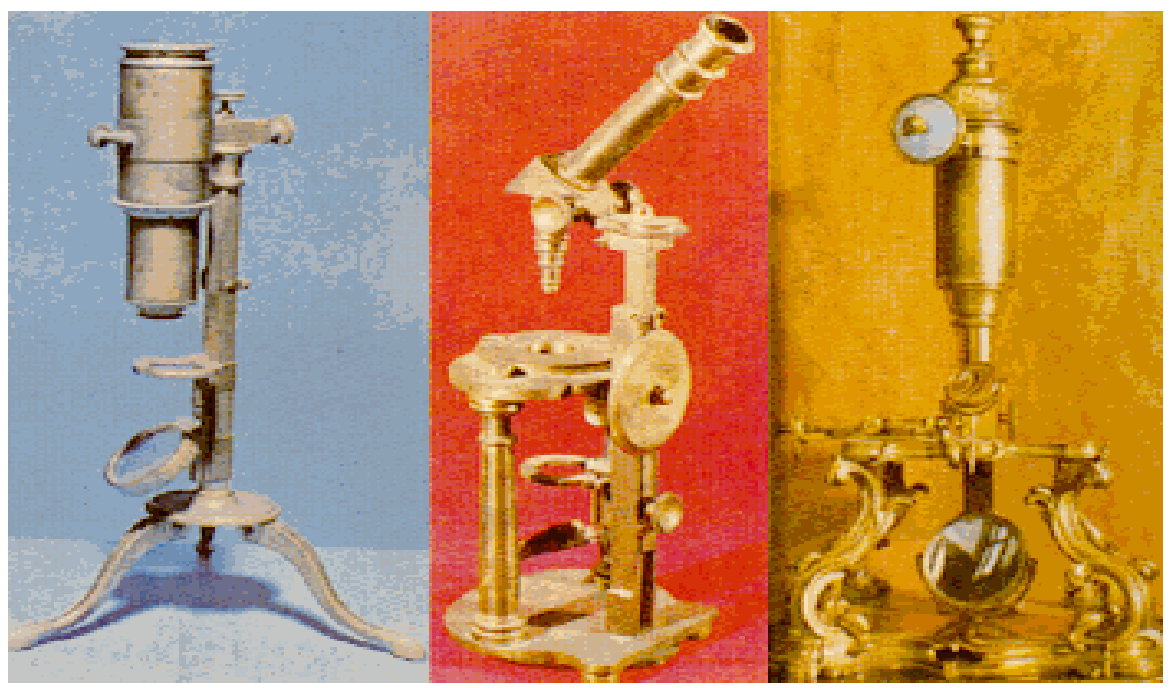

Fig.7.1 - Modelos Históricos

\section{CONSTITUIÇÃO DO Microscópio Óptico Composto}

Atualmente, o microscópio óptico composto (M.O.C.) é constituído por duas partes - uma parte mecânica e uma parte óptica. Cada parte engloba uma série de componentes constituintes do microscópio (fig.7. 2). A parte mecânica serve para dar estabilidade e suportar a parte óptica. Esta parte é constituída por:

- Pé ou Base - suporta o microscópio, assegurando a sua estabilidade. 
- Braço ou Coluna - peça fixa à base, na qual estão aplicadas todas as outras partes constituintes do microscópio.

- Tubo ou Canhão - cilindro que suporta os sistemas de lentes, localizando-se na extremidade superior a ocular e na inferior o revólver com objetivas.

- Platina - peça circular, quadrada ou retangular, paralela à base, onde se coloca a preparação a observar, possuindo no centro um orifício circular ou alongado que possibilita a passagem dos raios luminosos concentrados pelo condensador.

- Parafuso Macrométrico - engrenagem que suporta o tubo e permite a sua deslocação a da platina. É indispensável para fazer a focagem.

- Parafuso Micrométrico - imprime ao tubo ou à platina movimentos de amplitude muito reduzida, completando a focagem. Permite explorara a profundidade de campo do microscópio.

- Revólver - disco adaptado à zona inferior do tubo, que suporta duas a quatro objetivas de diferentes ampliações: por rotação é possível trocar rápida e comodamente de objetiva.

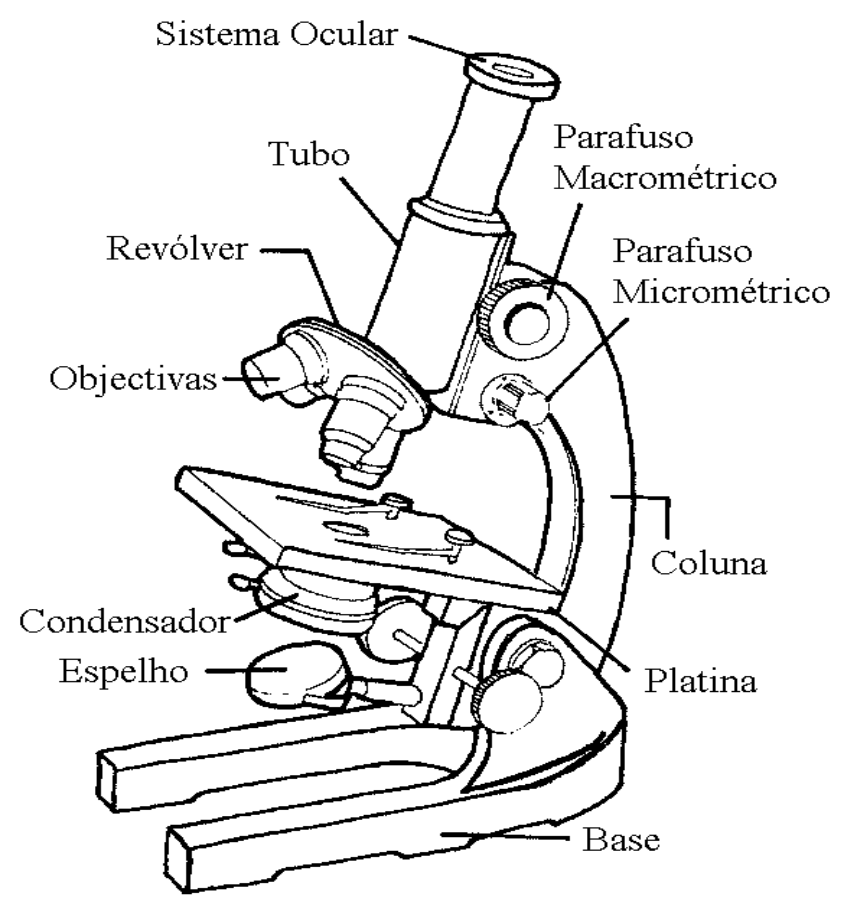

Fig.7.3 - Esquema de um M.O.C

\section{A parte óptica é constituída por:}


- Sistema de Oculares e Sistema de Objetivas - o conjunto de lentes que permitem a ampliação do objeto. A ampliação dada ao microscópio é igual ao produto da ampliação da objetiva pela ampliação da ocular.

- Fonte Luminosa - existem vários tipos de fontes luminosas (fig.7.3), podendo ser uma lâmpada (iluminação artificial), ou um espelho que reflita a luz solar (iluminação natural).

- Condensador - distribui regularmente, no campo visual do microscópio, a luz refletida pelo espelho.

- Diafragma - regula a intensidade luminosa no campo visual do microscópio.

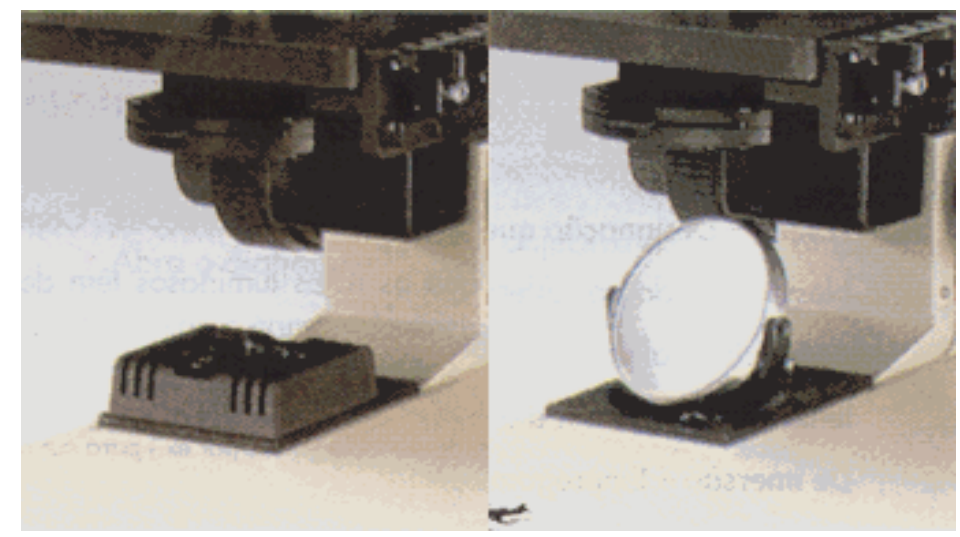

Fig.7.4 - Parte ótica de um microscópio composto.

\section{CARACTERÍSTICAS DA IMAGEM DO M.O.C.}

O objeto a ser observado deve ser colocado muito perto do foco objeto do sistema da objetiva, para que se forme uma imagem real, invertida, de maiores dimensões, que vai servir de objeto em relação à ocular. Esta, dá uma imagem virtual, invertida (nos dois sentidos) em relação ao objeto a ser observado. 


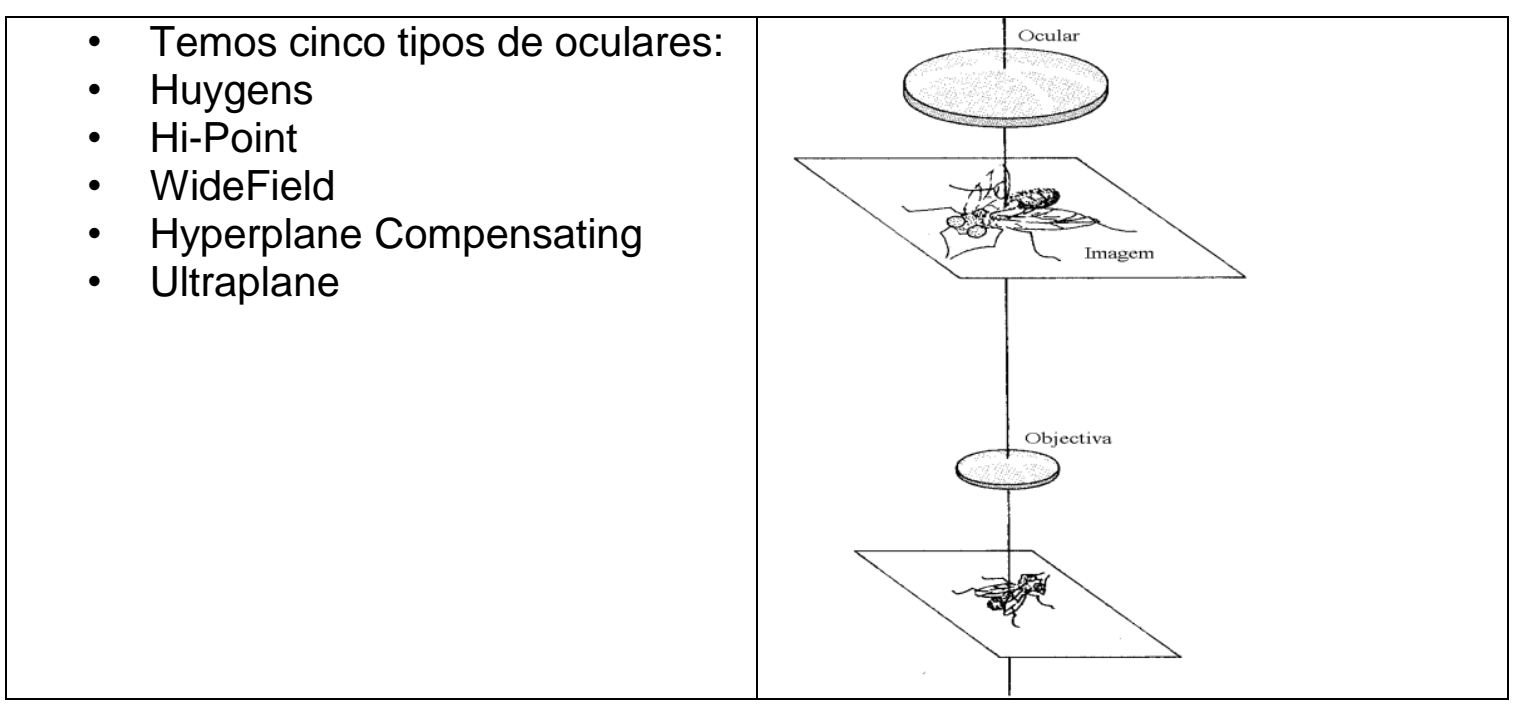

\section{Resolução}

Segundo Raleigh dois objetos podem ser distinguidos quando o máximo central de um coincide com o primeiro mínimo do outro. A intensidade entre dois picos descreve de $80 \%$ do pico inicial. A fig-7.6 mostra este critério para o microscópio.

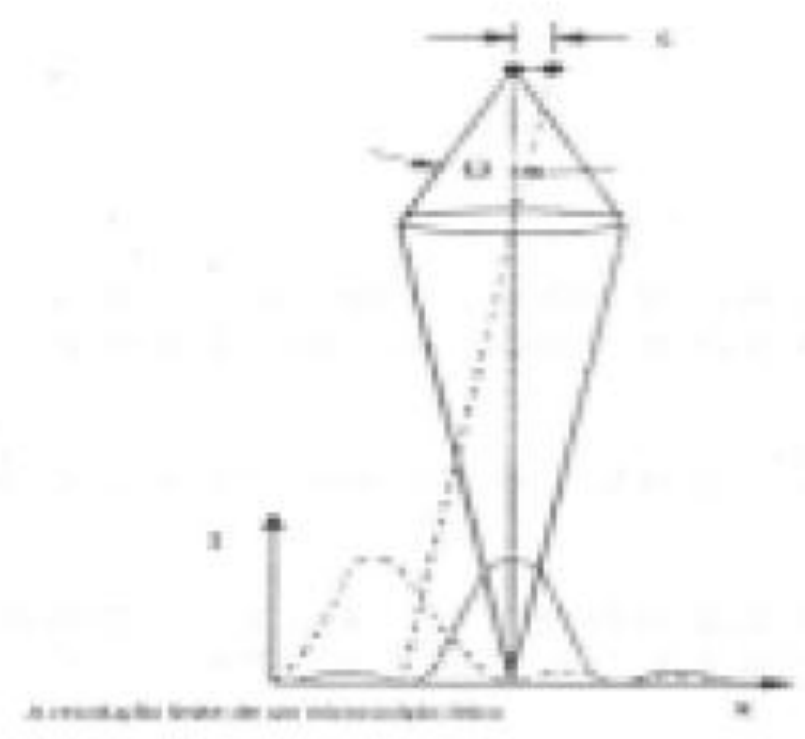

Fig.7.6 - A resolução limite de um microscópio ótico

A resolução é a mínima distância entre pontos ou partes de um objeto. A equação 1 define o limite de resolução de um microscópio óptico segundo o critério de Raleigh:

$$
\delta:=\frac{0.61 \cdot \lambda}{\mathrm{n} \cdot \sin (\theta)} \quad \text { ou } \quad \delta:=\frac{0.61 \cdot \lambda}{\mathrm{NA}}
$$


A abertura numérica que aparece na equação acima expressa o poder de resolução das lentes e o brilho da imagem formada, quanto maior a abertura numérica melhor a qualidade da resolução. Em compensação há um comprimento da profundidade de foco definida pela equação 2 :

$$
\text { Dfocus }:=\frac{\lambda}{4 \cdot(\mathrm{NA})^{2}}
$$

As lentes objetivas, são responsáveis pela ampliação da amostra. Para uma alta ampliação e uma alta resolução necessita-se de lentes objetivas com uma grande abertura numérica (NA). Esse parâmetro determina o poder separador do microscópio e é dado pela equação 3 :

$$
\text { - } N A:=n \cdot \operatorname{sen}(\theta)
$$

Onde:

n é o índice de refração do meio em que está imersa a lente frontal da objetiva.

$\Theta$ é o ângulo do cone de luz que penetra na objetiva.

\section{Poder Separador}

Já o poder separador do microscópio é a medida da capacidade de um instrumento óptico discriminar objetos pontuais muito próximos. Esta capacidade depende das figuras de difração, desde que as aberrações tenham sido corrigidas na equação 4.

$$
P:=\frac{N A}{61 . I}
$$

\section{Limite do M.O.C.}

"... No inicio do século XIX estava definido o limite de resolução do microscópio óptico. Segundo o físico alemão Ernst Abbe (1840-1905), esse limite dependia principalmente do comprimento de onda $(\lambda)$ da luz com que se observa o objeto. $\mathrm{O} M O$ não pode ver pontos do objeto mais próximos do que 0,2 micrometros $\left(1 \mu \mathrm{m}=10^{-3} \mathrm{~mm}\right)$, ou seja, seu aumento máximo está em torno de mil vezes. (Não muito mais do que Leeuwenhoek conseguia! ) [ ]

O conhecimento dos fenômenos ondulatórios permite-nos saber que a imagem de um ponto luminoso obtido através de uma lente é formada por um circulo central luminoso cercado de anéis claros, com intensidades decrescentes (difração). Quando buscamos aumentos baixos, não observamos essa figura, mas è ela que determina o limite de aumento para cada diâmetro da lente e para cada cor da luz de iluminação. Quanto maior $\lambda$ mais critica é a 
situação. Dai concluirmos que já atingimos o aumento máximo permitido pelo $\mathrm{MO}$, pois as aberrações (distorções) das lentes já foram suficientemente bem corrigidas, mas o nosso olho infelizmente não vê a luz com $\lambda$ menor que 0 violeta. É então que entramos com um novo universo que o ME pôde proporcionar.

\section{ATIVIDADES}

\section{Projetor caseiro}

Para fabricar um projetor de slides caseiro, corta-se a tampa da caixa de papelão e pintase a caixa nas cores preta por fora e branca por dentro (de preferência). Fazem-se dois buracos, um para encaixar a lente e outro para passar o fio da lâmpada. Logo após esse procedimento, encaixa-se a lâmpada no torniquete e cola-se no meio, um pouco mais para o fundo da caixa. Põe-se papel alumínio nas laterais internas da caixa, pois se não for colocado, a lâmpada refletirá a sua luz na lente. Faz-se um suporte para pendurar o slide, pois como terá uma tampa, a pessoa não poderá ficar segurando o slide para sua focagem. O suporte do slide pode ser feito com a caixa da lâmpada usando nos procedimentos anteriores. Depois De tudo pronto, encaixa-se o slide no seu suporte, põe-se a tampa e liga-se a lâmpada. Depois de tudo ligado, foca-se a imagem com a lente de acordo com a distância entre o projetor e a parede.

\section{ATIVIDADES}

\section{1 - Experimentos de Baixo custo}

\section{1 - A câmera escura de orifício}

O funcionamento de uma câmera escura de orifício pode ser entendido a partir de um arranjo bem simples. Tomemos uma caixa completamente fechada e nela fazemos um pequeno orifício. Uma vela colocada na frente do orifício produzirá uma imagem semelhante ao objeto (a vela) porém invertida. $O$ tamanho de imagem (i) e o tamanho do objeto (o) são relacionados com as distâncias do objeto (d) ao orifício e a distância da imagem ao orifício (d') através da relação.

$$
\frac{o}{i}=\frac{d}{d^{\prime}}
$$



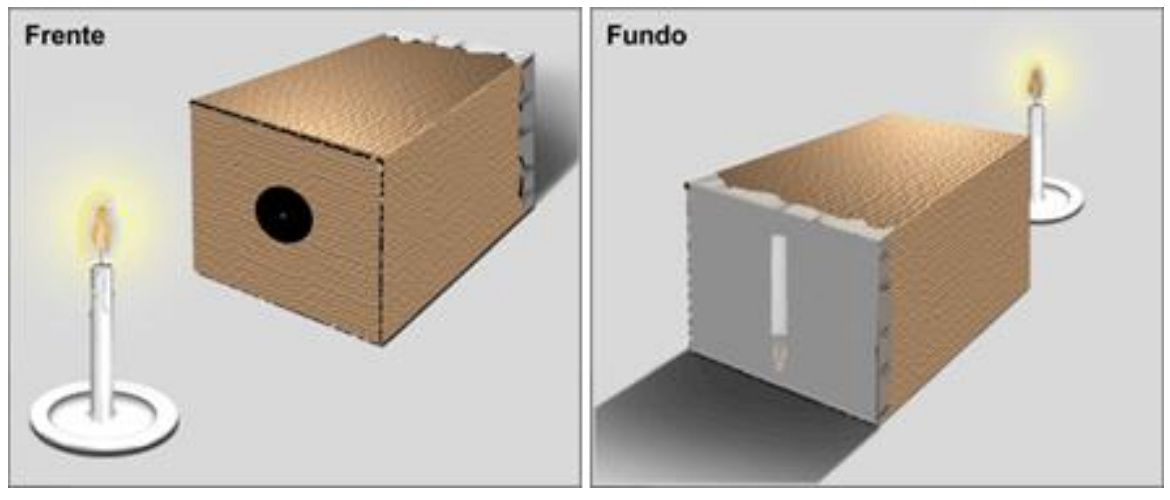

Conforme a posição da vela, a imagem pode não ficar muito nítida assim, mude a posição da vela em frente à caixa até obter uma imagem mais nítida.

\section{2 - Um projetor de feixes de luz [ ]}

Material:

- Lanterna.

- Fita adesiva.

- Cartolina preta.

- Uma caixa qualquer (pode ser uma caixa de sapatos).

Procedimento:

Cortam-se dois círculos do tamanho da frente da lanterna, em cada um desses círculos será desenhada uma fenda ao centro, que permitirá a visualização de um feixe de luz. No círculo 1, a fenda terá 2 milímetros de largura e um comprimento que vai até no máximo 5 milímetros da borda. No círculo 2 a fenda terá de largura 1 milímetro, já o comprimento será da mesma altura do círculo 1 , mas a parte de baixo será cortada até a borda. Como mostra a figura 1.
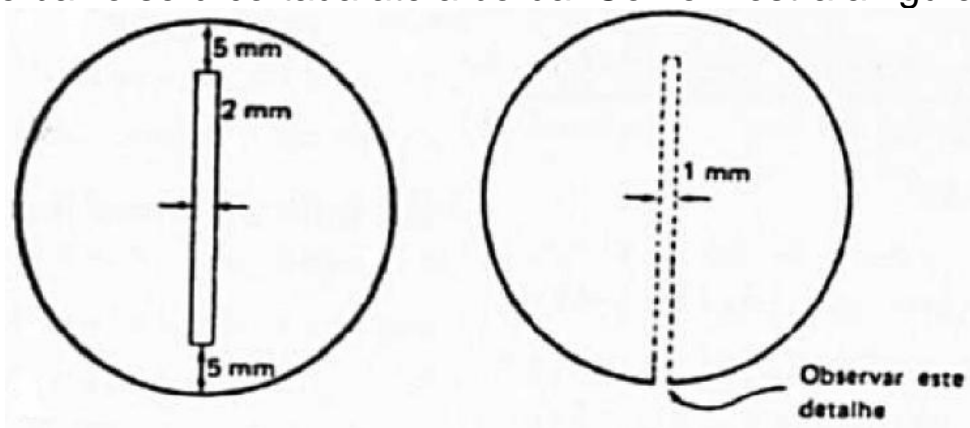

Figura 1 - Círculo 1 e círculo 2 para o projetor. Fonte: Violin (1979).

O círculo 1 deve ser colado na superfície da lanterna com a fita adesiva. Com a cartolina restante é feito um cilindro maior que a lanterna e que a envolva de tal forma a permitir que a lanterna se movimente dentro dele. Em uma das bases do cilindro é fixado o círculo 2, também com a fita adesiva, enquanto a outra base deve ficar livre para ser encaixada a lanterna. As fendas deverão ficar paralelas. Assim como mostrado na figura 2. 


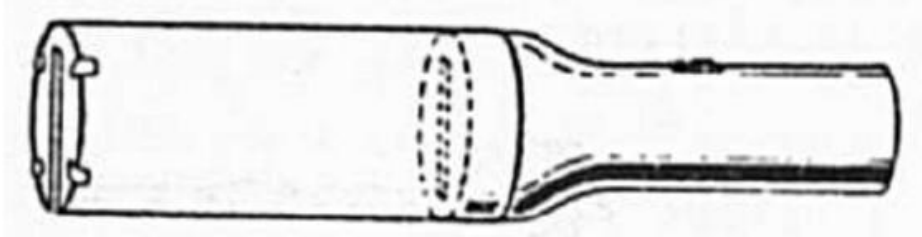

A parte mais difícil do projetor está pronta, agora se coloca a caixa de maneira que seja produzida sombra dentro dela e fixa a lanterna de modo que sua luz seja propagada dentro da caixa.

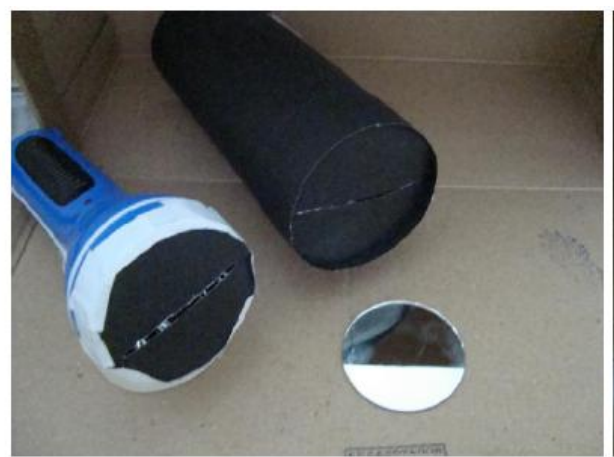

Figura 3 - Material para o projetor.

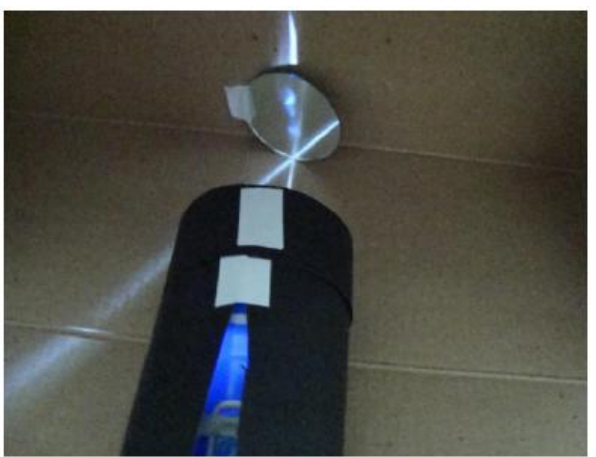

Figura 4 - Projetor e a reflexão da luz

Para realizar esse experimento é necessário: uma cartolina preta que custa em média $R \$ 0,50$; a lanterna que pode ser obtida em casa mesmo ou comprada por $\mathrm{R} \$ 7,00$; a fita adesiva que pode ser adquirida por $\mathrm{R} \$ 2,00$ e uma caixa qualquer. O gasto médio que se tem com esse projetor que pode ser utilizado em vários outros experimentos é de $R \$ 9,50$.

\section{1 - Walter-Fendt. http://www.walter-fendt.de/ph14br/refractor br.htm}

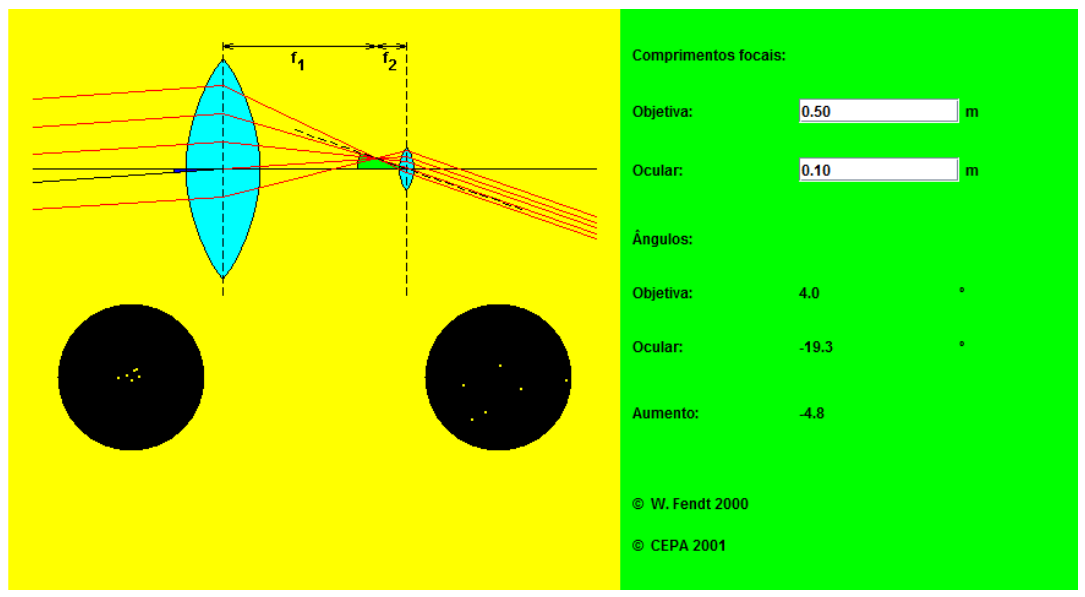




\section{3 - VÍDEOS AULAS}

3.1 - Experimento com Lupa. Ponto fogo no papel através da concentração dos raios luminosos. URL: http://www.youtube.com/watch?v=X-X2tlkp3rU

3.2 - Periscópio Caseiro - Prof Juary. URL:

http://www.youtube.com/watch?v=x nnVVRuR8g

3.3 - Pontociência - Periscópio parte1. URL:

http://www.youtube.com/watch?v=Dhjed4W7 14\&feature=related

Parte2. http://www.youtube.com/watch?v=qk1KICVSobk

Parte3. http://www.youtube.com/watch?v=lo 3-CNupJ4\&feature=relmfu

3.4 - Como construir um telescópio caseiro.

1. URL: http://www.youtube.com/watch?v=PToiv7po-TY\&feature=related

2. URL: http://www.youtube.com/watch?v=6tWxyCszakY\&feature=related

3.5 - Os Tipos de Telescópios.

1 - http://www.youtube.com/watch?v=UbBUqDJjqWs\&feature=related

2 - http://www.youtube.com/watch?v=N8Qp9Zh5bk4

3.6 - Microscópio caseiro usnado luz laser.

URL: http://www.youtube.com/watch?v=ZJWIRd4SnQg

COMENTÁRIOS:

CONCLUSÃO:

Referências 
1- http://www.colegiosaofrancisco.com.br/alfa/microscopio/aparecimento-domicroscopio.php

2 - Regis Eugenio dos Santos.

http://www.dsif.fee.unicamp.br/ furio/IE607A/MO.pdf

3 - Rudolf Kingslake (Ed.). "Applied Optics and Optical Engeneering”, Vol. IV, Parte I, Pág. 31-93, 1967.

4 - Pieter Burggraaf, "Guidelines for Optical Microscopy", Semiconductor International, Vol.8, No 2, pg 52, 1988

5 - Educar.sc - http://educar.sc.usp.br/otica/instrume.htm\#instrumentos

6 - Barroso. UM CURSO DE ÓTICA BASEADO EM EXPERIMENTOS. URL:

www.uece.br/.../71-um-curso-de-otica-baseado-em-experimentos

7 - 


\section{Cap10 - Física Moderna}

Meta: Fazer que o estudante comece a pensar no ensino de ciências como algo "orgânico" que está em profunda transformação. Fazer com que os alunos percebam, através de uma atividade lúdica, que podemos ensinar física através de experimentos muito simples. Fazer com que os estudantes percebam que podemos usar os softwares de ensino de matemática no ensino de física. Fazer com que o aluno percebam as aplicações da física no cotidiano.

Objetivos: Ao final da aula, os alunos devem estar cientes das novas possibilidades e dos desafios que envolvem o ensino de ciências em geral. Que para se ensinar física não precisamos ficar presos ao livro didático. Que ensinar física não é ensinar a resolver problemas e que a física é uma mera aplicação da matemática. Que ao ensinar física devemos, sempre que possível, mostrar como esta é importante no nosso mundo tecnológico.

Pré-requisitos: Os alunos deveram ter cursado psicologia da educação física A, B e C.

\section{Introdução:}

O assunto "Devemos ou não e como ensinar física moderna no segundo grau" é tema de largo debate nos meios de ensino. Ao contrário das outras aulas, vamos começar esta trazendo um estudo desenvolvido por [Souza e Germano] sobre este tema. Só depois vamos trazer um resumo de vários temas da física moderna como motivação para a introdução de experimentos de baixo custo, applets de ensino e vídeos aulas.

O atual contexto social nos direciona a um desafio primordial, que é um ensino de Física onde os conteúdos devam estar vinculados a questões sociais 
políticas, éticas, à construção de valores e à capacidade de contínuo aprendizado por parte dos alunos (CAVALCANTE, 1999).

Pensando neste desafio Souza e Germano concentrou esforços na elaboração de uma proposta para o ensino da Física Nuclear no Ensino Médio, contextualizada por questões de relevância em nossa sociedade, e articulando, ao mesmo tempo, três tópicos conceituais: física das partículas, radiações e energia nuclear. No entendimento deles tal contextualização, na atualidade, deve perpassar a discussão sobre a suposta necessidade de aumento da oferta de Energia Nuclear em nosso país; as atuais aplicações da Medicina Nuclear; os riscos de uso bélico para a energia nuclear pelas sociedades; bem como as pesquisas contemporâneas envolvendo a Física das Partículas.

Eles apresentam uma análise do tratamento dado à Física Nuclear em livros didáticos de Física do Ensino Médio identificados como os quatro livros mais utilizados por professores de escolas da rede particular de ensino de Natal-RN (com os alunos ou para consultas em seus planos).

\section{Quesitos}

Para direcionar nossa análise dos materiais didáticos, utilizamos, como referência, ênfases educacionais às quais estamos vinculando nossa proposta de ensino em elaboração, e que visam, primordialmente:

- a preparação dos alunos para compreenderem e influenciarem decisões sociais vinculadas à relação entre Ciência, Tecnologia e Sociedade (CTS), participando da necessária análise crítica dos benefícios e malefícios das ciências e tecnologias para as sociedades (ACEVEDO, 2004; AIKENHEAD, 2008; BAZZO, 1998; SANTOS E MORTIMER, 2001; CRUZ e ZYLBERSZTAJN, 2000);

- o estímulo às aprendizagens do aprender, do fazer, do conviver e do ser, propostos como os quatro pilares básicos da educação no "relatório Delors" (DELORS, 1999);

- o favorecimento à aproximação da Física como um exercício cultural de leitura e significação do mundo (BRASIL, 1998; 2002; 2006; ZANETIC, 1989).

Levando em consideração essas ênfases educacionais, e ainda observando outras propostas de critérios para o exame de materiais didáticos envolvendo o ensino das Ciências (ZORZI, 2006; FERREIRA e SALLES, 2004), estabelecemos os itens de observação, apresentados nos Quadros 01 e 02.

Quadro 01: Itens utilizados como referência para as análises dos livros didáticos em sua apresentação do conteúdo.

\begin{tabular}{|l|l|}
\hline Item & Descrição \\
\hline a & $\begin{array}{l}\text { Clareza e coerência. Verificou-se, através deste quesito, se o material } \\
\text { apresenta o tema de forma clara, e qual a estrutura utilizada na } \\
\text { apresentação dos conceitos físicos. }\end{array}$ \\
\hline b & $\begin{array}{l}\text { Aplicações. Analisou se o material discute aspectos da Física Nuclear } \\
\text { relacionados ao cotidiano do aluno e/ou com aplicações tecnológicas e } \\
\text { científicas da Física Nuclear, tais como: energia nuclear, esterilização } \\
\text { de alimentos e produtos, medicina nuclear, datação radioativa, }\end{array}$ \\
\hline
\end{tabular}




\begin{tabular}{|l|l|}
\hline & Astrofísica. \\
\hline c & $\begin{array}{l}\text { Dimensão social dos conteúdos. Buscou-se identificar relações entre } \\
\text { os conteúdos e questões sociais atuais, tais como: a implantação da } \\
\text { tecnologia nuclear visando o desenvolvimento de regiões ; decisões } \\
\text { políticas que envolvam estas tecnologias ou pesquisas ; questões } \\
\text { ligadas à influência mundial de países que possuam armas nucleares e } \\
\text { políticas que regulamentam o uso das tecnologias nucleares; ; menção } \\
\text { a acidentes nucleares e aos efeitos da tecnologia nuclear sobre o meio } \\
\text { ambiente. }\end{array}$ \\
\hline d & $\begin{array}{l}\text { Aspectos epistemológicos da construção da ciência . Examinou-se } \\
\text { a existência de contextualizações sobre o desenvolvimento interno da } \\
\text { ciência, bem como sobre a relação entre esse desenvolvimento e } \\
\text { aspectos sociais. }\end{array}$ \\
\hline e & $\begin{array}{l}\text { Interdisciplinaridade. A interdisciplinaridade entre as diferentes } \\
\text { ciências, sugerida tanto no enfoque CTS como nos PCN+ e nas OCN, } \\
\text { mais precisamente na forma de temas, também foi alvo da análise. }\end{array}$ \\
\hline F & $\begin{array}{l}\text { Estímulo ao prazer em conhecer. Analisaram-se, aqui, expressões } \\
\text { textuais de incentivo à curiosidade, ao aprendizado e à imaginação, na } \\
\text { tentativa de alimentar uma satisfação pessoal de compreender. }\end{array}$ \\
\hline G & $\begin{array}{l}\text { Apresentação da física como cultura. Buscou-se identificar a } \\
\text { percepção da Física como parte da tentativa humana de interpretar o } \\
\text { mundo, e sua articulação com outros saberes e expressões, como arte } \\
\text { e literatura. }\end{array}$ \\
\hline H & $\begin{array}{l}\text { Informações sobre a Física Nuclear no Brasil. Verificou-se se havia } \\
\text { informações e/ou análises sobre a contribuição do Brasil no } \\
\text { desenvolvimento da área, ou ainda sobre o potencial energético } \\
\text { brasileiro. }\end{array}$ \\
\hline I & $\begin{array}{l}\text { Orientações para aprofundamento. Verificou-se a orientação a outras } \\
\text { publicações e/ou sites da internet que possam ampliar a abordagem } \\
\text { iniciada. }\end{array}$ \\
\hline
\end{tabular}

Quadro 02: Itens utilizados como referência para as análises dos livros didáticos em suas propostas de atividades.

\begin{tabular}{|l|l|}
\hline a & Apresenta questões relacionadas com os conteúdos. \\
\hline B & Possui atividades em grupo que estimulem à cooperação. \\
\hline C & Possui atividades que estimulem à criticidade. \\
\hline D & $\begin{array}{l}\text { Possui atividades relacionadas com questões éticas, políticas, sociais ou } \\
\text { ambientais. }\end{array}$ \\
\hline E & Apresenta atividades problematizadoras. \\
\hline H & Apresenta atividades que desafiem ou estimulem a curiosidade. \\
\hline
\end{tabular}

Questões:

1 - Faça uma análise do seu livro didático, seguindo as normas acima. 


\section{Efeito Fotoelétrico [Sears, Weisstein]}

O efeito fotoelétrico é a emissão de elétrons por um material, geralmente metálico, quando exposto a uma radiação eletromagnética (como a luz) de freqüência suficientemente alta, que depende do material. Ele pode ser observado quando a luz incide numa placa de metal, literalmente arrancando elétrons da placa. Observado pela primeira vez por A. E. Becquerel em 1839 e confirmado por Heinrich Hertz em $1887^{[1]}$, o fenômeno é também conhecido por

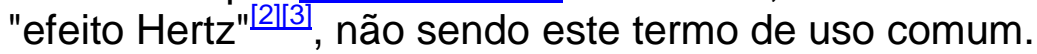

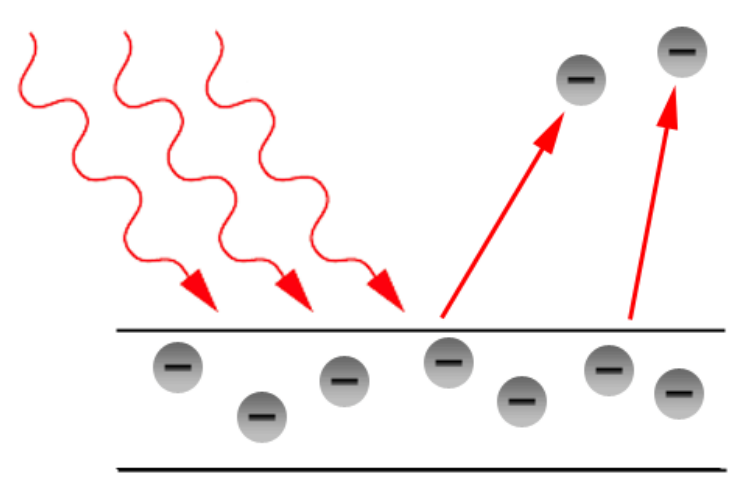

Fig. Efeito Fotoelétrico.

Os elétrons que giram à volta do núcleo são aí mantidos por forças de atração. Se a estes for fornecida energia suficiente, eles abandonarão as suas órbitas. O efeito fotoelétrico implica que, normalmente sobre metais, se faça incidir um feixe de radiação com energia superior à energia de remoção dos elétrons do metal, provocando a sua saída das órbitas: sem energia cinética (se a energia da radiação for igual à energia de remoção) ou com energia cinética, se a energia da radiação exceder a energia de remoção do elétrons.

A grande dúvida que se tinha a respeito do efeito fotoelétrico era que quando se aumentava a intensidade da luz, ao contrário do esperado, a luz não arrancava os elétrons do metal com maior energia cinética. $O$ que acontecia era que uma maior quantidade de elétrons era ejetado.

Por exemplo, a luz vermelha de baixa freqüência estimula os elétrons para fora de uma peça de metal. Na visão clássica, a luz é uma onda contínua cuja energia está espalhada sobre a onda. Todavia, quando a luz fica mais intensa, mais elétrons são ejetados, contradizendo, assim a visão da física clássica que sugere que os mesmos deveriam se mover mais rápido (energia cinética) do que as ondas.

Quando a luz incidente é de cor azul, essa mudança resulta em elétrons muito mais rápidos. A razão é que a luz pode se comportar não apenas como ondas contínuas, mas também como feixes discretos de energia chamados de fótons. Um fóton azul, por exemplo, contém mais energia do que um fóton vermelho. Assim, o fóton azul age essencialmente como uma "bola de bilhar" com mais 
energia, desta forma transmitindo maior movimento a um elétron. Esta interpretação corpuscular da luz também explica por que a maior intensidade aumenta o número de elétrons ejetados - com mais fótons colidindo no metal, mais elétrons têm probabilidade de serem atingidos.

A explicação satisfatória para esse efeito foi dada em 1905, por Albert Einstein, e em 1921 deu ao cientista alemão o prêmio Nobel de Física.

\section{Equações}

Analisando o efeito fotoelétrico quantitativamente usando o método de Einstein, as seguintes equações equivalentes são usadas:

Energia do fóton $=$ Energia necessária para remover um elétron + Energia cinética do elétron emitido

Algebricamente:

$$
h f=\phi+E_{c_{\max }}
$$

onde

- $h$ é a constante de Planck,

- fé a freqüência do fóton incidente,

- $\phi=h f_{0} \quad$ é a função trabalho, ou energia mínima exigida para remover um elétron de sua ligação atômica,

- $E_{c_{\text {max }}}=\frac{1}{2} m v_{m}^{2} \quad$ é a energia cinética máxima dos elétrons expelidos,

- $f_{0}$ é a freqüência mínima para o efeito fotoelétrico ocorrer,

- $m$ é a massa de repouso do elétron expelido, e

- $v_{m}$ é a velocidade dos elétron expelidos.

Notas:

Se a energia do fóton ( $h f$ ) não é maior que a função trabalho $(\phi)$, nenhum elétron será emitido. A função trabalho é ocasionalmente designada por $W$.

Em física do estado sólido costuma-se usar a energia de Fermi e não a energia de nível de vácuo como referencial nesta equação, o que faz com que a mesma adquira uma forma um pouco diferente.

Note-se ainda que ao aumentar a intensidade da radiação incidente não vai causar uma maior energia cinética dos elétrons (ou elétrons) ejetados, mas sim um maior número de partículas deste tipo removidas por unidade de tempo.

\section{Questões}

1- Explique como funcionam as calculadoras e relógios por energia solar. 


\section{Raios-X}

\section{Produção de Raios X}

Os raios $\mathrm{X}$ foram descobertos em 8 de novembro de 1895, quando o físico alemão Wilhelm Conrad Roentgen realizava experimentos com os raios catódicos. A história é apresentada no texto A Descoberta dos Raios X. Neste capítulo trataremos dos conceitos básicos envolvidos com a produção e alguns tipos de aplicações dos raios X na física e na ciência dos materiais. Não trataremos da primeira e mais importante aplicação, qual seja a obtenção de radiografias com os raios X. Apenas como uma ilustração, vejamos a animação abaixo. Com o mouse, desloque o quadrado para diferentes posições da mão e veja exemplos de radiografia.

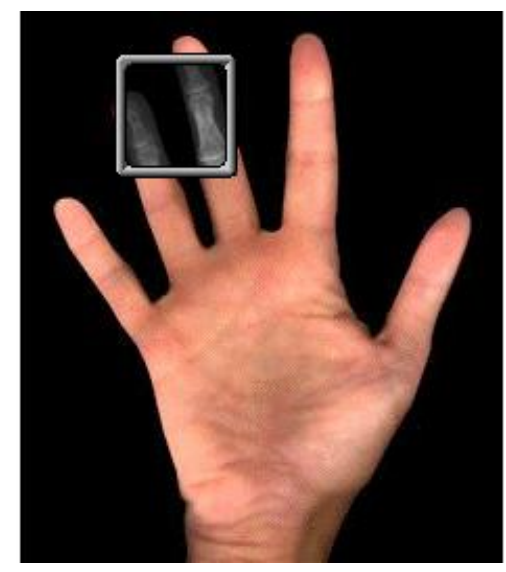

Raios $X$ podem ser produzidos quando elétrons são acelerados em direção a um alvo metálico.

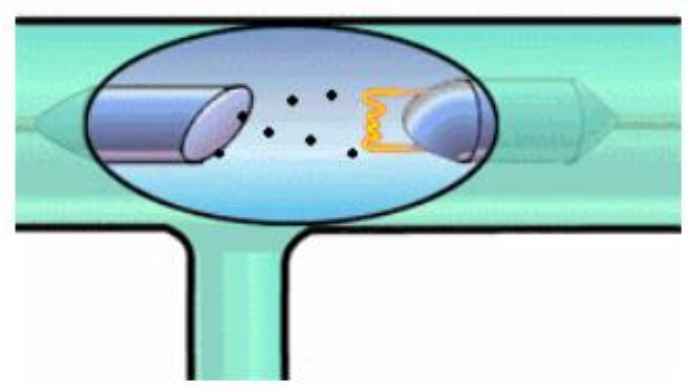

O choque do feixe de elétrons (que saem do catodo com energia de dezenas de $\mathrm{KeV}$ ) com o anodo (alvo) produz dois tipos de raios X. Um deles constitui o espectro contínuo, e resulta da desaceleração do elétron durante a penetração no anodo. O outro tipo é o raio $\mathbf{X}$ característico do material do anodo. Assim, cada espectro de raios $X$ é a superposição de um espectro contínuo e de uma série de linhas espectrais características do anodo. 
Vejamos alguns espectros contínuos obtidos com um anodo de tungstênio (figura extraída de http://www.tulane.edu/ sanelson/geol211/x-ray.htm). Os potenciais usados para acelerar o feixe de elétrons são indicados ao lado da curva correspondente.

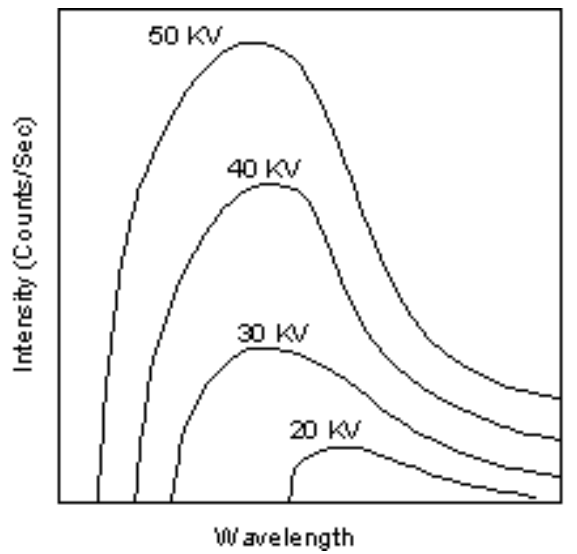

O espectro contínuo é simplesmente uma curva de contagens por segundo, versus comprimento de onda do raio $\mathrm{X}$, ou seja Intensidade versus $\lambda$. Observe que todas as curvas têm em comum o fato de que há um comprimento de onda mínimo, abaixo do qual não se observa qualquer raio X. O curioso é que este valor não depende do material do anodo.

Para entender este fenômeno, lembre-se do capítulo sobre o efeito fotoelétrico. Conforme foi proposto por Einstein, um fóton de radiação, com freqüência $f$, transporta uma energia $h f=h c / \lambda$, onde $\lambda$ é o comprimento de onda da radiação. Portanto, $\mathrm{O}$ raio $\mathrm{X}$ emitido deverá ter energia máxima igual à energia do elétron incidente. Ou seja, o espectro contínuo é limitado pelo comprimento de onda associado à energia máxima do elétron.

A partir das relações

$$
\mathrm{E}=\mathrm{hf}=\mathrm{hc} / \lambda \text {, }
$$

mostre que o comprimento de onda mínimo é dado por

$$
\lambda_{\min }=1.24 \times 10^{4} / \mathrm{V},
$$

onde o comprimento de onda é dado em $\AA$, e $V$, o potencial acelerador, é dado em volt.

Substituindo-se o alvo de tungstênio $(Z=74)$ por um de molibdênio $(Z=42)$, e mantendo-se as outras condições experimentais constantes, obtém-se o resultado ilustrado na abaixo (extraída de Tipler, Cap. 3). 


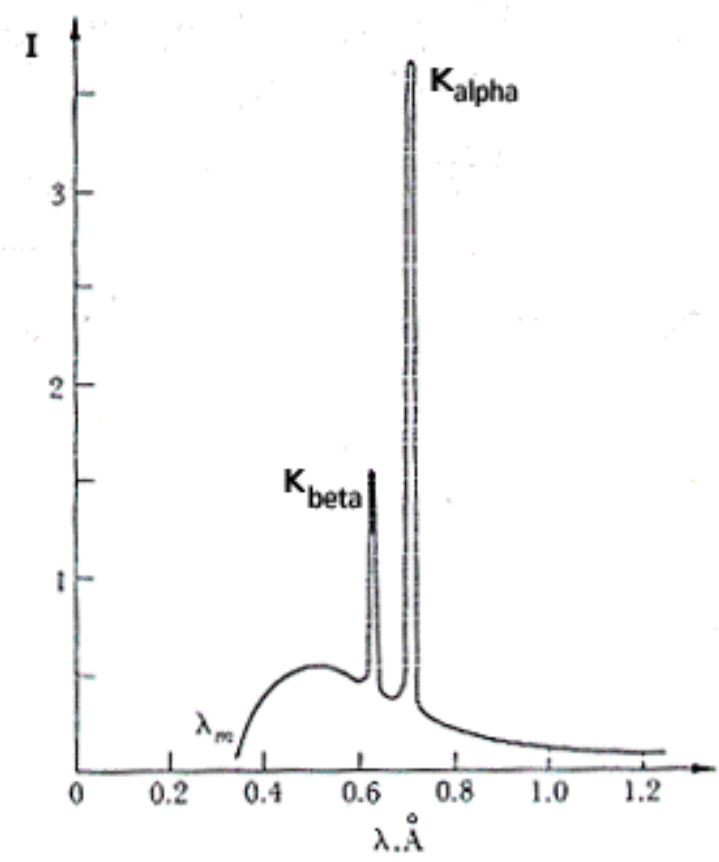

Fig. 5.4

Observe que as principais diferenças entre essas figuras são os picos existentes na última, em torno de $0.6 \AA$ e $0.7 \AA$. Tendo em conta que a única diferença entre uma medida e outra foi a substituição do alvo, é razoável admitir que os picos são devidos ao anodo de molibdênio. Estes picos constituem o espectro de raios $X$ característico do molibdênio.

Agora, baseados no modelo de Bohr podemos entender como são gerados os raios característicos, e por quê o espectro obtido com o tungstênio apresenta apenas espectro contínuo.

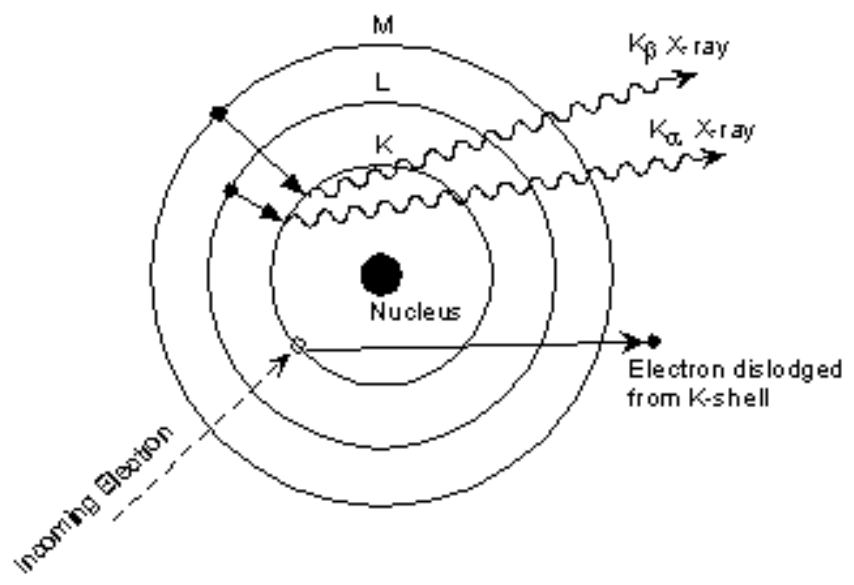

Fig. 5.5

Quando o elétron proveniente do catodo incide no anodo, ele pode expulsar um elétron orbital. A órbita de onde o elétron será expulso, depende da energia do elétron incidente e dos níveis de energia do átomo do anodo. A lacuna deixada por este elétron será preenchida por um elétron mais 
externo. Neste processo, a radiação $X$ será emitida, com freqüência dada pela eq. (4.14).

Questões

2- Explique como funcionam os aparelhos de Raio X.

Mais links

http://www.sofisica.com.br/cotidiano.php

\section{FÍSICA DAS RADIAÇÕES}

\section{0 que é radiação?}

Radiação é a propagação de energia através de partículas ou ondas. A radiação eletromagnética é uma forma de energia que se propaga como combinação de campos elétricos e magnéticos, variáveis no tempo e no espaço, que viajam no vácuo ou no ar à mesma velocidade da luz. Na Figura 1, mostra-se o espectro eletromagnético - a distribuição da radiação eletromagnética em suas diversas faixas de frequiências. Observando-se esta figura, percebe-se que as radiações podem ser classificadas entre ionizantes e não ionizantes.

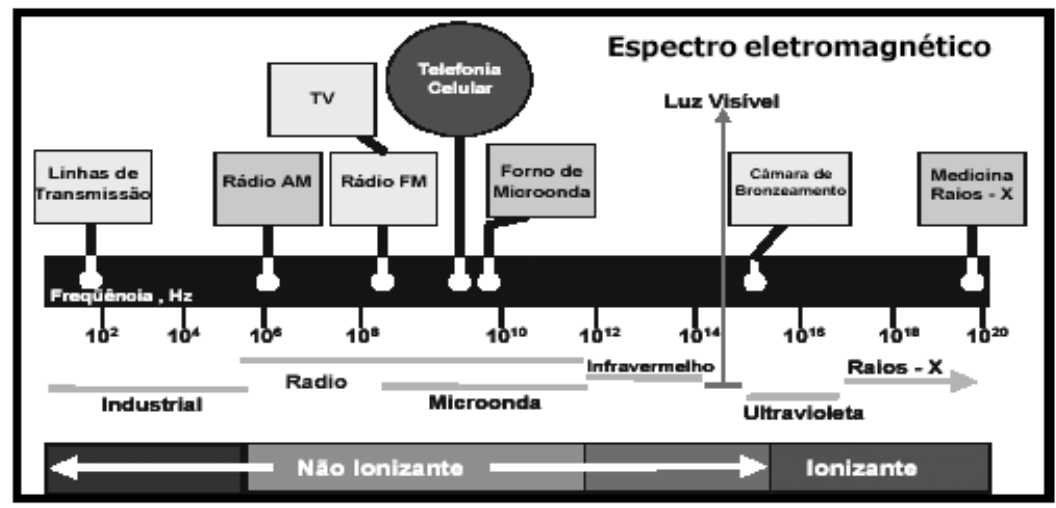

Figura 1: Espectro eletromagnético

\section{Radiação não ionizante}

Equipamentos como televisores, rádios e telefones celulares, entre outros, localizam-se na faixa de frequiência considerada não ionizante. O que isto significa?

Significa que a energia emitida por estes equipamentos não é suficiente para "arrancar" elétrons de átomos ou moléculas durante a sua passagem pela matéria.

Não existe ainda nenhum estudo que comprove que a radiação não ionizante causa efeitos deletérios à saúde. Seu principal efeito biológico é térmico: o aquecimento devido à energia eletromagnética. Este efeito não leva necessariamente a efeitos biológicos. $\mathrm{O}$ aquecimento de nossa pele pelos raios solares, por exemplo, é um efeito 
biológico. Haverá risco de queimaduras se não forem obedecidos os limites de exposição solar.

\section{Radiação ionizante}

Além da capacidade de ionização, isto é, de arrancar elétrons do material durante sua passagem pelo mesmo, as radiações ionizantes são bastantes penetrantes quando comparadas aos demais tipos.

Os principais tipos de radiação são a $\gamma, \mathrm{X}, \alpha$ (núcleos de Hélio), $\beta+, \beta$ - e nêutrons. Se ordenarmos de maneira crescente em relação ao poder de penetração, a radiação $\alpha$ não é capaz de atravessar uma folha de papel, a beta atravessa uma folha de papel mas não atravessa uma lâmina metálica, enquanto a radiação gama atravessaria até uma placa de chumbo, dependendo de sua energia e da espessura da placa.

Não há diferenças físicas entre as radiações gama e X, somente em relação à sua origem. Os Raios $\gamma$ são originados em transições nucleares e os raios X em transições eletrônicas.

\section{Qual é a origem destas radiações?}

As radiações podem ser originadas por processos de decaimentos, por processos de ajuste do núcleo ou pela interação da própria radiação com a matéria.

Por processos de decaimentos:

- Raios-X característicos

- Elétrons Auger

- Conversão interna

Por processos de ajuste do núcleo:

- Radiação Alfa

- Radiação beta

- Captura eletrônica

Por interação da radiação com a matéria:

- Bremsstrahlung

- Produção de pares

- Aniquilação de pares

\section{Processos de decaimento}

\section{Raios-X característicos}

São radiações eletromagnéticas de alta energia originadas em transições eletrônicas do átomo que sofreu excitação ou ionização após interação. Elétrons das camadas externas fazem transições para ocupar lacunas produzidas pelas radiações nas camadas mais internas, próximas do núcleo, emitindo o excesso de energia sob a forma de Raios-X. Como as energias das transições são típicas da estrutura de cada átomo, elas podem ser utilizadas para a sua identificação, numa técnica de análise de materiais denominada de fluorescência de RX.

\section{Exemplo: Átomo de Titânio (22 elétrons)}

1. Um elétron da camada $\mathrm{K}$ e ejetado do átomo por um fóton, criando uma vacância. (Fonte: http://www.amptek.com/xrf.html) 


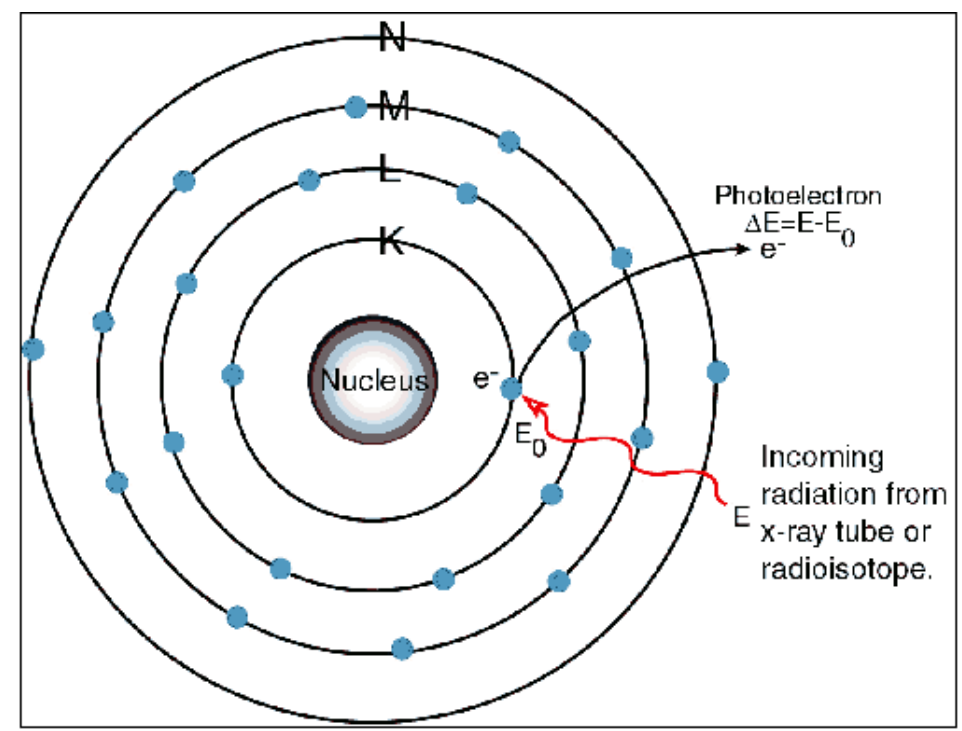

2. Um elétron da camada L ou M pula para encher a vacância. No processo, ele emite um RaioX característico, que caracteriza este átomo, e na volta ele produz uma vacância na camada L ou M.

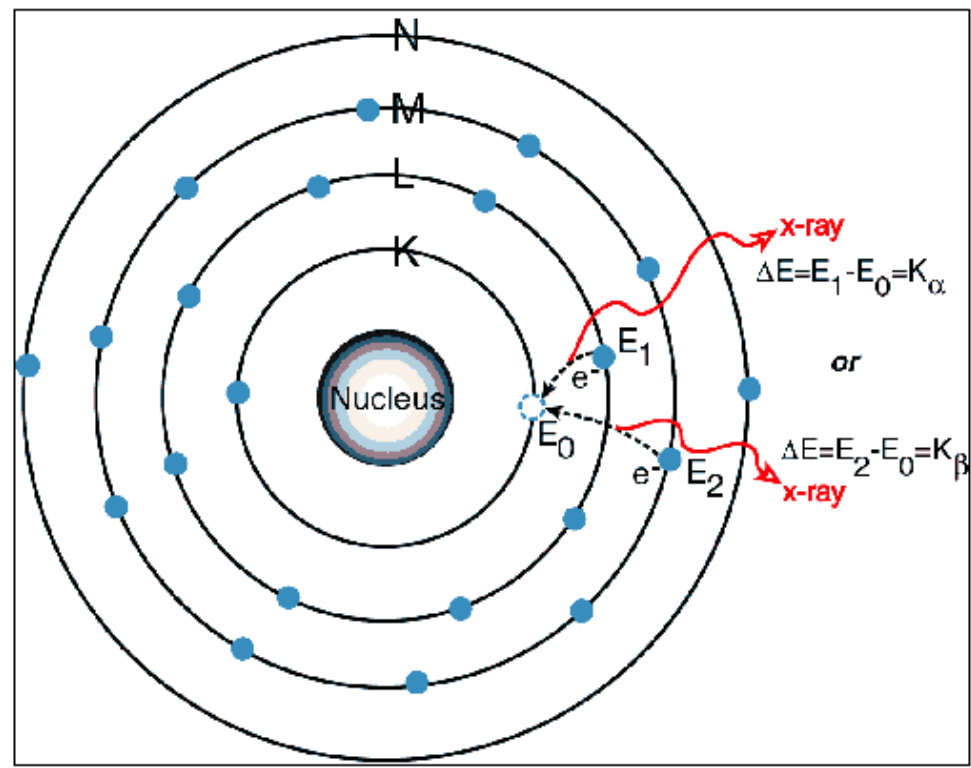

3. As linhas M. Quando uma vacância é criada na camada L, um elétron da camada M ou N pula para ocupar a vacância. Nesse processo produz raios X. 


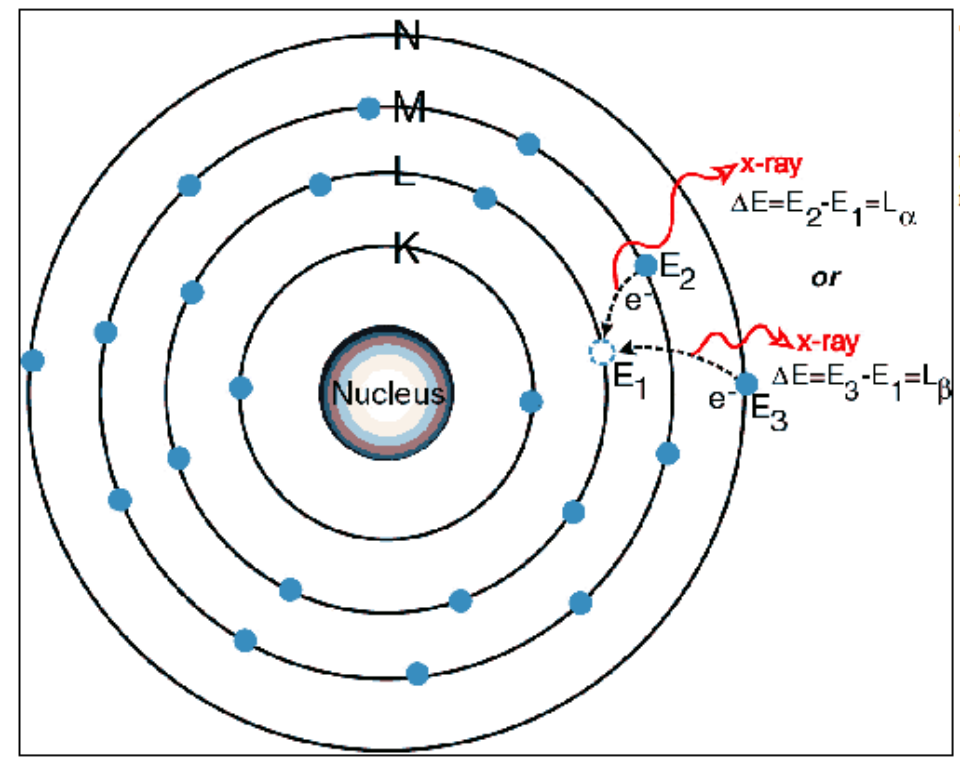

A tabela com as energias correspondentes aos Raios-X de cada elemento pode ser encontrada no anexo 1 (Fonte:http://xdb.lbl.gov/Section1/Table_1-2.pdf). Na tabela 1 são mostradas as energias até o elemento de $\mathrm{Z}=21$.

$X$-Ray Data Booklet Table 1-2. Photon energies, in electron volts, of principal $K=, L$, and $M$-shell emission lines.

\begin{tabular}{|c|c|c|c|c|c|c|c|c|c|}
\hline Element & $\mathrm{K} \alpha_{1}$ & $\mathrm{~K} \alpha_{2}$ & $\mathbf{K} \boldsymbol{\beta}_{1}$ & $\mathrm{~L} \alpha_{1}$ & $L \alpha_{2}$ & $\mathrm{~L} \beta_{1}$ & $\mathbf{L} \boldsymbol{\beta}_{2}$ & $\mathbf{L} \gamma_{1}$ & $\mathbf{M} \alpha_{1}$ \\
\hline $3 \mathrm{Li}$ & 54.3 & & & & & & & & \\
\hline $4 \mathrm{Be}$ & 108.5 & & & & & & & & \\
\hline $5 \mathrm{~B}$ & 183.3 & & & & & & & & \\
\hline $6 \mathrm{C}$ & 277 & & & & & & & & \\
\hline $7 \mathrm{~N}$ & 392.4 & & & & & & & & \\
\hline 80 & 524.9 & & & & & & & & \\
\hline $9 \mathrm{~F}$ & 676.8 & & & & & & & & \\
\hline $10 \mathrm{Ne}$ & 848.6 & 848.6 & & & & & & & \\
\hline $11 \mathrm{Na}$ & $1,040.98$ & $1,040.98$ & $1,071.1$ & & & & & & \\
\hline $12 \mathrm{Mg}$ & $1,253.60$ & $1,253.60$ & $1,302.2$ & & & & & & \\
\hline $13 \mathrm{Al}$ & $1,486.70$ & $1,486.27$ & $1,557.45$ & & & & & & \\
\hline $14 \mathrm{Si}$ & $1,739.98$ & $1,739.38$ & $1,835.94$ & & & & & & \\
\hline $15 \mathrm{P}$ & $2,013.7$ & $2,012.7$ & $2,139.1$ & & & & & & \\
\hline $16 \mathrm{~S}$ & $2,307.84$ & $2,306,64$ & $2,464.04$ & & & & & & \\
\hline $17 \mathrm{Cl}$ & $2,622.39$ & $2,620.78$ & $2,815.6$ & & & & & & \\
\hline $18 \mathrm{Ar}$ & $2,957.70$ & $2,955.63$ & $3,190.5$ & & & & & & \\
\hline $19 \mathrm{~K}$ & $3,313.8$ & $3,311.1$ & $3,589.6$ & & & & & & \\
\hline $20 \mathrm{Ca}$ & $3,691.68$ & $3,688.09$ & $4,012.7$ & 341.3 & 341.3 & 344.9 & & & \\
\hline $21 \mathrm{Sc}$ & $4,090.6$ & $4,086.1$ & $4,460.5$ & 395.4 & 395.4 & 399.6 & & & \\
\hline
\end{tabular}

Tabela 1 : Energia dos Raios-X característicos dos elementos com Z entre 1 e 21.

Elétrons Auger

A energia de excitação do elétron mais interno é transferido a outro mais externo causando a sua ejeção do átomo. 


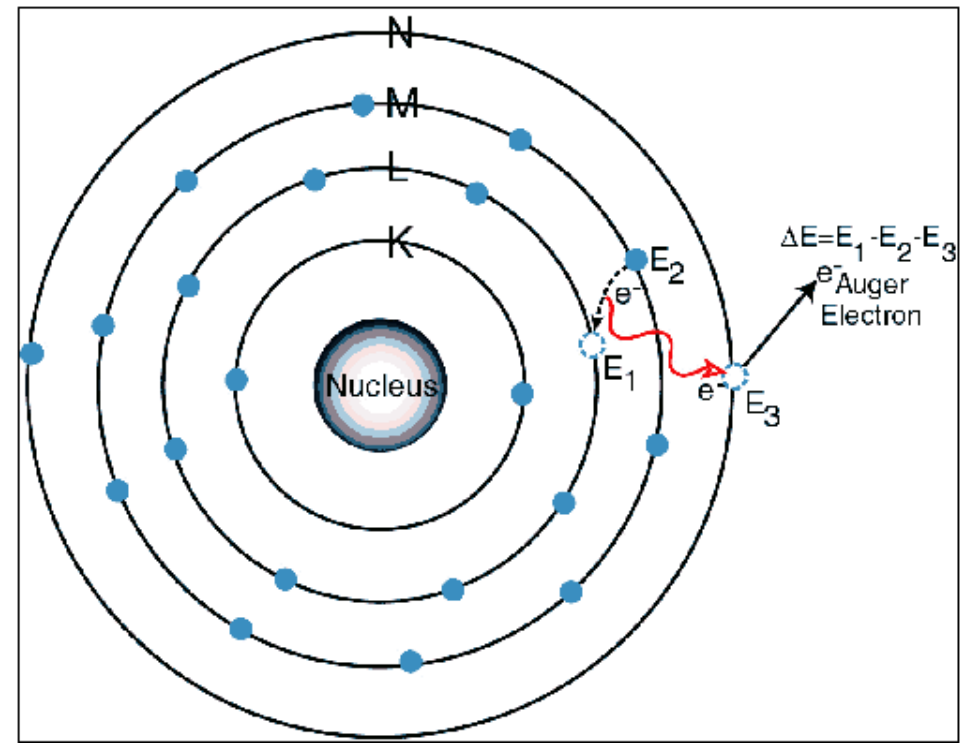

Conversão Interna

A energia de excitação do núcleo é transferida diretamente para um elétron orbital que é ejetado do átomo com uma energia dada pela diferença entre a energia de excitação do átomo e a energia de ligação do elétron na eletro esfera $E_{\mathrm{B}}$ :

$$
\mathrm{Ee}=\mathrm{E} \mathrm{Ex}-\mathrm{EB}
$$

\section{Processos de "ajuste" no núcleo}

\section{Radiação Alfa}

Quando o número de prótons e nêutrons é elevado, o núcleo pode se tornar instável devido à repulsão elétrica entre os prótons, que pode superar a força nuclear atrativa. Nesses casos pode ocorrer a emissão pelo núcleo de partículas alfa.

partículas alfa - o núcleo do átomo $4 \mathrm{He}$

Radiação beta (elétrons de origem nuclear)

Sua emissão constitui um processo em núcleos que possuem excesso de nêutrons ou de prótons em relação à estrutura estável correspondente.

\section{Emissão $\beta$ -}

Quando um núcleo tem excesso de nêutrons em seu interior, e, portanto, falta de prótons, o mecanismo de compensação ocorre através da transformação de um nêutron em um próton mais um elétron, que é emitido no processo de decaimento.

\section{Emissão $\beta+$}

Transformação de um próton em um nêutron que, por conservação de carga, produz um pósitron.

\section{Captura eletrônica}

Em alguns núcleos, a transformação do próton em nêutron, ao invés de ocorrer por emissão de um pósitron, se processa pela captura de um elétron orbital das camadas mais próximas.

A captura do elétron da camada mais interna provoca uma vacância que, ao ser preenchida, provoca a emissão de RX característicos. 


\section{Interação da Radiação com a matéria}

Bremsstrahlung

Bremsstrahlung é uma palavra em alemão que significa "radiação de frenagem".

As radiações constituídas por partículas carregadas como $\alpha, \beta$ e elétrons acelerados, ao

interagir com a matéria, podem converter uma parte de sua energia cinética em radiação eletromagnética. Esta é o resultado da interação entre os campos elétricos da partícula incidente, do núcleo e dos elétrons atômicos.

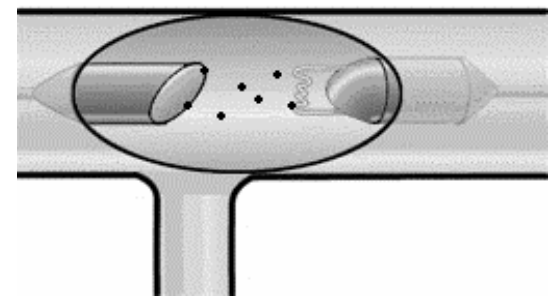

Figura 2: Esquema simplificado da produção da radiação de frenamento.

Fonte: http://www.colorado.edu/physics/2000/xray/making_xrays.html. (em inglês).

Um espectro típico é mostrado na figura abaixo.

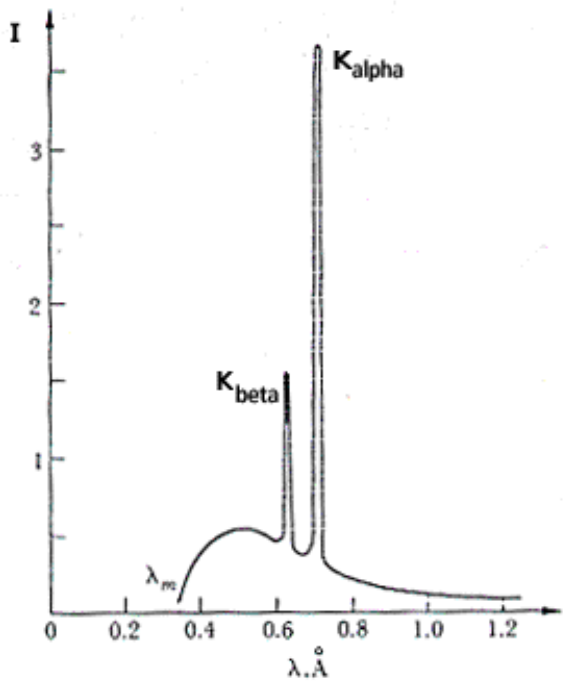

Figura 3: Espectro de radiação de frenagem (bremsstrahlung) típico.

Produção de pares

Este efeito ocorre quando fótons de energia superior a 1,022 Mev passam perto do núcleo de $\mathrm{Z}$ elevado, interagindo com o forte campo elétrico nuclear. Nesta interação, a radiação desaparece e dá origem a um par elétron-pósitron $(2 \mathrm{mc}=1,022 \mathrm{MeV})$.

Radiação de Aniquilação

Quando um pósitron, após perder toda a sua energia cinética, interage com um elétron, a matéria

\section{Fontes de Radiação}

Nós vivemos em um mundo radioativo. O tempo todo estamos inevitavelmente sujeitos a emissões radioativas, provenientes tanto de fontes naturais quanto artificiais. Os seres 
humanos estão expostos à radiação desde seu surgimento na Terra. As fontes de radiação incluem:

- o solo em que nós andamos

- o ar que respiramos

- a comida com a qual nos alimentamos

- o sistema solar como um todo.

Tudo em nosso mundo contém pequenas quantidades de átomos radioativos. Esses elementos radioativos tiveram sua origem quando da criação do universo ou são formados pela interação com a radiação cósmica. A Terra portanto, está constantemente recebendo radiação cósmica vinda do espaço.

\section{Fontes Naturais}

As fontes naturais representam cerca de $70 \%$ da exposição a que estamos submetidos, sendo o restante devido à fontes artificiais, conforme mostrado na figura abaixo.

Fração de doses na população para fontes naturais e artificiais

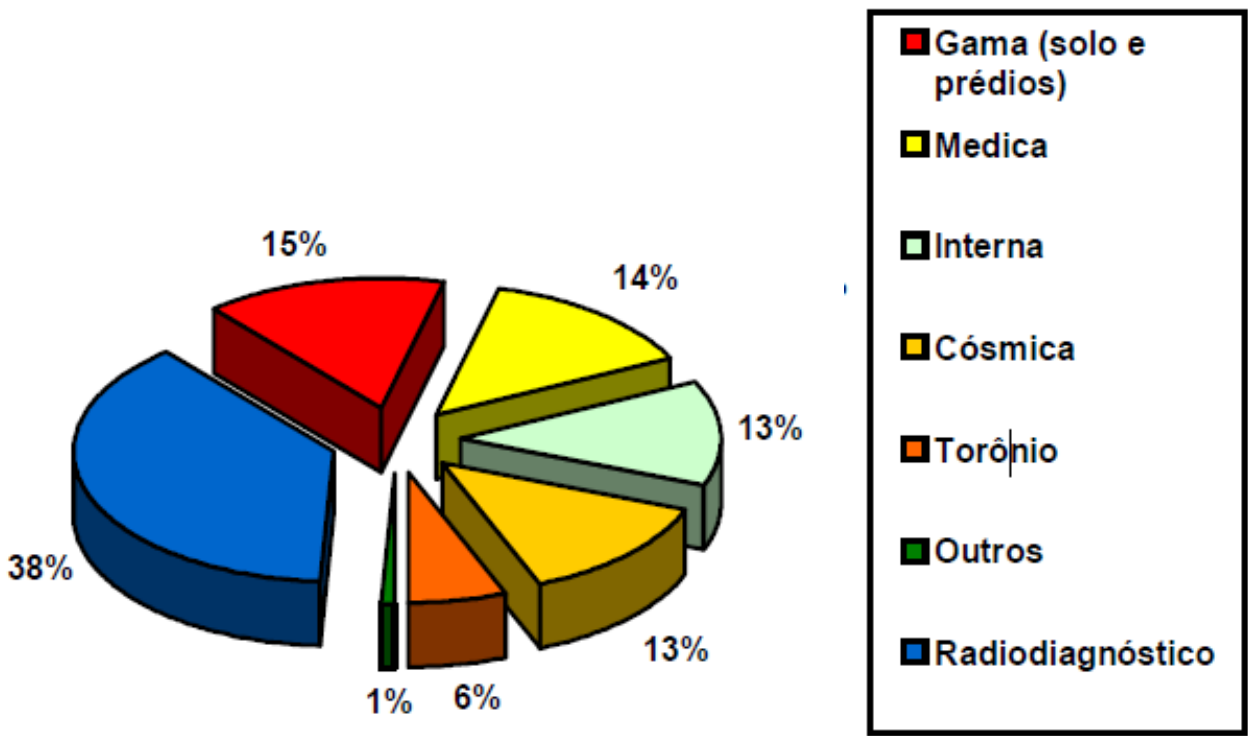

Figura 4: Distribuição da dose na população para fontes naturais e artificiais.

Radônio e o torônio

Produtos de decaimento do urânio e tório, são encontrados em rochas, solos, sedimentos e minérios. São gasosos e depositam-se nas partes mais baixas dos ambientes devido a seu alto peso atômico. Representam cerca de $80 \%$ da dose total recebida pelo homem devido à radiação natural.

Radiação cósmica

Proveniente do espaço sideral, como resultante de explosões solares e estelares. Grande parte dela é freada pela atmosfera, mas mesmo assim uma porcentagem importante atinge os seres humanos. Recentemente, com o aumento do buraco na camada de ozônio da atmosfera, o percentual devido a estas radiações tem aumentado substancialmente.

\section{Fontes artificiais}

As principais fontes artificiais são os Raios X médicos, odontológicos e industriais, e 
os aceleradores de partículas.

Tubos de Raios-X

O tubo de Raios-X é um conversor de energia: recebe energia elétrica e a converte em raios $\mathrm{X}$ e calor. Ele é constituído pelo anodo e pelo catodo. O catodo, geralmente é um filamento de tungstênio, é aquecido por um circuito apropriado, podendo atingir altas temperaturas e assim produzir os elétrons que atingem o alvo (anodo) num ponto bem determinado, chamado de ponto focal.

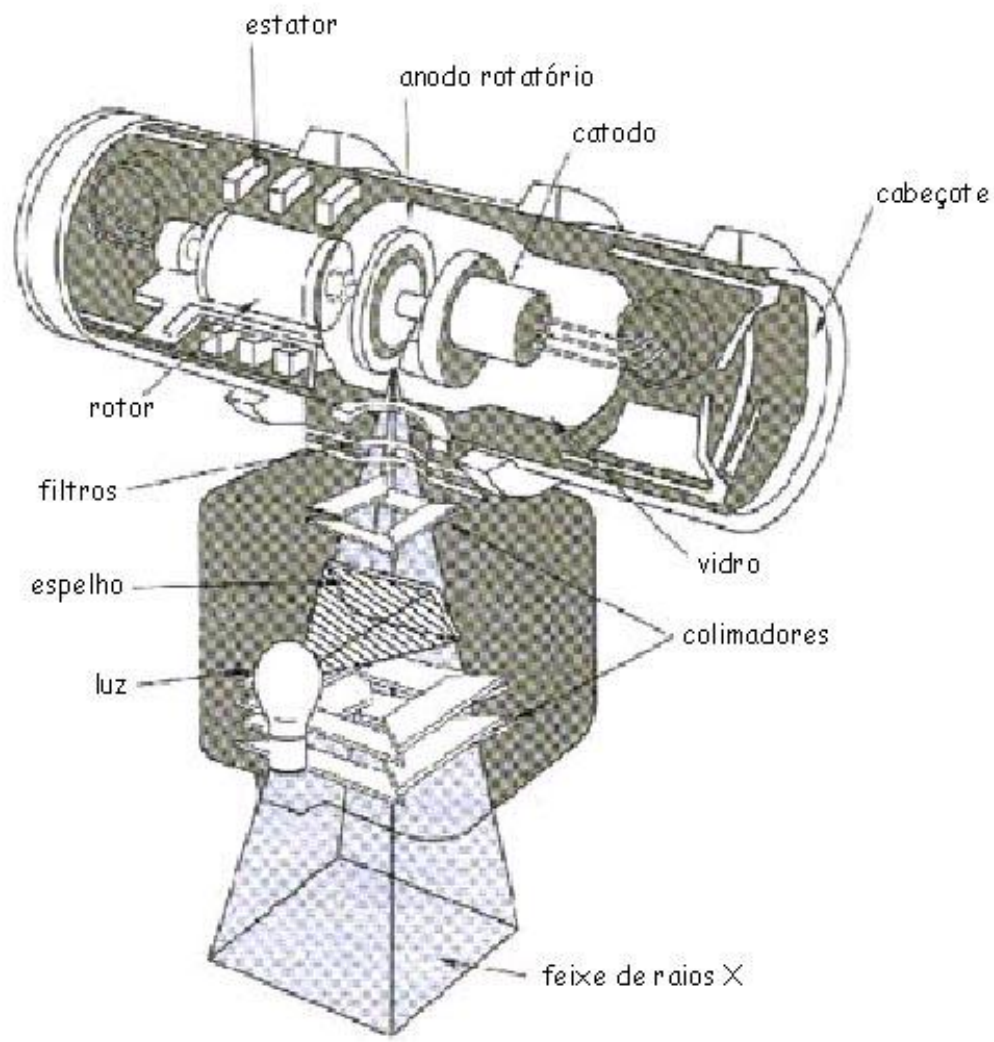

Figura 5: Esquema simplificado de um tubo de raios-X.

\section{Anodo}

O anodo é um disco de metal, geralmente de W (tungstênio) onde os elétrons incidem produzindo os raios X. Ele converte energia elétrica em raios X (5\%) e em calor (95\%). $\mathrm{O}$ material do anodo deve ter algumas características essenciais :

- Alto número atômico (alta eficiência na produção de raios X)

- Baixa taxa de evaporação (para evitar metalização do vidro da ampola)

- Alta resistência física quando aquecido

- Alto ponto de fusão

- Alta condutividade térmica (dissipação rápida de calor).

\section{Ampola}

A ampola é constituída de vidro de alta resistência e mantida a vácuo. Dentro dela estão fixados o anodo e o catodo. Sua função:é promover isolamento térmico e elétrico entre as partes. 


\section{Cabeçote}

O cabeçote contém a ampola e demais acessórios. É geralmente constituído de chumbo ou cobre cuja função é blindar a radiação de fuga. Possui uma janela radiotransparente por onde passa o feixe. O espaço interno é preenchido com óleo que atua como isolante elétrico e térmico.

\section{Acelerador de partículas}

Existem diversos dispositivos que permitem a geração de feixes intensos de partículas com energia variável, utilizando processos de aceleração baseados em campos elétricos e campos magnéticos. Os principais aceleradores de partículas são:

- aceleradores de elétrons

- acelerador Van der Graaff

- cíclotrons

- aceleradores de grande porte

\section{Acelerador de elétrons}

Os elétrons são gerados por filamentos aquecidos e injetados no tubo acelerador. Este tubo é dividido em várias seções, cada uma delas sujeita a uma ddp diferente, aumentando conforme o elétron se desloca no tubo, até atingir a energia desejada.

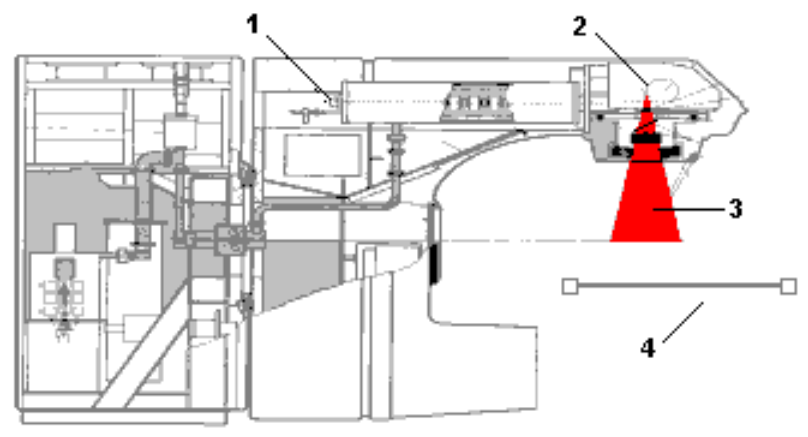

Figura 6: Esquema simplificado de um acelerador de elétrons médico.

1. Fonte de elétrons. 2. Alvo. 3. Feixe de elétrons ou fótons. 4. Mesa de tratamento.

\section{Van der Graaff}

As cargas são conduzidas através de uma correia até o coletor de carga que transfere a carga para o condutor esférico onde esta é armazenada. O potencial do condutor esférico é muito grande em relação ao potencial da Terra e essas partículas podem ser injetadas em outro tipo de acelerador (pré-aceleração) ou incidir em um tubo de Raios-X para produzir RX. É um acelerador eletrostático desenvolvido para acelerar partículas carregadas. 


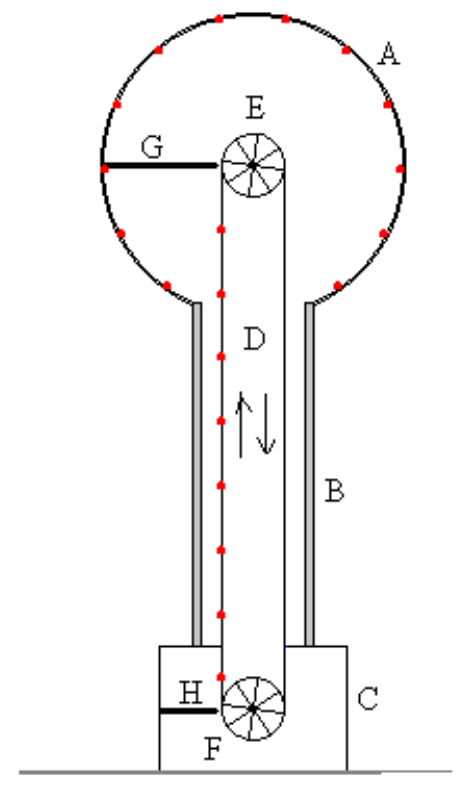

Figura 10: Esquema simplificado de um acelerador Van der Graaff

Entre na página citada abaixo para ver uma animação deste acelerador. Applet (em espanhol):

http://www.sc.ehu.es/sbweb/fisica/elecmagnet/campo_electrico/graaf/graaf.htm.

\section{Cíclotron}

O acelerador é constituído por duas câmaras metálicas, em forma de D, alimentadas por uma fonte de alta voltagem. O sistema inteiro é colocado na presença de um forte campo magnético, perpendicular aos D's. A trajetória dos íons no interior dos D's é circular, devido ao campo magnético. Além disso, deve-se controlar a freqüência $f$ da fonte de voltagem alternada para que os íons sejam acelerados continuamente.

Para o movimento não-relativístico, pode-se calcular a frequiência através das relações:

$$
\begin{aligned}
& F c p=m v 2 / r=q v B / c=F m a g \\
& w=v / r \\
& f=w / 2 p f=q B / 2 p m c
\end{aligned}
$$

sendo $f$ chamada de freqüência de ressonância do cíclotron.

Applet: http://www.phy.ntnu.edu.tw/java/cyclotron/cyclotron.html (em inglês).

Acelerador de grande porte: LEP(Large Electron-Positron Collider)

O LEP é o maior colisor de partículas do mundo (anel de $27 \mathrm{~km}$ de circunferência). Em um anel de $27 \mathrm{~km}$ de circunferência, feixes de elétrons e pósitrons viajam em direções opostas e são acelerados a velocidades próximas a da luz. 


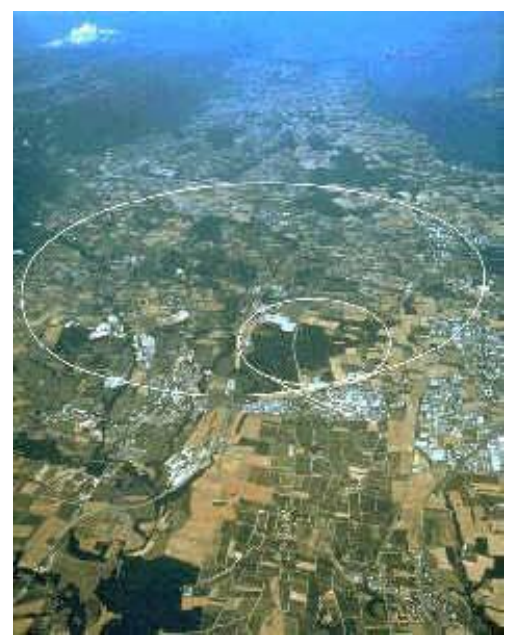

Texto super interessante da Faculdade de Ciências Farmacêuticas da Universidade de São

Paulo: http://www.fcf.usp.br/Ensino/Graduacao/Disciplinas/LinkAula/My-Files/interacao.htm

\section{Questões}

3- Cite as principais aplicações da radiação na medicina.

4- Cite as principais aplicações da radiação na indústria.

\section{ATIVIDADES}

\section{1 - Experimentos de Baixo Custo}

\section{1 - Espectros de emissão}

Vários trabalhos têm sido desenvolvidos [10-18] utilizando CDs como redes de difração envolvendo desde a construção de espectroscópios manuais [13-17] até a medida de comprimentos de onda através de anéis projetados [11]. Selecionamos três técnicas distintas de análise e se manuseadas adequadamente permitirão efetuar medidas com elevado grau de precisão.

\section{Espectro de emissão por projeção: Feixe refletido}

Este método fornece anéis de interferência projetados em uma tela. Os comprimentos de onda da radiação podem ser obtidos a partir da medida do ângulo de desvio de cada anel. Esta técnica de medida é descrita em detalhes por Cavalcante e Benedetto [11]. Uma montagem que permite a visualização destes anéis de interferência pode ser vista na Figura 1.

Valores dos comprimentos de onda podem ser estimados se construirmos uma curva de calibração deste espectroscópio. Para isso basta utilizar como fonte luminosa uma lâmpada eletrônica fluorescente de $\mathrm{Hg}$ compacta (aconselha-se no mínimo $24 \mathrm{~W}$ ), já que se pode observar nitidamente suas linhas características laranja, verde e violeta, cujos comprimentos de onda são 578 nm, 546 nm e 436 nm, respectivamente. Em seguida retira-se a fonte calibradora e dispõe-se na mesma posição uma fonte de luz cujo comprimento de onda se deseja medir. O gráfico da Figura 2 mostra a curva de calibração bem como os pontos obtidos para os comprimentos de onda de dois LEDs comerciais, vermelho e verde. Os resultados, $600 \mathrm{~nm}$ para o vermelho e $550 \mathrm{~nm}$ para o verde, estão próximos dos valores fornecidos pelo fabricante.

\section{Espectro de emissão por projeção: Feixe transmitido}

Para se obter a projeção do espectro por feixe transmitido usando o CD, é necessário retirar sua camada refletora de alumínio de modo a torná-lo transparente. Para isso, toma-se um CD gravável, 
recobre-se com fita crepe e faz-se um pequeno corte com um estilete na sua superfície, como indica a Figura 3a. Ao puxar a fita (Figura 3b), esta traz a camada refletora, deixando o CD completamente transparente.

Para a observação do espectro será necessário utilizar uma fonte colimada de luz, uma lupa, um CD transparente e réguas. Inicialmente ajusta-se a posição relativa entre tela, fonte e lupa de modo a se obter uma imagem bem nítida da fenda (Figura 4).

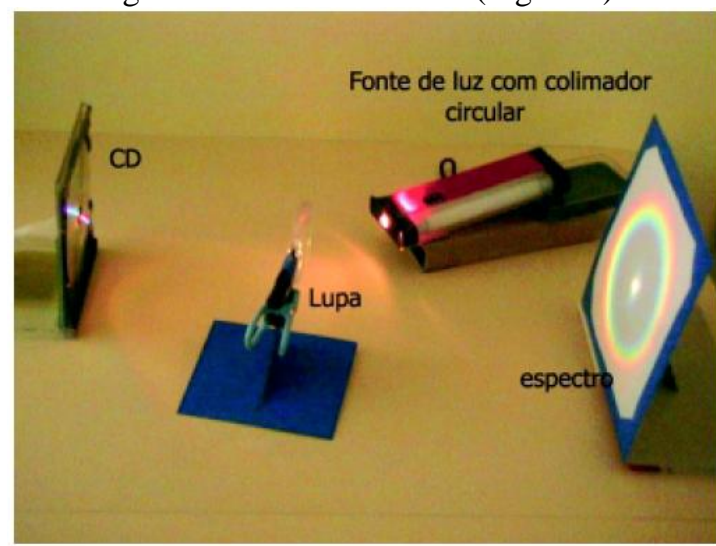

Figura 1. Montagem utilizada para a observação do espectro de emissão por reflexão no CD. Na tela, são observados os anéis de interferência.

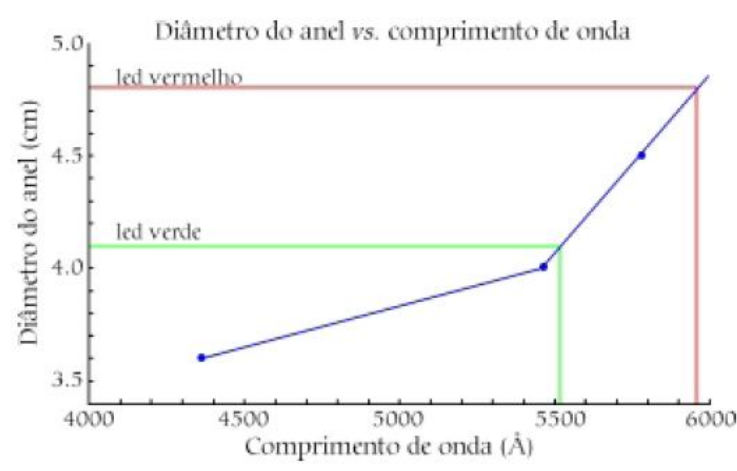

Figura 2. Curva de calibração e determinação dos comprimentos de onda de dois LEDs comerciais, vermelho e verde. Observe os valores obtidos para os comprimentos de onda, cerca de $600 \mathrm{~nm}$ e $500 \mathrm{~nm}$, respectivamente, são bem razoáveis e estão de acordo com os valores fornecidos pelos fabricantes.
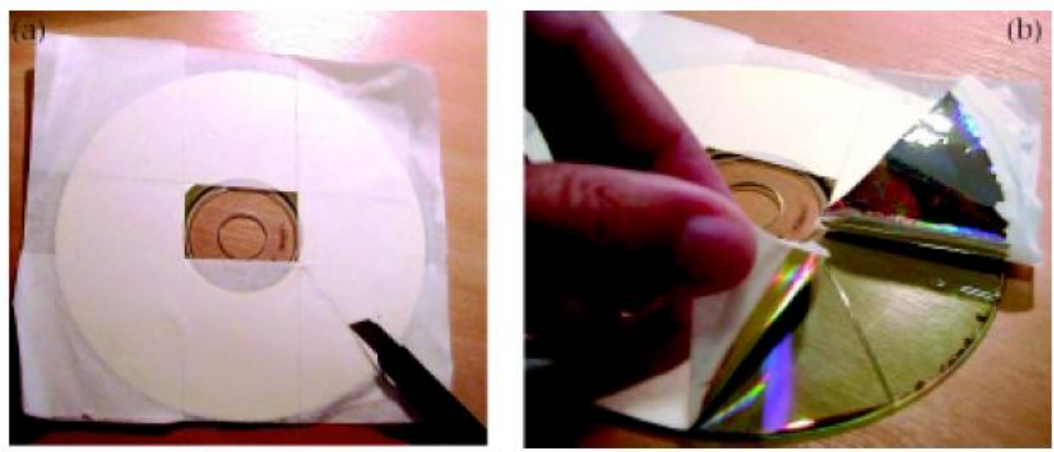

Figura 3. Procedimento para a retirada da superfície refletora de um CD.

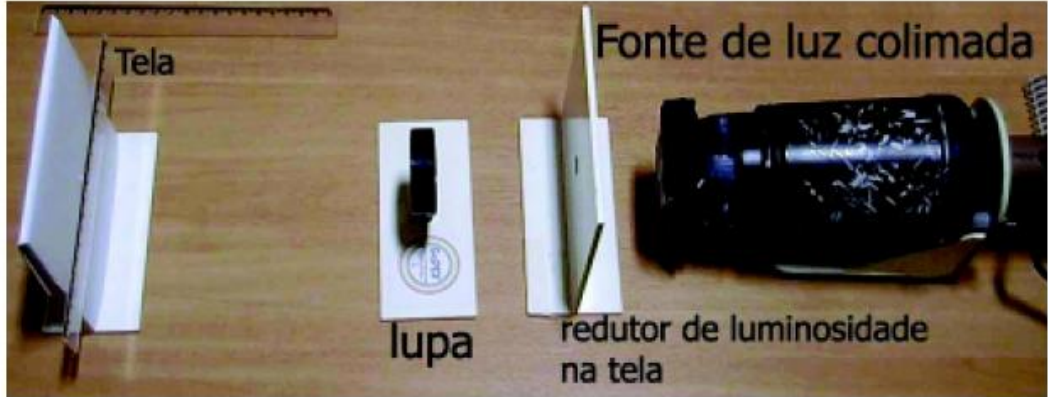

Figura 4. Montagem mostrando o ajuste inicial da imagem da fenda na tela. Algumas vezes a fonte de luz provoca uma luminosidade excessiva na tela prejudicando a visualização das linhas espectrais. Neste caso pode-se reduzir esta luminosidade interpondo uma placa com orifício entre a lupa e a tela, melhorando a visualização do espectro.

Em seguida coloca-se o CD entre a lupa e a tela até que se observe o espectro com nitidez (Figuras 5 e 6 ). Para a determinação dos comprimentos de onda devemos medir o desvio de cada linha projetada em relação à fenda, conforme o esquema da Figura 7. A equação que permite calcular o comprimento de onda $\lambda$ da radiação correspondente à linha escolhida é dada por:

$$
N \lambda=d \operatorname{sen} \theta \text {, }
$$

onde $N$ corresponde à ordem do espectro que será analisado, $d$ é a distância entre as ranhuras do CD $(d=1 / 625 \mathrm{~mm}$ pois o $\mathrm{CD}$ contém $625 \mathrm{ranhuras} / \mathrm{mm})$ e $\theta$ é o ângulo de desvio da linha escolhida em relação ao eixo correspondente à fenda projetada. Para determinar sen $\theta$, faz-se , 


$$
\operatorname{sen}(\theta)=\frac{X}{\left(D^{2}+X^{2}\right)^{1 / 2}}
$$

onde $X$ é o desvio medido na tela de projeção e $D$ é a distância entre o CD e a tela (Figura 7).

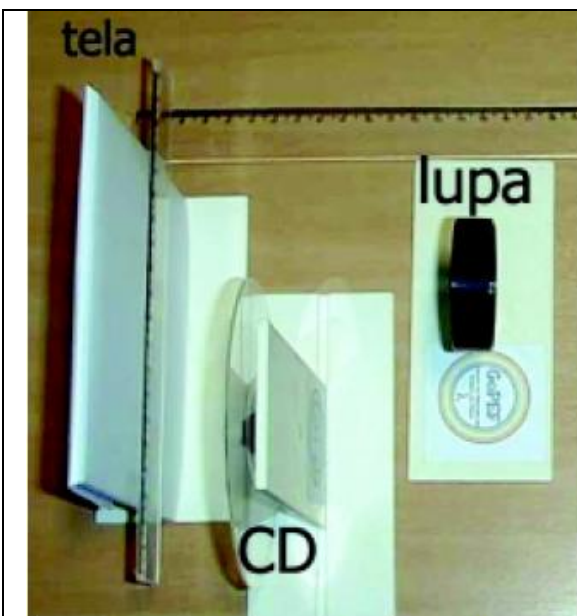

Figura 5. O CD disposto entre a lupa e a tela para a decomposição espectral.

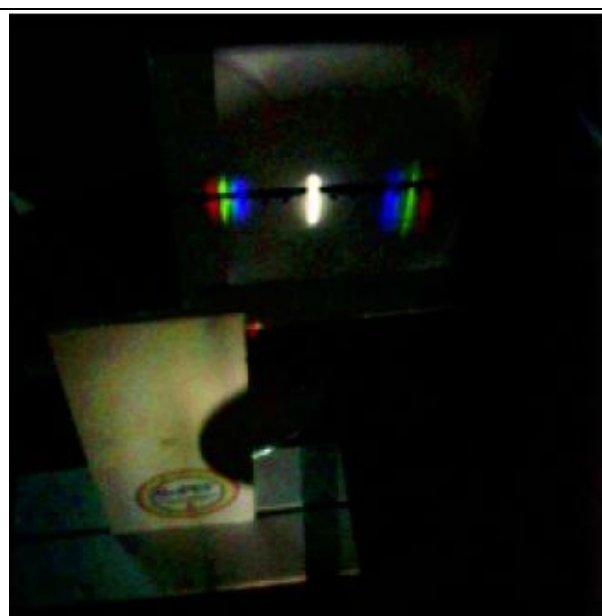

Figura 6. Espectro de $1^{\mathrm{a}}$ ordem obtido para o $\mathrm{Hg}$. As linhas que são observadas com maior nitidez são violeta, verde, azul, laranja e vermelha.

Para permitir uma comparação entre os resultados obtidos pelo método 1 (espectro de emissão por reflexão) e o método 2 (espectro de emissão por feixe transmitido), obtivemos informações relativas ao comprimento de onda médio emitido por um LED comercial vermelho. Para $5.0 \mathrm{~cm}$ de distância entre o CD e a tela obtivemos um desvio $X$ de $2,3 \mathrm{~cm}$, o que conduz a um comprimento de onda médio da emissão igual a $669 \mathrm{~nm}$. A Figura 8 mostra o espectro de $1^{\text {a }}$ ordem obtido. Para que se obtenha bons resultados, devemos garantir uma boa simetria para estes desvios em relação à imagem da fenda. Desvios simétricos garantem que tanto o CD quanto a tela encontram-se perpendiculares ao feixe incidente.

\section{Espectroscópio manual}

Uma opção muito interessante e bastante funcional para as escolas que não dispõem de laboratórios ou salas escuras para a observação dos espectros de projeção são os espectroscópios manuais. Detalhes sobre a construção de um espectroscópio manual podem ser encontrados em Cavalcante e Tavolaro [16]. A Figura 9 mostra uma foto de um desses espectroscópios. Trata-se de uma caixa em que em uma de suas extremidades é fixado um pedaço de CD transparente e na outra, onde ocorre a incidência de luz, dispomos de uma escala graduada que servirá de tela para a projeção do espectro. A fenda que colima o feixe é ajustada pelo observador, permitindo maior facilidade de manuseio.

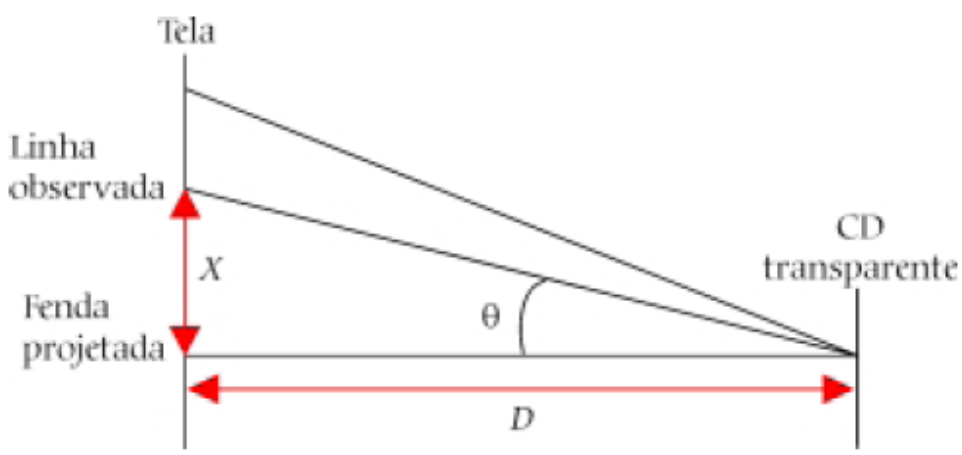

Figura 7. Esquema indica como determinar o comprimento de onda da radiação usando um CD como rede de difração. 
Vale a pena ver os experimentos sugeridos na referência [10]

\section{2 - Espectro de absorção de gases}

\section{3 - Determinação da constante de Planck utilizando LEDs}

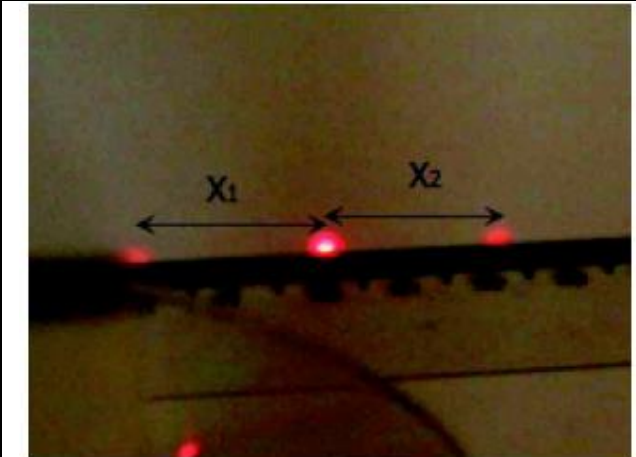

Figura 8. Espectro de $1^{\mathrm{a}}$ ordem de um LED vermelho. Nesta montagem $X_{1}=X_{2}$ mostrando uma perfeita simetria, condição necessária para se obter bons resultados. Essa simetria indica que tanto o CD quanto a tela encontram-se perpendiculares ao feixe incidente de luz.

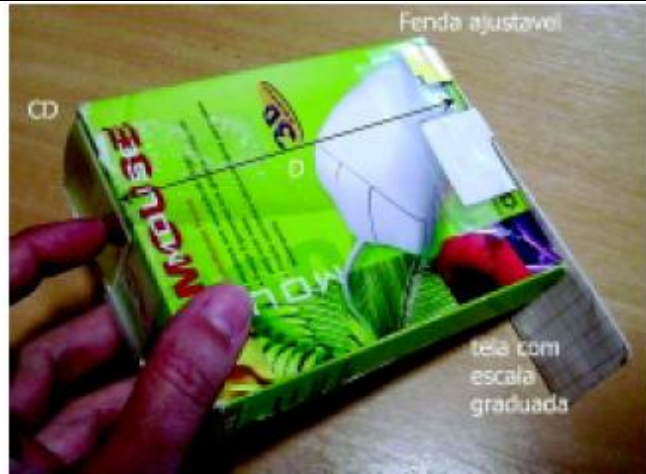

Figura 9. Espectroscópio manual segundo Cavalcante e Tavolaro [16].

Como sugestão, pode-se calibrar a escala a partir da relação expressa na Eq. (1), onde a distância da rede de difração à tela $(D)$ é característica de cada caixa (Figura 9). Como a distância entre as ranhuras de um CD é conhecida e assume o valor de 1,6 $\mu \mathrm{m}$, pode-se obter os valores de cada desvio para comprimentos previamente fixados. Para o espectroscópio da Figura 9 temos $D=12,5 \mathrm{~cm}$, fornecendo a Tabela 1.

A Figura 10 mostra o espectro de uma lâmpada de Hg comercial obtido com um espectroscópio manual. De modo a permitir comparações com os demais métodos, obtivemos o espectro de um LED vermelho também a partir deste espectroscópio, indicado na Figura 11.

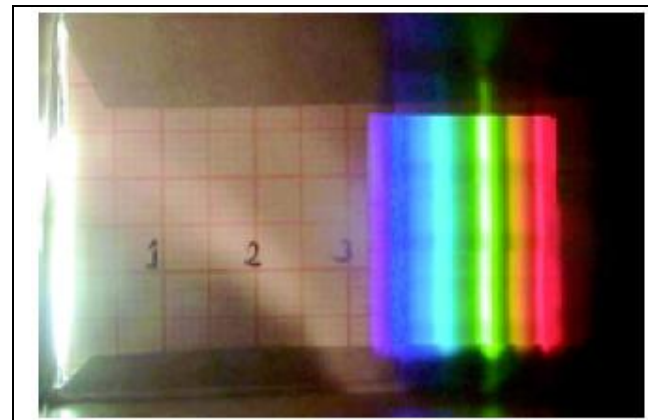

Figura10. Espectro observado em um espectroscópio manual com $D=12,5 \mathrm{~cm}$.

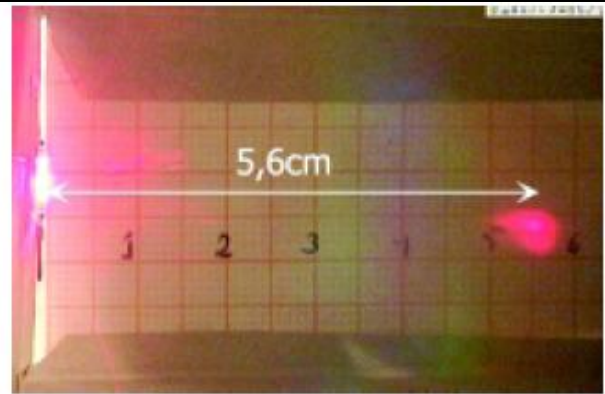

Figura 11. Espectro observado na tela de um espectroscópio manual. Pela tabela de calibração, temos um valor para o comprimento de onda médio de emissão do LED vermelho próximo a $650 \mathrm{~nm}$, valor compatível com os anteriormente obtidos. 
Tabela 1. Calibração de um espectroscópio manual com $D=12,5 \mathrm{~cm}$.

\begin{tabular}{ccc}
\hline$\lambda(\mathrm{nm})$ & $\operatorname{sen} \theta$ & $X(\mathrm{~cm})$ \\
\hline 400,00 & 0,25 & 3,23 \\
450,00 & 0,28 & 3,66 \\
500,00 & 0,31 & 4,11 \\
550,00 & 0,34 & 4,58 \\
600,00 & 0,38 & 5,06 \\
650,00 & 0,41 & 5,56 \\
700,00 & 0,44 & 6,08 \\
\hline
\end{tabular}

\section{2 - Applets de Ensino}

2.1 - Projeto de ensino de Física "Kings Centre of visualitation Science". Lá você pode encontrar vários applets de ensino de física moderna. Exemplos:

Efeito Compton

Start Photon Scattering Angle 45 Wavelength (pm)

http://www.kcvs.ca/site/projects/physics.html

Partícula em uma Caixa Unidimensional 


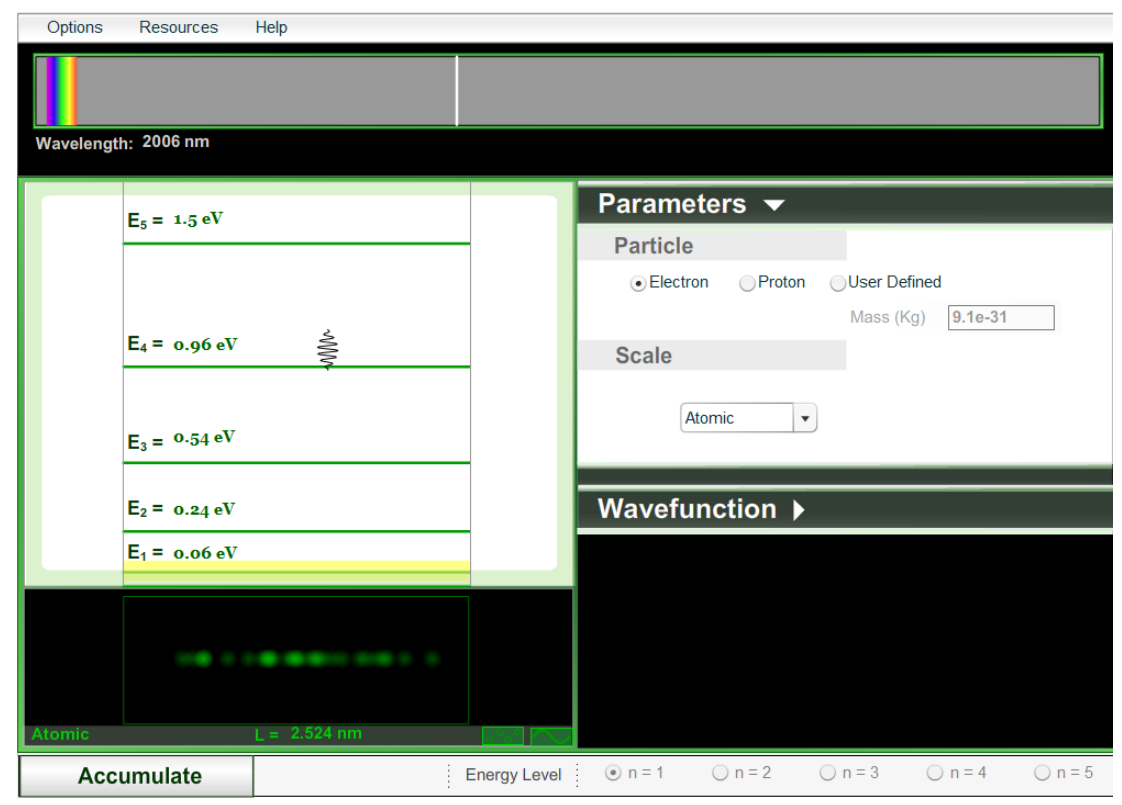

2.2 - Física Animada. Lá você pode encontrar vários applets de ensino de física moderna. Exemplos:

Átomo de Bohr. URL: http://www.fisicanimada.net.br/?q=fisica_moderna/bohr_nav

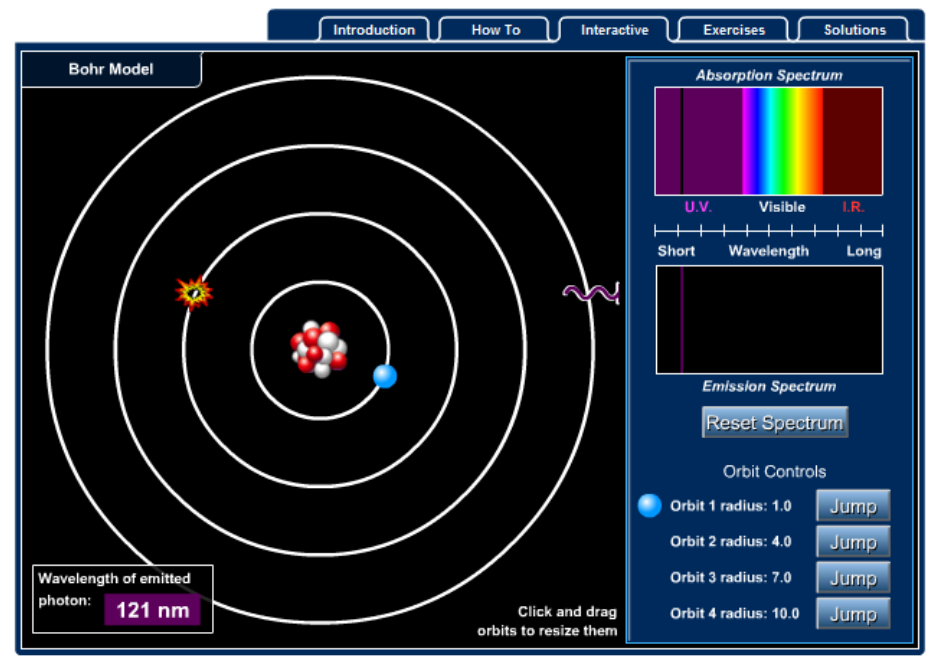

Radioatividade. URL: http://www.fisicanimada.net.br/?q=fisica_moderna/radioactivity 


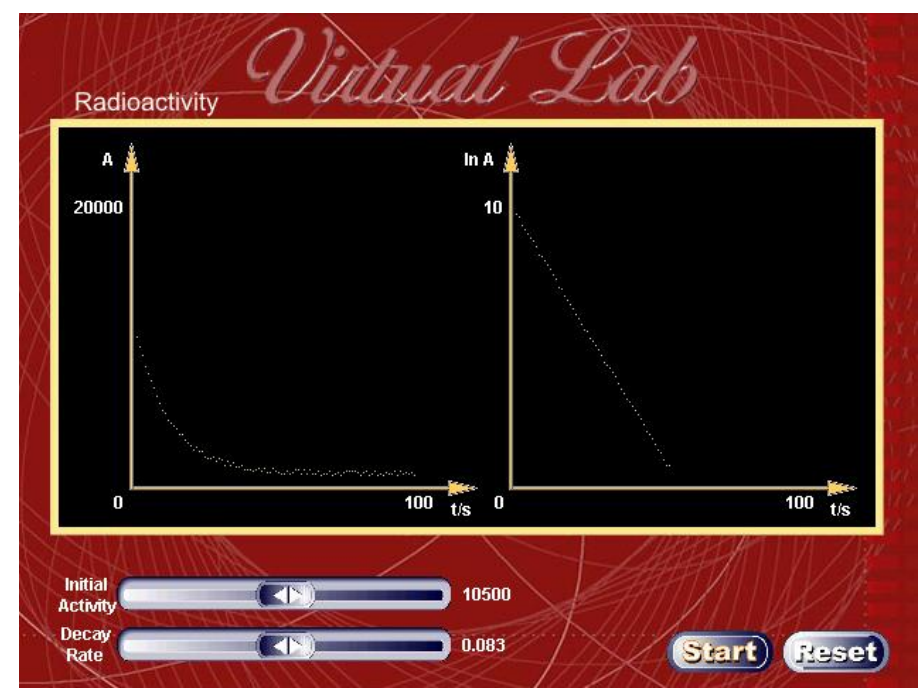

\section{3 - Física com Ordenador.}

http://www.fisica.ufs.br/egsantana/cuantica/fotoelectrico/fotoelectrico.htm

\section{4 - Portal do professor.}

http://portaldoprofessor.mec.gov.br/fichaTecnicaAula.html?aula=253

2.5 - Walter-Fendt. http://cepa.if.usp.br/walterfendt/phbr/photoeffect br.htm

2.6 - Abaixar o software VMC dc. Software que calcula dose de radiação no corpo humano. Calculo realístico. URL:

http://www.vmcsoftware.com/in\%20vivo.html

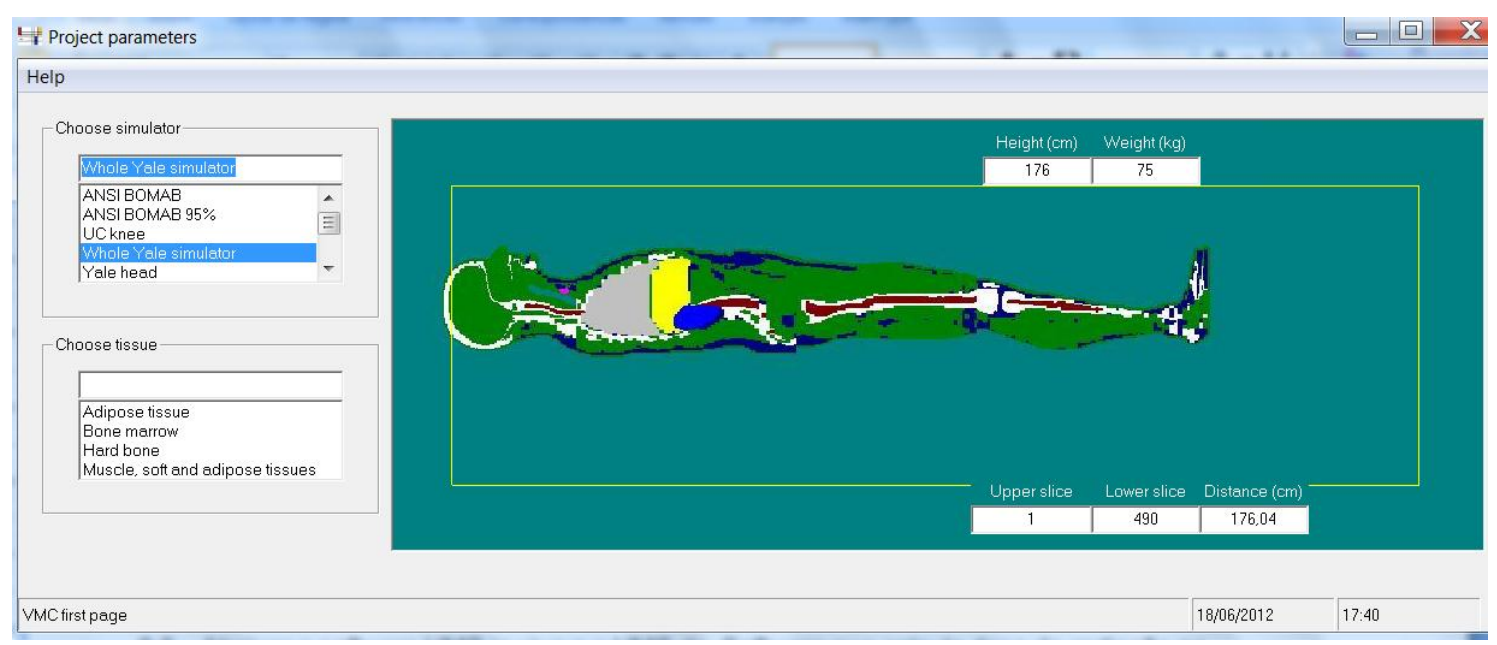

Manual no fim da aula.

3 - Vídeos Aula.

3.1 - Com ciência. Física Moderna.

Parte01. http://www.videolog.tv/video.php?id=284165

3.2 - Relatividade Restrita. 
Parte01. http://www.youtube.com/watch?v=IF37hgSMm1s

Parte02. http://www.youtube.com/watch?v=rUJg9rlmOZc

Parte1. Telecurso. URL: http://www.youtube.com/watch?v=8PJ2hhGo6X0

Parte2. Telecurso. URL: http://www.youtube.com/watch?v=Hs5TT9zND8Y

3.3 - Raio X. Muito bom. URL: http://www.youtube.com/watch?v=OQAwoOyVXO4

3.4 - Física Moderna. URL: http://www.youtube.com/watch?v=

nTzmkFWnark\&feature $=$ related

3.5 - Raio-x e planos de Bragg. URL:

http://www.youtube.com/watch?v=nLKUPwqoFas\&feature=related

3.6 - Telecurso2000. Ensaio de Materiais ou aplicação da física moderna na indústria. Série de 25 aulas. URL: http://www.youtube.com/watch?v=j4wkMsviSX4\&feature=related

\section{7 - Como funciona a ressonância magnética}

Parte 1 - http://www.youtube.com/watch?v=YeVHTjMwVTo

Parte 2 - http://www.youtube.com/watch?v=gxQIDDID5Pk

\section{8 - Física Médica. URL: http://www.youtube.com/watch?v=ZhmljYHTQ1o}

\section{COMENTÁRIOS:}

\section{Análise das obras}

Ao apresentarmos nossa análise para cada material didático, a seguir, relatamos inicialmente a forma como os conteúdos estão estruturados no texto, e, em seguida, sistematizamos a presença ou não dos itens selecionados para observarmos o material.

\section{LIVRO 1 - CURSO DE FÍSICA, VOLUME 3. AUTORES: Antônio Máximo e} Beatriz Alvarenga; Editora: Scipione, 6를 Ed.; 2006.

A obra tem estruturação centrada nos conceitos, nem sempre possui contextualização; quando esta ocorre, relaciona-se com a história ou com aplicações tecnológicas. Há seções destacadas do texto principal, duas delas são: "físic a no cotidiano" e "tópico especial". Na primeira temos textos curtos sobre a relação dos conceitos com situações do dia a dia, a segunda traz textos mais longos, como um complemento aos conteúdos com situações de contextos históricos, ou de aplicações tecnológicas ou ainda aspectos culturais.

Na seção "Tópico Especial" (p. 215) mostra o funcionamento do acelerador de partículas e comenta um pouco da história do cíclotron, destacando a importância dos aceleradores para o avanço da Física Nuclear. Dentro desta 
mesma seção aparecem resumos biográficos de Ernest Lawrence (1901-1985) e de César Lattes (1924-2005). Em outro tópico traz um esquema de fornecimento de energia elétrica a partir de uma usina nuclear, porém de forma ilustrativa, somente (p. 280 e p. 301) ou quando indica a transmissão e distribuição da energia elétrica (p. 301). Há, na página 297, uma descrição sobre as radiações nucleares: as emissões alfa, beta e gama são descritas quanto à capacidade de penetração na matéria e nas explosões de bombas atômicas.

O livro traz, no seu último capítulo, um programa com conteúdos de Física Moderna, com o título "Teoria da Relatividade e Teoria Quântica". Dentro deste capítulo, dividido em tópicos, o livro trata de conteúdos como a Relatividade Restrita, Geral, Quântica e, no tópico 25.11 aborda a Física das Partículas. O texto destaca a constituição do núcleo e as partículas atômicas com ênfase nos quarks, apresentando um histórico do desenvolvimento deste conhecimento num texto curto, com citações de datas e personalidades, descrevendo uma cronologia na descoberta das partículas nucleares. Aqui não há referências a qualquer aspecto social, embora a dimensão tecnológica se faça presente por meio dos aceleradores de partículas que são destacados pela engenharia e pelos recursos empregados. A influência da Física sobre as artes é um destaque muito interessante (p. 373) apresentando-se fotos de telas influenciadas pelas idéias da física das partículas.

\title{
CONCLUSÃO:
}

\section{Referências}

\author{
A.M. Souza e A.S.M. Germano. ANÁLISE DE LIVROS DIDÁTICOS DE FÍSICA \\ QUANTO A SUAS ABORDAGENS PARA O CONTEÚDO DE FÍSICA NUCLEAR. XVIII \\ Simpósio Nacional de Ensino de Física - SNEF 2009 - Vitória, ES.
}

ACEVEDO, J. A. - Reflexiones sobre las finalidades de la enseñaza de las ciências: educación científica para la ciudadanía. Revista Eureka sobre Enseñanza y Divulgación de las Ciencias. Vol. 1, no 1, p. 3 -16, 2004.

AIKENHEAD, G. -- STS Education: A Rose by Any Other Name. In R. Cross (Ed.): Crusader for Science Education: Celebrating and Critinquing the Viosion of Peter J. Fensham. New York: Routledge Press. Disponível em < http://www.usask.ca/education/people/aikenhead/stsed.html>. Acesso em: 18 fev. 2008.

BAZZO, W. A. Ciência, Tecnologia e Sociedade e o Contexto da Educação Tecnológica. Ed. UFSC, Florianópolis, 1998. 319 p.

BRASIL, Secretaria de Educação Média e Tecnológica. PCN+ Ensino Médio: Orientações Educacionais complementares aos Parâmetros Curriculares Nacionais. Linguagens, códigos e suas tecnologias. Brasília: Ministério da 
Educação/Secretaria de Educação Média e Tecnológica, 2002. 244p.

PCNEM: Parâmetros Curriculares Nacionais para o Ensino Médio. Ciências da Natureza, Matemática e suas Tecnologias, 1998. Disponível em: <http://portal.mec.gov.br/seb/arquivos/pdf/ciencian.pdf>. Acesso em: 03 ago. 2008.

OCNEM Ensino Médio: Orientações Curriculares Nacionais para o Ensino Médio. Ciências da Natureza, Matemática e suas Tecnologias, 2006. Disponível em: <http://portal.mec.gov.br/seb/arquivos/pdf/book_volume_02_ internet.pdf>. Acesso em 11 out. 2008.

CAVALCANTE, M. A. - O Ensino de uma Nova Física e o Exercício da Cidadania. Revista Brasileira de Ensino de Física, São Paulo, v. 21. n. 4. Dez. 1999.

[10] - Cavalcante, Tavaloro e Haag. Experiências em Física Moderna. http://www.sbfisica.org.br/fne/Vol6/Num1/exper-fis-mod.pdf

CRUZ, S. M. S. C. S. ; ZYLBERSZTAJN, A. O Evento Acidente de Goiânia: Uma Experiência de CTS no Ensino Fundamental. In: VII Encontro de Pesquisa em Ensino de Física, 2000, Florianópolis. VII EPEF, 2000.

DELORS, Jacques (Coord.). Os quatro pilares da educação. In: Educação: um tesouro a descobrir. 1ª Ed. São Paulo: Ed. Cortezo, 1999.

FERREIRA, M. S.; SALLES, S. E. Análise de livros didáticos em ciências: entre as ciências de referência e as finalidades sociais da escolarização. Revista Educação em Foco, Porto Alegre, v. 8, 2004.

MOREIRA, M. A. - A questão das ênfases curriculares e a formação do professor de ciências. Caderno Catarinense para o Ensino de Física.

Florianópolis, vol. 3 n. 2. Ago. 1986.

SANTOS, W. L. P.; MORTIMER, E . F. - Tomada de decisão para ação social responsável no ensino de ciências. Ciência \& Educação, vol. 7, n.1, p.95-111. 2001.

Sears, Francis W., Mark W. Zemansky e Hugh D. Young, University Physics, 6 edição, Addison-Wesley, 1983, pp. 843-4. ISBN 0-201-07195-9.

ZANETIC, J. Física Também é Cultura. Tese de Doutoramento. Universidade de São Paulo. São Paulo. 1989. 250 p.

ZORZI, M. B. S. O enfoque ciência, tecnologia e sociedade nos textos sobre radioatividade e energia nuclear nos livros didáticos de química. Dissertação de Mestrado. Paraná: Universidade Estadual de Maringá, 2006. 129 p.

Weisstein, Eric W., "Eric Weisstein's World of Physics", 2007, Eric Weisstein's World of Science, Wolfram Research 


\section{APENDICE}

\section{MANUAL SOFTWARE "MONTE CARLO IN VIVO“}

Software de pesquisa e ensino. Sua função é calcular a dose recebida em alguns orgãos e tecidos do corpo. O botão "Load the Simulator" inicia o programa.

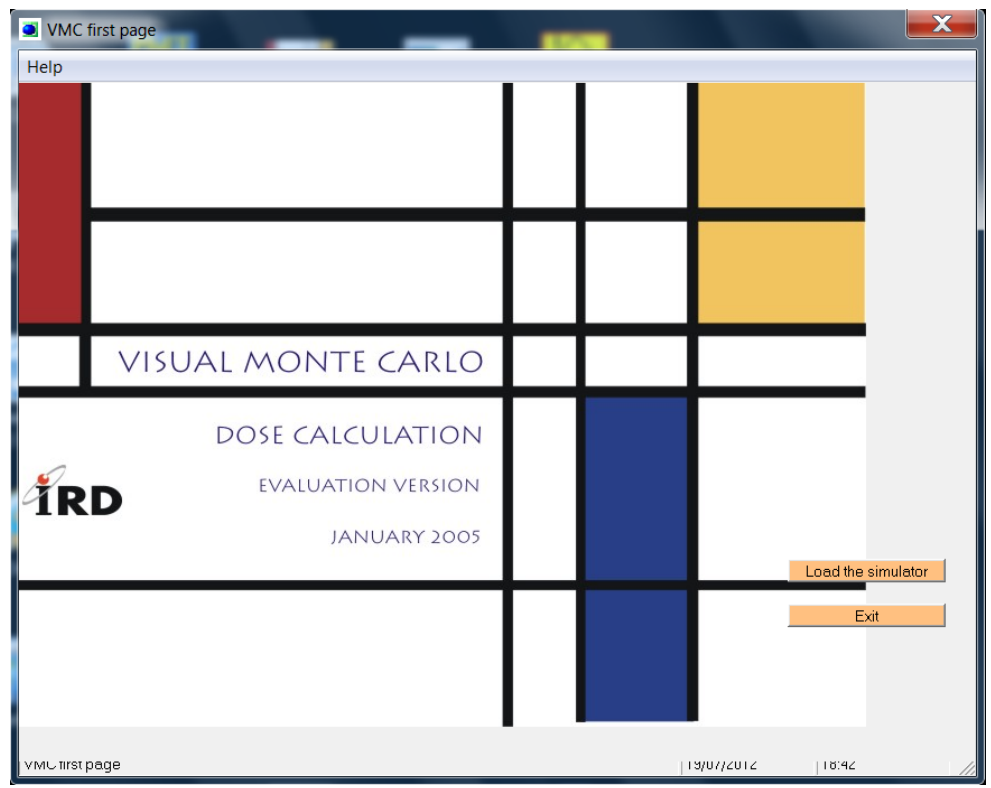

Ao abrir o simulador aparecerá a janela. (New = novo e Open = abrir).

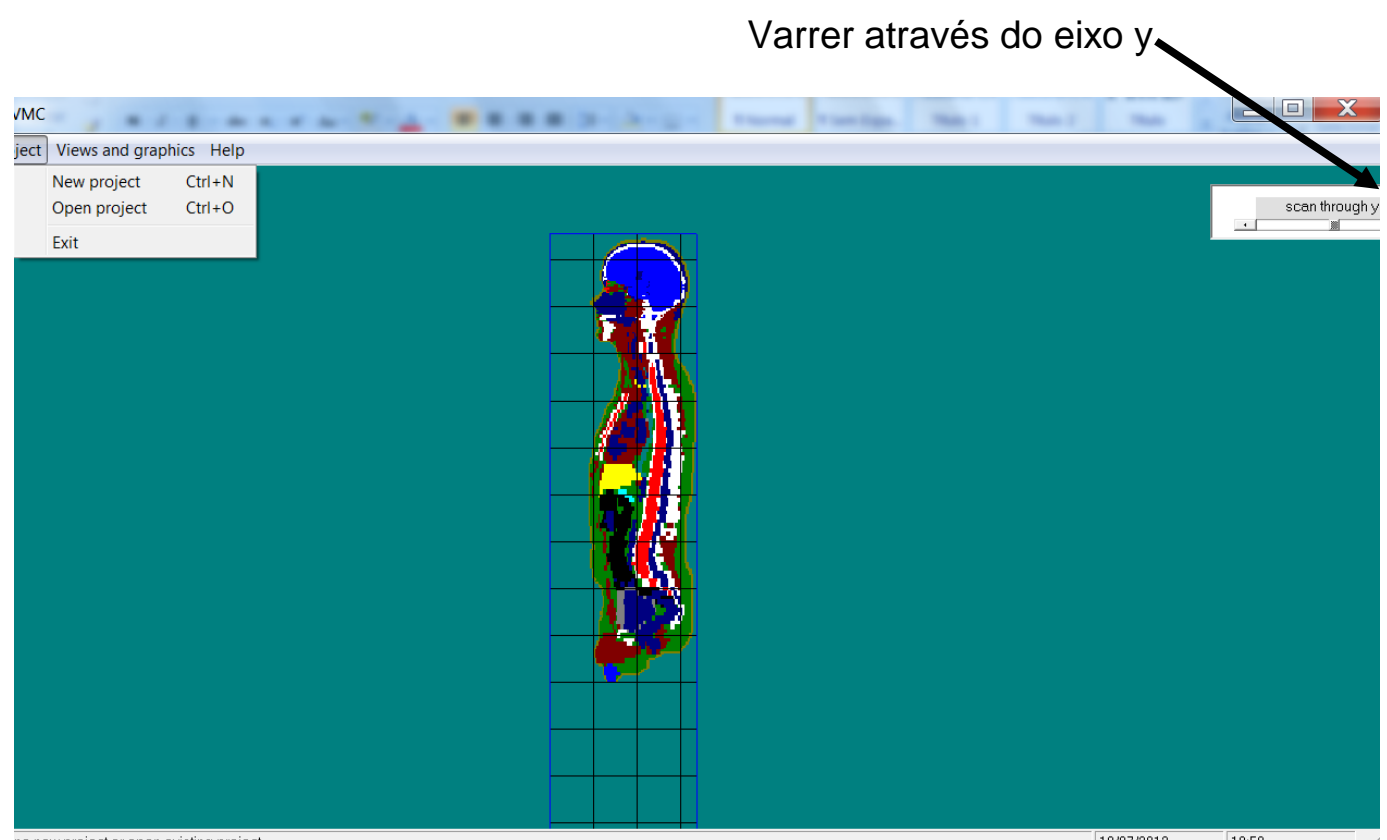

ne new project or open existing project

Se você clicar em 'new Project' aparecerá a tela abaixo. Nela você poderá escolher o tipo, a geometria, a atividade da fonte, o tempo de exposição e a desintegração total.

Nota: Radionuclide $=$ radionuclideo (fonte radioativa) 


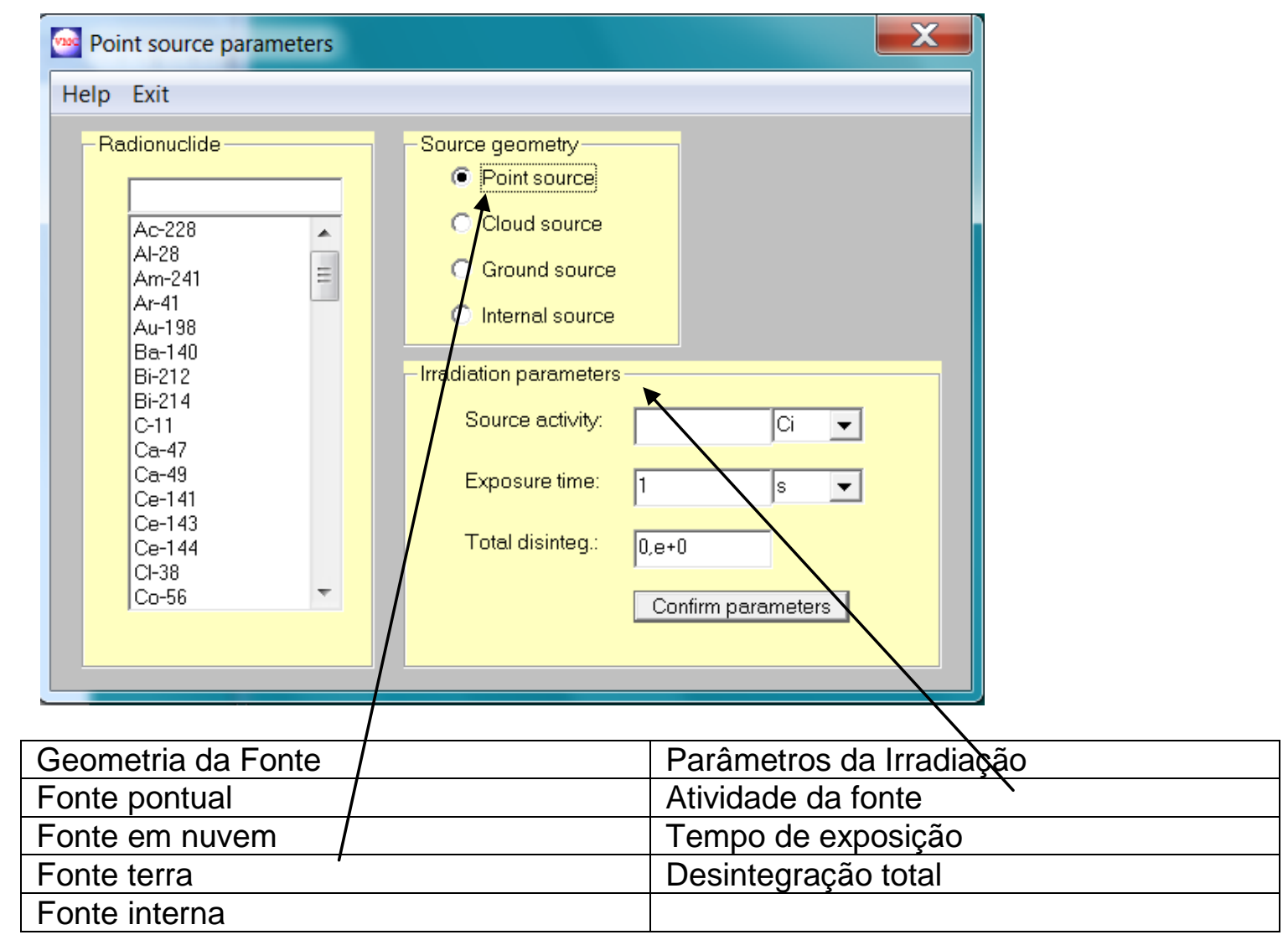

Depois que você escolher a fonte, sua geometria e parâmetros da irradiação deve confirmar os parâmetros. Aparecerá a tela de salvar projeto (dê um nome ao projeto). Ai aparecerá a tela:

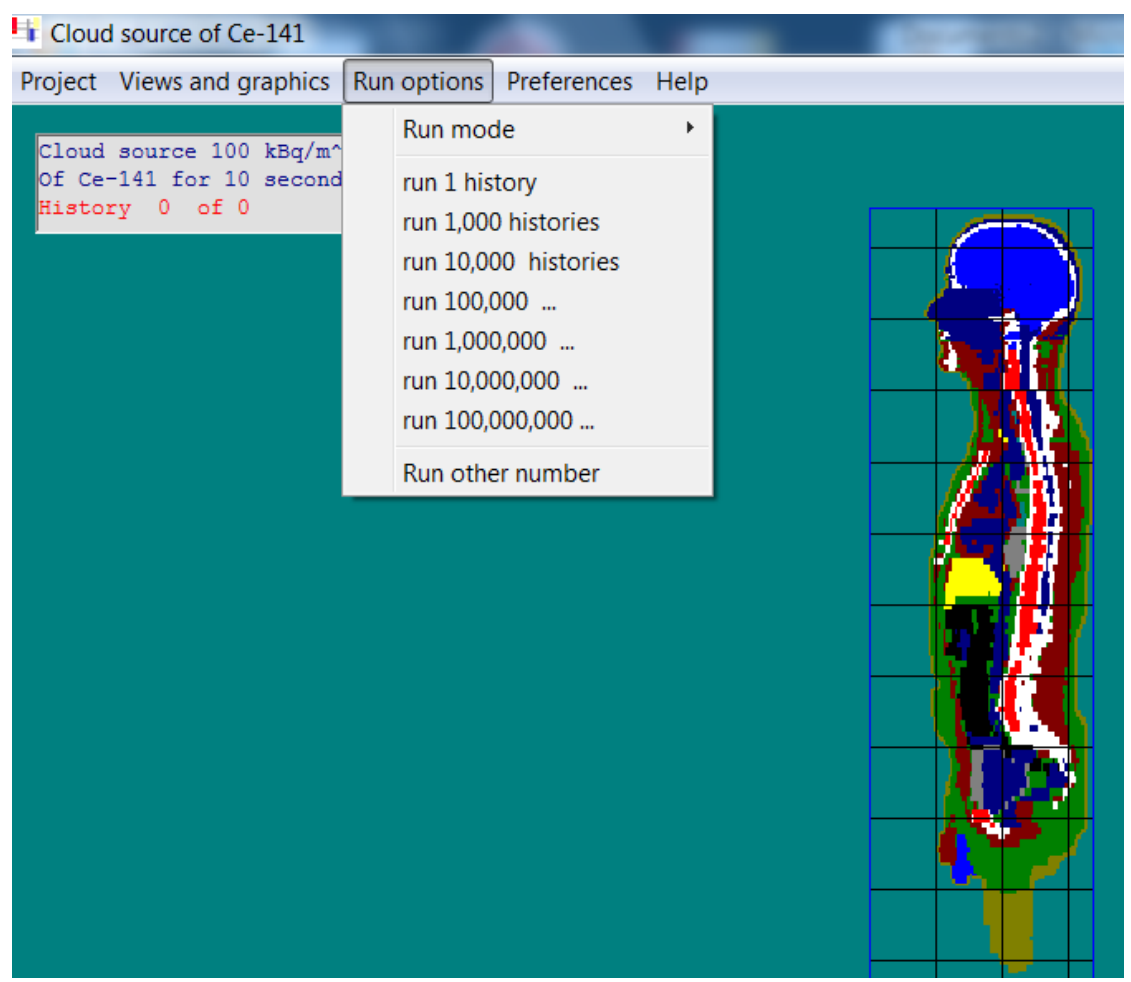


Finalmente você tem que escolher quantas simulações deve fazer. Botão: Opção de rodagem. 